
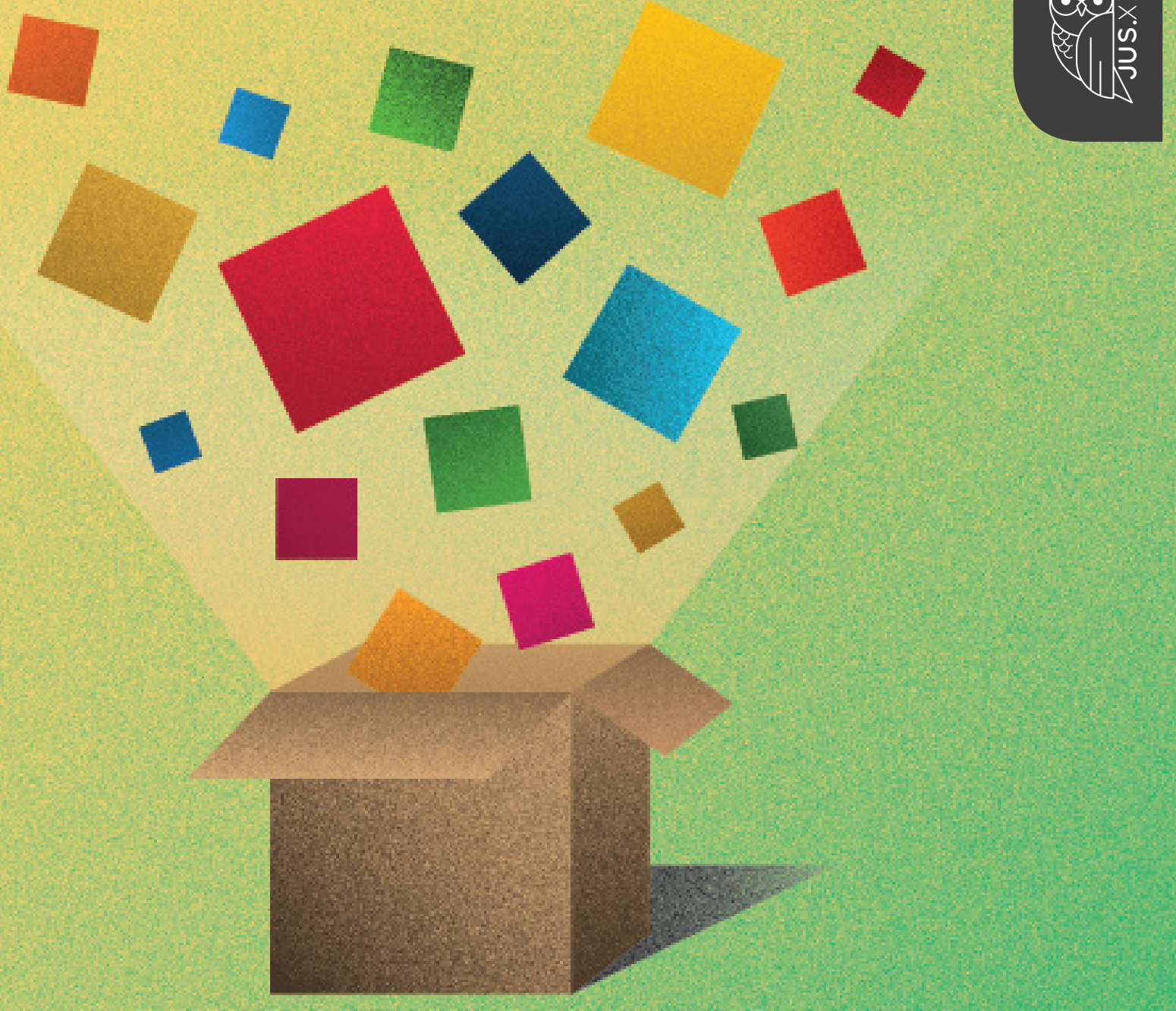

Atas da II Conferência Euro-Americana para o Desenvolvimento dos Direitos Humanos: Agenda 2030 - Um Novo Capítulo para a Evolução dos Direitos Humanos Coimbra, 12 e 13 de Outubro de 2020 [Formato Online]

Comissão Organizadora @CEDH2020:

Marco Ribeiro Henriques

Daniela Serra Castilhos

Anabela Paula Brizido 

Título

Atas da II Conferência Euro-Americana para o Desenvolvimento dos Direitos Humanos - Agenda 2030 - Um Novo Capítulo

para a evolução dos Direitos Humanos

Editores/as

\author{
Marco Ribeiro Henriques \\ Daniela Serra Castilhos \\ Anabela Paula Brizido
}

Revisão

Marco Ribeiro Henriques

Nadine Rita

Capa

Daniel Monteiro

Edição

® JUS.XXI

Data

(C) I Edição

Novembro 2020

Formato

e-Book

ISBN

978-989-54998-0-9

Feito na EU

Todos os direitos são reservados e o acesso à obra é totalmente aberto. Seja na totalidade ou em parte, este livro não pode ser reproduzido ou transmitido a título comercial sem a autorização por escrito da editora. All rights are reserved and access to this work is completely open and free. This book may not be, in whole or in part, reproduced or transmitted on a commercial basis without the written permission of the publisher.

Edições JUS.XXI é uma marca registada de Debates \& Equações, Lda. www.dee.pt

Atenção:

Os resumos estão publicados na sua versão original pelo que a responsabilidade por eventuais lapsos de escrita ou opção ou não pela utilização do novo acordo ortográfico é dos/as Autores/as.

As ideias veiculadas nos textos são da exclusiva responsabilidade dos/as autores/as

e não vinculam ou refletem necessariamente o pensamento da organização.

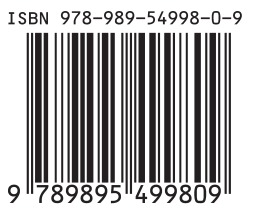



Atas da II Conferência Euro-Americana para o Desenvolvimento dos Direitos Humanos: Agenda 2030 - Um Novo Capítulo para a Evolução dos Direitos Humanos Coimbra, 12 e 13 de Outubro de 2020 [Formato Online]

Comissão Organizadora @CEDH2020:

Marco Ribeiro Henriques

Daniela Serra Castilhos

Anabela Paula Brizido 



\section{COMISSÃO CIENTÍFICA}

\section{Adriana Silva}

Universidade do Minho

Alessandra Rapacci Mascarenhas Prado

Universidade Federal da Bahia

Ana Costa Almeida

Instituto de Contabilidade e Administração de Coimbra

Ana Lambelho

Instituto Politécnico de Leiria

Ana Rita Gil

Faculdade de Direito da Universidade Nova de Lisboa

André Paulino Piton

Instituto Universitário da Maia

André Pereira Matos

Universidade Portucalense Infante D. Henrique

Andrea Sousa

Instituto Superior Miguel Torga

Carlos Silva

Universidade Católica de Salvador

Carmen Hein de Campos

Centro Universitário Ritter dos Reis

Cristina Nogueira da Silva

Faculdade de Direito da Universidade Nova de Lisboa

Cristiane de Souza Reis

Universidade Federal Fluminense

Daniela Serra Castilhos

Universidade Portucalense Infante D. Henrique

Dora Resende Alves

Universidade Portucalense Infante D. Henrique

Elenise Felzke Schonardie

Universidade Regional do Noroeste do Estado

do Rio Grande do Sul

Fábio Veiga

Instituto Iberoamericano de Estudos Jurídicos

Fabiola Miranda Pérez

Universidad Alberto Hurtado

Fabricia Milanezi

Escola Superior de Ciências da Santa Casa

de Misericórdia de Vitória

Fátima Castro Moreira

Universidade Portucalense Infante D. Henrique

Florita Cuhanga Telo

Centro de Direitos Humanos e Cidadania

da Universidade Católica de Angola

Francisco Pereira Coutinho

Faculdade de Direito da Universidade Nova de Lisboa

Gilmar Antonio Bedin

Universidade Regional do Noroeste do Estado

do Rio Grande do Sul

Ilda Massano

Instituto Superior Miguel Torga

Isa António

Escola de Direito da Universidade do Minho

Isabel Baltazar

Faculdade de Ciências Sociais e Humanas

da Universidade Nova de Lisboa
Isabelle Rocha Valenca Figueiredo

Centro de Estudos e Aperfeiçoamento Profissional/MP Joana Almeida

Centro de Estudos Sociais da Universidade de Coimbra João Proença Xavier

Universidade de Salamanca / Universidade Coimbra

Manuel Simas Santos

Instituto Universitário da Maia

Márcia Esteves de Calazans

Universidade Federal do Rio Grande do Sul

Márcia Regina Ribeiro Teixeira

Ministério Público da Bahia

Maria Ângela Rosa Soares

Universidade Vila Velha do Espírito Santo

Maria Assunção do Vale Pereira

Escola de Direito da Universidade do Minho

Maria Creusa de Araújo Borges

Universidade Federal da Paraíba

Maria João Escudeiro

Instituto Politécnico de Lisboa

Maria Barranco

Universidade Católica do Salvador

Paula Almeida

Instituto Politécnico de Tomar

Rafson Saraiva Ximenes

Defensoria Pública do Estado da Bahia

Rita Almeida

Instituto Politécnico de Leiria

Rogério Mota

Centro de Estudos e Aperfeiçoamento Profissional/MP

Rúben Miranda

Universidad de Santiago de Compostela

Sandra Fernandes

Universidade Portucalense Infante D. Henrique

Sidney Guerra

Universidade Federal Fluminense

Sílvia Gomes

CICS -Universidade do Minho / Florida State University

Sónia Guadalupe

Instituto Superior Miguel Torga

Soraya Nour Sckell

Faculdade de Direito da Universidade Nova de Lisboa

Susana Almeida

Instituto Politécnico de Leiria

Susana Costa

Centro de Estudos Sociais da Universidade de Coimbra

Vanessa Ribeiro Simon Cavalcanti

Universidade Católica de Salvador

Vera Mónica da Silva Duarte

ISMAI / CICS.NOVA

Vasco Becker-Weinberg

Faculdade de Direito da Universidade Nova de Lisboa

Wagner de Menezes

Universidade de São Paulo 


\section{AGRADECIMENTOS}

A II Edição da Conferência Euro-Americana para o Desenvolvimento dos Direitos Humanos: Agenda 2030 - Um Novo Capítulo para a evolução dos Direitos Humanos (CEDH2020) acontece num momento muito especial para o mundo. Ainda assim, 2020 foi o ano em que mais de 900 pessoas, oriundas de 12 países, participaram nesta edição, que foi a segunda do evento, e que contou com cerca de 500 trabalhos aprovados, entre quase 700 submetidos, renovando-se, pela amostra, a importância de continuar a ver refletidos múltiplos aspetos e perspetivas sobre o estado dos direitos humanos no mundo.

Este diálogo multidisciplinar e intersecional, entre academia e sociedade, seguindo o exemplo de sucesso na primeira edição em 2020, apenas foi possível de concretizar, por ser ancorado no trabalho resiliente de um conjunto de pessoas e entidades comprometidas com o desenvolvimento dos direitos humanos. Em 2020 a CEDH teve como entidades organizadoras o projeto Law \& Social, LAB, o Ministério Público do Estado de Tocantins e a Universidade Católica do Salvador, tendo contado ainda com o apoio institucional da Câmara Municipal de Coimbra, da Defensoria Pública do Estado da Bahia, do Observatório dos Direitos Humanos, do IBEROJUR e da Direção Regional de Coimbra da Associação Nacional de Jovens Advogados e uma publicação garantida em parceria com a editora conimbricense JUS.XXI.

Registamos o nosso agradecimento a todas as pessoas envolvidas na organização, secretariado, equipas técnicas e, sobretudo, um agradecimento muito especial a todas as pessoas que submeteram trabalhos à CEDH2020.

Agradecimento que abraça igualmente os/as especialistas que aceitaram o desafio de colaborar na CEDH2020, participando nas mesas plenárias, nomeadamente,

Isabelle Valença de Figueiredo, Patrícia Freire, João Luiz Lessa Neto, Vanessa Cavalcanti, Renee Ó Souza, Jorge Gato e Rafson Saraiva Ximenes, Defensor Público Geral do Estado da Bahia,

e, ainda, um agradecimento muito especial ao painel de especialistas que compôs a Comissão Científica da CEDH2020, participando da avaliação dos trabalhos num rigoroso processo de revisão por pares cegos. 


\section{ACKNOWLEDGES}

The Euro-American Conference for Human Rights' Development: Agenda 2030 - A New Chapter for the Evolution of Human Rights (CEDH2020) takes place at an exceptional time for the world. Around the current scenario, 2020 was the year in which more than 900 people from 12 countries participated in this edition, which was the second event. It had around 500 papers approved, among almost 700 submitted.

This multidisciplinary and intersectoral dialogue between academia and society, sustaining the first edition's success, was only possible because it was anchored in the resilient work of a group of people and entities committed to the development of human rights. In 2020 the CEDH had as organizers the Law \& Social Project, $L A B$, the Public Prosecution Service of the State of Tocantins and the Catholic University of Salvador, and also had the institutional support of the City Council of Coimbra, the Public Defender's Office of the State of Bahia, the Human Rights Observatory, IBEROJUR and the Regional Management of Coimbra of the National Association of Young Lawyers and a publication guaranteed in partnership with the publisher JUS.XXI.

We would like to thank all those involved in the organization, secretariat, technical teams, and, above all, a very special thank you to all those who submitted their work to the CEDH2020. Thanks also to the experts who took up the challenge of collaborating on the CEDH2020 by participating in the plenary tables, namely

Isabelle Valença de Figueiredo, Patrícia Freire, João Luiz Lessa Neto, Vanessa Cavalcanti, Renee Ó Souza, Jorge Gato and Rafson Saraiva Ximenes, General Public Defender of the State of Bahia,

and a special thanks to the panel of experts that composed the Scientific Committee of the CEDH2020, participating in the evaluation of the work in a rigorous process of blind peer review. 


\section{PROGRAMA GERAL}

DIA I - I2 DE OUTUBRO DE 2020

9h00

IOh00

IIh00

$14 \mathrm{~h} 00$

$15 \mathrm{~h} 00$

$16 \mathrm{~h} 00$

I7h00

$18 \mathrm{~h} 00$

$19 \mathrm{~h} 00$

$20 \mathrm{~h} 00$

$2 \mathrm{lh} 00$
Abertura de Portas

\section{Conferência Plenária I}

O Juíz como Propulsor de Ativo da Dialética Processual Oradora: Patrícia Freire

\section{ODS I}

Erradicação da Pobreza

ODS 2

Fome Zero e Agricultura Sustentável

ODS 3

Saúde e Bem-Estar

ODS 4

Educação de Qualidade

Mesa Redonda A

Conferência Plenária II

Direito Fundamental de Acesso à Justiça e Processo Multiportas Orador: Doutor João Luiz Lessa Neto

ODS 5

Igualdade de Género

ODS 8

Trabalho Decente e Crescimento Económico

\section{Conferência Plenária III}

Princípios ou Fins? Alianças, Redes e Presente-Futuro dos Direitos Humanos

Oradora:Vanessa Cavalcanti 
ODS 9

Indústria, Inovação e Infraestrutura

I Ih00

ODS 10

Redução das Desigualdades

$12 \mathrm{~h} 00$

Cidades e Comunidades Sustentáveis

Mesa Redonda B

Produção e Consumo Sustentáveis

$14 \mathrm{~h} 00$

\section{Conferência Plenária IV}

Os Direitos Humanos, o Dever de Tutela Penal e as Obrigações Positivas!

Orador: Renee Ó Souza

ODS 13

Ação Contra a Mudança Global do Clima

Mesa Redonda C

$16 \mathrm{~h} 00$

ODS 6

Água e Saneamento

\section{Conferência Plenária V}

Identidades LGBTQ: Entre a Igualdade Legal e a Invisibilidade Social Orador: Jorge Gato

ODS 16

Paz, Justiça e Instituições Eficazes

Parcerias e Meios de Implementação

\section{Conferência Plenária VI}

Acesso à Justiça e Defesa Pública

Orador: Rafson Saraiva Ximenes

- Defensor Público Geral do Estado da Bahia 


\section{ÍNDICE}

CAPÍTULO INTRODUTÓRIO

PERSPECTIVES AND

PLURAL CHALLENGES

FOR DELIVERING

2030 AGENDA - A NEW

CHAPTER FOR HUMAN

RIGHTS EVOLUTION

33

ODS I

\section{ERRADICAR}

A POBREZA

34

Ana Camões, Ana Noronha \& Susana Oliveira e Sá A PROTEÇÃO SOCIAL PARAA OU DA POBREZA: TESTEMUNHOS DE EXCLUSÃO SOCIAL

Marcela Magalhães De Paula

AS OCUPAÇÕES DE IMÓVEIS PROMOVIDAS POR CASAPOUND ITALIA, O DISCURSO DA SOLIDARIEDADE SELETIVA E DA TRADUÇÃO POLÍTICA DA IMIGRAÇÃO

36 José Lúcio \& Maria Filomena Marques HABITAÇÃO E DIREITOS HUMANOS - O CASO DOS SEM-ABRIGO

Ideni Terezinha Antonello

AS DESIGUALDADES SOCIOESPACIAIS EM LONDRINA: O PAPEL DAS POLÍTICAS PÚBLICAS NA REDUÇÃO DA POBREZA

Eloiza Da Silva Gomes De Olivera, Janaína Luana Rodrigues da Silva Valentim, Ricardo Alexsandro de Medeiros Valentim \& Ronaldo Silva Melo UM OLHAR PARA ALÉM DO CONCRETO: O CÁRCERE SELETIVO NO BRASIL E POSSIBILIDADES DA EDUCAÇÃO MEDIADA POR TECNOLOGIAS

39 Jordana Sofia da Silva \& Mickhael Erik Alexander Bachmann A GUARDA DE MENORES EM FAMÍLIAS SOCIALMENTE VULNERÁVEIS: UM CASO DE PROSTITUTAS DO INTERIOR DE SANTA CATARINA/BRASIL
AS EXPECTATIVAS FUTURAS CONSTRUÍDAS

POR RECLUSOS(AS) IDOSOS(AS)

\section{ODS 2}

\section{ERRADICAR A FOME}

Luana Sales Barros da Silva \& Maria Goretti dal Bosco

GARANTIA DO DIREITO À ALIMENTAÇÃO EM ÉPOCA DE PANDEMIA NO BRASIL: UM ESTUDO COMPARATIVO ENTRE AS REALIDADES PERIFÉRICAS DURANTE AS PANDEMIAS

Nicoly Stephani da Silva

A RELEVÂNCIA DA EFETIVAÇÃO DE AÇÕES POSITIVAS PARA A GARANTIA DA ALIMENTAÇÃO NO NORDESTE BRASILEIRO

Celso Lopes Seus

DIREITOS HUMANOS E A ERRADICAÇÃO DA MISÉRIA

Lorena Granja Hernández, Mauro Macedo Campos \& Caroline Saboia Rangel "FIAT PANIS:A ATUAÇÃO DA FAO NO BRASIL"

Leonora de Abreu Bernardes

AÇÕES CONTRA A FOME: UMA ANÁLISE DO PROGRAMA NACIONAL DE FORTALECIMENTO DA AGRICULTURA FAMILIAR DO BRASIL

ODS 3

O IDOSO ENCARCERADO:

CONSIDERAÇÕES CRIMINOLÓGICAS

Ana M Mernández Fernández 
Abliio Azevedo \& Patrícia Anjos Azevedo

DIREITO AO ENSINO: IGUALDADE DE ACESSO

E AS NOVAS TECNOLOGIAS AO SERVIÇO DAS ÁREAS DO DIREITO E DA SAÚDE

51

Vera Duarte, Susana Costa, Catarina Cardoso \& Mariana Soares

RISKS AND THREATS TO THE RIGHTS OF PETS

IN PANDEMIC TIMES:AN EXPLORATORY STUDY

52 Maria do Rosário Anjos

LIMITES À RESTRIÇÃO DE DIREITOS FUNDAMENTAIS EM ESTADO DE EMERGÊNCIA

Henrique Alexander Keske \& Claudine Freire Rodembusch

EUTANÁSIA COMO DIREITO HUMANO

FUNDAMENTAL À MORTE DIGNA: NECESSIDADE

DE LEGISLAÇÃO QUE REGULAMENTE A MATÉRIA

54 María Desamparados Bohigues Esparza

LA ENFERMEDAD DE LARGA DURACIÓN COMO FACTOR DE DISCRIMINACIÓN EN EL ÁMBITO LABORAL

55 Celsimar Custódio Silva

A CONDIÇÃO DE GARANTE DO ENTE ESTATAL AO DIREITO À SAÚDE EMTEMPOS DE PANDEMIA

sa António

O DIREITO À PLENA INFORMAÇÃO E O DIREITO À AUTONOMIA DECISÓRIA DO DOENTE COMO CONCRETIZAÇÕES DO PRINCÍPIO DA DIGNIDADE HUMANA

57 Tânia Regina Silva Garcez, Déa Marisa Brandão CubelYule \& Gisele Beraldo de Paiva

TRABALHADORES EM GRUPO DE RISCO E O LIMBO PREVIDENCIÁRIO-TRABALHISTA: HARMONIZAÇÃO DO PRINCÍPIO DA RESERVA LEGAL E DA DIGNIDADE HUMANA

Patrícia Estácio de Lima Corrêa

THE PORTUGUESE APPROACH ON UNDOCUMENTED MIGRANTS ACCESS TO HEALTHCARE DURING THE PANDEMIC:A NEW STEPTOWARDS A MORE INCLUSIVE STANDARD POL

59 Ana Rita Baracho Ferreira \& Andrea Isabel Oliveira da Costa e Sousa MAIS ALTERNATIVAS SÉNIOR - UM PROJECTO DE SAÚDE E QUALIDADE DEVIDA: ESTUDO DE CASO NUMA IPSS

Margarida Pocinho \& Soraia Garcês

A MEASURE OFWELLBEING TO PROMOTE HUMAN RIGHTS

61

Soraia Garcês \& Margarida Pocinho

HOW UNDERSTANDING PSYCHOLOGICAL GENDER DIFFERENCES INTOURISM EXPERIENCES CAN BE AWAYTO PROMOTE GENDER EQUALITY
Aline Regina Carrasco Vaz \& Suzana Mendonça

62

O DIREITO À SAÚDE NO CONTEXTO DOS MÉTODOS ALTERNATIVOS DE PARTO

Najah Jamal Daakour Barakat \& Eduardo Soares da Silva

PANDEMIA DA COVID-I9 EA POSSIBILIDADE

DE OFENSA AOS DIREITOS HUMANOS

Jefferson Rodrigo da Silva

64

O IMPACTO DA DISSEMINAÇÃO DO CORONAVÍRUS (COVID-19) ENTRE AS COMUNIDADES INDÍGENAS DA AMAZÔNIA BRASILEIRA

Raíssa Moreira Lima Mendes Musarra, Olivia de Quintana Figueiredo Pasqualeto, Regina Célia Martinez \& Renata Miranda Lima

PROTOCOLOS DE IDENTIFICAÇÃO,AVALIAÇÃO E MINIMIZACCÃO DE RISCOS PSICOSSOCIAIS LABORAIS SEM CONTEXTO DE COVID-I 9 ENTRE ADVOGADOS

Eduardo Manuel Val

O DIREITO A SAÚDE NAS AMÉRICAS:

A RECONFIGURAÇÃO DA ORGANIZAÇÃO

PAN-AMERICANA DA SAÚDE À LUZ DA TEORIA DO CONSTITUCIONALISMO GLOBAL

Fausy Vieira Salomão

A REVOGAÇÃO DA LEI DROGAS NO BRASIL COMO MEDIDA DE REDUÇÃO DA DESIGUALDADE SOCIAL E DISCRIMINAÇÃO RACIAL

João Proença Xavier

FECUNDACIÓN POS MUERTE EN CONTEXTO IBERICO

Luciana Nunes Fonseca \& Morgane Rein

SENTIDOS E PERSPECTIVAS DE ASSISTÊNCIA AO PARTO NO BRASIL

Kelda Sofia Da Costa Santos Caires Rocha \& Dyhelle Christina Campos Mendes COMUNIDADES QUILOMBOLAS DE ALCÂNTARA, POLITICA DESAPROPRIATÓRIA BRASILEIRA EM CONTEXTO DE PANDEMIA E A (DES)PROTEÇÃO DOS DIREITOS HUMANOS

Daniela Maria Manna Bartasevicius, Maria Isabel Chagas \& Ana Paula Caetano EDUCAÇÃO SEXUAL EM CONTEXTO ESCOLAR: UM INVENTÁRIO DAS INVESTIGAÇÕES ACADÉMICAS PORTUGUESAS NA ÚLTIMA DÉCADA

María Concepción Vega-Hernández \& Ana Victoria Torres-García REPERCUSIÓN EN LA SALUD FÍSICA YPSICOLÓGICA DE LA MUTILACIÓN GENITAL FEMENINA EN NIÑAS MIGRANTES

Carlos Cortez Ruiz

EFECTOS PROFUNDOS DE LA PANDEMIA DE COVID. LIMITACIONES PARA AVANZAR EN LOS ODS PARA LA POBLACIÓN RURAL EN MÉXICO 
Cláudia Valéria Fonseca da Costa Santamarina

ADESÃO E MULHERES VIVENDO COM HIVIAIDS - A DIFÍCIL TAREFA DO CUIDAR PARA ALÉM DE TRATAR

75 Mariana Mrosk Teixeira \& Lourival Barão Marques Filho SAÚDE E DIGNIDADEDA PESSOA HUMANA, COM ÊNFASE NO MEIO AMBIENTE LABORAL

Clarice Seixas Duarte, Roxana Marina Cortina Mendonza,Vania Bogado De Souza Di Raimo \& Amanda Salgado E Carvalho

PERU AND BRAZIL:WELFARE STATE'S COMMON CHALLENGES INTHE CONTEXT OF COVID-19

ica Cindra de Lima, Cristiane Diello Granville, Márcia Garritano \& Cleuber Lima REFLEXO DA DESIGUALDADE EM DIREITOS HUMANOS NOS ALUNOS DAS CLASSES POPULARES EM PERÍODO DE OUARENTENA POR CORONAVÍRUS

vone Dias Avelino

EPIDEMIAS NA HISTÓRIA.A GRIPE ESPANHOLA EM SÃO PAULO/BRASIL

\section{9}

ODS 4

\section{EDUCAÇ̃̃O DE QUALIDADE}

Benvindo de Jesus Rocha, Filipa Seabra \& Marta Abelha GESTÃO PEDAGÓGICA NAS ESCOLASTÉCNICAS CABO-VERDIANAS: ENTRE PERSPETIVAS ETENDÊNCIAS DAS LIDERANÇAS PARA A PROMOÇÃO DE MUDANÇAS

81 Edson Mitsuo Tiujo A MISSÃO DAS UNIVERSIDADES PARA A PROMOÇÃO DA DIVERSIDADE E DA INCLUSÃO SOCIAL

82 Cristiane de Souza Reis

A IMPORTÂNCIA DA MUDANÇA DE PARADIGMA NA FORMA DE ADMINISTRAÇÃO DE CONFLITO NO ÂMBITO ESCOLAR

Dilson Araújo Alves Peixoto \& Antonio Carlos da Silva CIDADANIA MUSICAL: UM DIREITO HUMANO IMPRESCINDÍVEL

Cristina Paula da Silva Dias \& Maria Isabel Borges ENSINO SUPERIOR E OBJETIVOS DE DESENVOLVIMENTO SUSTENTÁVEL TAS POR UMA ORIENTAÇÃO EDUCATIVA MUNDIAL
Suzy de Abreu Costa \& Filipa Seabra Borges

PERSPECTIVAS E PRÁTICAS PEDAGÓGICAS INCLUSIVAS: DOCENTES E USO DAS TIC

Paula Maria Santos Frazão

PROJETO EM EDUCAÇÃO ESPECIAL - DA EDUCAÇÃO ESPECIALÀ EDUCAÇÃO INCLUSIVA - UMA LINHA CONDUTORA

Ana Silvia Albuquerque, Sandra Fernandes \& Marta Abelha

EDUCAÇÃO PARA O DESENVOLVIMENTO SUSTENTÁVEL E RESPONSABILIDADE SOCIAL NO ENSINO SUPERIOR: UM ESTUDO DE CASO NA UNIVERSIDADE PORTUCALENSE

Maria Amelia Reis

FÉ ESPERANÇA E CARIDADE, ESCRAVIZADA,VIOLENTADA... PATRIMÔNIOS EDUCATIVO-CULTURAIS SEQUESTRADOS: DESAFIOS PARA AVANÇOS DOS DIREITOS HUMANO

Fernando Enrique Grenno, Christiana Cabecieri Profice \& Rhadson Resende Monteiro

DIREITOS HUMANOS E EDUCAÇÃO:A IMPORTÂNCIA DAS ÀREAS PROTEGIDAS E O DIREITO AO MEIO AMBIENTE EM CRIANÇAS E ADOLESCENTES

Carolina Piccolotto Galib \& Marina Martin

O DESAFIO DO ACESSO À EDUCAÇÃO DE CRIANÇAS MIGRANTES DURANTE A PANDEMIA: UMA ANÁLISE DAS POLÍTICAS PÚBLICAS DO ESTADO DE SÃO PAULO

Marcio Braz Do Nascimento

EDUCAÇÃO EM DIREITOS HUMANOS PARA JUVENTUDES DE ENSINO MÉDIO EMTEMPO INTEGRAL PROPOSTA PARA O ODS 4, EDUCAÇÃO DE QUALIDADE

Eduardo Soares Da Silva \& Najah Jamal Daakour Barakat

EDUCAÇÃO COMO FERRAMENTA DE IGUALDADE E EQUIDADE SOCIAL COM A AVERIGUAÇÃO DOS DIREITOS HUMANOS

Julio Cesar Rodrigues

A (TRANS)FORMAÇÃO SOCIAL ATRAVÉS DA EDUCAÇÃO INCLUSIVA

Tadeu Lucas de Lavor Filho

CARTOGRAFIA DE INTER(IN)VENÇÃO DO GRAFFITI NO COTIDIANO DA PERIFERIA DE FORTALEZA, BRASIL: INVENÇÕES EM DIREITOS HUMANOS

Leonardo Marques Vieira \& Maria Clara Giassetti DAS DESIGUALDADES SOCIAIS 

MAPEAMENTO DE ESPAÇOS CRIATIVOS EM CAMPO GRANDE NO RIO DE JANEIRO

Licicia Petry de Faria \& Claudia Maria Petry de Faria

A PRESERVAÇÃO DA INFÂNCIA ATRAVÉS DA PRODUÇÃO DE BRINQUEDOS DE MATERIAIS RECICLÁVEIS: UM PROJETO ESCOLAR PARA A DIGNIDADE E SOLIDARIEDADE

Sergio Belda-Miquel, Elena Mut Montalvà \& Ana Isabel Vázquez Cañete UN DESPLIEGUE TRANSFORMADOR DE LOS ODS EN LA EDUCACIÓN SUPERIOR:APLICANDO LOS ODS CON ENFOQUE DE CUIDADOS EN ELTRABAJO FIN DE GRADO

I00 Eloiza Cristiane Torres EDUCAÇÃO AMBIENTAL NA CASA DO CAMINHO: AÇÕES PARA ALÉM DA TEORIA

101 lago de Souza Marconi \& Luiz Nunes Pegoraro O DIREITO À EDUCAÇÃO NA PANDEMIA PROVOCADA PELO NOVO "CORONAVÍRUS": FLAGRANTE DE DESIGUALDADE SOCIAL E INEFICÁCIA ESTATAL

102 Jeani Delgado Paschoal Moura FORMAÇÃO DOCENTE PARA O ESTUDO DA COVID-I 9 NO CONTEXTO DAS GEOGRAFIAS DOS RISCOS EM MICROESCALA

Fernanda Maria Grasselli Freitas \& Gustavo Henrique Araújo dos Santos A IMPORTÂNCIA DA EDUCAÇ̃̃O AMBIENTAL, EM NÍVEL MUNICIPAL, E OS REFLEXOS NO ÍNDICE DA COLETA SELETIVA DE RESÍDUOS RECICLÁVEIS

Ana Cristyna Macedo L.S.Bosco

DIREITOS HUMANOS À EDUCAÇÃO: UMA ANÁLISE À LUZ DA AGENDA 2030

Elaine Cristina da Silva, Adriana Goulart de Sena Orsini, Lucas Jeronimo Ribeiro da Silva \& Cibele Aimée de Souza

UNIVERSIDADE DE DIREITOS: EDUCAÇÃO, INFÂNCIA E JUVENTUDE

Sheila Stolz \& Daniel Berlezi de Quadros

EDUCAÇÃO INCLUSIVA, EQUITATIVA E DE QUALIDADE: DESAFIOS PARA O ENSINO SUPERIOR EMTEMPOS DE COVID-19

Catarina Sobral \& Ana Paula Caetano

O CONFLITO NO JARDIM DE INF NCIA COMO OPORTUNIDADE DE DESENVOLVER UMA CULTURA COLABORATIVA, DE MEDIAÇÃO E DE PAZ
Vinicius Barbosa Albernaz

PARLAMENTO JOVEM - ANÁLISE COMPARATIVA DOS PROGRAMAS DO BRASIL E DE PORTUGAL

DE MENORES A CRIANÇAS EADOLESCENTES: AS CATEGORIAS MOBILIZADAS NA REDEMOCRATIZAÇÃO EMTORNO DA REGULAMENTAÇÃO DE DIREITOS INFANTOJUVENIS

Clara Marques

EDUCAÇÃO ARTÍSTICA, PARTICIPAÇÃO, ENVELHECIMENTO E DIREITOS CULTURAIS

Irene Pochetti \& Benjamin Denecheau

¿PRESENCIALIDAD EN LA DISTANCIA? CONFINAMIENTOY ALTERACIÓN DEVÍNCULO EN LA INTERVENCIÓN SOCIAL HACIA LOS NIÑOS, NIÑASY SUS FAMÍLIAS

Mariane Yuri Shiohara Lubke \& Arlei Costa Junior

PLANEJAMENTO DE POLÍTICAS PÚBLICAS EDUCACIONAIS PÓS-COVID E A NECESSIDADE DE ENFRENTAMENTO DA DESIGUALDADE ESTRUTURAL NO BRASIL

Márcia Esteves De Calazans \& Maria Aparecida Bergamaschi

AÇÕES AFIRMATIVAS NA PÓS-GRADUAÇÃO STRICTO SENSU: PERCEPÇÕES DOS DISCENTES SOBRE A RESERVA DEVAGAS NO PROGRAMA DE PÓS-GRADUAÇÃO EM EDUCAÇÃO

Renata Garcia Senlle

CONVERSAS DE MÃE EM REDE: UM PERCURSO NETNOGRÁFICO DO ATIVISMO DIGITAL MATERNO À BANCADA DE MÃES ATIVISTAS NAS ELEIÇÕES DE 2018

Juliano Bernardino de Godoy

EDUCAÇÃO E DIREITOS HUMANOS: PERSPECTIVAS PARA UM NOVO TEMPO COM MAIS IGUALDADE

VitorTomé

EDUCAÇÃO PARA A CIDADANIA DIGITAL EM ESCOLAS EUROPEIAS: DA TEORIA AOTERRENO

Milena de Bonis Faria

MEDIAR PARA EDUCAR: MEDIAÇÃO, CONCILIAÇÃO, MINDFULNESS NAS ESCOLAS OPR MEIO CÍRCULOS EM MOVIMENTOS

Andréa Arruda Vaz, Andressa lgnácio da Silva \& Tais Martins

A JUDICIALIZAÇÃO E O COMBATE DAS DESIGUALDADES SOCIAIS: AÇÕES AFIRMATIVAS DE ACESSO AO ENSINO SUPERIOR À LUZ DA ANÁLISE JURÍDICA E SOCIOLÓGICA 
Marcelo de Luz Batalha

JOVENS CIENTISTAS:A PROMOÇÃO DE GÊNERO NA CIÊNCIA A PARTIR DO PROGRAMA DE INICIAÇÃO CIENTÍFICA NO INSTITUTO FEDERAL GOIANO

121

Susana Sardinha Monteiro, Jenny Sousa \& Antónia Barreto

"DIREITOS HUMANOS E EDUCAÇÃO":

CONCEITOS E CONTEXTOS

122 Mauricio Rodrigues Peixoto

ESCOLA 2030:A AGENDA 2030 DA ORGANIZAÇÃO DAS NAÇÕES UNIDAS APLICADA EM UMA ESCOLA PÚBLICA DO DISTRITO FEDERAL, BRASIL

Sabrina Cesar Freitas \& Simone Meucc

ELABORAÇÕES DA ESPERANÇA: DIREITOS HUMANOS E SOCIOLOGIA NA EDUCAÇÃO BRASILEIRA

Jeani Delgado Paschoal Moura

DESCALÇOS NA SOLEIRA DOS NOVOS TEMPOS: FORMAÇÃO E OUTROS TEMAS EM EDUCAÇÃO HUMANISTA DE BASE FENOMENOLÓGICA

Chudnovskaya Irina

THE POTENTIAL OF MASS COMMUNICATION INTHE FORMATION OF AN INCLUSIVE CULTURE IN EDUCATION

Maria José Varadinov

"BE AWARE STUDENT: BUSINESS MODEL

- I, PASSIONATE IT PROFESSIONAL"

Alice Duarte

O DESAFIO DE UMA ABORDAGEM INTERCULTURAL PARA OS DIREITOS HUMANOS

Victoria Cardemil

EDUCACIÓN DESESCOLARIZADA, ESTUDIO DE CASO DE UNA COMUNIDAD EDUCATIVA EN LA CIUDAD DE IQUIQUE, CHILE

TODOS IGUAIS PELA EDUCAÇÃO: O PROGRAMA DE APOIO PERMANENTE DO ESTADO DO PARANÁ (BRASIL) EM PROL DE ESTUDANTES COM DEFICIÊNCIA MATRICULADOS EM ESCOLAS DA REDE PARCERIA DA SOCIEDADE CIVIL ORGANIZADA

Miguelangelo Gianezini, Thiago Henrique Almino Francisco \& António Teodoro BLENDED-LEARNING: POSSIBILIDADES NA FORMAÇÃO INCLUSIVA, EQUITATIVA E DE QUALIDADE PARA PROFESSORES E PESQUISADORES

I3 Thiago Henrique Almino Francisco, Miguelangelo Gianezzinni \& Pedro Antônio de Melo OS DESAFIOS DA REGULAÇÃO DO ENSINO SUPERIOR BRASILEIRO NO CONTEXTO DA PANDEMIA
Vianna, J., Grecco, C. H. S., Carvalho, P.V. R. \& Cosenza, C. A. N

HIERARQUIZAÇÃO DE FATORES CRÍTICOS PARA UMA EDUCAÇÃO EFICIENTE UTILIZANDO A TEORIA DOS CONJUNTOS EXPANDIDOS - FUZZY

ODS 5

\section{IGUALDADE DE GÉNERO}

A CONDIÇÃO FEMININA E OS CAMINHOS PARA A PRISÃO NO BRASIL

CLARA DOS ANJOS DE LIMA BARRETO: EMPODERAMENTO E LUTA PELOS DIREITOS HUMANOS DAS MULHERES NEGRAS BRASILEIRAS

María G. Navarro \& Noemi de Haro García

"FIXING THE SYSTEM":THE AUDIOVISUAL REPRESENTATION OF DELIBERATIVE CULTURE INSIDE THE PRISON

Isabel Baltazar

A IGUALDADE DE GÉNERO NO DESENVOLVIMENTO SUSTENTÁVEL DA ONU: O OBJECTIVO 5 DA AGENDA 2030

Maria Angela Rosa Soares, Patrícia Maria da Silva Merlo \& Vanessa Ribeiro Simon Cavalcanti

VIOLÊNCIAS CONTRA MULHERES E O DISCURSO JURÍDICO: UM ESTUDO DE SENTENÇAS CRIMINAIS DO MUNICÍPIO DEVILA VELHA/ES/BRASIL -1975-2010

Valéria Giumelli Canestrini \& Jaime Leônidas Miranda Alves

O RACISMO AMBIENTAL COMPREENDIDO SOB A PERSPECTIVA DA IGUALDADE COMO RECONHECIMENTO

Joana Torres \& Joana Topa

VIOLÊNCIA(S) DE GÉNERO NA GUINÉ-BISSAU PELA PERSPETIVA DE PROFISSIONAIS DO TERRENO

Eglatina Albuquerque de Oliveira Souza e Silva \& Deborah Bandeira de Deus e Mello

ESTUDO COMPARADO DA PROTEÇÃO DOS DIREITOS HUMANOS DA COMUNIDADE LGBTQIA+ NOS SISTEMAS REGIONAIS INTERAMERICANO E EUROPEU

Maria Cristina Vidotte Blanco Tarrega

VIOLÊNCIA CONTRA AS MULHERES DA RESISTÊNCIA CAMPONESA EA RESILIÊNCIA EMTEMPOS PANDÊMICOS 
A PRESENÇA DAS MULHERES NOS FÓRUNS DE PARTICIPAÇÃO POPULAR DE REVISÃO DO PLANO DIRETOR (20I8/2028) PARTICIPATIVO DE LONDRINA/ BRASIL

Renata Miranda Lima \& Raíssa Moreira Lima Mendes Musarra MECANISMOS GLOBAIS PARA CONCRETIZAÇÃO À IGUALDADE DE GÊNERO NAS CARREIRAS DA AD-VOCACIA E NA MAGISTRATURA: O ESTADO DE SÃO PAULO COMO ESTUDO

ernanda Proença de Azambuja, Luciana do Amaral Rabelo \& Andrea Flores DIREITOS FUNDAMENTAIS NOTRATAMENTO DAS VÍTIMAS DEVIOLÊNCIA DOMÉSTICA NO BRASIL: AVANÇOS NECESSÁRIOS

Ana Evelyne Cavalcante Costa Cerqueira \& Lorena Nogueira Rêgo AS PRÁTICAS RESTAURATIVAS COMO MEIOS EFETIVOS PARA A TRANSFORMAÇÃO DE CONFLITOS DEVIOLÊNCIA DOMÉSTICA

Michelli Linhares de Bastos

O AUTISMO FEMININO E OS ESTEREÓTIPOS DE GÊNERO: UM ESTUDO COM MENINAS E MULHERES DA CIDADE DE CACHOEIRINHA/RS, BRASIL

I48 Morgane Reina \& Luciana Nunes Fonseca

A ORAÇÃO DA MULHER SILENCIOSA:VIOLÊNCIA DOMÉSTICA CONTRA MULHERES EVANGÉLICAS E POLÍTICAS PÚBLICAS

I49 Lúcia Souza d'Aquino

A ERRADICAÇÃO DA VIOLÊNCIA OBSTÉTRICA COMO FORMA DE ALCANCE DE IGUALDADE DE GÊNERO E EMPODERAMENTO DAS MULHERES

I 50 Florita Cuhanga António

DESAFIOS A IMPLEMENTAÇÃO DO DIREITO DAS MULHERES AO TRABALHO EM ANGOLA

I 5 I Patrícia Tuma Martins Bertolin \&Werdeson Olimpio NOTIFICAÇÃO COMPULSÓRIA DA VIOLÊNCIA DOMÉSTICA CONTRA A MULHER NO BRASIL: ANÁLISE À LUZ DA BIOÉTICA FEMINISTA E DA TRANSVERSALIDADE DE GÊNERO

I52 Artenira da Silva e Silva \& José Augusto Sá Costa Leite A PROTEÇÃO DE MULHERES EM SITUAÇÃO DE VIOLÊNCIA DOMÉSTICA COM A PROLAÇÃO DE SENTENCCAS DE MÉRITO EM MEDIDAS PROTETIVAS DE URGÊNCIA INTERAMERICANA DE DERECHOS HUMANOS EN LA PROTECCIÓN DE DERECHOS DE MUJERES EN MÉXICO
Grazielly Alessandra Baggenstoss

UNIVERSIDADE FEDERAL DE SANTA CATARINA (UFSC) COMO INSTITUIÇÃO PROMOTORA DA IGUALDADE DE GÊNERO NO BRASIL

Nathaly Veloso Lehnen

TEORIA DAS JANELAS QUEBRADAS -“THE BROKEN WINDOWS THEORY” - E A SUA IMPORTACCÃO PARA O CENÁRIO BRASILEIRO

João Pedro Rodrigues Nascimento \& Luciana do Amaral Rabelo A VIOLÊNCIA DE GÊNERO CONTRA TRAVESTIS E MULHERES TRANSSEXUAIS E AS POSSIBILIDADES NORMATIVAS PARA COIBI-LA

Paulina Vergara Saavedra \& Camila Troncoso Zúñiga

GÉNEROY DERECHOS HUMANOS: NUDOY DEUDA DEL ESTADO CHILENO EN LA GESTIÓN DE EMERGENCIASY DESASTRES

Paloma Abelin \& Rosana Machin

AS IGREJAS ENQUANTO ELEMENTO DE INTERLOCUÇÃO ENTRE A ESFERA PRIVADA E PÚBLICA NA VIDA DAS MULHERES: UM ESTUDO A PARTIR DE HISTÓRIAS DEVIDA

Maria Clara Giassetti, Julia Henn Arcos \& Renata Silva Souza

A EDUCAÇÃO COMO CAMINHO AO EMPODERAMENTO FEMININO

Estefânia Silva

PERSPETIVAS DE GÉNERO SOBRE A PANDEMIA COVID-I 9 E OS SEUS IMPACTOS NAS MIGRAÇÕES

Breno Cypriano, Bárbara Angove Lopes \& Marlise Mato

UMA ANÁLISE DO ODS 5 NA CIDADE DE BELO HORIZONTE: UMA ANÁLISE AMPLIADA E O IMPACTO DA PANDEMIA DO COVID-19

Carina Jordão

A VIOLÊNCIA DOMÉSTICA EAS CONQUISTAS DAS MULHERES: REFLEXÕES A PARTIR DA SITUAÇÃO PORTUGUESA

Ananya Mishra \& Anurag Banerje

DEVELOPING A SUB-NATIONAL GENDER DEVELOPMENT INDEX IN INDIA

Taís Haywanon Santos Maia

A INCONSTITUCIONALIDADE DA CRIMINALIZAÇÃO DO ABORTO À LUZ DA ADPF 442 NO BRASIL 


\section{5}

\section{9}

166

167

BANCADA DE MÃES ATIVISTAS -DE ATIVISTAS DIGITAIS E CANDIDATAS ÀS ELEIÇÕES DE 2018 NO BRASIL

A QUESTÃO DO DIREITO À ÁGUA EA AUSÊNCIA DE PROTAGONISMO NO DEBATE PÚBLICO POLÍTICO
Renata Garcia Senlle

ODS 6

\section{ÁGUA POTÁVEL E SANEAMENTO}

\section{ODS 8}

\section{TRABALHO DIGNO E CRESCIMENTO ECONÓMICO}

AGRESSÕES ÀS POLÍTICAS PÚBLICAS DE COMBATE AO TRABALHO INFANTIL, NO BRASIL: SEU AGRAVAMENTO EMTEMPOS DE PANDEMIA

I7I Raúl Payá Castiblanque

IMPACT OFTHE DIRECT PARTICIPATION OFWORKERS INTHE DESIGN OF PREVENTION MEASURES OF PSYCHOSOCIAL ORIGIN ON THE LEVELS OF ABSENTEEISM

oão Paulo Dias, Paula Casaleiro \& Teresa Maneca Lima

CONDIÇÕES DETRABALHO NOS TRIBUNAIS: IMPACTOS DA PANDEMIA COVID-I9 NA REALIZAÇÃO DA JUSTIÇA

Amanda Cristina Campos de Almeida \& Carla Reita Faria Lea SAÚDE MENTAL NO TRABALHO: PERSPECTIVAS PARA O ENFRENTAMENTO AO ADOECIMENTO PSÍQUICO DOS TRABALHADORES SOB AS DIRETRIZES DA OIT E DA OMS

Eduardo Soares da Silva \& Najah Jamal Daakour Barakat OBSERVANDO OS DIREITOS HUMANOS E O CONTEÚDO DEVULNERABILIDADE ECONÔMICA
Claudia Maria Petry de Faria \& Letícia Petry de Faria

O DIREITO A DESCONEXÃO E O TRABALHO REMOTO: A IMPORTÂNCIA DO MEIO AMBIENTE DO TRABALHO NO DESENVOLVIMENTO DO HOMEM

Benedita de Fátima Delbono \& Pedro Gabriel Delbono Trivelato

A REPERCUSSÃO DOS EVENTOS DE MARIANA E BRUMADINHO À CONSECUÇÃO DO ODS 3 PARA A REDUÇÃO SUBSTANCIAL DO NÚMERO DE MORTES E DOENÇAS POR PRODUTOS

Tais Martins, Andréa Arruda Vaz, Maria das Dores Francelino \& Andressa Ignácio da Silva

A EXPLORAÇÃO HUMANA PELO TRABALHO ESCRAVO EM PLENO SÉCULO XXI: OS ENTRAVES DA NECESSIDADE DE EQUILIBRIO ENTRE CAPITAL ETRABALHO

Fernanda Brandão Cançado \& Carla Reita Faria Leal

A CRIAÇÃO DE SELOS SOCIAIS COMO CONCRETIZAÇÃO DO DEVER DEPREVENÇÃO AO TRABALHO ESCRAVO CONTEMPOR NEO NA CADEIA PRODUTIVA DA CARNE BOVINA

Nivea Corcino Locatelli Braga

A TRAGICIDADE DA PRECARIZAÇÃO DO TRABALHO EMTEMPOS DE NEOLIBERALISMO PANDÊMICO

Dorinethe dos Santos Bentes \& Igo Zany Nunes Corrêa AS DESIGUALDADES SOCIAIS E AS NOVAS RELAÇÕES DE TRABALHO: BRASIL, PORTUGAL E ITÁLIA

Érica Cindra de Lima, Cristiane Diello Granville \& Márcia Vieira Oliveira Garritano “AGRADECE QUE TEM EMPREGO”: DEGRADAÇÃO DO TRABALHO EVIOLAÇÃO DOS DIREITOS HUMANOS DOS PROFESSORES DA EDUCAÇÃO BÁSICA NO PERÍODO DE PANDEMI

Alexandre Alves \& Danilo Uler Corregliano

A "PLATAFORMIZAÇÃO” DO TRABALHO EA RELAÇÃO DE EMPREGO NOS APLICATIVOS DE TRANSPORTE

Mireia Llobera

LABOUR MOBILITY AND FREETRADE RULES: A NEW CHALLENGE FOR THE 2030 AGENDA?

DIREITOS HUMANOS ETRABALHO SEXUAL SOB A PERSPECTIVA DA PRECARIZAÇÃO MULHERES E HOMENS NO MERCADO DE TRABALHO EM PORTUGAL 
Sara Jordana Cabral Peixoto, Dolores Pereira Ribeiro Coutinho \& Mário Márcio da Rocha Cabreira

EMPREGOVERDE E CATADORES DE RECICLADOS: UM CASE DE SUSTENTABILIDADE
ODS 9

INDÚSTRIA,

INOVAÇÃO

\section{E INFRAESTRUTURAS}

190

Sheila Stolz

A AGENDA 2030 E OS OBJETIVOS DE DESENVOLVIMENTO SUSTENTÁVEL (ODS) DO MILÊNIO: INICIATIVAS EMPRESARIAIS PARA PROMOÇÃO DA IGUALDADE DE GÊNERO

I91 Arlei Costa Junior

O PAPEL DA SUSTENTABILIDADE ENERGÉTICA NA QUARTA REVOLUÇÃO INDUSTRIAL PARA A EVOLUÇÃO DOS DIREITOS HUMANOS

192

Raúl Payá Castiblanque

THE ROLE OFTHE UNITARY PREVENTION DELEGATES INTHE PARTICIPATIVE MANAGEMENT OF OCCUPATIONAL RISK PREVENTION

Antônio Carlos Efing \& Rudinei José Ortigara

RISCOS DAS NANOTECNOLOGIAS EA RESPONSABILIDADE DAS EMPRESAS PELA PROTEÇÃO AO CONSUMIDOR: UMA ANÁLISE A PARTIR DA CONCRETIZAÇÃO DE DIREITOS

Juliana Falci Sousa Rocha Cunh

PROTEÇÃO, MERCANTILIZAÇÃO EVALORAÇ̃̃O DE DADOS NA "DATA-DRIVEN SOCIETY"

Rudinei José Ortigara

RESPONSABILIDADE DAS EMPRESAS PARA A CONCRETIZAÇÃO DO OBJETIVO I 3 DA AGENDA 2030: MUDANÇAS CLIMÁTICAS E DIREITOS HUMANOS

Jéssica Cindy Kempfer, Regiane Nistler \& Caroline Bresolin Maia Cadore EMPRESASTRANSNACIONAIS E A PROTEÇÃO DOS DIREITOS HUMANOS EM UM CENÁRIO GLOBAL

Rafael Moll Noguer

LA EDAD COMO FACTOR DE DISCRIMINACIÓN EN EL ACCESO AL EMPLEO: PUNTOS CLAVES

Maria Luiza Diniz Almeid

GOVERNANÇA GLOBAL, COMPLIANCE E SETOR ENEGÉTICO: NOVOS PARADIGMAS FRENTE AOS OBJETIVOS DE DESENVOLVIMENTO SUSTENTÁVEL
Fabrizio Bom Vecchio \& Francis Rafael Beck

O COMPLIANCE PROGRAM COMO INSTRUMENTO DE PREVENÇÃO E REPRESSÃO DEVIOLAÇÕES AOS DIREITOS HUMANOS NO ÂMBITO DAS ORGANIZAÇÕES EMPRESARIAIS

Juliana Roman

CÓMO LASTECNOLOGÍAS DE LA INFORMACIÓNY COMUNICACIÓN PUEDEN AYUDAR A CUMPLIR LOS OBJETIVOS DE DESARROLLO SOSTENIBLE DE ONU

Thais Brito Cirne

TUTELA JURISDICIONAL EFETIVA DASVIOLAÇÕES DE DIREITOS HUMANOS POR EMPRESAS:A ADEQUAÇÃO DA MEDIAÇÃO

Carolina Rojas Lasch

¿EL FIN DE UNA ERA? LA FOCALIZACIÓNY LA PRODUCCIONTECNOLÓGICA DE DATOS EN LA ACCIÓN PÚBLICA

Paulina Morales-Aguilera

TECNOLOGÍAS, ESTADO Y NUEVAS VULNERABILIDADES: UNA REFLEXIÓN DESDE UN ENFOQUE DE DERECHOS ENTIEMPOS DE PANDEMIA

Helder Binimelis Espinoza

HACKEANDO EL GOBIERNO ELECTRÓNICO: ALTERNATIVAS CRÍTICAS AL GOBIERNO ABIERTO

sabella Faustino Alves

O CAPITAL NO BANCO DOS RÉUS: (RE)CONSTRUIR DIREITOS HUMANOS EMTEMPOS LÍQUIDOS

Osvaldo Caetano Neto

A EMPRESA COMO INSTRUMENTO

DE DESENVOLVIMENTO DOS DIREITOS HUMANOS

Cláudio Teixeira Damilano

OVIÉS COGNITIVO DO ALGORITMO

NA INTELIGÊNCIA ARTIFICIAL

Georgia da Cunha Bem

199 EMPREENDEDOR NO BRASIL 
$2 \mid \mathbf{l}$ ODS 10

\section{REDUZIR}

\section{AS DESIGUALDADES}

212 Amanda Maria Cunha Menezes \& Ana Cristina Brito Arcoverde

O NOVO LUGAR DO MINISTÉRIO PÚBLICO

DE PERNAMBUCO EA INDUÇÃO DE POLÍTICAS

PÚBLICAS PARA A PESSOA IDOSA

213 Maria Carolina Santos Barreira \& Daniela Castilhos

A PROTEÇÃO INTERNACIONAL DOS DIREITOS SOCIAIS NA EUROPA: SURGIMENTO,

AFIRMAÇÃO E PROTEÇÃO MULTINÍVEL

214 Marta Maia

A DISCRIMINÇÃO É QUE AFLIGE. DIREITOS HUMANOS, PREVENÇÃO DA INFEÇÃO POR VIH E SEROFOBIA

2I5 Najah Jamal Daakour Barakat \& Eduardo Soares Da Silva

AS RELAÇÕES DETRABALHO COM ÊNFASE AO MIGRANTE: EA POSSIBILIDADE DEVIOLAÇÃO DOS DIREITOS HUMANOS

Nivea Corcino Locatelli Braga

PELA CONSECUÇÃO DOS OBJETIVOS PROSPECTADOS PELA AGENDA 2030 COM FOCO NA ÉTICA DO CUIDADO

Luisa Vasconcelos Silva e Souz

TEORIA CRÍTICA DOS DIREITOS HUMANOS

E PENSAMENTO DECOLONIAL: UMA ANÁLISE DO PROCESSO SOCIOPOLÍTICO DE FORMAÇÃO DESIGUALDA AMÉRICA LATINA

Ana Lourena Moniz Costa \& Gabriela Henrique Carvalho

AS MÃES E SUA DOR: DIREITOS HUMANOS E POLÍTICA COMO CONSTRUÇÃO DE IDENTIDADE NO ESPAÇO PÚBLICO NO CASO DOS MENINOS EMASCULADO

219 Alessandra Benedito \& Luciana Costa Silva VIOLÊNCIA OBSTÉTRICA:A (DES)HUMANIZAÇÃO DO PARTO NO BRASIL

Camila Bertoleto Roque

A REVITIMAÇÃO DAS MULHERES VÍTIMAS DE VIOLÊNCIA DOMÉSTICA PELO JUDICIÁRIO BRASILEIRO

22I Natalie Maria de Oliveira de Almeida VIOLÊNCIA INSTITUCIONAL NASVARAS DE FAMÍLIA DE SÃO LUÍS DO MARANHÃO

Andressa Franch Carloni \& Rafael Ferreira de Albuquerque Costa CONCEITOS JURÍDICOS INDETERMINADOS:A LUTA DOS DIREITOS HUMANOS CONTRA O ARBÍTRIO EA SELETIVIDADE PENAL
Raquel Gomes Valadares

MULHERES, DEMOCRACIA E CIDADANIA: O PLANEJAMENTO URBANO COMO FERRAMENTA DE REDUÇÃO DA DESIGUALDADE

ODS II

\section{CIDADES \\ E COMUNIDADES SUSTENTÁVEIS}

Suzana Mendonça

TURISMO E DIREITO-DEVER DE PROTEÇÃO

DO PATRIMONNIO HISTÓRICO E NATURAL

Leia Aparecida Veiga

ÁREAS DE MAIOR E MENOR PODER AOUISITIVO EM LONDRINA/PR/BRASIL E O ESPRAIAMENTO ESPACIAL DO COVID-19

Adriana Castreghini de Freitas Pereira

GEOPROCESSAMENTO E CARTOGRAFIA

PARA A ANÁLISE DA GEOGRAFIA DOS RISCOS MONITORAMENTO DA COVID-I9 NA REGIÃO METROPOLITANA DE LONDRINA, PR

Henrique Lopes Dornelas

ANÁLISE DO PRINCÍPIO DA PRECAUÇ̃̃O PELA CORTE INTERAMERICANA DE DIREITOS HUMANOS NA PROTEÇÃO DO MEIO AMBIENTE COMO DIREITO HUMANO

Maria Luíza Diniz Almeida \& Larissa Emnlia Guilherme Ribeiro

BIG PUSH PARA SUSTENTABILIDADE, COMPLIANCE E O SETOR ENERGÉTICO: ENERGIA E DESENVOLVIMENTO SUSTENTÁVEL NA AMÉRICA LATINA

Mickhael Erik Alexander Bachmann \& Elizeu de Oliveira Santos Sobrinho HAVERÁ JUSTIFICAÇÃO PARA A DEPREDAÇÃO DE PATRIMÔNIO HISTÓRICO MORALMENTE QUESTIONÁVEL?

Fátima Lampreia Carvalho

DEVELOPING HUMAN RIGHTS SCALES FOR A NO HARM TOURISM

Andreza da Cruz, Kelly Gianezini, Miguelangelo Gianezini \& Silvio Parodi Oliveira Camilo

POLÍTICAS PÚBLICAS TRIBUTÁRIO-AMBIENTAIS NO BRASIL E O ECODESENVOLVIMENTO: (CO)RELAÇÕES POSSÍVEIS 
ODS 12

\section{PRODUÇÃO \\ E CONSUMO SUSTENTÁVEIS}

236

Tulio de Bonis Martins

UMA ANÁLISE BIBLIOMÉTRICA SOBRE ECONOMIA COMPARTILHADA: 2017-2020

237 Ana Cristina Pego

FEATURES FOR SUSTAINABLE ECONOMY BASED ONTHE RENEWABLE ENERGY.THE EUROPEAN POINT OFVIEW FOR 2030

Marcia Perencin Tondato \& Dayse Maciel de Araújo

ENTRE A NECESSIDADE E A SOCIABILIDADE: TRANSFORMAÇÕES NAS RELAÇÕES DE CONSUMO NA PANDEMIA COVIDI 9

Juliana Mattos dos Santos Joaquim

ECONOMIA CIRCULAR COMO GARANTIA DE UMA GESTÃO SUSTENTÁVEL DOS RECURSOS GLOBAIS TERRESTRES

Fernando Castelló-Sirven:

AGENDA 2030 EN ESPAÑA: UN ANÁLISIS DE LOS OBJETIVOS DE DESARROLLO SOSTENIBLE (ODS) DURANTE EL PERÍODO 2015-2020

Jamile Gonçalves Calissi \& Renato Zanolla Montefusco DESENVOLVIMENTO REGENERATIVO:A ECONOMIA CIRCULAR REDEFININDO A SUSTENTABILIDADE

Renato Zanolla Montefusco \& Jamile Gonçalves Calissi

CARBON PRICING:A ECONOMIA CIRCULAR COMO GARANTIA DO DIREITO FUNDAMENTAL À SUSTENTABILIDADE POR MEIO DA PRECIFICAÇÃO DAS EMISSÕES DE CARBONO

Arnelle Rolim Peixoto \& Arkaitz Pascual Martína

O DECRESCIMENTO COMO VIA PARA O DESENVOLVIMENTO SUSTENTÁVEL

Giovana BatistiVieira \& Cinthia Obladen de Almendra Freitas

A CARACTERIZAÇÃO DE PERFIL (PROFILING) DO CONSUMIDOR COMO MECANISMO PROPULSOR DO CONSUMO NÃO SUSTENTÁVEL

Rodrigo Moreira

COMUNIDADES SUSTENTÁVEIS: COESÃO TERRITORIAL POR MEIO DOS PRINCÍPIOS DOS ODS II E I2 APLICADOS A ASSENTAMENTO PRECÁRIO NO BRASIL
Valeria Tavares De Santanna, Bernardo Jose Ferreira Gicquel De Deus \& Guilherme De Souza Santanna

UM NOVO MODELO DE SOCIEDADE ATRAVÉS DA CIDADANIA GLOBAL, CONSUMO CONSCIENTE E ACESSO À JUSTIÇA

Arlete Assumpção Monteiro

TECER FIOS E FAZER RENDAS. UM ESTUDO SOBRE AS RENDEIRAS DO NORTE DA IKHA DE SANTA CATARINA, FLORIANÓPOLIS, SANTA CATARINA, BRASIL

ODS 13

AÇÃO CLIMÁTICA

Bernardo Jose Ferreira Gicquel De Deus \& Carla Maria Alcofra Tocantins TRANSIÇÃO ENERGÉTICA, MEIO AMBIENTE, DESENVOLVIMENTO HUMANO, SOCIAL E ECONÔMICO

Kaliany Gonzaga de Santana Ribeiro

NÚCLEO DE GESTÃO AMBIENTAL DA DEFENSORIA PÚBLICA DO ESTADO DA BAHIA -NUGAMA

Ana Julia Ramos Padua \& Luiz Nunes Pegoraro

A VIOLAÇÃO DO DIREITO À ÁGUA E DO SANEAMENTO BÁSICO ATRAVÉS DA IMPROBIDADE ADMINISTRATIVA

OBSERVATÓRIO DE POLÍTICAS MARÍTIMAS: APORTE METODOLÓGICO DE ANÁLISE,AVALIAÇÃO E PROPOSITURA DE POLITICAS PÚBLICAS NO AMBIENTE MARÍTIMO

Soraya Fonteneles de Menezes \& André Panno Beirão

ASTRANSFORMAÇÕES DO ÁRTICO EM DIÁLOGO COMA AGENDA 2030

Maria Damian Ribeiro Pessoa, Frank Pavan de Souza \& Bianca Monteiro de Castro DIREITOS HUMANOS E MEIO AMBIENTE ECOLOGICAMENTE EQUILIBRADO:ASPECTOS DA CONSTITUIÇÃO FEDERAL DE 1988

Camila Parente Almeida \& Carlos Teodoro José Hugueney Irigaray

O ESTADO DE DIREITO ECOLÓGICO COMO CONDIÇÃO PARA O CUMPRIMENTO DOS OBJETIVOS DE DESENVOLVIMENTO SUSTENTÁVEIS FIXADOS PELA AGENDA 2030

PELAAGENDA 2030 
SUSTENTABILIDADE, OU UM PLANETA PARA TODOS - OS CAMINHOS DA AGENDA 2030

Pegía Regina Pinheiro Sampaio \& Juliana Patricio da Paixão REGULAÇÃO E O NOVO MARCO LEGAL DO SANEAMENTO BÁSICO NO BRASIL:AVANÇOS E DIFICULDADES

María del Carmen Ledo García

EL DERECHO HUMANO A LA DISPONIBILIDAD DE AGUA POTABLE DENTRO DE LAS VIVIENDAS EN COCHABAMBA, BOLIVIA

262 Vanessa Cristina São Pedro Abreu da Costa A MUDANÇA CLIMÁTICA CONTEMPOR NEA: UMA QUESTÃO POLÍTICO-ECONÔMICA OU SOCIOAMBIENTAL?

ODS I5

\section{PROTEGER}

\section{A VIDA TERRESTRE}

265 Christiane Madalena Matheus de Alcantara da Costa AS INDICAÇÕES GEOGRÁFICAS COMO FERRAMENTAS DE FORTALECIMENTO DA AGRICULTURA FAMILIAR E INCLUSÃO SOCIAL NO BRASIL

Renata Martins Vasconcelos \& José do Carmo Alves Siqueira POLÍTICAS PÚBLICAS DE FORTALECIMENTO DA AGRICULTURA FAMILIAR NO CERRADO E COMBATEÀ FOME

Vitória da Costa Caruso

A GRILAGEM QUE ESTRUTURA A ORGANIZAÇÃO FUNDIÁRIA DA AMAZÔNIA E SUA ÍNTIMA RELAÇÃO COM O DESMATAMENTO: UMA ANÁLISE DO DISCURSO PARLAMENTAR

niTerezinha Antonello

TERRITÓRIOS DE RESISTÊNCIAS NA LUTA POR UMA CIDADE INCLUSIVA EM LONDRINA - PARANÁ/BRASIL

Cristina Veloso de Castro, Fausy Vieira Salomão \& Solange Teles da Silva DIREITO HUMANO À ÁGUA E SANEAMENTO NO BRASIL: O PAPEL DOS MUNICÍPIOS NA CONCRETIZAÇÃO DO ODS 6
Solange Teles da Silva

A PROTEÇÃO DA BIODIVERSIDADE BRASILEIRA À LUZ DOS OBJETIVOS DO DESENVOLVIMENTO SUSTENTÁVEL (ODS)

Karla Karolina Harada Souza

DIPLOMACIA AMBIENTAL - EFETIVIDADE DA RESPONSABILIDADE AMBIENTAL, GOVERNANCA, GESTÃO DE SERVIÇOS ECOSSISTÊMICOS, PROTEÇÃO DA AMAZÔNIA

Daniele Galvão De Sousa Santos

DIREITOS HUMANOS, DESLOCAMENTOS AMBIENTAIS EAUMENTO DO NÍVEL DO MAR: UMA REALIDADE EMERGENTE

Adriana Goulart de Sena Orsini, Nancy Vidal Meneghini, Igor Sousa Gonçalves \& Juliana Castro Sander Morais

RACISMO AMBIENTAL E ACESSO À JUSTIÇA PELA VIA DOS DIREITOS: UMA REFLEXÃO SOBRE O DESASTRE AMBIENTAL EM BRUMADINHO E OS DESAFIOS PARA A CONCRETIZAÇÃO DA AGENDA 2030

Natália Mayumi Gonçalves Miyaza \& Lucas Brito Silveira Santos CIDADES INTELIGENTES:A POLÍTICA DE RESÍDUOSSÓLIDOS EA NECESSIDADE DE IMPLEMENTAÇÃO DE POLÍTICAS PÚBLICAS SUSTENTÁVEIS - ESTUDO DE CASO P.

Thaïs de Mendonça Jorge \& Francisco Verri

VALORES NAS NOTÍCIAS, PATRIMONIALISMO E DIREITOS SOCIAIS

ODS 16
Maria Irene da Fonseca e $\mathrm{S}$ JOSÉ SARAMAGO: OS DIREITOS E OS DEVERES HUMANOS

Milena de Bonis Faria

A PAZ E A SOLUÇÃO DE CONFLITOS POR UMA ÓTICA MULTIDISCIPLINAR, INTERDISCIPLINAR ETRANSVERSAL

Emanuela Vasconcelos Leite \& Cláudia dos Santos Costa
PARCERIAS ENTRE ÓRGÃOS PÚBLICOS E PRIVADOS NA EFETIVAÇÃO DE PROJETOS DE MEDIAÇÃO DE CONFLITOS 
Cláudia dos Santos Costa \& Sabrine Vasconcelos Guimarães

MEDIAÇÃO COMUNITÁRIA COMO ESTRATÉGIA DE PACIFICAÇÃO NO MUNICÍPIO DE FORQUILHA-CE

284

enata Caroline Pereira de Macedo

APAC'S:A SOCIO-LEGAL ANALYSIS FOR THE CREATION OF PUBLIC POLICIES TOWARDS RESOCIALIZATION

Ravel Lopes Queiroz Chacu

PROPOSTAS DE MODELOS DE SOLUÇÕES DE PROBLEMAS FUNDIÁRIOS A PARTIR DE DADOS DOS ÓRGÃOS PÚBLICOS DA CIDADE DE SÃO CARLOS - SP

Deborah Bandeira de Deus e Mello

COLISÃO DE DIREITOS FUNDAMENTAIS:

ESTUDO DE CASOS DE DIVULGAÇÃO DE IMAGEM DE SUSPEITO DE CRIME

Alexis Mendonça Cavichini Teixeira de Siqueira

A IMPORTÂNCIA DO LEGISLATIVO COMO INSTÂNCIA DE REPRESENTAÇÃO DEMOCRÁTICA

Daniely Pinheiro Pimentel \& Fábio Rodrigues Milioni

DIREITOS HUMANOS CONSTITUÍDOS:AÇÕES

EVALORES INCLUSIVOS NO DIÁLOGO COM

O COTIDIANO DEALUNOS DA REDE PÚBLICA DE ENSINO NO RIO DE JANEIRO/B

no Alberto Ferreira \& Verçulina Firmino dos Santos

O DIREITO HUMANO FUNDAMENTALÀ PARTICIPAÇÃO POLÍTICA E A ATUAÇÃO DO MOVIMENTO INDÍGENA NA ESFERA PÚBLICA BRASILEIRA

29I Gustavo Worcki Sato

A INFILTRAÇÃO VIRTUAL DE AGENTES E O COMBATE À PEDOPORNOGRAFIA DIGITAL. ESTUDO DA LEI 13.44I, DE 8 DE MAIO DE 2017

Marisa Brandão CubelYule

POLÍTICA JUDICIÁRIA NACIONAL PARA UMA JUSTIÇA DO TRABALHO INCLUSIVA EACESSÍVEL: PROGRAMAS E AÇÕES PERMANENTES VOLTADAS À PROMOÇÃO DA INCLUS

Cleber Mesquita dos Santos

AS MANIFESTAÇÕES PELOS DIREITOS HUMANOS NAS REDES SOCIAIS GERAM ENGAJAMENTO NA LUTA PELA EFETIVIDADE DESSES DIREITOS? UMA ABORDAGEM NEUROCIÊNTIFICA
Ana Teresa Carneiro \& Ana Guerreiro

O CRIME DETRÁFICO DE PESSOAS: UM INCISIVO ETRANSVERSAL DESAFIO AOS DIREITOS HUMANOS

Mateus Trinta Bruzaca

A GARANTIA COMPARTILHADA DOS DIREITOS HUMANOS NA AMÉRICA LATINA:A PARTICIPAÇÃO DA CORTE IDH NOS JULGADOS ADPF I53 E CASO SIMÓN

Igor Sousa Gonçalves Filiação, Nancy Vidal Meneghini, Karem Carvalho Barcelos \& Natália Campos de Souza Pimenta

ACESSO À JUSTIÇA PELA VIA DA PROFISSIONALIZAÇÃO: CONTRATOS DE APRENDIZAGEM E OBJETIVOS DE DESENVOLVIMENTO SUSTENTÁVEL

Maria Lucia de Paula Oliveira

COMUNICAÇÃO DEMOCRÁTICA E POLÍTICAS PÚBLICAS VOLTADAS PARA A SUPERAÇÃO DA DESIGUALDADE DE GÊNERO

Bruna Ferrari Pereira

MEMÓRIA,VERDADE E JUSTIÇA NO BRASIL APÓS A COMISSÃO DA VERDADE

Adriana Guillermina Ríos Vázquez \& Luz Maria Consuelo Jaimes Legorreta MEDIDAS DE SEGURIDADY RESTRICCIÓN DE LA MOVILIDAD TRANSFRONTERIZA ENTRE MÉXICO Y ESTADOS UNIDOS EN EL MARCO DEL COVID 19

Luis Renato Vedovato \& Carolina Piccolotto Galib

A NOVA LEI DE MIGRAÇÃO NOS TRIBUNAIS E A PROTEÇÃO DOS MIGRANTES DIANTE DA PANDEMIA

Nadir Oliveira Galrão Leite de Almeida

ENTRE POLÍTICA, ÉTICA E SUBJETIVIDADES: SOBRE O EXERCÍCIO E O OFÍCIO DE PROMOVER CIDADANIA

Fernanda Schuhli Bourges \& Mariane Yuri Shiohara Lubke

RESPONSABILIDADE INTERNACIONAL DO ESTADO POR OMISSÃO NA PROTEÇÃO DOS DIREITOS HUMANOS NA EXPLORAÇÃO DE BENS PÚBLICOS POR EMPRESAS PARTICULAR

Alessandra Balestieri \& Daniel Blume Pereira de Almeida

A EFICIÊNCIA DAS RAL'S REALIZADAS DE FORMA PRE PROCESSUAL

Arkaitz Pascual \& Arnelle Rolim Peixoto

A IMPORT NCIA DE UMA POLÍTICA PÚBLICA DE SEGURANÇA COM ENFOQUE NOS DIREITOS HUMANOS NO BRASIL 
André Luiz de Matos Gonçalves \& Júlio Edstron S. Santos

CRISE E ORÇAMENTO PÚBLICO:A NECESSIDADE DE SE ACOMPANHAR A DISTRIBUIÇÃO DE RECURSOS PARA EFETIVAÇÃO DOS DIREITOS FUNDAMENTAIS NO BRASIL

Regiane Nistler, Jéssica Cindy Kempfer \& Caroline Bresolin Maia Cadore A PROPOSTA DE UNIVERSALISMO DAS NAÇÕES UNIDAS E A EFETIVAÇÃO DE DIREITOS HUMANOS NO CENÁRIO MUNDIAL TRANSNACIONAL

Carlos Henrique Vale de Paiva \& Natália Andrade Rocha O IMPACTO DAS FAKE NEWS NA DEMOCRACIA: ANÁLISE DE ESTUDOS REALIZADOS NO BRASIL

3II Musa M.Yusupov

VALUE-BASED INTERPRETATION OF HUMAN RIGHTS INTHE POST-CONFLICT REGION

312 José Campos Amorim

AS REGRAS GERAIS DE PROTEÇÃO INTERNACIONAL DOS REFUGIADOS

313 Dessana Paiva De Oliveira

MÃES IMIGRANTES E FILHOS BRASILEIROS: OS DESAFIOS DA CIDADANIA

314 Aline Michele Nascimento

JUSTIÇA PÓS-TRANSICIONAL - O PAPEL DAS INSTITUIÇÕES NO DIREITO À MEMÓRIA, À VERDADE EÀ JUSTIÇA NO BRASIL

315 James Gabriel Mendes Garcez,Talles Evangelista Silva Araujo. Augusto Danie Pessoa Gabina de Oliveira, Gabriella Barbosa Pereira Zayringue Ribeiro \& Thiago Allison Cardoso de Jesus

VINGANÇA PRIVADA E EXPRESSÕES NA AMÉRICA LATINA: UMA ANÁLISE HISTÓRICA, POLÍTICA E FENOMENOLÓGICA SUL-AMERICANA

316 Lorena Nogueira Rêgo \& Ana Evelyne Cavalcante Costa Cerqueira AS PRÁTICAS RESTAURATIVAS COMO MEIOS EFETIVOS PARA A TRANSFORMAÇÃO DE CONFLITOS FAMILIARES

317 Gabriella Barbosa Pereira Zayringue Ribeiro, Augusto Daniel Pessoa Gabina Thiago Allisson Cardoso de Jesus, lames Gabriel Mendes Garcez \& Talles Evangelista Silva Araujo

VINGANÇA PRIVADA NO ESTADO DO MARANHÃO: SUA PERPETUAÇÃO ATRAVÉS DO ESTADO EMTEMPOS DE DESENCANTAMENTO DO PÓS-88

Emerson Wendt

CIBERCRIME, INTERNET E DIREITOS HUMANOS NO BRASIL: UMA PERSPECTIVA DE OLHAR PELA SOMBRA E NÃO SOBRE A SOMBRA
Milena De Carvalho Neves Mendoza

INTELIGÊNCIA ARTIFICIAL:A PERSONALIDADE ELETRÔNICA DE SISTEMAS AUTÔNOMOS À LUZ DO DIREITO PORTUGUÊS E BRASILEIRO

Sandra Tavares

A DIRETIVA (UE) 2016/343 DO PARLAMENTO EUROPEU E DO CONSELHO DE 9 DE MARÇO DE 2016 - CONFRONTO COMA LEGISLAÇÃO NACIONAL

Aline Betiatto

O PRINCÍPIO ANTICORRUPÇÃO COMO INSTRUMENTALIZAÇÃO DO OBJETIVO N. 16 DA AGENDA 2030 DA ONU

Milena De Carvalho Neves Mendoza

MEDIAÇÃO DIGITAL:A TECNOLOGIA A FAVOR DO ACESSO À JUSTIÇAÀ LUZ DO DIREITO PORTUGUÊS E BRASILEIRO

Cátia Marques Cebola \& Susana Sardinha Monteiro

A MEDIAÇÃO COMO INSTRUMENTO DE PROMOÇÃO DO DIREITO DE ACESSO À JUSTIÇA E CONSTRUÇÃO DE SOCIEDADES PACÍFICAS E INCLUSIVAS

Luciana do Amaral Rabelo \& Rejane Alves de Arruda

A IMPORTÂNCIA DA SENTENÇA PENAL CONDENATÓRIA PARA A REPARAÇÃO DO DANO PROVENIENTE DA PRÁTICA DA INFRAÇÃO PENAL À LUZ DO ART. $5^{\circ}$ DA CF/88

Luciana do Amaral Rabelo, Andréa Flores \& Fernanda Proença Azambuja A REMIÇÃO DA PENA PELA LEITURA NO ESTADO DE MATO GROSSO DO SUL:ANÁLISE A LUZ DOS DIREITOS HUMANOS

Fabiana Gomes Rodrigues, Gilza Santos Simão Ferreira \& Juliano Soares Rangel O ATIVISMO JUDICIAL NA SAÚDE EMTEMPOS DE PANDEMIA

Kelda Sofia Da Costa Santos Caires Rocha

A PROTEÇÃO AO DIREITO DE LIBERDADE DE CRENCA E O IMPACTO DO DIREITO INTERNACIONAL QUANTO A PROPOSITURA DE POLÍTICAS PÚBLICAS DE ENFRENTAMENTO

María G. Navarro \& Jonathan Piedra

MEACTO DE LA ROBOTIZACIÓN DEL RAZONAMIENTO ÉTICO-JURÍDICO SOBRE LOS DERECHOS HUMANOS

Antonio Carlos da Silva TERRITORIAL HEGEMONY OF THE BRAZILIAN STATE AGAINST CAPITAL'S STRUCTURAL CRISIS 
A NATUREZA DO DECRETO CONDENATÓRIO PENAL DE PRIMEIRO GRAUNO BRASIL: JUÍZO DE PRELIBAÇÃO OU SENTENÇA INEFICAZ?

Isabelle Rocha Valença Figueiredo \& Maria Carolina Silveira Beraldo JUSTIÇA RESTAURATIVA PENAL NO BRASIL:É O ACORDO DE NÃO PERSECUÇÃO PENAL UM CAMINHO?

Walmir Pereir

AVANÇOS E DESAFIOS DOS DIREITOS HUMANOS NO BRASIL DO SÉCULO XXI: O CASO DA CONSULTA PRÉVIA JUNTO AOS POVOS INDÍGENAS

333 Claudia Maria Barbosa

A FRAGILIDADE DA ACCOUNTABIITY SOCIAL JUDICIAL EXPRESSA NOS INDICADORES EUROPEAN NETWORKS OF COUNCILS FOR THE JUDICIARY (ENCJ)

Lucas Jeronimo Ribeiro da Silva \& Elaine Cristina da Silva NÃO-VIOLÊNCIA E RESTAURAÇÃO: UMA QUESTÃO DE DIREITOS

Eduardo Pereira Monteiro

O USO DA FORÇA NO DIREITO INTERNACIONAL: AS MISSÕES HUMANITÁRIAS

Da Silva Menezes

ACESSIBILIDADE DEMOCRÁTICA E O AMICUS CURIAE NO PROCESSO CIVIL BRASILEIRO: ESPERANÇA OU DESALENTO ANÁLISE DA COECV NA IMPLEMENTAÇÃO DA MEDIAÇÃO NOS CONFLITOS COLETIVOS FUNDIÁRIOS NO MARANHÃO

JUSTIÇA PREDITIVA:VANTAGENS E PERIGOS DO USO DA INTELIGÊNCIA ARTIFICIAL EM SISTEMAS JUDICIÁRIOS

339 Diego El-Jaick Rapozo MEDIAÇÃO COMO PROCEDIMENTO POSSÍVEL NO CAMINHO DA CONSTRUÇÃO DE PAZ

Valéria Reis Gravino

INSUFICIÊNCIA DOS MECANISMOS DA JUSTIÇA DE TRANSIÇÃO BRASILEIRA: O CASO CELSO DA ROCHA MIRANDA

34 I Igo Zany Nunes Corrêa, Laura Fernanda Nascimento, Dorinethe dos Santos Bentes \& Rafael Vinheiro Monteiro Barbosa

DIREITO DOS EXCLUÍDOS:ANÁLISE DO DIREITO DE ACESSO À JUSTIÇA PROPORCIONADO AOS CIDADÃOS DO INTERIOR DO ESTADO DO AMAZONAS
Lucas Brito Silveira Santos \& Natália M. G. Miyazak

POLICIAMENTO PREDITIVO - ESTUDO DO CASO PREDPOL E POSSÍVEL APLICAÇÃO

Natália Mayumi Gonçalves Miyaza \& Lucas Brito Silveira Santos

RESPONSABILIDADE CIVIL POR ABANDONO AFETIVO

Helena Rocha Matos, Taiguara Libano Soares e Souza, Roberta Duboc Pedrinha \& Bruno Joviniano de Santana Silva

THE BRAZILIAN CRIMINAL JUSTICE SYSTEM AND ITS DIMENSIONSWITH PUBLIC HARM REDUCTION POLICIES: EFFORTS OFTHE "JUSTIÇA PRESENTE” PROGRAM

Hannah Pereira Alff \& Sérgio Augusto da Costa Gil

A NECESSÁRIA VIRTUALIZAÇÃO DAS AUDIÊNCIAS JUDICIAIS PARA A GARANTIA DO ACESSO À JUSTIÇA E DO DEVIDO PROCESSO LEGAL EMTEMPOS DE CRISE

Guilherme Berriel

"LAWFARE" E O USO DO DIREITO COMO INSTRUMENTO DE GUERRA: UMA ANÁLISE SEGUNDO CLAUSEWITZ

Carolina Pasin, Luís Claúdio Martins de Araújo \& Rodrigo Augusto Fatudo Magalhães

THE COLLECTIVE HABEAS CORPUS AS A MITIGATING INSTRUMENT FOR WOMEN MASS INCARCERATION PROBLEMATICS IN BRAZIL

Renata Lorena Rebouças \& Josemita Rebouças

A ERA DIGITAL E O DESAMPARO DO CONTRIBUINTE ANTE A AUSÊNCIA DE LEGISLAÇÃO ACERCA DAS NOVASTECNOLOGIAS: UM ESTUDO COMPARADO DO ORDENAMENTO PORTUGUÊS E BRASILEIRO

Jenny Gil Sousa

PROMOÇÃO E DEFESA DOS DIREITOS DAS CRIANÇAS EM RISCO/PERIGO EM CONTEXTO DE PANDEMIA POR COVID-I9, EM PORTUGAL

Paulynne Rocha Valença Figueiredo \& Isabelle Rocha Valença Figueiredo

A MUDANCCA DA VISÃO SOCIAL SOBRE A INFÂNCIA EA REDUÇÃO DA MAIORIDADE PENAL NO BRASIL

Jesus Tupã Silveira Gomes, Sergio Urquhart de Cademartori \& Lucas Uelinton Graciolli

A RETÓRICA GOVERNAMENTAL E A PROTEÇÃO DA PESSOA HUMANA NO ESTADO FEDERAL BRASILEIRO: CORONAVÍRUS - COVID-19 - E OSD 3

Jacson Gross \& Daniela Mesquita Leutchuk de Cademartori UMA POSSÍVEL RESPOSTA EFETIVA AOS DIREITOS HUMANOS DOS POVOSTRADICIONAIS LATINO-AMERICANOS 
357 João Luiz Lessa Neto \& Paulynne Rocha Valença Figueiredo SEQUESTRO INTERNACIONAL DE CRIANÇAS EA CONVENÇÃO DE HAIA: PROTEÇÃO AOS DIREITOS HUMANOS OF INTERNATIONAL JUDICIAL COOPERATION: TOWARDS THE IMPROVEMENT OF EQUAL ACCESS TO JUSTICE FOR ALL?

RECONHECIMENTO DE SENTENÇA ESTRANGEIRA: UM DEVER DO ESTADO PORTUGUÊS ANTE A INFRINGÊNCIA DA SUA ORDEM PÚBLICA? ECONOMIA SOLIDÁRIA E DELIBERAÇÃO PARTICIPATIVA. UM IMPORTANTE RESGATE DA SOBERANIA POPULAR EACCONTABILITY PARA A RESPONSABILIZAÇÃO SOCIAL DOS OBJETIVOS

Camila Parente Almeida, Barbara Natali Botelho Rodrigues Dos Santos \& Carlos Teodoro José Hugueney Irigaray

O PAPEL DAS ENTIDADES FISCALIZADORAS NA EFETIVAÇÃO DAS SALVAGUARDAS SOCIOAMBIENTAIS: A AGENDA 2030 EM PERSPECTIVA

PROFESIONALES PSICOSOCIALES EN JUSTICIA: REVISIÓN DE LA EXPERIENCIA CHILENA Y PERSPECTIVAS

Sra Ribeiro \& Ana Quaresma

MEASURING THE IMPLEMENTATION OF PLANET GOVERNANCE

AS PARCERIAS MULTISSETORIAIS COMO INSTRUMENTOS DE EFETIVAÇÃO DE POLÍTICAS E PRESTAÇÃO DE SERVIÇOS PARA O DESENVOLVIMENTO SUSTENTÁVEL 


\section{PERSPECTIVES AND PLURAL CHALLENGES FOR DELIVERING 2030 AGENDA - A NEW CHAPTER FOR HUMAN RIGHTS EVOLUTION}

Marco Ribeiro Henriques \& Daniela Serra Castilhos

The year 2020 will go down in history as the year in which societies have put the brakes on from every possible angle. We have gone from a health scare to a kind of "cat and mouse game" between a climate of fear and anxiety about the uncertainty surrounding the world.

This was also a year in which we collectively witnessed nature's drastic return to its natural inhabitants. Clairvoyance and marine animal resources returned to the canals of eternal Venice, planes remained on land for months, and it was possible to revisit residual amounts of pollution as not seen since almost immemorial times. Has Human Being changed?

Indeed, the scenario of reconfirmation of humanity as such in this balance between security and the adequacy of social behavior has forced us to transform our days, and our routines will perhaps remain unwritten in the heralds of history whether or not we become better people in 2020.

On the other hand, the reconfiguration of academic practices in the 21st century is already a process with no return, and 2020 has consolidated it in some respects, notably by joining the virtual universe. This was also the case with the 2nd edition of the Euro-American Conference on Human Rights Development, initially designed to take place in person and somewhat like the 1 st edition, to add value to the human contact between the academic commu- nity and civil society on days of intense debate and scientific reflection in 2020 under the aegis of Agenda 2030.

The Euro-American Conference on Human Rights Development in its 2nd edition in $\mathbf{2 0 2 0}$ had as its theme "Agenda 2030 - A New Chapter for the Evolution of Human Rights" and allowed not only an integrated reflection on Agenda 2030, facilitating the articulation of research and academic debate on the different Sustainable Development Goals (SDGs), but also networking among more than 900 people among academics and experts in these areas, promoting the development and aggregation of international and multidisciplinary research networks proposing to bring together the knowledge of scholars and experts, at the international level, who can contribute to the research, implementation, and achievement of these objectives and reflect good practices in the implementation of the United Nations Agenda 2030.

On the 2030 Agenda, we can also assert that 2015 already has a captive place in history as the year of setting the 17 Sustainable Development Goals, set at a UN summit in New York (USA) from 25-27 September, which brought together world leaders to adopt an ambitious agenda for poverty eradication and global economic, social and environmental development by 2030 , known as the "Agenda 2030 for Sustainable Development". 
Agenda 2030 is the fruit of the joint work of governments and citizens around the world to create a new global model for ending poverty, promoting prosperity and well-being for all, protecting the environment, and combating climate change and incorporates 17 Sustainable Development Goals (SDGs), successors to the 8 Millennium Development Goals, to be implemented by all countries and covering areas as diverse but interconnected as equitable access to education and quality health services; the creation of decent jobs; energy and environmental sustainability; ocean conservation and management; the promotion of effective institutions and stable societies; and combating inequality at all levels.

However, when we least expected it, the pandemic took hold, turning our world upside down. Unexpectedly, this pandemic showed that what began as a health crisis quickly turned into a socio-economic situation. The devastating impact on SDG, especially on the poorest countries and the most vulnerable people, shows us how important it is to mobilize to rethink and rebuild the world in a more just, equal, and sustainable way. Never before have SDGs been so important.

Besides, with increased uncertainty about the future, there has been increased concern about the spread of false news, so that SDG has gained a new strength: that of combating misinfor- mation.

Portugal played an important role in the process of defining this Agenda 2030 , with the emphasis on more strongly advocating the goals of promoting peaceful and inclusive societies, eradicating all forms of gender-based discrimination and violence, and conserving the seas and oceans by managing their resources in a sustainable manner.

The document adopted at the Summit, to run until 2030, is entitled "Transforming our World: The 2030 Sustainable Development Agenda".

This active role in the elaboration and consequent implementation of Agenda 2030 in Portugal in 2017 reinforced the commitment by being one of the countries that voluntarily presented a "National Report on the Implementation of Agenda 2030 for Sustainable Development", where the actions carried out at national level in relation to each of the SDGs could be verified. In 2019, a UN report on sustainable development, led by independent scientists, highlighted Portugal as one of the most sustainable countries in the world. In 26th place (out of 162 countries assessed), Portugal had, at the time, a better performance in ODS number 7: Renewable and Affordable Energy.

The United Nations Agenda 2030 is, therefore, an expanded program that presents several dimensions of sustainable development of societies. The Sustainable Development Goals (SDGs) 
set out in Agenda 2030 form a shared vision for humanity, which can only be achieved through the cooperation and collaboration of societies committed to the priorities and aspirations set out in Agenda 2030.

Thus, the new United Nations Agenda 2030 for sustainable development constitutes a plan of action focused on people, the planet, prosperity, peace, and partnership. It is an ambitious agenda towards the goal of global poverty eradication and economic, social, and environmental development, but it is also a universal agenda based, as mentioned above, on the achievement of 17 Sustainable Development Goals (SDGs) and 169 targets to be implemented by all countries in the United Nations.

The assessment of progress in implementing the Agenda will have to be carried out regularly by each country, involving governments, civil society, business, and other development actors. This monitoring requires overall coordination of efforts.

The truth is that for many years scientists have been warning that environmental problems resulting from human activities are endangering both the health of the planet and that of human beings.

The coronavirus has made it clear that we are not invulnerable to these threats, and their impact cannot make us forget the great challenge of humanity: the fight against climate change.
Bodies such as the European Union (EU), the International Monetary Fund (IMF), and the World Bank (WB) have already positioned themselves in favor of Green Recovery to overcome this health, economic and social crisis, following the path mapped out by Agenda 2030 in search of a more sustainable world.

This publication builds on these multidisciplinary and intersectional questions based on the discussion of cooperation processes for sustainable development, which proposes to embrace all the different disciplinary and methodological views of research.

The main objective of the CEDH2O20 is to develop an academic dialogue on the promotion of peaceful and inclusive societies for sustainable development in all its forms at national, regional, and international levels.

The event also aimed to strengthen the epistemological debate on issues relating to peace and justice from an international perspective and reflect on access to justice across societies and build effective, accountable, and inclusive institutions.

It also intended to reflect on the necessary efforts of both the most vulnerable and the institutions struggling to combat this social asymmetry; to recognize the multidimensional human rights-centered response as a tool for building more just and inclusive societies, as well as to propose acceptable practices and methodologies in inter- 
vention with the most vulnerable and resource-building to the countries involved.

The CEDH2020 has a multidisciplinary nature, receiving proposals that embody descriptive studies on theoretical, methodological or social research issues in general, thus accepting work on case studies, literature review, empirical, qualitative or quantitative methodologies, on models, processes and/or institutions that reflect, among other topics, on the eradication of poverty and hunger, gender equality and the promotion of equality, inclusion, health and education as fundamental rights and the promotion of human dignity.

The event proposed to discuss the two days of the event, necessarily virtual, the different theoretical perspectives, supported by general, legal, national, and international literature and principles.

This was very special participation, not only for the opportunity of the theme or for the growth in human terms with the adhesion of more than 900 people from 12 countries involved in the authorship of the almost 500 approved works, but above all for the resilience of all people, the whole academic community and the civil society, institutional partners and others, who allied themselves to this 2. The second edition of the Euro-American Conference on Human Rights Development working collectively for the development of international and multidisciplinary dialogue on the design of public policies to promote more peaceful, inclusive, and just societies for sustainable development and the achievement of social justice, seeking to create solid frameworks based on development strategies for the most vulnerable. 
32 


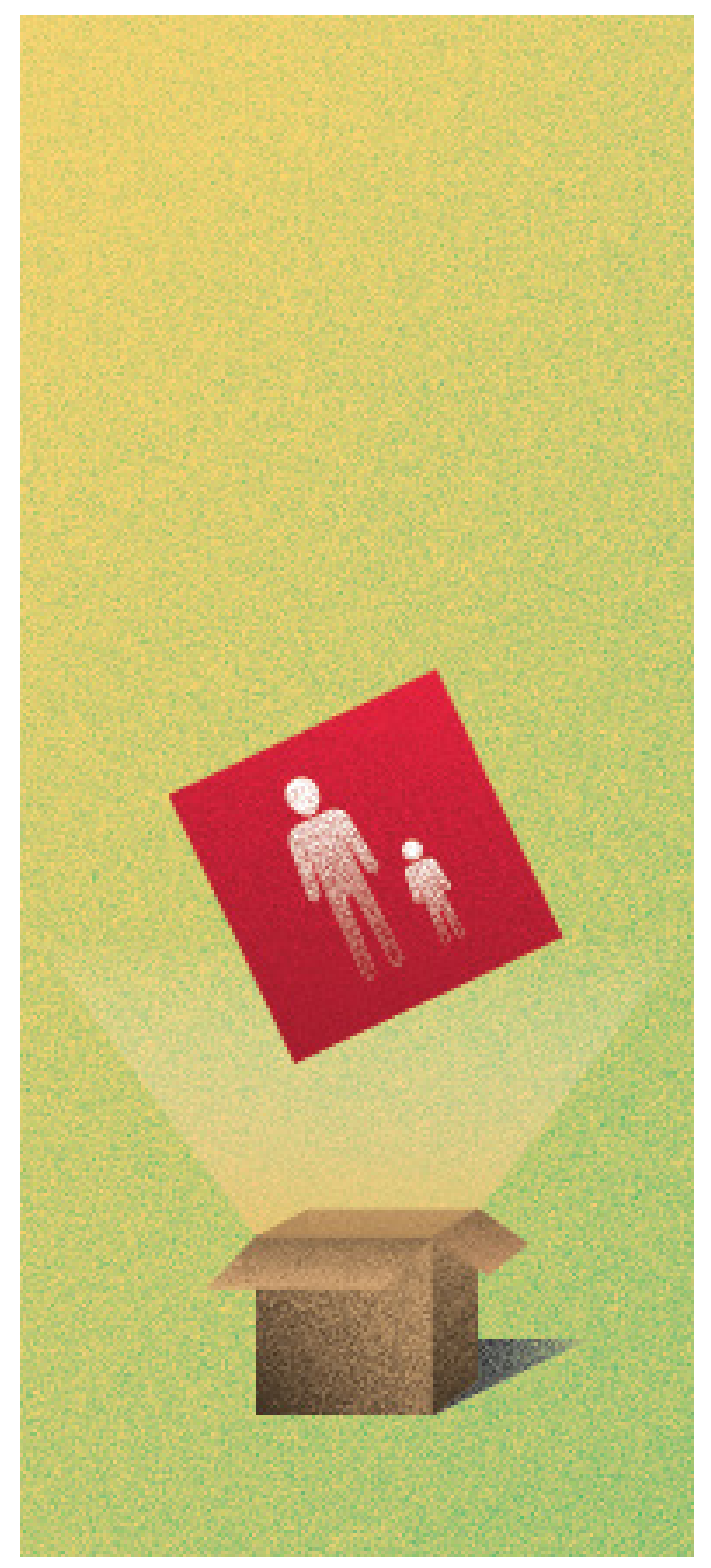

ATAS DA II CEDH:

AGENDA 2030 - UM NOVO CAPÍTULO

PARA A EVOLUÇÃO DOS DIREITOS HUMANOS

\section{ODS I \\ ERRADICAR \\ A POBREZA}

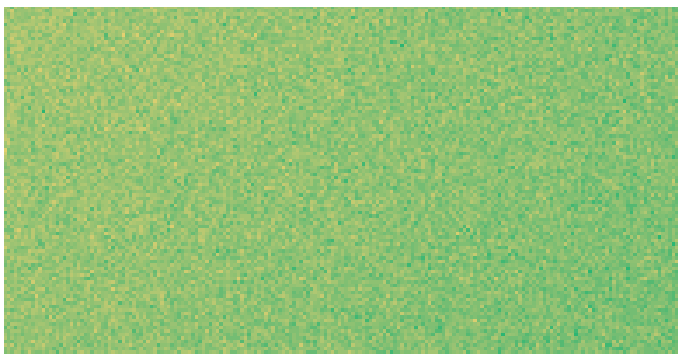




\section{A PROTEÇÃO SOCIAL PARA A OU DA POBREZA: TESTEMUNHOS DE EXCLUSÃO SOCIAL}

O estudo responde ao primeiro Objetivo de Desenvolvimento Sustentável: erradicar a pobreza, no sentido de implementar medidas e sistemas de proteção social. Segundo o Observatório das Desigualdades (OD), Portugal apresenta o segundo valor mais alto no índice de desigualdade social da União Europeia. Segundo os indicadores recentes, do ano de 2017, da taxa de risco de pobreza do OD, o risco de pobreza aumentou cerca de 0,7\% para os indivíduos com 65 ou mais anos, tendo diminuído $1,4 \%$ para os indivíduos entre os 18 e 64 anos. O desemprego, os baixos salários e a baixa formação profissional contribuem para aumentar o risco de pobreza. Há situações de pobreza absoluta quando os indivíduos não têm as necessidades básicas de sobrevivência preenchidas, para que possam garantir a sua subsistência física. A pobreza relativa traduz-se na incapacidade de participarem, em termos económicos, devido à inviabilidade que têm face aos recursos que Ihes permitam viver dignamente de acordo com os padrões de vida, costumes e atividades estabelecidos pela sociedade. $O$ estudo norteou-se pela seguinte problemática: quais as perceções que as pessoas em condições de privação e assistência fazem da sua situação de "pobreza". A metodologia de natureza qualitativa com carácter exploratório, socorreu-se do instrumento: entrevista semiestruturada. A amostra é constituída por doze elementos de doze famílias aleatoriamente selecionas que se encontravam em situação de precariedade económica: seis identificadas pelas Técnicas Supe- riores de Serviço Social de uma Junta de Freguesia do Concelho da cidade do Porto; e seis identificadas pelo Gabinete de Apoio ao Sobreendividado da DECO do Porto. As entrevistas foram audiogravadas, e efetuadas por uma das autoras do presente estudo, com consentimento dos participantes, sendo que os cuidados éticos estiveram presentes ao longo do estudo, quer nas permissões para a recolha de dados quer no seu tratamento, salvaguardando o anonimato. As entrevistas foram realizadas nas instalações da Junta de Freguesia. Os dados foram tratados e analisados com um software de análise qualitativa, o webQDA $®$. Os dados foram triangulados entre as diferentes famílias e as características socioeconómicas dos entrevistados. As categorias validadas pelo método de Delphi, são emergentes: Trajetória, Vulnerabilidade e Cidadania Social. As principais conclusões: privação; falta de recursos; e ausência de cidadania. As famílias encontravam-se em situação de exclusão social, uma vez que, sentindo-se vulneráveis, colocavam em causa a participação plena da pessoa na sociedade, em termos ambientais, culturais, económicos, políticos e sociais. É urgente impulsionar ações de solidárias de proteção social, reforçar os laços de vizinhança e os familiares e a Educação Social, recorrendo a ações localizadas, pois a ajuda oriunda destes componentes, para além de serem verdadeiros promotores de manifestações de solidariedade, poderão complementar os apoios sociais governamentais.

Palavras-Chave: Pobreza, Educação Social, Exclusão Social, Proteção Social, Vulnerabilidade.
Ana Camões, Ana Noronha \& Susana Oliveira e Sá Instituto de Estudos Superiores de Fafe 


\section{AS OCUPAÇÕES DE IMÓVEIS PROMOVIDAS POR CASAPOUND ITÁLIA, O DISCURSO DA SOLIDARIEDADE SELETIVA E DA TRADUÇÃO POLÍTICA DA IMIGRAÇÃO}

Marcela Magalhães de Paula Universidade de Coimbra
O trabalho pretende ilustrar as ocupações efetuadas pelos movimentos de Direita na Itália e a apropriação do vocabulário e do discurso ligado ao direito à moradia (geralmente associados aos movimentos de esquerda), através de um estudo de caso: as ocupações de CasaPound Italia (CPI), em Roma. Para tanto, é apresentado um pequeno esboço histórico da criação e atuação da CPI, bem como noções gerais do conceito de solidariedade seletiva, da tradução política da imigração e do conceito de cidadania nacional. Tal cidadania é aqui abordada como marco de linha abissal, responsável pela divisão entre humanos e sub-humanos, a partir de conceitos de Boaventura Sousa Santos. CasaPound Italia (CPI), hoje reconhecido como um partido político de extrema direita italiano, iniciou suas atividades com a organização de uma ocupação ilegal, no qual famílias que precisavam de moradia invadiram um palácio público, no bairro multiétnico de Esquilino, no dia 26 de dezembro de 2003. Somente naquela primeira ocupação, cerca de 20 famílias, aparentemente sem recursos, começaram a viver em apartamentos de vários tamanhos, na Via Napoleone III. Após um encontro ocasional com integrantes de CasaPound e, em um momento de análise crítica da falência das utopias políticas a partir de leituras sobre os conceitos da corrente da terceira via da democracia-social, calcada esta nas ideias de distributismo e promotora do liberalismo social, chamou-me a atenção o discurso assistencialista e a apropriação de um vocabulário notadamente de esquerda de um movimento que se autodenomina "neofascista". Deste modo, resolvi investigar o que parecia paradoxal, através de leituras e da observação direta da ocupação inicial da CasaPound. Para isso, eu dormi algumas noites na sede da CasaPound, em Roma, e participei de algumas atividades colaterais como conferências "para poucos convidados", em outras instituições ligadas, mesmo não declaradamente, aos membros da CPI. Interessava-me, sobretudo, avaliar de perto os conceitos de solidariedade seletiva e o direito à moradia, bem como o uso de palavras como "revolução e rebeldia". Quanto ao conceito de solidariedade, de acordo com Pasini e Reichlin (2001), devemos ter em conta que este não é uma herança da tradição iluminista ou da ideologia liberal, podendo tais origens serem atribuídas à ideologia democrática católica-cristã e à tradição socialista. Assim, essas tradições foram fatores determinantes em alguns modelos do estado de bem-estar social, que foram criados em muitos países europeus após a Segunda Guerra Mundial. Nas últimas décadas, após a queda do muro de Berlim, o debate sobre a justiça social na teoria política e social, bem como a luta entre o liberalismo e o comunitarismo, tiveram grandes implicações em relação também à solidariedade.

Palavras-Chave: Direito à Moradia, Ocupações, Neofascismo, Direita, Europa. 


\section{HABITAÇÃO E DIREITOS HUMANOS \\ - O CASO DOS SEM-ABRIGO}

O Direito à Habitação constitui um dos pilares principais de qualquer estratégia integrada de desenvolvimento. Pelo impacto quer sobre a qualidade de vida, quer sobre o que respeita à saúde individual e familiar, quer, ainda, sobre os mecanismos de reprodução da força de trabalho, a habitação tende a constituir um palco de múltiplos interesses, estratégias e oposições. A nossa comunicação pretende analisar a questão do direito à habitação enquanto elemento chave para uma verdadeira inclusão social. Iremos tomar como caso de estudo, a realidade vivida na Cidade de Lisboa, fazendo referência a um caso particular de população excluída, correspondente aos denominados sem-abrigo. A nossa comunicação encontra-se dividida em três partes fundamentais, sendo a primeira dedicada a uma análise de diferentes perspetivas teóricas sobre a universalidade do direito à habitação e respetiva influência sobre as questões da pobreza e privação. Num segundo momento, apresentaremos um quadro relativo aos problemas sentidos pela população sem abrigo da Cidade de Lisboa e terminaremos com uma referência a possíveis linhas de ação rumo ao futuro. É intenção dos autores apresentar, de modo sintético, algumas estratégias recentes que têm vindo a ser desenvolvidas no território urbano da principal cidade do país, analisando pressupostos e primeiros resultados obtidos. Recorreremos, enquanto fontes informativas, a dados contidos em estatísticas oficiais e também apresentaremos alguns elementos obtidos via questionário/inquérito lançado junto a população que, a dado momento do seu trajeto de vida, se encontrava em situação de carência habitacional. Deste modo, pensamos que a complementaridade entre dados oficiais (disponíveis em estatísticas, estudos e relatórios) e dados oriundos de pesquisa "no terreno" constituirá um garante de uma análise mais completa e diversificada, proporcionando maior riqueza no domínio das conclusões a apresentar na parte final do trabalho.

Palavras-Chave: Habitação, Direitos, Sem-Abrigo, Lisboa, Estratégia.
José Lúcio UNL-FCSH/CICS-NOVA \& Maria Filomena Marques Câmara Municipal de Lisboa 


\section{AS DESIGUALDADES SOCIOESPACIAIS EM LONDRINA: O PAPEL DAS POLÍTICAS PÚBLICAS NA REDUÇÃO DA POBREZA}

Ideni Terezinha Antonello

Universidade Estadual de Londrina/UEL
O rebatimento das políticas públicas no território de Londrina se insere de forma heterogenia na escala municipal, no caso da habitação observa-se uma situação crítica em termos de inadequação e precariedade das habitações, essas características estão presentes nos assentamentos precários e nas favelas totalizando 4.709 famílias nessa condição de habitat, em 2010, as quais estão espacialmente concentradas na Região Leste $(67,47 \%)$ e na Região Sul $(66,48 \%)$. O levantamento realizado para identificar as favelas registou 2.291 famílias nessa condição de habitabilidade, em 2015 (COHAB-Companhia de Habitação de Londrina, 2016). Além de famílias vivendo em loteamentos irregulares, sendo $55,45 \%$ localizadas na Região Norte da cidade. Insere-se na análise os dados gerais da demanda habitacional, que era de 57.492 famílias londrinenses, em 2018 (COHAB), compreendendo por déficit habitacional as deficiências do estoque de moradias (quantidade disponível), bem como as que não possuem condições de habitabilidade devido à precariedade das construções ou ausência de infraestrutura como energia elétrica, abastecimento de água, esgotamento sanitário por fossa séptica ou por rede e coleta de lixo direta ou indireta. Entrelaçado ao acesso precário a moradia está a questão da renda familiar, já que as famílias que não possuíam renda definida (10.112) somada as sem renda (7.975) totalizavam 18.087 famílias, em 2016, que viviam na incerteza do dia a dia de conseguir sobreviver. Sendo que 68.373 famílias estão inscritas no
Sistema de Informatização da Rede de Serviços da Assistência Social de Londrina, destas 16.575 recebiam o benefício bolsa família (programa federal de transferência de renda), localizadas nas Regiões Norte $(30,5 \%)$ e Sul $(22,5 \%)$ do perímetro urbano. Os dados são a expressão da desigualdade socioespacial presente em Londrina, denunciando a exclusão, social, econômica, espacial, sofrida por essa população. É uma realidade preocupante destas famílias que se encontravam no estado de vulnerabilidade social que se liga a problemática habitacional, o que se constitui no cerne da questão da negação do direito à cidadania. Torna-se evidente a relação intrínseca entre a renda das famílias a situação de vulnerabilidade social que se vincula ao acesso a uma moradia digna, sem a qual não é possível pensar em qualidade de vida para a população. É necessário se ponderar as condições de sustentabilidade deste sistema de elaboração de políticas públicas, uma vez que os resultados da investigação revelaram a capacidade limitada de atuação do poder estatal, relativa as três escalas de poder (federal, estadual, municipal) na aplicação de políticas públicas nos diferentes setores sociais (educação, saúde, habitação), tendo em vista que os dados da realidade socioeconômica e espacial demonstram a situação crítica vivenciada por uma parcela da população de Londrina, principalmente no quadro de pandemia do Covid-19.

Palavras-Chave: Desigualdade Social, Política Pública, Habitação, Pobreza, Pandemia. 


\section{UM OLHAR PARA ALÉM DO CONCRETO: O CÁRCERE SELETIVO NO BRASIL E POSSIBILIDADES DA EDUCAÇÃO MEDIADA POR TECNOLOGIAS}

O texto discute o sistema prisional brasileiro, as desigualdades sociais que sofre a população carcerária e apresenta uma breve contextualização histórica deste processo. Apresentamos uma revisão teórica sobre o sistema prisional, os aspetos legais, sociais, culturais, políticos e ideológicos. Identificamos que o Brasil tem uma Lei de Execução Penal considerada uma das mais modernas do mundo, no entanto, ainda mantém um modelo de segregação social, seletivo e punitivo no seu sistema prisional. Abordamos criticamente algumas injustiças sociais praticadas no sistema prisional, muitas vezes executadas pelos próprios mecanismos da justiça brasileira. Todavia, nem tudo é pessimismo, pois é possível descrever possibilidades abertas pela legislação, que trouxe avanços às Políticas Públicas do encarceramento através da educação e do trabalho. Da população prisional brasileira, apenas 16,53\% realizam atividades educacionais. É muito pouco, considerando que, a partir de 2011, foi aplicada a remição, por trabalho ou por estudo, de parte do tempo de execução da pena. A educação destinada aos encarcerados deve compreender ações de formação humana que resgatem ao homem aptidões que, além da sobrevivência e da ressocialização, constituam aptidões para desenvolver uma visão de mundo compatível com a ética e a cidadania; para a alteridade e o desenvolvimento da identidade e a recuperação da autoestima; para o reconhecimento e a convivência social com o outro na sua diversidade. A educação a distân- cia mediada por tecnologias pode ser uma boa alternativa para aumentar os índices de pessoas privadas de liberdade que realizam atividades educacionais, com aprendizagens significativas e pode contribuir para a reinserção das mesmas na sociedade. Apontamos três motivos para a sua utilização. 0 primeiro é o alcance em larga escala, permitido pela mediação das tecnologias de informação e comunicação, que se harmoniza com a extensão numérica da população carcerária do Brasil, quarto país do mundo em número de encarceramentos. O segundo é o caráter democrático da EAD, estimulando o protagonismo e a autonomia de quem aprende e respeitando o ritmo e o estilo de aprendizagem de cada um. Em terceiro lugar, se almejamos a ressocialização dos encarcerados na vida social, ao alcançarem a liberdade pós-cárcere, a atualidade e a modernidade da educação a distância são favorecedores, característicos da "era da informação" que vivemos. Esse investimento formativo no humano aponta nas três direções comumente atribuídas à educação: a construção simbólica da realidade, através da aquisição e desenvolvimento de variadas linguagens; a aquisição de conhecimentos e habilidades que vinculem fortemente a teoria à prática; e a formação do sujeito ético. Pode assumir, assim, importante papel como instrumento de indução de políticas públicas e representando forma de rompimento da dureza do concreto das paredes da prisão e do estabelecimento de um olhar para o futuro e a liberdade.
Eloiza Da Silva Gomes

De Oliveira,

Universidade do Estado do Rio de Janeiro

Janaína Luana Rodrigues da Silva Valentim, Universidade Federal do Rio Grande do Norte Ricardo Alexsandro de Medeiros Valentim Universidade Federal do Rio Grande do Norte \& Ronaldo Silva Melo Universidade do Estado do Rio de Janeiro
Palavras-Chave: Direitos Humano, Educação, Privação de liberdade, Mediação Tecnológica, Sistema Prisional Brasileiro. 
Ref.: 3 IOCEDHM22020

\section{A GUARDA DE MENORES EM FAMÍLIAS SOCIALMENTE VULNERÁVEIS: UM CASO DE PROSTITUTAS DO INTERIOR DE SANTA CATARINA/BRASIL}

Jordana Sofia da Silva

\& Mickhael Erik Alexander

Bachmann

Centro Universitário

para o Desenvolvimento

do Alto Vale do Itajaí - UNIDAVI
O objetivo do presente trabalho é analisar a possibilidade da guarda de menores em famílias socialmente vulneráveis, considerando a realidade de genitoras que exercem a prostituição nas cidades de Imbuia-SC e Vidal Ramos -SC, como uma questão de direitos humanos. A pesquisa realizada foi bibliográfica, complementada com a extração de dados in loco através de entrevista semiestruturada. No presente trabalho é explorada a proteção a dois sujeitos que compõem as relações familiares: as genitoras e o(s) seu(s) filho(s) menor(es), do ponto de vista dos direitos humanos. Os objetivos específicos retratam de maneira sintetizada a divisão dos capítulos do trabalho, sendo eles: Contextualizar e introduzir, utilizando elementos históricos, o exercício da prostituição, a principiologia do direito de família e os contextos gerais dos direitos humanos; Analisar os institutos do poder familiar, da guarda, das visitas e dos alimentos nas relações familiares atuais; Apresentar a legislação de direitos humanos correlata, com ênfase nos diplomas de proteção aos direitos das mulheres, das crianças e aos direitos reprodutivos, bem como verificar a aplicação dos princípios da dignidade da pessoa humana, da liberdade reprodutiva e do melhor interesse da criança; e, enfim, investigar a possibilidade, com análise de dados obtidos, da guarda de menores por genitoras prostitutas nas cidades de Imbuia - SC e Vidal Ramos - SC, ponderando, para tanto, os princípios da dignidade da pessoa humana com relação ao direito da mulher em ter consigo seu filho, em virtude da liberdade reprodutiva, em contraposição ao melhor interesse do menor. Pelos resultados percebidos, considera-se que as instituições devem ser eficientes ao analisar os princípios indicados no trabalho, como os direitos reprodutivos da mulher e a dignidade da criança, no sentido de buscar a solução menos prejudicial, mais justa e benéfica para os envolvidos. $E$, por tais motivos, o estudo desta temática tem extrema importância quando vislumbrado que não existe atualmente previsão nacional legislativa nem jurisprudencial específica que verifique a guarda de menores com genitoras prostitutas, embora abundem os casos no mundo real. Enfim, a conclusão do trabalho expõe a análise das hipóteses levantadas no início da pesquisa, destacando os obstáculos do exercício da profissão e da maternidade exercida por tais mulheres, bem como verificando a necessidade de análise casuística relacionada a possibilidade da guarda.

Palavras-Chave: Direitos Humanos, Guarda, Menores, Prostitutas. 


\section{AS EXPECTATIVAS FUTURAS CONSTRUÍDAS POR RECLUSOS(AS) IDOSOS(AS)}

Portugal atravessa nos tempos de hoje um processo de envelhecimento da população. Os Censos realizados em 2011 vieram evidenciar essa mesma realidade, ressaltando que 2 milhões dos portugueses contam com mais de 65 anos. A população prisional não tem sido imune ao fenómeno de enveIhecimento demográfico. A literatura demonstra que o número de reclusos/ as mais velhos tem crescido de modo particularmente célere nos países desenvolvidos. Também em Portugal, a estatísticas prisionais disponibilizadas pela Direção-Geral de Reinserção e Serviços Prisionais, evidenciam, de ano para ano, um amento da reclusão de pessoas mais velhas. No entanto, a literatura refere que esta população é invisível no sistema prisional e consequente há uma ausência de políticas institucionais específicas. Partindo de um conjunto de 46 entrevistas com mulheres e homens, realizadas no Estabelecimento Prisional Especial de Santa Cruz do Bispo e no Estabelecimento Prisional de Paços de Ferreira, esta comunicação almeja explorar as expetativas de reintegração que vão sendo contruídas por estes reclusos durante a pena de prisão.
Os dados mostram que as expectati- Adriana Silva vas sociais, familiares e laborais futuras Universidade do Minho dos/as reclusos/as idosos/as, estas, no geral, são pautadas por uma ausência de planos e por uma falta de esperança no futuro, potenciadas pelo medo de morrer durante a reclusão.

Palavras-Chave: Reclusão, Envelhecimento, Expectativas Futuras. 


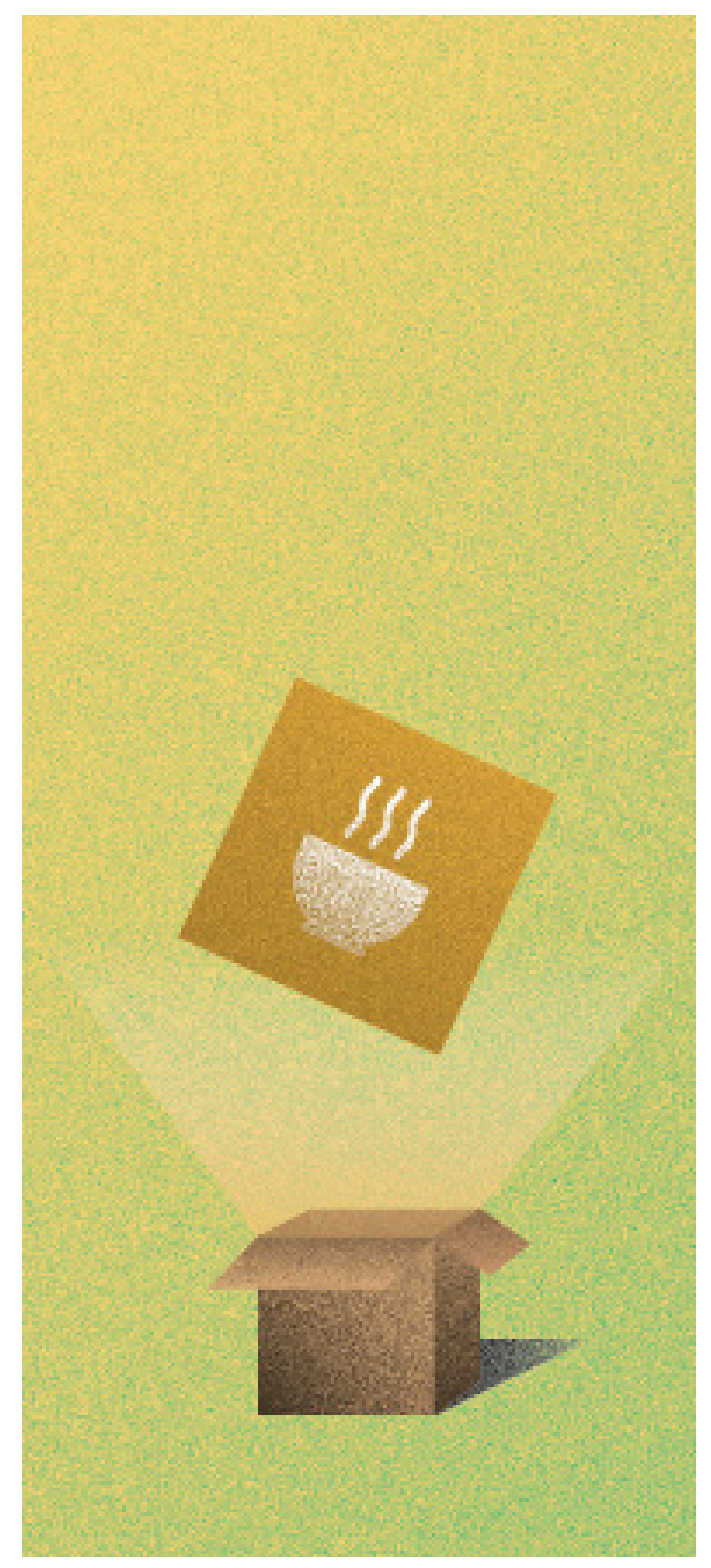

\section{ODS 2 \\ ERRADICAR A FOME}

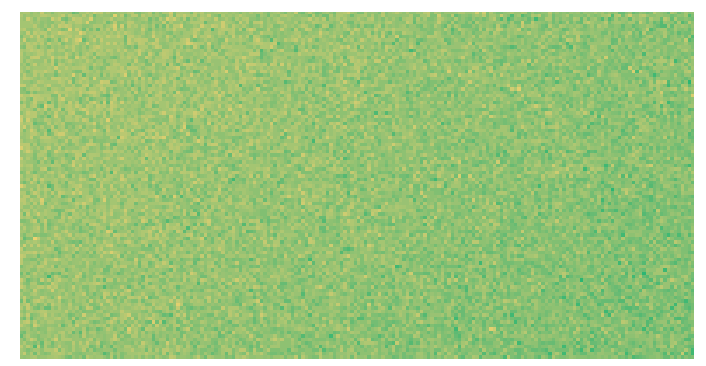




\section{GARANTIA DO DIREITO À ALIMENTAÇÃO EM ÉPOCA \\ DE PANDEMIA NO BRASIL: UM ESTUDO COMPARATIVO ENTRE AS REALIDADES PERIFÉRICAS DURANTE AS PANDEMIAS}

Ainda que cem anos as separem, a Gripe Espanhola e a COVID-19 têm características comuns. Ambas as doenças adquiriram proporções mundiais, tendo, ainda, um caráter desconhecido para a comunidade científica, fazendo-a recorrer a tratamentos experimentais em uma "corrida contra a doença". Outra semelhança entre as enfermidades e de grande importância é a maneira como ambas acometeram profundamente as comunidades periféricas, tendo em vista que a precariedade das condições sanitárias e a aglomeração inevitável são dois dos principais motivos para a disseminação e o agravamento de doenças. Entretanto, um ponto fundamental e pouco discutido é a questão da segurança alimentar e da garantia do direito à alimentação nessas circunstâncias. A Declaração Universal dos Direitos Humanos de 1948, em seu artigo 25, estabelece que todo ser humano tem direito a um padrão de vida capaz de assegurar a si e à sua família saúde e bem-estar, o que incluía alimentação. Atualmente, o direito à alimentação é entendido como um direito humano básico, reconhecido também pelo Pacto Internacional de Direitos
Humanos, Econômicos, Sociais e Culturais de 1966, ratificado por 153 países, sendo o Brasil também signatário. $O$ presente trabalho se propõe a ser um estudo comparativo entre as realidades dos cortiços em meio à pandemia da Gripe Espanhola no século XX e das favelas no século XXI durante a pandemia da COVID-19 no contexto brasileiro, a partir de uma abordagem hipotético-dedutiva. Com o apoio de uma pesquisa documental e bibliográfica, buscar-se-á discutir como a ocorrência de pandemias desvela as desigualdades sociais e impacta principalmente o direito à alimentação, previsto pelo artigo $6^{\circ} \mathrm{da}$ Constituição Federal, tendo em vista as condições econômicas e sanitárias das comunidades periféricas.

Palavras-Chave: COVID-19, Gripe Espanhola, Direito à Alimentação, Pandemia.
Luana Sales Barros da Silva \& Maria Goretti dal Bosco Universidade Federal da Paraiba 
Nicoly Stephani da Silva Pontifícia Universidade Católica de São Paulo (PUC-SP)

Ref.: I09CEDHM42020

\section{A RELEVÂNCIA DA EFETIVAÇÃO DE AÇÕES POSITIVAS PARA A GARANTIA DA ALIMENTAÇÃO NO NORDESTE BRASILEIRO}

Embora o direito humano à alimentação adequada esteja contemplado na Declaração Universal dos Direitos Humanos de 1948 -instrumento internacional de prerrogativas fundamentais, o mesmo só foi inserido como um direito social na hodierna Constituição Federal em 2010 através da Emenda Constitucional 64.

Sob a luz da segunda geração de direitos humanos, a partir do fortalecimento da ideia de bem-estar social na França de 1789, o direito à alimentação pôde ser observado como aquele imprescindível para a garantia da dignidade da pessoa humana. Isso porque promove não só uma sadia qualidade de vida como preconiza a Lei Suprema, mas também a igualdade entre as heterogêneas regiões do País.

A concentração de renda e problemas migratórios, agrários e climáticos encontram-se inertes, padrões análogos àqueles do século XX. A ausência de políticas públicas, isto é, de ações positivas estatais para um desenvolvimento integral, acarretam inúmeras consequências negativas para a população local, dentre elas o agravo da fome. Tal situação se enrijece ao passo que somente classes média e alta se integram regionalmente.

Mesmo que o direito à alimentação esteja abrangido pelo status positivus, permitindo que pessoas e grupos exijam uma atuação prestacional, observa-se na prática que essa obrigação no plano material de fornecer bens ou serviços não é devidamente concretizada. À vista disso, têm-se a fome como um fenômeno social que não deve ser naturalizado, já que é uma consequência da falta de compromisso estatal para se mobilizar e construir políticas públicas no fortalecimento dessa garantia social.

A presente discussão tem como objetivo evidenciar a importância de se promover mecanismos capazes de efetivar práticas que favoreçam a atenuação das dissemelhanças sociais. Procura-se averiguar por meio de um raciocínio dedutivo de pesquisa, a inobservância não só de atividades governamentais no amparo das populações que se encontram em escassez alimentar, mas também de normas constitucionais que garantem o alimento como um direito de todos.

Ao final do presente estudo, espera-se cooperar para a confirmação desse direito indispensável à existência do ser humano, bem como propiciar a consciência coletiva acerca da relevância da implementação de políticas públicas, uma vez que são capazes de promover a minimização da fome no nordeste brasileiro -um território negligenciado pelo Estado.

Palavras-Chave: Alimentação, Direitos Sociais, Políticas Públicas, Fome, Inobservância. 


\section{DIREITOS HUMANOS E A ERRADICAÇÃO DA MISÉRIA}

Direitos Humanos e dignidade material da pessoa humana são interdependentes. Por este motivo, documentos internacionais de DDHH contêm disposições relativas à superação da miséria. Trata-se de colocar a dignidade da pessoa humana em um nível material efetivo de real condição econômica, superando declarações jurídicas que são apenas formais. A Declaração Universal de Direitos Humanos da ONU, do ano de 1948, prevê, em seu artigo XXII que todo ser humano, como membro da sociedade, tem direito à realização pelo esforço nacional, pela cooperação internacional e de acordo com a organização e recursos de cada Estado, dos [necessários] direitos econômicos, indispensáveis à sua dignidade [também material]. Por sua vez, A Carta dos Direitos Fundamentais da União Europeia, de 2000, prevê, em seu artigo 36 o acesso a serviços de interesse económico geral. A Convenção Americana de Direitos Humanos, de 1966, trata de direitos econômicos, em seu artigo 26, para que os Estados Partes se comprometam a adotar cooperação econômica e técnica, para dar a efetividade dos direitos que decorrem das normas econômicas.

A Carta Africana dos Direitos dos Povos, de 1981, prevê em seu artigo 22 que os povos têm direito ao seu desenvolvimento econômico e ao gozo do patrimônio comum da humanidade, bem como o dever de assegurar o direito ao desenvolvimento. Vê-se a importância de o ser humano usufruir de uma condição econômica tão intensa que lhe dê a superação à miséria por usufruir bens e serviços de relevante expressão econômica. As metas internacionais de superação à miséria não podem ficar esquecidas. Para o ano de 2030 está prevista a efetiva redução da miséria mundial. E não se trata de apenas iniciar atividades públicas com essa finalidade. Naquele futuro ano de 2030 a redução da miséria deverá ter acontecido em caráter permanente. A Europa é o continente de melhor condição econômica do ser humano. Nos demais continentes há imensas populações que não dispõem de nenhuma perspectiva de superação à miséria. Há povos dos demais continentes que não vivem materialmente nem mesmo no Século XX. A meta proposta não foi realista: foi apenas otimista. Os governos dos países aderentes àqueles documentos internacionais devem realizar atividades plenas para erradicar a miséria. Trata-se de promulgar novas leis, de promover mudanças econômicas, de reduzir os impostos sobre os bens de consumo mais essenciais ao ser humano. Mas o tempo é bastante escasso. Os problemas para alcançar-se essa meta são complexos porque exigem intensas alterações sociais, legislativas, econômicas, individuais e coletivas, realizadas por novos paradigmas econômicos, e da mudança de legislações criadoras de miséria. Mas, faltou o elemento catalisador para essas mudanças: um órgão supraestatal e pluriestatal capaz de realizá-las. Sua ausência mantém o desinteresse geral, o deverá acontecer mesmo nos países ricos.

Palavras-Chave: Direitos, Humanos,

Erradicação, Miséria.
Celso Lopes Seus Universidade La Salle, Canoas, Estado do Rio Grande do Sul, Brasil 
Ref.: I86CEDHM42020

\section{"FIAT PANIS: A ATUAÇÃO DA FAO NO BRASIL"}

Lorena Granja Hernández, PPGRI-UERJ

Mauro Macedo Campos CCH-UENF

\& Caroline Saboia Rangel CCH-UENF
Este artigo busca compreender a atuação de organismos internacionais no suporte aos Estados nacionais para tratar problemáticas que ultrapassam as fronteiras físicas dos países, como a Segurança Alimentar e Nutricional (SAN). Com o avanço da globalização, o papel dos regimes internacionais na conformação de políticas públicas tem tido crescente protagonismo, em um universo cada vez mais extenso de assuntos. A saúde e a segurança alimentar parecem estar no topo da agenda na atualidade. As ações de combate à fome que a FAO tem desenvolvido na América Latina e o Caribe através de seu escritório regional tiveram impacto no tratamento que os países impuseram dentro de suas fronteiras; como por exemplo, a saída do Brasil do mapa da fome em 2014. Embora esse esforço venha sendo solapado nos últimos anos, e com perspetivas cada vez mais danosas no contexto da iminente recessão econômica após a pandemia do Novo Coranavirus (ou Covid-19) em 2020. Este artigo procura fazer uma sistematização das principais ações tomadas na trajetória de cooperação internacional entre a $\mathrm{FAO}$ e os países da região, com foco no Brasil. E, neste sentido, busca-se compreender o caminho das políticas públicas de SAN no Brasil, em que pese a capacidade de abrir novas perspetivas de cooperação e análise dos impactos de tais políticas no momento atual, em um ambiente no qual a necessidade de estabelecimento de regimes internacionais de ação paliativa à crise econômica e suas consequências sociais é cada vez maior.
O processo de globalização, intensificado a partir da Terceira Revolução Industrial, envolve a ideia de "mundo sem fronteiras", onde as economias são interligadas, na maioria das vezes, por blocos regionais e alianças comerciais, produtivas e tecnológicas, ocupando mercados e cadeias de valor globais. Tem-se discutido muito sobre o caráter interdependente dessa economia global que traria, por consequência, uma sociedade mais globalizada. Estados Nacionais. Nesse contexto, surgiram novos atores com condições efetivas de ação globalizante: empresas internacionais, movimentos sociais, blocos regionais e organismos internacionais que, em maior ou menor medida, se valem do multilateralismo como ferramenta para a vigência de regimes que influenciem as condutas dos atores e instituições nos distintos contextos específicos de ação.

Nesse sentido, os organismos internacionais têm se destacado por influenciar as condutas dos Estados nos mais variados campos, desde a política econômica -Fundo Monetário Internacional (FMI), Banco Mundial (BM). - , até as políticas culturais, -Organização das Nações Unidas para a Educação, a Ciência e a Cultura (UNESCO). Nessa mesma linha, em regiões marcadas pelas desigualdades sociais e de renda, as políticas de combate a fome, segurança alimentar e desenvolvimento sustentável tem adquirido um caráter determinante para a vida das pessoas.

Palavras-Chave: FAO, Combate à Fome, Segurança Alimentar e Nutricional, Cooperação Internacional, Combate à Pandemia. 


\section{AÇÕES CONTRA A FOME: \\ UMA ANÁLISE DO PROGRAMA NACIONAL DE FORTALECIMENTO DA AGRICULTURA FAMILIAR DO BRASIL}

Este trabalho visa analisar a participação do Brasil em ações voltadas à alimentação de sua população. Tem como referência o Programa Nacional de Fortalecimento da Agricultura Familiar-PRONAF, apresentado como alternativa para os esforços da comunidade internacional na formulação e implementação de políticas econômicas, ambientais e sociais voltadas à criação de um ambiente propício ao fortalecimento da agricultura familiar. Um importante pilar para a economia e responsável por uma expressiva porcentagem dos alimentos consumidos mundialmente, a agricultura familiar possui uma evidência apagada frente a sua importância no combate à fome. Somente em 2017 ela ganha um destaque mundial ao ser destacada pela Organização das Nações Unidas como "Uma Década das Nações Unidas para a Agricultura Familiar", que conta como protagonistas a Organização das Nações Unidas para Alimentação e Agricultura e o Fundo Internacional para o Desenvolvimento Agrícola. O intuito dessa década é buscar a promoção e implementação de marcos normativos e políticas públicas voltadas à agricultura familiar, sendo que cada país elabora o seu planejamento. Nesta pesquisa, recorre-se à pesquisa documental em legislações pertinentes ao tema, e à pesquisa bibliográfica de textos que discutem as políticas nacionais voltadas à agricultura familiar. No que tange ao
Brasil, observa-se que, entre as políticas públicas voltadas para a questão alimentar, merece destaque o PRONAF, que estimula o pequeno produtor a adotar melhorias em sua propriedade por meio de linhas de crédito. A seu favor, argumenta-se essa política poderá gerar renda e melhoria de condições de vida para os agricultores familiares, com baixa taxa de juros. Afirma-se, ainda, que a modernização dos recursos físicos do produtor pode contribuir para maior produtividade agrícola, a fim de atender suas necessidades e suprir a demanda de outras famílias. Entre as críticas ao Programa apontam-se a inadequação dos bancos para liberar recursos a famílias sem condições de lhes oferecer garantias patrimoniais e contrapartidas na tomada dos empréstimos, e liberações limitadas para os produtores de alimentos dirigidos ao mercado interno, privilegiando os produtos que têm ligação direta com o negócio agroindustrial e de exportação. O estudo leva à reflexão sobre quais seriam as políticas mais adequadas para os agricultores familiares, as agrárias e sociais ou as de crédito.

Palavras-Chave: Agricultura Familiar, PRONAF, Alimentação, Políticas Públicas.
Leonora de Abreu Bernardes

Universidade Estadual Paulista "Júlio Mesquita Filho" 


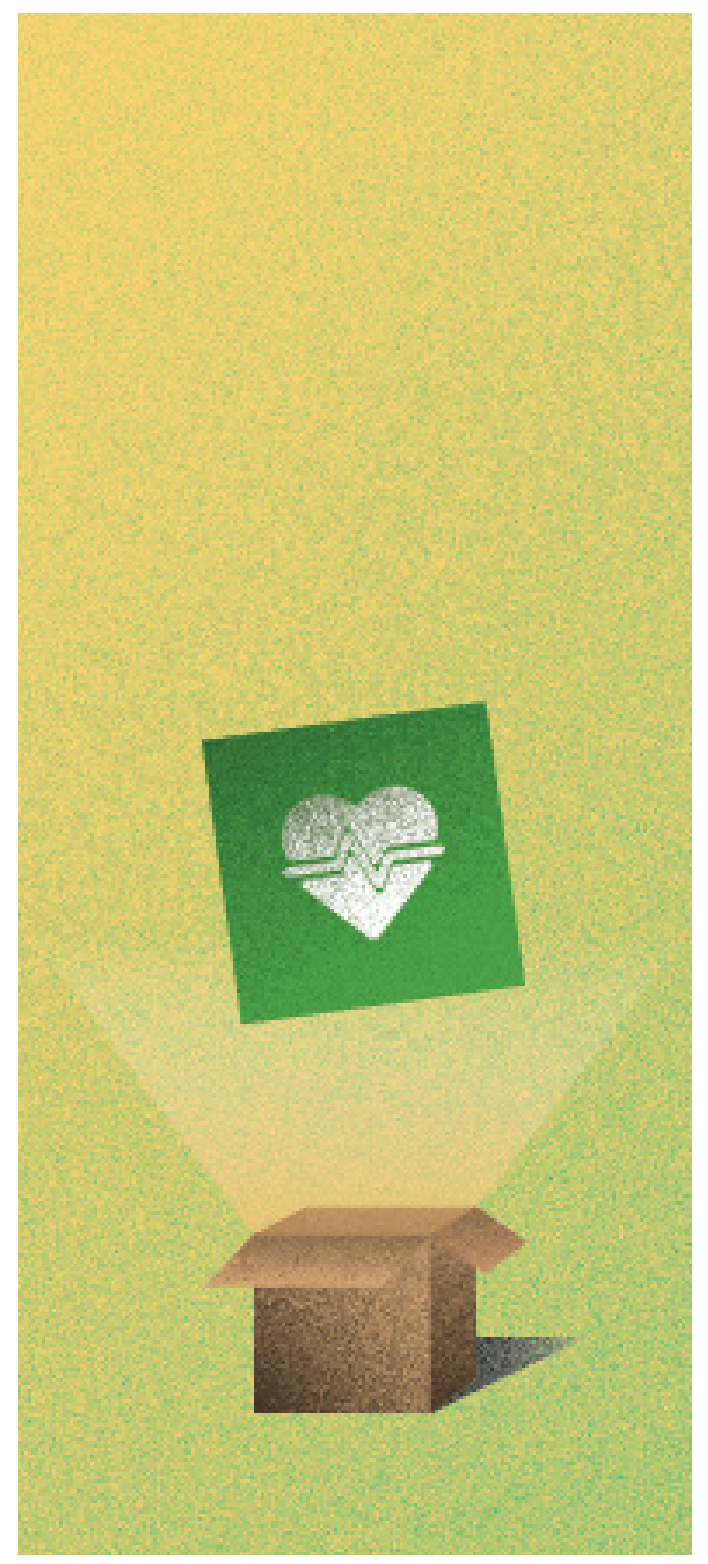

\section{ODS 3 SAÚDE DE QUALIDADE}




\section{O IDOSO ENCARCERADO: CONSIDERAÇÕES CRIMINOLÓGICAS}

Visando demonstrar que o envelhe-
cimento populacional, como uma das
características mais marcantes da atualidade, acarreta diversas modificações sociais, requerendo abordagens em todos os campos do saber, o presente trabalho, oriundo de dissertação de mestrado, vinculada à linha de pesquisa Criminologia e Controle Social do Programa de Pós-Graduação em Ciências Criminais da Pontifícia Universidade Católica do Rio Grande do Sul, tem como objetivo primordial apresentar a questão específica dos idosos envolvidos com o sistema penal e carcerário. Nesse viés, levando-se em conta as peculiaridades do envelhecimento, abordagem respaldada na gerontologia inicia o presente estudo, apresentando-se as principais características e implicações do envelhecimento populacional, o papel do idoso ao longo dos séculos, bem como os estudos sobre o envelhecimento. Para contextualizar o idoso no direito brasileiro, dedica-se parte do trabalho à análise do tratamento dado pela Constituição Federal, pelo Estatuto do Idoso, e pelas legislações penais e processuais penais em relação ao idoso. Para ilustrar a referida situação, alguns julgamentos criminais cujos réus são pessoas idosas são dis- Marina Portella Ghiggi cutidos. Consequência lógica de estarem os idosos, obviamente, também à mercê do sistema jurídico penal, é que podem eles ser submetidos ao sistema penitenciário. Assim, a próxima abordagem feita é exatamente acerca do idoso inserido no sistema penitenciário, com apresentação de um panorama do idoso encarcerado no Brasil além de considerações sobre o envelhecimento em uma penitenciária e a violência do cárcere sobre o corpo dos idosos. A título de conclusão, por ser o sistema prisional responsável por degradações irreparáveis, é mister que iniciativas tendentes primeira e principalmente a impedir o envolvimento com o sistema penal e, caso não seja possível, a melhor adequar as penitenciárias aos preceitos ditados pela primazia dos direitos humanos sejam vislumbradas também sob a ótica dos idosos nele envolvidos. Acredita-se que é por intermédio principalmente da Criminologia e da Gerontologia que alternativas para a situação apresentada devem ser buscadas.

Palavras-Chave: Envelhecimento Populacional, Idoso Encarcerado, Execução Penal,

Gerontocriminologia, Envelhecimento e Cárcere. 
Ref.: 012CEDHM22020

\section{MUJERES CON DISCAPACIDADY CENTROS ESPECIALES DE EMPLEO TRAS LA CRISIS DEL COVID- I 9}

Ana $M^{a}$ Hernández

\section{Fernández}

Profesora del Departamento de Análisis Social de la Facultad de Ciencias Sociales y Jurídicas

(Universidad Carlos III de Madrid, España)
Desde el año pasado trabajo en una tesis sobre empleo y discapacidad, y uno de los posibles capítulos de ésta va a ser el de la mujer con discapacidad y empleo en los Centros Especiales de Empleo.Como podemos imaginar ser mujer y ser discapacitada es una situación doble de discriminación, y sobre todo que lleva consigo una mayor dificultad para romper los techos de cristal. Pero, tras el género, posiblemente el otro aspecto de mayor exclusión y marginación entre seres humanos ha sido y es el de la discapacidad. Sin llegar a profundizar en la amplitud del término y las diferencias significativas existentes entre las múltiples causas y grados que la originan, hablar de discapacidad es hacerlo de un colectivode personas que históricamente ha sido, y en muchos casos en la práctica lo sigue siendo, objeto de exclusión social. Como ya hemos visto, la combinación de discapacidad y género colocan a las mujeres con discapacidad como uno de los colectivos que sufre un mayor grado de discriminación en nuestra sociedad. Si nos colocamos en el mundo laboral como herramienta clave de la inclusión, nos vamos a encontrar una realidad para nada esperanzadora. Para FEAPS y AFEM la mujer discapacitada padece una de discriminación múltiple que se ve agravada cuando dicha discapacidad es intelectual, así, nos encontramos con una tasa de inactividad en las mismas que ronda el $70 \%$ que aumenta en el caso de que la discapacidad sea intelectual, teniendo en cuenta que la tasa de inactividad de la mujer sin discapacidad se sitúa alrededor del 32\%. Como bien sabemos, las desigualdades se incrementan en las situaciones de crisis. La pandemia de COVID-19 lo demuestra. António Guterres, Secretario General de la ONU, ha hablado sobre esta situación y ha declarado que "debemos garantizar la igualdad de derechos de las personas con discapacidad al acceso a los cuidados sanitarios y a los procedimientos que les salven la vida"; y cuando hablamos de igualdad también nos referimos a la igualdadentre hombres y mujeres con discapacidad, fundamentalmente en un tema tan importante como el empleo.La mujer discapacitada y afectada por el COVID-19, con claras secuelas, puede que llegue a sufrir situaciones de discriminación que serán doblemente más agudas y problemáticas que las de sus compañeros con discapacidad.Por ello, nos preguntamos lo siguiente: ¿Los CEE ayudarán a la inserción de las mujeres con discapacidad?¿Qué ocurrirá con las mujeres discapacitadas tras la crisis del COVID-19? ¿Qué sucederá con las mujeres con discapacidad cuyas secuelas por el COVID19 haya empeorado su situación? Para responder a todas estas preguntas de investigación utilizaremos el método cualitativo, y técnicas de investigación cualitativa como las entrevistas semiestructuradas y grupos de discusión. El trabajo de campo se realizará en Castilla-La Mancha y en Madrid, y en este Congreso se presentarán los primeros resultados.

Palavras-Chave: Discapacidad, Empleo, Mujer, Crisis, Salud. 


\section{DIREITO AO ENSINO: IGUALDADE DE ACESSO E AS NOVAS TECNOLOGIAS AO SERVIÇO DAS ÁREAS DO DIREITO E DA SAÚDE}

O direito ao ensino garante uma educação inclusiva, equitativa e de qualidade e constitui um grande desafio, requerendo ações participativas de governos, organizações e da sociedade como um todo. Assumindo esta temática uma extrema importância a nível global, a Assembleia Geral das Nações Unidas, através de uma das suas metas universais de desenvolvimento sustentável, estabeleceu um conjunto de objetivos baseados nas necessidades prementes no sentido de envidar esforços para garantir educação de qualidade. Apesar de a liberdade de aprender e ensinar se encontrar constitucionalmente consagrada como um Direito, Liberdade e Garantia na Constituição da República Portuguesa, nem sempre são garantidas, pelo Estado, as condições de igualdade de acesso ao ensino. A tecnologia assume-se cada vez mais como um importante fator de promoção de igualdade de acesso ao ensino, nomeadamente nas áreas do Direito e da Saúde, com a aplicação de um vasto conjunto de metodologias de implementação prática. O objetivo do artigo é enquadrar e apresentar uma perspetiva relativa aos desafios do direito ao ensino, igualdade de acesso e aplicação das novas tecnologias nas áreas do Direito e da Saúde. Nesse sentido, para melhor definir o tema, é utilizada uma metodologia qualitativa de revisão bibliográfica. As aplicações das novas tecnologias têm um grande potencial no ensino, facilitando o acesso a conteúdos e materiais didáticos às populações menos privilegiadas, estando disponíveis online e permitindo consultar, simultaneamente, um vasto conjunto de fontes distintas. A flexibilidade e apoio à aprendizagem social e personalização do ensino são outras das grandes vantagens associadas ao uso da tecnologia, como o caso da inteligência artificial no ensino online, uma vez que possibilita que cada estudante possa aprender de acordo com o seu próprio ritmo, no momento mais oportuno e de acordo com o seu perfil. Especificamente no domínio do Direito, as práticas educativas terão de se adaptar a novas modalidades, designadamente ao ensino totalmente à distância, o que é urgente e necessário para a comunidade académica e ocupará os profissionais da educação jurídica em encontros, congressos e seminários. No que diz respeito à área da Saúde, a tecnologia já se encontra a transformar a educação médica, pois serve como meio de atração e interação com os estudantes, permitindo alargar as redes de contactos e o trabalho colaborativo. Apesar de o uso das novas tecnologias ser atualmente implementado num grande número de situações, existe a necessidade de encontrar mecanismos e estratégias que difundam de forma mais ampla o acesso ao ensino. Apesar de individualmente não resolver a complexa questão do direito ao ensino, fica claro que ao aliar estratégias e ações conjuntas e complementares, o contributo da tecnologia surge como um forte elemento potenciador na garantia do desejável acesso universal ao ensino por todos aqueles que têm o direito de o alcançar.

Palavras-Chave: Direito ao Ensino, Igualdade de Acesso ao Ensino, Novas Tecnologias, Direito, Saúde.

\author{
Abílio Azevedo \\ Universidade do Porto, \\ Faculdade de Engenharia, PT \\ \& Patrícia Anjos Azevedo \\ Politécnico do Porto, Escola Superior \\ de Tecnologia e Gestão, PT
}




\section{RISKS AND THREATS TO THE RIGHTS OF PETS IN PANDEMICTIMES: AN EXPLORATORY STUDY}

Vera Duarte, ISMAI, CICS.NOVA Susana Costa, ISMAI, CES

Catarina Cardoso UICCC.ISMAI

\& Mariana Soares UICCC.ISMA
"They're just animals" is a paradigmatic expression of the relationship that humans have established with animals over time, and that has been at the basis of their domestication and objectification. This Cartesian view of animals, without conscience or feelings, seen as objects, offered, for a long time, the theoretical justification for animal exploitation.

Since the end of the 20th century, people and animals get closer. There is a strengthening of affective bonds with pet animals; the scientific advanceon the world of animals, with new concepts of animal welfare; and the emergence of new democratic ideals that include greater respect for animal rights (Fonseca \& Dias, 2011; Chan \& Wong, 2019). At this level Portugal has taken two significant steps towards the protection of animals. We speak of Law No. 69/2014, of 29 August and Law No. 8/2017, of 3 March. The first, criminalize mistreatment of pets. The second comes to establish a legal status for animals, recognizing them as living beings with sensitivity, ceasing to be considered as mere things. The theme becomes even more relevant when several studies suggest that animal abuse is a predictor of interpersonal violence (Ascione, 2001; Ascione et al., 2007; Petersen \& Farrington, 2007; Alleyne and Parfitt,2017).

The current pandemic moment of the new coronavirus (COVID-19) has caused many uncertainties to everyone and also constitutes a threat to the welfare of pets. However, although there is no scientific evidence that companion animals, such as dogs andcats, are infected with the coronavirus or may carry the disease, people are afraid that they may get sick and spread the virus. A misinformation that can lead to fear, abandonment of the animal and its abuse/ mistreatment. It was in this context that theresearch team of the project "The relationship between animal abuse and interpersonal violence", which is being developed at the Research Unit in Criminology and Behavioral Sciences of the Instituto Universitário da Maia (UICCC, ISMAI), created and applied an online questionnaire on behavior and attitudes towards pets before and during the Coronavirus pandemic (COVID-19) in Portugal. The questionnaire was applied between May 11 and June 1, 2020, with 2198 validated responses.

The purpose of this communication is to present some data resulting from this study, seeking to answer the following questions: What is the impact of the pandemic on people's relationship with their pets? To what extent does the pandemic has been exposing pets to risk? And how do people position themselves in relation to issues such as animal welfare, animal abuse and criminalization of animal abuse.

Palavras-Chave: Animal Rights, Animal Welfare, Animal Abuse, Risk, Coronavirus Pandemic. 


\section{LIMITES À RESTRIÇÃO DE DIREITOS FUNDAMENTAIS EM ESTADO DE EMERGÊNCIA}

O presente estudo tem como objetivo analisar as medidas policiais adotadas pela República Portuguesa para conter a pandemia do COVID 19, no contexto do estado de emergência. Analisa o confronto entre os direitos e liberdades fundamentais e a medida do necessário para contenção da pandemia. O estudo é desenvolvido a partir da análise das medidas legislativas, especialmente o fortalecimento dos poderes de polícia poderes para garantia do cumprimento das regras de confinamento impostas. É apresentado um estudo histórico e comparativo entre a situação vivida em 2020 e outras situações de pandemias ocorridas no passado. Focamos a análise nas medidas de interdição de circulação, quarentena obrigatório e cerco sanitário, a fim de examinar sua adequação aos princípios constitucionais sobre direitos, liberdades e garantias individuais e o respeito pelo princípio da proporcionalidade. A metodologia adotada compreende o estudo de legislação, decisões administrativas, relatórios e pareceres de várias autoridades nacionais. Procedeu-se também à recolha de dados estatísticos existentes e elaboração de um inquérito, cujos resultados serão apresentados no artigo final. Nas conclusões apresentamos os resultados do estudo realizado e a análise dos dados recolhidos a partir dos quais é possível extrair qual o grau de aceitação dos diferentes grupos sociais e etários face às restrições adotadas.

Palavras-Chave: COVID 19, Direitos

Fundamentais, Estado de Emergência, Medidas de Polícia, Princípio da Proporcionalidade.
Maria do Rosário Anjos IJP Portucalense Institute of Legal Researcher

ULP -Lusófona University of Porto, Portugal

IPMAIA - Polytechnique Institute of Maia 
Henrique Alexander Keske

Grupo de Estudos de Direitos

Humanos e Transformação Social,

da Universidade Ritter dos Reis,

Núcleo FAPA

\& Claudine Freire Rodem-

busch

Faculdade Estácio do Rio Grande do Sul

Ref.: 06 I CEDHM22020

\section{EUTANÁSIA COMO DIREITO HUMANO FUNDAMENTAL À MORTE DIGNA: NECESSIDADE DE LEGISLAÇÃO QUE REGULAMENTE A MATÉRIA}

No presente artigo, a preocupação básica quanto à saúde de qualidade e à promoção do bem-estar para todos, em todas as idades e, acrescentamos, em quaisquer condições, se volta para o objeto da pesquisa que diz respeito a se postular a possibilidade de antecipação da morte como um direito humano fundamental, devidamente inserido no ordenamento legal brasileiro, de forma a garantir que os sujeitos de direito possam decidir quanto ao momento da morte, da mesma forma que o fazem em relação às questões existenciais ligas à sua saúde e à própria vida, mormente quando se tratam de pacientes terminais, sem possibilidade alguma de cura, sofrendo dores atrozes, ou sendo relegados à inconsciência dos estados comatosos. Daí se depreende a relevância da temática, em que se chocam os avanços da medicina, com a possibilidade de, por meios tecnológicos, reduzir a condição humana a mero objeto manipulável, por meio da obsessão terapêutica, negando-se ao ser humano o direito de morrer dignamente. A metodologia empregada parte de pesquisa e análise da legislação brasileira em que se excepcionaliza o direito à vida, permitindo matar, bem como a criminalização da eutanásia e a possibilidade de seu emprego, via normativa do Conselho Federal de Medicina, que, entretanto, não tem força de lei. Da mesma forma, se emprega o método de pesquisa doutrinário-bibliográfica e sua consequente análise. Nesse sentido, o artigo se articula em torno da discussão doutrinária acerca das questões suscitadas pela antecipação da morte, de maneira a postular, como objetivo, a possibilidade de se estender o princípio fundamental constitucional de garantia à vida, no direito brasileiro, baseada na dignidade da pessoa humana, (Constituição Federal/88, art. $1^{0}$, inciso III), ao momento da morte, dado não se poder separar esses dois momentos existenciais, ou seja, uma vida digna, de uma morte com dignidade. Assim, ao se questionar a legislação do país, pois que se limita a criminalizar tais práticas, chega-se ao objetivo de propor a elaboração de legislação abrangente, que regulamente a matéria, trazendo para o abrigo do direito esse problema que se verifica em uma espécie de limbo jurídico. Como resultado parcial se evidenciam as diversas formas de antecipação da morte elencadas pela doutrina, para que sirvam de paradigma para a abordagem do problema, a servirem de norteadores dessas possibilidades legais de decisões extremas, para se respeitar a vontade livre e soberana dos sujeitos nelas envolvidos, ou a quem a legislação autoriza decidir, quando essa vontade não pode ser auferida. Por fim, se ratifica que se elabore legislação específica, no Brasil, capaz de se aproximar de parâmetros humanistas, para dar conta de uma angustiante demanda social, normatizando tais práticas, mormente quando se está diante de pacientes terminais.

Palavras-Chave: Eutanásia, Direitos Humanos, Doente Terminal, Legalização. 


\section{LA ENFERMEDAD DE LARGA DURACIÓN COMO FACTOR DE DISCRIMINACIÓN EN EL ÁMBITO LABORAL}

La sociedad es consciente de la gran relevancia social que presenta la discapacidad, pues se trata de un amplio colectivo que además tiende a crecer, con una tasa de desempleo más alta, una remuneración inferior y unas necesidades específicas para la protección de su estado. Así pues, la inclusión social de las personas con discapacidad es un derecho reconocido en todas las sociedades democráticas y avanzadas, siendo necesario abandonar el enfoque médico que ha venido marcando la discapacidad y centrar los esfuerzos en que dicha inclusión sea plena y efectiva. En el ámbito laboral, la jurisprudencia ha supuesto un cambio significativo en cuanto a la interpretación de la enfermedad y su asimilación con la discapacidad. En este sentido, la jurisprudencia comunitaria a partir de la Directiva 2000/78 del Consejo y la Convención de Naciones Unidas sobre los derechos de las personas con discapacidad, prevé que la enfermedad pueda ser equiparada a la discapacidad en el sentido de dicha Directiva. A nivel interno, cabe señalar la ausencia de una normativa específica que garantice los derechos de las personas enfermas, y en concreto frente al despido, cuando se encuentran en una situación de especial vulnerabilidad. A nivel europeo, los pronunciamientos dictados por el TJUE han supuesto un avance en esta materia, sin embargo, todavía queda un largo camino por recorrer para lograr la total protección de los trabajadores en materia de despido por razón de la enfermedad. En el presente trabajo, se analiza laproblemática existente que se deriva de la calificación de la enfermedad y su asimilación a la discapacidad en el ámbito laboral, como causa motivadora del despido, así como las consecuencias derivadas de dicha calificación como factor de discriminación, al integrar en su tipología, la enfermedad como "causa" motivadora del despido. Pues bien, como se verá a lo largo de este trabajo, existe una enorme litigiosidad en materia de despido por razón de la enfermedad, aunque éste no goza de una tutela garantista en el derecho interno. Si bien, la derogación del despido por absentismo ha supuesto un avance en este sentido. Por ello, considero necesario de lege ferenda una regulación específica que prevea estas situaciones, que prohíba el despido en situación de incapacidad temporal y por ende, una bonificación o incluso exoneración en las cuotas de seguridad social de las personas trabajadoras que se encuentran en esta situación, eliminando de esta forma, que los empresarios tengan que acudir a mecanismos considerados ilícitos por el elevado coste que deben asumir cuando un trabajador se encuentra en situación de incapacidad temporal.

Palavras-Chave: Enfermedad, Discapacidad, Despid, Discriminación, Inclusión.
María Desamparados

Bohigues Esparza Universidad de Valencia. Facultad de Derecho. Departamento de Derecho del Trabajo y de la Seguridad Social 
Celsimar Custódio Silva Ministério Público do Estado do Tocantins

Ref.: 094CEDHM22020

\section{A CONDIÇÃO DE GARANTE DO ENTE ESTATAL AO DIREITO À SAÚDE EMTEMPOS DE PANDEMIA}

O direito à saúde tal como assegurado na Constituição Brasileira de 1988, configura direito fundamental de segunda dimensão, expresso nos artigos 196 a 200. Tais direitos, também chamados de direitos econômicos e sociais, são caracterizados, em regra, pela possibilidade de se exigir do Estado prestações positivas voltadas à sua concretização, o que implica o dever constitucional da Administração Pública de dar as condições para que o indivíduo tenha os seus direitos de subsistência preservados. Visando materializar esses mandamentos constitucionais, o legislador infraconstitucional estabeleceu preceitos que tutelam e garantem o direito à saúde, por meio da chamada Lei do SUS -Sistema Único de Saúde (Lei 8.080/90). O art. $2^{\circ}$ da legislação destacada cumpriu a finalidade de regular as ações e serviços de saúde, dispondo acerca das condições para promoção, proteção e recuperação da saúde, bem como a organização e funcionamento dos respetivos serviços, destacando, mais uma vez, o papel garantidor do Estado na vertente do direito à saúde, sobretudo no papel de reduzir os riscos de doenças. O arcabouço jurídico destacado atribui à saúde um novo patamar conceitual e político, aumentando a responsabilidade do Estado e dos demais atores institucionais envolvidos no processo de formulação, execução, fiscalização e avaliação de políticas públicas. As ações e os serviços de saúde passam a ser reconhecidos como de relevância pública, demonstrando a necessidade de implementação de medidas seguras e eficazes. Revela-se evidente que o direito público subjetivo à saúde representa consequência indissociável do direito à vida. É uma prerrogativa jurídica indisponível assegurada à generalidade das pessoas pela Constituição, isso porque trata-se de bem jurídico constitucionalmente tutelado, devendo zelar, de maneira responsável. Outrossim, os direitos fundamentais, em caso de omissão estatal, ensejam a possibilidade de se exigir prestações mínimas do Estado e abarcam a saúde, moradia, educação, tudo isto tendo em vista a preservação do princípio da Dignidade da Pessoa Humana, previsto na Constituição Federal, como fundamento da República Federativa do Brasil. Nesse cenário, cumpre rememorar que os entes da federação, em decorrência da competência comum prevista na Constituição Federal, são solidariamente responsáveis nas demandas prestacionais na área da saúde, incumbindo-Ihes o dever de bem prestar esse serviço, primando pela universalidade e igualdade para todos. Nessa perspectiva, é certo que a pandemia do COVID-19 vivenciada no mundo inteiro, inclusive no Brasil, exige do Estado lato sensu, a realização de uma política pública sanitária eficaz e eficiente, como meio de proteger o cidadão desse mal. Insere-se nessa perspectiva, a oferta de tratamento clínico com o mínimo de evidências científicas, perpassando, inexoravelmente, por protocolos médicos assertivos, medicamentos adequados, insumos e de demais instrumentos para contenção da doença.

Palavras-Chave: Saúde, Responsabilidade Estatal; Garantidor, Direito Fundamental, Pandemia. 


\section{O DIREITO À PLENA INFORMAÇÃO E O DIREITO À AUTONOMIA DECISÓRIA DO DOENTE COMO CONCRETIZAÇÕES DO PRINCÍPIO DA DIGNIDADE HUMANA}

São objetivos do presente estudo, demonstrar que está atualmente ultrapassada a ideia de que o profissional de saúde pode, no exercício da prática médica, decidir unilateralmente sobre a melhor estratégia de tratar o doente (v.g. tratamentos, cirurgias, exames médicos), omitindo informação clínica ou recusando prestá-la.

A "relação paternalista" que ditava a "relação médico-paciente" de há 20 anos, em que o primeiro sabedor da arte e ciência médicas, é que decidia sobre o estado de saúde do doente, sem auscultá-lo previamente, sem cuidar da sua opinião, receios e dúvidas, é, na verdade, contrária às boas práticas e ao Direito. A prática do ato médico conforme ao Direito e à legis artis possui uma dupla legitimidade, a do profissional de saúde e a do doente.

É imperativo que se faculte ao doente uma plena informação sobre o seu real estado de saúde, sobre as diversas alternativas para o respetivo tratamento e os efeitos adversos ou colaterais associados a essas terapêuticas, de modo a que, de forma absolutamente esclarecida possa tomar uma decisão sobre a sua vida.
O consentimento do paciente, válido e conforme à Lei, tem de ser livremente prestado. Ora, o pressuposto da "liberdade da vontade" da pessoa depende necessariamente do esclarecimento cabal sobre todos os aspetos relevantes para a tomada de decisão.

Trata-se, na verdade, de uma imposição constitucional, o respeito pela autodeterminação física e psíquica do ser humano e ao livre desenvolvimento da personalidade humana, como corolários do princípio da dignidade humana.

Qualquer desvio ao direito à informação influi negativamente sobre a prestação do consentimento do doente, condicionando a autonomia decisória do doente sobre o seu corpo, saúde.

Em termos de resultados da investigação: mostraremos que a violação destes direitos conduz a uma responsabilização de carácter cível com objetivos ressarcitórios, responsabilização criminal, sem prejuízo da queixa junto da Entidade Reguladora da Saúde e Ordens Profissionais respetivas.

Palavras-Chave: Cuidados Centrados no Doente, Consentimento, Autodeterminação do doente, Responsabilidade.
Isa António

Universidade do Minho e Instituto Superior de Ciências Empresariais e do Turismo 
Tânia Regina Silva Garcez, UFMS - Universidade Federal de Mato Grosso do Sul

Déa Marisa Brandão Cubel Yule

Tribunal Regional do Trabalho $24^{a}$ Região

\& Gisele Beraldo de Paiva Faculdade Insted

Ref.: I I 3CEDHM22020

\section{TRABALHADORES EM GRUPO DE RISCO E O LIMBO PREVIDENCIÁRIO-TRABALHISTA: HARMONIZAÇÃO DO PRINCÍPIO DA RESERVA LEGAL E DA DIGNIDADE HUMANA}

Desde há muito tempo o trabalhador no Brasil vivencia um relevante problema com pouca solução legal e jurisprudencial, denominado limbo previdenciário-trabalhista, ou seja, tem seu benefício previdenciário cessado, mesmo com a manutenção da sua incapacidade laboral diagnosticada pelo médico assistente e, ao tentar retornar ao seu ofício é impedido por ter sido considerado inapto pelo médico do trabalho de seu empregador. Em tempo de pandemia, uma nova situação emerge quando o assunto é limbo, já que milhares de trabalhadores que se enquadram no grupo de risco de óbito e que não conseguem o afastamento previdenciário por não apresentarem incapacidade para o trabalho, já que possuem apenas o "atestado por prevenção", tampouco obtém do empregador a interrupção de seus contratos de trabalho a partir do $15^{\circ}$ dia de afastamento, ficando sem benefício e sem salário. A partir dessa nova realidade extraordinária e pandêmica, antes não pensada pelo legislador, interpretar o requisito legal de falta de incapacidade laborativa para o afastamento previdenciário previsto para situações ordinárias do cotidiano, e garantir direito ao afastamento por prevenção, a ser assegurada pela previdência social, é um grande desafio para os operadores do direito. O fundamento do Estado Democrático de Direito que se baseia na dignidade da pessoa humana deve se sobrepor ao princípio constitucional da reserva legal. Caberá ao Estado, através da Seguridade Social, em uma de suas ações: saúde, assistência social e previdência social estabelecer uma nova diretriz priorizando o afastamento preventivo, embasado no conceito de saúde, estabelecido pela Organização Mundial de Saúde, consistente no completo bem estar físico-mental-social e não apenas a ausência de patologia, a fim de evitar desequilíbrio na relação empregado-empregador, oriunda de uma situação exógena e não provocada por nenhuma das partes. Esta pesquisa busca, por meio do método dedutivo e com pesquisa bibliográfica, documental e empírica demonstrar que existem mecanismos na legislação pátria para determinadas situações daqueles que estão no grupo de risco de morte pela pandemia de COVID-19, podendo ainda ser desenvolvidas políticas públicas a fim de resguardar a dignidade humana do segurado-trabalhador sem acarretar um ônus insuportável ao empregador. Sua relevância se justifica pela necessidade de proteção e promoção de direitos humanos, previdenciários e trabalhistas direcionada aos trabalhadores-segurados, visando resguardar o objetivo número 3 da Agenda 2030 garantindo a saúde e promovendo o bem-estar destes. Conclui-se que a proteção ao trabalhador em grupo de risco é questão relevante para o Estado como cumpridor dos objetivos de desenvolvimento do milênio, que deve adotar uma postura protetiva e preventiva, e que também há, por parte do empregador, mecanismos de cooperação com o Estado, seja para prevenção, seja para solução do chamado "limbo previdenciário-trabalhista" em época de pandemia.

Palavras-Chave: Limbo Previdenciário-trabalhista, Covid-19, Brasil, Dignidade da Pessoa Humana, Acesso à Saúde e Bem-estar. 


\section{THE PORTUGUESE APPROACH ON UNDOCUMENTED \\ MIGRANTS ACCESS TO HEALTHCARE DURING THE PANDEMIC: A NEW STEP TOWARDS A MORE INCLUSIVE STANDARD POL}

Despite being an old problem, the current coronavirus outbreak has shed a light on the lack of access to proper healthcare by undocumented migrants, which is one of the many violations of fundamental they face not only in Europe, but also all over the world. However, amidst the global response to the pandemic, the Portuguese policy of granting those migrants full citizenship rights in order to ensure full healthcare coverage has been a much-applauded one. It was of great value to public health and to the protection of other fundamental rights of migrants. This essay addresses the subject from the perspective of the European Union framework, presenting an overview of migrants' access to healthcare in Member States, especially in Portugal. Finally, it raises the question of the Portuguese approach of granting undocumented migrants access to healthcare during the pandemic can be the first step towards a more inclusive standard policy not only in Portugal, but also in Europe.

Palavras-Chave: Coronavirus, Pandemic, Undocumented Migrants, Fundamental Rights, Healthcare.
Patrícia Estácio de Lima Corrêa

Universidade Católica Portuguesa - Escola do Porto 
Ref.: I5ICEDHMI 2020

\section{MAIS ALTERNATIVAS SÉNIOR \\ - UM PROJECTO DE SAÚDE E QUALIDADE DE VIDA: ESTUDO DE CASO NUMA IPSS}

Ana Rita Baracho Ferreira \& Andrea Isabel Oliveira da Costa e Sousa

Instituto Superior Miguel Torga
O projecto MAIS ALTERNATIVAS SÉNIOR da Associação de Bem Estar Social e Recreativa de Alpedriz, apoiado pelo Portugal Inovação Social, visa MELHORAR A QUALIDADE DE VIDA DO IDOSO pelo COMBATE ÀS DOENÇAS DOS IDOSOS. Sendo o envelhecimento da população, uma realidade que evolui naturalmente na nossa sociedade que acarreta problemas de saúde e ausência de bem-estar e contribui para o aumento dos custos de saúde, que recaem sobre o Estado. Promover um envelhecimento associado ao bem-estar e qualidade de vida segundo Barros, Otani \& Lima (2010) estará dependente, de aspectos como: (i) possuir autonomia para executar as actividades do dia-a-dia, (ii) manter uma relação familiar e/ou com o exterior regular, (iii) ter recursos económicos suficientes e (iv) realizar actividades lúdicas e recreativas regularmente.

MAIS ALTERNATIVAS SÉNIOR é dirigido a 30 idosos da freguesia de Alpedriz, concelho de Alcobaça, e apresenta um conjunto de terapias, não evasivas, focadas na individualidade de cada pessoa, sendo uma solução integrada e direcionada aos idosos. Esta solução, visa a manutenção da saúde e da qualidade de vida, porque aplica um conjunto de terapias alternativas integrativas que promovem a igualdade de acesso a um público, que pela sua condição de velho, não é valorizado. A dúvida e o descrédito da capacidade de melhoria destes idosos, reduz a oferta de soluções/actividades que potenciem o bem-estar, nesta fase da vida. Esta condição condena-os à dependência e fragilidade.
O projecto integra duas dimensões de intervenção: individual e grupal. Individualmente através das intervenções terapêuticas do domínio visceral e sacra-craniano articuladas com a reabilitação motora, que irão actuar de forma sinérgica. Colectivamente através da intervenção da ludoterapia, yoga e musicoterapia, que potenciam momentos de socialização emocional e das relações interpessoais, bem como o desenvolvimento de capacidade cognitivas, de coordenação e de renovação de pertença.

Este projecto permite um maior acompanhamento dos idosos, mitigando o isolamento, com impacto na segurança e vigilância da saúde. A partilha e a consciência de cada idoso, tornará o processo de melhoria mais viável, principalmente pela melhoria da qualidade de escuta e de atenção/ concentração, que no seu conjunto desbloqueia o corpo e a mente e que a através da aplicação destas terapias, desencadeiam um processo de melhoria contínua.

Esta actuação conjunta contribuí para melhorar a condição geral e a saúde dos idosos, numa filosofia profilática e preventiva da dor, com implicações positivas na diminuição da toma de fármacos, já com provas dadas. É um projecto único e potenciador de novas reflexões e práticas no domínio das intervenções e políticas públicas e sociais, na prestação de cuidados aos idosos.

Palavras-Chave: Terapias Alternativas, Qualidade de Vida, Bem Estar, Idoso. 


\section{A MEASURE OF WELLBEING TO PROMOTE HUMAN RIGHTS}

Mental health is, as is physical health, a must to promote an overall healthy life for all people. Wellbeing is, therefore, a crucial variable to understand and thus develop new interventions that will help to improve individual and overall community lives. When people feel good and have their needs provided, they are more willing to help others and be part of those who look to defend and protect those less fortunate. Positive Psychology brings awareness to the importance of focusing on the good of each one of us to build strength and resilience to surpass those moments less positive that invariably happen in life. This study focuses on wellbeing understood through Positive Psychology. Having this theory in mind, we aim to highlight how the science of wellbeing, in this case, Positive Psychology, can be an ally to promote human rights, but also to highpoint the importance of using scientific methods and measures to back up our narratives about wellbeing strategies and interventions that may have a lasting impact on human rights development. Thus, we question how can effective wellbeing intervention methods be applied if we do not how efficient they are? This communication brings to attention a new measure that aims to evaluate wellbeing in a Portu- guese sample of 200 participants. This is an exploratory factor analysis study. KMO was .79. A two-factor measure seems to be the best structure, with an explained variance of $53.16 \%$. Overall, internal consistency was .759, and factors reliability was .738 and .722 . Psychometrically, the measure sounds adequate, but further studies are needed to confirm this analysis. The goal with this communication is to bring, not only a new instrument to practice, but to empathize the importance of having scientific and rigorous instruments to measure and analyze data, which are fundamental to develop strategies that will have positive effects in increasing people wellbeing and, therefore, be a support to intervene and have confidence that those same strategies are indeed effective. If a good plan is made, with a sound methodology and adequate measures it is possible to promote wellbeing which will be undoubtedly a tool that will not only promote a healthier life but also will be a mean to advocate for people rights to have a fulfilling life and thus ensure life quality which is undeniably a human right.

Keywords: Wellbeing, Mental Health, Exploratory Factor Analysis, Quality of Life, Human Right.
Margarida Pocinho UMa-CIERL

\& Soraia Garcês CinTurs-UAlg 
Ref.: I62CEDHM22020

\section{HOW UNDERSTANDING PSYCHOLOGICAL GENDER DIFFERENCES IN TOURISM EXPERIENCES CAN BE A WAY TO PROMOTE GENDER EQUALITY}

Soraia Garcês

CinTurs-UAlg

\& Margarida Pocinho UMa-CIERL
Psychology is a scientific field that brings new insights into the tourism industry by focusing on its consumers which are people who are away from their daily homes. A recent but very interesting topic of research joins both tourism and aspecific sub-field of Psychology called Positive Psychology. Links between fields are being developed bringing new ways of perceiving and understanding the tourism phenomena. A key point is the study of tourism experiences which are, more than ever, an important topic to tourism entrepreneurs particularly with the emergence of the so-called "experience economy". Tourism experiences refer, in broad terms, to how people perceive, feel, behave, and interpret their experiences lived in settings that are usually different from their daily lives. One of the main research questions of the authors' study is if gender influences the way women and men perceive their tourism experiences and if so, how can destinations offer products accordingly. This communication will focus on an empirical study in a sample of Portuguese tourists that aims to explore gender psychological differences In this preliminary and exploratory study, 399 Portuguese tourists participated. Women partake for $69.4 \%$ of the sample and men $30.6 \%$. Ages range from 18 to 73 years old, with a mean of 28.99 and a standard deviation of 10.97. Results showed that gender differences exist in the overall wellbeing variable, with women displaying higher means than men. Significant differences were also found in the variable positive emotions and accomplishment. For both variables' women scored higher than men. These preliminary results lead us to think that both women and men have different ways of perceiving their tourism experiences particularly regarding theway they experience their emotions and their achievements. These study results are important since these can lead to a better understanding of the concept of tourism experience but also bring a new perspective for this field and opens doors to the relevance of developing new experiences that consider women's and men's perceptions in what makes an experience memorable and meaningful, for both of them, equally. Therefore, to promote tourism experiences that are more fulfilling and have the potential to enhance women's and men's wellbeing, both gender perspectives should be considered in its design.ng, both gender perspectives should be considered in its design.

Keywords: Tourism Experiences, Positive Psychology, Gender, Meaning. 


\section{O DIREITO À SAÚDE NO CONTEXTO DOS MÉTODOS ALTERNATIVOS DE PARTO}

Representando um período de virada na existência da mulher, a gestação é o marco temporal e biológico da formação de uma nova vida humana. A partir disso, deve ser consolidada toda uma estrutura de saúde em torno da gravidez suficientemente apta a garantira adequada assistência à mulher e ao nascituro. Entretanto, uma das maiores preocupações das mulheres grávidas encontra-se no momento do parto, em particular quando se considera a relativamente recente exposição de uma pluralidade de ocorrências danosas verificadas por práticas obstétricas inapropriadas -e até mesmo violentas. Tal conjuntura retratou um aspeto que contribuiu para a ampliação da força do crescente movimento por formatos alternativos de parto, geralmente executados no domicílio familiar e com especificidades diversas a depender das preferências da mulher e demais envolvidos. Observa-se, inclusive, a sedimentação do potencial de impacto desses novos métodos a partir da busca gradativamente maior por alternativas ao parto considerado convencional, muitas vezes desconectadas da apropriada assistência médico-hospi- talar. Muito embora a manifestação da vontade seja essencial para a materialização das escolhas femininas -principalmente ao dar à luz a uma vida -, não se pode afastar a viabilização dos meios substanciais ao devido amparo da mulher traduzido pela concretização do seu direito à saúde. As atuações estatais positivas garantem a efetivação do direito à saúde, cujo preenchimento prático está profundamente associado às prestações materialmente possíveis, como o compatível acompanhamento médico. No momento do parto não é diferente, uma vez que se trata de um procedimento marcado pela indispensabilidade de atenção médico-hospitalar diferenciada, de modo que a satisfação toca substancialmente no direito à saúde da mulher. Institui-se, nessa perspetiva, uma circunstância paradoxal que necessita ser equacionada para assegurar o devido amparo da mulher, especialmente no que tange o pleno exercício do direito à saúde no contexto do parto.

Palavras-Chave: Parto Humanizado, Direito à Saúde, Direito da Mulher, Direito Médico, Violência Obstétrica.
Aline Regina Carrasco Vaz \& Suzana Mendonça Universidade de Lisboa 


\section{PANDEMIA DA COVID-I 9 E A POSSIBILIDADE DE OFENSA AOS DIREITOS HUMANOS}

Najah Jamal Daakour

Barakat

Universidade Federal do Mato Grosso do Sul - UFMS

\& Eduardo Soares da Silva Universidade Católica Dom Bosco UCDB
Na perspetiva de abordar uma ação a promover o fim das epidemias, é muito crível verificar acerca do momento atual neste, a saber a pandemia do COVID19. No final de 2019 e início de 2020 na China, mais precisamente em Wuhan vivenciou um surto epidêmico de um vírus do tipo Sars-cov, trazendo danos significativos a esta comunidade. $\mathrm{Na}$ sua contaminação o novo coronavírus dizimou milhares de pessoas por toda a China, espalhando e se alastrando de forma bastante rápida pelo planeta. Após esse surto já no início de 2020 a OMS analisou o vírus denominando-o de COVID-19, no dia 11 de fevereiro, um mês após a organização declara o novo coronavírus como uma pandemia. No Brasil, o COVID-19 teve seu primeiro caso confirmado pelo Ministério da Saúde no dia 26 de fevereiro e a primeira morte, menos de vinte dias. Nesse liame a premissa proposta é analisar a funcionalidade dos Direitos Humanos e a possibilidade da ocorrência de violação dos mencionados direitos em face ao combate e prevenção desse novo vírus. A dinâmica foi observada ao rol dos Direitos Humanos que por sua vez tem uma importante menção ao aparato jurídico mundial e nacional, evocando para si elementos capazes de efetivar a proteção dos seres humanos tendo em vista a sua particularidade alinhada à sua dignidade e a sua humanidade. Esses dois pressupostos condicionam de maneira plena ao exercício de todos os direitos colacionados aos homens, configurados em apreciação a inerência de tais direitos, bem como a impossibilidade de que tais possam ser violados e preteridos pelo Estado Democrático de Direito na realização das ações destinadas a proteção e resguarda desses valores, totalmente presentes e intrínsecos ao homem. Nesta senda, a análise é recorrente em face a possibilidade de ofensa aos Direitos Humanos tendo como pano de fundo a pandemia do COVID-19, que trouxe a todo planeta um quantitativo de quase 600 mil mortes e mais de treze milhões de indivíduos infetados, logo uma situação bastante atípica e com nuances jamais imaginadas e preocupante aos sistemas de saúde e aos governos mundiais. Nesta preocupação tem a utilização de ações governamentais disponíveis ao combate dessa pandemia, e a assistência a ser prestada aos doentes. Haja vista tais ações direcionadas ao combate e a prevenção, devem ter consigo o liame de restar alinhada aos Direitos Humanos e que não venham a suprimir direitos e ou deixar de prestar a devida assistência.

Palavras-Chave: Direitos Humanos, Pandemia, COVID-19, Combate, Prevenção. 


\section{O IMPACTO DA DISSEMINAÇÃO DO CORONAVÍRUS (COVID-19) ENTRE AS COMUNIDADES INDÍGENAS DA AMAZÔNIA BRASILEIRA}

O primeiro caso de COVID-19 em indígena, no Brasil, deu-se no estado do Amazonas, mais precisamente na aldeia São José, que fica a 880 quilômetros de Manaus. Tratava-se de uma jovem da etnia kokama, de 20 anos de idade. Já o primeiro caso em indígena aldeado foi o de um jovem de 15 anos, da etnia yanomami, em 9 de abril de 2020. Ele estava internado no Hospital Geral de Roraima (HGR), onde já tinha sido internado no, no dia 18 de março, com sintomas do COVID-19, mas foi liberado sem fazer o teste para saber se estava ou não infetado pelo vírus. Passados 2 meses e 7 dias dessa morte, ou seja, em 16 de junho de 2020, o senado brasileiro aprovou, por unanimidade, o projeto de lei no 1142/2020, que estabelecia um conjunto de medidas para frear o avanço do COVID-19 nas comunidades indígenas. Pelo projeto estava previsto um auxílio financeiro emergencial, no valor de um salário mínimo por família, o acesso à água potável, a distribuição de materiais de limpeza e de higiene pessoal, além de equipes de saúde especializada na área indígena para ajudar no enfrentamento ao COVID-19 nas aldeias.

Passados mais 22 dias, ou seja, 2 meses e 29 dias após a morte do indígena por COVID-19, o poder executivo, sancionou, com vetos, a lei 14.021/2020, publicada no Diário oficial da União, em 8 de julho, criando o plano emergencial de enfrentamento a COVID-19 em comunidades indígenas. $O$ texto da lei especifica que a função do governo federal seria de coordenação das ações a serem desenvolvidas pelos estados e municípios. Nesse contexto, entre a postura progressista do senado em relação à saúde do índio e a austeridade do poder executivo diante das medidas a serem empregadas no combate ao COVID-19 em territórios indígenas, o Supremo Tribunal Federal (STF) acatou, no dia 8 de julho de2020, a Arguição de Descumprimento de Direito Fundamental (ADPF), da Articulação dos Povos Indígenas do Brasil (Apib), onde afirmava-se ter havido omissão do poder público na prevenção e no combate ao COVID-19 entre os indígenas. Será que eles têm razão? A postura do estado foi de omissão no que diz respeito aos cuidados com a saúde indígena diante do avanço do vírus nas aldeias da Amazônia? A partir desse questionamento, aplicou-se a metodologia reflexiva, onde documentos oficiais, entrevistas e matérias jornalísticas veiculadas em portais de notícias foram a base das interpretações que culminaram na comovente constatação de que as etnias analisadas estiveram excluídas do acesso ao tratamento inicial contra o COVID-19. Um exemplo foi o falecimento da anciã Bernaldina José Pedro, da etnia macuxi, que depois de passar 11 dias lutando contra o COVID-19, faleceu por não ter cilindro de oxigênio a tempo de atendê-la no HGR, em 23 de junho de 2020. A morte dela foi sentida no vaticano, que divulgou em seu site um vídeo com o canto que ela fez especialmente para o encontro com o Papa Francisco, em novembro de 2018.

\section{Palavras-Chave: Direitos Indígenas,} Coronavírus (COVID-19), Saúde Indígena, Amazônia, Brasil.
Jefferson Rodrigo da Silva Universidade Federal do Amazonas (UFAM) 
Ref.: 2 I 3CEDHM42020

\section{PROTOCOLOS DE IDENTIFICAÇÃO,AVALIAÇÃO E MINIMIZAÇÃO DE RISCOS PSICOSSOCIAIS LABORAIS EM CONTEXTO DE COVID-I 9 ENTRE ADVOGADOS}

Raíssa Moreira Lima

Mendes Musarra,

Olivia de Quintana

Figueiredo Pasqualeto,

Regina Célia Martinez

\& Renata Miranda Lima ESAOABSP
O enfrentamento da Covid-19 imprime novas demandas à redução de riscos psicossociais associados ao trabaIho, especialmente diante de restrições à locomoção por tempo indeterminado e adaptações ao trabalho remoto. 0 objetivo do artigo é estabelecer protocolos de identificação, avaliação e minimização de riscos psicossociais em contexto de pandemia por Covid19 entre os advogados inscritos na OABSP (Ordem dos Advogados do Brasil, Seccional São Paulo, favorecendo a existência de um ambiente de trabalho (presencial ou remoto) saudável, valorização, apoio e estímulo ao melhor desempenho laboral possível. Para o atingimento do objetivo, prende-se utilizar a conjugação de métodos e protocolos internacionais e nacionais em saúde e segurança mental, tais quais: Escala de Avaliação dos Danos Relacionados ao Trabalho; Inventário de Riscos de Sofrimento Patogênico no Trabalho; Escala de Estilos de Funcionamento Organizacional; e método internacional de avaliação WISH (Workplace Integrated Safety and Health Assessment), adaptando-os ao contexto da pandemia. Como resultado, o trabalho contribuirá com formulação de recomendações para ações específicas que promovam a saúde mental laboral nos níveis individual e organizacional de escritórios de advocacia, e para o desenvolvimento de ferramentas, orientação, educação, treinamento, interlocução e conscientização para enfrentamento da Emergência de Saúde Pública decorrente da Covid-19 e dos riscos psicossociais a ela associados, a fim de contribuir para a implementação da ODS 3 ("Assegurar uma vida saudável e promover o bem-estar para todos, em todas as idades").

Em cenário sem Coronavírus, transtornos mentais são os principais motivos para afastamentos no trabalho na área jurídica, motivando 30\% das licenças médicas de advogados e 60\% de procuradores entre 2012 e 2018. Podem ser citados como fatores que levam ao adoecimento no meio jurídico, ambientes de trabalho que prezam pela rigidez criando uma relação de frieza entre os colegas e sobrecarga de trabalho.

Vale frisar que, em virtude da pandemia de Covid-19, mais de 10 mil advogados solicitaram Benefício Alimentar Temporário à CAASP (Caixa de Assistência dos Advogados de São Paulo) e OAB/ SP no período entre 16 e 22 de abril de 2020, o que revela a importância do amparo institucional que a Ordem dos Advogados do Brasil pode promover em nível local, repercutindo, sobremaneira, na saúde mental e global dos Advogados e Advogadas.

É um momento de atenção à manutenção da vida e da saúde em um cenário em que a noção de governança tem sentido enquanto a tentativa de construção de políticas em um contexto em que o Estado não detém mais a capacidade e os recursos necessários para operacionalizar suas ações de forma vertical. Assim, outros arranjos institucionais emergem como promotores de práticas sociais relacionadas com os temas de saúde mental em um espaço social marcado por relações de competição, mas também de cooperação.

Palavras-Chave: Saúde Mental, Riscos Psicossociais, Advocacia, ODS 3 (Saúde), Ordem dos Advogados do Brasil. 


\section{O DIREITO A SAÚDE NAS AMÉRICAS: A RECONFIGURAÇÃO DA ORGANIZAÇÃO PAN-AMERICANA DA SAÚDE À LUZ DA TEORIA DO CONSTITUCIONALISMO GLOBAL}

O Direito a Saúde se encontra consagrado no sistema interamericano de direitos humanos desde a Declaração de Bogotá (1948), confirmado na Convenção de São José de Costa Rica (1969) e no Protocolo de San Salvador, sobre direitos econômicos, sociais e culturais (1988). A OPAS é órgão especializado na área sanitária da Organização de Estados Americanos (OEA) e braço regional da Organização Mundial da Saúde (OMS). Trata-se do mais antigo órgão de saúde do mundo criado em 1902. No contexto de crise global de governança global evidenciado pela pandemia do COVID-19 evidenciou-se uma tensão entre a OMS e a OPAS com Estados partes que assumiram posições negacionistas ou relativizadoras das políticas e regras orientadas pela organização. $A$ humanidade que aguardava uma ação unificada vivenciou e ainda vivencia esta tensão. Antes da pandemia, o Professor Ferrajoli em novembro de 2019 publicou um manifesto lançando a ideia do constitucionalismo global que foi oficializado, com o apoio de intelectuais de destaque internacional como Raniero La Valle e Adolfo Pérez Esquivel, em 21 de fevereiro do corrente ano em Roma, a partir da Escola Constituinte da Terra. Este conceito de Constitucionalismo Global tem suas raízes nos estudos de tradição garantista do Professor Ferrajoli e particularmente em sua Teoria dos Bens Públicos Comuns e na sua Teoria do Constitucionalismo
Democrático, que são base para o Manifesto da Igualdade (2019). Trata-se de um chamado a reflexão para concretizar a utopia urgente e pragmática de impor uma rutura com o sistema de governança presente e propõe passar a considerar bens públicos da humanidade uma série de direitos, dentre os quais o direito a saúde pública. A partir dessa matriz teórica que se insere na linhagem de autores da escola da crítica e decolonial dos direitos humanos como Joaquin Herrera Flores, Anibal Quijano e Helio Gallardo e em plena sintonia com o objetivo número 3 da Agenda 2030 relativo à: "assegurar uma vida saudável e promover o bem-estar para todos, em todas as idades" nosso trabaIho se propõe analisar a reforma institucional da OPAS a partir de uma nova configuração que implique na transferência de competências por parte dos estados membros da OEA para órgãos colegiados da OPAS com participação de representantes governamentais, da comunidade científica e a sociedade civil organizada (movimentos sociais fundamentalmente) com o objetivo de dar efetividade as políticas de saúde pública em nosso continente. A metodologia utilizada será a de revisão bibliográfica interdisciplinar conjuntamente com a abordagem de técnicas de direito comparado e direito internacional.

Palavras-Chave: Direito, Saúde, Reconfiguração, Internacional, Agenda 2030.
Eduardo Manuel Val Doutor em Direito. Professor do Programa de Pós-graduação em Direito - PPGD-UNESA 


\section{A REVOGAÇÃO DA LEI DROGAS NO BRASIL COMO MEDIDA DE REDUÇÃO DA DESIGUALDADE SOCIAL E DISCRIMINAÇÃO RACIAL}

Fausy Vieira Salomão

UEMG - Universidade do Estado de Minas Gerais/UPM

- Universidade Presbiteriana Mackenzie
Dentro das metas da Agenda 2030 para o atingimento dos Objetivos do Desenvolvimento sustentável faz-se previsão da garantia da igualdade de oportunidades e redução das desigualdades de resultados, inclusive através da eliminação de leis, políticas e práticas discriminatórias. No Brasil, a desigualdade social é gritante e o racismo é estrutural. Segundo dados levantados pela Fundação Getúlio Vargas, entre 2014 e 2018, a renda dos 5\% mais pobres caiu $39 \%$ e nesse mesmo período o Brasil aumentou em $67 \%$ a população que vive em situação de extrema pobreza. Segundo relatório divulgado pelo PNUD - Programa das Nações Unidas para o Desenvolvimento o Brasil é o sétimo país mais desigual do mundo. Considerando o fator raça e segundo dados de 2019 levantados pela PNAD -Pesquisa Nacional por Amostra de Domicílios do IBGE, $56,10 \%$ da população e $54,9 \%$ da força de trabalho do país é negra. Todavia, em 2018 a renda de um trabalhador branco era o dobro da renda de um trabalhador negro. No que se refere ao exercício de mandato eletivo, negros são apenas $24,4 \%$ dos deputados federais, $28,9 \%$ dos deputados estaduais eleitos em 2018 e nas eleições municipais de 2016 eles eram $42,1 \%$ dos vereadores eleitos. Essa baixa representatividade da população negra reflete na produção normativa que passa a ser pensada e produzida por uma maioria branca. A Lei de Dro- gas de 2006, em tese, almejava dar tratamento digno à pessoa do usuário à medida que despenalizou o uso de substância entorpecente e separou o tráfico de drogas em tipo penal distinto. Todavia, passados quase 15 anos da adoção da lei 11.343/06 o que se viu foi uma explosão da população carcerária brasileira. o $27^{\circ}$ relatório global da organização Human Rights Watch, em 2005, 9\% dos presos no Brasil haviam sido detidos por crimes relacionados às drogas e em 2014 eram 28\%. De acordo com o INFOPEN em dezembro de 2019 o Brasil tinha 748.009 presos, sendo que $96,31 \%$ dessa população era de indivíduos do sexo masculino e 44.79 dos presos tinha de 18 a 29 anos de idade. Ainda conforme a mesma base de dados, em 2005 o Brasil possuía 361.402 presos e em 2020 esse número saltou para 755.274 indivíduos. Entre os presos, $61,7 \%$ são pretos ou pardos e s brancos são $37,22 \%$. O que se observa então é que a política de drogas no Brasil, em verdade, tem sido instrumento de encarceramento da população jovem e negra que é privada de direitos sociais básicos, o que demanda sua revogação como forma de atingimento das metas da Agenda 2030 para o atingimento dos Objetivos do Desenvolvimento sustentável.

Palavras-Chave: Encarceramento, Lei de Drogas, Discriminação, Desigualdade. 


\section{FECUNDACIÓN POS MUERTE EN CONTEXTO IBERICO}

La ley Portuguesa de Reproducción Medicamente Asistida, Lei 32/2006 de 26 de Julio, trata de la "Inseminação post mortem" en su Artículo 220, donde caracteriza esta cuestión como la posibilidad de una mujer viuda de ser inseminada (después de la muerte de su marido o compañero) con semen del fallecido. La ley Portuguesa prohíbe esta posibilidad aunque que el marido o compañero: "haja consentido no acto de inseminação." Pero ya considera lícita la transferencia post muerte de embrión establecido que este, con el consentimiento escrito previó del "decuius", otorgado con la intención de posibilitar a la pareja la construcción de la familia y descendencia realizando su proyecto parental. De modo distinto, en esta materia, la Ley Española de Técnicas de Reproducción Humana Asistida, Ley 32/2006 de 26 de Mayo, determina que el consentimiento previo y escrito del "fallecido" será prestado por documento público, (escritura/testamento/ etc.) para que su material genético pueda ser utilizado hasta el primero aniversario de su muerte.

Véanse nuestras conclusiones, en esta materia, en el Capítulo XII de la Tesis. Ateniéndonos al Artículo 9 apartado 2 de la Ley Española Cit.: "el marido podrá prestar su consentimiento, en el documento a que se hace referencia en el artículo 6.3, en escritura pública, en testamento o documento de instrucciones previas, para que su material reproductor pueda ser utilizado en los 12 meses siguientes a su fallecimiento para fecundar a su mujer."
En la opinión de la Profesora Vera Lúcia Raposo, los Derechos reproductivos son derechos fundamentales, y según ella, son fundamentalmente y principalmente derechos fundamentales, porque existen dentro del cuadro constitucional, dentro de las ordenes constitucionales internas, existen en el ámbito del horizonte del Estado y son garantizados y protegidos por él. En la teoría de los Derechos Humanos, estos derechos (Humanos) se refieren a los derechos de los seres humanos, que les son innatos e inalienables, propios de cada ser humano por el simple hecho de existir, así en mi opinión, los derechos reproductivos son, como defiende la estimada Profesora de Coímbra, derechos fundamentales en el cuadro constitucional nacional cuando están positivados en las constituciones nacionales; pero. de un modo distinto, pienso que los derechos reproductivos son eminentemente Derechos Humanos generales y universales porque están reconocidos por el derecho internacional y como tal defendidos por él y oponibles nacionalmente a los estados, por la naturaleza obligatoria constitucional de la supranacionalidad del derecho internacional. (Este es un tema muy debatido).

Revisitando la terminología de Pérez Luño, consideramos que los derechos reproductivos son sin embargo Derechos Humanos de $4^{a}$ Generación.

Palavras-Chave: Derechos Humanos, Fecundación Pos Muerte, Derecho Comparado, Portugal, España.
João Proença Xavier

Universidade De Coimbra | CEIS20UC - Centro De Estudos Interdisciplinares Do Século $X X$ 
Luciana Nunes Fonseca \& Morgane Reina

Universidade de Brasilia

Ref.: 267CEDHM22020

\section{SENTIDOS E PERSPECTIVAS DE ASSISTÊNCIA AO PARTO NO BRASIL}

A centralidade médica e a medicalização no atendimento obstétrico mudaram o contexto sociocultural do parto, que nos séculos anteriores era desempenhado exclusivamente por mulheres. $\mathrm{Se}$, por um lado, intervenções oportunas podem ter contribuído para a redução das mortes maternas e infantis, por outro, superestimou a racionalidade tecnológica. Assim, a relação entre profissional de saúde e parturiente acaba sendo caracterizada por uma relação de poder desigual, baseada no "controle social", baseada na autoridade médica de sanar problemas e na ideia de que esse profissional possa "blindar" os corpos femininos contra os riscos do parto. Essa autoridade, com o poder de definir atitudes e práticas, reside na pessoa do médico e na tecnologia utilizada, sendo exercida sobre corpos individualizados e pode ser conceituada como "controle social médico" (Conrad, 1992). Nos anos de 1970 a literatura sociológica, especificamente os estudos da sociologia médica, tratou do conceito de medicalização. Esses estudos caracterizaram-se pela realização de análises críticas dos sistemas sociais e das macroestruturas de poder, apontando, conforme Conrad (1992) "Um processo pelo qual problemas não médicos são definidos e tratados como problemas médicos, geralmente em termos de doenças ou distúrbios" (op.cit, p. 209, tradução livre). O objetivo deste artigo é o de analisar os níveis de entendimento expressos em qualquer modelo de parto, seja médico ou social: (1) o prático; (2) o nível ideológico e (3) o analítico (Van Teijlingen, 2005). A questão-chave aqui é: em que nível o modelo médico e o modelo social foram utilizados como conceitos teóricos por obstetras e enfermeiras obstetras brasileiras? Como procedimentos de coleta foram realizadas, principalmente, entrevistas em profundidade com profissionais de assistência obstétrica de várias regiões do país, de 2019 a 2020. O estudo trabalha os discursos em torno da assistência obstétrica, a identidades e fronteiras profissionais. Os resultados da pesquisa apontam para o compartiIhamento de símbolos e reflexões sobre práticas obstétricas, parto humanizado e tecnicismo em saúde.

Palavras-Chave: Parto Humanizado, Tecnicismo em Saúde, Medicalização. 


\section{COMUNIDADES QUILOMBOLAS DE ALCÂNTARA, POLÍTICA DESAPROPRIATÓRIA BRASILEIRA EM CONTEXTO DE PANDEMIA E A (DES)PROTEÇÃO DOS DIREITOS HUMANOS}

O desenvolvimento econômico e tecnológico em prol do suposto progresso surge como discurso do Estado Nacional em detrimento ao direito das comunidades tradicionais que é caracterizado por uma expressão de decadência e necessidade de ser ultrapassado, inclusive sob a ótica do comprometimento da proteção dos direitos humanos internacional e nacionalmente previstos. Alcântara, segundo Müller (2010, p. 92) se trata de um município localizado "[...] no extremo norte do Estado do Maranhão, nordeste do Brasil, há 22 quilômetros de sua capital, São Luís, e possui uma área de $1.483 \mathrm{~km}$, e surge nesse contexto na sua luta histórica pela proteção dos direitos humanos das comunidades quilombolas. Nos anos 1980, período ditatorial militar brasileiro, a área atraiu o interesse do Governo em razão da sua localização geográfica estratégica para a "instalação de um grande projeto desenvolvimentista de caráter tecnológico e militar em seus territórios, 0 Centro de Lançamento de Alcântara CLA" (ALMEIDA, 2006, p. 7), pois se encontra próximo à linha do Equador e é cercado pelo oceano. O processo de desapropriação por utilidade pública abrangeu 52 mil hectares em 1980 por parte do governo estadual (Decreto Estadual no 7.320/80) e cabe ressaltar que "[...] posteriormente foram acrescidos mais 10 mil hectares, totalizando 65 mil hectares de um município cuja área conta com pouco mais de 120 mil hectares" (NUNES, 2013, p. 3). O segundo Decreto (BRASIL, 1991) que declarou de utilidade pública para fins de desapropriação pelo Ministério da Aeronáutica entrou em vigor durante o governo do presidente Fernando Collor, pós-ditadura militar, e foi deflagrado pela União. O decreto "[...] instituiu ameaças de expulsão das terras a totalidade das famílias que residiam e trabalhavam (na localidade) há muitas gerações" (LOPES, 2018, p. 2). Em 2020 a luta continua sob o contexto da pandemia da Covid-19 com a publicação da Resolução no 11/2020 do GSI que determinou a realocação de famílias quilombolas no auge da contaminação no Brasil. Mediante Ação Popular questionou-se a determinação do governo e em sede liminar obteve provimento parcial do pedido para que "até a conclusão do processo de consulta prévia das comunidades afetadas" fosse suspenso o remanejamento. Assim, pretende-se no presente artigo analisar os fundamentos da referida decisão considerando a luta das comunidades em face do Centro de Lançamento e os reflexos do descumprimento do art. 68 do ADCT e, consequentemente, a Convenção 169 da OIT. Mediante a aplicação da etnografia de documentos tendo por objeto os discursos contidos no processo de no 1016857-96.2020.4.01.3700 objetiva-se demonstrar a invisibilidade das comunidades e a atuação do Poder Judiciário frente ao Poder Executivo consoante o pensamento de Mbembe em "A Política da Inimizade". Pesquisa bibliográfica sob a perspetiva indutiva sustenta o estudo ao aperceber-se o contexto internacional e nacional da luta das comunidades quilombolas no Brasil.

Palavras-Chave: Comunidades Quilombolas, Alcântara, Centro De Lançamento, Convenção 169 Da Oit, Racismo Institucional.
Kelda Sofia Da Costa Santos Caires Rocha \& Dyhelle Christina Campos Mendes Universidade Estadual Do Maranhão 
Ref.: 284CEDHM22020

\section{EDUCAÇÃO SEXUAL EM CONTEXTO ESCOLAR: UM INVENTÁRIO DAS INVESTIGAÇÕES ACADÉMICAS PORTUGUESAS NA ÚLTIMA DÉCADA}

Daniela Maria Manna

Bartasevicius,

Maria Isabel Chagas

\& Ana Paula Caetano

Instituto de Educação

- Universidade de Lisboa
A Sexualidade é um dos principais fatores que contribuem para a formação da personalidade de um indivíduo compreendendo as dimensões biológicas, psicoafectivas, socioculturais, relacionais e éticas do comportamento humano. Compreendê-la pode auxiliar no desenvolvimento do autoconhecimento e do bem-estar individual e coletivo. O tema, entretanto, suscita muitas dúvidas, principalmente entre crianças e adolescentes que buscam entender, por exemplo, mudanças no seu corpo, sentimentos, preferências e valores. A Educação Sexual em Contexto Escolar (ES) tem como objetivo ajudar no esclarecimento dessas questões e fomentar reflexões individuais e coletivas que estimulem o espírito crítico e a formação de indivíduos responsáveis com si próprio e com o mundo. Em 1987, Portugal passa a integrar a Rede Europeia de Escolas Promotoras de Saúde (REEPS). Em 2018, ainda integrado às ações europeias de promoção de saúde, o PES (Programa de Promoção e Educação para a Saúde) passa por novas atualizações, trazendo o foco da saúde para uma perspetiva transversal e transdisciplinar. Com essas ações, o governo busca o cumprimento dos objetivos propostos pela OMS para a 'Saúde e bem-estar na Europa' e para as estratégias da 'EU2020' além de contribuir com os objetivos da 'Agenda 2030para o Desenvolvimento Sustentável, das Organização das Nações Unidas' nas questões de sustentabilidade do planeta. A PES por sua vez, dentro do currículo escolar português, faz parte do programa de 'Educação para a Cidadania' e sua abrangência está especificada no documento: 'Referencial para a Saúde' editada em conjunto pelos ministérios da Saúde e da Educação. Pensar em ES nos remete a considerar determinadas categorias de investigação como: a formação dos professores para esse tema, as abordagens usadas para ES, os cursos que se dedicam à pesquisa da ES, 0 currículo oferecido pelo governo, entre outras. Considerando a complexidade da ES tanto nas categorias de investigação quanto na aplicação prática do tema em ambiente escolar, um levantamento das investigações que foram realizadas na última década pode nos trazer uma melhor compreensão dos progressos e limites enfrentados pelas escolas e Universidades no emprego dessa temática. Assim, almejando responder à questão: "O que se investiga em Portugal para Educação Sexual?" este artigo visou apresentar um estado da arte das investigações realizadas em Portugal entre os anos de 2010 e 2020 nos âmbitos de dissertações de mestrado e teses de doutoramento. Os documentos foram obtidos através das bibliotecas on-line nos sites das Universidades Portuguesas públicas e privadas que oferecem pós-graduações na área de Ciências da Educação. Os resumos dos trabalhos académicos foram analisados e classificados de acordo com seus objetivos, metodologia e sujeitos investigados. Não foram contempladas nessa análise outras formas de produção literária, garantindo assim que se referem a investigações já concluídas e aprovadas pelo meio académico.

Palavras-Chave: Educação Sexual em Contexto Escolar, Estado da arte, Educação para Saúde. 


\section{REPERCUSIÓN EN LA SALUD FÍSICAY PSICOLÓGICA DE LA MUTILACIÓN GENITAL FEMENINA EN NIÑAS MIGRANTES}

Una de las manifestaciones más graves de violencia contra la mujer es la mutilación genital femenina, que atenta claramente contra la salud física y psicológica, así como hacia los derechoshumanos de aquellas niñas que la sufren. La mutilación genital femenina es una práctica ancestral, basada en convicciones y percepciones muy arraigadas en una estructura social, económica, política y religiosa, que se sigue realizando en determinados lugares del mundo. El tipo de práctica que se lleve a cabo, depende del lugar en que se realice, variando en función de factores culturales, sociales, religiosos, para favorecer las relaciones sexuales o incluso por cuestiones estéticas o de belleza. Se calcula que entre los 100 y 140 millones de mujeres y niñas en el mundo han sufrido alguna forma de mutilación genital siendo sometidas a dicha práctica en torno a dos millones de niñas y adolescentes cada año. Por ello, miles de niñas se ven obligadas a migrar hacia países occidentales. Determinar la repercusión de la mutilación genital femenina en las niñas migrantes. Se realizó un estudio sobre niñas en riesgo de mutilación genital femenina que migraron a la Unión Europea desde países africanos. El conjunto de datos utilizado se extrajo del Instituto Europeo para la Igualdad de Género y consiste en una muestra de niñas migrantes de 0 a 18 años que han residido en algún estado miembro de la Unión Europea durante al menos un año. La cantidad de niñas migrantes en riesgo de mutilación genital femenina se va reduciendo. La mayoría de las migraciones se producen del oeste de África. Italia y Francia son los países europeos que más niñas reciben. Según su origen y país de destino, se observaron diferencias en las niñas con escenarios de alto y bajo riesgo de mutilación. Es necesario seguir combatiendo y visibilizando este tema.

Palavras-Chave: Mutilación Genital Femenina, Violencia Sexual, Salud, Migraciones,

Análisis Multivariante.
María Concepción Vega-Hernández \& Ana Victoria Torres-García Universidad de Salamanca 


\section{EFECTOS PROFUNDOS DE LA PANDEMIA DE COVID. LIMITACIONES PARA AVANZAR EN LOS ODS PARA LA POBLACIÓN RURAL EN MÉXICO}

Carlos Cortez Ruiz

Universidad Autonoma Metropolitana
La desigualdad económica y social es una característica que recorre la historia de México, y en las últimas décadas ha aumentado. El Informe de Evaluación del Consejo de Evaluación de la Política Social (CONEVAL) 2018 sobre los Derechos Sociales y sus dimensiones, advierte que hay grupos de población cuyo ejercicio de derechos se ve comprometido. En particular, la población indígena enfrenta brechas respecto a la población no indígena; La situación empeora cuando, además de ser indígenas, son mujeres. EI gobierno actual, que inició en Diciembre de 2018, planteó poner fin a las políticas neoliberales, mediante cambios en los enfoques de políticas para reducir la pobreza, la desigualdad y la exclusión. El Plan Nacional de Desarrollo no se refiere centralmente a los ODS, pero sí incluye propuestas importantes para su avance. A lo largo del año 2019, se hicieron cambios importantes en políticas, dirigidas a enfrentar la pobreza y la exclusión, referidas a; mejoras salariales, apoyos a sectores prioritarios de población (jóvenes, pequeños productores, discapacitados), así como en las políticas de salud, educación y producción de alimentos. Un cambio fundamental, es que el objetivo de las políticas es garantizar los derechos de toda la población. Puede considerarse que la Política Social, Ambiental y Agrícola son las principales definiciones sobre las formas de avanzar hacia el cumplimiento de los ODS. Justo des- pués del primer año de estos cambios, la pandemia de COVID ha cambiado todas las condiciones y puesto en duda las posibilidades de avanzar em los propósitos gubernamentales y de Ios ODS. La Comisión Económica para América Latina (CEPAL) ha analizado los posibles efectos de la pandemia; "La economía de México se contraerá un 9 por ciento este año... Hay 500,000 empresas formales en México en riesgo de desaparecer en los próximos seis meses..." Cualquiera sea la dimensión de los efectos, seguramente el aumento de la pobreza afectará a millones de personas que regresarán a la pobreza y la pobreza extrema. El Consejo Nacional para la Evaluación de laPolítica de Desarrollo Social (Coneval) presentó en Mayo de 2020 una primera aproximación del impacto de COVID-19, que mostró que hasta 10.7 millones de mexicanos podrían caer en pobreza en el finale de 2020, debido a la crisis de salud causada por el coronavirus y sus consecuencias económicas. Otros estudios estiman que al menos 16 millones de mexicanos habrían caído en la pobreza extrema. Así, uno de los efectos más graves de la pandemia será alejarse de la posibilidad de cumplir con los ODS. El trabajo analizará los primeros efectos e implicaciones de la pandemia COVID en el aumento de la pobreza y la desigualdad expresadas en la posibilidad de avanzar en la realización de los derechos humanos para toda la población y en el logro de los ODS.

Palavras-Chave: Desigualdad, Politicas, Derechos, Pandemia-COVID, Rural. 


\section{ADESÃO E MULHERES VIVENDO COM HIVIAIDS - A DIFÍCIL TAREFA DO CUIDAR PARA ALÉM DE TRATAR}

Um dos objetivos propostos pela Agenda 2030 é o de acabar com as epidemias de AIDS, tuberculose, malária e doenças tropicais negligenciadas. Mesmo com importantes mudanças no enfrentamento ao Vírus da Imunodeficiência Humana/Acquired Immunodeficiency Syndrome (HIV/aids) no Brasil, que adotou uma política de ampliação de acesso à testagem e diagnóstico, tratamento para todos e tratamento como prevenção, a noção de cuidado em saúde, cara ao alcance deste objetivo, ainda não foi incorporada de modo amplo nem por profissionais nem por usuários do Sistema Único de Saúde. Isso tem efeitos complexos quando, em algum momento do percurso terapêutico, pessoas vivendo com HIV/Aids interrompem, mesmo temporariamente, seu acompanhamento ambulatório.

Com o advento da Terapia Antirretroviral (TARV), a aids assumiu características de doença crônica, em especial nos países onde o acesso aos medicamentos é efetivamente garantido (BRASIL, 2008). No entanto, a condição de cronicidade depende da eficácia do tratamento, medida pelos níveis de supressão viral e que, por sua vez, exige um uso do esquema terapêutico igual ou superior a $95 \%$ das doses prescritas. Ou seja, a não-adesão ou adesão insatisfatória pode facilitar o desenvolvimento de resistência viral (PATERSON et al., 2000; PHILIPS et al., 2005; SMITH, 2004).

O abandono e a resistência viral reforçam entre trabalhadores da saúde a ideia de que as pessoas vivendo com HIV/aids são as principais responsáveis por aderir às prescrições terapêuticas e a não-adesão acaba por se tornar mais uma fonte de estigma, discriminação, exclusão e culpabilização, cooperando para o ocultamento de diferentes modos do cuidar de si, estabelecidos por quem tem agravos crônicos com seu corpo ao longo de sua vida, e que dependem, inclusive, das manifestações de agudização e dos períodos de silenciamento, assim como de fatores relacionados ao profissional de saúde, ao tratamento, às condições socioeconômicas e ao sistema e equipe de saúde.

Este trabalho reflete teoricamente sobre a não-adesão de mulheres cisgênero e transgénero ao tratamento, um dos entraves para alcance dos objetivos de desenvolvimento propostos pela agenda 2030, abordando-a como um dos efeitos do não-cuidado forjado por performances conservadoras de profissionais e de pacientes. Problematiza-se como um 'cuidado à saúde' orientado exclusivamente pela aplicação de tecnologias biomédicas pode suprimir o interesse pela vida do par profissional- paciente. Com os conceitos de cuidado de si (Foucault), performance (Mol, Butler), adesão (Haynes; WHO) e abandono ao tratamento (Brasil), examinaremos como situações fora-de-controle, ao longo do convívio com um funcionamento atípico crônico do corpo, podem desnortear profissionais amalgamados aos protocolos rígidos e produzir barreiras à assunção de uma escolha terapêutica pela adesão, no sentido de melhor condição de vida e de cuidado de si possível em cada momento da história de vida de mulheres que convivem com o HIV.

Palavras-Chave: Adesão ao Tratamento, HIV-Aids, Cuidado em Saúde, Mulheres Seropositivas, Vínculo Terapêutico.
Cláudia Valéria Fonseca da Costa Santamarina Instituto Fernandes Figueira - Fiocruz 
Ref.: I08CEDHMI 2020

\section{SAÚDE E DIGNIDADE DA PESSOA HUMANA, COM ÊNFASE NO MEIO AMBIENTE LABORAL}

Mariana Mrosk Teixeira \& Lourival Barão Marques Filho

Escola dos Magistrados do Trabalho do Paraná (BRASIL)
A pesquisa pretende analisar os direitos dos trabalhadores e a influência que o meio ambiente laboral exerce na vida pessoal do obreiro, especialmente na constante busca pelo trabalho digno em meio ao crescimento econômico e os avanços tecnológicos. Com o objetivo de demonstrar a correlação entre patologias psíquicas, meio ambiente de trabalho e o princípio da dignidade da pessoa humana, serão analisados diversos conceitos ligados ao tema, como o assédio moral e a síndrome de "burnout", enfatizando a proteção da saúde mental e a importância de um local de trabalho digno e sadio, colaborando para o desenvolvimento dos Direitos Humanos. Nesse sentido, o presente artigo se justifica por abordar a relevância que o trabalho possui como influência na identidade de vida do indivíduo. Mais ainda, em tempos de instabilidade econômica e crise em diversos setores, como tivemos nos últimos tempos, os ânimos ficam ainda mais exaltados, já que o trabalho é peça fundamental na vida do homem para manter sua sobrevivência e de seus dependentes. Nesse ponto, a reinvenção da base estrutural das relações laborais deve ser obser- vada, considerando que o direito ao meio ambiente saudável, incluindo o meio ambiente do trabalho, trata-se de um direito fundamental. Dessa forma, é importante que em casos onde percebe-se uma alteração psicológica do trabalhador e uma conduta insensível do empregador, essa situação não fique sem proteção e sem maiores respaldos, afinal, trata-se de um ser humano, o qual deve ter preservada sua dignidade e segurança para o desenvolvimento da sua vida. Para tanto, a metodologia empregada consiste em revisão bibliográfica e jurisprudencial, de forma qualitativa, de países europeus e do Brasil. Dentre os resultados, tem-se que a proteção ao meio ambiente de trabaIho é extremamente importante, a fim de que, por consequência, haja o trabalho digno da pessoa humana, com a possibilidade de responsabilização civil, caso isso não ocorra, sendo essa uma das formas de materialização da tutela ao empregado.

Palavras-Chave: Dignidade, Trabalho Digno, Meio Ambiente Laboral, Saúde Mental, Responsabilidade Civil. 


\section{PERU AND BRAZIL:}

\section{WELFARE STATE'S COMMON CHALLENGES IN THE CONTEXT OF COVID-I 9}

According to official data, Brazil and Peru are included in the list of the five countries in the world with the highest rate of Covid-19 cases. Even before the sanitary crisis, Latin America, known as one of the most unequal regions in the world, was already experiencing a lot of regress in terms of social protection, impacting in a devastating manner the most vulnerable people. There are some common factors that contribute to increasing the negative impact of the pandemic in these countries. The first factor is related to the political crisis both countries were facing when the pandemic arrived in their territories. The second factor is the low budget and precariousness of their public health care systems. Brazil is one of the few developing countries in the world that has a universal, free access national health system (SUS). However, its budget has been chronically insufficient to deal with the needs of the system. In Peru, access to the public health care system does not guarantee a prompt and adequate provision of services. In fact, before Covid-19 arrived in Peru, the system was already collapsed. In contrast, private health care is expensive and it only reaches $10 \%$ of the population. The third factor is that both countries have gone through neoliberal reforms that weakened social protection in theirlabor market. Such aspects are derived from the decline of the Welfare State, affecting the working conditions, labor rights, and workers' bargaining power. As a result, the unemployment rate has increased, reaching $13.1 \%$, according to the Brazilian Institute of
Geography and Statistics (IBGE). In Peru, $47 \%$ of formal workers have lost their jobs and $50 \%$ of the informal activity has decreased due to the pandemic. Considering this scenario, the article aims to discuss the importance of the Welfare State regime to mitigate the impacts of the Covid-19 pandemic in these countries, which were already suffering an increase of their poverty and inequalities rates before the pandemic, making it really hard to accomplish the 2030 SDGs. To this purpose, an analyticaldeductive methodology with a bibliographical review will be applied. The method also draws a comparative conjunctural analysis of political, social and economic data published by Economic Commission for Latin America and the Caribbean -ECLAC. If the regressive measures face no changes, in order to enable both States to respond to the pandemic in an appropriate way, the disparities already existing in the region will only increase. As ECLAC proposed in its latest report on the situation of the new coronavirus in Latin America and the Caribbean, it is necessary to implement integrated economic and social measures, such as emergency basic income programs, for at least six months for the entire population living in poverty in the region. In conclusion, the pandemic has revealed the importance of a strong coordinated Welfare State.

\footnotetext{
Palavras-Chave: Welfare State, Covid-19, Right To Health, Employment, Agenda 2030.
}

Clarice Seixas Duarte, Universidade Presbiteriana Mackenzie Roxana Marina Cortina Mendonza, Universidad De San Martin De Porres Vania Bogado De Souza Di Raimo Universidade Presbiteriana Mackenzie \& Amanda Salgado e Carvalho Universidade Presbiteriana Mackenzie 


\section{REFLEXO DA DESIGUALDADE EM DIREITOS HUMANOS NOS ALUNOS DAS CLASSES POPULARES EM PERÍODO DE QUARENTENA POR CORONAVÍRUS}

Érica Cindra de Lima,

Colégio Notre Dame

Cristiane Diello Granville,

Colégio Notre Dame

Márcia Vieira Oliveira

Garritano

Consultório

\& Cleuber Cindra de Lima

Petrobrás
Este artigo apresenta ao leitor a síntese das publicações sobre os reflexos da desigualdade de direitos humanos na população oriundas das camadas populares na crise do coronavírus, no ano de 2020. O objetivo desta pesquisa é analisar as propostas do Ministério da Educação e cultura (MEC) para as escolas, bem como os documentos estaduais e municipais e identificar o quanto essas propostas violam os direitos humanos ao determinarem um ensino a distância que prevê o uso de tecnologias que são inacessíveis a grande maioria das crianças e dos adolescentes das camadas populares. Notadamente esta população tem sido restrita de seus direitos mais básicos e em momentos de crise mundial provocada pela pandemia essa desigualdade se apresenta ainda de forma mais alarmante. Neste sentido foi realizada uma busca nos artigos produzidos durante o período de pandemia no Brasil (2020) para identificar as principais causas dessas desigualdades e seus impactos na vida dos estudantes oriundos das escolas públicas do Rio de Janeiro. A principal relevância social desse estudo é apresentar o panorama da desigualdade visando a criação de políticas públicas que atenda esta camada da população. MÉTODO Delineamento Para atingir o objetivo geral desta pesquisa será utilizada a pesquisa exploratória, qualitativa e descritiva, com utilização de procedimentos metodológicos da Revisão Integrativa da Literatura. Esta revisão integrativa será operacionalizada através de procedimentos de busca eletrônica, conduzidos em nível nacional e internacional. Para tanto para padronizar a linguagem de busca dentre as diversas bases de dados eletrônicas, serão utilizados os descritores de saúde DeCS e Mesh. Para a estratégia de busca, os descritores e termos livres escritos foram "direitos humanos" and "EaD" and "coronavirus" and "educação básica".

Os descritores foram utilizados isoladamente ou combinados entre si, com o auxílio dos operadores booleanos AND e OR, de acordo com as especificidades de cada base de dados pesquisada, no período de 2019 a 2020. A pergunta formulada que norteia a presente pesquisa é a seguinte: Qual o reflexo da desigualdade em direitos humanos nos alunos das classes populares em período de quarentena por coronavírus? Critérios de inclusão e exclusão: procedimentos. As RILs recuperadas foram analisadas em relação aos critérios de inclusão. Os títulos e resumos dos artigos foram analisados, sendo considerados passíveis de inclusão, na Revisão Sistemática, o artigo que teve como resposta afirmativa em todas as 5 (cinco) questões sobre o tema da pesquisa.

Palavras-Chave: Desigualdade Social, Classes Populares, Direitos Humanos, Educação Básica. 


\section{EPIDEMIAS NA HISTÓRIA.}

\section{A GRIPE ESPANHOLA EM SÃO PAULO/BRASIL}

Apresentar o processo da imigração portuguesa na cidade de São Paulo no início do século vinte, quando a população aumentava, a modernidade nascia, a cidade se embelezava e os sonhos e os desejos eram expressos no cotidiano, no trabalho e sobretudo nas criações poéticas dos seus grandes literatos em reuniões intelectuais que se realizavam nas mansões da elite paulistana. Eram os anos da Belle Epoque onde a cidade se transformava e cenários novos iam surgindo. Exatamente neste espetáculo que metamorfoseava o ambiente os estrondos da Primeira Grande Guerra Mundial que acontecia na Europa chegou até aqui porque o Brasil mandava o primeiro contingente de soldados para formarem tropas ao lado dos aliados. Ao lado dessa grande mazela que consumia uma parte do mundo vamos ver surgir aqui e no mundo todo e talvez pior que a guerra era a Gripe Espanhola. Nosso objetivo é exatamente relatar os 66 dias de sofrimento de outubro á dezembro de 1918 que castigaram a cidade de São Paulo .Relatar o cotidiano, as providencias e sobretudo enaltecer a solidariedade da população de médicos, instituições, imigrantes, empresá- rios, homens, mulheres, ricos, pobres, negros, brancos e amarelos, unidos para vencer o fantasma que matava mais que a guerra. São Paulo vivia o início da industrialização e um intenso processo de imigração europeia, principalmente de portugueses, italianos e espanhóis que buscavam melhores condições de vida e de trabalho na cidade de São Paulo ou na agricultura cafeeira que necessitava de mão de obra para a lavoura que se espadia com a exportação, desbravando as matas no interior paulista. Políticas públicas foram implantadas para conter o avanço da gripe espanhola que atingiu mais a cidade de São Paulo e os municípios vizinhos que se industrializavam também pela facilidade do transporte ferroviário.

Palavras-Chave: Cidades, Imigração, Saúde, Epidemias, Direitos Humanos.
Yvone Dias Avelino

Pontifícia Universidade Católica de São Paulo 


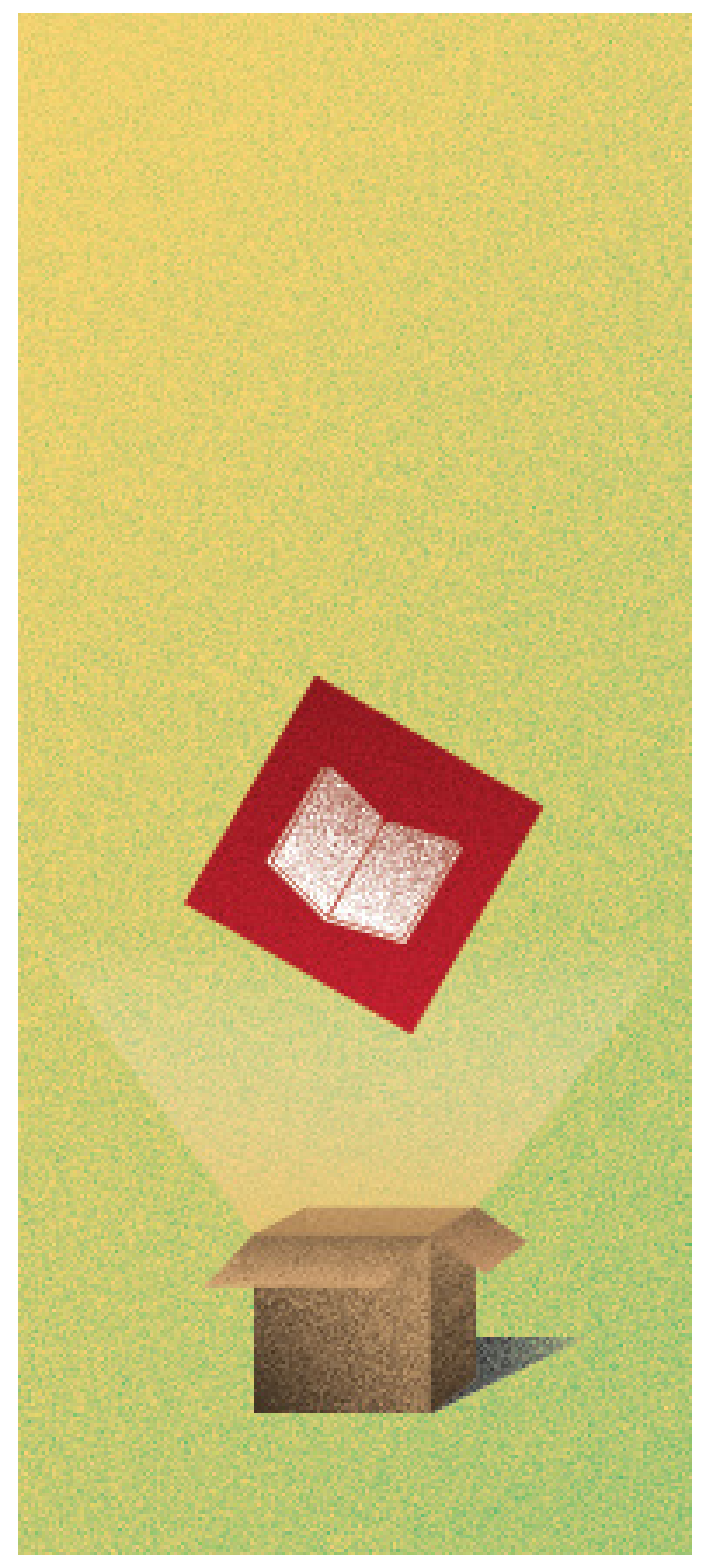

ATAS DA II CEDH:

AGENDA 2030 - UM NOVO CAPÍTULO

PARA A EVOLUÇÃO DOS DIREITOS HUMANOS

\section{ODS 4 EDUCAÇÃO DE QUALIDADE}




\section{GESTÃO PEDAGÓGICA NAS ESCOLASTÉCNICAS CABO-VERDIANAS: \\ ENTRE PERSPETIVAS ETENDÊNCIAS DAS LIDERANÇAS PARA A PROMOÇÃO DE MUDANÇAS}

As reformas educativas têm sido orientadas pela busca de um desiderato particularmente difícil de definir e operacionalizar, pela profunda diversidade de entendimentos e perspetivas possíveis que estão em jogo no seu equacionamento - a qualidade educativa (Benedito, 2014; Fu, 2020). Esta perspetiva está fortemente presente nas agendas educativas no plano internacional, constituindo inclusivamente um dos Objetivos do Desenvolvimento Sustentável (ODS4: Educação de Qualidade, nomeadamente acesso a uma educação técnica de qualidade).

As perspetivas orientadas para a eficácia e a eficiência das instituições educativas entendidas como caminhos para a prossecução dessa qualidade, são uma das tendências que tem estado associada à promoção de reformas educativas orientadas para o desenvolvimento de competências. Reconhecemos a globalização de uma agenda globalmente estruturada (Dale, 2004) como uma forte componente destes processos de promoção de políticas eficientistas associadas a uma lógica de mercado (Pacheco \& Seabra, 2010), no contexto dos quais o desenvolvimento de competências pode ser associado à valorização do conhecimento útil, e às necessidades do mercado de trabalho (Jover \& García Fernandez, 2015).

No entanto, assumimos também a complexidade desses processos, e a existência de respostas contra-hegemónicas que influenciam a forma como essas agendas são assumidas, interpretadas e implementadas pelos países periféricos (Seabra, 2015; Varela, 2015). Em particular, os professores são decisivos na efetivação de qualquer desígnio de reforma, e os líderes educativos pivôs das ações estratégicas para a mudança (Flores, 2014; Morgado \& Silva, 2019), o que fundamenta a necessidade de conhecer as perspetivas de atores locais sobre as reformas, como é o caso da implementação de um currículo por competências no Ensino Técnico em Cabo-Verde.

Este artigo baseia-se numa pesquisa desenvolvida no âmbito do Doutoramento em Educação na Universidade Aberta. Procura-se conhecer o papel das lideranças na promoção de mudanças pedagógicas relacionadas com a implementação de um currículo por competências no ensino técnico em Cabo Verde, na perspetiva de líderes de topo e intermédios e de professores.

Para recolha dos dados, aplicou-se um questionário a 149 professores, e foram realizadas 16 entrevistas aos diretores, subdiretores e coordenadores dos centros de formação técnico-profissional de Cabo Verde. No presente artigo, apresentam-se resultados parciais das entrevistas e dos questionários, focalizando a relação entre as lideranças e a promoção de práticas inovadoras pelos docentes, incluindo as que se relacionam com o ensino por competências. Os resultados apresentados apontam para a ausência de envolvimento dos líderes de topo e intermédios nesse processo. A abordagem curricular e pedagógica por competências é perspetivada pelos participantes do estudo numa ótica prescritiva, distanciada da realidade das suas práticas docentes.

Palavras-Chave: Ensino Técnico-Profissional, Competências, Lideranças, Educação de Qualidade, Reforma Educativa.
Benvindo de Jesus Rocha, LE@D, Universidade Aberta e CIED-UMinho e CIPEM/INET-MD Filipa Seabra

LE@D, Universidade Aberta e CIED-UMinho e CIPEM/INET-MD \& Marta Abelha CEIS20, Universidade de Coimbra, Universidade Portucalense e Universidade Aberta (UAb) 
Edson Mitsuo Tiujo

Pontifícia Universidade Católica do Paraná (PUCPR)
Ref.: 047CEDHM22020

\section{A MISSÃO DAS UNIVERSIDADES PARA A PROMOÇÃO DA DIVERSIDADE E DA INCLUSÃO SOCIAL}

O advento do Estado social no Brasil trouxe consigo a ordem de implementação de políticas públicas, especialmente, no campo dos direitos sociais. Tais políticas consolidaram-se no Brasil, tendo como fundamento o princípio da diferença proposto por Rawls. Todavia, políticas dessa natureza, por vezes, geram repulsas. Gargarella parte da premissa de que as políticas de grupos provocam rivalidades e preconceitos e consequentemente segregação. MacIntyre afirma que a cultura do individualismo leva as pessoas a discordar acerca dessas políticas, a partir do momento em que passam a interferir na esfera de direitos de outros. John Rawls abordou o problema da inveja no último capítulo do seu livro "Uma teoria da justiça". Buscou-se, assim, pesquisar as externalidades provocadas por tais políticas, como a exclusão, o preconceito e a discriminação. Propõe-se, assim, um problema: a política social, quando gera externalidades negativas, deixa de ser justa segundo a teoria da justiça dos liberais comunitários? A hipótese é a de que um arranjo justo levará a um resultado justo e, por consequência, propiciará um comportamento justo. Políticas fundadas no princípio da diferença tendem a, paulatinamente, incutir as virtudes cívicas nos cidadãos. A partir da iniciativa de ações baseadas no princípio da diferença permite-se chegar ao último estágio do consenso sobreposto preconizado por Rawls. É preciso, no entanto, que as missões das universidades estejam de acordo com a política implementada, sob pena de não se incutir no amago das univer- sidades o verdadeiro fim da política. A missão de uma universidade é definida de acordo com as instituições sociais que figuram mais frequentemente nos debates sobre justiça. Uma vez que a universidade defina sua missão e estabeleça seus padrões de admissão, por exemplo, por critérios de beneficiamento a grupos minoritários, uma pessoa tem direito à legítima expectativa de ser admitida em detrimento de outra ao preencher os critérios. Assim, seja por cotas ou por méritos, a justiça da seleção depende dos critérios previamente definidos pela missão das universidades. Pouquíssimas universidades no Brasil trazem como missão a promoção da diversidade e a inclusão social, como ocorreu na Universidade do Texas, no caso Cheryl Hopwood. Dentre as universidades públicas do Estado do Paraná, apenas a Universidade de Londrina apresenta como missão a igualdade de condições de acesso e permanência aos estudantes, denotando, assim, um arranjo institucional completo à adoção do sistema de cotas, mediante a promoção da diversidade e da inclusão social. As demais universidades primam apenas pela produção de conhecimento e saber científico, por meio da pesquisa docente e discente, com vistas ao desenvolvimento socioeconômico e regional, o que, de certo modo, contribui para a persistência dos vícios nos ambientes universitários, na medida em que privilegia, única e exclusivamente, a capacidade intelectual e o desempenho do estudante.

Palavras-Chave: Educação, Justiça, Social, Cotas, Missão. 


\section{A IMPORTÂNCIA DA MUDANÇA DE PARADIGMA NA FORMA DE ADMINISTRAÇÃO DE CONFLITO NO ÂMBITO ESCOLAR}

Os conflitos fazem parte da sociedade e não é diferente no contexto escolar, onde as crianças e os jovens deparam-se constantemente com o conflito, seja entre seus pares, entre corpo discente e docente, entre os alunos e os funcionários e até envolvendo os pais. As medidas de administração de conflito, via de regra, são punitivas, disciplinares, corretivas. Recaindo o olhar sobre Portugal, estão estas medidas previstas tanto no Estatuto do Aluno e Ética Escolar (Lei n. ${ }^{\circ}$ $51 / 2012$, de 05 de setembro) quanto na lei de protecção de crianças e jovens em perigo (Lei n.o 147/99, de 1 de setembro) e na Lei Tutelar Educativa (Lei n. ${ }^{\circ}$ 166/99, de 14 de setembro). Não raras vezes, a polícia intervém, sendo certo que inclusive há um programa policial para o âmbito escolar: a Escola Segura. Nestes modelos há pouco espaço de diálogo, não se prioriza a empatia, não se tenta compreender e ouvir o outro, e, de fato, administrar o conflito. O modelo punitivo reforça a violência, enquanto a mediação do conflito como forma de administração, ensina um novo olhar sobre este conflito, fazendo desenvolver na população infanto-juvenil competências positivas em relação à administração do conflito, onde o diálogo e a empatia fazem-se presentes, levando ao desenvolvimento de uma cultura de paz, que favorecerá a construção de uma sociedade mais justa, solidária e igualitária. É justamente a importância desta mudança de paradigma frente à administração de conflito que se pretende demonstrar, por meio de revisão de literatura, neste trabalho.

Palavras-Chave: Mediação Escolar, Conflitos, Administração de Conflitos, Punição, Cultura de Paz.
Cristiane de Souza Reis Instituto de Estudos Comparados em Administração de Conflitos Universidade Federal Fluminense 


\section{Ref.: 050CEDHMI 2020 \\ CIDADANIA MUSICAL: UM DIREITO HUMANO IMPRESCINDÍVEL}

Dilson Araújo Alves Peixoto \& Antonio Carlos da Silva Universidade Católica do Salvador (UCSal)
Para promover o reconhecimento e apreender com as alteridades dos distintos sujeitos históricos -entre performances e corpos em movimento de gênero, etnia, raça e territorialidade -acreditamos que a linguagem musical é a forma totalizante para compreensão deste mundo e realização de outro mundo possível. Isto porque, sob a lógica econômica irracional do atual "campo" histórico, a identificação do SER está intrinsecamente vinculada na forma jurídica -são considerados humanos apenas aqueles que estão inseridos (direta ou indiretamente) no sistema de produção ou consumo vigente. Portanto, há uma mercantilização de todos os aspectos da Vida na qual as relações sociais são determinadas por uma representação simbólica: a contínua transformação de trabalho abstrato em mais dinheiro. Sem olvidar que o modelo neoliberal, legitimado pela ideologia democrática, busca desconstruir os sujeitos e não reconhecê- los em seus plenos direitos e cidadania (jurídica, política e social). Deste modo, o presente artigo busca contribuir com uma abordagem crítica sobre a educação musical como princípio ético e emancipatório, em especial frente às idiossincrasias do tecido social e político brasileiro. Compreender que sob os auspícios de uma crise sistêmica, que fragiliza os Direitos Humanos tornando-os tautológicos ou vazios, a educação musical pode auxiliar na concepção de projetos sociais em contraposição à alienação, a barbárie e o fetichismo da mercadoria. A Teoria Crítica (valor e dissociação do Valor) será o nosso norte epistemológico para tal empreendimento, em especial de Robert Kurz e Anselm Jappe, além das proposições de Judith Butler, Jaques Rancière e Hannah Arendt sobre o papel primacial da ação política (corpos em aliança) como fundamentação libertária. A orientação de Walter Benjamin sobre "o artista como produtor" será manifesta na alusão aos modelos pedagógicos e métodos participativos que conduzem a realização de projetos sociais que constituem o cerne da "cidadania musical". Afinal, tal como a coruja de Minerva, nós compreendemos que, apesar das circunstâncias, a educação musical é capaz de realizar outro mundo possível, pois o impulso gerador dessas transformações não é apenas ontológico, mas histórico e, portanto, passível de transformação.

Palavras-Chave: Direitos Humanos, Cidadania Musical, Emancipação, Projetos Sociais. 


\section{ENSINO SUPERIOR E OBJETIVOS DE DESENVOLVIMENTO SUSTENTÁVEL}

O objetivo principal deste estudo é o de perceber o estado atual em Portugal do acesso a uma educação dita inclusiva e equitativa de qualidade para os jovens (e menos jovens) no que concerne às oportunidades de aprendizagem ao longo da vida, de acordo com os Objetivos de Desenvolvimento Sustentável (ODS) e as metas definidas para alcançar até 2030 . O foco do estudo são os alunos que entram para o ensino superior português através das ditas formas "não tradicionais". Pretendeu-se caracterizar os estudantes que entram pelo regime de maiores de 23, por via de Cursos de Especialização e de Cursos Técnicos Superiores Especializados (TeSP), os vindos de sistemas estrangeiros em mobilidade e os estudantes provenientes dos PALOP, numa instituição de ensino superior publico português. A metodologia empregada neste estudo é a revisão bibliográfica, consubstanciada pela análise e comparação dos resultados académicos obtidos pelos alunos que entraram no ensino superior através de diferentes contingentes, às unidades curriculares de métodos quantitativos e estatística da licenciatura em Gestão.

Palavras-Chave: Educação, Aprendizagem ao Longo da Vida, Ensino Superior, Estatística, Desenvolvimento Sustentável.
Cristina Paula da Silva Dias

\& Maria Isabel Borges Instituto Politécnico de Portalegre Escola Superior de Tecnologia e Gestão, Instituto Politécnico, Portugal 
Ref.: 076CEDHM42020

\section{AGENDA 2030: \\ CAPITAL E HUMANISMO NAS DISPUTAS POR UMA ORIENTAÇÃO EDUCATIVA MUNDIAL}

Rafael Peçanha de Moura

Universidade Federal Fluminense
Através da recuperação do conceito de antropeugogia, cunhado por Manuel Patrício, a pesquisa em tela busca analisar a vinculação entre esta noção e os discursos de publicações de organismos internacionais acerca da educação nos últimos anos, tendo como estudo de caso o Objetivo 4 da Agenda 2030, cujo foco é a educação, entre os 17 Objetivos para o Desenvolvimento Sustentável do texto. O foco é compreender de que maneira o aprofundamento dos atuais paradigmas globais do capital e do humanismo encaixam-se ou não nas orientações textuais e imagéticas da cartilha em questão, bem como de que maneiras unidades ou sistemas educacionais micro têm respondido a tais direcionamentos. Em artigo de 2006, Maia retoma o conceito patriciano, propondo uma visão de educação "necessária para o homem (...) enquanto for homem (o que significa durante toda a vida)" (Maia, 2006, p. 138). Entretanto, o que são caminhos maus? E resultados melhores? E finalidade boa? O que, objetivamente, pode ser ou não definido como bom, como valor positivo ou negativo? Como vimos, o próprio Maia reconhece a inatingibilidade desse objeto. De facto, nesse contexto, é fundamental compreender qual o sentido do termo para a compreensão do conceito. Com o título introdutório "transformando nosso mundo", a Agenda 2030 da ONU aponta, na continuação de sua apresentação, para o que chama de objetivos do desenvolvimento sustentável, termo que, de certa forma, resume o documento de 49 páginas (ONU, 2015). Uma publicação da UNESCO (2017), referente especificamente à área de ensino e aprendi- zagem da Agenda 2030, define-a como "uma agenda ambiciosa e universal para transformar nosso mundo" (UNESCO, 2017, p. 6). Dentre os 17 pontos, discorreremos brevemente sobre aquele que será nosso objeto de pesquisa: o objetivo de número 4: "Garantir educação inclusiva e equitativa de qualidade, e promover oportunidades de aprendizado ao longo da vida para todos". As reflexões preliminares elencadas neste exposto apontam para um cenário possível da relação entre organismos internacionais e as orientações para a educação no mundo. Este cenário apresenta um panorama no qual ferramentas simbólicas e discursivas podem ser usadas, propositalmente ou não, para orientar o aprofundamento da redução do processo educativo à mera vinculação com o mundo do trabalho e do capital, na direção da manutenção da hegemonia das forças produtivas. Essa construção discursiva parece dar-se em detrimento tanto das especificidades culturais locais quanto das noções mais amplas de formação humanista. Nesse sentido, resgatar a via patriciana de interpretação e aplicação do conceito de antropeugogia pode ser uma das possibilidades para despertar e reforçar a orientação humanista da discussão, tendo sempre como Norte a análise de discursos, comparados a fontes teóricas, tendo em vista o questionamento de seus significados, em paralelo às práticas educacionais que são vistas ou que se queiram ver.

Palavras-Chave: Antropeugogia, Educação, Agenda 2030, ONU, Objetivo 4. 


\section{PERSPECTIVAS E PRÁTICAS PEDAGÓGICAS INCLUSIVAS: DOCENTES E USO DASTIC}

O trabalho de investigação que subjaz ao presente artigo, no âmbito da educação inclusiva, insere-se numa tese de doutoramento em educação que teve como objetivo geral caracterizar o uso de tecnologias com vista à inclusão, considerando a socialização, a aprendizagem, bem como o respeito pelos direitos dos alunos com deficiências nas Escolas Municipais de Ensino Regular do Município de Taquara, Brasil. Entende-se assim a educação como direito humano fundamental para todos, inclusive para os alunos com deficiência, ancorando-nos numa perspetiva de equidade.

Os objetivos específicos do trabalho foram: caracterizar os recursos tecnológicos e humanos disponíveis nas escolas para o atendimento aos estudantes com deficiência; conhecer as perceções dos professores titulares e os de apoio relativamente ao seu nível de competência na utilização destes recursos tecnológicos; analisar as perspetivas dos vários intervenientes sobre os impactos da utilização das TIC durante o processo de ensino e aprendizagem nos alunos especiais, incluindo ao nível pedagógico, curricular e extracurricular; e, por último, analisar as perspetivas dos vários intervenientes sobre as limitações dos recursos existentes e entraves à sua efetiva utilização.

A metodologia empregue foi de cunho quanti-qualitativo, com o objetivo de obter-se uma maior compreensão dos fenômenos investigados. Em concreto, foi aplicado um inquérito por questionário a 143 (cento e quarenta e três) pro- fessores titulares e de apoio aos alunos especiais, e foram aplicadas entrevistas semiestruturadas à Diretora da Secretaria de Educação Especial do Município e a 16 (dezasseis) professores. Destes, oito eram professores de apoio e oito professores titulares de turma, tendo como critério de seleção destes participantes a natureza das deficiências dos alunos com quem trabalham, de modo a representar perspetivas sobre o trabalho com pessoas com cada um dos tipos de deficiência que existiam nas escolas do município no momento da recolha de dados (deficiência visual, deficiência motora, deficiência mental e deficiência múltipla), e cada uma das séries de educação (séries iniciais e séries finais). Em particular, no presente texto, propomo-nos analisar os resultados relacionados com as práticas pedagógicas conducentes a uma aprendizagem significativa dos alunos especiais destes dezasseis professores entrevistados, considerando as suas competências ao lidar com TIC; e, o acesso ao uso destas tecnologias em sala de aula.

Os resultados apontam para a fragilidade da formação de grande parte dos docentes entrevistados, com destaque para as professoras de apoio, e para a carência ou desconhecimento da existência de recursos TIC na sala de recursos, sobretudo nas séries iniciais, fatores que limitam o impacto que o uso das TIC poderia ter para a inclusão dos alunos com deficiência.

Palavras-Chave: Inclusão, Tecnologia de Informação e Comunicação (TIC), Formação, Aprendizagem, Alunos com Deficiência.
Suzy de Abreu Costa \& Filipa Seabra Borges Universidade Aberta de Portugal 
Ref.: 084CEDHM42020

\section{PROJETO EM EDUCAÇÃO ESPECIAL \\ - DA EDUCAÇÃO ESPECIAL À EDUCAÇÃO INCLUSIVA - UMA LINHA CONDUTORA}

Paula Maria Santos Frazão

Universidade do Algarve - Escola

Superior de Educação e Comunicação
À semelhança de muitos países, Portugal tem feito mudanças no seu sistema educativo de forma a torná-lo mais inclusivo, isto é fazer com que as escolas regulares se reformem de forma a acolher e a educar capazmente todos os alunos incluindo os que têm condições de deficiência. Este Ensaio procura traçar um panorama atual da Educação Especial e Inclusiva em Portugal em particular depois da publicação do Decreto Lei 319/91 de 23 de agosto.

As novas realidades discursivas procuram trazer os docentes para o centro desta discussão como uma retórica que se repete quanto à necessidade de valorizar o seu papel, a sua autonomia ou a sua imagem social, porque thes cabe formar as novas gerações em conformidade com as exigências do futuro, da sociedade, da informação, do desenvolvimento económico ou qualquer outra razão, que seja atual.

É dentro dessa dialética que se apresentará uma reflexão sobre o conceito de inclusão, as atitudes e as contradições que resultam das evidencias fornecidas, sobre a situação profissional da classe dos professores em Portugal, designadamente quanto aos impactos que os fatores políticos e sociais recentes tiveram na profissão e na medida em que essas dimensões podem condicionar as atitudes potenciadoras de uma escola mais inclusiva. Assume-se assim, o pressuposto de que uma verdadeira escola inclusiva só é possível com um docente devidamente empenhado, mas também motivado e valorizado.

Reflete também as principais questões que têm sido discutidas nacional e internacionalmente, quando se trata de educação inclusiva. Embora todos os educadores estejam de acordo quanto à necessidade de melhorarmos a qualidade das respostas educativas das nossas instituições de ensino aprendizagem para todos os alunos: crianças, adolescentes, jovens e adultos, apesar de já haver algum consenso quanto à forma de levar o sistema gestor de políticas educacionais e as nossas escolas a assumirem a orientação inclusiva.

Como processo contínuo, dialético e complexo diz respeito a qualquer aluno que, por direito de cidadania, deve frequentar escolas de boa qualidade, onde aprenda a aprender, a fazer, a ser e onde participe, ativamente e numa dialética de equidade. Carvalho,(1995)

Palavras-Chave: Educação Especial, Educação Inclusiva, Equidade. 


\section{EDUCAÇÃO PARA O DESENVOLVIMENTO SUSTENTÁVEL E RESPONSABILIDADE SOCIAL NO ENSINO SUPERIOR: UM ESTUDO DE CASO NA UNIVERSIDADE PORTUCALENSE}

As instituições de ensino superior ao pretenderem uma educação de qualidade, incluem na formação dos seus estudantes a sensibilização para práticas de sustentabilidade e responsabilidade social, envolvendo-os em dinâmicas da própria escola a que pertencem. $\mathrm{O}$ presente artigo pretende trazer à luz o modo como a Universidade Portucalense tem contribuído para esse fim, no âmbito da comunidade académica. É consabida a existência de um Observatório da Responsabilidade Social e Instituições de Ensino Superior -ORSIES -com o qual tem ocorrido uma ligação constante, dando lugar a uma interação profícua, resultando no incremento de ações promotoras de consciência ética e cívica na presente e futura comunidade académica, porque profiláticas, na sua essência. Para além de várias unidades curriculares nos diversos cursos contemplarem temáticas sobre direitos humanos, igualdade de género, multiculturalismo, outras há, transversais, vocacionadas para a promoção do empreendedorismo numa perspetiva de desenvolvimento sustentável. Acresce a existência de um órgão constituído por docentes e colaboradores -RES-UPT -
Responsabilidade e Sustentabilidade Social Universidade Portucalense, sob a alçada da Entidade Instituidora, que colabora estreitamente com os núcleos de estudantes das várias áreas científicas de modo a incutir-lhes o sentido de pertença a um mundo globalizado, que deve, imperativamente, de ser protegido como legado para as gerações vindouras. De um modo satelizador, os núcleos de estudantes interagem com toda a comunidade académica nacional e internacional, inclusivamente, sendo múltiplos os exemplos, através da prática de voluntariado em países em situação de assinalável vulnerabilidade. Nos tempos atuais, de contingência devida à pandemia COVID-19, também nesta situação assaz invasiva do quotidiano da população em geral, o apoio dado aos estudantes assumiu facetas exponenciadas de práticas já existentes, adequando-as em tempo útil de modo a minimizar danos e a superar dificuldades acrescidas.

Palavras-Chave: Desenvolvimento Sustentável, Educação de Qualidade, Responsabilidade Social, Ensino Superior, Direitos Humanos.
Ana Sílvia Albuquerque, IJP, INPP, Universidade Portucalense Sandra Fernandes INPP, Universidade Portucalense \& Marta Abelha CEIS20, Universidade de Coimbra INPP, Universidade Portucalense 
Maria Amelia Reis

Universidade Federal do Estado do Rio de Janeiro UNIRIO/BR Centro de Estudos Interdisciplinares do Século XX- CEIS 20/UC/PT

Ref.: 09ICEDHMI 2020

\section{FÉ ESPERANÇA E CARIDADE, ESCRAVIZADA, VIOLENTADA... PATRIMÔNIOS EDUCATIVO - CULTURAIS SEQUESTRADOS: DESAFIOS PARA AVANÇOS DOS DIREITOS HUMANO}

Fé Esperança e Caridade...um corpo negro feminino, escravizado sem origem e sem identidade, supostamente sem alma a necessitar cristianização em meio a seu patrimônio sociocultural e educativo é tema deste artigo que articula a questão de gênero à escravização como geradora das desigualdades sociais profundas existentes no Brasil contemporâneo. Esta temática carrega em seu bojo a história comum dos povos escravizados pela diáspora africana através do Oceano Atlântico ao constituir-se como formadora da constituição étnica e cultural dos brasileiros. A literatura científica com o passar dos séculos de estranhamentos nos indica que antes do Brasil Colônia em Portugal já se contava com inúmeros escravos provenientes da África subsaariana. A partir do medo dos hábitos e atitudes do "outro" desconhecido, em seus mistérios e perigos, à suposta degeneração presente na morfologia de seus corpos físicos e mentais se incluem os discursos científicos da Antropologia Física que discrimina a partir de forças intangíveis. Traços, indícios e suspeitas identificam as mulheres negras fomentando um racismo estrutural contínuo e institucional que em versão brasileira ao embaralhar os velhos códigos de identificação e a hierarquia dos sistemas disciplinares aos novos modelos socioculturais, recusa-se a morrer, apesar de leis que o ilegalizam e criminalizam apoiados que estão em instituições educativas e práticas sociais fundamentadas em sistemas disciplinares de poder. Identifica-se que os corpos são portadores de valores, presentes nos gestos, nas aparências, nas urgências e em uma dinâmica de trocas que passam a organizar a vida social e cultural tomando por base a cor da pele. Reconhece-se que diversas culturas e civilizações tradicionais constituíram suas culturas sexuais com base nas artes de uma sensibilidade erótica e que as mulheres africanas se tornaram alvos fáceis frente aos seus proprietários e ao poder absoluto de seus corpos como função reversa de mecanismos de controle da vida sexual nos confessionários cristãos. Atualmente no tráfico de seres humanos predominam escravas sexuais em maioria negras como indica relatório da ONg Walk Free Foundation. Este estudo fundamentado nas experiências interdisciplinares de ensino, pesquisa e extensão junto aos alunos de graduação e pós-graduação, efetivadas entre 2005-2019, objetivando indicar as possibilidades de quebrar estruturas políticas racistas a partir de uma educação intercultural, integral e libertadora no exercício profissional futuro dos alunos e capaz de introduzi-los no conhecimento dos patrimônios culturais e pessoais das diferentes populações como possibilidades para melhor exercerem seus trabalhos. Eis o desafio deste estudo teórico-analítico que toma por eixo a desigualdade social e cultural historicamente construída a partir de uma educação acrítica escondida em narrativas que incluem a diversidade humana e teses de uma democracia racial no Brasil, demonstrando que nem o branqueamento da população.

Palavras-Chave: Direitos Humanos, Racismo, Mulher Negra, Educação Inclusiva, Patrimônio Cultural. 


\section{DIREITOS HUMANOS E EDUCAÇÃO: A IMPORTÂNCIA DAS ÁREAS PROTEGIDAS E O DIREITO AO MEIO AMBIENTE EM CRIANÇAS E ADOLESCENTES}

O meio ambiente é parte fundamental para o alcance da efetivação dos direitos humanos, pensando o direito à vida e ao ambiente ecologicamente equilibrado como essencial para qualidade de vida e a dignidade da pessoa humana. Os ambientes naturais são cruciais para o pleno desenvolvimento humano, sobretudo das crianças, porém, os estilos de vida atuais e a grande concentração urbana em escala global acabou por afastá-las da natureza. Um exemplo dessa separação são as escolas, onde crianças passam a maior parte de seu tempo em ambientes construídos e, muitas vezes, isolados. Compreendendo que a Educação Ambiental se constitui como elemento que garante o direito humano a um ambiente saudável, possibilitando relações de proximidade com elementos naturais, brindar experiências que possam fornecer momentos de contato livre e exploratório entre crianças e adolescentes e, em nosso caso particular, ambientes naturais protegidos, podem contribuir na formação de uma consciência crítica de nossas ações no planeta para um desenvolvimento sustentável. Desta forma o seguinte trabalho aborda as relações entre seres humanos e natureza, considerando o direito ao ambiente como respeito à condição biofílica das pessoas, e o reconhecimento dessa condição como garantia de direitos humanos. Na primeira parte, por meio de uma busca bibliográfica, analisamos o espaço esco- lar como oportunidade de reconectar crianças com o mundo natural, contribuindo na formação de gerações futuras cada vez mais comprometidas em preservar e valorar o nosso entorno natural. Na segunda parte e como exemplo prático do debatido anteriormente, investigou-se o impacto da visita à Unidade de Conservação de Proteção Integral Parque Estadual da Serra do Conduru, em crianças e adolescentes participantes de duas escolas da região, no Estado da Bahia, Brasil. Por meio de atividades de desenhos e aplicações de um questionário com perguntas abertas e fechadas (pré e pós visita) indagamos sobre as considerações dos participantes, visando em identificar aspetos tanto de conhecimento do local e expectativas quanto impressões, sentimentos e pontos de interesse antes e após da experiência vivida. Os resultados desta pesquisa sugerem que experiências em Unidades de Conservação geram relacionamentos de afeição e carinho com o local visitado, mostrando a sua importância para a sensibilização ambiental e o desenvolvimento emocional e cognitivo em crianças e adolescentes. Por último, observa-se a importância em ouvir os pontos de vista e aspirações dos mais jovens, que devem ser considerados pelos responsáveis na tomada de decisões políticas locais, regionais e globais.

Palavras-Chave: Criança-Natureza, Unidades de Conservação, Vivência, Biofilia, Sustentabilidade.
Fernando Enrique Grenno, Christiana Cabecieri Profice \& Rhadson Resende Monteiro Universidade Estadual de Santa Cruz 
Carolina Piccolotto Galib PUC-CAMPINAS e PUC-SP

\& Marina Martin UNIMEP

Ref.: I 28CEDHM22020

\section{O DESAFIO DO ACESSO À EDUCAÇÃO DE CRIANÇAS MIGRANTES DURANTE A PANDEMIA: UMA ANÁLISE DAS POLÍTICAS PÚBLICAS DO ESTADO DE SÃO PAULO}

A Agenda 2030 para o Desenvolvimento Sustentável criada pela Organização das Nações Unidas (ONU) prevê 17 objetivos para transformação do mundo atual. Dentre eles, o objetivo 4 trata do direito universal à educação, pois pretende "assegurar a educação inclusiva e equitativa e de qualidade, e promover oportunidades de aprendizagem ao longo da vida para todas e todos" 1 . A Convenção sobre os Direitos da Criança, em seu artigo 28, dispõe que os Estados Partes da Convenção devem atuar no sentido de reconhecer o direito à educação da criança em igualdade de condições. No entanto, sabe-se que a criança migrante enfrenta várias barreiras ao acesso à educação, tais como linguísticas, culturais e sociais. Tais dificuldades foram potencializadas pela nova dinâmica de ensino-aprendizagem à distância em virtude da pandemia do COVID-19, em razão do necessário isolamento social para a contenção do vírus. Assim, tendo em vista a vulnerabilidade da criança migrante e a necessidade de pensar políticas públicas específicas para concretizar o direito à educação, bem como o objetivo 4 da Agenda 2030 da
ONU, a presente pesquisa visa analisar as medidas tomadas pelo Estado de São Paulo e mais especificamente pelo município de São Paulo, o município brasileiro com o maior número de migrantes e refugiados registrados, para que a criança migrante em idade escolar tenha acesso à educação pública de qualidade em tempos de pandemia. Para tanto, utilizou-se da metodologia de pesquisa exploratória, pautada na análise de documentos oficiais divulgados pela Secretaria de Educação do Estado de São Paulo, pela Prefeitura da cidade de São Paulo e por organizações internacionais com atuação na temática, como OIM e UNICEF, além de pesquisa bibliográfica pertinente ao tema. Foi verificado que há um esforço por parte da Secretaria de Educação do Estado e da Prefeitura de São Paulo para orientar os participantes do processo de ensino-aprendizagem (escola, aluno e família) e disponibilizar materiais que visam uma maior inclusão do aluno migrante.

Palavras-Chave: Educação, Criança, Migrante, Pandemia. 


\section{EDUCAÇÃO EM DIREITOS HUMANOS PARA JUVENTUDES \\ DE ENSINO MÉDIO EMTEMPO INTEGRAL - PROPOSTA PARA O ODS 4, EDUCAÇÃO DE QUALIDADE}

\begin{abstract}
A presente pesquisa está vinculada à linha de Estudos Comparados em Educação (ECOE), do Programa de Pós-graduação em Educação (PPGE), da Universidade de Brasília (UnB) e foi desenvolvida no âmbito do Grupo de Pesquisa Gerações e Juventude
\end{abstract} (GERAJU). O objetivo desta pesquisa qualitativa reconstrutiva é relacionar ao Objetivo de Desenvolvimento Sustentável -ODS 4, da Educação de qualidade, a oferta da educação em direitos humanos (EDH) no Ensino Médio em Tempo Integral (EMTI) como proposta de educação múltipla e inclusiva para o desenvolvimento dos jovens, sujeitos sociais, em sujeitos de direitos humanos. Como método de pesquisa, foi realizado grupo de discussão com estudantes de 15 a 18 anos de unidade de EMTI do Distrito Federal, em 2019. O referencial teórico versa sobre: juventude e gerações, em Mannheim; teoria crítica dos direitos humanos, educação em direitos humanos e sujeito de direitos, em Flores, Santos, Rúbio, Gallardo, Magendzo, Carbonari e Sousa, entre outros. A análise dos dados empíricos foi realizada pelo método documentário, desenvolvido pelo sociólogo Ralf Bohnsack, a partir da Sociologia do Conhecimento de Karl Mannheim. Os resultados da pesquisa evidenciaram que as juventudes de EMTI, representativas da diversidade cultural e humana, apresentaram seus quadros coletivos de referências e experiências sobre educação integral, direitos humanos e educação em direitos humanos, nomeando essa de educação fundamental. Conclui-se, que a EDH ofertada no EMTI é avaliada pelos estudantes como instrumento educacional de formação multíplice, contribuindo para a constituição cidadã e política dos jovens, sobretudo, no desenvolvimento de seus projetos de vida. Esta associação corrobora com a proposta de educação transformadora e abrangente do ODS 4, pois que, juventudes e EDH representam a possibilidade da experiência com a educação multidimensional, em face às múltiplas dimensões do desenvolvimento humano e da necessária superação do fenômeno da interseccionalidade, que se evidencia na realidade juvenil, nas diferenças sociais, de gênero, de cor, de identidade sexual, inclusive, no acesso e na formação escolar. Para as juventudes de EMTI, a EDH os insere no contexto da vivência com a cidadania ativa e participativa em caráter de consolidação de sociedade democrática.

Palavras-Chave: ODS 4, Educação em Direitos Humanos, Ensino Médio em Tempo Integral, Sujeito de Direitos, Método Documentário.
Marcio Braz

Do Nascimento

Universidade De Brasilia - UNB 


\section{EDUCAÇÃO COMO FERRAMENTA DE IGUALDADE E EQUIDADE SOCIAL COM A AVERIGUAÇÃO DOS DIREITOS HUMANOS}

Eduardo Soares Da Silva Universidade Catolica Dom Bosco \& Najah Jamal Daakour Barakat

Universidade Federal De Mato Grosso Do Sul
Considerando uma linha inicial, é sabido que a educação sugere de maneira efetiva a projeção e desenvolvimento do indivíduo, formando-o em cidadão e o alocando na sociedade organizada. Em face a aplicabilidade dos Direitos Humanos e tendo como pano de fundo a educação, no estabelecimento de ser evocada como ferramenta a proposição da igualdade de da equidade social, vem a ser instaurada como mecanismo capaz de propiciar o pleno desenvolvimento do indivíduo, capacitando-o e o preparando dará a plenitude do seu exercício de cidadania. Desse modo é percetível que a educação traz consigo fortes elementos prontos em possibilitar a igualdade social e a equidade social, ou seja, a educação é resultante de uma averiguação da igualdade, pois propicia a todos o direito da educação, e, por conseguinte, trata de assuntos sociais referendando um conceito que a igualdade sobressai ao nível de equidade, acabando com desnivelamentos e assim conquistando de forma latente a justiça. Tendo o liame do conteúdo que ressoa na igualdade e equidade, é muito intrínseco e também inolvidável presumir que a garantia da oferta da educação deve ser compatibilizada com intuito disponível em eliminar as disparidades dessa oferta, que é consoante ao gênero, a vulnerabilidade social, deficiência física, logo garantindo o processo de inclusão de maneira totalitária, e que por sua vez faz remessa direta ao conteúdo dos Direitos Humanos. Evocando a presença dos Direitos Humanos a educação é veiculada como amaneira eu uma determinada pessoa possa ter para si uma vida com dignidade de valorização, e uma forma adequada de promoção da justiça. Nesse condão, todo cidadão merece uma resposta de âmbito social, na qual a educação é compreendida como direito e devendo ser disponibilizada pelo Estado e sociedade é colocada num patamar que elenca as funções sociais sobremaneira, ou seja, a remessa e postulação da educação como obrigação estatal é erigida por causa da sua real importância para toda a sociedade, bem como a sua construção, por meio dos seus componentes, ou seja, os cidadãos. Nessa dinâmica e dada sua importância a educação não pode ser configurada em face a sua oferta a um determinado grupo, ou mesmo, o preterimento de indivíduos que se encontram incompreendidos na sociedade, assim o atendimento é ponto vital em assistir o direito à educação a todos, sem distinção e sem discriminação. Tendo essa senda como ponto de partida, a oferta da educação pelos entes públicos traz consigo a exata configuração de propiciar de modo profícuo além do atendimento aos indicadores de igualdade e equidade, a satisfação do alcance a todos participes da sociedade organizada, gerando mecanismos de inclusão, de qualidade e assegurando o ingresso e a inclusão. Diante dos pressupostos apresentados é crível a conclusão que a Educação como direito, e preconizada pelo conteúdo de Direitos Humanos tem a grata satisfação de promover a igualdade e a equidade social no âmbito da sociedade em geral.

Palavras-Chave: Direitos Humanos, Educação, Direitos Sociais, Igualdade, Equidade. 


\section{A (TRANS)FORMAÇÃO SOCIAL ATRAVÉS DA EDUCAÇÃO INCLUSIVA}

A educação é um ato político e através dela é possível ofertar ao educando condições reflexivas de entender o mundo que o rodeia, e ao entendê-lo, tem a própria realidade e sua relação com o mundo modificadas e este é em si igualmente um ato político. Faz-se importante trazer mais luz sobre o tema da inclusão de portadores de necessidades especiais entendendo-os como cidadãos de direito e, portanto, possuidores do direito à uma educação regular e que é preciso pensar a escola como a instituição própria para este papel, considerando suas particularidades como membros da sociedade, tanto como os demais indivíduos. Este objetivo é cumprido considerando o estudante portador de necessidades especiais aquele que precisa de um atendimento educacional especializado de acordo com suas necessidades físicas, motoras e intelectuais. No entanto, falar de inclusão não deve promover restrições especialmente em virtude de tantas segregações existentes em diversas dimensões. Devem ser contemplados todos aqueles que foram excluídos do sistema tradicional de ensino por anos e que demandam um olhar especial no pensar a educação inclusiva. Falamos de grupos sociais severamente discriminados e que, por suas singularidades, devem receber atenção e respeito: comunidades quilombolas, indígenas, ciganas, idosos e LGBTQI+. Este artigo tem como objetivo apresentar reflexões sobre a Educação Inclusiva como meio de (trans)formação de cidadãos através do rompimento dos mais diversos tipos de preconceito desde a primeira infância. É na Educação que se deve trabalhar a construção social de cidadãos com valores pautados no respeito às diferenças. Para este fim, foi realizado um levantamento bibliográfico em fontes pertinentes ao assunto Educação no Brasil para estruturar o estado da arte deste trabalho. Se entendemos a escola como uma agente de transformação, é preciso ressignificar este espaço valorando estes públicos-alvo vítimas de preconceitos e consequente exclusão social. Entretanto, é ir além da oferta da Educação formal. Educar é um processo de consciência, o que dá condição para a libertação do indivíduo que se educa, daí ser a Educação um direito humano fundamental. Conclui-se que é preciso repensar a inclusão compreendendo como algo fundamental para a formação de uma sociedade mais sadia. A inclusão deve privilegiar o sujeito reconhecendo as subjetividades existentes com suas diversas formas de expressão. Deve-se buscar um comprometimento com a criação de uma nova realidade social. É preciso pensar em todos os indivíduos que compõem uma sociedade. É enxergar os que não são de fato invisíveis garantindo a liberdade de ser. A escola não deve ser território de antagonismos que somente tem a função de segregar as partes que estão juntas num mesmo território social e com a mesma finalidade: a educação. Cabe à escola apontar para os valores e atitudes inclusivos de todas as raças, cores, gêneros, sexualidades, religiões, formas físicas e intelectuais, sem restrições.

Palavras-Chave: Educação Inclusiva, Inclusão Social, Preconceito Social, Cidadania, Diversidade.
Julio Cesar Rodrigues Investigador Independente 


\section{CARTOGRAFIA DE INTER(IN)VENÇÃO DO GRAFFITI NO COTIDIANO DA PERIFERIA DE FORTALEZA, BRASIL: INVENÇÕES EM DIREITOS HUMANOS}

Tadeu Lucas de Lavor Filho

Universidade Federal do Ceará
O presente enseja discutir a experiência da pesquisa desenvolvida em 2018-2019 intitulada: "spray nas mãos, afetos nos muros: cartografia de inter(in)venções do graffiti no cotidiano de jovens inventores, realizada da periferia da cidade de Fortaleza, Ceará, Brasil. A proposta centra na investigação de articulação entre territórios educacionais e escolares, graffiti e subjetivação por meio de uma pesquisa-intervenção. Nosso objetivo foi cartografar as intervenções e tensões que engendram produções de graffiti com jovens agenciadas em práticas educacionais dentro e fora do cotidiano escolar em território periférico. Situou-se no âmbito da pesquisa as produções de graffiti nos muros da escola, ruas, praças e nas instituições sociais. Com isso, acompanhamos grupos de grafiteiros crew -que desenvolve intervenções ativistas em Direitos Humanos com foco no combate do racismo, das desigualdades sociais e do extermínio do tráfico de drogas na periferia de Fortaleza. Tais produções são apropriadas pelos jovens da comunidade e passaram a ser engendradas em uma disciplina curricular de graffiti em uma escola pública de ensino médio em tempo integral. Esta articulação permitiu que o ensino de Direitos Humanos na escola por meio do graffiti atravessasse a cultura escolar. É nesse interstício que o graffiti engendra modos de subjetivação que podem tensionar o cotidiano escolar. O método foi uma pesquisa-intervenção com manejo da cartografia dos estudos pós-estruturalistas e da filosofia da diferença. Os dispositivos teórico-metodológicos operados foram: observação-participante e conversas no cotidiano, diário de campo, entrevistas semiestruturadas, e realização de um grupo focal com jovens estudantes. A análise dos dados da pesquisa consistiu no dispositivo da Análise de Discursos na perspetiva foucaultiana. A guisa de conclusão, os graffitis produzidos nas periferias têm sido agenciados sob questões coletivos e individuais pautados no enfrentamento de temas como racismo, desigualdade social, participação das mulheres e democratização da arte urbana nos territórios periféricos e essas questões são linhas de forças que mobilizam e são subjetivadoras das trajetórias de jovens grafiteiros e grafiteiras, fortalecendo o emblema das culturas artísticas de periferia na educação de direitos humanos. Como resultado, no tocante de práticas educativas, o graffiti é experimentado como dispositivo de educação para promover transformação social na vida de jovens residentes da periferia com ações fora e dentro dos espaços escolares. Por último, a disciplina eletiva de graffiti se mostrou como uma experiência de ensino em que o componente político esvaziou-se em função da ênfase no ensino da técnica e estética da arte. A guisa de conclusão, espera-se que essa pesquisa possa contribuir para os estudos em Psicologia e outras áreas que se centram sobre os processos de subjetivação e fenômenos da arte em contextos educacionais.

Palavras-Chave: Brasil, Direitos Humanos, Periferia, Graffiti, Juventudes. 


\section{O ACESSO À INTERNET COMO MEIO DE REDUÇÃO DAS DESIGUALDADES SOCIAIS}

Vivemos em uma sociedade hiperconectada, na qual tudo está se tornando digital e, em quase tudo o que fazemos, utilizamos a internet. A tecnologia vem alterando o modo como as pessoas interagem e exercem cidadania atualmente, se tornando uma ferramenta multidisciplinar. Evidente que o acesso à Internet pode reduzir as desigualdades, entretanto, ao invés de aperfeiçoar a vida dos mais desfavorecidos e marginalizados, tem potencial de aumentar as desigualdades já existentes. Assim, em uma sociedade globalizada em rede, conectada por novas tecnologias, consequentemente, surgem novos desafios quanto sua acessibilidade.

Como já mencionado, é certo que a Internet se liga intrinsecamente aos direitos políticos, elemento fundamental para a efetivação do pleno exercício da cidadania, e constitui possível meio para redução das desigualdades.

Isso porque esta remove fronteiras e cria pontes entre grandes espaços geográficos e sociais, podendo ser utilizada como mecanismo de denúncia e publicidade de pontos contrários à igualdade, além de fomentar a inclusão social e política em meio à diversidade populacional e garantir voz aos oprimidos.

A igualdade é direito humano que pode ser formal ou material. Quando formal, presta a vedar distinções legais entre as pessoas, bem como garantir a proteção a iguais direitos. A igualdade material, por sua vez, não possui foco meramente jurídico, buscando a igualdade real. Ou seja, tratar iguais de forma igual e desiguais de forma desigual, proporcionalmente.
Outrossim, segundo a ONU, a Internet é considerada Direito Humano, por meio do qual indivíduos podem exercer seus direitos de liberdade de expressão e opinião, conforme positivado no artigo 19 da Declaração Universal dos Direitos Humanos, além de ser meio de facilitar a participação ativa dos cidadãos na construção de sociedades democráticas.

A relevância da discussão é nítida ante à consolidação da ideia de que acesso à Internet é essencial ao acesso à informação, à educação, justiça e cidadania e ao fato de que $53 \%$ da população mundial não possui acesso à Internet. No Brasil, por exemplo, uma em cada quatro pessoas não o tem.

Pode-se constatar que a condição socioeconômica, bem como o acesso geográfico a serviços públicos podem ser transpostos e superados com a Internet, de modo a promover a igualdade material.

Assim, é certo que, sanada a dificuldade de acesso à internet, esta pode ser uma ferramenta favorável ao combate à desigualdade.

Destarte, tem-se como problema de pesquisa os seguintes questionamentos: a internet pode contribuir na redução das desigualdades sociais? De quais formas?

Ademais, o método adotado para a presente pesquisa é o dedutivo, alinhado a técnicas de pesquisa bibliográficas e análise de dados qualitativos e quantitativos.

Assim, os resultados tendem a apontar que a viabilização do acesso à Internet facilita a promoção da redução das desigualdades sociais.
Leonardo Marques Vieira \& Maria Clara Giassetti Universidade Presbiteriana Mackenzie 
Natália de Andrade Rocha

Universidade do Estado

do Rio de Janeiro

\& Carlos Henrique Vale de Paiva

Universidade Candido Mendes

Ref.: I 73CEDHM22020

\section{MAPEAMENTO DE ESPAÇOS CRIATIVOS EM CAMPO GRANDE NO RIO DE JANEIRO}

Nos últimos anos, tem-se observado um crescimento exponencial das áreas que compõem a Indústria Criativa, um conjunto de negócios baseados no capital intelectual, cultural e na criatividade para gerar valor econômico (SEBRAE, 2018). A construção de cidades criativas tornou-se de suma importância para o desenvolvimento econômico sustentável, pois congrega valores econômicos e culturais, contribuindo para o cumprimento da "Agenda 2030" da Organização das Nações Unidas (ONU). Todavia, os projetos de construção de espaços criativos nas cidades brasileiras utilizam um modelo exógeno e pouco democrático, retirando o protagonismo dos atores locais na ressignificação dos territórios (FERNANDES; HERSCHMANN, 2018). Por isso, a criação de mapas sensíveis destes espaços é importante para a elaboração de políticas e ações mais inclusivas. A pesquisa apresenta o mapeamento sensível dos espaços criativos do bairro de Campo Grande, na Zona Oeste do Rio de Janeiro, um dos bairros mais populosos da cidade (SEBRAE,2016). O objetivo é investigar as identificações e os simbolismos que compõem estes locais de cultura e lazer. A hipótese é a de que estes espaços, que possuem um grande fluxo de comunicação e de pessoas, são propícios à formação de identidades e da construção simbólica dos territórios. Não à toa, comerciantes e políticos têm utilizado este potencial para criar espaços criativos nas cidades, a fim de alavancar a economia, como aconteceu no processo de reconstrução da Lapa na última década (DIAS, 2014). O método utilizado foi o cartográfico (DELEUZE; GUA-
TARRI, 1995), mapeando sensivelmente o lugar a partir do que vemos, ouvimos e sentimos; e a observação participante, para compreensão das práticas socioculturais. Foram selecionados três locais para fazer o mapeamento. A "Rua da Fox", um espaço com público predominantemente jovem, que estão à procura de relacionamentos casuais, beber e dançar. A "Praça do Magali", um lugar visitado tanto por famílias com crianças, quanto por jovens em busca de diversão. Percebe-se que é um bairro tipicamente residencial, frequentado por moradores da região. Por fim, o "Polo Gastronômico do Rio da Prata", um dos pontos movimentados do Carnaval em Campo Grande, frequentado por muitos casais e famílias. É um local para "ver" e "ser visto", demonstrando a capacidade financeira de estar ali. Em todos estes locais percebeu-se uma divisão dos corpos no espaço, que não é previamente acordada, mas que depende da identificação de cada público com a sua tribo (MAFFESOLI, 1998). Cada bar, com sua singularidade, contribui para construir o território, bem como os diversos públicos que migram entre os bares. A pesquisa revelou que há um potencial em Campo Grande de contribuir para os projetos que querem tornar o Rio de Janeiro uma cidade criativa. No entanto, falta aos comerciantes uma visão mais ampla e embasada no marketing para alcançar melhores resultados com a população da região e de outros bairros.

Palavras-Chave: Indústria Criativa,

Desenvolvimento Sustentável, Espaços Criativos, Cartografia Sensível, Rio De Janeiro. 


\section{A PRESERVAÇÃO DA INFÂNCIA ATRAVÉS DA PRODUÇÃO DE BRINQUEDOS DE MATERIAIS RECICLÁVEIS: UM PROJETO ESCOLAR PARA A DIGNIDADE E SOLIDARIEDADE}

\begin{abstract}
O brincar deve ser desenvolvido no ambiente escolar e valorizado como instrumento de ensino. As crianças devem realizar brincadeiras todos os dias. Um dos fatores favorecidos por essa habitualidade é o desenvolvimento motor. A criatividade é outro ponto relevante, pois ali consta uma oportunidade de
\end{abstract} ampliação das possibilidades através do olhar infantil. É nos primeiros anos de vida que a criança aprende inúmeros conceitos que levará em todos os seus dias. A transformação de alguns materiais em brinquedos completamente diferentes faz parte do processo criativo da criança. Essas práticas podem ser aliadas a preservação do meio ambiente com a construção de brinquedos recicláveis. O uso de resíduos que não teriam mais utilidade pode conscientizar os alunos sobre o uso excessivo de matérias e seu descarte. Este estudo foi desenvolvido com o objetivo de compreender que o brincar assim como a produção de suas possibilidades pode ser efetuado por todos, independentemente das condições financeiras. Para tanto, foi realizado um estudo qualitativo onde os alunos dos anos finais do ensino fundamental de uma escola municipal produziram brinquedos recicláveis para os estudantes da educação infantil de sua escola. Também foram inquiridos, através de questionário, sobre o desenvolvimento do projeto e suas perceções quanto a ele. Brinquedos recicláveis são uma forma de preservação da infância e cuidado com meio ambiente. Com isso em mente, ocorre o desdobramento do projeto.
Os alunos de sexto ao nono ano produziram, em grupos, brinquedos com materiais recicláveis durante as aulas e em suas casas como forma de estender o aprendizado além dos portões da escola. O retorno dos estudantes com os artefactos foi surpreendente. Houve empenho e interesse na construção dos modelos. Tanto que alguns alunos informaram de forma oral que gostaram tanto da atividade que estão produzindo mais brinquedos. Através do questionário foi visualizado que o sentimento de generosidade esteve presente desde o princípio e eles ficaram felizes em contribuir para o brincar de outras crianças. Compreenderam também que existem possibilidades de produção e qualificação do brincar com materiais que não são os de brinquedos usualmente consumíveis no comércio. Ademais, ainda resgataram muitos brinquedos desenvolvidos por seus familiares durante as suas infâncias. Para a entrega, os próprios alunos que confecionaram os brinquedos ofereceram esses para a educação infantil e brincaram com eles. As crianças presenteadas foram surpreendidas e ficaram nitidamente encantadas. Brincaram entre si e com os alunos mais velhos. O objetivo do projeto foi plenamente alcançado e devido a isso será realizado novamente no próximo ano. Os relatos dos alunos deixaram claro sua satisfação com esse plano mostrando que importar-se com o próximo é algo a ser visto na escola e que a infância deve ser preservada.

Palavras-Chave: Infância, Brinquedos, Projeto, Escola, Educação.
Letícia Petry de Faria Escola Municipal Doutor Alberto Pasqualini

\& Claudia Maria Petry de Faria

Universidade Feevale 
Ref.: I89CEDHM22020

\section{UN DESPLIEGUE TRANSFORMADOR DE LOS ODS EN LA EDUCACIÓN SUPERIOR: APLICANDO LOS ODS CON ENFOQUE DE CUIDADOS EN ELTRABAJO FIN DE GRADO}

Sergio Belda-Miquel, Elena Mut Montalvà \& Ana Isabel Vázquez Cañete

Universitat de València
Las universidades españolas, como ocurre en buena parte del mundo, están abrazando los Objetivos de Desarrollo Sostenible (ODS) como forma de contribuir al avance hacia modelos más sostenible desde el punto de vista económico, social y ambiental. Como prueba de ello, están favoreciendo su implementación de manera transversal en distintas estrategias, políticas y acciones, particularmente en el ámbito de la docencia. A nivel tanto teórico como metodológico como empírico, existe una creciente reflexión y literatura sobre la forma en la que esta incorporación del ODS se puede realizar y se está de hecho realizando.Este trabajo pretende contribuir a estas reflexiones, pero abordando dos limitaciones fundamentales en el debate. Por un lado, una corriente crítica apunta que la adopción de los ODS no necesariamente lleva a la transformación profunda que requieren los procesos de enseñanza-aprendizaje en la educación superior. Por otro lado, se ha reconocido que son necesarios más trabajos que detallen implicaciones concretas que la adopción de ODS puede tener en distintos aspectos de la enseñanza-aprendizaje. Para ello, este estudio pretende, por un lado, contribuir apensar cómo adoptar los ODS desde un planteamiento crítico que permita un cambio profundo en los marcos de pensamiento y posibilite una acción radicalmente transformadora de la sociedad desde la Universidad. Por ello se propone explorar las implicaciones de los ODS para la enseñanza-aprendizaje desde la perspectiva de los cuidados, un enfoque que ha demostrado su relevancia y potencial para la sostenibilidad de la vida.Por otro lado, se exploran implicaciones concretas que esta perspectiva de los ODS desde los cuidados puede tener para pensar la docencia universitaria. Desde este punto de partida se exploran las posibilidades de adoptar los ODS desde una perspectiva crítica para pensar el desarrollo del Trabajo Final de Grado (TFG), una asignatura común a todas las disciplinas en la universidad española. El desarrollo del TFG es un momento de especial trascendencia en el proceso de enseñanza-aprendizaje, por su carácter integrador, de modo que es muy relevante para proponer cambios transformadores.El trabajo se articula del siguiente modo: revisa la situación de la adopción de los ODS en la educación superior y en la universidad española en general; plantea la necesidad de articular un enfoque más crítico de los ODS; propone un marco propio combinando los ODS con elementos del enfoque de cuidados; explora las implicaciones que, para distintos aspectos de la enseñanza aprendizaje (desde las competencias a trabajar hasta las metodologías de aula, las conexiones con el entorno, y las relaciones entre los actores implicados), puede tener la adopción de este enfoque; y concreta estas implicaciones para el caso de la realización del TFG en dos disciplinas distintas de las ciencias sociales, el trabajo social y la administración de empresas.

Palavras-Chave: ODS, Enfoque de Cuidados, Educación Superior, Trabajo Fin de Grado. 


\section{EDUCAÇÃO AMBIENTAL NA CASA DO CAMINHO: AÇÕES PARA ALÉM DA TEORIA}

A Educação Ambiental tem como princípios básicos a multi e a interdisciplinaridade, o pensar no global agindo no local e as atividades em continuidade. Trabalhar com práticas desde a formação inicial das crianças possui um papel muito importante, fazendo com o que aluno se sensibilize e possa vir a ser um adulto conscientizado de seu papel de cidadão ambiental com olhar aguçado para a preservação, solução de problemas e desafios que possa encontrar. Levando em conta estas premissas desde 2014 um projeto de educação Ambiental vem sendo desenvolvido na Instituição Filantrópica Casa do Caminho em Londrina-Paraná-Brasil. Tal instituição atende crianças e adolescentes carentes do município em período de contra turno. Como atividades regulares da Casa têm-se ginástica, culinária, reforço escolar, ou seja, uma educação complementar de caráter geral visando a formação do indivíduo como um todo. Para as atividades de Educação Ambiental tem-se um projeto maior que envolve algumas universidades como Universidade Federal Tecnológica e a Universidade Estadual de Londrina. As atividades da Universidade Estadual de Londrina fazem parte do contexto prático da disciplina Geografia Física e Educação Ambiental do Programa de Pós-Graduação em Geografia. Nesta disciplina os pós-graduandos trabaIham os conceitos de forma teórica e na sequência organizam oficinas que são desenvolvidas com as crianças, professores e funcionários durante o primeiro semestre. O segundo semestre configura-se como acompanhamento de forma indireta e voluntária observando e sistematizando os resultados das ações. Durante os seis anos de configuração do projeto várias oficinas foram desenvolvidas (sempre bem articuladas com a teoria e as diretrizes da Educação Ambiental e pautadas no Iúdico): Construção de hortas, jardins verticais, jogos teatrais, jogos de tabuleiros, resgate de memória viva, uso de tecnologia, trabalhos de campo, gestão de recursos gestão de resíduos, compostagem, mapa mental, teatro entre outras... Seja em sala de aula, no pátio, na rua, os oficineiros buscaram trabaIhar os conceitos sempre pautados no local e no conhecimento prévio das crianças. O que mais vale é resgatar o cotidiano, a realidade local para que as atividades em Educação Ambiental funcionem e tenham sentido. Além do lúdico, para cada ano havia um tema norteador das atividades, proporcionando identidade ao grupo que desenvolvia as atividades, assim para um ano teve-se o resgate de jogos e brincadeiras dos avós, para outro a reciclagem, para outros filmes infantis. A base teórica para o desenvolvimento das ações pedagógicas é a fenomenologia, pois a mesma proporciona uma ponte entre o meio e o social. Como resultados é possível observar mudança significativa no comportamento e pensar das crianças ao longo destes anos, havendo maior envolvimento com as questões ambientais. Isto visa reforçar que as práticas em Educação Ambiental podem e devem ser desenvolvidas em todas as esferas de ensino, seja formal ou não.

Palavras-Chave: Educação Ambiental, Ensino, Lúdico, Casa Do Caminho, Sociedade.
Eloiza Cristiane Torres Universidade Estadual de Londrina 
lago de Souza Marconi \& Luiz Nunes Pegoraro Centro Universitário de Bauru, mantido pela Instituição Toledo de Ensino (CEUB-ITE)

Ref.: I 99CEDHM22020

\section{O DIREITO À EDUCAÇÃO NA PANDEMIA PROVOCADA PELO NOVO "CORONAVÍRUS": FLAGRANTE DE DESIGUALDADE SOCIAL E INEFICÁCIA ESTATAL}

O direito à educação deve ser entendido como um direito humano primário, como fator integrador do sujeito na comunidade em que está inserido. A educação está diretamente ligada ao princípio democrático e é por meio de uma educação de qualidade, inclusiva e equitativa que se pode solidificar as benesses de um estado social. Em meio à crise institucional ocasionada pela pandemia de "covid-19", a qual afetou diversos países ao redor do globo, os Estados veem-se forçados a não paralisar a educação, sob pena de afetar toda uma geração. Em se tratando do Brasil, os níveis que já eram alarmantes mostram-se ainda mais preocupantes, pois o desinteresse e as dificuldades do ensino à distância vêm associados à crise sistêmica do mecanismo educacional brasileiro que há décadas luta contra altos índices de evasão escolar, analfabetismo funcional e um abismo insofismável entre o ensino básico e o acesso ao ensino superior. O objetivo da presente pesquisa é identificar as falhas sistêmicas a partir da evidência provocada pelo novo método de ensino causado pelo estado de emergência por conta do novo coronavírus. Identificadas as falhas, há que se pensar em fundamentos teóricos que legitimem institutos democráticos para sanar a ineficiência estatal e remodelar não só o período de crise atual, mas a visão dada até então para a educação no Brasil. Utilizando os métodos hipotéti- co-dedutivo e dialético aplicados a pesquisas bibliográficas e coleta de dados de fontes oficiais, os autores buscam empregar uma hermenêutica constitucional ao esquema de flagrante violação de direitos humanos. Incidentalmente, analisa-se a ação da Comissão Interamericana de Direitos Humanos (CIDH) e sua influência no caso. Como resultados, pode-se concluir que o direito à educação há muito vem sendo negligenciado, de modo a não cumprir com as metas acordadas em tratados internacionais e compromissos institucionais, quadro evidenciado principalmente pelos indicadores durante a pandemia de covid19. Também é possível observar que há a necessidade de se entender o Direito Humano constitucionalmente previsto de forma a garantir maior efetividade, bem como, alinhado ao "neoconstitucionalismo", promover a legitimidade a funções estatais pouco tradicionais para sanar falhas estruturais ligadas à educação e seus prejuízos decorrentes. Por fim, despontam propostas para cumprir as metas acordadas por meio de institutos essencialmente democráticos, como o Estado de Coisas Inconstitucional (ECI) e formas mais brandas, como ações de (in)constitucionalidade voltadas à formulação e implementação de políticas públicas eficientes.

Palavras-Chave: Educação,

Neoconstitucionalismo, Efetividade,

Covid-19, Estado de Coisas Inconstitucional. 


\section{FORMAÇÃO DOCENTE PARA O ESTUDO DA COVID-I 9 NO CONTEXTO DAS GEOGRAFIAS DOS RISCOS EM MICROESCALA}

Os estudos no campo da Geografia dos Riscos, mas especificamente em torno da discussão conceitual de riscos e capacidade de resposta em microescala é relevante, principalmente, neste momento em que o mundo é surpreendido pela pandemia da Covid-19 (doença causada pelo novo coronavírus -Sars-CoV-2 Síndrome Respiratória Aguda Grave 2). Os riscos, perigos e vulnerabilidades estão presentes na sociedade e são dimensões de um mesmo fenômeno. O perigo expressa os eventos que causam danos, enquanto 0 risco é a probabilidade ou a ameaça do perigo. Já a vulnerabilidade expressa tanto a capacidade de resposta quanto a sua incapacidade. A forma de responder aos riscos tem relação direta com a maneira como compreendemos e fazemos a leitura da nossa realidade. Atuar no campo da perceção individual e coletiva é essencial para o enfrentamento dos riscos por que permite compreender as dimensões do evento em cada circunstância. O olhar atento a particularidade do contexto geográfico é essencial para avaliar a capacidade da comunidade para participar da gestão para o enfrentamento da pandemia e a construção de resiliência, ou seja, da capacidade de absorver e enfrentar impactos, recuperando-se. Nesse sentido se investiga o potencial dos professores como mediadores na avaliação de riscos e vulnerabilidades a que a comunidade escolar está exposta. $O$ estudo busca valorizar o papel relevante desses profissionais e a necessidade de incorporar, em suas metodologias e conteúdos, a problemática global em torno da pandemia buscando ganhar uma dimensão prática, ou melhor, para que sejam revertidas em práticas sociais cotidianas, em escala local. Dessa forma, este período de pandemia tem permitido agregar informações e conhecimentos relativos a vida cotidiana e voltados para a Geografia dos riscos, vulnerabilidades e resiliência no contexto de mudanças profundas em suas múltiplas dimensões, manifestações e coexistência espacial, a partir da realidade vivida pelos educadores em suas comunidades. O objetivo central da pesquisa é investigar as suas perceções, conhecimentos e/ou opiniões sobre a pandemia e seus efeitos práticos, relativos ao modo de ser, de pensar e de agir no mundo em que vivemos. Como metodologia de estudo, esta pesquisa qualitativa é pautada em entrevistas grupais para captar como se formam e se diferem as perceções, opiniões e atitudes dos participantes acerca do tema, considerando que as perceções, opiniões e atitudes são socialmente construídas (KIND, 2004). Assim, buscamos reunir subsídios para avaliar o potencial dos educadores para desenvolverem pesquisas, em escala local, em três frentes de trabalho: perceção e avaliação do risco; enfrentamento da vulnerabilidade e construção de resiliência; e a capacidade de resposta. Conclui-se que a informação e o conhecimento são essenciais para aprendermos a perceber os riscos e perigos e desenvolver a capacidade de respostas aos problemas vividos para a construção de resiliência.

Palavras-Chave: Perceção, Vulnerabilidades, Resiliência, Pandemia, Educadores.
Jeani Delgado Paschoal Moura

Universidade Estadual de Londrina 
Ref.: 209CEDHM42020

\section{A IMPORTÂNCIA DA EDUCAÇÃO AMBIENTAL, EM NÍVEL MUNICIPAL, E OS REFLEXOS NO ÍNDICE DA COLETA SELETIVA DE RESÍDUOS RECICLÁVEIS}

Fernanda Maria Grasselli

Freitas

Universidade Federal Do Rio Grande Do Sul

\& Gustavo Henrique Araújo dos Santos

Universidade Federal De Santa Catarina
O objetivo do presente trabalho foi descrever e analisar como a implementação do Projeto de Educação Ambiental Reciclar (PEAR) em duas cidades da região do litoral norte do Estado do Rio Grande do Sul (RS), Brasil, notadamente Capão da Canoa e Xangri-lá, realizado por uma associação (ASAGEE -Associação de Agentes Econômicos e Ecológicos de Capão da Canoa), ajudou a melhorar os índices da coleta seletiva destas cidades, contribuindo, ainda, para a erradicação da pobreza. $O$ estudo foi concretizado através da integração entre a abordagem quantitativa e qualitativa, instrumentalizada por revisão bibliográfica e documental, bem como pesquisa empírica. Através desta metodologia, buscou-se responder o seguinte problema de pesquisa: de que forma a concretização da educação ambiental por uma associação pode promover o acesso à renda por pessoas hipossuficientes e concretizar os objetivos do desenvolvimento sustentável preconizados pela Agenda 2030? Como objetivos específicos, pretendeu-se identificar como o gerenciamento integrado de resíduos sólidos urbanos (RSU), por meio da cooperação intermunicipal, pode fomentar o desenvolvimento e fortalecimento de organizações coletivas, possibilitando a inclusão e redução das desigualdades sociais. Além disso, procurou-se descrever todo o processo de implementação do projeto de educação ambiental, desde a caracterização da entidade promotora, até as atividades de campo realizadas.
Também, objetivou-se quantificar os índices da coleta seletiva destes municípios, comparando com a média estadual, relacionando esses resultados com a prática da educação ambiental. E por fim, com o surgimento da pandemia do novo coronavírus, avaliou-se como o isolamento social impactou o PEAR, e quais foram as alternativas buscadas para a continuidade das atividades do projeto, sem colocar em risco a vida de seus colaboradores e colaboradoras. Como resultados, identificou-se um aumento no volume de resíduos recicláveis comercializados pela associação, gerando um incremento nos rendimentos dos associados e associadas. Ainda, percebeu-se uma melhora nos índices da coleta seletiva no primeiro ano de implementação do projeto, e uma queda neste mesmo índice no primeiro semestre de 2020. Uma das hipóteses é de que, a ausência de atividades presenciais do PEAR, consequência da quarentena imposta para o enfrentamento da pandemia, pode ter influenciado este resultado. Com isso, identificou-se também a importância da Educação Ambiental para a concretização da Agenda 2030 para o Desenvolvimento Sustentável, especialmente na perspetiva econômica, social e de práticas sustentáveis, que se concretizam através de uma política ambiental de desenvolvimento equilibrado e a capacidade de gestão ambiental.

Palavras-Chave: Associativismo, Coleta Seletiva, Educação Ambiental, Desenvolvimento Sustentável, Pandemia Coronavírus. 


\section{DIREITOS HUMANOS À EDUCAÇÃO: UMA ANÁLISE À LUZ DA AGENDA 2030}

A pesquisa faz uma análise dos Direitos Humanos à Educação, com base em um momento de desafio democrático, econômico e histórico, vivenciado atualmente no cenário internacional. As indagações acerca dos Direitos Humanos à Educação, perpassam pela junção de normas e consequente surgimento de necessidades e reconhecimento desses Direitos, já admitidos por diversos documentos internacionais e, fomentados pela Agenda 2030. Com o intuito de diminuir a pobreza extrema e obter um mundo próspero, a Agenda inclui em seus objetivos para o desenvolvimento sustentável a necessidade da educação, bem como a redução das desigualdades. Dessa forma, tem-se como problemática a determinação do acesso de qualidade à educação em todos os níveis, bem como aos cuidados de saúde e proteção social assegurados. No entanto, diante do cenário de pandemia, uma indagação é necessária, como a Comunidade dos Países de Língua Portuguesa resgatará o crescimento qualitativo educacional para conseguirem cumprir a Agenda 2030? A atual situação mundial, com a economia global afetada, bem como a incapacidade de alguns países em controlar mortos e doentes pelo novo Coronavírus (COVID-19), impossibilita a continuidade da educação de qualidade, o que pode acarretar consequências severas para o cumprimento da Agenda. O objetivo do presente estudo é analisar os possíveis impactos provocados na educação em tempos de pandemia, um desafio dos tempos normais, e as formas para que a Agenda 2030 seja menos afetada. Ainda como possível hipótese, o que a Unesco apresentará como solução para recuperação desse tempo, sem que exista um comprometimento na validação do Direito à Educação. Assim, com base em análise bibliográficas, de forma descritiva-buscando observar, descrever, classificar e analisar, coletar dados sobre o objeto-problema e utilizando o método indutivo, o estudo percorrerá o caminho para uma assimilação jurídica coerente.

Palavras-Chave: Direito, Internacional, Escola, Agenda 2030, Pobreza.
Ana Cristyna Macedo L.S. Bosco

Doutoranda em Direito do Programa de Pós-graduação em Direito - PPGD-UNESA 
Ref.: 222CEDHM22020

\section{UNIVERSIDADE DE DIREITOS: EDUCAÇÃO, INFÂNCIA E JUVENTUDE}

Elaine Cristina da Silva,

Doutoranda - Universidade Federal de Minas Gerais

Adriana Goulart de Sena

Orsini,

Universidade Federal de Minas Gerais

Lucas Jeronimo Ribeiro

da Silva

Universidade Federal de Minas Gerais

\& Cibele Aimée de Souza

Universidade Federal de Minas Gerais
Tendo em vista as graves crises políticas e institucionais no Brasil, direitos humanos e sociais têm sido relativizados e negligenciados pelas diversas esferas do Poder Público. Uma expressiva parcela da população ainda se encontra excluída do acesso ao que se denomina de dignidade humana, demonstrando que a possibilidade do acesso à justiça pela via dos direitos ainda não é uma realidade para muitos cidadãos brasileiros. Assim, é preciso compreender, educar e formar para realizar as dimensões do acesso à justiça pela via dos direitos. A primeira delas se refere à garantia de efetividade dos direitos, que neste trabalho envolverá um dos seus pressupostos: a informação acerca destes. Na segunda dimensão, interessa a possibilidade de participação dos envolvidos na configuração do próprio direito. Sob a ótica da efetividade e nos limites deste trabalho, o acesso à justiça será atingido quando indivíduos, grupos e coletivos lesados tiverem a consciência e oportunidade de conhecer e de se informar acerca de seus direitos. Desta feita, as políticas no âmbito da informação, educação e divulgação de conhecimentos jurídicos, que visem a capacitar os cidadãos e as comunidades para, por si mesmos, perante uma situação de violação, exclusão ou privação de direitos, a reconheçam como tal é pressuposto fundamental para o acesso que se realiza pela via dos direitos. Quanto à educação pública brasileira, assolada pela precarização e ausência de investimentos que aprofundam as desigualdades educacionais e sociais, atores sociais resistem criando alternativas de caráter contra hegemônico e de proximidade com a comunidade. Nessa conjuntura, o presente trabalho científico destaca o locus preponderante e estratégico da Universidade Pública para a promoção da agenda de educação de qualidade até a década de 2030. Serão apresentadas ações de ensino, pesquisa e extensão desenvolvidas pelo Programa Acesso à Justiça e Solução de Conflitos da Faculdade de Direito da Universidade Federal de Minas Gerais sobre o acesso à justiça infantojuvenil pela via dos direitos e à promoção da cultura de paz e de não-violência junto à crianças e adolescentes. Para tanto abordar-se-á a) o acesso à justiça pela via dos direitos infantojuvenis; b) a contextualização do Estatuto da Criança e do Adolescente eo Estatuto da Juventude no Brasil, como marcos normativos de garantia dos direitos humanos; c) a apresentação de projetos realizados com o público universitário e com alunos de escolas públicas e d) a apresentação de resultados alcançados por meio de pesquisas acerca dos próximos passos da Universidade quanto à inserção da juventude brasileira no exercício da cidadania global, tendo como marcos teóricos, Paulo Freire, Boaventura de Sousa Santos e Leonardo Avritzer; Marjorie Marona e Lílian Gomes. Espera-se que tais iniciativas contribuam para o acesso à justiça pela via dos direitos, bem como inspirem outras fundadas na educação dialógica, transformadora e humanística.

Palavras-Chave: Acesso à Justiça Infantojuvenil, Direito da Criança e do Adolescente, Cultura de Paz, Não-Violência, Educação. 


\section{EDUCAÇÃO INCLUSIVA, EQUITATIVA E DE QUALIDADE: DESAFIOS PARA O ENSINO SUPERIOR EMTEMPOS DE COVID-19}

A desigualdade -em suas distintas faces e interconexões: socioeconômica, educativa, étnico-racial -sempre foi um abismo presente no ensino superior brasileiro, que vinha sendo minimizado pelas distintas políticas públicas e ações afirmativas implementadas nestas últimas duas décadas. Não obstante, com a crise sanitária e também política (no caso brasileiro) desencadeada pela Covid-19, o espectro da desigualdade tornou-se evidente novamente. $E$, no que concerne a assegurar a igualdade de acesso para todas as pessoas à educação formal básica, mas também, a educação técnica, profissional e superior de qualidade, gratuita e/ou a preços acessíveis, parece ser um, entre tantos outros Direitos Humanos reiterados na Agenda 2030 para o Desenvolvimento Sustentável das Nações Unidas (NU), que o atual Governo brasileiro, como Estado membro das NU, não pretende cumprir. A estas constatações estruturais deve ser adicionado o fato de que uma parte das(os) estudantes universitárias(os) tenham acesso mais facilitado à tecnologia do que outras(os) ou que algumas(alguns) professoras(es) se sintam mais confortáveis com a sua utilização do que outras(os), não pode ser uma justificativa para limitar as opções de acesso pleno a uma educação de qualidade somente para um grupo de privilegiadas(os). Ademais, são significativas as alterações, no que se refere às interações estudante-docente, que estão sendo idealizadas pelas instituições de ensino para manter as atividades acadêmicas em meio a necessidade de isolamento social. As análises que se pretende realizar, terão como foco a pesquisa online implementada pela Universidade Federal do Rio Grande -FURG junto ao corpo discente e na qual se averiguam, entre outras questões, suas condições socioeconômicas, às possibilidades/limitações de acesso remoto aos conteúdos de ensino e a assistência a aulas em modalidade EaD. A pesquisa em tela, buscará, com fundamento na teoria geral dos Direitos Humanos, descrever a diversidade da realidade estudantil, identificar as principais necessidades do alunado, bem como analisar as possíveis diretrizes que a FURG adotará para a retomada das atividades de ensino.

Palavras-Chave: Educação Inclusiva,

Equitativa e de Qualidade, Direitos Humanos,

Desigualdade, Isolamento Social, Ambientes

Virtuais de Aprendizagem (EaD).
Sheila Stolz

\& Daniel Berlezi

de Quadros

Universidade Federal do Rio Grande - FURG 
Catarina Sobral \& Ana Paula Caetano Instituto de Educação da Universidade de Lisboa

Ref.: 24ICEDHM22020

\section{O CONFLITO NO JARDIM DE INFÂNCIA COMO OPORTUNIDADE DE DESENVOLVER UMA CULTURA COLABORATIVA, DE MEDIAÇÃO E DE PAZ}

\begin{abstract}
O conflito é uma das bases relacionais pelas quais o dinamismo e a criatividade se desenvolvem e importa não o diabolizar como fenómeno a controlar e evitar a todo o custo. Através dele manifesta-se a diversidade e expressa-se a singularidade que tanto apreciamos quando valorizamos a pluralidade e quando defendemos a inclusão, a equidade e a democracia como princípios de construção edificador das nossas sociedades.
\end{abstract}

Assim sendo, importa que a educação se ocupe de favorecer processos construtivos e criativos de lidar com o conflito e de promover aprendizagens de gestão e de mediação desde a primeira infância. Neste sentido temos vindo a investigar sobre o conflito, sobre o papel dos educadores e professores na mediação do conflito e sobre a formação desses professores, dos auxiliares de educação, dos mediadores profissionais, das famílias e de crianças e jovens, em situações de educação formal e não formal. Investigação que, numa abordagem de investigação-ação, simultaneamente promove mudanças sentidas como necessárias pelos diversos atores sociais e através da qual se promove uma cultura de paz nos jardins de infância.

Esta comunicação baseia-se num duplo olhar: i) retrospetivo, refletindo sobre as investigações de mestrado e de doutoramento na temática da mediação de conflitos em contexto de educação de infância; e ii) prospetivo, refletindo ativamente sobre as questões: Estamos no caminho certo? / Ambições para a década de ação?
Releva-se a importância de um vasto leque de aspetos essenciais a considerar sob este tema: uma conceção positiva do conflito; a atuação intencional dos educadores, articulada com a dos auxiliares e que se pretende como de referência para os pais; e a indispensável disponibilidade da direção. Pretende-se evidenciar a importância da compreensão do fenómeno do conflito entre crianças no sentido da promoção da gestão/mediação de situações de conflitos enquanto oportunidades de aprendizagem socio-emocional desde tenra idade. E destacar a necessária sensibilização da comunidade educativa, educadores, auxiliares, pais e direção dos jardins de infância, num processo inclusivo, promotor da sã convivência social.

Na educação, em geral, e na educação de infância, em particular, é imperativa a abordagem transversal de todos os Objetivos de Desenvolvimento Sustentável (ODS). Documentos oficiais da União Europeia, Nações Unidas, ConseIho da Europa e Unesco, bem como a Convenção sobre os Direitos da Criança, acentuam a importância do acesso a uma educação inclusiva, de qualidade e equitativa, que promova saberes básicos dos cidadãos do século XXI, tais como a cidadania ativa e a gestão e/ou resolução de situações problemáticas e conflitos, numa perspetiva de educação para a paz. Deste modo, para esta comunicação, iremos focar-nos no objetivo 4 -Educação de Qualidade.

Palavras-Chave: Educação de Infância, Mediação Socioeducativa, Conflito, Cultura Colaborativa, Educação para a Paz. 


\section{ALFABETIZAÇÃO DE ADULTOS - UM DIREITO SILENCIADO}

A comunicação resulta de uma investigação mista, sobre o analfabetismo, realizada em Portugal, a partir da análise de dados estatísticos, das políticas públicas de educação de adultos e da perspetiva de adultos analfabetos. A análise, simultânea, destas três dimensões permite-nos compreender que o analfabetismo é um fenómeno complexo, resultante de fatores sociais, culturais e políticos, que tende a perdurar no tempo. O analfabetismo em Portugal, embora seja particularmente notório no grupo etário com idade superior a 65 anos, está presente em todos os grupos etários. A taxa de analfabetismo é maior nos territórios rurais e isolados geograficamente. As políticas públicas de educação de adultos têm contribuído para silenciar e tornar invisível o analfabetismo, pelo facto de não assumirem uma oferta de alfabetização de adultos, nas últimas décadas, adequada à dimensão e à complexidade do problema. Numa sociedade cada vez mais escolarizada, a persistência do analfabetismo revela um mundo injusto, onde as desigualdades são, com frequência, naturalizadas e silenciadas. O contacto com os analfabetos permite-nos perceber que a sua condição, resultante do contexto socioeconómico, é considerada pelos mesmos uma grande limitação na sua vida, geradora de um sentimento de tristeza que os acompanhou ao longo da vida, desde a infância até à velhice. Nesse sentido, a aprendizagem da leitura e da escrita revelou-se sempre um sonho por cumprir. Estes elementos reforçam a importância de se assegurar o direito à aprendizagem da leitura e da escrita a todos os cidadãos, independentemente da sua idade, através de uma política pública de alfabetização de adultos. $\mathrm{Na}$ investigação entendeu-se o analfabetismo como fenómeno social complexo, resultante de uma multiplicidade de fatores - culturais, económicos e políticos (CANÁRIO, 1999; FREIRE, 1992; LAHIRE, 1999). Partindo do pressuposto anterior, assumimos que o analfabetismo não depende de opções do indivíduo e da sua família, mas de elementos estruturais, o que permite um distanciamento crítico relativamente à perspetiva da responsabilização individual, que com frequência marca a discussão em torno desta problemática. Como se verifica em Portugal, o analfabetismo é um fenómeno social que "não obedece a padrões de uniformidade e aleatoriedade" (CANÁRIO, 1999, p.54), ao manifestar-se de uma forma expressiva nas regiões mais pobres, rurais e menos acessíveis, assim como em determinados grupos -as mulheres e os idosos. Os resultados desta investigação revelam que naturalização e o silenciamento do analfabetismo são processos concomitantes com a naturalização e o silenciamento da pobreza e das desigualdades sociais, tornando-se mais difícil que os próprios analfabetos reivindiquem ao Estado o seu direito para aprender a ler e a escrever.

Palavras-Chave: Analfabetismo, Alfabetização, Políticas Educativas, Adultos, Direito

À Educação.
Carmen Cavaco

Instituto de Educação da Universidade de Lisboa 
Ref.: 244CEDHMI 2020

\section{PARLAMENTO JOVEM \\ - ANÁLISE COMPARATIVA DOS PROGRAMAS DO BRASIL E DE PORTUGAL}

Vinicius Barbosa Albernaz
Realizada por diversas instituições legislativas no mundo, a simulação parlamentar através dos programas de educação para a democracia ou educação cívica tornaram-se casos de sucesso de ações de fomento da participação política dos jovens. O presente trabalho tem o objetivo de apresentar um estudo comparativo sobre os programas de educação para a democracia denominados "Parlamento Jovem" do Brasil e de Portugal, organizados pela Assembleia da República de Portugal e pela Câmara dos Deputados do Brasil. O percurso metodológico realizado através de um estudo descritivo numa perspectiva comparada levando em conta as diferenças existentes nos programas, mas ressaltando o objetivo comum a ser difundido: a educação para democracia. Pretende-se, e em maior grau, a percepção de como os programas de Parlamento Jovem estão contribuindo na formação política, cidadã e profissional dos jovens estudantes. A escolha do tema baseia-se na necessidade de contribuir na avaliação destes programas de Parlamentos Jovens, com vistas a desenvolver uma cultura política voltada à democracia cívica. A principal conclusão é de que, ao promover a educação para a democracia, amplia-se a confiança dos jovens nas instituições políticas e estimula-se o engajamento cívico, partidário, alterando o processo de desilusão e descontentamento da ação política.

Palavras-Chave: Participação Política, Parlamento Jovem, Educação, Democracia, Juventude. 


\section{DE MENORES A CRIANÇAS E ADOLESCENTES: AS CATEGORIAS MOBILIZADAS NA REDEMOCRATIZAÇÃO EMTORNO DA REGULAMENTAÇÃO DE DIREITOS INFANTOJUVENIS}

A regulamentação infraconstitucional dos direitos infantojuvenis na redemocratização brasileira deve ser compreendida como continuidade da promulgação da Constituição da República Federativa do Brasil de 1988, que pela primeira vez conferiu a crianças e adolescentes o status jurídico de sujeitos de direitos. Em abril de 1987, a população foi convidada a participar da produção da nova Carta Constitucional, elaborando 'Emendas Populares'. Organizações da sociedade civil e movimentos populares apresentaram a 'Emenda da Criança, Prioridade Nacional', que reuniu mais de um milhão de assinaturas. Demandados socialmente, os constituintes aprovaram, por unanimidade, o artigo 227 da Constituição, que estabelece prioridade absoluta para direitos de crianças e adolescentes.

A partir de então, o debate em torno da legislação infraconstitucional dos direitos infantojuvenis passa a sero foco da incidência política destes atores. Havia três possibilidades em disputa, a adequação do Código de Menores de 1979, a elaboração de um novo Código de Menores ou a elaboração do Estatuto da Criança e do Adolescente.

A metodologia adotada no presente trabalho consiste na análise de discurso, tendo como objeto os diários oficiais do Congresso Nacional da época, artigos e matérias na imprensa, e os arquivos da tramitação dos projetos de lei que estavam no cerne da disputa -a saber projetos de lei no Senado no 193/1989 e no 255/1989 e na Câmara 1506/1989 e 5172/1990. A partir desta análise, percebem-se movimentos de dois grupos da sociedade; um ligado ao trabalho de atendimento de crianças e adolescentes em situação de extrema vulnerabilidade -que também reunia acadêmicos e juristas; e outra formada por, em maioria, magistrados. Valendo-se de instrumentos clássicos daquilo que, posteriormente, se convencionou chamar advocacy, as ações destes grupos iam do diálogo direto com parlamentares, publicação de artigos e cartas na imprensa, participação em audiências públicas e nos debates realizados ao longo de toda a tramitação dos projetos de lei nas duas casas legislativas.

A disputa entre Código de Menores e Estatuto da Criança e do Adolescente, se dava não apenas na escolha dos termos "Código" ou "Estatuto", mas sobretudo ao termo de referência para os destinatários da lei "menores" ou "crianças e adolescentes". Tais categorias não são sinônimos, "Menores" são aqueles em situação de abandono ou em conflito com a lei. Mais de uma vez, os contornos políticos e sociais fundantes dessa diferença lexical ficaram explicitados em artigos e discursos que traziam à tona as categorias mobilizadas, os objetivos e sentidos atribuídos à legislação a ser criada.

Como resultado preliminar, indica-se a participação da sociedade civil como ponto fundamental nas disputas em torno das categorias apontadas e na aprovação de uma legislação que tem como destinatários todas as crianças e adolescentes e que reconhece a condição peculiar da pessoa em desenvolvimento e garante proteção.

Palavras-Chave: Direitos da Criança

e do Adolescente, Código de Menores,

Estatuto da Criança e do Adolescente, Incidência Política, Participação Popular.
Carla Baranzini Egydio

Faculdade de Filosofia Letras e Ciências Humanas da Universidade de São Paulo (USP)

\& Renata de Assumpção

Araujo

Consejo Latino Americano de Ciencias Sociales (CLACSO) 


\section{EDUCAÇÃO ARTÍSTICA, PARTICIPAÇÃO, ENVELHECIMENTO E DIREITOS CULTURAIS}

Clara Marques

Instituto de Educação Universidade de Lisboa
O envelhecimento e funcionamento do mundo ocidental como nos é dado a conhecer na contemporaneidade, coloca questões e desafios profundos à humanidade, exige reflexão e a reelaboração de novas abordagens.

Convocar e promover a participação dos cidadãos na descoberta e criação de soluções inclusivas para esta demanda, poderá talvez, colaborar na renovação do equilíbrio necessário não só funcional, mas também do bem viver. $A$ educação, a arte e a cultura são fatores vivos e dinâmicos das narrativas de desenvolvimento e normatização de todos os sistemas sociais e políticos, mas também assumem uma faceta desobediente e disruptiva na vivência desses processos que pode desmontar antigas aproximações ao que é disfuncional e rasgar novas e desconhecidas possibilidades rumo a uma sociedade convivial. A educação artística poderá pelo seu caráter cíclico de desconstrução-construção desempenhar neste cenário um papel preponderante na edificação de universos de diversidade em oposição à dominância das monoculturas. Uma abordagem realista sobre os direitos humanos diz também respeito às práticas suportadas pelas condições sociais, económicas e culturais das sociedades através das suas relações de poder, que analisadas podem contribuir para ampliar a voz de alguns grupos menos audíveis, num reforço positivo da vivência intercultural. Esta comunicação pretende apresentar a observação feita a um grupo de pessoas maiores de 55 anos a desenvolver um projeto de educação e intervenção artística na zona de Lisboa, com o objetivo de perceber de que forma a educação artística nesse contexto se apresenta como ignição para a reflexão e participação individual e coletiva, valorizando o património afetivo e material dos participantes, numa afirmação para si próprios, para o grupo e para os públicos envolvidos, dos seus direitos. A informação de carater qualitativo e crítico, foi recolhida através de entrevistas semiestruturadas, análise documental e audiovisual, observação participante e registo fotográfico, numa perspetiva artográfica, seguindo todos os procedimentos éticos. Os intervenientes consideraram a prática colaborativa das atividades desenvolvidas uma forma de ativação e participação efetiva na sua comunidade, estabelecendo ligações e redes de aprendizagem em grupo, na cocriação de objetos artísticos interdisciplinares, de valorização do património cultural local e na interação gratificante estabelecida com os diversos públicos. É destacado o estímulo, a dinâmica e o corpo do grupo como amplificador da potência participativa e também realçada a experimentação dos processos artísticos como eventos de aprendizagem, na fortificação dos direitos de expressão cultural. Este testemunho possibilita reconhecer as práticas educativas e artísticas, numa perspetiva de educação ao longo da vida, promotoras da democratização cultural e da participação da população idosa, potenciando a sua experiência, competência e criatividade, na reinvenção e promoção de sociedades mais inclusivas, equitativas, humanizadas.

\footnotetext{
Palavras-Chave: Educação Artística, Participação, Envelhecimento, Direitos Culturais, Inclusão.
} 


\section{¿PRESENCIALIDAD EN LA DISTANCIA? CONFINAMIENTO Y ALTERACIÓN DE VÍNCULO EN LA INTERVENCIÓN SOCIAL HACIA LOS NIÑOS, NIÑASY SUS FAMÍLIAS}

En Francia, el estado desempeña su papel en la educación de los niños y niñas, en primer lugar, a través de la escuela, pero también interviene en lo que sucede en la familia y en lo que se espera de los padres, madres y cuidadores, como prácticas educativas. Esta acción se inscribe en el marco de las políticas de protección de la infancia, que tienen por objeto proteger al niño o niña contra los abusos cuando se considera que existe un peligro o un descuido. Entre los dispositivos de protección, la intervención educativa en «entorno abierto»-que difiere mucho del trabajo que se realiza cuando el menor está en un alojamiento fuera de la familia-despliega un seguimiento por parte de trabajadores sociales, quienes supervisan en el hogar a las familias y los niños y niñas. Acompañando las practicas educativas de la vida cotidiana (sobre salud nutrición, por ejemplo) o de laescuela (trabajo escolar fuera del aula, vínculo con los profesionales de la escuela, orientación) el trabajo que se desarrolla, opera mediante intercambios, la mayoría de las veces cara a cara, entre los trabajadores sociales, los padres y los niños y niñas protegidos. Estos encuentros en presencial son más o menos regulares según la situación y los objetivos del trabajo establecidos por el juez y consisten en tiempos de control, intercambio, elaboración. Las medidas sanitarias introducidas en marso 2020 en Francia para reducir la contaminación por COVID-19 han limitado gravemente esas oportunidades de intercambio. Los trabajadores sociales se han visto obligados a trabajar en un primer tiempo a distancia, desplazándose únicamente para situaciones de crisis, y en un segundo tiempo, reprogramado citas presenciales que quedan de todas formas excepcionales y con medidas espaciales de distanciamiento físico. Esto ha dado lugar a profundas reconfiguraciones del trabajo de acompañamiento, haciendo que los profesionales se replanteen sus prácticas y cuestionen sus significados. Además, estas intervenciones suelen estar dirigidas a los sectores más precarios, cuyas vidas que ya vienen marcadas por las desigualdades, han visto agravada su situación debido al encierrohacinado. Basándose en los primeros análisis de un estudio etnográfico que hizo seguimiento al trabajo de Intervención a distancia de un equipo entre marzo y junio de este año, esta presentación quiere dar cuenta de las reconfiguraciones observadas en laspracticas que caracterizan acompañar a la distancia y de las consecuencias de la situación sanitaria en términos de desigualdades y reducción al derecho a la educación para niños y niñas.

Palavras-Chave: Distancia, Educación, Crisis, Desigualdades, Infancia.
Irene Pochetti

\& Benjamin Denecheau Université Paris Est Créteil UPEC, LIRTES EA 7313 (France) 


\section{PLANEJAMENTO DE POLÍTICAS PÚBLICAS EDUCACIONAIS PÓS-COVID E A NECESSIDADE DE ENFRENTAMENTO DA DESIGUALDADE ESTRUTURAL NO BRASIL}

Mariane Yuri Shiohara Lubke

\& Arlei Costa Junior

Pontificia Universidade Catolica Do Paraná
A pandemia do COVID-19 trouxe à tona parte das dificuldades existentes na implementação do objetivo do desenvolvimento sustentável n. 4, que propõe "Assegurar a educação inclusiva e equitativa e de qualidade, e promover oportunidades de aprendizagem ao longo da vida para todas e todos". A impossibilidade de continuidade das aulas presenciais, substituídas por aulas remotas, especialmente quando se analisa o sistema de ensino público, tem revelado várias mazelas pelas quais a sociedade brasileira, em especial, as camadas mais carentes passam. Desde a carência alimentar de crianças e jovens que, por vezes, tinham na escola sua única ou prioritária fonte de alimentação diária, até a impossibilidade de acesso às aulas remotas pela ausência à tecnologia da informação como equipamentos de informática (computador, telefone) e acesso à internet. A pandemia, neste viés, escancara uma das facetas da desigualdade estrutural brasileira. Algumas medidas emergenciais estão sendo adotadas pelo Estado para viabilizar a oferta de aulas remotas, tais como a contratação de canais de TV para transmissão das aulas e disponibilização de alimentos da merenda escolar às famílias dos alunos. Apesar de todos os esforços para que o ano letivo não seja prejudicado, o Estado não conseguiu superar o pano de fundo estrutural que a pandemia expôs: a ausência de políticas públicas educacio- nais pautadas no princípio da universalidade, garantindo o direito à educação a todos os alunos nesse período de pandemia. O objetivo do estudo é, a partir da deteção do problema na oferta de sistemas de ensino inclusivo, apontar que a atividade de planeamento do Estado neste momento de pandemia já deve se voltar para a formulação de políticas públicas educacionais para um cenário pós-COVID que possam superar as dificuldades atualmente experimentadas. Ressalta-se a importância de que esse planeamento não seja segmentado ou limitado à área educacional, mas que possa abranger igualmente setores como a infraestrutura/telecomunicações/tecnologia, saúde, alimentação, dentre outros elementos que integram o ciclo educacional de tantas crianças e jovens em nosso país. O método a ser utilizado é o hipotético-dedutivo, para que, a partir deste problema geral levantado, possa se buscar hipóteses que levem a construção de uma solução adequada ao ensino, "visando ao pleno desenvolvimento da pessoa, seu preparo para o exercício da cidadania e sua qualificação para o trabalho" (art. 206 da Constituição Federal). A função de planeamento do Estado é essencial para apontar novas perspetivas e traçar possíveis caminhos para a implementação de políticas públicas universais que assegurem o direito humano à educação.

Palavras-Chave: Pandemia, Educação, Desigualdade Estrutural, Planeamento, Políticas Públicas. 


\section{AÇÕES AFIRMATIVAS NA PÓS-GRADUAÇÃO STRICTO SENSU: PERCEPÇÕES DOS DISCENTES SOBRE A RESERVA DE VAGAS NO PROGRAMA DE PÓS-GRADUAÇÃO EM EDUCAÇÃO}

As políticas afirmativas no Brasil são responsáveis pelo ingresso crescente de setores da sociedade historicamente alijados das universidades e do ensino superior, como negros(as), indígenas, quilombolas, pessoas surdas e com deficiência, pessoas travestis e transexuais. Essas políticas também decorrem de lutas históricas destes setores que, entre outras justas reivindicações, apontam para o ingresso no ensino superior e a participação em espaços de produção do conhecimento.

O presente artigo apresenta as Ações Afirmativas criadas no Programa de Pós-Graduação em Educação da Universidade Federal do Rio Grande do Sul, refletindo sobre o processo de sua implementação, os dados referentes aos três primeiros processos seletivos e a perceção da primeira turma de egressos do mestrado, que responderam ao questionário on-line encaminhado pela Coordenação do Programa com perguntas compondo eixos de investigação, a saber: ingresso, permanência, egressos.

E tem como objetivo central mostrar as perceções dos egressos em relação ao sistema de reserva de vagas do programa, considerando o processo seletivo, a permanência e o impacto da formação após sua conclusão.

Metodologicamente nos valemos inicialmente de um banco de dados previamente construído pela Comissão de Ações Afirmativas no âmbito do programa de pós-graduação stricto sensu do PPGEDU/UFRGS, o qual já havia sistematizado dados de ingresso e permanência no período de vigência destas Ações (2017, 2018 e 2019), incluindo informações como os quantitativos de candidatos(as) e ingressantes, e tendo como base os relatórios anuais elaborados pela Comissão de Ações Afirmativas do Programa.

A partir destes documentos e informações organizamos uma listagem dos egressos 2017-2019. Concomitante a estes primeiros movimentos e proposição ocorreram reuniões com Coordenação do PPGED e Comissão de Ações Afirmativas para construção de uma pesquisa, atualmente em implementação por um grupo de professoras. Em uma demanda da Coordenação do programa com vistas a uma primeira avaliação realizada pelos egressos das reuniões realizadas trabalhou-se a partir da possibilidade de aplicação de um questionário on-line.

O formulário recebeu ajustes, pela compreensão da necessidade de uma análise da perceção dos egressos em relação ao sistema de reserva de vagas bem como a possibilidade de aprimoramento e institucionalização da Política de Reserva de Vagas no Programa de Pós-Graduação em Educação da Universidade Federal do Rio Grande do Sul.

Nesse sentido apresentaremos, informações, dados sistematizados ao longo destes anos, pela Comissão de Ações Afirmativas e informações produzidas acerca das perceções da primeira turma de egressos de Mestrado que ingressaram no Programa por meio de reserva de vagas, analisado as informações produzidas por meio do questionário on-line aplicado.

Palavras-Chave: Ações Afirmativas, Pós-graduação, Educação, Stricto-senso, Reserva de Vagas.
Márcia Esteves De Calazans \& Maria Aparecida

Bergamaschi

Universidade Federal Do Rio Grande Do Sul 
Ref.: 336CEDHMI 2020

\section{CONVERSAS DE MÃE EM REDE: UM PERCURSO NETNOGRÁFICO DO ATIVISMO DIGITAL MATERNO À BANCADA DE MÃES ATIVISTAS NAS ELEIÇÕES DE 2018}

Renata Garcia Senlle

Escola de Comunicações e Artes da Universidade de São Paulo
A pesquisa "Conversas de Mãe em Rede: um percurso netnográfico do ativismo digital materno à Bancada de Mães Ativistas nas eleições de 2018", se dedica a investigar os modos de usos das redes sociais pelas mães e de como esses meios impactam e proporcionam base para a organização de uma maternidade política e politizada, na qual as mães se tornam ativistas digitais maternas e candidatas às eleições 2018. Por meio de levantamento bibliográfico de referência, investiga-se questões que circundam o tema, como: as contribuições da cibercultura (LEVY, Pierre) e do ciberfeminismo (HARAWAY, Donna) para organizar as possibilidades de conexão em rede para as mulheres e seus impactos nas democracias avançadas (SUSSKIND, Jamie); as perspectivas históricas da maternidade em cada onda feminista (GARCIA, Carla Cristina) e de um feminismo para as mães (O'REILLY, Andrea); das interfaces entre o feminismo e as novas redes sociais digitais para a construção e desconstrução dos papéis sociais da mãe e da articulação delas com vieses políticos.

O estudo traz uma investigação exploratória de trabalhos do Brasil e do exterior, que se debruçam sobre o modo como as mães usam as redes sociais e de como esses meios propiciam uma outra forma de articulação, conexão, ativismo e influência. A investigação organiza as interações das mães em rede em quatro momentos de análise, marcados pela chegada de novas plataformas digitais e em comportamentos interativos com rituais particulares (NASSAR; FARIAS). São eles: "O Pessoal é Público": uma história social de mães brasileiras e os seus diários maternos em rede; "O pessoal é privatizado: mães blogueiras e influenciadoras digitais"; "O pessoal é político -Ativismo Digital Materno nas ruas, na rede e na academia", e, por último, "O privado é político e partidário -\#mãesnapolítica".

Aliado ao arcabouço teórico, utiliza-se como objeto de estudo a organização em rede das integrantes da Bancada de Mães Ativistas nas eleições de 2018, com investigação que utiliza da metodologia netnográfica (KOZINETS,Robert). Observa-se as fan pages dessas 11 mulheres-mães candidatas da 'Bancada de Mãe Ativistas' no Facebook e das descrições que fazem delas mesmas na seção "Sobre", o que traz a possibilidade de verificar como utilizam do conceito de "autodefinição" (COLLINS, Patricia Hill) quando dizem de si mesmas e se descrevem, ou não, como: mães, feministas e ativistas. A investigação visa contribuir com o entendimento das redes sociais digitais como espaço de articulação e empoderamento cidadão (CASTELLS, Manuel)e a multiplicação de vozes de novas identidades à luz de conceitos como ciberfeminismo (HARAWAY, Donna), do feminismo matricêntrico (O'REILLY, Andrea) e ativismo digital materno (SOARES, Ana Paula) como meio de proporcionar novos regimes representativos edemocráticos, bem como novas identidades e narrativas em disputa para as mães. 0

estudo contribui para as intersecções entre os campos da comunicação, de gênero e da política.

Palavras-Chave: Mães Blogueiras, Mães Influenciadoras, Ativismo Digital Materno, Ciberfeminismo, Ciberfeminismo. 
Ref.: 338CEDHM22020

\section{EDUCAÇÃO E DIREITOS HUMANOS: PERSPECTIVAS PARA UM NOVO TEMPO COM MAIS IGUALDADE}

Esse trabalho parte de uma revisão bibliográfica contundente, sobre a importância do estudo fundamental e sua aplicação dos Direitos Humanos no campo da educacional. Buscamos em educadores internacionais que eram conscientes e solidários sobre o tema e sua importância como Paulo Freire (1982, 1998), Dewey (2004), Saviani (1984, 1989) e também teóricos do campo dos Direitos Humanos como Miranda (2006), Soares (2006), Marshall (1976). Pretendemos organiza essa relação dentro do contexto brasileiro com suas leis e decretos federais. Na Declaração Universal dos Direitos Humanos, a educação aparece não apenas como um direito, mas também como um meio para que se alcance os objetivos propostos no documento. Em seu preâmbulo, ela pede que cada indivíduo e cada órgão da sociedade, se esforce, através do ensino e da educação, por promover o respeito a esses direitos e liberdades. A escola, como instituição de referência na educação e central na formação dos indivíduos, não pode abrir mão do debate, prática, promoção e garantia dos direitos humanos. A instituição só conseguirá cumprir seu papel se olhar para este tema. O papel da educação em direitos humanos é capacitar o homem a desenvolver suas habilidades, potencialidades e sua consciência crítica. Em decorrência disto, torna-se consciente de seus direitos e de sua atuação social superando o caráter de reprodução predominante nos sistemas educativos postos. A educação para os direitos humanos é uma educação comprometida com a mudança, possibilitando ao homem a prerrogativa de atuar como condutor de seu conhecimento, fazendo desta educação seu instrumento de luta e superação das injustiças, opressões e exclusões. Assumindo o caráter libertador em relação à opressão de um sistema educacional alienante, faz-se necessário criar condições com dignidade, para o questionamento e a criticidade acerca da realidade vivenciada para que os sujeitos se conscientizem de seu papel, e o assumam frente às necessárias transformações sociais. Direitos humanos é uma expressão que abrange diversas conceções e abordagens, em torno de um conjunto de direitos que fazem parte da própria natureza humana e da dignidade a ela inerente. A proteção a tais direitos é resultado de um lento processo histórico que foi se reconhecendo legislativamente a partir dos imperativos sociais postos ao longo do tempo e nunca esteve dissociado das relações educativas desde a mais tenra idade. No entanto, embora o reconhecimento dos direitos humanos e sua consequente positivação em algumas regulamentações, como a Declaração Universal dos Direito Humanos, tenham se expandido ao longo dos anos, ainda vislumbram-se constantes afrontas a tais direitos evidenciando-se a necessidade de constante observância dos dispositivos postos visando o respeito e a garantia de proteção a todos em suas diversidades, valorizando a sua importância no campo educacional.

\footnotetext{
Palavras-Chave: Direitos Humanos, Educação, Cidadania, Formação de Professores, Globalização.
}

Juliano Bernardino de Godoy 
Ref.: 353CEDHMI 2020

\section{EDUCAÇÃO PARA A CIDADANIA DIGITAL EM ESCOLAS EUROPEIAS: DATEORIAAO TERRENO}

Vitor Tomé

Universidade Autónoma de Lisboa CIES - Instituto Universitário de Lisboa
Este artigo centra-se nos resultados de um estudo exploratório desenvolvido, entre outubro de 2019 e junho de 2020, em escolas de cinco países europeus (Eslovénia, França, Portugal, Turquia e Ucrânia), no âmbito do projeto "Educação para a Cidadania Digital, implementado pelo Conselho da Europa.

Iniciado em março de 2016, o projeto fez o levantamento de estratégias internacionais e nacionais de formação de cidadãos, de boas práticas e sua avaliação, além de recursos teóricos ('Digital Citizenship Handbook', 2019; 'DCE -Trainers' Pack', 2020), e criou recursos pedagógicos. Criou ainda uma rede de especialistas nacionais, de 25 países europeus, cuja colaboração foi essencial no estudo exploratório.

De acordo com a literatura produzida pelo projeto, ser cidadão digital consiste em ter a "capacidade de envolvimento positivo e competente com as tecnologias (criar, trabalhar, partilhar, socializar, investigar, jogar, jogar, comunicar e aprender); participar de forma ativa e responsável (valores, capacidades, atitudes, conhecimento e compreensão crítica) em comunidades (local, nacional, global), a todos os níveis (político, económico, social, cultural e intercultural); estando envolvido num processo de aprendizagem ao longo da vida (em contexto formal, não-formal e informal); defendendo os Direitos Humanos e a dignidade humana" (Frau-Meigs, O’Neill, Soriani e Tomé, 2017).

Esta definição tem como base as competências e cultura democrática (Conselho da Europa, 2018), organizadas em quatro grupos: valores, atitudes, capacidades, conhecimento e compreensão crítica. Desenvolver estas competências implica políticas, atores, estratégias, infraestruturas/recursos e instrumentos de avaliação, que possam atuar nos 10 domínios da Cidadania Digital: Acesso e inclusão; Aprendizagem e Criatividade; Literacia dos media e da Informação; Ética e empatia; Saúde e bem-estar; Presença online e comunicação; Participação ativa; Direitos e Responsabilidades; Privacidade e Segurança; Consumo informado.

As escolas, do Pré-escolar ao Secundário, num máximo de 10 por país, poderiam escolher atuar num ou em mais domínios. Os docentes tiveram acesso a um mini-curso online (criado pelo projeto) e beneficiaram do apoio do especialista nacional. Criaram as atividades, implementaram-nas e reportarem sobre elas, apresentando evidências e resultados.

Apesar da mudança abrupta das atividades letivas presenciais para o regime de ensino de emergência a distância, alunos e professores concretizaram atividades que consistiram na criação de produtos digitais (sítios web, jogos, cartazes, vídeos...). Os resultados mostram que o ensino de emergência a distância criou dificuldades (ex: acesso, inclusão), mas também oportunidades (ex: criatividade, intercâmbios internacionais). Mostram ainda que as atividades de Cidadania Digital ajudaram, pelo menos em alguns casos, a que o ensino de emergência a distância se tornasse uma experiência mais motivadora e enriquecedora em termos de aprendizagens.

Palavras-Chave: Cidadania Digital, Competências de Cultura Democrática, Direitos Humanos, Professores, Alunos. 


\section{MEDIAR PARA EDUCAR: MEDIAÇÃO, CONCILIAÇÃO, MINDFULNESS NAS ESCOLAS OPR MEIO CÍRCULOS EM MOVIMENTOS}

A mediação, conciliação, mindfuless com aplicação dos métodos círculos e movimentos nas escolas tem expandido horizontes em diversos países, como um modelo multifacetário de solução de conflitos. Os contornos basilares que permeiam esses novos mecanismos resolução de conflitos na justiça em âmbito mundial, opta em empondeiramento (empowerment) das partes na solução da divergência criadas por elas. A realização árdua de interpretar as possibilidades hodiernas de transformar a realidade social através da mediação e conciliação, acentua-se em um plano maior, com uma visão holística, focada no futuro, em alcançar a pacificação em um âmbito social, e com reflexos benéficos e incalculáveis no mundo social, jurídico, económico, cultural e educacional. Opta-se então, por coroar a criança, e sua capacidade cognitiva de aprendizado eficiente e eficaz na constituição do seu próprio ser como agente de transformação social, possibilitando por meio da educação a compreensão da mediação e conciliação, mindfulness por meio do método de círculos e movimentos no início do desenvolvimento da aprendizagem escolar, como forma de resolver os conflitos escolares, colaborando diretamente para autodeterminação da criança na solução das pequenas divergências cotidianas, convergindo para adultos tolerantes e com capacidade de desenvolver a pacificação social através de um tratado de paz assimi- lado na infância. Oportuno salientar que disseminá-los seria a mola propulsora da pacificação social como cultura na sociedade, educação é um dever de todas as áreas do conhecimento, dentro da multidisciplinariedade e interdisciplinaridade estabelecida entre sociedade, educação, segurança, saúde, cultura, com propósito de promover o bem-estar social através dos desenvolvimentos de competências para resolução dos conflitos sociais cotidianos. A extensão da evolução e a inserção da mediação, conciliação, mindfulness nas escolas, a princípio, é difícil de ser medida, tendo em vista que estaria proporcionalmente relacionada à sua real aplicabilidade prática, ou seja, os esforços de todos os envolvidos acarretariam em quebra de paradigma, em uma nova cultura e conhecimento sobre conflitos, aprimoraria a capacidade do indivíduo em solucionar seus próprios conflitos através da autocomposição, proporcionaria indivíduos mais conscientes de seu papel como agentes no contexto social. Assim, para o desenvolvimento do presente trabalho, a metodologia utilizada foi o hipotético-dedutivo, com foco em elencar as formulações teóricas trazidas pela literatura existente acerca dos temas, em um ambiente multidisciplinar, interdisciplinar, transversal e transfronteiriços.

Palavras-Chave: Educar, Mediar, Meditar, Conciliar, Pacificar a Sociedade do Futuro.
Milena de Bonis Faria

Universidade Autónoma De Lisboa 


\section{A JUDICIALIZAÇÃO E O COMBATE ÀS DESIGUALDADES SOCIAIS: AÇÕES AFIRMATIVAS DE ACESSO AO ENSINO SUPERIOR À LUZ DA ANÁLISE JURÍDICA E SOCIOLÓGICA}

Andréa Arruda Vaz,

UniBrasil e Unifaesp

Andressa Ignácio da Silva Unifaesp

\& Tais Martins

UniBrasil e Unifaesp
Este artigo apresenta o conceito de igualdade formal e material, sob o viés do direito e da sociologia. Tal pesquisa perpassa o instituto da judicialização e políticas afirmativas quando o assunto é o acesso ao ensino superior e o eixo temático quatro da agenda 2030 para um mundo melhor. Ademais, em uma constituição moderna como é a constituição brasileira de 1988 é importante que os preceitos democráticos e de igualdade, para além da previsão no texto constitucional, permeiem a sociedade de forma concreta, efetiva e inclusiva. Quando o assunto é a acessibilidade ao ensino superior, importante é a atuação do Poder Judiciário no país. Ademais, é por meio de demandas judiciais que em muitos momentos da história da sociedade brasileira, houve a efetivação de direitos e garantias fundamentais, inclusive educação. Assim sendo, age o poder judiciário de forma ativa e protagonista, mediante provocação, determinando a implementação de direitos e garantias fundamentais, como elemento essencial de um Estado Democrático. Este artigo, tem como objetivo, apresentar os principais elementos para combater a desigualdade social no sistema educacional, cuja pesquisa será bibliográfica e na metodologia indutivo dedutivo. A pesquisa perpassa os vieses jurídico e sociológico, propondo uma reflexão a respeito da necessidade de judicialização de temas que embora comportem uma igualdade formal, permeiam o campo do material sob a vértice da exclusão e da segregação. Ainda, apresentará os principais elementos fundamentadores e a essencialidade das políticas afirmativas, quando o assunto é assegurar o acesso ao ensino superior. Ao longo do tempo os sistemas de inclusão ao ensino superior proporcionam distanciamento daqueles que não possuem uma condição privilegiada na sociedade, em regra. A igualdade não pode ser um mero texto constitucional de praticidade morta ou inalcançável do ponto de vista material. Ademais, a lei pela lei é uma simples sensação de direito, ademais ao negro, ao pobre e ao índios, exemplicativamente, o que muda a sua condição de vida, é a possibilidade de acesso as universidades. Tal acesso, diga-se de passagem, em regra deverá ser em universidades públicas, dada a desigualdade material existente entre tais minorias. Logo, quando o assunto é a efetivação do direito, cabe ao Estado e especialmente ao Poder Judiciário, determinar políticas que de fato proporcionem o acesso igualitário a educação. Não se pode falar em igualdade entre desiguais, mas se pode mudar o curso da história, proporcionando igualdade dentro da desigualdade! Enfim, um sistema igualitário é aquele que contempla aos vulneráveis acesso de forma equivalente aos direitos e garantias fundamentais. Cada indivíduo, dentro da sua particularidade!!

Palavras-Chave: Judicialização, Ações Afirmativas, Desigualdade, Educação, Inclusão. 
Ref.: 204CEDHMI 2020

\section{JOVENS CIENTISTAS:}

\section{A PROMOÇÃO DE GÊNERO NA CIÊNCIA A PARTIR DO PROGRAMA DE INICIAÇÃO CIENTÍFICA NO INSTITUTO FEDERAL GOIANO}

O Instituto Federal Goiano (IF Goiano) faz parte da Rede Federal de Educação Profissional e Tecnológica, cuja história remete há mais de 100 anos de política de educação profissional no Brasil. As suas atividades iniciais eram voltadas para as "classes desprovidas" e hoje se configura como uma importante estrutura para que todas as pessoas tenham efetivo acesso às conquistas científicas e tecnológicas. O IF Goiano é uma autarquia federal detentora de autonomia administrativa, financeira, didático-pedagógica e disciplinar, equiparado às universidades federais brasileiras. $O$ estudo tem como campo de investigação o campus Ceres, que atende cerca de 1700 estudantes nos cursos tecnológicos integrado ao ensino médio, além de licenciaturas, bacharelados e programas de pós-graduação. Com o objetivo de incentivar a preparação de novos pesquisadores e profissionais diferenciados, por meio da aprendizagem de técnicas e métodos de pesquisa, do desenvolvimento do pensar científico e da criatividade, o campus Ceres participa de programas institucionais que visam à Iniciação Científica (IC). Os programas são constituídos pelas modalidades: Programa Institucional de Bolsa de Desenvolvimento Tecnológico e Inovação (Pibiti), Programa Institucional de Bolsa de Iniciação Científica (Pibic) e Programa Institucional Voluntário de Iniciação Científica (Pivic), para estudantes de cursos superiores, e Pibic-Jr e Pivic-Jr para estudantes de cursos de nível médio. A partir da problematização da questão de gênero na ciência, tomamos como pressuposto o fato histórico que a ciência sempre foi vista como uma atividade realizada pelos homens. O Programa de Vocação Científica (Provoc), da Fundação Oswaldo Cruz, é considerado o primeiro programa brasileiro a inserir o estudante de ensino médio no ambiente de pesquisa. O programa é um referencial para o estudo da participação das mulheres na ciência, pois as jovens superam em número os rapazes desde a sua criação, em 1986. Contudo, é necessário questionar o fato de que, mesmo que a presença das mulheres na ciência seja maior, ainda existem impedimentos para que elas participem dos centros de decisão, dos escalões superiores na ciência e na tecnologia. Nos últimos dois ciclos de IC do IF Goiano -campus Ceres (2019-2020 / 20202021), foram aprovados 130 projetos, sendo 62 jovens pesquisadores do sexo masculino e 68 femininos. Destes projetos, 15 propostas de investigação estão diretamente voltadas para pesquisas no campo das questões de gênero, que, a partir das experiências e interesses de pesquisa dos estudantes, buscam respostas para problemas de gênero na educação, no mundo do trabalho, violências e preconceitos na escola e fora da escola. A partir de entrevistas identificamos os interesses, as motivações e dificuldades na IC, e como esta experiência impactou na formação escolar, na definição ou redefinição das escolhas acadêmicas e/ou profissionais futuras dessas jovens pesquisadoras.

Palavras-Chave: Gênero, Educação, Ciência e Tecnologia, Desigualdade, Inclusão.
Marcelo de Luz Batalha Instituto Federal Goiano 
Ref.: 258CEDHMI 2020

\section{“DIREITOS HUMANOS E EDUCAÇÃO”: CONCEITOS E CONTEXTOS}

Susana Sardinha Monteiro,

IJP-IPLeiria, ESECS

Politécnico de Leiria

Jenny Sousa

CICS.Nova.IPLeiria, Cl\&DEI,

ESECS-Politécnico Leiria

\& Antónia Barreto

ESECS - Politécnico de Leiria
Proclamados no rescaldo da II Guerra Mundial, as razões que ditaram o reconhecimento dos Direitos Humanos são tão válidas hoje, como eram em 1948. Enquanto existir, nalgum lugar do mundo, uma pessoa silenciada e impedida de expressar a sua opinião, uma mulher violentada, uma criança abusada; enquanto existirem atentados à vida, à liberdade - nas suas mais variadas manifestações - importa educar e consciencializar para os Direitos Humanos.

Reconhece-se, desta forma, o papel essencial da Educação na promoção desses direitos e responsabilidades, na promoção dos valores fundamentais da democracia, dos Direitos Humanos e do Estado de Direito.

A Educação para os Direitos Humanos constitui uma prática participativa com o objetivo de mobilizar pessoas e comunidades; capacitá-las com os conhecimentos, as atitudes, os valores e as aptidões necessárias para usufruírem e exercerem esses direitos e para respeitarem e defenderem os direitos dos outros. Esta capacitação faz-se através do conhecimento e da educação levando-as a atuar, tanto através das suas ações individuais como através de ações coletivas.

Educar para os Direitos Humanos e para a Cidadania constitui o propósito central da Unidade Curricular (UC) de "Direitos Humanos e Educação", inserida no $1 .^{\circ}$ ano da Licenciatura em Educação Social da Escola Superior de Educação e Ciências Sociais do Politécnico de Leiria. Pretende-se promover o conhecimento do que são os Direitos Humanos, do seu significado, dos valores, princípios e instrumentos que os apoiam e prote- gem, da sua importância e incidência em contextos genéricos e específicos, neste caso, contextos educativos e sociais. Precisando, pretende-se refletir sobre a importância do Direito à Educação como direito e fator fundamental para o desenvolvimento integral de toda e qualquer pessoa, que se revela imprescindível para a consolidação dos outros Direitos Humanos. Mais ainda, pretende-se contribuir para a formação de pessoas responsáveis, autónomas, solidárias, que conhecem e exercem os seus direitos e deveres, em diálogo e no respeito pelos outros.

As metodologias utilizadas na lecionação da UC são diversificadas, de modo a envolver a participação ativa dos estudantes. Compreende a realização de trabalho autónomo estimulando a capacidade de pesquisa, seleção, interpretação e utilização da informação na produção fundamentada de juízos relativos a Direitos Humanos e a situações de educação com eles relacionados. Nos últimos anos letivos e tentando focalizar a investigação, tem sido proposto aos estudantes a realização de um trabaIho de investigação, perspetivando a aplicação em contexto, de um dos 17 ODS e/ou das 169 metas previstas na Agenda 2030 para o Desenvolvimento Sustentável.

Tem este texto o propósito de discorrer sobre a prática na lecionação da UC de "Direitos Humanos e Educação": os respetivos conceitos e os contextos concretos em que se desenvolve o processo de ensino/aprendizagem.

Palavras-Chave: Direitos Humanos, Educação, Educação para os Direitos Humanos, Educação para a Cidadania, ODS. 


\section{ESCOLA 2030:}

\section{A AGENDA 2030 DA ORGANIZAÇÃO DAS NAÇÕES UNIDAS APLICADA EM UMA ESCOLA PÚBLICA DO DISTRITO FEDERAL, BRASIL}

A Organização das Nações Unidas (ONU) é uma organização internacional que, dentre muitas outras atividades, busca garantir os Direitos Humanos em todos os países, sem distinção de nacionalidade, etnia, gênero, orientação sexual ou qualquer outra característica pessoal. Com esse intuito, foi criada a Agenda 2030, documento em que todos os signatários se comprometem a realizar ações que garantam a aplicabilidade dos Direitos Humanos para todos. Os Direitos Humanos são direitos inerentes a todos os seres humanos e são discutidos em vários âmbitos. Inclusive, é de fundamental importância que eles também sejam discutidos nas escolas, principalmente nas escolas públicas das periferias do Brasil. É fato que as comunidades mais carentes sofrem por falta de informação e por problemas sociais e culturais, como o machismo, racismo, homofobia e pouco acesso à educação de qualidade. As escolas públicas do Distrito Federal, e do Brasil como um todo, carecem de atividades e eventos que abordem o tema Direitos Humanos; assim, o projeto ESCOLA 2030 surgiu, trazendo os temas propostos na Agenda 2030 para o âmbito local. Além de dis- cutir sobre Direitos Humanos, o projeto objetiva oportunizar aos jovens do primeiro ano do ensino médio a falarem e expressarem as suas questões pessoais, familiares e suas percepções sobre os problemas vividos na escola, na comunidade em que vivem e na sociedade como um todo em um ambiente amistoso, descontraído e disposto a ouvi-los. Exercendo esse trabalho de escuta ativa, os jovens são incentivados a se expressar e a pensar no que eles podem fazer para solucionar esses problemas. Isso só será possível por que o projeto ESCOLA 2030 prevê um momento de capacitação em elaboração de projetos. Por fim, o ESCOLA 2030 teve como objetivo empoderar os jovens e capacitá-los a realizar projetos que busquem minimizar, e até mesmo acabar, com os problemas vividos por eles na escola e em sua comunidade.

Palavras-Chave: Escola 2030, Agenda 2030, Educação, Escola Pública, Protagonismo Juvenil.
Mauricio Rodrigues Peixoto UNODC Brasil - Programa Embaixadores da Juventude 
Ref.: 300CEDHM42020

\section{ELABORAÇÕES DA ESPERANÇA: DIREITOS HUMANOS E SOCIOLOGIA NA EDUCAÇÃO BRASILEIRA}

Sabrina Cesar Freitas

Escola de Educação em Direitos Humanos (ESEDH/SEJUF-PR)

\& Simone Meucci

Universidade Federal do Paraná
Neste artigo analisamos dois projetos de ação educacional delineados no Brasil. Debruçamo-nos, particularmente, sobre a constituição da Educação em Direitos Humanos (EDH) durante o período de 1987 até 1995 e a introdução da Sociologia no Ensino Médio entre os anos de 1996 e 2008. Buscamos compreender, pois, as justificativas e sentidos atribuídos ao ensino desses conteúdos durante o período de construção da institucionalidade democrática brasileira. Em grande medida, apesar de não serem acontecimentos coetâneos, encaramos esses processos como expressivos do valor atribuído à conteúdos e disciplinas escolares no processo de redemocratização (Bendix, 377). Rigorosamente, não foram os mesmos agentes que sustentaram os dois projetos. No início, a construção da EDH foi articulada por agentes ligados à Comissão Justiça e Paz de São Paulo (CJPSP) -instituição ligada à Arquidiocese de São Paulo dedicada a defesa dos direitos humanos -, ao passo que aqueles responsáveis pela introdução da Sociologia na Educação Básica estavam reunidos em torno da Federação Nacional dos Sociólogos de São Paulo.
Todavia, ambos grupos demonstram um sentimento comum marcado pela esperança de que a ação educacional tinha capacidade de instituir valores e sentimentos considerados imperativos para a democracia recém estabelecida. A fim de reconhecer e matizar os ideais educacionais que inspiraram estes projetos, acionaremos, para essa interpretação, os documentos do fundo documental da CJPSP e os pareceres na Câmera de Deputados, Senado e Conselho Federal de Educação. Com efeito, atravessados pela promulgação da Constituição (1988) e depois da LDB (1996), ambos os processos revelam os esforços de construção, via educação, de uma socialização para a democracia e de um novo padrão de civilidade.

Palavras-Chave: Pensamento Social, Pensamento Educacional, Democracia, Sociologia, Educação em Direitos Humanos. 


\section{DESCALÇOS NA SOLEIRA DOS NOVOS TEMPOS: FORMAÇÃO E OUTROS TEMAS EM EDUCAÇÃO HUMANISTA DE BASE FENOMENOLÓGICA}

Em dois termos latinos encontro a essência da Educação, educare e educere, o primeiro, no sentido externo, de orientar, nutrir e decidir, fenômeno humano que alcanço quando levo uma pessoa de um ponto a outro que se deseja alcançar; e o segundo, de dentro para fora, emana da experiência existencial e das potencialidades criadoras do indivíduo. Em seu sentido radical o educere extrapola os limites das instituições formais pela sua imanência nas relações entre as pessoas, seus modos de ser, criar e recriar mundos. A sua raiz é o seu complexus, ou o que está tecido junto, o que implica pensar a sua realidade de forma conjuntiva (MORIN, 1991). À luz da abordagem fenomenológica posiciono o debate sobre a formação integral da pessoa humana a partir de dois pontos de vista distintos, mas imbricados: o acadêmico e o humano-espiritual. Formação, do latim formatio, ou ação e efeito de se formar e dar forma, é a meta a ser alcançada pelo ser humano, revelado por meio de sua individualidade, liberdade, espiritualidade, empatia e intersubjetividade (HUSSERL, 2006; STEIN, 2003; BELLO, 2000). Para me embrenhar na formação do ser e de sua pessoalidade, inspirada nos princípios fenomenológicos, preciso me descalçar dos "sapatos sujos" do espírito antropocêntrico da modernidade, cujos fins racionalistas e individualistas colocam o humano como fundamento e centro de todas as coisas, gerando um pensamento superficial, incapaz de se abrir para uma experiência existencial (COUTO, 2005). O homem moderno perdeu o encantamento pelo mistério da vida, sendo a sua individualidade o último mistério que nenhum homem poderá penetrar plenamente (STEIN, 2003), com isso, se tornou ele mesmo impermeável para as coisas do espírito, dificultando a possibilidade de "ser mais" em um mundo em construção. "Ser mais", no sentido freiriano (FREIRE, 1987), indica a potencialidade transformadora dos sujeitos ao se abrirem ao mundo pelas vias da educação, fenômeno existencial que se desenvolve ilimitadamente no transcorrer da vida em comunidade. Para se desenvolver plenamente em sua individualidade, o sujeito inacabado precisa ser formado em comunidade (STEIN, 2003; BELLO, 2000,2006 ), a qual vai se (de)formando frente as singularidades pungentes que caracterizam o dinamismo da vida social. Neste movimento, é preciso se colocar descalço na soleira dos novos tempos, vislumbrando uma formação integral da pessoa, em suas singularidades e potencialidades, cuja tarefa é de se apropriar da bússola que permitirá navegar nesses novos tempos de incertezas, de riscos e perigos, porém com perceção clara de seu devir, o que permitirá alcançar a meta última da Educação, qual seja, a autoeducação. Eis o intento de Educação Humanista de base fenomenológica!

\footnotetext{
Palavras-Chave: Fenomenologia, Educação

Humanista, Formação, Individualidade,

Autoeducação.
}

Jeani Delgado Paschoal

Moura

Universidade Estadual De Londrina 


\section{THE POTENTIAL OF MASS COMMUNICATION IN THE FORMATION OF AN INCLUSIVE CULTURE IN EDUCATION}

Chudnovskaya Irina

Lomonosov Moscow State University, Moscow, Russia
Education is the social institution with which any member of society deals in one way or another. The educational sphere is a reflection of social relations inherent in a particular society, with the system of views on the hierarchy of rights that has developed in it. International regulatory documents are aimed at minimizing existing social gaps, while the regulatory framework of individual states focuses on their own specifics. As the content analysis of Russian regulatory documents has shown, for historical and social reasons in Russian practice, inclusion implies, first of all, an attitude towards persons with disabilities.

Inclusive education involves the in-depth development of at least three components: inclusive policies, inclusive activities, and inclusive culture. These components are mutually dependent, but if the former are developed mainly by the state and public organizations, then an inclusive culture is associated with a broad public opinion and attitude, which, as practice shows, in reality can act as a powerful barrier to the implementation of the first two components. This circumstance leads to the conclusion that it is necessary to create a theory of inclusive culture, especially in the field of education.

Building an inclusive culture in a society means continuously working to establish and maintain inclusive values and stereotypes that are generated either as a result of personal experience or through mass communication. In the proposed work, mass media were analyzed in three functional aspects: as a means for informing, for cultural impact, and for social communication. Qualitative content analysis of Russian media texts showed a correlation between the dominant stereotypes of persons with disabilities (victim / hero) and the main models of inclusion: segregation, integration, and social inclusion.

Based on the methodological basis of the hypothesis of cultivation and the agenda setting, the article considers the representation of the topic of inclusion in TV programs and in new media in a comparative manner. It is concluded that social interest in the issues of inclusion, in particular in the field of education, has increased according to the principle of "other-alien". It is shown that mass communication in its traditional institutional form and in a new form of mass self-communication (M. Castells) is capable of forming an inclusive culture that determines the realization of equal rights in the field of education.

Keywords: Inclusive Culture, Education, Persons with Disabilities, Mass Communication, Social Stereotypes. 


\section{“BE AWARE STUDENT: BUSINESS MODEL - I, PASSIONATE IT PROFESSIONAL"}

The project n.:2018-1-PL 01-KA203051137, from Erasmus + Programme, Key Action 2: Strategic Partnerships for higher education has the intention to Increase student awareness of specialty choice; improve the level of student entrepreneurship; and minimizing the competence gap between curricula and labour market requirements. In this way the computer science major students (and related) have to attend the training course "Business Model -I, Passionate IT Professional". The mail goal is to develop skills of individual planning of the educational path and future professional career using the Design Thinking framework, supporting techniques that develop creativity and entrepreneurship as well as thinking in terms of a personal business model. The specific objectives are: 1) transfer knowledge about the process, techniques and tools for planning the education path, and a vision of professional development based on the specificity of the working environment and requirements for the future profession (job position or group of job positions) with emphasis on the social responsibility; 2 ) to develop skills in the use of techniques supporting the discovery of own interests, abilities and passions, as well as determining the relationship between character traits and the specificity of the job position, which significantly affect the level of job satisfaction and professional fulfillment; 3) to develop skills in the use of business model canvas and personal business model canvas techniques in the process of planning and designing the educational path and professional career. As part of the project, each student individually develops the selected canvas of a personal business model and prepares, based on online resources (advertising services, movies, papers, industry reports), analysis of the market potential of selected job position (group of job positions). Students prepare an outline of the plan of his/her educational path, indicating the subjects of greatest importance for professional development and the major that he/she would like to select. An important element of the project is also an analysis of strengths and weaknesses in terms of skills and areas of knowledge, as well as a plan for the development of weak areas by using the resources offered by the university (e.g. students research groups, scholarship programs, open lectures). On successful completion of this course, students will understands the need for continuous learning and developing professional, personal and social competences. The students will be able to freely use the concepts and ideas related to work, career planning, social responsibility of employees and organizations as well as techniques used in planning the path of education and professional development. Second, students will be able to use techniques to identify and analyze his/her interests, passions, abilities.

Keywords: Skills, Knowledge, Labour Market, Business, Entrepreneurship.
Maria José Varadinov Instituto Politécnico de Portalegre 


\author{
Ref.: 342CEDHM42020
}

\title{
O DESAFIO DE UMA ABORDAGEM INTERCULTURAL PARA OS DIREITOS HUMANOS
}

Alice Duarte

Universidade do Porto,

Faculdade de Letras
Em certa medida a história do Direito Internacional é a história dos esforços desenvolvidos para minimizar ou amenizar os efeitos dos conflitos armados e o sofrimento humano. Este artigo pretende discutir as possibilidades de uma efetiva universalização dos Direitos Humanos hoje. Começa por identificar os antecedentes medievais e humanistas do Direito Internacional e do que se virá a constituir como o discurso moderno dos Direitos Humanos. Os dados históricos considerados permitem elucidar como a emergência de uma ideia de compaixão sem exceções pelo Outro não encontrava fundamento suficiente no argumento religioso e como a sua ultrapassagem foi a condição exigida para a adoção de uma perceção mais ampla do Outro como semelhante. Ao mesmo tempo, esses dados históricos tornam também evidente como tal percurso é, no essencial, europeu ou ocidental. Na segunda parte do artigo defendo, então, que o adjetivo "universal" não é ainda adequado para descrever a situação atual dos direitos humanos, mas não rejeito a possibilidade de o vir o ser. Essa possibilidade estará dependente da efetiva consolidação de uma abordagem intercultural dos Direitos Humanos. Só esse caminho permitirá que se fale com propriedade de Direitos Humanos universais, sendo que a dimensão política de tal mudança é inquestionável. Em certa medida a história do Direito Internacional é a história dos esforços desenvolvidos para minimizar ou amenizar os efeitos dos conflitos armados e o sofrimento humano. Este artigo pretende discutir as possibilidades de uma efetiva universalização dos Direitos Humanos hoje. Começa por identificar os antecedentes medievais e humanistas do Direito Internacional e do que se virá a constituir como o discurso moderno dos Direitos Humanos. Os dados históricos considerados permitem elucidar como a emergência de uma ideia de compaixão sem exceções pelo Outro não encontrava fundamento suficiente no argumento religioso e como a sua ultrapassagem foi a condição exigida para a adoção de uma perceção mais ampla do Outro como semelhante. Ao mesmo tempo, esses dados históricos tornam também evidente como tal percurso é, no essencial, europeu ou ocidental. $\mathrm{Na}$ segunda parte do artigo defendo, então, que o adjetivo "universal" não é ainda adequado para descrever a situação atual dos direitos humanos, mas não rejeito a possibilidade de o vir o ser. Essa possibilidade estará dependente da efetiva consolidação de uma abordagem intercultural dos Direitos Humanos. Só esse caminho permitirá que se fale com propriedade de Direitos Humanos universais, sendo que a dimensão política de tal mudança é inquestionável.

\footnotetext{
Palavras-Chave: Direitos Humanos, Direito Internacional, Antecedentes Medievais e Humanistas, Abordagem Intercultural dos Direitos Humanos, Democracia Deliberativa.
} 


\section{EDUCACIÓN DESESCOLARIZADA, ESTUDIO DE CASO DE UNA COMUNIDAD EDUCATIVA EN LA CIUDAD DE IQUIQUE, CHILE}

Esta investigación se desarrolla en el área de la Sociología de la Educación y busca describir e interpretar los procesos sociales y culturales que aportan al desarrollo de una educación desescolarizada. Entendiendo la educación desescolarizada como una forma de transformar la escuela (no eliminarla), proponiendo un modelo de educación integral, que contempla el desarrollo de habilidades sociales y culturales, además del desarrollo académico, flexibilizando las condiciones para el aprendizaje, prescindiendo de formalidades como el uso de uniforme escolar, la asistencia obligatoria y la separación por rango etario.

La perspectiva teórica que dirige esta investigación indica que la escuela, como ente socializador, responde a una construcción social que necesita integrar el desarrollo de habilidades sociales y culturales, además de los objetivos académicos, con el fin de lograr aprendizajes más significativos para sus participantes.

Metodológicamente, se trata de un estudio de caso en donde se han utilizado tres técnicas de investigación en función del objetivo a alcanzar: (1) entrevistas abiertas a los y las participantes de la escuela libre, (2) observación participante y elaboración de un cuaderno de campo, (3) análisis de discurso pertenecientes a los documentos publicados por la"Escuela Libre Ayni".

Los principales resultados de esta investigación indican que existe una real necesidad de cambio de paradigma dentro de las escuelas, ya que los y las menores en edad escolar sufren de violencia simbólica, arbitrariedad cul- tural y autoritarismo pedagógico en su escuelas. La escolarización entiende a la enseñanza como un acto obligatorio de producción y reproducción cultural, normalizando dicótomas sobre lo que es educación y lo que no es educación, obviando uno de los principales propósitos de la educación que es valorar la belleza de la vida, hacer buen uso del tiempo y dominar la imaginación.

Toda escuela educa en valores y moral. Dentro de la escuela libre investigada, se enseña y no se enseña, se enseña acerca de la hermandad de los pueblos originarios, se enseña la descolonización, se enseña el derecho a la huelga, se enseña la participación a marchas por la educación, se enseñan los derechos humanos, se enseña a argumentar y se enseña a no utilizar la violencia para resolver los problemas. También no se enseña, es decir no se enseña el patriotismo, no se enseña religión, no se celebran los días de los uniformados, ya que esta escuela no cree en que la guerra pueda ser una opción para resolver cualquier clase de problemas. La religión no se enseña debido a que se asume que es un tema personal de cada familia, en donde el contexto de la escuela libre no busca generar un espacio para su desarrollo.

Estas experiencias educativas al margen del ministerio de educación en Chile han ido enaumentos y en esta investigación de describe como se desarrolla una experiencia educativa desde la creación, el dialogo y la responsabilidad social-ecológica.

Palavras-Chave: Escolarización,

Desescolarización, Socialización, Violencia, Cultura.
Victoria Cardemil

Universidad Arturo Prat e Instituto Profesional Santo Tomás 
Ref.: 369CEDHM22020

\section{TODOS IGUAIS PELA EDUCAÇÃO: \\ O PROGRAMA DE APOIO PERMANENTE DO ESTADO DO PARANÁ (BRASIL) EM PROL DE ESTUDANTES COM DEFICIÊNCIA MATRICULADOS EM ESCOLAS DA REDE PARCERIA DA SOCIEDADE CIVIL ORGANIZADA}

Elizabete Aparecida Pereira Pontifícia Universidade Católica do Paraná
Apesar de todo o empenho em se promover a inclusão do estudante com deficiência na rede pública de ensino, juntamente com estudantes sem deficiência, ainda persiste 0 atendimento educacional realizada por organizações da sociedade civil, mantenedoras de escolas de Educação Especial. No Brasil, mais especificamente no Estado do Paraná, estas instituições ofertam verdadeira escolarização destes estudantes e contam com o apoio do Poder Público, justamente porque colaboram na prestação de um serviço público. Esta parceria abrange o universo de aproximadamente 39.000 (trinta e nove mil) estudantes, o que expressa a relevância do estudo. $\mathrm{O}$ artigo analisa o direito à educação da pessoa com deficiência matriculada em rede parceira do Poder Público. Propõe a identificação desse direito no ordenamento jurídico brasileiro e avalia a condição do estudante com deficiência como destinatário de um serviço público configurado como direito fundamental. Utiliza-se a metodologia pautada em estudo de caso, partindo da apresentação da origem e história da referida cooperação. Em seguida, adentra na fundamentação normativa que embasa a educação da pessoa com deficiência no ordenamento jurídico brasileiro, até alcançar as bases legais que respaldam a parceria existente. Os resultados apurados demonstram que o apoio prestado pelo Poder Público ao Terceiro Setor não consiste em favor ou benemerência, mas justamente um dever decorrente da colaboração firmada sob um respaldo normativo. Também é constatada a convergência dos propósitos pedagógicos das escolas da rede parceira aos postulados da educação previstos para a pessoa com deficiência, sobretudo intelectual, com para a Convenção Internacional sobre os Direitos da Pessoa com Deficiência e a Lei Brasileira de Inclusão e a Declaração de Salamanca. Muito embora tratar-se de uma Política de Estado e não Governo, conclui-se que ainda são muitos os desafios a serem enfrentados pelas instituições parceiras, sobretudo no contexto de renovação dos instrumentos de parceria, pelo desconhecimento ou incompreensão da sociedade ou mesmo de agentes públicos quanto à preservação de direitos conquistados, luta para elidir retrocessos e acima de tudo, oferta de educação de qualidade para o estudante com deficiência. Sem o necessário conhecimento da trajetória percorrida pelas partes envolvidas na construção da cooperação, o artigo propõe reflexões para o enfrentamento da questão, buscando contribuir para o adequado entendimento e reconhecimento do serviço prestado pelas entidades parceiras.

Palavras-Chave: Estudante com Deficiência, Brasil, Parceria, Poder Público, Sociedade Civil Organizada. 


\section{BLENDED-LEARNING: \\ POSSIBILIDADES NA FORMAÇÃO INCLUSIVA, EQUITATIVA E DE QUALIDADE PARA PROFESSORES E PESQUISADORES}

O crescimento sem precedentes da população mundial e a busca por maior conhecimento e aprimoramento profissional têm provocado impactos inimagináveis no cenário da educação, em especial, se observados à luz de um dos Objetivos do Desenvolvimento Sustentável (ODS), que visa assegurar a educação inclusiva e equitativa e de qualidade, e promover oportunidades de aprendizagem ao longo da vida para todas e todos. Ao mesmo tempo, o atendimento da demanda e distribuição igualitária de oportunidades de acesso e permanência se tornam desafios para instituições formativas (como escolas e universidades) em um ambiente globalizado e praticamente sem fronteiras para a difusão de conhecimento(s), propalada por uma sociedade cada vez mais digital. Nesse contexto, por ser 0 nível de ensino mais alto, e de adultos que circulam e efetivamente participam das decisões da sociedade global, a aplicação de Tecnologias de Informação e Comunicação (TICs) na educação superior pós-graduada tem se apresentado como um fenômeno irreversível, ainda que complexo e multifacetado. Mas como lidar com esse fenômeno e buscar um equilíbrio entre suas raízes históricas e a dinâmica das organizações modernas? Como a tecnologia pode propiciar a inclusão e ampliação de horizontes na educação inclusiva e formação de pesquisadores e professores? Estas são perguntas que muitos docentes e gestores universitários têm se feito desde o início desta década. Considerando tais questionamentos, o objetivo principal que guia a pesquisa em andamento reside em conhecer experiências e tecnologias para o ensino híbrido, semi-presencial ou "B-Learning", aplicadas ao aperfeiçoamento e aumento substancial do contingente de professores qualificados, inclusive por meio da cooperação internacional para a formação em nível de Pós-Graduação nos países em desenvolvimento como o Brasil, lócus da pesquisa. Embora não se trate de um estudo comparativo, se busca, mediante a realização do mesmo, subsídios que permitam pautar a condição específica de oferta da Graduação stricto sensu no Brasil perante outros contextos nos quais a compreensão da cooperação acadêmica interinstitucional possa acrescentar elementos à discussão de publicações derivadas dos projetos dos grupos de pesquisa, articulando B-Learning e a Internacionalização e o acesso à educação de qualidade, entendida nessa discussão contemporânea como um direito presente nos ODS.

Palavras-Chave: Agenda 2030, Educação

de Qualidade, Educação Superior,

Desenvolvimento Socioeconômico,

Pós-Graduação.
Miguelangelo Gianezini, UNESC - Universidade Lusófona Thiago Henrique Almino Francisco UNESC - UFSC \& António Teodoro Universidade Lusófona 
Thiago Henrique Almino Francisco, Miguelangelo Gianezzinni \& Pedro Antônio de Melo Universidade do Extremo Sul Catarinense

Ref.: 377CEDHM42020

\section{OS DESAFIOS DA REGULAÇÃO DO ENSINO SUPERIOR BRASILEIRO NO CONTEXTO DA PANDEMIA}

A pandemia do COVID-19 trouxe consigo diversos desafios, dentre os quais a manutenção da oferta de educação de qualidade, enquanto um dos Objetivos do Desenvolvimento Sustentável (ODS). No âmbito da Educação de Jovens e Adultos, mais notadamente universitário, um conjunto de importantes impactos no sistema de governança das Instituições se fez sentir desde o início da pandemia. Entre os países em desenvolvimento, o caso brasileiro ganhou destaque, não apenas pelo discurso destoante, mas também pela ação dos entes governamentais junto às universidades e demais instituições de ensino superior brasileiras. Neste estudo são destacados pontos da atuação dos órgãos reguladores deste segmento educacional, que desde 2004 instituíram diretrizes norteadoras para a prática acadêmica articulada com um sistema nacional de avaliação. Contudo, no momento em que estas entidades mais precisaram de apoio regulatório e direcionamentos imediatos, o panorama revelou-se "confuso". Nesse sentido, este artigo tem o objetivo de discutir os impactos dos movimentos regulatórios nas IES brasileiras a partir do pano- rama apresentado nos atos regulatórios publicados desde o início da Pandemia de COVID-19 no Brasil. Por meio de uma análise documental, considerando portarias, pareceres e medidas provisórias publicadas desde março de 2020, buscou-se compreender a dinâmica regulatória neste período de crise e o papel de cada entidade neste processo. Ao analisar os dados, as categorias de análise foram concebidas a partir da "análise de conteúdo" ofereceram condições para compreender o movimento que impactou o ensino superior brasileiro. Os resultados demonstram que o papel do Conselho Nacional da Educação (CNE) foi essencial para a prototipação do modelo brasileiro de ensino mediado por tecnologias. À guisa de conclusão, é possível identificar que ainda há uma lacuna significativa, por parte das secretarias regulatórias do MEC, na perspetiva e prática da regulação ne educação superior brasileira em tempos de pandemia.

Palavras-Chave: Regulação, Ensino Superior, Governança. 


\section{HIERARQUIZAÇÃO DE FATORES CRÍTICOS PARA UMA EDUCAÇÃO EFICIENTE UTILIZANDO ATEORIA DOS CONJUNTOS EXPANDIDOS - FUZZY}

A experiência juntamente com uma forte cultura de resultados positivos, devem ser desenvolvidas e aplicadas durante todo o ciclo de aprendizado de base do ser humano. Processo este que deve incluir todos envolvidos nesta formação. Alguns conceitos como aprendizado holístico e criativista tem passado a fazer parte com mais frequências da metodologia de ensino em países classificados de referência como a Finlândia. Outro panorama inesperado, surgiu com a pandemia, mudando significativamente todo o sistema de ensino do planeta, fazendo as instituições, sem planeamento prévio e em curto espaço de tempo, atualizarem suas práticas de ministração das aulas. Medida esta que foi necessária devido ao corrido, caso contrário as mesmas permaneceriam com as atividades inertes. Até hoje cada país utilizou um padrão de aprendizado, que deveria tornar o ser humano capaz de desenvolver características relacionadas a habilidades, tomada de decisões e execução de ações seguras em todos os âmbitos. Neste período que estamos convivendo com o COVID-19, a falta de uniformidade foi ainda em maior escala, dados que serão possível aferir somente com estudos futuros relacionados ao impacto na educação. Os itens que precisariam estar no escopo do programa padrão de cada instituição, muitas vezes podem ser afetadas por lacunas de conhecimento como, por exemplo, deficiência ou ausência de alguns fatores que tornariam a educação mais completa. A partir deste panorama, surgiu o desejo de construir uma pesquisa, com obje- tivo de tornar este compartilhamento de conhecimento eficiente. Para isso é importante identificar métodos, barreiras ou fatores críticos que afetam o sucesso neste processo de gestão e compartilhamento do conhecimento (GCC). Na perspetiva da maioria das escolas, não existe um quadro sistemático sobre a caracterização de um conjunto de fatores críticos (CFCs) para uma educação eficiente inserindo a Gestão do Conhecimento (GC). Além disso, não existem métodos adequados que possam avaliar satisfatoriamente os CFCs e resolver plenamente a subjetividade do GCC durante o aprendizado. Nesse contexto a demanda para criar um grupo de fatores teve início. Este trabalho irá apresentar um método para tomada de decisão utilizando a teoria dos conjuntos expandidos, teoria fuzzy, para delinear o compartilhamento do conhecimento pelas instituições de ensino, utilizando CFCs capazes de identificar tarefas que contribuem como também as barreiras que afetam a GCC, dificultando o aprendizado eficiente dos indivíduos. Utilizaremos dados a partir da construção de pesquisa através de questionários, baseados em dados criteriosamente pesquisados e em comum orientação e auxílio das instituições de países com histórico de alto e baixo padrão em educação.

Palavras-Chave: Aprendizado, Gestão do Conhecimento, Fatores, Teoria Fuzzy, Escola.
Vianna, J.,

Grecco, C.H. S., Carvalho, P.V. R.

\& Cosenza, C.A. N

Comissão Nacional de Energia Nuclear, Instituto de Engenharia Nuclear, IEN/CNEN, COPPE/UFRJ 


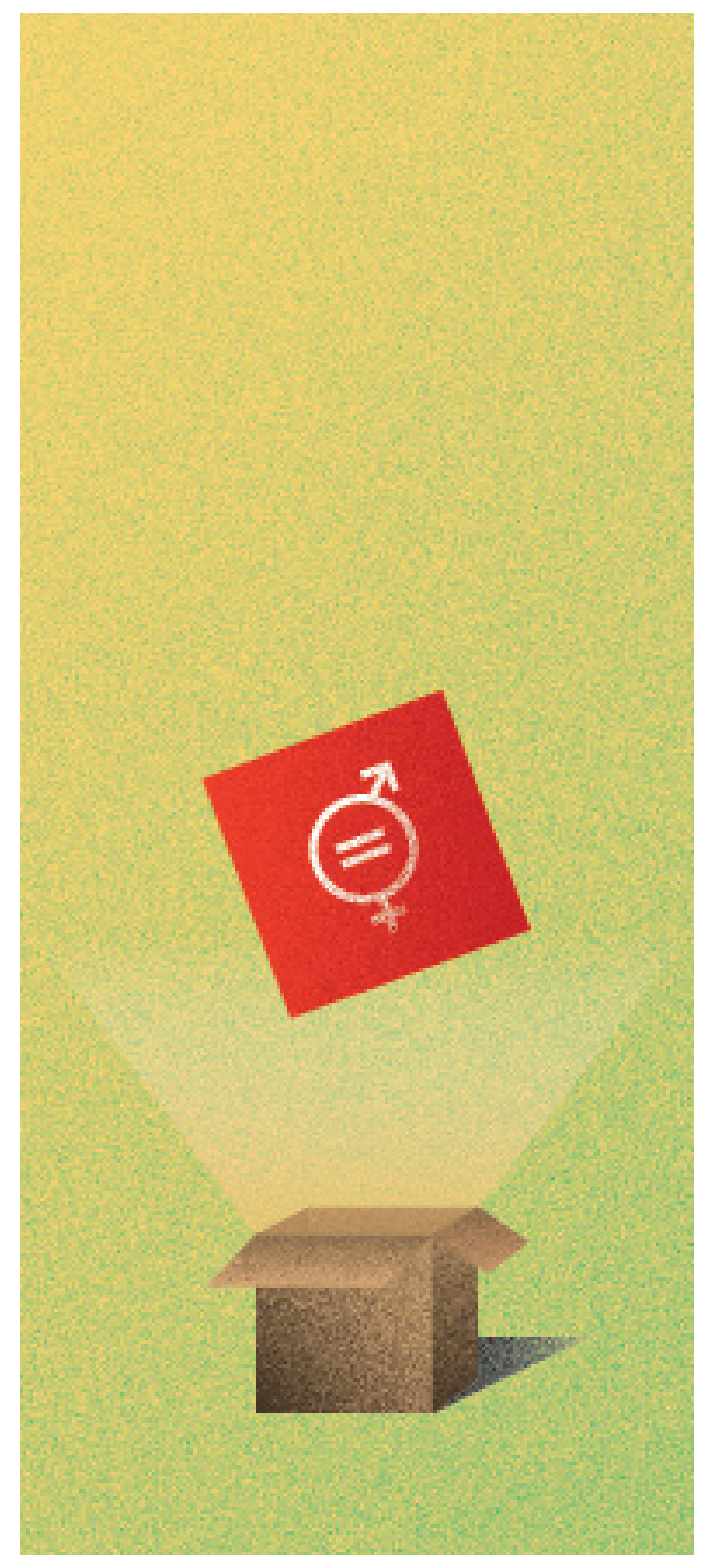

\section{ODS 5 IGUALDADE DE GÉNERO}

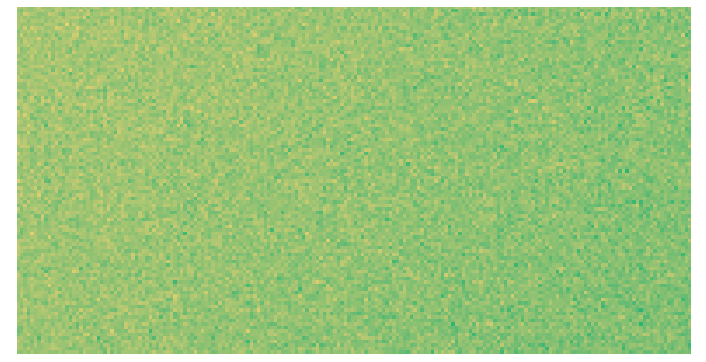




\section{A CONDIÇÃO FEMININA E OS CAMINHOS PARA A PRISÃO NO BRASIL}

Trata-se de analisar o resultado de uma pesquisa realizadas em ambientes prisionais com mulheres detidas e seus familiares, no período de 2016 a 2019, na perspetiva de se compreender a relação entre a condição feminina e os caminhos para a prisão. Do ponto de vista metodológico, a pesquisa abordou a relação entre a epistemologia clássica da culpa e a prática da vida cotidiana feminina, desde as suas condições sociais concretas às subjetividades associadas às realizações afetivas. Com esta perspetiva utilizou-se a metodologia da entrevista aberta, gravada, com mulheres em situação de prisão e seus familiares. Conclui-se que, a condição de vulnerabilidade social, tanto do ponto de vista da sobrevivência material quanto em relação à afetiva e relacional, apresenta-se como motivação central ao agir circunstancial fora das normas e regras sociais, a partir da própria perda da autonomia individual constituindo-se assim os caminhos para a prisão. A condição de vulnerabilidade social leva a uma situação de risco às individualidades uma vez que a epistemologia das regras sociais parte do postulado da homogeneidade, não possuindo condições de atribuir racionalidade aos comportamentos singulares. Os caminhos da mulher para a prisão não se constitui de um simples agir pessoal, mas de uma complexidade envolvendo a história de vida, as condições sociais e os próprios contextos dos eventos envolvendo a questão feminina na contemporaneidade. Neste contexto dois fatores se sobressaem conjugados, como explicação sintética desta realidade do aumento substancial das mulheres na prisão: a relação entre a epistemologia da culpa e a condição de vulnerabilidade social. Constata-se que independentemente da condição social familiar das mulheres detidas, suas histórias de vida foram recheadas por grandes perdas que se apresentam com muito significado em seis situações concretas: no âmbito da relação com vínculos de trabalho; com a escola; conflitos familiares; relação afetiva; a capacidade/incapacidade de consumo e o envolvimento familiar com atividades de risco. Observa-se uma conexão entre estes fatores, um detonando o outro. Observa-se também uma relação entre a natureza feminina, o acento à emoção, à paixão, ao afeto, não reconhecido e levado em conta pelo modelo racionalista da epistemologia da culpa. Certamente que este contexto de vulnerabilidade social que se expressa no âmbito da história pessoal da vida, não age sozinho para delinear os caminhos femininos para a prisão, mas é preciso associá-lo aos novos processos sociais que ocorrem em escala mundial envolvendo a mulher, especialmente no que diz respeito a um novo protagonismo delas no contexto social e político. Isto se expressa no âmbito da atividade produtiva, política e mesmo na condição de arrima de família.

Palavras-Chave: Condição Feminina, Vulnerabilidade, Caminhos para a Prisão, Direitos Humanos.
Lindomar Wessler Boneti

Pontifícia Universidade Católica do Paraná - Brasil

\& Ana Lúcia Langner Universidade Federal do Paraná - Brasil 
Rômulo Filizzola Nogueira

Faculdade de Direito da Universidade Federal do Rio de Janeiro (UFRJ)

Ref.: 038CEDHM42020

\section{CLARA DOS ANJOS DE LIMA BARRETO: EMPODERAMENTO E LUTA PELOS DIREITOS HUMANOS DAS MULHERES NEGRAS BRASILEIRAS}

A Declaração de Pequim, adotada pela Quarta Conferência Mundial sobre as Mulheres de 1995, reafirmou o compromisso dos governos participantes com a defesa dos direitos humanos das mulheres, com o seu empoderamento e a sua plena participação em todas as esferas sociais. Este documento reconheceu, ademais, que a igualdade universal só pode ser alcançada mediante a erradicação da "persistente e crescente pobreza que recai sobre as mulheres", além das "múltiplas barreiras" por elas enfrentadas em "virtude de fatores como raça, idade, língua, origem étnica (...)" (ONU, 1995). Estima-se que o Brasil recebeu 4,8 milhões de africanos escravizados, sendo o principal destino do tráfico negreiro no continente americano (Schwarcz; Gomes, 2018). Em razão disso, as mulheres de ascendência africana sofreram abusos cotidianos no regime escravista e iriam vivenciar no pós-abolição a permanência dessas mesmas estruturas opressivas que negavam a sua humanidade no passado. O escritor Lima Barreto (1881-1922) engajou-se na defesa dos direitos humanos das afrodescendentes ao produzir uma literatura de ficção comprometida com a superação das desigualdades de gênero, raça e classe social. Ao longo da vida, o intelectual negro projetou o romance Clara dos Anjos, cuja última versão é analisada neste artigo. $O$ estudo explora os aspectos jurídicos da narrativa, como os crimes de defloramento praticados pelo vilão, a crítica ao sistema jurídico criminal e a influência dos estereótipos de raça e gênero na proteção dos direitos das mulheres negras. A historiografia sobre o crime de defloramento (Caulfield, 2000; Esteves, 1989; Fausto, 2014) é empregada para contextualização da época, sendo, porém, relida conforme a literatura atual da teoria crítica racial (Crenshaw, 1999; Collins, 2004), teoria feminista (Andrade, 2005) e pensamento feminista negro (Davis, 2016; Carneiro, 2019) sobre o crime de estupro. A análise desenvolve-se a partir da analogia estrutural entre os dois crimes sexuais, defloramento e estupro, sugerida pelo escritor na epígrafe do romance Clara dos Anjos. A leitura interdisciplinar desenvolvida neste estudo identifica na narrativa ficcional uma mensagem de empoderamento e luta pelos direitos humanos das mulheres negras brasileiras.

Palavras-Chave: Direitos Humanos e Literatura, Empoderamento, Mulher Negra, Diáspora Africana, Clara Dos Anjos. 


\section{“FIXING THE SYSTEM": \\ THE AUDIOVISUAL REPRESENTATION OF DELIBERATIVE CULTURE INSIDE THE PRISON}

\begin{abstract}
"Fixing the System" is a one-hour-long documentary that interrogates racial inequities within America's criminal justice system. The film is also unique because several scenes feature Barack Obama talking with inmates about the general situation of the prison system in the USA. In fact, this is a historic document: Obama was the first sitting president of the USA ever to visit a federal prison.
\end{abstract}

In a sense it can be said that these group conversation scenes reproduce the typical dialogue conditions of a national debate. In this article we will analyse the speech both of Obama and of the people who engage into conversation with him. Our objective is to apply the characteristic methodology of Critical Discourse Analysis in order to describe the deliberative cultures represented by this documentary. Our starting hypothesis is the idea that deliberative cultures have a strong visual component and the analysis of this documentary makes it possible for us to analyse precisely this.

Within the conceptions of democracy and, in particular, in the deliberative model of democracy (i.e. deliberative democracy) the notion of deliberative culture has been investigated especially in the last five years. One of the most important authors in this field is the political scientist John Dryzek. In this article we will assume many of Dryzek's theoretical approaches, but we will apply them to a limited and filmed communicative event.

Our purpose is to analyse the deliberative culture in this documentary to determine if there is any rhetorical, dialectical and visual pattern informing the scenes.

We will also analyse and comment on the social and political repercussions of this documentary and we will establish the fundamental elements of the deliberative culture that is used here. Our overall goal will be to interpret and assess the impact such a representation of deliberative culture might have.

Keywords: Deliberative Culture, Deliberative Democracy, Visual Culture, Civil Society, Political and Moral Psychology.
María G. Navarro

Universidad de Salamanca

\& Noemi de Haro García

Universidad Autónoma de Madrid 
Ref.: 046CEDHM22020

\section{A IGUALDADE DE GÉNERO NO DESENVOLVIMENTO SUSTENTÁVEL DA ONU: O OBJECTIVO 5 DA AGENDA 2030}

Isabel Baltazar

Universidade Nova de Lisboa
A Igualdade de Género é um dos 17 objectivos do desenvolvimento da ONU, considerada como uma meta a atingir até 2030. Para que este objectivo seja cumprido, é preciso, antes de mais, educar para esta igualdade de género desde o ensino pré-escolar até ao fim da escolaridade obrigatória, para que os futuros cidadãos tenham uma mentalidade formada para a igualdade e para a não discriminação em função do género. É essencial combater todas as formas de discriminação de meninas e de mulheres, na Escola e na Sociedade. É urgente acabar com todas as formas de violência, na esfera pública e privada, incluindo o tráfico e exploração sexual e de outros tipos. Também é preciso actuar sobre todas as práticas nocivas que envolvam crianças, casamentos prematuros ou mutilações genitais. A nível social, é necessário reconhecer e valorizar o trabalho de assistência e doméstico não remunerado, por meio da disponibilização de serviços públicos, infraestrutura e políticas de protecção social, bem como a promoção da responsabilidade partilhada dentro do lar e da família, conforme os contextos nacionais. Trata-se, também, de garan- tir a participação plena e efectiva das mulheres e a igualdade de oportunidades para a liderança em todos os níveis de tomada de decisão na vida política, económica e pública. Por último, de assegurar o acesso universal à saúde sexual e reprodutiva, de acordo com a Plataforma de Pequim e de dar às mulheres direitos iguais e empoderamento tecnológico. Nesta igualdade de Género, está subjacente uma igualdade de Direitos Humanos. Este estudo será feito através de uma análise qualitativa dos dados, integrados num enquadramento teórico do tema, para sustentar a tese de que a igualdade de género é um direito humano e que precisa de ser ensinada. Por isso, a Educação para a Igualdade de Género é uma das metas do Desenvolvimento Sustentável da ONU, como meio privilegiado de socialização, a escola tem como missão promover a igualdade de oportunidades e educar para os valores do pluralismo e da igualdade entre homens e mulheres.

Palavras-Chave: Género, Igualdade, ODS, ONU, Agenda 2030. 


\section{VIOLÊNCIAS CONTRA MULHERES E O DISCURSO JURÍDICO: UM ESTUDO DE SENTENÇAS CRIMINAIS DO MUNICÍPIO DE VILA VELHA/ES/BRASIL - 1975-2010}

O presente trabalho, ainda em desen-
volvimento, analisa sentenças criminais
que envolvem violências contra mulhe-
res no município de Vila Velha, estado
do Espírito Santo/Brasil, no período de
1975 a 2010 , objetivando identificar a adequação do discurso jurídico às transformações do papel das mulheres na sociedade, bem como analisar a (des)construção do sujeito mulher por esse discurso. Justifica-se a presente pesquisa, considerando que os valores misóginos, fortemente presentes na sociedade brasileira, são heranças de uma desigualdade estrutural, objetivamente criada para manter o controle sobre as mulheres. Essa desigualdade produz violências que as vitimizam desde os mais remotos tempos e a permanência desse fenômeno nos convida a aprofundar os estudos, a fim de pensar estratégias que possam quebrar esse ciclo. Nessa perspectiva, considera-se o fenômeno das violências contra mulheres como um dos graves problemas que - Brasil enfrenta, uma vez que o país figura como o $5^{\circ} \mathrm{em}$ homicídio feminino, dentre os oitenta e três analisados pela pesquisa da FLACSO, de acordo com o Mapa da Violência 2015. Essa mesma pesquisa apresenta o estado do Espírito Santo como o segundo colocado em comparação às vinte e seis unidades da federação brasileira e Vitória, capital do estado, como a primeira colocada quando comparada às demais capitais. A hipótese que orienta o trabalho é a de que a instrumentalização do discurso jurídico impede a eficácia social e a aplicabilidade adequada da lei, uma vez que, na crença da neutralidade jurídica, a linguagem técnica desse campo de saber se apresenta pouco sensível às desigualdades de direitos existentes entre homens e mulheres e não atua em uma perspectiva interseccional que contemple a pluralidade do feminino e nem as violências cometidas contra as mulheres como afeitas aos Direitos Humanos. Parte-se do pressuposto de que o Poder Judiciário permanece fiel à cultura patriarcal vigente e oferece uma resposta pragmática, pautada na materialidade do crime e que, dessa forma, reproduz a assimetria de poder nas relações de gênero, reforçando a inferiorização social das mulheres. São utilizados como fontes, livros de sentenças criminais relativas a violências contra mulheres no município pesquisado. As fontes serão trabalhadas na perspectiva qualitativa, orientadas pela metodologia da análise de discurso crítica. O resultado esperado remete à compreensão da atuação do direito no trato das violências envolvendo mulheres, no sentido de perceber em que medida suas práticas têm atuado como catalisadoras de soluções para esse tipo de conflito ou funcionado como instâncias reprodutoras das desigualdades e violências.

Keywords: Discurso Jurídico, Formação Jurídica, Relações de Gênero, Cultura Patriarcal,

Violências Contra Mulheres.
Maria Angela Rosa Soares, Universidade Federal do Espírito Santo - UFES

Patrícia Maria da Silva

Merlo

Universidade Federal do Espírito Santo - UFES

\& Vanessa Ribeiro Simon

Cavalcanti

Universidade Católica de Salvador - Bahia, Brasil 
Valéria Giumelli Canestrini \& Jaime Leônidas Miranda Alves

UNIVALI

Ref.: 092CEDHM22020

\section{O RACISMO AMBIENTAL COMPREENDIDO SOB A PERSPECTIVA DA IGUALDADE COMO RECONHECIMENTO}

O racismo ambiental é um fenômeno, analisado na década de 80 , por ativismo do movimento negro nos Estados Unidos, consistindo, em síntese, numa prática generalizada de discriminação das minorias, seja por rações étnicas, econômicas, sociais ou raciais, em políticas públicas, não lhes garantindo os direitos socioambientais. Ao se tratar do racismo ambiental, se está no campo do que é justo ou injusto. O racismo ambiental é um dos alertas globais que surge em um contexto em que os problemas ultrapassam os limites estatais e alcançam dimensões fronteiriças, reclamando, portanto, soluções transnacionais. Nesse diapasão, a pesquisa analisa a prática do racismo ambiental à luz do princípio da igualdade como forma de reconhecimento. A situação de insustentabilidade ambiental que se constata hodiernamente, com a efetivação de ações excludentes, que estão cada vez mais piorando a qualidade de vida no planeta, afetando em especial, as minorias, que sofrem com enchentes, falta de saneamento básica, falta de moradia adequada, afetando principalmente as pessoas negras ou pardas. Já em relação à igualdade como reconhecimento, esta traz o dever do Poder Público e também das diversas instâncias de poder transnacional de, enquanto aproxima os indivíduos e grupos sociais no tocante às oportunidades, reconhecer as suas diferenças a partir de um matiz idiossincrático no sentido de possibilitar a existência de espaços públicos e plurais de construção da pessoalidade, de modo que as pessoas possam construir e reconstruir sua identidade em um processo plural de reconhecimento. Diante do que foi analisado a partir da metodologia elegida, percebeu-se que há verdadeiro descompasso entre a prática do racismo ambiental quando percebida a partir do princípio da igualdade por reconhecimento, devendo essa prática ser freada e combatida pelos poderes nacionais e transnacionais.

Palavras-Chave: Direitos Fundamentais, Igualdade; Racismo Ambiental, Reconhecimento. 


\section{VIOLÊNCIA(S) DE GÉNERO NA GUINÉ-BISSAU PELA PERSPETIVA DE PROFISSIONAIS DOTERRENO}

A Violência de Género é definida, pelo Comitê das Nações Unidas sobre a Eliminação da Discriminação contra as Mulheres (CEDAW), como "violence that is directed against a woman because she is a woman or that affects women disproportionately" (Artigo 6) (UN, 1992). Tida como uma grave violação dos direitos fundamentais das mulheres (WHO, 2014), a violência de género é uma manifestação extrema da desigualdade, onde as mulheres, detentoras de um poder desigual nas relações estabelecidas com os homens, vão assumindo um estatuto inferior que as vulnerabiliza socialmente. Na Guiné-Bissau, a violência baseada no género é o reflexo de um modelo patriarcal, que legitima as práticas culturais tradicionais, sob as quais, vários grupos étnicos, que constituem o país, regem os seus comportamento e suas atitudes (Baldé \& Mendes,n.d.). Tais práticas, vão desde o tratamento diferenciado entre rapazes e raparigas no que diz respeito à escolaridade e alfabetização, as limitações da capacidade da mulher em ser independente do marido ou dos próprios pais, aos casamentos precoces, à violência doméstica, à poligamia, levirato, gerontofilia e à mutilação genital feminina (MFG). Assim, e pelos motivos elencados até então, na Guiné Bissau, muitas mulheres acabam por recorrer a projetos de missões humanitárias e/ ou ONGD's que estão e/ou se deslocam ao terreno para prestar apoio em várias áreas (e.g., alimentar, saúde), percecionando estes contextos como espaços protegidos que possibilitam a desocultação de vários problemas por elas vivenciadas, dos quais se destacam situações de violência de género. Posto isto, a comunicação que aqui se apresenta pretende problematizar e discutir, a partir de uma recolha de dados realizada em contexto de missão humanitária de uma ONGD -a HumanitAVE-junto de profissionais que trabalham em estruturas de respostas formais e não formais do país, o fenómeno da violência de género vivenciado por mulheres guuineenses sob o prisma da perspetiva da Criminologia Cultural (Ferrell, 1999). Do estudo qualitativo efetuado, que contemplou a realização de grupos focais e entrevistas individuais a profissionais, podemos apurar que os seus resultados clarificam os dados apontados na literatura no que respeita à associação entre condições estruturais de desigualdade social e vulnerabilidade às vivências de violência de género noforo das intimidades. Este estudo fornece ainda novas pistas de reflexão/ação sensíveis à diversidade das vítimas e às formas de prevenção e intervenção passíveis de serem contempladas para a realidade da Guiné Bissau mas também, para a realidade portuguesa, servindo de inspiração para políticas públicas de combate à violência de género junto de mulheres guineenses migrantes em Portugal e, mais concretamente, para o combate da MGF. Espera-se que os resultados possam contribuir para o desenvolvimento, planeamento e implementação de políticas e programas contra a violência de género que sejam culturalmente sensíveis.

\section{Joana Torres \\ Instituto Universitário da Maia/Faculdade de Direito da Universidade do Porto/Universidade Fernando Pessoa}

\& Joana Topa ISMAI, CIEG-ISCSP ULisboa 
Eglatina Albuquerque de Oliveira Souza e Silva IGC Universidade de Coimbra \& Deborah Bandeira de Deus e Mello UNIFACOL /FDUNL

Ref.: | 33CEDHMI 2020

\section{ESTUDO COMPARADO DA PROTEÇÃO DOS DIREITOS HUMANOS DA COMUNIDADE LGBTQIA+ NOS SISTEMAS REGIONAIS INTERAMERICANO E EUROPEU}

\begin{abstract}
Sabe-se que os direitos humanos da população Igbtqia + sempre foram invisibilizados, esses indivíduos sempre sofreram discriminação e violência homofóbica e transfóbica e os dados sobre essas violências são alarmantes. Esse artigo propõe analisar a atual concepção do Sistema Europeu e do Sistema Interamericano de Direitos Humanos no que concerne a proteção da população Igbtqia+ uma vez que ambos os sistemas possuem cláusulas de igualdade e proibição de discriminação inclusive quando se fala em orientação sexual e identidade de gênero e por serem os sistemas regionais mais bem estruturados e desenvolvidos. Além disso, propomos uma análise dos casos levados à corte dos dois sistemas, levando em consideração que o Sistema Europeu de Direitos Humanos vem decidindo casos contenciosos sobre o tema desde os anos 1980 e que o Sistema Interamericano teve seu primeiro caso sentenciado pela Corte em 2012. Questionamos qual a razão para a disparidade de datas das decisões e se essa diferença influencia no resultado dos casos. Como metodologia apresentaremos uma pesquisa qualitativa, desta
\end{abstract}

forma será feita uma análise bibliográfica sobre o tema, análise das normativas internacionais e, ainda, uma análise comparativa entre as jurisprudências do sistema europeu e do sistema americano com relação ao tema, observando quais os resultados obtidos nos últimos anos. De início, abordaremos a evolução dos direitos Igbtqia+ na América e na Europa, apresentaremos a estrutura de ambos os sistemas, funcionamento e composição, dando enfoque ao sistema contencioso de ambos e seus aspectos. Espera-se com esse estudo comparativo observar os dois sistemas para demonstrar os aspectos comuns e os divergentes e, também, as diversas formas de resolução de conflitos de direitos humanos com relação a comunidade Igbtqia + e a razão da diferença na quantidade de casos resolvidos.

Palavras-Chave: $L G B T Q I A+$, Direitos

Humanos, Sistemas Regionais, Cortes Regionais, Comparação. 


\section{VIOLÊNCIA CONTRA AS MULHERES DA RESISTÊNCIA CAMPONESA E A RESILIÊNCIA EMTEMPOS PANDÊMICOS}

Esse trabalho traz reflexões a respeito da violência contra as mulheres que estão à frente da resistência camponesa e as alternativas de luta encontradas por elas para acolher e orientar as suas companheiras, no momento da pandemia do COVID 19. O estudo tem por objetivo refletir sobre as causas e condições em que acontece a afronta aos direitos das mulheres visando à instrumentalizar e fortalecer a luta por aqueles direitos. O resultado é tributário dos levantamentos realizados pela Comissão Pastoral da Terra referentes aos conflitos no campo, no ano de 2019 e de informações obtidas junto ao Movimento dos Trabalhadores Rurais Sem Terra. Trata-se de uma pesquisa exploratória, tendo se servido de dados empíricos, análise de casos e levantamento bibliográfico. A matriz teórica de análise dos dados fornecidos e dos casos relatados constantes do repositório da Comissão Pastoral da Terra fundou-se no pensamento feminista de Segato, notadamente no conceito de patriarcado, na ideia de despossessão de Butler e Athanasiou, e das expressões da violência de Zizek. A violência contra as mulheres da resistência camponesa ocorre de forma simbólica e sistêmica, no contexto de um sistema mundo de capitalismo avançado, patriarcal. As instituições sociais e o Estado participam desse sistema mundo e, portanto, são algozes. As agressões contra as camponesas é expressão do racismo ambiental vigente. A violência contra as mulheres é antes de tudo a violência contra o que o feminino representa na nossa sociedade. Com base no patriar- cado a sociedade naturaliza algumas "verdades" como a hegemonia masculina, fragilidade e domesticidade da mulher, a prevalência da propriedade privada, do capital, o gênero. Essas verdades tecem um véu que invisibiliza os excluídos, os que estão fora desse padrão hegemônico. Romper esse véu é violar as normas estabilizadores que garantem a preservação do patriarcado, do colonialismo-normas de gênero, de propriedade, capital etc. Nesse contexto, o primeiro desafio para a mulher é a aparição política. Quando a mulher sai do espaço doméstico, naturalizado, ela rompe com o padrão e é duramente punida por isso, por que ela põe em desconstrução todo uma estrutura. A resistência da mulher camponesa é uma nova esfera política que desafia "verdades consolidadas" - não só a referente ao gênero, mas a toda a estrutura patriarcal - a propriedade privada, o capital, a raça. Elas recebem violência como resposta à "ousadia" de desafiar a ordem posta, ainda extremamente injusta. Em 2019, ocorreram102 atos de violência contra as mulheres em conflitos no campo-assassinatos, ameaças de morte, prisões, torturas. Isso tem-se agravado, tendo em vista o retrocesso de direitos, no Brasil contemporâneo, e as crises ocasionadas pela pandemia de COVID19. As mulheres integrantes dos movimentos sociais têm reagido contra essa situação e proposto orientação e acolhimento às vítimas.

Keywords: Direitos das Mulheres, Violência Contra Mulheres, Mulheres Camponesas, Pandemia, Racismo Ambiental.
Maria Cristina Vidotte Blanco Tarrega Universidade Federal de Goiás 


\section{A PRESENÇA DAS MULHERES NOS FÓRUNS DE PARTICIPAÇÃO POPULAR DE REVISÃO DO PLANO DIRETOR (20 I 8/2028) PARTICIPATIVO DE LONDRINA/BRASIL}

Léia Aparecida Veiga \& Ideni Terezinha Antonello Universidade Estadual de Londrina - Programa de Pós-Graduação em Geografia
O Planejamento urbano é entendido como uma forma de pensar as cidades no sentido de serem ambiental, social e economicamente sustentáveis, com áreas adequadas para as residências e que estejam conectadas aos equipamentos urbanos que as pessoas necessitam para viverem. Tendo por recorte o espaço municipal, pode-se afirmar que o plano diretor, um dos principais instrumentos norteadores da ação da gestão pública, ao ser repensado em uma perspetiva democrática, carrega o potencial de atender os interesses da coletividade e assim contribuir para a construção de uma cidade inclusiva. A produção e/ou revisão do plano diretor a partir da participação de diferentes segmentos da sociedade e da população como um todo, pode contribuir para atender diferentes grupos da sociedade, entre os quais, as mulheres, que podem ter por meio de políticas públicas municipais a igualdade nas funções de gênero facilitadas. Em Londrina, município situado no norte do estado do Paraná/Brasil, a revisão do plano diretor foi iniciada em 2018, e encontra-se em fase de aprovação junto a câmara de vereadores municipal. Foram realizados nove fóruns de participação popular no período de quatro meses, envolvendo a população das zonas urbanas e rurais, com o levantamento dos problemas vivenciados e, em seguida, a proposição de ações para melhorar a qualidade de vida dos moradores daquela porção em questão. Objetiva-se, identificar como se deu a participação da mulher nos fóruns de participação popular realizados em
2018, buscando mensurar os problemas e propostas que perpassam a questão da mulher. Essa pesquisa de abordagem qualitativa e pautada no método materialismo dialético foi realizada a partir de levantamentos primários e secundários. Verificou-se no decorrer dos fóruns de participação popular que a presença das mulheres (representantes de diferentes segmentos e como cidadã Iondrinense) foi equilibrada em comparativo a presença masculina, variando de um fórum popular para outro ora para mais ora para menos. A Secretaria Municipal da mulher não se fez presente nos fóruns, comprometendo assim o apontamento de problemas e a organização de propostas voltadas para atender o universo feminino, maioritariamente maior na cidade conforme dados do IBGE (2010). Conclui-se que em Londrina, não houve um movimento organizado para inserir um recorte de gênero dentro das diretrizes que norteiam a política urbana do plano diretor municipal e tão pouco houve a organização de grupos da sociedade civil para inserir essas questões no decorrer dos fóruns de participação popular. Essa lacuna em relação a mulher nas políticas publicas acabou por reforçar a invisibilidade da mulher e a não proposição de ações que possam contribuir para a igualdade entre gênero no campo das políticas públicas municipais.

Palavras-Chave: Plano Diretor Municipal, Gênero, Londrina, Participação Popular, Políticas Públicas Femininas. 


\section{MECANISMOS GLOBAIS PARA CONCRETIZAÇÃO À IGUALDADE DE GÊNERO NAS CARREIRAS DA AD-VOCACIA E NA MAGISTRATURA: O ESTADO DE SÃO PAULO COMO ESTUDO}

No presente trabalho, objetiva-se compreender a mobilidade profissional de mulheres nos setores da advocacia e da magistratura por meio de método monográfico com estudo de caso no Brasil, estado de São Paulo, e técnicas de pesquisa baseadas em análise bibliográfica e documental ao redor do mundo. A mobilidade profissional de mulheres será aferida a partir da ideia de igualdade material para a construção de modelos e processos capazes de conduzir a superação das desigualdades de gênero nas profissões jurídicas nos grupos referidos. Os países têm construído legislações internas com a finalidade de promoção de igualdade de gênero, contudo, tal igualdade ainda não foi alcançada e esta disparidade se torna mais gritante quando verificados os espaços de decisão e poder na sociedade. Em razão da permanência de desigualdade de gênero, o quinto objetivo das Nações Unidas propõe aos países superarem esse tema de forma mais efetiva.

Este cenário de discriminação é corroborado nos dados referentes a segunda instância da magistratura do Estado de São Paulo, em que, em 2017, a primeira instância era constituída por 373 juízas e 340 juízes na capital, enquanto a segunda instância é composta por 361 juízes e 28 juízas. Ou seja, apesar de haver uma maioria de mulheres da primeira instância, essa não se reproduz de forma igual nos Tribunais Superiores e cargos de poder das instituições. Igual situação acontece na advocacia, que, até 13/07/2020, conta com 597.593 advogadas e 603.027 advogados ativos no Brasil. Contudo, mulheres são minoria nos postos de comando de empresa e escritórios de advocacia, até 2020, a Ordem dos Advogados do Brasil Federal nunca teve mulheres em cargo de presidência e os cargos de decisão da $O A B$ foram exercidos apenas por homens.

Acredita-se que a discussão deste tema é emergente diante do fato de que a inclusão equânime das instâncias de poder é importante fator para redução de desigualdades estruturais na sociedade, pois se não há participação equânime nas instâncias de poder de uma sociedade, como se pode pensar em construção de horizontes deferentes? Assim, a manutenção das formas será capaz de tão somente reproduzir as velhas formas de viver. Diante desse contexto, acreditamos que é de suma importância compreender as estruturas legais e sociais que mantém a imobilidade de mulheres nas carreiras da advocacia e da magistratura para, após, construirmos mecanismos de promoção de igualdade de gênero sob uma perspetiva do Direito à igualdade material. Essa sub-representação das mulheres em cargos de decisão e protagonismo na área jurídica endossa, em certa medida, constatações de que "a esfera profissional é monopolizada pelos homens".

Assim, as autoras propõem a apresentação da análise de relações entre o acesso ao bem social educação superior de homens e mulheres e mobilidade social de ascensão desigual em carreiras de jurídicas, para assim colaborar para a constatação da persistência de desigualdades.

Keywords: Direito à lgualdade de Gênero, Mobilidade Laboral, Advocacia, Magistratura, Estado de São Paulo, Brasil.
Renata Miranda Lima \& Raíssa Moreira Lima Mendes Musarra ESAOABSP 


\section{DIREITOS FUNDAMENTAIS NO TRATAMENTO DAS VÍTIMAS DE VIOLÊNCIA DOMÉSTICA NO BRASIL: AVANÇOS NECESSÁRIOS}

Fernanda Proença

de Azambuja,

Luciana do Amaral Rabelo

\section{\& Andrea Flores}

Universidade Federal de Mato Grosso do Sul (UFMS)
O presente artigo faz uma incursão dos direitos fundamentais aplicáveis às mulheres vítimas de violência doméstica no Brasil. Apresenta considerações iniciais sobre Vitimologia, como ciência própria, derivada da Criminologia. Em seguida, explora o papel da vítima na persecução penal expondo a sua evolução histórica até os dias atuais, com a sua redescoberta, pautada pela dignidade humana, no contexto de um Estado Social Democrático. Passa-se, a seguir, à análise das espécies de vitimização, além daquela derivada diretamente do delito. Após, explora os marcos normativos internacionais relacionados aos direitos das vítimas penais, a Declaração Universal dos Direitos Humanos (1948), a Declaração de Princípios Básicos de Justiça relativos às vítimas de criminalidade e abuso de poder (Resolução 40/34), os Princípios e Diretrizes Básicas sobre o direito a recurso e reparação para vítima de violações flagrantes de normas internacionais de direitos humanos e de violações graves do direito internacional humanitário (Resolução 60/247), o Protocolo de Palermo, entre outros. No âmbito interno, sustenta que o direito das vítimas deve ser construído pelo Direito Penal e Administrativo, como objeto de políticas públicas específicas, especialmente no que diz respeito a mulheres vítimas de violência doméstica, em relação a quem o tratamento deve ser multidisciplinar, integral e não revitimizante, conforme preconiza a Lei Maria da Penha e orienta o ODS n. 5. Pontua os principais direitos das vítimas, destacando os deveres do Estado de proteção, de investigar, de sancionar e de garantir uma justa e eficaz reparação. Embora haja avanços normativos na legislação doméstica, a exemplo da Lei $11.340 / 2006$ e do artigo 387, inciso IV, do Código de Processo Penal, que previu que a sentença fixará valor mínimo de reparação à vítima; estes ainda não são suficientes. Com efeito, o Brasil ainda não dispõe de um estatuto de proteção às vítimas nem de fundo de indenização, apesar de a Constituição Federal assegurar assistência aos herdeiros e dependentes carentes de pessoas vitimadas por crime doloso, sem prejuízo da responsabilidade civil do autor do ilícito (art. 245). Daí ressai a necessidade de se adequar a legislação interna ao ODS n. 16 da ONU (Promover sociedades pacíficas e inclusivas para o desenvolvimento sustentável, proporcionar o acesso à justiça para todos e construir instituições eficazes, responsáveis e inclusivas em todos os níveis), para que as vítimas obtenham uma resposta estatal satisfatória. Nesse norte, analisa o Projeto de Lei do Senado $n$. 64, de 2016, que cria o Ato Nacional dos Direitos das Vítimas visando a sanar a omissão legislativa detetada. Ainda, menciona a Resolução n. 181/2017 e a Proposta de Resolução n. 705/2019, do Conselho Nacional do Ministério Público, enquanto diretrizes dirigidas ao órgão de acusação no tratamento a ser assegurado às vítimas de criminalidade. Utiliza método dedutivo, com auxílio de pesquisa bibliográfica e documental.

Palavras-Chave: Direitos Das Vítimas, Vitimologia, Vitimização, Violência Doméstica, Justiça Restaurativa. 


\section{AS PRÁTICAS RESTAURATIVAS COMO MEIOS EFETIVOS PARA A TRANSFORMAÇÃO DE CONFLITOS DE VIOLÊNCIA DOMÉSTICA}

A sistemática perpetrada atualmente pela justiça retributiva prioriza o tratamento punitivo dos casos de violência doméstica e, somente em segundo plano, trata da assistência individual à vítima e prevenção da violência, o que leva grande parte das mulheres a desistirem do processo criminal. Pode parecer um contrassenso, contudo, é o foco no escopo punitivo que promove desigualdades e fragiliza ainda mais a vítima, que tem questões muito mais complexas do que o processo criminal tradicional pode supor. É função do Estado atuar positivamente para permitir o acesso à justiça e garantir o respeito aos direitos fundamentais. Nessa toada, o Conselho Nacional de Justiça incluiu a utilização de práticas restaurativas como política pública nacional (Resolução no 225/2016), com atuação fulcral no direito criminal. Por isso, esta pesquisa objetiva colocar a Justiça Restaurativa como novo paradigma de justiça, mormente na Violência Doméstica, sem excluir a atuação do Poder Judiciário, mas o complementando, pela percepção dos direitos humanos nas questões de gênero, pautada na comunicação não-violenta, no acoIhimento da vítima, na identificação das necessidades dos envolvidos e na transformação de pessoas e conflitos. A vítima como ponto fulcral para a implementação de justiça, a necessidade de seu empoderamento e a evitabilidade de revitimização, a partir da aplicação de práticas restaurativas. Para isso, foi feita uma pesquisa qualitativa apresentando um estudo acerca da razoa- bilidade das citadas práticas ao serem utilizadas para transformação destes conflitos de gênero, por meio de uma análise dialética. Porquanto violência doméstica, em todas as suas formas, afeta o íntimo dessas mulheres receptoras e sua identidade como sujeito, o Poder Judiciário precisa ter uma abordagem humanizada, proporcionando um ambiente seguro e espaço de fala, onde a mulher consiga dizer o que aconteceu e entender as possíveis formas de reparação. Em razão do acima exposto, vislumbram-se as seguintes práticas restaurativas como aplicáveis aos casos de violência doméstica: círculo de apoio à mulher -atendimentos individuais e coletivos; círculos de diálogos, encontro entre autores e receptores de relações afetivas desestruturais diferentes, grupos de feminilidade com mulheres receptoras de violência doméstica e círculo de construção de paz. Esses encontros, liderados por facilitadores, buscam ofertar um ambiente seguro e horizontal para as partes falarem sobre suas vulnerabilidades, angústias, expressarem seus sentimentos e trabalharem para chegar a uma transformação dos conflitos relacionados à violência doméstica. A aplicação do modelo restaurativo em conflitos de gênero humaniza o processo e depende da voluntariedade dos interessados, busca pela reparação dos danos, empoderamento da vítima e responsabilização ativa e direta dos participantes, oportunizando o diálogo, incluindo nesse processo colaborativo as microcomunidades das partes.

Keywords: Conflito, Violência Doméstica,

Justiça Restaurativa, Empoderamento,

Comunicação Não-violenta.
Ana Evelyne Cavalcante Costa Cerqueira

\& Lorena Nogueira Rêgo Universidade Federal do Rio Grande do Norte - UFRN 
Michelli Linhares de Bastos Centro Universitário Ritter dos Reis UNIRITTER

Ref.: 255CEDHM22020

\section{O AUTISMO FEMININO E OS ESTEREÓTIPOS DE GÊNERO: UM ESTUDO COM MENINAS E MULHERES DA CIDADE DE CACHOEIRINHA/RS, BRASIL}

Os índices mundiais sobre o espectro autista revelam um número significativamente maior de indivíduos do sexo masculino com o diagnóstico de autismo em comparação a indivíduos do sexo feminino. Esse fato ensejou pesquisas baseadas em fatores biológicos, como a genética, para encontrar respostas para essa disparidade. A ausência de conclusões efetivas ampliou os horizontes para a investigação sobre o autismo feminino, chegando a estudos sobre a camuflagem de características por parte dos indivíduos do sexo feminino que retardam ou impedem um diagnóstico do transtorno. Essa camuflagem está vinculada a estereótipos de gênero, em padrões de condutas sociais femininas nas quais meninas e mulheres lutam para enquadrarem-se. Esta pesquisa apresenta estudos empíricos qualitativos realizados com mulheres autistas e com cuidadores e cuidadoras de meninas autistas residentes no município de Cachoeirinha, no estado do Rio Grande do Sul, no Brasil, que partiu da hipótese desenvolvida na Inglaterra de que existe uma camuflagem de sintomas do autismo pelos sujeitos femininos baseada em padrões sociais de gênero. Além do objetivo principal de verificar a hipótese de camuflagem de sintomas, esta pesquisa visa promover a discussão sobre a duplo enfoque que envolve as mulheres com deficiência, partindo de uma análise intersecional entre estudos de gênero e direitos das pessoas com deficiência que demonstram uma situação de dupla vulnerabilidade envolvendo o autismo feminino. Os resultados desta pesquisa revelam que existe um padrão de corpo ideal na sociedade que é homem e repleto de capacidades. Meninas e mulheres autistas partem de um preconceito existente com o corpo feminino, pois não é o modelo social promovido como superior, e encontram no autismo um segundo preconceito que é o comportamento social dissonante com os padrões preceituados como ideais.

Palavras-Chave: Autismo Feminino, Camuflagem, Estereótipos de Gênero, Pessoas com Deficiência. 


\section{A ORAÇÃO DA MULHER SILENCIOSA: VIOLÊNCIA DOMÉSTICA CONTRA MULHERES EVANGÉLICAS E POLÍTICAS PÚBLICAS}

De acordo com estatísticas cruzadas do Censo 2010 e do Instituto Brasileiro de Geografia e Estatística (IBGE), no Brasil, cerca de $23 \%$ das mulheres são evangélicas/pentecostais. No entanto, como relatado por Valéria Vilhena (2010), quase $40 \%$ das mulheres que buscam ajuda após terem sofrido violência doméstica se declaram evangélicas. Como se explica tal descompasso? Que papel desempenham as lideranças religiosas destas igrejas? Em um ambiente de submissão à instituição eclesial e ao marido, e de proibição moral do divórcio, as mulheres pentecostais parecem ainda mais expostas e vulneráveis à violência doméstica. A presente pesquisa visa compreender como a instituição, onde as representações cristãs de gênero participam da conservação e da continuidade de padrões de masculinidade e feminilidade bem definidos, pode se tornar um lugar onde este tipo de violência é mais frequente e abafado ao mesmo tempo. É nessa perspetiva que este estudo, na intersecção da sociologia das religiões, sociologia de gênero e sociologia das políticas públicas, pretende investigar a questão da violência de gênero dentro da igreja a partir de quatro eixos de pesquisa: a) compreender a eficiência das estratégias de unificação da agência e de socialização dos sujeitos produzidas nas igrejas evangélicas; b) entender as atitudes e posturas das autoridades religiosas; c) analisar o impacto das políticas públicas de enfrentamento à violência de género -Lei Maria da Penha (2006) e Lei Feminicídio (2015) -entre as mulheres evangélicas; d) investigar as possibilidades, em termos de programas e medidas, para refletir o combate à violência contra esse recorte populacional. Para este fim, foram realizadas sete entrevistas não estruturadas e semiestruturadas -de acordo com a preferência das mulheres dado o desconforto causado pelo objeto de estudo -com mulheres de diferentes denominações evangélicas que sofreram violência doméstica (principalmente física, psicológica e sexual) por parte do companheiro, do marido ou até do pai.

Keywords: Igrejas Evangélicas, Mulheres, Violência Doméstica, Padrões de Feminilidade.

\section{Morgane Reina}

\& Luciana Nunes Fonseca Universidade de Braslia 
Ref.: 278CEDHMI 2020

\section{A ERRADICAÇ̃̃O DA VIOLÊNCIA OBSTÉTRICA COMO FORMA DE ALCANCE DE IGUALDADE DE GÊNERO E EMPODERAMENTO DAS MULHERES}

Lúcia Souza d'Aquino Universidade Federal do Rio Grande do Sul
Ainda que a gestação esteja constantemente relacionada a situações de amor e alegria extremos, essa não é a realidade no Brasil. Em pesquisa realizada no ano de 2010, apurou-se que 1 a cada 4 mulheres sofre violência no momento do parto. Essa violência pode ser praticada tanto pelos profissionais da área médica quanto aos outros profissionais que têm contato com a parturiente e sua família, desde a recepção até o momento em que têm alta hospitalar. A violência obstétrica, termo conceituado pela Rede Global de Mulheres para Direitos Reprodutivos como uma combinação entre violência institucional e violência contra a mulher durante a gestação, parto e pós-parto, que pode se manifestar tanto através da negativa de atendimento durante o parto quanto de práticas invasivas e de intervenções médicas forçadas e não consentidas, além de diversos tipos de discriminação, ocorre com uma frequência que a torna naturalizada. No ano de 2014, a discussão tomou proporções nacionais quando uma gestante foi conduzida pela polícia para o hospital para que nela fosse realizada uma cirurgia cesariana, apesar do conhecimento da equipe médica de que ela pretendia ter a experiência de um parto vaginal. Mais de 6 anos após o ocorrido, a situação no Brasil ainda é a mesma, não havendo modificações legislativas ou práticas suficientes para coibir a violência. A título de exemplo, no ano de 2019 o Ministério da Saúde, provocado a se manifestar sobre violência obstétrica, afirmou que a expressão tem conotação inadequada, não agrega valor e preju- dica a busca do cuidado humanizado, sustentando a existência de estratégias para a abolição de seu uso. Tal negação caracteriza também uma tentativa de invisibilidade das mulheres violentadas, eis que tira delas a sua voz e a possibilidade de uma discussão legislativa a respeito do tema. Dessa forma, o presente trabalho pretende discutir como a erradicação da violência obstétrica através da adoção efetiva de boas práticas no atendimento à mulher no ciclo gravídico-puerperal, bem como da efetivação de legislação que enfrente - tema e coíba a sua prática podem auxiliar no alcance da meta de alcance da igualdade de gênero e empoderamento de mulheres, eis que permitirá um acesso qualificado à saúde sexual e aos direitos reprodutivos. Para tanto, através da utilização de uma metodologia hipotético-dedutiva, serão debatidos os direitos da mulher durante os processos de atendimento ao parto e ao abortamento, tanto no Brasil quanto diretrizes da Organização Mundial de Saúde, normativas internacionais e legislações estrangeiras para, de posse de tais informações e dos dados a respeito da prática no Brasil, apresentar uma proposta de medidas administrativas e legislativas para implementar os direitos supramencionados. A pesquisa encontra-se atualmente em fase final de elaboração da proposta, já tendo sido feitas a coleta de dados e a estruturação do texto do artigo final a ser apresentado.

Palavras-Chave: Violência Obstétrica, Igualdade de Gênero, Saúde Reprodutiva, Boas Práticas, Empoderamento. 


\section{DESAFIOS A IMPLEMENTAÇÃO DO DIREITO \\ DAS MULHERES AO TRABALHO EM ANGOLA}

Este texto pretende fazer uma avaliação do artigo $324 .^{\circ}$ da Lei do Geral do Trabalho de Angola a luz dos princípios de direitos humanos fundamentais, nomeadamente a proibição de discriminação e a igualdade. O citado preceito estabelece "trabalhos proibido se condicionados" as mulheres, por causa da sua "função genética". A partir de uma revisão bibliográfica faço duas críticas a esta previsão legal. Primeiro, o mesmo viola os direitos humanos das mulheres ao trabalho. E em segundo, reforça estereótipos de género vigentes na sociedade angolana há muitos anos. Estas abordagens serão feitas através de dois princípios fundamentais no âmbito dos direitos humanos: a proibição de discriminação e a igualdade. $O$ princípio da proibição de discriminação é um direito importante, ela está prevista na actual Constituição de Angola. A sua disponibilidade ou a falta dela afecta a capacidade de gozo de muitos outros direitos. O princípio da não discriminação baseada no sexo foi consagrado, em Angola, desde a primeira Constituição. Tal preceito surge num contexto social de grande desigualdade de género. Enquanto província ultramarina, vigorava em Angola um sistema de género em muitos aspectos semeIhante ao vigente na Europa daquele tempo. Onde se defendia a supremacia masculina em relação ao feminino, a sua fragilidade física e pouca capacidade intelectual de executar trabalhos tidos como mais complexos do ponto de vista intelectual e físico. O princípio da igualdade é visto aqui na sua perspectiva substancial. Possibilitando tratar igual a situação de modo idêntico. Diferentes situações de modo diferente. Tanto no primeiro como neste princípio, o critério de justiça é fundamental, para evitar violar ao invés de promover direitos. Esta norma legal é um atentado ao direito das mulheres ao trabalho. É reflexo do Estado patriarcal actual herdado do período colonial. Reduz-se a mulher a categoria de mãe e dona de casa. Excluindo-a completamente dos espaços historicamente tidos como masculinos, em nome de um paternalismo infundado. Outrossim, muitos dos trabalhos proibidos pela mencionada Lei são de excelente remuneração. Logo, esta proibição, referente apenas às mulheres arrisca a perpetuar sua a dependência económica, a manutenção das desigualdades de género. Partindo deste raciocínio, concluo que a citada norma deve ser expurgada do ordenamento jurídico angolano através do expediente da inconstitucionalidade. A igualdade não implica aniquilar a diferença. No entanto, as diferenças não podem ser utilizadas para derrogar direitos, sob pena de violação de direitos humanos fundamentais e do Estado democrático e de direito.

Keywords: Direitos das Mulheres, Angola, Lei Geral do Trabalho, Patriarcado, Direitos Humanos.
Florita Cuhanga António Observatório de Políticas Públicas na Perspectiva de Género - Assoge 
Patrícia Tuma Martins

Bertolin

Universidade Presbiteriana Mackenzie, São Paulo, Brasil

\& Werdeson Olimpio Universidade Federal do Maranhão, São Luís-MA, Brasil

Ref.: 085CEDHMI 2020

\section{NOTIFICAÇÃO COMPULSÓRIA DA VIOLÊNCIA DOMÉSTICA CONTRA A MULHER NO BRASIL: ANÁLISE À LUZ DA BIOÉTICA FEMINISTA E DATRANSVERSALIDADE DE GÊNERO}

Os conflitos éticos relativos às condutas a serem tomadas em face dos avanços das biotecnociências, em detrimento dos valores e direitos dos seres humanos, é objeto da chamada Bioética. Contudo, em razão das interfaces entre as teorias de gênero e as demais ciências, com uma postura crítica no enfrentamento das desigualdades concernentes a um processo histórico de dominação patriarcal, surgiu a Bioética Feminista. Paralelamente, objetivando o enfrentamento das desigualdades de gênero em todos os campos da vida social e política, oriundo das Conferências e documentos internacionais de proteção às mulheres, emergiu a ideia de transversalidade de gênero. A problemática objeto deste artigo envolve questões como a autonomia da mulher, a confidencialidade da relação médico- paciente e a efetividade da notificação compulsória nos casos de violência doméstica contra a mulher no Brasil, como política pública que observe a transversalidade do gênero. Para se alcançar o objetivo central deste artigo, foi feita uma revisão bibliográfica e uma análise qualitativa. A discussão versa acerca da autonomia da mulher em fase da notificação compulsória, assemeIhando-se ao debate da ADI n 4.424, em que o Supremo Tribunal Federal, a Corte Suprema brasileira, decidiu que as ações referentes às lesões corporais em violência doméstica são de natureza pública incondicionada. Como resultado, observou-se que tal política pública é apenas uma parcela da construção de um cenário de superação dos desequilíbrios entre os gêneros e de uma dominação patriarcal, na medida em que há uma necessidade de harmonização junto às tomadas de decisões em todas as esferas e políticas públicas da vida social, a fim de que esse quadro de igualdade seja concretizado. Ao Estado cabe implementar ações afirmativas, reduzindo as desigualdades, a fim de construir uma sociedade em que a autonomia das mulheres seja efetiva, desgarrada das influências do gênero e do patriarcado.

Palavras-Chave: Bioética Feminista, Violência Doméstica, Transversalidade De Gênero, Violência Contra A Mulher, Notificação Compulsória. 


\section{A PROTEÇÃO DE MULHERES EM SITUAÇÃO DE VIOLÊNCIA DOMÉSTICA COM A PROLAÇÃO DE SENTENÇAS DE MÉRITO EM MEDIDAS PROTETIVAS DE URGÊNCIA}

As medidas protetivas de urgência, previstas na Lei no 11.340, de 2006, a legislação voltada a coibir a violência doméstica no Brasil, mais conhecida como "Lei Maria da Penha", foram forjadas com o propósito de tentar impedir a reunião das condições fáticas imediatas, propícias à violência doméstica e familiar, prevenindo, em caráter de urgência, as consequências graves e nefastas advindas desse tipo de violação de direitos humanos. A inclusão das Medidas Protetivas de Urgência ao texto legal trouxe indubitável inovação, uma vez que constituem mecanismos cujo regime se volta à proteção imediata das mulheres em situação de violência doméstica e familiar, por meio de providências que procuram assegurar a integridade das vítimas em conflitos intrafamiliares. Ocorre que, muito embora representem a maioria das ações judiciais manejadas em casos de violência doméstica, esse instrumento processual ainda possui os contornos pouco explorados pela doutrina e pela jurisprudência brasileiras, de forma que se pode divisar essa área como um campo frutífero de desenvolvimento de pesquisas. Nesses termos, o presente artigo procura abordar a efetividade das Medidas Protetivas de Urgência a partir da prolação de sentenças que tragam solução de mérito às causas, a partir da experiência advinda da prolação de sentença de mérito na Vara Especial em Violência Doméstica e Familiar contra a Mulher de São Luís do Maranhão, fazendo-se uso da análise de conteúdo da mesma. Pretende-se ainda analisar a importância de se prolatar decisões judiciais com esse conteúdo, de modo a permitir uma proteção mais efetiva às mulheres em situação de violência doméstica por meio da utilização da técnica de estudo de caso, mostrando o sucesso que essa demanda em particular galgou no sentido de proteção da integridade da mulher agredida, a partir do emprego desta técnica processual.

Keywords: Medidas Protetivas de Urgência, Sentença de Mérito, Efetividade, Violência Doméstica, Violência Contra a Mulher.
Artenira da Silva e Silva \& José Augusto Sá Costa Leite

Universidade Federal do Maranhão, São Luís-MA, Brasil 
Luz Maria Consuelo Jaimes Legorreta

Facultad de Derecho de la Universidad Autónoma del Estado de México

\& Adriana Guillermina

Ríos Vázquez

Universidad Autónoma de Baja

California, México

Ref.: I 22CEDHM22020

\section{TRASCENDENCIA DE LAS SENTENCIAS DE LA CORTE INTERAMERICANA DE DERECHOS HUMANOS EN LA PROTECCIÓN DE DERECHOS DE MUJERES EN MÉXICO}

Actualmente tenemos un número significativo de tratados, tanto a nivel regional como universal, que están dirigidos al reconocimiento pleno de los derechos de la mujer. Instrumentos que buscan eliminar la subordinación y discriminación entre los géneros y alcanzar el respeto de normas, costumbres y prácticas que garanticen una igualdad real entre el hombre y la mujer.

En este sentido, las sentencias emitidas por la Corte Interamericana de Derechos Humanos (CIDH) han evidenciado la histórica situación de desigualdad, discriminación y violencia de la cual son víctimas las mujeres, así como las enormes brechas entre los discursos y las acciones desarrolladas por los Estados. Por lo cual, podemos afirmar que los casos llevados a la jurisdicción internacional se han convertido en un mecanismo de acceso a la justicia para mujeres, que además ha evidenciado los aciertos y deficiencias denormas y políticas estatales.

En el caso de México, desde el año 2001 se han generado disposiciones legales que constituyen la base de acciones jurídicas, administrativas, políticas y sociales, para erradicar la discriminación de las mujeres y alcanzar la igualdad real de los géneros. Ordenamientos entre los que se puede citar: la Ley del Instituto Nacional de las Mujeres, la Ley Federal para Prevenir y Eliminar la Discriminación, la Ley General para la Igualdad entre Mujeres y Hom- bres, y la Ley General de Acceso de las Mujeres a una Vida libre de Violencia; las cuales reflejan explícitamente las obligaciones contraídas en instrumentos internacionales que reconocen y protegen los derechos de este sector de la población; sin embargo, el tema de la desigualdad, discriminación y violencia contra las mujeres es un asunto pendiente. Las estadísticas permiten afirmar, que los principios de no discriminación e igualdad establecidos en los documentos jurídicos se ven opacados por una realidad en la que existe discriminación, relaciones desiguales, falta de oportunidades, estereotipos sociales y violencia contra las mujeres. Violencia que se encuentra generalizada, invisibilizada, tolerada y además constituye una violación a los derechos humanos, al obstaculizar la igualdad real, el desarrollo y la paz.

Tan es así, que la CIDH ha emitido 14 sentencias, de las cuales 5 revisten especial interés en cuanto al reconocimiento y protección de los derechos de las mujeres. Por lo que en este trabajo se realizará su análisis, a fin de conocer la perspectiva de género aplicada por la CIDH al resolver los casos sometidos a su jurisdicción, así como la interpretación realizada de los tratados internacionales aplicables y el impacto que dichas resoluciones han tenido en nuestro país en materia de legislación y políticas públicas.

Palavras-Chave: Derechos Humanos, Mujeres, Igualdad, Violencia, Discriminación. 


\section{UNIVERSIDADE FEDERAL DE SANTA CATARINA (UFSC) COMO INSTITUIÇÃO PROMOTORA DA IGUALDADE DE GÊNERO NO BRASIL}

O presente estudo tem como objetivo apresentar a Universidade Federal de Santa Catarina -UFSC, localizada no Sul do Brasil, como instituição de ensino universitária que promove ações institucionais e educacionais visando à igualdade de gênero, em cumprimento ao prescrito pela Agenda 2030 da Organização das Nações Unidas -ONU. A UFSC, no contexto brasileiro, apresenta-se como pioneira na atuação ao combate às desigualdades sociais. Em 2008, a universidade implementou política de ações afirmativas para reserva de vaga, em todos os cursos, para pessoas advindas de ensino público, pessoas negras e pessoas indígenas -isso antes mesmo da legislação nacional, que disciplinou a organização de cotas em 2012. Em 2016, na temática diversidade e gênero, a UFSC instituiu, em sua estrutura administrativa e como órgão executivo central, a Secretaria de Ações Afirmativas e Diversidades SAAD, criada com a proposta de auxiliar o gabinete da Reitoria a propor, implementar, consolidar e monitorar políticas de ações afirmativas e diversidades. Assim, consolidou-se como a primeira (e, atualmente, a única) instituição de ensino superior com tal estrutura para a promoção de ações afirmativas e garantias de diversidade no Brasil. Nesse contexto e para o foco desta proposta, é estudada a Coordenadoria de Diversidade Sexual e Enfrentamento da Violência de Gênero-CDGEN, que compõe a estrutura da SAAD e tem como finalidade o estabelecimento de políticas de enfrentamento à LGBTfobia e violência contra a mulher, na luta pela promoção dos direitos da população universitária LGBTQI+ e mulheres, aliando-se a outros setores da universidade responsáveis pelo combate às discriminações referentes a outros marcadores sociais além do gênero. Posteriormente, em específico, são examinadas as ações das CDGEN, tais como produção de cartilhas e manuais (por exemplo: cartilha de orientação para retificação de nome de pessoas trans; manual sobre diversidades para educadoras e educadores), mapas de violência contra mulheres. 0 estudo também se debruça sobre as ações relacionadas ao ensino e ao apoio institucional de iniciativas, de pesquisa e de extensão, de promoção à igualdade de gênero dentro da instituição e, ainda, acerca das ações relacionadas à prevenção e repressão à violência contra mulheres no ambiente universitário. Para tanto, a pesquisa constitui-se como de abordagem qualitativa, viés indutivo, de cunho exploratório-descritivo, com procedimento de estudo de caso, abrangendo levantamento bibliográfico, documental e com previsão de realização de entrevista. Pretende-se, com essa pesquisa, demonstrar a importância do enfrentamento à desigualdade de gênero em instituição de ensino, visando, além da formação de profissionais conscientes, a constituição de pessoas com mais responsabilidade social e com postura ética para alcançar a igualdade de gênero e empoderar todas as mulheres e meninas.

Keywords: Instituição de Ensino Superior, Mulheres, Gênero, Igualdade de Gênero, Ações Afirmativas.
Grazielly Alessandra Baggenstoss

Universidade Federal de Santa Catarina (UFSC), Brasil 


\section{TEORIA DAS JANELAS QUEBRADAS - "THE BROKEN WINDOWS THEORY" - E A SUA IMPORTAÇÃO PARA O CENÁRIO BRASILEIRO}

Nathaly Veloso Lehnen

Universidade de Coimbra Mestrado em Ciências Criminais
O presente trabalho se apresenta na análise da teoria que surgiu em meio ao movimento chamado "law and order" como uma política criminal eficaz, sendo intitulada e publicada em um periódico por James Wilson e George Kelling como uma forma de diminuir as altas taxas de criminalidade na década de 90 nos EUA, a qual trazia a alegação de que a desordem e o crime estão diretamente ligados segundo um estudo realizado por Philip Zimbardo baseado no resultado do experimento em que fora deixado dois carros idênticos em regiões diferentes com sua consequente deterioração. Há a ramificação de aplicação da política criminal em Nova York, chamada de Tolerância Zero de cunho conservador, taxativo e com atuação violenta de policiais pelas ruas a fim de punir e excluir o desordeiro (prostitutas, bêbados, mendigos, moradores de rua em geral) da sociedade. Ora, reflito sobre uma lacuna quanto aos crimes mais graves, por exemplo, a repressão de crises menores não necessariamente resulta no impedimento de homicídios, o que deve ser feito pra diminuir esse índice?

E partindo dessa base faço uma comparação com a realidade brasileira (UPP - Unidade de Polícia Pacificadora que tinha como intuito combater o crime organizado nas favelas do Rio de Janeiro) que buscou importar e aplicar uma política criminal baseada na tolerância zero e que consequentemente não tem tido resultados tão satisfatórios quanto se esperava. Não houve a aplicação nos mesmos moldes, mas ao passarmos o olho em ambos cenários muito a de se considerar em semelhança. Alguns ideais importados de início resultaram em certa diminuição da criminalidade, uma vez que o objetivo era também a promoção do desenvolvimento social, mas ao longo dos anos voltou a aumentar consideravelmente. O movimento de lei e ordem discursava e impunha máxima intervenção do direito penal e estava recheada de abusos das autoridades. Muitos dados demonstram que muitas unidades foram fechadas no Brasil, ora estamos diante de contextos completamente diferente, brasileiro e americano, logo realidades diferentes não podem ser vistas da mesma forma. Dispensando a repressão agressiva à população seria melhor uma maior atuação do Estado fortalecendo a existência de lei e seu funcionamento a fim de influenciar a população a defender bem mais seus valores e objetivos. Isso resultaria em melhoria no desenvolvimento sócio cultural e político e consequente adoção de uma postura mais proativa. O Brasil passa por sérias crises estatais e certa omissão faz com que a população se torne descrente diante da melhoria da sua realidade. Portanto antes de qualquer atuação é preciso uma análise pormenorizada das possíveis consequências e não só dos benefícios políticos e financeiros que surgirão. A metodologia da pesquisa teórica investigativa analítica baseou-se em fontes bibliográficas doutrinais, jurisprudenciais de materiais documentais e plataformas digitais, e estrutura conforme orientações da Faculdade de Direito da Universidade de Coimbra.

Palavras-Chave: Política Criminal, The Broken Windows Theory, UPP, Criminalidade, Semelhanças aplicativas. 


\section{A VIOLÊNCIA DE GÊNERO CONTRA TRAVESTIS E MULHERES TRANSSEXUAIS E AS POSSIBILIDADES NORMATIVAS PARA COIBI-LA}

Pensar a sexualidade e o gênero induz à necessária reflexão sobre como as ideias e práticas a elas relacionadas são produzidas historicamente no interior de sociedades concretas em determinado período e de que forma são capazes de construir estigmas que diferenciam determinados indivíduos pelo compartilhamento de algum traço em comum. Ao se delimitarem os diferentes campos do sexo e do gênero, vê-se que os cerceamentos de direitos infligidos às mulheres, em razão do patriarcado e da sociedade machista ocidental, que delimitam de forma muito clara os papéis sociais de cada gênero, não se aplicam unicamente àquelas que nasceram com o sexo feminino, mas também àquelas que, embora tenham nascido com o sexo masculino, se identificam com o gênero feminino. As violências direcionadas às travestis e mulheres transexuais têm por fundamentos centrais o preconceito e o estigma irracional ocasionados pela quebra nos padrões esperados de gênero. Considerando que o respeito às diferentes identidades de gênero é essencial para assegurar a dignidade e a humanidade de cada pessoa, vê-se que o enfrentamento à violência de gênero contra travestis e transexuais é primordial para garantir o desenvolvimento humano. Nesse sentido, a partir do método hipotético-dedutivo e com o auxílio dos tipos de pesquisa bibliográfico e documental, o presente trabalho tem por objetivo analisar de que forma os tribunais brasileiros têm interpretado o ordenamento jurídico nacional para punir e coibir a violência de gênero contra a população de mulheres transgênero. Parte-se da hipótese de que o Poder Judiciário, a partir da hermenêutica jurisprudencial, pode adaptar determinadas leis, especialmente a Lei no 11.340/2006 (Lei Maria da Penha), a Lei no 13.104/2015 (Lei do Feminicídio) e a Lei no 7.716/1989 (Lei do Racismo), para atingir tais objetivos. De facto, a Constituição Federal de 1988 consagra como núcleo do sistema jurídico o respeito à dignidade humana, dotando os princípios da igualdade e da isonomia de potencialidade transformadora na configuração de todas as relações jurídicas, o que leva à proibição de discriminação e de posturas transfóbicas. Nesse sentido, percebe-se que o Estado não pode se utilizar do Direito e dos sistemas de Justiça como subterfúgios para privilegiar uma posição moral heterossexual e cisnormativa, provocando a conformação compulsória ou então a invisibilização de sujeitos dissidentes de sexo e gênero. Ao contrário, é dever inafastável da República democrática a proteção de minorias contra a violência e estigmatização, para que todos possam exercer o gênero e a sexualidade livremente em todas as suas potencialidades.

Palavras-Chave: Identidade De Gênero, Travestis, Mulheres Transexuais, Violência, Possibilidades Normativas.
João Pedro Rodrigues Nascimento

\& Luciana do Amaral Rabelo Universidade Federal de Mato Grosso do Sul 
Ref.:285CCEDHM32020

\section{GÉNEROY DERECHOS HUMANOS: NUDOY DEUDA DEL ESTADO CHILENO EN LA GESTIÓN DE EMERGENCIASY DESASTRES}

Paulina Vergara Saavedra

Universidad de Chile / Universidad Alberto Hurtado (Chile)

\& Camila Troncoso Zúñiga Universidad Academia Humanismo Cristiano / Asociación de Abogadas Feministas (ABOFEM) (Chile)
Chile se encuentra entre los países del mundo con el mayor registro de ocurrencia de desastres no solamente debido a su sismicidad, sino por su diversa geografía y exposición al cambio climático (Pérez, 2018; UNISDR, 2015). Pese a la experiencia chilena frente a catástrofes, a los acuerdos internacionales que ha suscrito (entre los cuales Hyogo y Sendai), y a los avances en lagestión de riesgo de desastre, ante la pandemia COVID-19, se han vuelto a evidenciar las desigualdades de género como un nudo crítico de las respuestas estatales ante las crisis.

Para el Instituto Nacional de Derechos Humanos INDH (2015), las materias relacionadas con derechos humanos y catástrofes o emergencias han tenido un creciente impacto en Chile desde el terremoto y maremoto 2010, y entre éstas, los temas de género han sido particularmente complejos. Lo anterior, es consistente con la evidencia internacional que sostiene que ante desastres mayores, hay grupos específicos de la población que se ven más fuertemente impactados que otros por estos eventos catastróficos, entre los cuales la variable de género influye de forma crucial (Casares, 2013; Gomez y Zedillo, 2018).

Este trabajo busca evidenciar cómo en Chile, el género ha sido un objeto de estudio y preocupación constante por parte de la sociedad civil y de organismos de derechos humanos en contextos de crisis y desastres, pues estos man- tienen y reproducen las desigualdades de género, lo que torna necesario su consideración en las políticas adoptadas para su gestión.

A través de un enfoque socio-histórico de los principales desastres chilenos entre 2010 a 2020, este estudio analiza las conclusiones y recomendaciones más relevantes por parte de la sociedad civil organizada, academia e instituciones expertas en materia de género y derechos humanos en contexto de crisis; complementando la revisión de fuentes primarias con entrevistas para determinar, cuáles factores incidirían en que pese a ser considerado el género en la respuesta a los desastres, ante la crisis actual por Coronavirus, aún este nudo se constituya más bien como una deuda. El artículo concluye que, si bien se han adoptado acuerdos sobre medidas para enfrentar las desigualdades de género ante riesgos de desastres, esto no ha tenido traducción institucional en términos de gestión de emergencias y desastres sino sólo de manera tangencial.

Palavras-Chave: Género; Derechos

Humanos, Gestión de Riesgo de Desastre,

Crisis, COVID-19. 


\section{AS IGREJAS ENQUANTO ELEMENTO DE INTERLOCUÇÃO ENTRE A ESFERA PRIVADA E PÚBLICA NA VIDA DAS MULHERES: UM ESTUDO A PARTIR DE HISTÓRIAS DE VIDA}

Este trabalho apresenta recorte de estudo que teve como objetivo investigar a relação entre as vivências na esfera privada e na esfera pública de mulheres militantes pelos direitos sexuais e direitos reprodutivos no Brasil, a partir da metodologia das histórias de vida. Foram colhidos os relatos de cinco mulheres militantes, diversas em raça/ cor, classe social e geração, explorando aspetos de suas vivências privadas e públicas no tocante ao exercício dos direitos sexuais e reprodutivos. Dentre os resultados da pesquisa, aponta-se a igreja enquanto elemento importante de articulação entre as esferas pública e privada. A igreja católica e, mais recentemente, as igrejas neopentecostais, têm histórico importante de atuação para a restrição do exercício de direitos das mulheres no Brasil, em especial no que se refere aos direitos sexuais e direitos reprodutivos. As igrejas são reconhecidamente responsáveis pela restrição do exercício dos direitos das mulheres, atuando politicamente no sentido de não garantir a efetivação desses direitos, até mesmo em contextos em que apresentam perspetivas progressistas. As influências para a não descriminalização do aborto, a restrição da discussão sobre sexualidade e reprodução, a insistência em um modelo familiar que pesa de maneira drástica sobre as vidas das mulheres são algumas dessas restrições. Nos relatos, observou-se que houve impor- tante participação política das mulheres da pesquisa na igreja, indicando-se que em diversas situações os grupos religiosos abriram caminho para a militância, conformando-se em espaços que permitiram a circulação das mulheres em uma esfera pública. Ainda assim, os questionamentos do ponto de vista das estruturas sociais se efetivaram ou foram potencializados especialmente em espaços não religiosos. Na esfera privada, por outro lado, o exercício da sexualidade ligado à culpa e ao segredo esteve presente nos relatos, assim como as dificuldades na luta pela efetivação dos direitos sexuais e reprodutivos. Observou-se na pesquisa a importância das igrejas enquanto espaço de participação social para mulheres; a atuação de grupos na igreja católica que se identificaram com ideais progressistas; a influência dos ideais da igreja católica nas perceções e vivências referentes à sexualidade na adolescência. Diante do contexto político atual, observam-se também perspetivas desanimadoras para os direitos das mulheres diante do avanço do neopentecostalismo aliado à ofensiva legislativa na contramão da laicidade do Estado.

Palavras-Chave: Direitos Sexuais e Reprodutivos, Religião, Ativismo Político, Histórias de Vida.
Paloma Abelin USP \& Rosana Machin Departamento de Medicina Preventiva/FM-USP 
Ref.: 307CEDHM22020

\section{A EDUCAÇÃO COMO CAMINHO AO EMPODERAMENTO FEMININO}

Maria Clara Giassetti, Julia Henn Arcos \& Renata Silva Souza Universidade Presbiteriana Mackenzie
Historicamente, mulheres tiveram que lutar para ter seu espaço dentro da sociedade e garantir seus direitos de maneira igualitária, fato este que persiste até os dias atuais. Isso porque, em muitos lugares ao redor do globo, as vozes das mulheres não são ouvidas e, em tantos outros, são abafadas pela discriminação.

Impossível olvidar a parcela de responsabilidade do feminismo na luta por esses direitos, porquanto, desde a Revolução Francesa, em 1789, busca direitos políticos, liberdade e igualdade, pela primeira vez apresentando as mulheres como sujeitos políticos, com interesse na vida pública. Dessa forma, no século XIX, com o estabelecimento do capitalismo na sociedade mundial, nasce a luta sufragista, durando sete décadas e defendendo que o poder do voto levaria a uma maior acessibilidade feminina ao parlamento, possibilitando uma mudança legislativa.

Necessário salientar que o conceito de sujeito político ora adotado tange a conceção de política lato sensu, abrangendo a ideia de influência sobre as pessoas.

O enfoque da pesquisa é analisar a inserção de mulheres na política, partindo da ótica feminista. Importante, contudo, salientar que as discussões e reflexões aqui trazidas não devem se restringir meramente à esta esfera, pois a discriminação de gênero se dá em inúmeros outros âmbitos, tais quais, tráfico e exploração sexual, direitos reprodutivos, etc.

Também por conta dessa discussão, a Agenda 2030 da Organização das Nações Unidas (ONU) tem como objetivo a igualdade de gênero. É certo que a educação de qualidade, que também perfaz objetivo da referida Agenda, se mostra grande aliada para tanto, uma vez que, quanto maior o acesso à educação de qualidade, maiores as chances de mulheres alcançarem posições importantes de tomada de decisão e influência na sociedade, inspirando, consequentemente, outras mulheres.

Assim a questão que permeia o trabalho é: quais as condições da educação no mundo e como elas fomentam - ou não - a igualdade de gênero por meio do empoderamento das mulheres, nos termos da agenda 2030 da ONU?

O objetivo, destarte, é demonstrar que a educação motiva a inserção de mulheres no setor público/privado, impactando no empoderamento de outras mulheres e contribuindo, assim, para a redução da desigualdade de gênero.

Por isso, o método adotado para o desenvolvimento é o dedutivo, alinhado a técnicas de pesquisa bibliográficas e análise de dados essencialmente qualitativos.

Palavras-Chave: Feminismo, Educação de Qualidade, Igualdade de Gênero. 


\section{PERSPETIVAS DE GÉNERO SOBRE A PANDEMIA COVID-19 E OS SEUS IMPACTOS NAS MIGRAÇÕES}

Face ao aumento significativo dos movimentos migratórios, a presente comunicação pretende refletir, a partir de uma perspetiva de género, sobre os impactos da crise pandémica nas diferentes esferas de vida das mulheres imigrantes. O pressuposto teórico que enquadra esta comunicação assenta numa grelha de análise que o atual surto do novo coronavírus e da COVID-19 agrava determinadas desigualdades de género com a reprodução de velhas assimetrias e a acentuação dos papéis tradicionais ao nível da responsabilidade da vida familiar, sendo as mulheres imigrantes mais vulneráveis e desproporcionalmente afetadas (EC, 2020). Os dados recentes apontam ainda para o risco acrescido das mulheres imigrantes em contrair a COVID19 pela precariedade e a insegurança dos seus contextos socioeconómicos (e.g., imigração irregular e trabalhos sem proteção fortemente afetados pela pandemia), pela fragilidade e ausência de recursos e rede de suporte (e.g., comodidades básicas, condições de habitação), pelas barreiras no acesso aos serviços e cuidados de saúde (e.g., barreiras linguísticas, culturais e legais, falta de conhecimento dos serviços disponíveis) e por estarem mais expostas a situações de vitimação, discriminação e exclusão social (UN, 2020). Assente, numa matriz intersecional, ao reconhecer a diversidade das experiências e ao direcionar-se para vulnerabilidades específicas das mulheres migrantes, esta comunicação, procura também mostrar como os riscos e impactos da COVID-19 são moldados e se entrecruzam com diferentes pertenças identitárias, como o estatuto socioeconómico, tipo de família, nacionalidade, idade, orientação sexual, contexto geográfico, priorizando e sublinhando, deste modo, a necessidade de se definirem programas de intervenção e medidas de proteção para mitigar os efeitos da pandemia, bem como, de se adotarem respostas concertadas e adaptadas para este grupo.

Palavras-Chave: Mulheres Imigrantes, Género, Pandemia.
Estefânia Silva ISMAI/CIEG 
Ref.: 356CEDHM22020

\section{UMA ANÁLISE DO ODS 5 NA CIDADE DE BELO HORIZONTE: UMA ANÁLISE AMPLIADA E O IMPACTO DA PANDEMIA DO COVID-I 9}

Breno Cypriano, Bárbara Angove Lopes \& Marlise Matos
Buscando entender as questões da igualdade de gênero na Cidade de Belo Horizonte, ressaltando principalmente os elementos específicos da política local e das características sociodemográficas da Cidade, construímos, a partir da parceria do Observatório do Milênio da Prefeitura de Belo Horizonte com o Núcleo de Estudos e Pesquisas sobre a Mulher (NEPEM/UFMG), um instrumental de indicadores e em uma metodologia própria sobre este Objetivo de Desenvolvimento Sustentável (ODS 5). Desta forma optamos, a partir da reflexão sobre a relevância de determinados indicadores coletados pelos diversos órgãos da Prefeitura e de organismos públicos do Estado de Minas Gerais, em focar nas metas que dizem respeito principalmente: à eliminação da violência, aos dados de feminicídio, valorização do trabalho doméstico, acesso à saúde e igualdade de oportunidades, participação e liderança (levando também em consideração os aspetos interseccionais). Alinhamos a discussão com o Objetivo de Desenvolvimento Sustentável 10, que tem como foco a redução das desigualdades dentro dos países e entre eles mesmos, pois também optamos por focar, prioritariamente, nos indicadores que nos possibilitam fazer inferências sobre a desigualdade de renda no município. Ressaltamos a importância desta discussão a nível da política local, principalmente no atual contexto, que também possibilita tratar os impactos da pandemia do Covid-19 e quais desdobramentos ela acarreta à conquista das metas estabelecidas, principalmente nas consequências do desemprego, aumento das tarefas domésticas e de cuidado e violência contra as mulheres. Acredita-se que ao analisar esta dimensão contingencial apontaremos os obstáculos que dificultam a se conquistar as metas propostas pela Agenda 2030 das Nações Unidas. Por fim, apresentamos algumas considerações sobre a Igualdade de Gênero e propostas específicas de Políticas Públicas locais.

Palavras-Chave: Igualdade de Gênero, Belo Horizonte, Desenvolvimento Sustentável, Pandemia Covid- 19, Políticas Públicas Locais. 


\section{A VIOLÊNCIA DOMÉSTICA E AS CONQUISTAS DAS MULHERES: REFLEXÕES A PARTIR DA SITUAÇÃO PORTUGUESA}

Este artigo tem como principal objetivo refletir e examinar, a partir de uma perspetiva regional, hipotéticas relações entre o 'progresso' das mulheres em vários domínios/dimensões de análise (como por exemplo em termos de trabalho, de conhecimento, de tempo, de poder, etc.) e os níveis de violência doméstica contra cônjuges ou análogos em Portugal. A investigação, baseada na análise comparativa de dados das sete regiões portuguesas (nível NUTS2), procura verificar se as diferenças regionais em termos de 'conquistas' femininas podem ajudar a explicar as oscilações no número de ocorrências de violência doméstica registadas pelas autoridades policiais. Pretende-se, nomeadamente, responder à seguinte questão: Será que, em Portugal, as 'conquistas' ou 'realizações' das mulheres tem implicações no número de crimes de violência doméstica denunciados às autoridades policiais nas diferentes regiões? Para atingir o propósito do estudo e para responder a esta questão, foram mobilizados para análise os resultados de um indicador composto (IC) desenvolvido por Norleén, Papadimitriou e Dijkstra (2019): o Female Achievement Index (FemAI). O FemAI permite medir o nível de desempenho das mulheres em comparação com o melhor desempenho regional nas 270 regiões da União Europeia em sete dimensões de análise: trabalho e dinheiro, conhecimento, tempo, poder, saúde, segurança e confiança e quali- Carina Jordão dade de vida. Os resultados deste IC, Universidade de Aveiro que agrega informação de mais de 30 indicadores, foram usados para aferir a 'realização' das mulheres em cada uma das sete regiões em estudo. Já para determinar a incidência de crimes de violência doméstica em cada região, recorreu-se ao número de participações de "violência doméstica contra cônjuges ou análogos" registados pelas forças policiais portuguesas em 2017. Os resultados do trabalho conduzido evidenciam que, em 2017, no contexto português, a região que apresentava a taxa de incidência de violência doméstica (registada) contra cônjuges ou análogos mais elevada era também aquela em que as mulheres apresentavam menores níveis de 'realização'/'conquistas' (Região Autónoma dos Açores). 0 artigo termina com uma breve reflexão teórica que chama atenção para a complexidade da problemática em estudo, o seu carácter interseccional e para a necessidade de, no futuro, realizar mais estudos neste domínio.

Palavras-Chave: Conquistas Femininas, Mulheres, Violência Doméstica, Portugal, Regiões. 


\section{DEVELOPING A SUB-NATIONAL GENDER DEVELOPMENT INDEX IN INDIA}

Ananya Mishra \& Anurag Banerjee People's Initiative
The conventional metrics and indices quantifying gender equality in India are based on Health, Education and Quality of Life. A few indices do incorporate institutional metrics such as representation in the Parliament. However, all such metrics have a few shortcomings.

Firstly, there is no mechanism to track all such metrics for independent States or districts, mostly because of data deficiency. This hinders the State from tracking gender development levels in the State, and creating a lacuna as far as gender development policies are concerned. Secondly, most of these indicators are institutional or macroscopic, not touching upon issues that affect "common woman".

In this regard, the study attempts to develop Gender Development Index based on 6 broad pillars: "Health", "Nutrition", "Social", "Access", "Economic" and "Reproductive Care" to track, compare and set policy targets for the States at State levels. The six pillars cover approximately 30 variables. The index is based on the data from National Family Health Survey 4 (2015-16). The study covers therural, urban and total coverage of the States for more effective policy targeting. Each of the State are scored on basis of their performance and the total score under each pillar is calculated. This score is then scaled and the Geometric mean of the scores is taken to arrive at the Gender Development Index score for a State/ area. These Gender Development Index scores were mapped to each State to represent divergences and inequalities. The study clusters the States on basis of the Performance as "Achiever", "Front runner", "Performer" and "Aspirant" states. The study also shows the trends of these variables from National Family Health Survey 3 to National Family Health Survey 4, analyzing which states have improved over the decade when it comes to Gender Development.

As a litmus test for performance and tool for policy planning, the index is a point of convergence of multiple Sustainable Development Goals: Sustainable Development Goal-3 for "Good Health and Well Being", Sustainable Development Goal-5 for "Gender Equality", Sustainable Development Goal-2 for "Zero Hunger" and Sustainable Development Goal-4 "Quality Education ". Therefore, the index is an opportunity to track the performance of individual States with respect to multiple Sustainable Development Goals.

More importantly, it gives the States the opportunity to develop tangible targets for Gender Equality moving from Gender Budgeting to a more elaborate institutional attempt to tackle issues hampering Gender Equality in India. Up until now, policy making in India with respect to gender equality has focused on enabling provisions, creating separate non-lapsing funds, Gender Budgeting or forming populist laws like death penalties for violent crimes against women, but deep seated Gender inequalitiesrequire more nuanced approach of governance and the study identifies metrics that assist in shifting the paradigm to such governance.

Palavras-Chave: Gender Development Index, Gender Equality, Reproductive Health, Sustainable Development Goals, Sub-National Policy Making. 


\section{A INCONSTITUCIONALIDADE DA CRIMINALIZAÇÃO DO ABORTO À LUZ DA ADPF 442 NO BRASIL}

O presente artigo propõe a discussão acerca da questão do aborto, ainda criminalizado no Brasil, que se constituiu em um tema de grande complexidade no cenário político jurídico nacional, visto que o país, embora laico, é influenciado por uma ideologia cristã que trata da matéria de maneira dogmática e fundamentalista, não visando, dessa forma, os direitos fundamentais que cerceiam a existência da mulher. Como objeto principal, busca-se entender à luz da ADPF 442, ajuizada pelo Partido Socialismo e Liberdade, tendo relatoria da ministra Rosa Weber, de que modo a vigente legislação do Código Penal em seus artigos 124 e 126, se adequa de maneira a contrariar a Constituição Federal de 1988, que garante postulados fundamentais como a dignidade da pessoa humana, a não discriminação, a inviolabilidade da vida, a liberdade, a igualdade, a proibição de tortura ou o tratamento desumano e degradante, a saúde e o planejamento familiar das mulheres e os direitos sexuais reprodutivos, previstos nos arts. $1^{0}$ I e II, 30, IV, 50, caput e I e III, 60, caput, 196 e 226, §70, da Constituição Federal. Todo o supracitado é discutido tendo em vista a política estatal-legislativa que, de certo modo, foi constituída por homens cristãos, dispondo do corpo da mulher como objeto de tutela do Estado, que impõe uma gestação sem analisar o contexto social o qual a mulher está inserida, sendo esse último pressuposto, essencial para garantir à criança a qualidade de vida necessária. Através da ADPF 442, busca-se que haja outra forma de aborto lícito e permi- tido, sendo este até a décima segunda semana de gestação, acompanhada das já existentes: aborto em caso de estupro; aborto em caso de risco para a vida da mulher e, por fim, aborto de feto anencefálico. Chegou-se a conclusão de que versar sobre o tema é de extrema necessidade, não obstante, mesmo que ainda criminalizado, de acordo com o Ministério da Saúde, uma mulher morre a cada dois dias por praticar aborto inseguro no país, ou seja: mesmo cerceado de dogmas e pressupostos religiosos, mulheres ainda abortam. Tal fator implica diretamente no direito a vida da mulher, em que pese à ilegalidade da ação contribuir para a situação de extremo risco de mulheres negras, indígenas e nordestinas, as mais prejudicadas com a situação da clandestinidade. Entende-se que, embora assegurado ao nascituro através do Código Civil de 2002, direitos da personalidade, sendo o direito a vida corolário, mulheres, enquanto sujeito de direitos, com necessidades que vão além da gravidez e do parto, necessitam de ações efetivas que garantam a si e a criança, qualidade de vida. Desse modo, a ADPF 442 serve de impulso para que haja uma concreta discussão acerca do tema, superando pressupostos patriarcais, misóginos e religiosos que se moldam à existência da mulher.

Palavras-Chave: Aborto, Criminalização,

Direitos Fundamentais, Mulher,

Inconstitucionalidade.
Taís Haywanon Santos Maia 


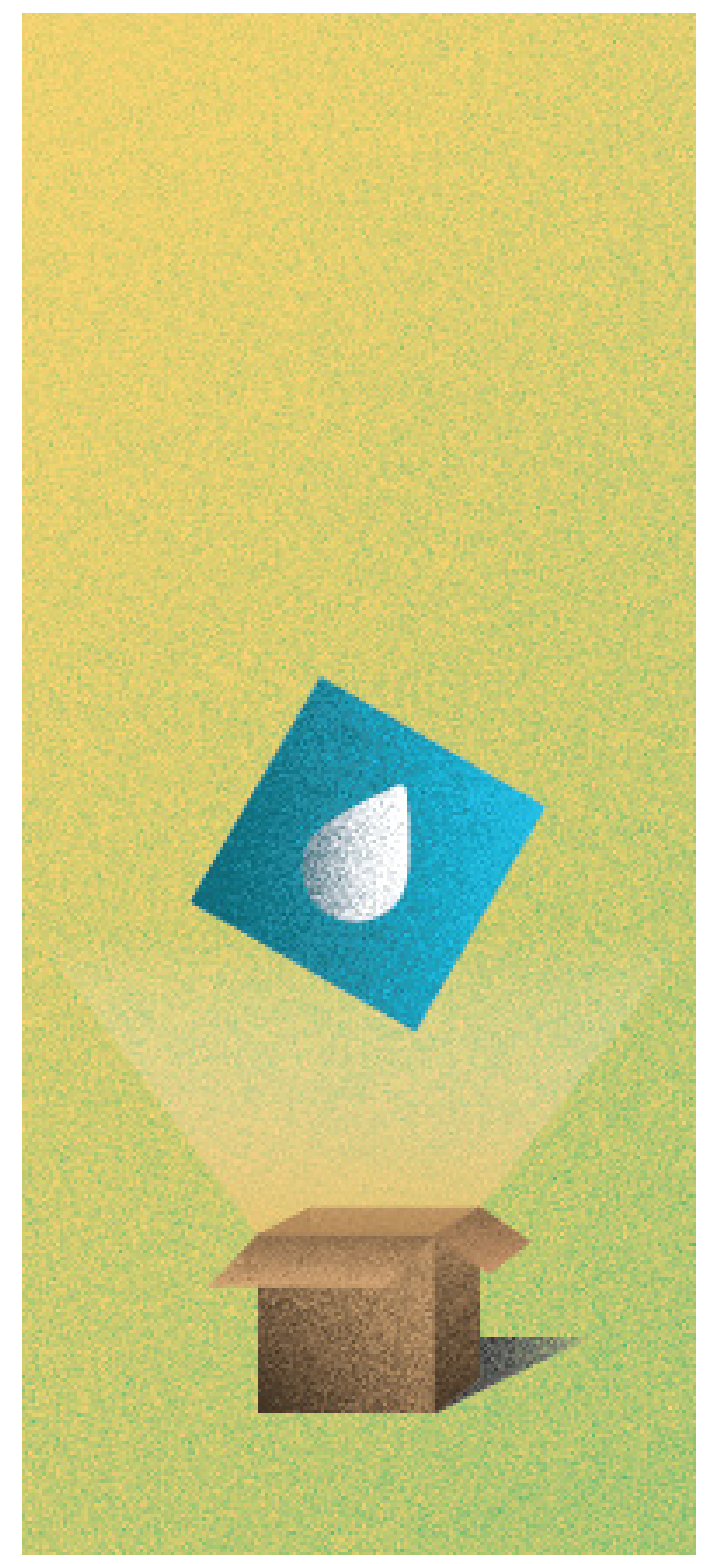

ATAS DA II CEDH:

AGENDA 2030 - UM NOVO CAPÍTULO

PARA A EVOLUÇÃO DOS DIREITOS HUMANOS

\section{ODS 6 ÁGUA POTÁVEL E SANEAMENTO}


Os compromissos na ONU relativos ao $6^{\circ}$ Objetivo do Desenvolvimento Sustentável para garantir o acesso universal à água até 2030 tornará o Brasil num valioso campo de observação para a análise das políticas públicas. Seu desafio será transformador: atender cerca de 40 milhões de pessoas sem direito a água potável, massa populacional que aumenta para 100 milhões de indivíduos desprovidos de serviços de esgotos e saneamento básico. O Brasil é detentor da maior reserva de água doce do planeta, que se distribuem inúmeras redes fluviais e volumosos aquíferos. A biodiversidade da Amazônia acrescenta uma carga pluviométrica incomum que realimenta outras partes do território. Inteiramente distinto é o vizinho Semi-árido Nordestino, alvo de obras concluídas após dez anos para a transposição do rio São Francisco, sujeito a sérios riscos de sustentabilidade (CGU, 2018). A bacia hidrográfica reúne 507 municípios, dos quais só um, Lagoa da Prata (MG, 52 mil habitantes), tem tratamento integral dos esgotos (CBHSF, 2020). Para enfrentar a explosão demográfica e a mobilidade social previstas para este século, a água é elemento determinante para ampliar a oferta de alimentos e energia. Resultado de investimento científico e tecnológico, o Brasil é global player agroalimentar, condição ímpar na latitude tropical ao empregar menos de $1 \%$ do caudal nos rios nacionais, estimado em $280 \mathrm{mil} \mathrm{m3/s}$ (Embrapa, 2019). A energia hidráulica (65\% da matriz brasileira), fora do ciclo de carbono, resulta de investimento em barragens cuja "energia limpa" não recupera danos ambientais, tam- pouco conflitos com etnias tradicionais, nem a alteração do regime hidrológico. Construída sem exigência de licença ambiental (1975/1984), Tucuruí inundou uma área de $2.830 \mathrm{~km} 2$ (Santana et al., 2014), inutilizando impressionante floresta: entre $40 \mathrm{~m} 3$ e $60 \mathrm{~m} 3$ por hectare (Junk e Mello, 1990). Só 10\% da madeira teria sido aproveitada (FSP, 2000). Precipitação em desequilíbrio compromete lençóis freáticos em solos impermeáveis ocupados por 84,7\% da população brasileira (IBGE, 2015). A desigualdade nas habitações se estende aos 5.570 municípios do país, onde $70 \%$ não têm esgotos (ANA, 2018). No Morumbi, bairro de classe média alta da cidade de São Paulo, ainda se utiliza fossa sética, pois o saneamento atende $92,6 \%$ do município. Em suma, apenas 22 dos 100 maiores municípios do país oferecem água potável à totalidade da população (Trata Brasil, 2019). O incumprimento das leis de conservação dos biomas e mananciais e hábitos de desperdício agravaram crises energéticas e de abastecimento urbanos (2014-2018). Business as usual, foi aprovado pelo Congresso novo quadro jurídico para o setor inspirado em parcerias público-privadas regionais com participação cívica. A nova fórmula de governança com investimentos em infraestrutura básica terá toda a primeira década pós-pandemia para testar sua eficácia na solução de um compromisso inadiável de direito ambiental.

Palavras-Chave: Maternidade e Novas Mídias, Ativismo Digital Materno, Narrativas de Mãe, Maternidade Feminista, Mães Na Política.
Luiz Carlos de Brito

Lourenço

Universidade de Lisboa, Instituto de Ciências Sociais (ICS) 


\section{A QUESTÃO DO DIREITO À ÁGUA E A AUSÊNCIA DE PROTAGONISMO NO DEBATE PÚBLICO POLÍTICO}

Tatiana Calmon ISCTE
Em 28 de Julho de 2010, a Assembleia Geral das Nações Unidas declarou a água limpa e segura como um direito humano essencial para uma existência com dignidade. Na agenda de desenvolvimento Sustentável (2015), o objetivo de expandir significativamente 0 acesso a água potável é retificado com o firme propósito de garantir, até 2030, a disponibilidade e a gestão sustentável da água para todos os indivíduos do planeta. Se a água é vida, a ausência deste recurso fundamental e escasso é uma ameaça para qualquer projecto de desenvolvimento social e económico. Apenas 3\% da superfície terrestre é composta por água doce (naturalmente própria para consumo) e cerca de 2,1 mil milhões de pessoas, segundo a OMS e o UNICEF, não têm acesso a água potável. São realidades alarmantes que, no entanto, não conseguiram produzir um entendimento comum entre os países sobre a fundamentalidade do direito ao acesso à água potável. Ainda assim, podemos considerar que a sociedade contemporânea se transformou numa sociedade ambientalista no sentido de que foi implantado um debate contínuo e aguerrido sobre as relações humanas e o meio ambiente. O ambientalismo tornou-se finalmente pauta de interesse público e fenómenos como o aquecimento global, capital mediático e político. Países desenvolvidos e em vias de desenvolvimento firmaram vários acordos e protocolos com o objetivo de reduzir o impacto das mudanças climáticas em todo o mundo como a Cúpula de Ação Climática em 2019. E dentre as ambiciosas propostas da ONU para manter o compromisso das lideranças globais em reduzir o aquecimento glo- bal, estava o desejo de construir um planeta para TODOS mas a questão da água ainda não referida com o protagonismo político que tanto necessita. Sem esquecer de que os direitos fundamentais de terceira geração, também chamados de direitos de fraternidade ou de solidariedade, puderam situar a figura humana numa dimensão de proteção coletiva assegurando o direito ao meio ambiente equilibrado e saudável. Nesse enquadramento, como um recurso essencial para o bem comum, podemos afirmar que o direito à água está em consonância com o direito à vida e com a dignidade da pessoa humana. Portanto a gestão, a manutenção e a distribuição dos recursos hídricos mundiais deveria gozar do mesmo entusiasmo e atenção que questões ambientais igualmente relevantes como a destruição de florestas ou a emissão de gases com efeito de estufa. Por meio de uma revisão bibliográfica, o presente trabaIho pretende compreender o aspeto da água enquanto direito fundamental e recurso essencial para a vida dos seres humanos ao longo da história contemporânea e dos acordos e políticas públicos mais recentes. Afinal, como é materializada a relação entre o acesso a água potável e uma existência digna e salutar. Para o aprofundamento teórico desta questão partiremos da ideia da água como um direito fundamental nato, ou seja, a todos os indivíduos deve ser garantido acesso por ser pedra basilar da dignidade humana.

Palavras-Chave: Água, Direito Fundamental, Dignidade Humana, Protagonismo Político. 


\section{BANCADA DE MÃES ATIVISTAS - DE ATIVISTAS DIGITAIS E CANDIDATAS ÀS ELEIÇÕES DE 2018 NO BRASIL}

A pesquisa se dedica a investigar de quais maneiras as redes sociais digitais impactam e proporcionam base para a organização de uma maternidade política e politizada, na qual as mães se tornam ativistas digitais e candidatas às eleições 2018. A partir desse argumento, por meio de levantamento bibliográfico de referência, investiga-se outras questões importantes que norteiam o tema, tais como: as contribuições do ciberfeminismo e do feminismo contemporâneo para a articulação de mães, os modos de interação delas no ambiente das redes sociais, as interfaces entre o feminismo e as novas redes sociais digitais para a construção e desconstrução dos papéis sociais da mãe e a compreensão da maternidade nas ondas feministas.

Além de aporte teórico, a netnografia (KOZINETS, Robert) é a metodologia utilizada como base para a observação das interações das mães em redes sociais digitais, com enfoque na hashtag \#MãesNaPolítica para identificar as candidatas às eleições de 2018 que utilizaram da pauta das maternidades e infâncias em campanhas políticas em rede, compartilhando informações e divulgando suas candidaturas na internet. A investigação partiu da observação do movimento de três mães blogueiras maternas que se candidataram pela primeira vez em 2018: Anne Rammi, do blog e fan page 'Mamatraca', que foi candidata a codeputada estadual (Bancada Ativista), Andrea Werner do blog e da fan page 'Lagarta Virou Pupa', candidata a deputada federal (PSOL-DF), e Ligia Moreiras Sena, do antigo blog, agora plataforma digital de jornalismo independente e fan page 'Cientista Que Virou Mãe', que foi candidata a deputada estadual (PSOL-SC). Para isso, foram coletados todos os posts dessas candidatas em suas fan pages do Facebook no período de 16 de agosto de 2018, data do primeiro dia da campanha autorizada pelo Tribunal Superior Eleitora (TSE), até 7 de outubro de 2018, data da realização do primeiro turno das eleições do ano em questão. Numa prévia dessa análise, encontra-se uma publicação anunciando a campanha da 'Bancada de Mães Ativistas organizadas pelo Brasil', com 11 integrantes, entre as quais estão inseridas as três acima citadas. Num ano de eleições polarizadas no País, como em 2018, com pautas reacionárias ocupando espaço, é de extrema relevância se debruçar sobre iniciativasque pretenderam dar conta de uma representação política progressista, organizada por integrantes das sociedades civil incomumente representados no ambiente político partidário, como é o caso das mães. A investigação visa contribuir com o entendimento das redes sociais digitais como espaço de articulação e empoderamento cidadão (CASTELLS, Manuel) e a multiplicação de vozes de novas identidades (HALL, Stuart) de grupos minoritários à luz do ciberfeminismo (HARAWAY, Donna) e do feminismo matricêntrico (O'REILLY, Andrea) como meio de proporcionar novos regimes representativos e democráticos.

Palavras-Chave: Sociologia do Ambiente, Água

e Saneamento, Desenvolvimento Sustentável,

Governança; Brasil
Renata Garcia Senlle Universidade de Lisboa, Instituto de Ciências Sociais (ICS) 


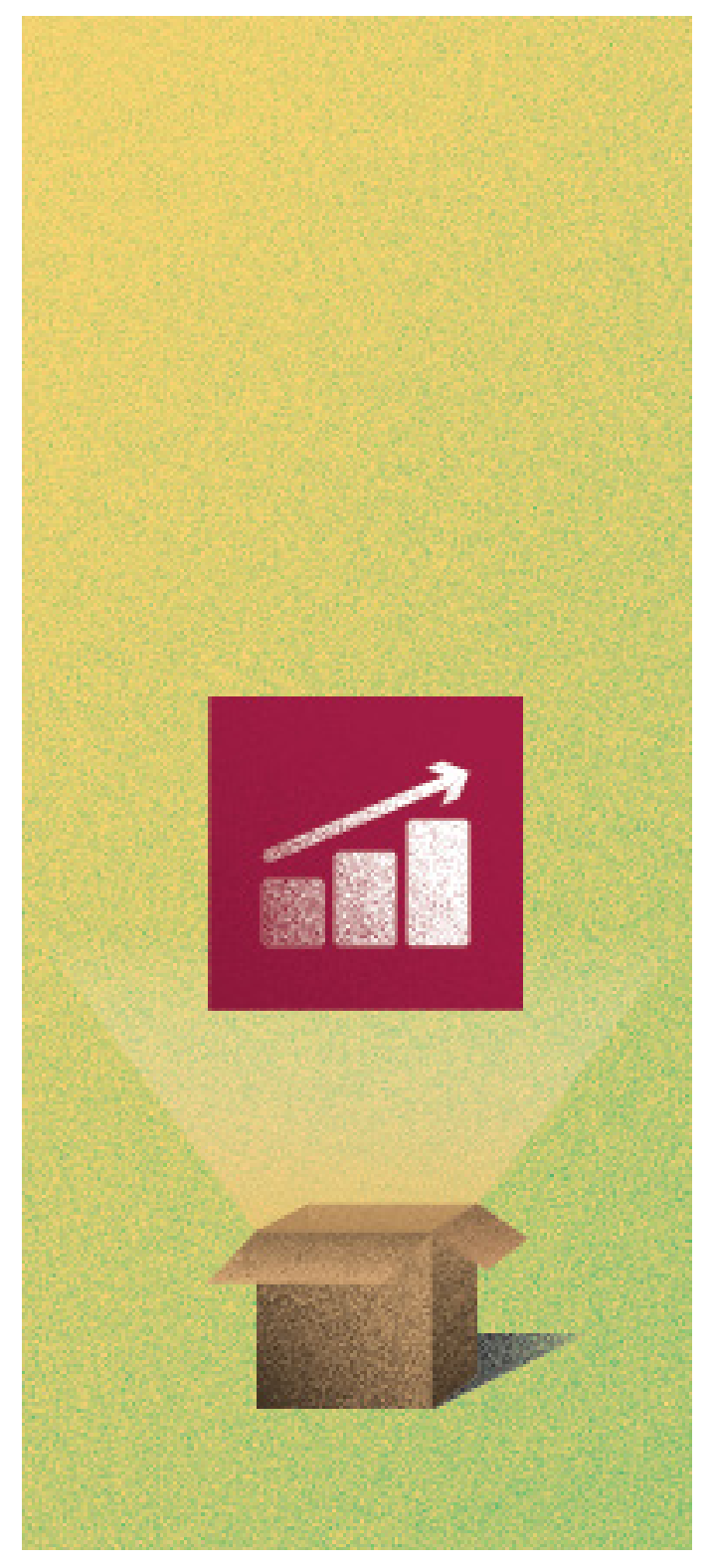

\section{ODS 8 TRABALHO DIGNO E CRESCIMENTO ECONÓMICO}




\section{AGRESSÕES ÀS POLÍTICAS PÚBLICAS DE COMBATE NO TRABALHO INFANTIL, NO BRASIL: SEU AGRAVAMENTO EM TEMPOS DE PANDEMIA}

No presente artigo, a motivação de sua escritura, ou seja, o transcurso, em 12.06, do Dia Mundial de Combate ao Trabalho Infantil, veio a se converter em seu objeto de pesquisa, uma vez centrado na sistemática agressão às políticas públicas já instituídas no país, na busca de enfrentamento desse grave problema social, que culminou na extinção da Comissão Nacional de Erradicação do Trabalho Infantil, pelo atual Governo Federal e, ainda mais, além do desmonte dessas ações específicas do Estado, pelo firmar-se de uma política de desinformação, já que, há dois anos, o IBGE -Instituto Brasileiro de Geografia e Estatística, não publica os dados referentes ao tema, provavelmente como estratégia de invisibilizar essa terrível mazela social e que, agora, impacta, de forma precípua, a violação dos direitos humanos e da dignidade da pessoa humana, dessa parcela extremamente vulnerável da população brasileira, em função da pandemia do coronavírus. A metodologia empregada parte de análise doutrinária e legal, ao apresentar os fundamentos constitucionais de proteção, juntamente com o ECA -Estatuto da Criança e Adolescente, bem como pelo Plano Nacional de Proteção e Erradicação do Trabalho Infantil e, ainda pelas Convenções da OIT -Organização Internacional do Trabalho, ratificadas pelo Brasil. A seu turno, o objetivo se coloca como centrado em denunciar o que se mostra como uma deliberada atuação, no sen- tido de ocultar e não fornecer os dados atualizados, como forma de obstaculizar ações concretas de órgãos do próprio Estado, no cumprimento da tarefa para a qual foram constituídos, o que causa um problema ainda maior, pois, em função da pandemia, o poder aquisitivo das famílias mais pobres acentua o uso da mão-de-obra infantil, como forma de completar os rendimentos econômicos mínimos, já perdidos, além de expor esses vulneráveis ao risco ainda maior de contágio, pelo rompimento do isolamento social e falta quase que completa dos mecanismos protetivos mínimos. Como resultado parcial, se pode auferir o descompasso entre as determinações do Governo Federal com os órgãos do próprio Estado que se insurgem contra tais agressões, a que se somam os esforços das organizações da sociedade civil, estruturadas com esse fim, bem como de denúncias levadas a efeito pelo jornalismo investigativo, que busca ocupar o espaço vazio da falta de dados e de ações concretas direcionadas a combater o agravamento dessa situação. Por fim, nesse sentido, se propugna que todas as políticas públicas, mormente essas, voltadas para a proteção da infância e adolescência, devam ser compreendidas e assumidas em seu caráter permanente de políticas de Estado, não podendo ser politizadas, ideologicamente, por ações governamentais transitórias, de quaisquer matizes.

Palavras-Chave: Trabalho Infantil, Desmonte de Políticas Públicas, Desinformação, Pandemia, Agressões aos Direitos Humanos.
Claudine Freire

Rodembusch

Faculdade Estácio Do Rio Grande Do Sul

\& Henrique Alexander Keske

Grupo De Estudos De Direitos Humanos ETransformação Social Da Universidade Ritter Dos Reis - Núcleo Fapa - Porto Alegre/Rs 
Raúl Payá Castiblanque

University of Valencia

Ref.: I04CEDHMI 2020

\section{IMPACT OF THE DIRECT PARTICIPATION OF WORKERS INTHE DESIGN OF PREVENTION MEASURES OF PSYCHOSOCIAL ORIGIN ON THE LEVELS OF ABSENTEEISM}

It is known that the indirect and representative partition of workers improves the workplace and reduces the rates of accidents at work. However, less studied is the benefits of the direct participation of the workers themselves in the management of occupational health. Therefore, the objective of this research was to study the relationships between the different levels of direct participation (passive, consultative or active-delegating) in preventive management with levels of absenteeism in the Spanish workplace. For this purpose, a cross-sectional study was carried out through the microdata of the Second European Survey of Companies on New and Emerging Risks (ESENER-2 -Spain, 2014) prepared by the National Institute for Occupational Health and Safety (INSHT) with a master population of 3,162 work centers in Spain. A multinomial logistic regression model was carried out, the dependent variable being the levels of absenteeism and the independent variables, the indicators of participation and preventive management, calculating the adjusted Odds Ratio (aOR) among all the independent and control variables, with their cor- responding Intervals of $95 \%$ confidence ( $95 \%$ IC). The results obtained showed how the active-delegative participation of the workers in the design and the adoption of measures to prevent psychosocial risks reported 2.33 less likely to have a very high or quite high level of absenteeism (aOR=0,43; 95\% IC:0.270.69 ), and yet that organizations had documented preventive management indicators (plan, risk assessment, planning measures) had no impact on absenteeism levels. In Spain, $88 \%$ of the work centers have the risk assessment prepared because the law requires it, but, nevertheless, only $34.5 \%$ of the workers actively participate in its elaboration, which shows that We can fall under an unrealistic institutional mirage of security, and active co-education or co-management policies are necessary to create a preventive culture within organizations that have a real positive impact on work absenteeism.

Palavras-Chave: Work Absenteeism, Direct

Participation; Prevention Management,

Preventive Culture, Co-Management. 


\section{CONDIÇÕES DE TRABALHO NOS TRIBUNAIS: IMPACTOS DA PANDEMIA COVID-I 9 NA REALIZAÇÃO DA JUSTIÇA}

O contexto sociolaboral associado à pandemia COVID-19, e consequentemente ao retorno progressivo ao trabalho, veio reforçar a importância crítica da implementação de medidas de segurança e saúde ocupacional e do reforço/controlo das condições de trabalho em todos os sectores de atividade. Os tribunais portugueses sentiram inúmeras dificuldades em adaptar-se e garantir padrões mínimos de segurança e saúde no trabalho adequados às exigências impostas pelo combate à pandemia. Neste cenário, o funcionamento, durante e após o confinamento obrigatório, caracterizou-se por uma diminuição operacional, registando-se quer uma suspensão quer um atraso na intervenção da justiça, com potenciais graves danos para os direitos humanos.

A declaração do estado de emergência, a 18 de março de 2020, estabeleceu a suspensão dos prazos e diligencias e prestação apenas dos serviços mínimos e urgentes, aplicando o regime das férias judiciais até à cessação da situação excecional. Durante o mesmo período, foi promovido o uso de meios de comunicação digitais, permitindo a realização de quaisquer atos processuais e procedimentais à distância, recomendando o uso de e-mail ou de telefone para obter informações junto dos tribunais; e fomentando a modalidade de teletrabalho sempre que a natureza das tarefas o permitisse.

Com o levantamento do estado de emergência, cessou o regime de férias judiciais e estabeleceu-se o uso de meios de comunicação à distância nas audiências de discussão e julgamento e diligências, sempre que estas não pudessem ser feitas presencialmente, de acordo com as regras da Direção-Geral da Saúde (DGS). Ao mesmo tempo, os órgãos competentes da administração da justiça, juntamente com a DGS, definiram as "Medidas para Reduzir o Risco de Transmissão do Vírus nos Tribunais", com, por exemplo, a distribuição de material de proteção e desinfeção ou a reorganização dos tribunais.

A falta de recursos digitais, e até mesmo de um enquadramento jurídico para dar continuidade à modalidade de teletrabalho nos atos processuais permitidos através de meios de comunicação digitais, a par da falta de condições físicas seguras adequadas para acomodar serviços e recursos humanos, fez, contudo, que muitos tribunais demorassem a retomar a normalidade possível e/ou retomassem sem as condições de saúde e segurança mínimas. Assim, a crise da COVID-19 expôs, relativamente às condições laborais e organizacionais presentes nos tribunais portugueses, algumas das fragilidades preexistentes na organização judiciária portuguesa, nomeadamente deficiências nos espaços físicos partilhados pelos diferentes profissionais e pelo público em geral.

O principal objetivo deste artigo é analisar as respostas institucionais do sistema judicial português em relação à adequação das condições de trabalho num momento de excecional preocupação com a saúde pública e com o normal funcionamento das instituições, e, consequentemente, os impactos sentidos na realização da justiça.

Palavras-Chave: Condições de Trabalho, COVID-19, Tribunais.
João Paulo Dias, Paula Casaleiro \& Teresa Maneca Lima Centro de Estudos Sociais da Universidade de Coimbra 
Ref.: I 58CEDHM22020

\section{SAÚDE MENTAL NO TRABALHO: PERSPECTIVAS PARA O ENFRENTAMENTO AO ADOECIMENTO PSÍQUICO DOSTRABALHADORES SOB AS DIRETRIZES DA OIT E DA OMS}

Amanda Cristina Campos de Almeida

\& Carla Reita Faria Leal

Programa de Pós-Graduação

em Direito da Universidade Federal de Mato Grosso (PPGD/UFMT)
As recentes transformações no mundo do trabalho, representadas pelo avanço tecnológico, pelo advento de novos métodos de gestão e pelo acirramento da competitividade no mercado de trabalho, implicam no surgimento de novos e complexos riscos psicossociais laborais. Estes, por sua vez, contribuem para o desenvolvimento crescente de patologias mentais, tais como depressão, transtorno de ansiedade, síndrome de burnout etc. Assim, a exposição a fatores psicossociais de risco no trabalho afeta trabalhadores de todas as profissões e classes sociais, impedindo-os de conduzir uma vida econômica e socialmente produtiva. Os problemas psicológicos estão entre as maiores causas de incapacidade e de afastamento do trabalho no mundo, prejudicando não só os trabalhadores, mas também os núcleos familiares, as empresas (com o aumento do absenteísmo, do presenteísmo e da rotatividade de pessoal), a economia (os transtornos de depressão e ansiedade custam mundialmente US\$ 1 trilhão ao ano em perda de produtividade) e a sociedade em geral. Tal cenário se opõe frontalmente a dois dos 17 Objetivos de Desenvolvimento Sustentável das Nações Unidas, quais sejam, o de assegurar uma vida saudável e promover o bem-estar para todas e todos, em todas as idades (ODS 3), e o de promover o crescimento econômico sustentado, inclusivo e sustentável, emprego pleno e produtivo e trabalho decente para todas e todos (ODS 8). Estes objetivos, compreendidos conjuntamente, asseguram a proteção à saúde mental do trabalhador, direito humano possibilitado pela vivência em um meio ambiente do trabalho equilibrado. Neste sentido, a pesquisa objetiva investigar as diretrizes e metas para a garantia da saúde mental do trabalhador elaboradas pela OIT e pela OMS, orientações que visam facilitar o desenvolvimento de políticas públicas e empresariais, em níveis nacional e internacional, bem como auxiliar no planejamento e na prestação de serviços de saúde, oportunizando a construção de uma cultura preventiva global dos riscos psicossociais no trabalho. Para atingir tal intento, serão utilizados o método de abordagem dedutivo e as técnicas de pesquisa bibliográfica e documental. Como resultado parcial aponta-se que a superação do adoecimento mental no trabalho é urgente e necessária, e só será viabilizada com a reformulação das condições e da organização do trabalho, reduzindo-se os riscos psicossociais existentes no ambiente laboral. Alguns caminhos para essa mudança têm sido apontados pela Organização Internacional do Trabalho e pela Organização Mundial da Saúde, em especial no Plano de Ação para a Saúde Mental 2013-2020 da OMS, estendido até 2030, e no relatório Trabalhar para um Futuro Melhor (2019), da OIT. Estes e outros documentos propõem uma agenda empresarial e econômica centrada no ser humano, promovendo-se a função socioambiental da propriedade e o desenvolvimento econômico sustentável com emprego justo, trabalho decente e sadia qualidade de vida para todos, metas da Agenda 2030 da ONU.

\section{Palavras-Chave: Saúde Mental, Ambiente} Laboral Equilibrado, Diretrizes, Organização Mundial da Saúde, Organização Internacional do Trabalho. 


\section{O TRABALHO DA PESSOA COM DEFICIÊNCIA COMO INSTRUMENTO DE IGUALDADE E INCLUSÃO SOCIAL}

Houve um longo caminho até que se percebesse que as pessoas com deficiência não devem ser vistas como inválidas, devendo ser consideradas pessoas capazes e dignas, exatamente como os demais seres humanos com aptidão plena. Entretanto, a despeito dessa evolução, as pessoas com deficiência ainda enfrentam grandes dificuldades em sua inserção no mercado de trabalho, principalmente pela ausência de compreensão quanto à responsabilidade da sociedade pela inclusão de todas as pessoas. Isso tem provocado a discriminação das pessoas com deficiência também quanto a acesso ao trabalho e às promoções, ainda sendo comum que recebam salário inferior a quem desempenha trabalho de igual valor ou que a elas não seja ofertado trabalho decente. O objetivo deste estudo é abordar o trabalho da pessoa com deficiência sob a ótica da igualdade e inclusão social. Serão analisados quais os principais desafios para 0 acesso e a permanência das pessoas com deficiência no trabalho e, ainda, quais os principais instrumentos para a efetiva inclusão social delas por meio do trabalho, sob o enfoque do modelo social da deficiência e do seu atual conceito. $O$ artigo possui relação com o Objetivo de Desenvolvimento Sustentável da ONU de no 8 , de que emprego pleno e produtivo e o trabalho decente sejam alcançados por todos, inclusive, pessoas com deficiência $A$ pesquisa é do tipo bibliográfica, com fins descritivos e exploratórios, mediante análise da legislação nacional e, ainda, do Direito Internacional aplicável, notadamente as normas da ONU e da OIT sobre a temática. Conclui-se que o trabalho é um elemento indissociável da concretização da cidadania e dignidade de todas as pessoas, inclusive as que possuem algum tipo de deficiência. Assim, a sociedade precisa avançar para perceber que o trabalho da pessoa com deficiência interessa a todos, devendo ajustar-se à diversidade para superar os desafios de inclusão das pessoas com deficiência e promover a igualdade de oportunidades, a não discriminação e a prosperidade a elas. Somente desta forma será concretizado o sistema de proteção e garantias da Constituição da República Federativa do Brasil de 1988, reforçado pela Convenção da ONU sobre os direitos das pessoas com deficiência (2006), promulgada no Brasil no status de emenda constitucional, e do ordenamento jurídico brasileiro.

Palavras-Chave: Pessoa com Deficiência, Direito ao Trabalho, Igualdade, Inclusão Social, Prosperidade.
Theanna De Alencar Borges

Universidade Autónoma De Lisboa "Luís De Camões" 
Eduardo Soares da Silva

Universidade Católica Dom Bosco - UCDB

\& Najah Jamal Daakour Barakat

Universidade Federal do Mato Grosso do Sul - UFMS

Ref.: I80CEDHM42020

\section{OBSERVANDO OS DIREITOS HUMANOS E O CONTEÚDO DE VULNERABILIDADE ECONÔMICA}

A vulnerabilidade econômica é um dos fatores bastante hodiernos e configurada como compromisso mediante aos governos mundiais e de igual modo o Brasil concatenados aos Direitos Humanos com a observância de promover por meio de leis e políticas públicas a contento de concretizar por meio da dignidade da pessoa humana a redução desse conteúdo de vulnerabilidade econômica. A vulnerabilidade aqui destacada não é algo novo na sociedade conhecida como organizada, a questão econômica, principalmente em países de terceiro mundo ou mesmo os que ainda estão se desenvolvendo é uma faceta bastante recorrente. As desigualdades atualmente tem sido uma preocupação latente de vários segmentos da sociedade em geral, com o plano de minimizar e reduzir essas desigualdades promovendo condições de combate, prevenção e assistência com vistas em compatibilizar mecanismos que visem de maneira contumaz além do combate às desigualdades, e a vulnerabilidade econômica, tendenciada em ainda erradicar a pobreza. A pobreza por sua vez é contingenciada como um dos maiores problemas em estagnar o processo de desenvolvimento do indivíduo na sociedade, e ainda na produção de impactos negativos e significativos a determinados grupos que necessitam de um olhar mais preciso e direcionado em condicionar elementos e subsídios capazes a traçar uma nova linha. O estabele- cimento da erradicação da pobreza, passa por um liame bastante desafiador, sobretudo na ideia que paira ao papel de vários protagonistas, desde os organismos sociais quanto jurídico e estatais. Dessa forma a devida promoção de ações que contenham a finalidade de combater e erradicar a pobreza ao foco da vulnerabilidade econômica, são totalmente percetíveis com elementos próximos ao compêndio de Direitos Humanos, bem como na igualdade que é encontrada nesses direitos e ainda na Dignidade da Pessoa Humana. Este último ressoa em que a dignidade que é inerente exclusivamente a condição humana, parece estar desassistida ao quesito de condições como a de sobrevivência por exemplo. Essa questão levantada na erradicação da pobreza e vulnerabilidade econômica, ainda recai em que a condição de pobreza é visualizada como uma espécie de violação própria dos Direitos Humanos. Partindo dessa premissa é muito intrínseca essa relação que é alusiva a erradicação da pobreza passando pela orientação dos direitos compreendidos aos Direitos Humanos e a dignidade que é totalmente presente ao ser humano.

Palavras-Chave: Direitos Humanos, Vulnerabilidade Econômica, Dignidade da Pessoa Humana, Igualdade, Políticas Públicas. 


\section{O DIREITO A DESCONEXÃO E O TRABALHO REMOTO: A IMPORTÂNCIA DO MEIO AMBIENTE DOTRABALHO NO DESENVOLVIMENTO DO HOMEM}

O trabalho no Século XXI, em decorrência dos grandes avanços tecnológicos surgidos a partir das décadas 40/50 do século passado vem alterando significativamente as relações sociais. 0 lócus para o exercício do labor assume caráter itinerante, deslocando-se dos pavilhões e prédios físicos, assim como da subordinação direta do empregador para espaços a critério do trabalhador, agora um parassubordinado de fato e, pela alteração legislativa brasileira de 2017, de direito. A terceira revolução industrial, a Revolução Tecnológica, temida pela diminuição de postos de trabalho de maneira formal, é reverenciada em 2020, justamente pela situação oposta: a manutenção do trabalho com a consequente diminuição de custos para o empregador e possibilidade de aumento de produtividade. O home office se tornou necessário como medida de saúde em face da Pandemia Covid19, assim declarada pela Organização Mundial da Saúde em março de 2020. O trabalhador realiza remotamente e através de meios telemáticos suas atividades. Não há mais deslocamentos, não há reuniões presenciais, somente virtuais. O trabalho é desenvolvido sem controle de horário. Os efeitos, embora incipientes, começam a ser percebidos: diminuição da poluição, alteração na mobilidade urbana, aumento de produtividade, novo dimensionamento acerca dos espaços domiciliares, distanciamento social, desequilíbrio na saúde mental, como por exemplo, aumento de casos de depressão. O meio ambiente do trabalho equilibrado, assegurado pela Constituição Federal de 1988, ratificando conceito desenvolvido internacionalmente assume importância vital nesta nova realidade empregatícia. O afastamento presencial substituído pelo trabalho remoto, implica na ausência de limitação da tradicional jornada laboral, o que poderá levar o trabalhador a deixar de exercer o direito fundamental a desconexão do seu labor. Constitui-se o direito a conexão no direito a saúde física e mental, no direito ao lazer, a convivência familiar, a prática de atividades não obrigatórias relacionadas ao trabalho, pondo fim a denominada "escravidão virtual". É, portanto, direito fundamental do indivíduo, tornando imprescindível o debate e a elaboração de propostas impondo limitações a este novo modelo de relações laborais, às vezes, análogas a escravidão, não mais física e sim virtual.

Palavras-Chave: Desconexão,

Parassubordinado, Home Office, Escravidão.
Claudia Maria Petry de Faria

\& Letícia Petry de Faria Universidade Feevale 


\section{A REPERCUSSÃO DOS EVENTOS DE MARIANA E BRUMADINHO À CONSECUÇÃO DO ODS 3 PARA A REDUÇÃO SUBSTANCIAL DO NÚMERO DE MORTES E DOENÇAS POR PRODUTOS}

Benedita de Fátima

Delbono

Universidade Presbiteriana Mackenzie - UPM

\& Pedro Gabriel Delbono

Trivelato

Faculdade de Medicina de Petrópolis - FMP/FASE
O Objetivo do Desenvolvimento Sustentável 3 -ODS 3 -disciplina assegurar uma vida saudável e promover o bem- estar para todas e todos, em todas as idades. Indica, dentre os seus objetivos específicos, assegurar até 2030 a redução substancialmente do número de mortes e doenças por produtos químicos perigosos, contaminação e poluição do ar, água e do solo. Entende-se, porém, que para que isso se efetive necessário se faz o compromisso de todos, inclusive, das pessoas jurídicas -empresas, organizações públicas e privadas e corporações -, notadamente, a título não só de responsabilidade ambiental, mas também, como responsabilidade social dessas pessoas jurídicas, frente ao compromisso com o ODS 3. Essa ideia vem de encontro com as recentes experiências no Brasil representadas pelas catástrofes decorrentes do rompimento das barragens de Mariana e Brumadinho que, além dos danos ambientais de grande proporção, comprometeram comunidades inteiras, em sua saúde física e psicológica, sem exclusão do comprometimento efetivo do bem-estar, que deveria ser objeto de preocupação extrema de todos. Esses dois eventos promoveram substancialmente um número de mortes; proveram doenças oriundas de produtos químicos perigosos; contaminaram e poluíram o ar, a água e o solo, não só local e do entorno, mas até regiões mais distantes no País. Ademais, esses eventos danosos destruíram a memória, promoveram o caos, levaram o sistema público de saúde ao socorro das vítimas o colapsando, de certo modo, nas regiões dos eventos. Hoje promove um desgaste considerável sobre as indeni- zações dos atingidos, que constituem um grupo de pessoas sacrificadas e hipossuficientes, os quais estão -como mundo está -enfrentando a COVID 19. A COVID 19 está colocando em risco o auxílio prestado aos atingidos pela ameaça de suspensão. Apesar da repercussão nacional e internacional desses eventos, não se observam ações efetivas dos responsáveis pelos danos, no sentido de mitigá-los e aprender com estes, a fim de preveni-los e, para servir a todos, como exemplo. Também, não se evidenciam ações de reparação da saúde e bem-estar dessas pessoas, cuja discussão, ainda, se firma apenas no resgate indemnizatório da propriedade. Há, porém, danos irreversíveis e, estudos ajudariam a prevenir e estimular a responsabilidade empresarial frente as questões dessa ordem. As pessoas jurídicas, conforme a construção constitucional, civil e empresarial brasileira, são responsáveis pelo meio ambiente e pelas pessoas, portanto, tem a responsabilidade socioambiental. Para o presente artigo, pretende-se promover uma investigação sistematizada, por meio da pesquisa bibliográfica, documental, ex-post-facto, de levantamento (exploratória e descritiva), em face dos dois eventos suscitados, aliando-os ao ODS 3, a fim de que se aproxime, minimamente no Brasil, de sua consecução em 2030 e, também, para que sirva ao mundo como estudo para o enfrentamento de questões assemelhadas, com a finalidade de prevenção e compromisso.

Palavras-Chave: ODS 3, Saúde, Meio

Ambiente, Mariana, Brumadinho. 


\section{A EXPLORAÇÃO HUMANA PELO TRABALHO ESCRAVO EM PLENO SÉCULO XXI: OS ENTRAVES DA NECESSIDADE DE EQUILÍBRIO ENTRE CAPITAL E TRABALHO}

A presente pesquisa tem como objetivo fazer uma abordagem sobre o tema do trabalho escravo no Brasil, sua evolução histórica ao longo dos anos, bem como a exploração humana no trabalho e a escravidão ainda existente em pleno século XXI. A luta dos negros contra a escravidão se inicia desde 753 a.C, a qual está sendo combatida por mecanismos jurídicos nacionais e internacionais. Internacionalmente por meio da OIT e nacionalmente pelos pactos já ratificados bem como a proteção do trabalhador por meio da evolução dos direitos e garantias. No que se refere ao princípio da dignidade do valor social e a pessoa humana, serão analisados tais preceitos que visam proteger os valores sociais do trabalho bem como a proteção do trabalhador, pois buscam diminuir as desigualdades sociais e promover o bem-estar de todos mantidos na Constituição de 1988, além da proteção por meio da CLT.

Serão analisados os preceitos de proteção do trabalho, a evolução das Constituições brasileiras, bem como o combate pela OIT. Os entraves da necessidade de equilíbrio entre capital e trabalho, partindo do princípio do valor social e da dignidade da pessoa humana. Será verificada a economia ao longo da história e a teoria da mais valia. Ainda será feita uma análise do trabalho escravo no Brasil e as Convenções de no 29 e no 105 da OIT. Abordar-se-á a necessidade de medicar o trabalhador, em razão da exploração do trabalho humano.

Por fim será explorado o trabalho escravo perante os pactos internacionais e o entendimento dos tribunais internacionais e brasileiros frente aos pactos já ratificados pelo Brasil. Ainda, os julgados relevantes referentes à exploração humana e o entendimento dos tribunais no Brasil. O objetivo do presente documento é servir como referência para o diálogo multissetorial e interinstitucional em relação ao tema do combate ao trabalho escravo, explicitando o posicionamento da equipe das Nações Unidas no Brasil em relação ao assunto. Espera-se, por meio dele, estabelecer uma visão norteadora para consolidar e fortalecer o trabalho daqueles que estão envolvidos com a temática e lutam para superar essa grave e persistente violação de direitos no País. (ONU, 2016).

Palavras-Chave: Escravidão, Equilíbrio, Capital, Trabalho, Exploração.
Tais Martins,

UniBrasil e Unifaesp

Andréa Arruda Vaz, UniBrasil e Unifaesp

Maria das Dores Francelino Bom Bosco

\& Andressa Ignácio da Silva UniBrasil e Unifaesp 


\section{A CRIAÇÃO DE SELOS SOCIAIS COMO CONCRETIZAÇÃO DO DEVER DEPREVENÇÃO AO TRABALHO ESCRAVO CONTEMPORÂNEO NA CADEIA PRODUTIVA DA CARNE BOVINA}

Fernanda Brandão Cançado \& Carla Reita Faria Leal Universidade Federal de Mato Grosso
O fato de o Brasil ter uma legislação considerada avançada com relação à temática trabalho em condição análoga à de escravo não tem por si só garantido bons resultados no combate desta modalidade de maxiexploração do ser humano. Mato Grosso ocupou o posto de vice-campeão nacional na utilização de trabalho escravo contemporâneo em 2018 (MPT/OIT, 2018), sendo que aproximadamente $30 \%$ (trinta por cento) destas ocorrências se deu no setor produtivo rural bovino (MPT/OIT, 2018). Considerando que os mecanismos de fiscalização nacionais não têm se mostrado capazes de eliminar ou mesmo inibir referido crime de lesa-humanidade, propõe-se investigar a contribuição da utilização de selos sociais como concretização do dever de prevenção reconhecido pela Corte Interamericana de Direitos Humanos no Caso Trabalhadores da Fazenda Brasil Verde vs. Brasil (2016). Além disso, a Organização das Nações Unidas (ONU) já se posicionou acerca da responsabilidade dos empregadores não se restringir àquelas violações relacionadas diretamente às suas atividades, mas também aos casos em que suas operações e parceiros comerciais estiverem envolvidos (UN, 2012), motivo pelo qual seria recomendável que referidos selos incluíssem critérios sociais e estendessem suas avaliações à cadeia produtiva. O Governo de Mato Grosso e o respetivo setor produtivo criaram recentemente o Instituto Mato-Grossense de Carne, que tem como finalidade promover a carne bovina de Mato Grosso através da criação do selo de compliance que garante a procedência da carne em consonância com a lei federal que dispõe sobre a aplicação de rastreabilidade na cadeia produtiva bovina (BRASIL, 2009). Objetiva-se, com utilização de pesquisa básica (pura) teórica e prática, abordagem qualitativa, objetivos explanatório e exploratório, procedimentos bibliográfico e documental, e raciocínios dedutivo e hipotético-dedutivo, avançar sobre a discussão relacionada ao papel regulatório que os selos sociais têm cumprido na sociedade como forma de concretização do dever de prevenção. As convenções da Organização Internacional do Trabalho (OIT) serviriam como um patamar mínimo de referência para a certificação, de forma que se evitaria a concorrência desleal, diminuiria a assimetria das informações entre os consumidores (AKERLOF, 1970), reforçaria o dever de prevenção por parte do Estado e garantia o respeito a condições dignas de trabalho em toda cadeia produtiva da carne.

Palavras-Chave: Trabalho Escravo Contemporâneo, Cadeias Produtivas, Selos Sociais, Dever Estatal de Prevenção. 
Ref.: 282CEDHMI 2020

\section{A TRAGICIDADE DA PRECARIZAÇÃO DO TRABALHO EMTEMPOS DE NEOLIBERALISMO PANDÊMICO}

O presente estudo visa analisar e tensionar a precarização do trabalho no contexto brasileiro, como um efeito colateral advindo do neoliberalismo que impera no cenário hodierno. A pesquisa justifica-se pelo avanço do capitalismo financeiro, que projetou seus efeitos na sociedade contemporânea, com ênfase ao Direito do Trabalho e promoveu um redesenho das relações de trabalho no Brasil, que teve como marco recente a Reforma Trabalhista implementada pela Lei no 13.467/2017 que alterou substancialmente a Consolidação das Leis do Trabalho. Nesse cenário, o movimento do trabalho e as condições do trabalho foram brutalmente impactados pelas mutações tecnológicas, no nível da tecnologia digital e informacional, utilizadas pela política do neoliberalismo com o nítido objetivo de maximização do lucro a todo o custo e minimização dos direitos trabalhistas, com chancela do Estado. A hipótese que se procurou verificar diz respeito aos efeitos perniciosos do desmantelamento do Direito do Trabalho em prejuízo ao trabalhador, com a utilização da metodologia bibliográfica com análise da doutrina sobre a temática. Importante mencionar, que a situação se complexificou na pandemia do Coronavirus Disease 2019 que inaugurou o século XXI e desafiou os Poderes Constituídos para a adoção do isolamento social, com redução do contato presencial entre as pessoas, inclusive no trabalho, mantidos somente aqueles considerados trabalhos essenciais. Nesse sentido, o isolamento social recomendado pela Organização Mundial de Saúde e adotado no Brasil constituiu um solo fértil para a potencialização de dois pilares do neoliberalismo, a saber: a informalidade e a maximização do uso das novas tecnologias. A título de conclusão verificou-se que os pilares estruturais do Direito do Trabalho, frutos de longo processo de lutas, de choques e entrechoques, de evolução e involução no decorrer da história têm sido desmantelados pela engenharia intrínseca ao neoliberalismo e seu modus operandi, revelando seus traços de desumanidade viscerais, causando a precarização das relações de trabalho, flexibilização, aviltamento dos direitos trabalhistas, desemprego conspurcando em síntese a dignidade da pessoa humana, pedra angular valorativa do Estado Democrático de Direito.

Palavras-Chave: Tragicidade, Precarização, Relações, Trabalho, Neoliberalismo.
Nivea Corcino Locatelli Braga

Universidade Estácio de Sá 


\section{AS DESIGUALDADES SOCIAIS E AS NOVAS RELAÇÕES DE TRABALHO: BRASIL, PORTUGAL E ITÁLIA}

Dorinethe dos Santos

\section{Bentes}

Universidade Federal do Amazonas Universidade Federal de Minas Gerais

\& Igo Zany Nunes Corrêa

Universidade Federal do Amazonas
Para reduzir as desigualdades sociais existentes no mundo é necessário que os Estados desenvolvam políticas públicas e legislativas que visassem proteger os mais vulneráveis em todas as suas dimensões. Infelizmente, o Brasil tem caminhado na contramão desses objetivos, na medida em que reduz direitos sociais e trabalhistas, a exemplo da Lei n. $13.467 / 2017$, inserida num contexto de grandes ataques aos direitos sociais, trazendo mudanças das quais se destaca a criação de um novo tipo de contrato empregatício até então inexistente na legislação brasileira: o contrato de trabalho "intermitente". Esse tipo contrato caracteriza-se por ter jornada e salários variáveis que se ajustam à demanda do empregador. Foi instituído no ordenamento brasileiro com a justificativa de reduzir os índices de desemprego, criando emprego e renda para os trabalhadores. O artigo busca realizar um estudo comparativo entre as características do trabalho intermitente na legislação brasileira e nas legislações italiana e portuguesa, pois, foram os dois paradigmas utilizados pelo legislador brasileiro para justificar a criação desse novo modelo de contrato de trabalho no ordenamento jurídico pátrio. O método utilizado na pesquisa foi ojurídico-sociológico, as fontes de pesquisa concentraram-se na legislação pertinente ao tema no Brasil (CLT e Lei n. 13.467/2017), na Itália (Decreto Legislativo 81/2015) e em Por- tugal (Lei 07/2009); na jurisprudência e nos teóricos dos países em análise. No modelo italiano, segundo Nogueira (2017) o trabalho intermitente foi instituído pelo Decreto Legislativo $n$. $276 / 2003$ e agora é regulado pelo art. 13 e seguintes do Decreto Legislativo $n$. $81 / 2015$. A modalidade é popularmente conhecida como "contrato de trabalho a chamada" e, ressalta ainda que, tal como na proposta brasileira, o objetivo era o de introduzir novas modalidades mais flexíveis de contratos de trabalho possibilitando emprego e renda para os trabalhadores que estavam fora do mercado de trabalho. $O$ artigo 443, §3० da CLT e os artigos do Decreto italiano apresentam diferenças importantes no que se refere ao marco temporal, o dispositivo celetista brasileiro estabelece que a prestação de serviços com subordinação é determinada em dias, horas ou meses, enquanto no caso italiano em semanas, meses e anos. O trabaIho intermitente em Portugal é regulado pela Lei n. 07/2009, a partir do artigo 157. O estágio atual da pesquisa demonstra que essa nova modalidade contratual, tal como regulamentada pela Lei n. 13.467/2017, precariza as relações de trabalho violando em vários aspectos os direitos humanos, além de ser omissa em aspectos fundamentais, tais como previdência, saúde e segurança dos trabalhadores.

Palavras-Chave: Violações de Direitos Humanos do Trabalho, Precarização das Relações de Trabalho, Contrato Trabalho Intermitente, Lei n. 13.467 de 13 de Julho de 2017 , Brasil, Itália, Portugal. 


\section{“AGRADECE QUE TEM EMPREGO": DEGRADAÇÃO DOTRABALHO E VIOLAÇÃO DOS DIREITOS HUMANOS DOS PROFESSORES DA EDUCAÇÃO BÁSICA NO PERÍODO DE PANDEMIA}

Este artigo tem por objetivo identificar as práticas de degradação do trabalho e violação dos direitos humanos em professores da Educação básica no período de pandemia por coronavírus. A pandemia do Covid-19 trouxe a necessidade de isolamento físico e o consequente fechamento das instituições de ensino. As medidas adotadas pelos governantes impactaram na organização do trabalho docente e na redefinição das relações entre professores e suas respetivas instituições de ensino. Atenta-se para o fato de que as instituições adotaram o regime de ensino à distância, e que esta medida provocou alterações significativas nas relações de trabalho, principalmente na quantidade de horas destinadas ao exercício do magistério. No período de suspensão das aulas presenciais pela pandemia do Covid-19 foram adotadas medidas governamentais que provocaram efeitos desproporcionais aos professores que já enfrentam barreiras à educação e a degradação das condições de trabaIho. Para agravar este fato estamos em num governo que não tem um projeto que dê conta da educação de verdade impondo uma proposta de ensino que não alcança a todos os alunos e que submete o professor uma modalidade de ensino ao qual não foi preparado e que por vezes violam as condições dignas de exercício da sua profissão.

Observamos que o projeto de precarização do Ensino público é anterior a pandemia, e que se acentua no momento do COVID 19. A precarização do ensino se ampara em quatro tendências: corte de recursos públicos, censura dos alunos e professores, privatização do ensino e a padronização. Essas 4 tendências ganham uma amálgama no período de Covid 19, e o ensino remoto é muito funcional na efetivação deste processo. A experiência do ensino remoto justificada neste contexto de emergência, seguindo as orientações das secretarias de educação que justificam nas falas "fazer o que dá pra fazer" isto é um risco ao direito à educação e é muito coerente com o projeto de precarização e o ataque que as escolas públicas vinham sofrendo.

Os professores da Rede privada, por outro lado, com a flexibilização das leis trabalhistas, a adoção do regime de trabalho domiciliar e a imposição do uso do Ensino à Distância tiveram que lidar com um novo sistema de ensino que tem se mostrado bastante precário, principalmente do ponto de vista das ferramentas disponíveis e da formação dos professores para o uso destas metodologias.

O que se observamos é que os professores da rede privada precisam lidar com a improvisação como tônica deste processo e a completa ausência de mecanismos que garantam condições dignas de trabalho. MÉTODO Delineamento Para atingir o objetivo geral desta pesquisa será utilizada a pesquisa exploratória, qualitativa e descritiva, com utilização de procedimentos metodológicos da Revisão Integrativa da Literatura. Esta revisão integrativa será operacionalizada através de procedimentos de busca eletrônica, conduzidos em nível nacional e internacional.

Palavras-Chave: Degradação do Trabalho

Docente, Educação Básica, Ensino Remoto.
Érica Cindra de Lima, Colégio Notre Dame

Cristiane Diello Granville Colégio Notre Dame \& Márcia Vieira Oliveira Garritano Consultório 


\section{A "PLATAFORMIZAÇÃO" DO TRABALHO E A RELAÇÃO DE EMPREGO NOS APLICATIVOS DETRANSPORTE}

Alexandre Alves

Universidade Federal do ABC

\& Danilo Uler Corregliano

Universidade São Judas
As inovações tecnológicas modificam as relações de trabalho, reduzem o número de vagas disponíveis no mercado, dificultam a capacidade de organização dos trabalhadores e contribuem para o enfraquecimento e a precarização dos direitos trabalhistas. Nesse sentido, entre a terceira e a quarta revoluções industriais, surgem as plataformas digitais potencializando o trabalho informal por meio de um falso empreendedorismo para disfarçar a "plataformização" da mão de obra, com o objetivo de diminuir os encargos dos empregadores e reduzir os direitos trabalhistas conquistados ao longo do tempo. Essa nova forma de divisão do trabalho exclui milhões de trabalhadores do mercado formal, diminuindo a sua remuneração e, como consequência, para manterem sua renda, aumentam a jornada de trabalho, ultrapassando em muitos casos 12 horas diárias, sem qualquer tipo de adicional ou intervalo mínimo entre jornadas, por vezes exercendo mais de uma atividade laboral. É a flexibilização do trabalho fragilizando os direitos sociais resultantes de conquistas históricas, a face obscura do capitalismo agindo de modo perverso sobre os trabalhadores para maximizar o lucro das empresas, tornando-os descartáveis e ampliando o número de desempregados. Nesse contexto, insere-se o trabalho digital mediante a utilização de aplicativos para entrega de mercadorias e transporte de passagei- ros. E, com ele, a controvérsia sobre a existência, ou não, de elementos que caracterizam a relação de emprego entre as empresas responsáveis pelos aplicativos, os entregadores e os motoristas. Para as empresas de aplicativo, os obreiros que realizam o transporte são considerados trabalhadores independentes e, por isso, não possuem vínculo de emprego. Porém, os trabaIhadores ao exercerem suas atividades identificam a presença de elementos que caracterizam a relação empregatícia entre eles e as empresas de aplicativos. Por esse motivo, foram movidas ações trabalhistas em vários países da Europa e da América pleiteando o reconhecimento da relação de emprego entre as empresas responsáveis pelos aplicativos e os trabalhadores que efetivamente transportam as mercadorias e os passageiros. O presente artigo, utilizando o método hipotético dedutivo, buscou compreender o contexto social em que a temática se insere, analisou os elementos caracterizadores da relação de emprego entre trabalhadores e empresas de aplicativo para transporte de mercadorias e de passageiros, por meio de estudo das decisões judiciais brasileiras, favoráveis e contrárias, proferidas pelos tribunais, da compreensão dos diferentes entendimentos da doutrina e à luz da legislação trabalhista pátria.

Palavras-Chave: Plataformização, Aplicativo, Transporte, Emprego, Trabalho. 
Ref.: 349CEDHMI 2020

\section{LABOUR MOBILITY AND FREE TRADE RULES: A NEW CHALLENGE FOR THE 2030 AGENDA?}

Labor mobility is now governed by free trade in services' rules. This is the case of mode 3 and mode 4 of provision of services under the General Agreement on Trade in Services (GATTS). The same happens with European Union (EU) rules. A posted worker is not considered anymore as a migrant worker. Thus, transnational labor mobility for the provision of services is excluded from the legal protection of the EU Treaty associated with the free movement of workers.

International Labor Organization (ILO) rules and European labor rules are losing foot as far as transnational labor markets are concerned. Very often, mobile workers are deprived of their international legal status as migrant workers, which grants them a broad legal protection under ILO Conventions.

Dissociating social protection of posted workers from the scope of emigration rules grants transnational companies (TNC) a free access to labour force across borders; without being subject to the legal limits imposed on typical emigration. Which implies, in the case of intragroup mobility, to select workers at origin to "post" them abroad them as long as the provision of services requires, and to resort to subcontracting or companies temporary work when necessary.

Free trade rules confer new rights to transnational operators. While freedom of movement rights under EU Treaties grant a legal status similar to human rights. Such fundamental freedoms sometimes collide with government's attempts to oblige multinational companies to comply with social or environmental standards. In this sense, the discourse on human rights is reversed. Traditionally, human rights' regulations have aimed at preventing abuse of power by TNC. Now instead, this discourse contemplates companies as holders of rights originally conceived for the protection of natural persons (human rights). As a result, corporations are implement such rights in the United States and EU jurisdictions to submit to scrutiny the exercise of governments' sovereignty on economic matters.

Keywords: Human Rights, Trade In Services, Labor Mobility, Transnational Companies, Posting OfWorkers.
Mireia Llobera

Universidad De Valencia (Spain) 
Ref.: 355CEDHM22020

\section{DIREITOS HUMANOS E TRABALHO SEXUAL SOB A PERSPECTIVA DA PRECARIZAÇÃO}

Carmen Hein de Campos

Professora do Programa de Mestrado em Direitos Humanos e do Curso de Direito, UniRitter/RS

\& Paula Franciele da Silva Mestranda em Direitos Humanos pela Uniritter/RS
O presente artigo objetiva discutir os elementos sociais e ausência de políticas públicas que legitimam a precarização do trabalho sexual e de que forma isso passa a ser um fator de incremento às violências contra essas mulheres. Essa análise se dará a partir de uma perspetiva voltada aos direitos humanos das mulheres. O problema que pretendemos responder é qual o local social que se destina às trabalhadoras sexuais e quais são os reflexos desse local nas vidas dessas trabalhadoras. A hipótese apresentada é que há uma escolha política pela precarização do trabalho sexual e das vidas dessas mulheres. Essa hipótese se sustenta, pois, a construção da legislação não se ocupa da proteção das mulheres. Por outro lado, as políticas públicas são precárias ou inexistentes, e que como consequência empurram as mulheres para a marginalidade social. Por essa linha, as leis que tratam da matéria parecem apresentar uma função óbvia: o isolamento que coloca as profissionais do sexo nas fronteiras e longe da proteção do Estado. Os reflexos desse isolamento se verificam na vida política dessas trabalhadoras, e essa vida polí- tica está ligada ao potencial de exposição à violência. A partir disso passa-se a trabalhar a vulnerabilidade social dos corpos como um dos elementos do processo de desumanização e morte. O referencial teórico utilizado na pesquisa inclui as ideias de vidas precárias, necrobiopolítica e necropolítica, propostas por Judith Butler, Berenice Bento e Achile Mbembe a fim de demonstrar a precariedade e as políticas de morte em relação às vidas das trabalhadoras sexuais e às condições sociais e locais de submissão de seus corpos. Nesse sentido, pensa-se em zonas de guerra e fronteiras. A partir da construção de marginalidade e de precarização do trabalho sexual se buscará evidenciar as violações de direitos humanos e como a ausência de proteção estatal contribui para essas violações.

Palavras-Chave: Vidas Precárias, Trabalho Sexual, Necrobiopolítica. 


\section{IMPLICAÇÕES DE PERÍODOS DE CRISE E DE EMERGÊNCIA NA DES/IGUALDADE ENTRE MULHERES E HOMENS NO MERCADO DE TRABALHO EM PORTUGAL}

Em Portugal, tal como em muitos outros países, a igualdade entre mulheres e homens no mercado de trabalho está ainda longe de ser alcançada. A pandemia Covid-19 -um desafio sem precedentes, não só em termos médicos e científicos, mas também em termos sociais, humanitários, económicos e políticos -veio ameaçar os avanços das últimas décadas e colocar-nos perante um cenário de retrocesso evidente, marcado já pelo exacerbamento das desigualdades de 'género' em múltiplos domínios. No mercado de trabaIho, as mudanças desencadeadas pela pandemia vieram ameaçar o emprego de milhares de pessoas e parecem ter ainda agravado as condições de trabalho de muitas outras. A investigação aqui proposta visa explorar as implicações da Covid-19 nas des/igualdades entre mulheres e homens no mercado de trabalho (formal) em Portugal. Pretende-se, nomeadamente, verificar se as mulheres estão (ou não) a ser desproporcionalmente afetadas e/ou penalizadas pelas transformações decorrentes da pandemia, tecendo um paralelo com o sucedido no período de crise anterior (2008). O estudo tem, portanto, dois objetivos principais. O primeiro objetivo é identificar, caracterizar e analisar -através de uma perspetiva de género -a evolução das dinâmicas laborais ocorridas no mercado de trabalho português no período 2006-2019/2020. O segundo objetivo é identificar e estudar as implicações de períodos de crise e de emergência nacional nas dinâmicas laborais, na composição e na distribuição por sexo da força de trabalho. Para alcançar estes objetivos, é proposto um exercício de foro essencialmente quantitativo. A análise realizada, de natureza exploratória, é sustentada na análise longitudinal de dados secundários relativos às últimas décadas e mobiliza indicadores diversos, passíveis de representaras múltiplas desigualdades laborais existentes entre mulheres e homens -relacionadas com os níveis de participação no mercado de trabaIho, com a desigualdade salarial, com o acesso a cargos de chefia e liderança, com as condições de trabalho e/ ou com a precariedade laboral. Assim, com base na análise de um conjunto alargado de indicadores estatísticos, disponibilizados por entidades nacionais e internacionais como o Instituto Nacional de Estatística e/ou o Eurostat, procura-se caracterizar a situação portuguesa em matéria de des/igualdade de 'género' no mercado de trabalho na atualidade e refletir comparativamente a evolução da situação das mulheres e dos homens ao longo do período em estudo. O artigo termina com uma reflexão sobre as principais implicações de períodos de crise e de emergência nacional na des/igualdade laboral entre mulheres e homens.

Palavras-Chave: Covid-19, Desigualdade Entre Mulheres e Homens, Mercado de Trabalho, Portugal.
Carina Jordão

Universidade de Aveiro 
Sara Jordana Cabral

Peixoto,

Dolores Pereira Ribeiro

Coutinho

\& Mário Márcio da Rocha

Cabreira

Universidade Católica Dom Bosco

Ref.: 383CEDHM22020

\section{EMPREGO VERDE E CATADORES DE RECICLADOS: UM CASE DE SUSTENTABILIDADE}

\begin{abstract}
Consoante ao Objetivo do Desenvolvimento Sustentável -ODS8, o presente trabalho objetivou demonstrar a importância do Emprego Verde, popularmente conhecido como emprego sustentável, bem como identificar as condições de sua aplicabilidade em realidade territorial específica, a do modelo
\end{abstract} vivenciado nas empresas de reciclagem da cidade de Campo Grande, estado de Mato Grosso do Sul, Brasil, com vistas ao reconhecimento da aplicação de padrões que propiciem reflexão nas dimensões legal, social e econômica da sustentabilidade. Assim, investigou-se um Arranjo Produtivo Local APL de empresas de recicláveis, com suas redes de catadores na cidade, em seu funcionamento e sua estruturação, realizando-se uma análise baseada nos Direitos Humanos e na cidadania, a partir dos desafios e da relevância, que se tornaram, ainda, mais evidentes em uma época pandêmica. A investigação qualitativa se fez com pesquisa exploratória e dedutiva, utilizando-se como procedimento a coleta de informações em bibliografia, documentos e rodas de conversa, cotejadas com dados obtidos a partir de diálogos descontraídos, vivenciados em momentos nos quais protagonistas puderam expressar suas impressões sobre a realidade vivida. Constatou-se que, em Campo Grande-MS, a empresa que realiza o serviço de recolhimento e descarga dos materiais, para as Cooperativas, absorve prestadores de serviços para fazerem a separação do material e, posteriormente, os lucros e as despesas são divididos, igualitariamente, entre todos os funcionários. As condições de trabalho encontradas podem ser tidas como decentes, conforme teorizam Ignacy Sachs e os princípios preconizados pela OIT. Contudo, verificou-se elevada taxa de rotatividade e ausência de proteção social, pela condição de trabalhadoras e trabalhadores sem vínculo empregatício. As mulheres, em sua maioria, foram identificadas como responsáveis pelo manejo dos equipamentos e apontadas como executaras de tarefas com maior qualidade, refletindo-se características oriundas da socialização feminina.

Palavras-Chave: Emprego Verde, ODS 8, Reciclagem, Sustentabilidade, Trabalho Decente. 


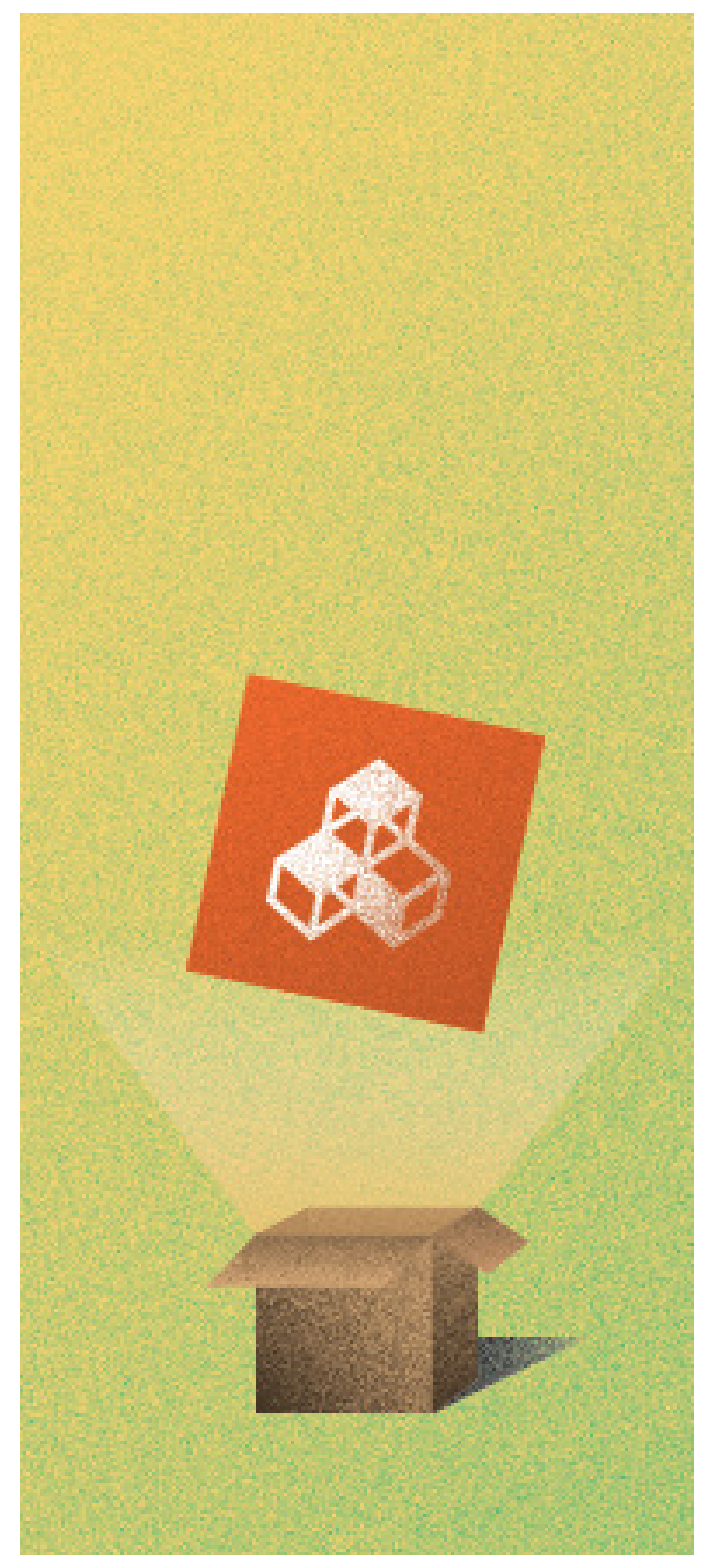

\section{ODS 9 INDÚSTRIA, INOVAÇÃO E INFRAESTRUTURAS}




\section{A AGENDA 2030 E OS OBJETIVOS DE DESENVOLVIMENTO SUSTENTÁVEL (ODS) DO MILÊNIO: INICIATIVAS EMPRESARIAIS PARA PROMOÇÃO DA IGUALDADE DE GÊNERO}

A igualdade de gênero e étnico-racial são importantes demandas de justiça social, e requisitos indispensáveis para a promoção e crescimento econômico equânime, pois a incorporação das mulheres no mundo produtivo representa geração de renda e riqueza para toda população, principalmente em uma sociedade tão profundamente desigual e excludente como a brasileira. O contexto empresarial e o mundo dos negócios também são espaços onde estas desigualdades podem ser claramente percebidas e reforçadas interseccionalmente. No Brasil, a diferença de outros países, inexiste uma política de Estado e uma legislação sólida que trate de incentivar práticas proativas de emprego/trabalho com vistas a aumentar a representação dos grupos sociais vulneráveis e discriminados e diminuir, através desta via de inclusão, as desigualdades. O descaso estatal em desenvolver políticas públicas nesta seara, também se refletiu no setor privado até o início do novo milênio quando, alguns setores do empresariado vinculados, sobretudo, as empresas multinacionais e transnacionais, começaram a alterar este quadro. As empresas que aderiram ao Pacto Global (proposto pelas Nações Unidas em 2000) mudaram suas estratégias empresariais alinhando-se aos 10 princípios universais constantes no "Guiding Principles on Business and Human Rights" (2011), responsabilizando-se, ademais, por colaborarem com a efetivação dos Objetivos de Desenvolvimento Sustentável (ODS) do Milênio e da Agenda 2030. Fatos que contribuíram, em algum grau ou medida, para que o tema da valorização da diversidade da força de trabaIho entrasse na agenda empresarial. A pesquisa que vem sendo desenvolvida junto ao Núcleo de Pesquisa e Extensão em Direitos Humanos (NUPEDH) e ao Grupo de Pesquisa Direito, Gênero e Identidades Plurais (DGIPLUS) -ambos sediados junto a Faculdade de Direito da Universidade Federal do Rio Grande (FADIR/FURG/RS/BRASIL)-, buscará identificar e catalogar os tipos de programas de Responsabilidade Social Empresarial (RSE) desenvolvidos pelas empresas com sede no Brasil, bem como avaliar seus efeitos no que tange à promoção da igualdade de gênero e étnico-racial no âmbito do trabalho.

Palavras-Chave: Igualdade de Gênero e Étnico-Racial, Justiça Social, Agenda 2030 e os ODS, Iniciativas Empresariais, Relações de Trabalho.
Sheila Stolz

Universidade Federal do Rio Grande (FURG/RS/BRASIL) 
Ref.: 098CEDHM22020

\section{O PAPEL DA SUSTENTABILIDADE ENERGÉTICA NA QUARTA REVOLUÇÃO INDUSTRIAL PARA A EVOLUÇÃO DOS DIREITOS HUMANOS}

Arlei Costa Junior

Pontifícia Universidade Católica do Paraná - PUC-PR
Quando surgem ondas de rutura, como as revoluções industriais, a sociedade se questiona se esse é o tipo de desenvolvimento desejado ou mesmo se esse modelo pode ser considerado desenvolvimento. A quarta revolução industrial (4RI) é um exemplo desse dilema; traz uma difícil e sacrificante transição para a humanidade, mas pode ser indutora do desenvolvimento sustentável ao harmonizar o crescimento econômico, o bem-estar social e o aumento das liberdades individuais. Assim, as pessoas poderão desenvolver suas capacidades e viver o tipo de vida que valorizam, promovendo, assim, uma evolução dos direitos humanos diante de seu potencial de elevar os níveis de renda global e a qualidade de vida das populações pelo mundo. Essa possibilidade proporcionada pela 4RI é inovadora, pois as revoluções industriais anteriores resultaram em concentração econômica, associada a um uso massivo de energia que teve como consequência impactos ambientais que comprometeram o direito das gerações futuras a um meio ambiente saudável e equilibrado. O objetivo central deste artigo é analisar a eficiência energética das tecnologias emergentes da 4RI, que pode ser afetado pela disponibilidade limitada de energia elétrica sustentável. Busca, ainda, verificar a existência de correlação entre a sustentabilidade energética e desenvolvimento, pois se os pressupostos apresentados forem verdadeiros, pelo método hipotético dedutivo, infere-se que o desenvolvimento somente será alcançado se acompanhado de sustentabilidade energética. Os temas da sustentabilidade energética e desenvolvimento são correlatos aos objetivos do desenvolvimento sustentável n. 7 -energia limpa e acessível, n. 9 -indústria, inovação e infraestrutura, n. 11 -cidades e comunidades sustentáveis e n. 13 -ação contra mudança global do clima. O principal conflito na implementação do desenvolvimento sustentável, é sua compatibilização com o crescimento econômico em um sistema capitalista. A 4RI tem a possibilidade de ser a primeira a conseguir evitar que o consumo de energia aumente na mesma proporção do crescimento da economia. O aumento da eficiência energética, combinado com as possibilidades tecnológicas de um projeto energético que promova a migração da energia poluente e não-renovável, para energia limpa e renovável, viabiliza o desenvolvimento com sustentabilidade. Aliás, o desenvolvimento duradouro só será obtido a partir da sustentabilidade multidimensional, onde se inclui a sustentabilidade energética, reforçando-se a ideia de que o desenvolvimento não pode ser considerado apenas no seu aspecto econômico, mas também social, ambiental e como liberdade. A 4RI pode promover esse desenvolvimento através do expressivo incremento da eficiência na geração de energia e a integração das fontes de energia renováveis distribuídas, destacando-se a solar e a eólica, criando perspectivas otimistas quanto ao futuro do abastecimento energético sustentável, e com isso possibilitar novos horizontes à humanidade.

Palavras-Chave: Sustentabilidade Energética, Quarta Revolução Industrial, Direitos Humanos, Desenvolvimento Sustentável, Geração de Energia. 


\section{THE ROLE OF THE UNITARY PREVENTION DELEGATES IN THE PARTICIPATIVE MANAGEMENT OF OCCUPATIONAL RISK PREVENTION}

There is growing concern about the increase in systems of representation of non-unionized workers in occupational health and safety matters (unitary prevention delegates). Previous studies have shown that workplaces with unionized prevention delegates have better prevention management rates, greater worker involvement and a reduction in occupational accidents. However, there is no comparable scientific evidence on the impact of unitary prevention delegates, and there is concern about a lower impact on occupational health and safety. Therefore, the aim of this research is to study the direct and indirect impact of the unitary prevention delegates on the Spanish working environment. To this end, a cross-sectional study was carried outusing microdata from the National Survey on Health and Safety Management in Companies (ENGE-2009) with a sample of 5147 work centres. To measure the relationship between the presence of unitary prevention delegates in the work centres with the indicators of preventive management, direct participation of workers (indirect impact) and damage to health (direct impact), individual and multiple logistic regression models were carried out, calculating the crude (cOR) and adjusted (aOR) odds ratios by sociodemographic covariates, with their corresponding 95\% confidence intervals ( $95 \% \mathrm{CI})$. Ambivalent results were obtained. On the one hand, a positive impact of the unitary prevention delegates was found, in that in those centres where they were present there was a greater probability that prevention plans would be carried out $(\mathrm{aOR}=3.97 ; \mathrm{CI} 95 \%: 3.26-4.83)$, risk assessments (aOR $=5.96$; IC95\%:4.448.01) and preventive action was planned $(\mathrm{aOR}=3.01$; IC95\%:2.55-3.56), as well as, 1.59 less probabilities of registering minor occupational accidents with sick leave $(\mathrm{aOR}=0.63 ; \mathrm{IC}=0.53-0.75)$. But, on the other hand, the presence of the unitary prevention delegates did not promote the activation of an active participative culture in the work centres and was not predictive in the reduction of serious and fatal work accidents. In conclusion, the unitary prevention delegates have a moderate impact, being necessary the activation of the active participation of the workers to improve the results.

Keywords: Unitary Prevention Delegates, Preventive Management, Workers' Participation, Cultural Activation, Accidents At Work.
Raúl Payá Castiblanque University of Valencia 
Ref.: I07CEDHM22020

\section{RISCOS DAS NANOTECNOLOGIAS E A RESPONSABILIDADE DAS EMPRESAS PELA PROTEÇÃO AO CONSUMIDOR: UMA ANÁLISE A PARTIR DA CONCRETIZAÇÃO DE DIREITOS}

Antônio Carlos Efing Pontifícia Universidade Católica do Paraná - PUCPR

\& Rudinei José Ortigara FAE Centro Universitário
Devido à complexidade, as nanotecnologias são marcadas pela ambivalência. Ao mesmo tempo que são elementos inovativos para empresas, há pesquisas que demonstram potenciais riscos à saúde e segurança de vulneráveis. Este aspecto é problemático para a proteção ao consumidor, pois elas tendem a ser compreendidas pelas empresas mais como elemento de inovação que de riscos. Assim, o aspecto do risco e a proteção ao consumidor merecem discussões. A pesquisa possui por objetivo geral analisar, ante os riscos das nanotecnologias, o papel e a extensão da responsabilidade das empresas na proteção ao consumidor, e se este pode ser reconhecido como direito humano. Parte-se da hipótese de que deve haver alargamento da responsabilidade da atividade empresarial a partir da proteção de direitos humanos, e da compreensão da proteção do consumidor como dever de direito humano, a ser observada pelas empresas. Extrai-se a afirmação a partir do reconhecimento constitucional da proteção ao consumidor como direito fundamental, como no caso da legislação brasileira, de declarações das Nações Unidas, especialmente no objetivo 12 da Agenda 2030, cuja finalidade é "assegurar padrões de produção e de consumo sustentáveis", e dever de "todos os países e todas as partes interessadas", bem como dos Princípios Regentes sobre Empresas e direitos Humanos. Não consta diretamente nas metas do objetivo 12 a proteção ao consumidor como matéria de direitos humanos; no entanto, há o imperativo de que o sistema de produção deve atuar conjuntamente com Estados para garantir proteção aos vulneráveis, minimizando impactos sobre a saúde humana e meio ambiente, em via preventiva, com adoção de práticas e controle de processos produtivos sustentáveis; compreende-se, portanto, que o objetivo alberga responsabilidade de proteção aos consumidores como dever de direitos humanos, e que sua observação é condição para produção sustentável. Como matéria de direitos humanos, a proposta da pesquisa é a de que uma forma de implementação e concretização do objetivo 12 é a adoção da devida diligência em direitos humanos, sobretudo ante riscos das nanotecnologias, instrumento presente nos Princípios Regentes sobre Empresas e Direitos, visando minimizar impactos negativos, atuação preventiva e controle de informações de sustentabilidade nos ciclos produtivos. O método utilizado é o hipotético-dedutivo, e o procedimento de pesquisa é o bibliográfico, fundamentando teoricamente os parâmetros para reconhecimento da defesa do consumidor como direito humano e seu desdobramento na responsabilidade da empresa. O resultado, parcial, indica que a proteção ao consumidor deve ser compreendida como direito humano e que empresas possuem responsabilidade em respeitá-lo, sobretudo quando da fabricação de produtos com potencial de riscos à saúde e segurança, como os nanotecnológicos, implementando o processo de devida diligência com o fim de assegurar padrões de produção sustentáveis, conforme objetivo 12 da Agenda 2030.

Palavras-Chave: Nanotecnologias, Proteção ao Consumidor, Responsabilidade Empresarial, Objetivo 12 da Agenda 2030, Direitos

Humanos. 


\section{PROTEÇÃO, MERCANTILIZAÇÃO EVALORAÇÃO DE DADOS NA "DATA-DRIVEN SOCIETY"}

Na sociedade da informação os direitos fundamentais à proteção de dados e à privacidade assumem grande relevância notadamente no mundo digital. Contudo, mesmo sendo tais direitos objeto de instrumentos internacionais e multilaterais, bem como de legislações nacionais, a sua efetiva proteção continua em risco. Esta insegurança deve-se, em grande parte, à transformação substancial da economia ao longo dos séculos, tendo a valorização da terra dado lugar à valorização de dados na "data-driven society". Hodiernamente, os dados são utilizados por empresas e governos objetivando, por exemplo, desenvolver políticas públicas mais assertivas, analisar a concessão de crédito e criar perfis de consumo. A Internet e a Tecnologia da Informação e Comunicação -TIC fomentaram a crescente utilização de equipamentos eletrônicos, tais como, "smartphones", "smartwatches" e carros inteligentes, os quais deixam "pegadas digitais" do seu utilizador. Além disto, as TICs facilitaram sobremaneira a coleta, o tratamento e o armazenamento de dados pessoais, tornando cada vez mais relevante tanto a sua proteção quanto a sua segurança. Em tal contexto, a mercantilização de dados, certas vezes sob a alegação da livre iniciativa, movimenta a economia, em detrimento da proteção de dados e da privacidade do seu titular. Como nenhum direito é absoluto, é pertinente discutir, por exemplo, a possibilidade da utilização do Princípio da Proporcionalidade frente aos direitos envolvidos. Neste mercado impera a assimetria de informação entre o titular de dados pessoais e empresas e governos, sendo que estes empregam "big data", "Internet das Coisas" e inteligência artificial para melhor explorar as informações, que podem ser utilizadas como fonte de poder. Desta feita, dados pessoais passam a ser considerados como um ativo, sendo assim prudente analisar a possibilidade de sua valoração monetária, por exemplo, sob o prisma do titular dos dados, das empresas e dos governos, bem como do custo da "data breach". Deste modo, inicialmente objetiva-se analisar o direito fundamental à proteção de dados pessoais. Em seguida, tenciona-se estudar a comercialização de informações, que é uma realidade no mercado mundial, mesmo frente as diversas iniciativas de nações e organismos internacionais no sentido de inviabilizá-la. Finalmente, pretende-se investigar a possibilidade de mensuração do valor monetário dos dados pessoais. Tal estudo será realizado sob o enfoque do direito comparado entre o ordenamento jurídico do Brasil e da União Europeia, em especial a Lei Geral de Proteção de Dados (Lei 13.709/2018) e o Regulamento Geral de Proteção de Dados (Regulamento (UE) 2016/679), respectivamente.

Palavras-Chave: Direito Fundamental, Dado Pessoal, Comercialização,Valoração.
Juliana Falci Sousa Rocha Cunha

Faculdade de Direito da Universidade de Coimbra 


\section{RESPONSABILIDADE DAS EMPRESAS PARA A CONCRETIZAÇÃO DO OBJETIVO I 3 DA AGENDA 2030: MUDANÇAS CLIMÁTICAS E DIREITOS HUMANOS}

Rudinei José Ortigara

FAE Centro Universitário
O objetivo 13 da Agenda 2030 visa "tomar medidas urgentes para combater a mudança do clima e seus impactos", consonante a esforços internacionais, sobretudo da Convenção Quadro das Nações Unidas sobre Mudança do Clima. É imperativo para a promoção do desenvolvimento sustentável, pois consequências negativas das mudanças climáticas podem violar direitos humanos, como o equilíbrio ambiental, vida digna, saúde, desenvolvimento, dentre outros. No objetivo 13 não há orientação direta ou dever de observância das metas por empresas. Isto se constitui em problema, pois o atual modelo de desenvolvimento e de produção, encampado principalmente por empresas, contribui para emissão de gases de efeito estufa, principais causadores de mudanças climáticas, conforme estudos científicos. O presente estudo tem por principal objetivo analisar se, e em que medida, empresas possuem responsabilidade para a concretização do objetivo 13 da Agenda 2030, desenvolvendo medidas para combater causas da mudança climática, bem como para promover direitos humanos. A pesquisa parte da hipótese de que as mudanças climáticas, sobretudo seus impactos sociais e ambientais, constituem violações a direitos humanos, e devem ser compreendidas como problema de direitos humanos, sendo as empresas responsáveis por respeitá-los. Tal aspeto deriva do entrelaçamento de diversos documentos internacionais, como a Agenda 2030 e os Princípios Regentes sobre Empresas e direitos Humanos das Nações Unidas. Indica o presente estudo que pode ser efetivo para a responsabilidade empresarial a implementação do instrumento da devida diligência em matéria de combate às mudanças climáticas e promoção de Direitos Humanos, presente nos Princípios das Nações Unidas. Defende que embora anterior aos compromissos assumidos para mitigação de mudanças climáticas, inclusive aos objetivos da Agenda 2030, a observância dos Princípios, aprovados em 2011, e a aplicação da devida diligência à atividade empresarial, é essencial para implementar ações voltadas à promoção de direitos humanos no contexto de mudanças climáticas. O método utilizado é o hipotético-dedutivo, sendo o procedimento de pesquisa bibliográfico, fundamentando teoricamente os parâmetros para reconhecimento de que mudanças climáticas se relacionam com direitos humanos e de que empresas são responsáveis por respeitá-los, bem como do desdobramento desta responsabilidade. O resultado, parcial, aponta para que empresas são responsáveis por medidas efetivas de combate a mudanças climáticas, pois problema de Direitos Humanos, embora não constem expressamente nas metas do objetivo $13 \mathrm{da}$ Agenda 2030. Neste caso podem ser auxiliadas pelo instrumento da devida diligência em matéria de direitos humanos, avaliando os impactos potenciais e reais de suas atividades em mudanças climáticas, internalizando estratégia de direitos humanos na tomada de decisões, e respeitando o objetivo 13 da Agenda 2030 para a promoção do desenvolvimento sustentável.

Palavras-Chave: Objetivo 13 da Agenda 2030, Direitos Humanos, Responsabilidade Empresarial, Devida Diligência, Princípios Regentes sobre Empresas e Direitos Humanos. 


\section{EMPRESAS TRANSNACIONAIS E A PROTEÇÃO DOS DIREITOS HUMANOS EM UM CENÁRIO GLOBAL}

A abordagem em apreço tem como objetivo a análise da atuação das Empresas Transnacionais no atual contexto global, notadamente no que diz respeito a sua efetivação. Problematiza-se, por meio desde estudo, se as Empresas Transnacionais podem efetivar direitos humanos. Com esse fim, o estudo indutivo inicia com algumas considerações relevantes acerca dos direitos humanos, com foco no seu conceito e suas dimensões, também intituladas de gerações. Em seguida, analisa o que são Empresas Transnacionais, traçando suas características, bem como o espaço e o papel que têm assumido frente aos direitos humanos, em especial visando a sua proteção. Ao arremate, são elencados alguns casos práticos que narram a atuação das respetivas empresas em relação a esses direitos mínimos e a que tudo indica, as mesmas podem estar demonstrando, há muito, uma atuação destacada e eficiente no que tange a efetivação desses direitos. A título de desenvolvimento e caminhando para as considerações finais elencam-se como importantes as seguintes considerações: (a) a maior parte das empresas nos dias atuais estabelece suas intensas relações sem qualquer tipo de controle do Estado. Aliás, suas atitudes não possuem limitações fronteiriças, não sendo possível auferir o alcance territorial de suas ações; (b) assim, as empresas hoje se relacionam na sociedade global e ostentam atuação direta na sociedade, podendo impactar de forma positiva ou negativa a vida dos seres humanos de todo o mundo, uma vez que são geradoras de empregos e consequentemente de renda e receitas, atuam no combate à pobreza, são autoras de eficientes programas de prevenção e cura de doenças em todo o globo, como exposto na breve pesquisa; (c) assim, o estudo em tela demonstra que, sem prejuízo de alguns casos de violação de direitos humanos, as empresas transnacionais têm atuado como importantes agentes da efetivação de direitos dessa natureza, se considerados os casos práticos aqui analisados, que não findam o rol de exemplos, mas narram indubitavelmente a efetivação de direitos humanos como saúde, alimentação e educação, entre tantos outros considerados mínimos para garantir a dignidade humana.

Palavras-Chave: Direitos Humanos, Empresas

Transnacionais, Proteção, Globalização,

Transnacionalismo.
Jéssica Cindy Kempfer,

Universidade Luterana do Brasil (ULBRA), Campus de Carazinho (RS)

Regiane Nistler

Universidade Estácio de Sá (UNESA), Campus do Rio de Janeiro (RJ)

\& Caroline Bresolin Maia Cadore

Centro Universitário Leonardo da Vinci (UNIASSELVI), Campus de Florianópolis (SC) 
Ref.: 205CEDHM22020

\section{LA EDAD COMO FACTOR DE DISCRIMINACIÓN EN EL ACCESO AL EMPLEO: PUNTOS CLAVES}

Rafael Moll Noguera

Facultad de Derecho, Universidad de Valencia
En el ámbito de las relaciones laborales, el principio de igualdady el derecho a la no discriminación continúa, en el siglo XXI, informando al ordenamiento legal y práctica judicial en relación con el derecho fundamental del derecho al trabajo, pues todavía no existe una cultura social íntegramente igualitaria y ello senota y se padece también en la esfera laboral. Como es sabido, son varios los motivos que los ordenamientos jurídicos internacionales y nacionales contemplan como discriminatorios, entre los que destacan por su especial intensidad práctica, el sexo, raza o religión. No obstante, junto a los factores discriminatorios más tradicionales, y por tanto más estudiados, han aparecido otros colectivos igualmente vulnerables a sufrir discriminación en el empleo por razones como la edad o la condición sexual.

Este trabajo pretende acercarse a la realidad social y jurídica que rodea la discriminación por edad en España, prestando especial atención a la discriminación en el acceso al empleo, tanto el público como el privado.

A tal fin, se analizarán los mimbres jurídicos que sancionan o no este comportamiento empresarial, la aplicación e interpretación de los mismos por los tribunales, completando dicho análisis con las diferentes aportaciones doctrinales efectuadas hasta el momento, y terminado con una crítica y propuesta de reforma para solventar y superar las deficiencias detectas en la tutela preventiva y reparadora de las víctimas de este tipo de discriminación. Así, se repasará la protección internacional, constitucional, de legalidad ordinaria, a nivel convencional, jurisprudencial y de práctica judicial. Como premisa inicial se parte del diferente alcance en términos de protección que recibe esta causa de discriminación en el conjunto de la Unión Europea y en España y cómo ello se traduce, a su vez, en una mayor vulnerabilidad de este sector social cada vez más elevado.

En definitiva, con este trabajo se pretende ofrecer una lectura global de la situación legal y social que las personas trabajadoras, especialmente las mujeres, sufren en el acceso al empleo por razón de edad, tanto jóvenes como mayores, con el objetivo de apuntar posibles mejoras de cara al futuro en aras de proteger de forma más eficaz el derecho al trabajo en conexión con el principio de igualdad y no discriminación. En otros términos, se intentará dibujar con suficiente nitidez las aristas y contornos de esta causa de discriminación, concurrente con otras posibles causas como el sexo, a fin de proponer posibles puntos de mejora legislativa para reducir su impacto en la realidad laboral.

Palavras-Chave: Discriminación, lgualdad, Edad, Protección, Vulnerables. 


\section{GOVERNANÇA GLOBAL, COMPLIANCE E SETOR ENEGÉTICO: NOVOS PARADIGMAS FRENTE AOS OBJETIVOS DE DESENVOLVIMENTO SUSTENTÁVEL}

O presente trabalho tem por escopo abordar o papel do Setor Energético no alcance dos Objetivos de Desenvolvimento Sustentável (ODS) sob a ótica da relação entre a economia e as energias renováveis. Como sabido, são 17 objetivos acordados pelos países signatários que ratificaram a Agenda 2030. No que diz respeito ao financiamento climático, o Acordo de Paris determina que os países desenvolvidos deverão investir 100 bilhões de dólares por ano em medidas de combate à mudança do clima e adaptação, em países em desenvolvimento. Uma novidade no âmbito do apoio financeiro é a possibilidade de financiamento entre países em desenvolvimento, chamada "cooperação Sul-Sul", o que amplia a base de financiadores dos projetos. No eixo do Desenvolvimento da Economia há muito a ser discutido para mudar o mindset dos investidores a respeito. A fim de contribuir com os estudos, pensamos que sob o viés econômico, a Governança e a Sustentabilidade têm um grande papel de destaque principalmente quando se pensa a longo prazo, que é o caso dos ODS. É um conjunto de processos que caminham juntos nessa nova trajetória para economias verdes, sendo este o cerne do presente trabalho. A transição para economias low carbon precisa de um apoio muito forte de discussões no âmbito privado porque como se sabe, o Setor Energético demanda investimentos vultuosos que o Estado por si só não suporta. Portanto, torna-se necessário incluir os investidores, e não só eles como veremos, mas a princípio, estes devem fazer parte dessa mudança estrutural de paradigma. A despeito do que foi falado, a economia atualmente se desenvolve voltado ao que se chama de capitalismo de stakeholders que prega a ideia de que a empresa tem um papel na sociedade e, por conseguinte, no meio ambiente. O principal objetivo desse novo pensamento é a integração, comportamento crucial que consegue envolver setor público, privado e a comunidade num objetivo comum que ultrapasse a compreensão de só gerar lucros, torna-se impreterível gerar valor, um dos maiores pilares da compliance ambiental no momento presente. Nesse sentido, são muitos os aspectos a serem abordados nessa nova relação, como compreender de plano a função da governança para gerir as figuras que integram esse processo, a importância de cada um e como a regulação tem sido exercida para auxiliar a cooperação destes.

Palavras-Chave: Compliance, ODS, Energia, Cooperação.
Maria Luiza Diniz Almeida CEDIN 
Ref.: 266CEDHMI 2020

\section{O COMPLIANCE PROGRAM COMO INSTRUMENTO DE PREVENÇÃO E REPRESSÃO DE VIOLAÇÕES AOS DIREITOS HUMANOS NO ÂMBITO DAS ORGANIZAÇÕES EMPRESARIAIS}

Fabrizio Bom Vecchio \& Francis Rafael Beck Unisinos - Universidade do Vale do Rio do Sinos
Na sociedade moderna, principalmente após a Declaração Universal da Organização das Nações Unidas de 1948, os direitos humanos vêm ocupando um papel cada vez mais importante no mundo, seja com o objetivo de corrigir históricas injustiças socioeconômicas, seja para assegurar que sejam não apenas conhecidos e difundidos, mas também consolidados e respeitados.

Nas organizações empresarias, a tutela dos direitos humanos assume especial relevância diante da sociedade contemporânea, onde as relações orgânicas apresentam uma tendência de supervalorização de critérios de natureza econômica, muitas vezes desconsiderando direitos básicos de seus colaboradores.

De facto, nos termos da referida Declaração, todo ser humano tem capacidade para gozar os direitos e as liberdades que lhes são assegurados, sem distinção de qualquer espécie, seja de raça, cor, sexo, idioma, religião, opinião política ou de outra natureza, origem nacional ou social, riqueza, nascimento, ou qualquer outra condição. Referidos direitos, como resulta lógico, não apenas se estendem para o âmbito das organizações empresariais como também por elas deve ser devidamente assegurada.

Ao mesmo passo, o ambiente de trabalho é um local onde não raro ocorrem discriminações das mais diversas formas, que podem ocorrer desde o processo de seleção e contratação, passando pela execução das atividades até o desligamento do colaborador.

Diante desse quadro, os compliance programs podem e devem servir como instrumento de prevenção e repressão de violações aos direitos humanos no âmbito das organizações, especialmente em razão de tratamentos discriminatórios que guardem relação com a raça, cor, sexo, orientação sexual, intimidade, idade, idioma, religião, opinião e origem regional ou nacional, naturalmente constrangedores e intimidantes, representando verdadeira violência psicológica (aqui entendida como a conduta que cause dano emocional e diminuição da autoestima, que prejudique e perturbe o pleno desenvolvimento ou que vise degradar ou controlar ações, 
comportamentos, crenças e decisões mediante ameaça, constrangimento, humilhação, manipulação, isolamento, vigilância constante, perseguição contumaz, insulto, chantagem, violação de sua intimidade, ridicularização, exploração e limitação do direito de ir e vir e à autodeterminação).

Partindo deste cenário, pretendemos trazer este assunto para um debate profundo e atual, através de fundamentação teórica e estudo de casos (em particular, de violações de direitos humanos no âmbito empresarial e organizações que adotam programas de compliance voltados aos direitos humanos), de modo a construir uma investigação que aponte como um compliance program pode alcançar a prevenção e mitigação de riscos vinculados a violações de direitos humanos, bem como detetá-las (inclusive, sem que ocorra nova violação a direitos, como a intimidade) e sancioná-las, dentro de uma ideia de criação e fomento de uma cultura de compliance também em relação aos direitos humanos.

Palavras-Chave: Direitos Humanos, Violação,

Ambiente De Trabalho, Relações Laborais,

Compliance Program.
Fabrizio Bom Vecchio \& Francis Rafael Beck Unisinos - Universidade do Vale do Rio do Sinos 
Ref.: 27ICEDHMI 2020

\section{CÓMO LASTECNOLOGÍAS DE LA INFORMACIÓN Y COMUNICACIÓN PUEDEN AYUDAR A CUMPLIR LOS OBJETIVOS DE DESARROLLO SOSTENIBLE DE ONU}

Juliana Roman UFRGS
En 2050, según las Naciones Unidas (ONU), la poblaciónmundial alcanzará los 9.700 billones de personas, lo que representa un crecimiento del $26 \%$ en relación a los 7.700 billones de habitantes en 2019. Incluso según este pronóstico, cerca de 6.500 billones de personas vivirán en ciudades. A medida que crece la población, aumentan las demandas de servicios y el uso de recursos, lo que provoca una mayor demanda de energía, agua, residuos, movilidad y otros servicios esenciales. Estas previsiones sobre el crecimiento de la población mundial requieren medidas que tengan como objetivo la protección del futuro sostenible del planeta, respetando los derechos conferidos a la persona humana, al medio ambiente y a las generaciones futuras. En un intento por garantizar un futuro digno y sostenible, en 2015, durante la Cumbre de las Naciones Unidas sobre el Desarrollo Sostenible, se adoptó una agenda global, compuesta por los Objetivos de Desarrollo Sostenible (ODSs): 17 objetivos y 169 metas que se estiman cumplir para el 2030. Los tres pilares principales de la agenda son: la erradicación extrema de la pobreza, la lucha contra la desigualdad y la injusticia y, por fin, la lucha contra el cambio climático. En este sentido, considerando que es una tarea vital construir un futuro sostenible y que esto supone una responsabilidad de todos los implicados, ¿cómo pueden ayudar las Tecnologías de la Información y Comunicación (TICs) hacia el logro de los objetivos propuestos? Siguiendo la misma línea, la Unión Internacional de Telecomunicaciones (UIT), lanzó la campaña
\#ICT4SDG (Tecnología de Información y Comunicación para Objetivos de Desarrollo Sostenible), que propone la ayuda de las TICs para lograr el cumplimiento de los ODSs. En el escenario de importancia indiscutible de las innovaciones tecnológicas en el siglo XXI, un período también conocido como $4^{a}$ Revolución Industrial, las TICs tienen cualidades que pueden ayudar a mejorar el desarrollo económico, la inclusión social y la protección del medio ambiente. A partir de este estudio, se descubrió que, para que el potencial de las TICs sea utilizado a favor de la población mundial y para el cumplimiento de los ODSs, es necesaria la cooperación multilateral de los actores, es decir, la asistencia del sector privado, de los gobiernos, ciudadanos, académicos y de la sociedad civil para hacer frente a los impactos sociales, éticos, legales y económicos, así como para maximizar los beneficios sociales y minimizar el daño causado por las nuevas tecnologías. También se constató que existe la necesidad de hacer que la tecnología digital sea más inclusiva, de modo que más mujeres, jóvenes, poblaciones rurales, pequeñas empresas y países en desarrollo puedan beneficiarse, construyendo así una sociedad y economía digital inclusivas. El método aplicado en el desarrollo de la investigación fue el método inductivo, utilizando datos particulares para llegar a una conclusión general.

Palavras-Chave: Tecnologías de la Información y Comunicación, Objetivos de Desarrollo Sostenible, Sociedad, Digital. 


\section{TUTELA JURISDICIONAL EFETIVA DAS VIOLAÇÕES DE DIREITOS HUMANOS POR EMPRESAS: A ADEQUAÇÃO DA MEDIAÇÃO}

O acesso à justiça teve a sua compreensão alargada nos últimos anos, passando a ser compreendido para além de um mero acesso aos tribunais, isto é, estendendo-se à ideia de uma solução efetiva para o conflito. Nesse cenário, a mediação, enquanto meio alternativo de resolução de litígios, surge como uma via para a solução de conflitos e, portanto, para o alcance de uma tutela jurisdicional efetiva.

Por sua vez, as violações de direitos humanos por empresas, que são cada vez mais recorrentes, tendem a tornar-se ainda mais presentes em um cenário pós pandemia, e, consequentemente, haverá uma necessidade ainda maior de discussão e análise acerca das possibilidades de remediar essas questões. Nesse sentido, identifica-se um grande problema de acesso à justiça no âmbito dessas violações, qual seja: a dificuldade de alcance de uma tutela jurisdicional efetiva.

Portanto, é necessário pensar em formas que possam garantir uma melhor e mais completa tutela em casos de violações de direitos humanos por empresas, para além da justiça tradi- cional que, muitas vezes, não é capaz de fornecer a mais adequada solução ao caso concreto. Destarte, a mediação poderá fornecer uma resposta rápida, econômica e eficaz a estas situações.

Dessa forma, o objetivo desse estudo é concluir se a mediação é adequada para prestar uma tutela jurisdicional efetiva às violações de direitos humanos cometidas por empresas. Para tanto, será feita uma análise doutrinária e de instrumentos internacionais, nomeadamente regulamentações e projetos, como, por exemplo, "Os Princípios Orientadores sobre Empresas e Direitos Humanos", as "OECD Guidelines for Multinational Enterprises" e o Projeto em construção do CEDR sobre a utilização da Mediação em disputas comerciais e de direitos humanos. Além disso, serão analisadas jurisprudências de tribunais internacionais de direitos humanos.

Assim, analisar-se-á, por um lado, as dificuldades e as limitações que a mediação poderá apresentar para atuar neste tipo de casos, como, por exemplo, o desequilíbrio de poderes, o problema no consentimento e a pres-
Thais Brito Cirne

Faculdade de Direito da Universidade Nova de Lisboa 
Thais Brito Cirne

Faculdade de Direito da Universidade Nova de Lisboa
Ref.: 272CEDHMI 2020

TUTELA JURISDICIONAL EFETIVA DAS VIOLAÇÕES DE DIREITOS HUMANOS POR EMPRESAS: A ADEQUAÇÃO DA MEDIAÇÃO

tação de transparência; e, por outro lado, as possíveis contribuições deste meio alternativo de resolução de litígios à tutela destas violações, como uma maior integração de questões, maior margem para interpretação da situação em concreto, maior velocidade de resposta e menor custo.

Dessa forma, a busca por uma tutela efetiva das violações de direitos humanos por empresas promove, direta ou indiretamente, diversos Objetivos da Agenda 2030 das Nações Unidas para o Desenvolvimento Sustentável, nomeadamente a redução de desigualdades (ODS 10), na medida em que, através da mediação, poderá permitir a diminuição das desigualdades perpetradas por essas violações, bem como o objetivo 16 (paz, justiça e instituições eficazes), como uma possibilidade de garantir às vítimas dessa espécie de violação de direitos humanos, em tempo razoável, acesso à justiça.

Palavras-Chave: Mediação, Direitos Humanos, Empresas, Resolução Alternativa de Litígios, Tutela Jurisdicional Efetiva 


\section{¿EL FIN DE UNA ERA? LA FOCALIZACIÓNY LA PRODUCCION TECNOLÓGICA DE DATOS EN LA ACCIÓN PÚBLICA}

Chile es un país pionero en la instalación de sistemas de hiperfocalización de las políticas públicas y asociado a esto, en la construcción de producción tecnológica de datos sociales. Esto ha requerido la definición de modelos teóricos, normativos, matemáticos y tecnológicos que permitan operacionalizar la medición de la pobreza (asociada a ingresos) y de vulnerabilidad (asociada a capacidad de enfrentar riesgos). En esta ponencia, entenderé que estas tecnologías, necesarias para la toma de decisiones y operacionalización de las políticas públicas, son prácticas políticas ya que estructuran simbólicamente jerarquías que delimitan las capacidades de importar, materializar y corporeizar (Dixon-Román, 2017) lo vulnerable. Estas formas de medición producen diferencias y logran estructurar y reforzar simbólicamente jerarquías culturales y sociales: grupos vulnerables y no vulnerables. Entiendo que los datos son prácticas discursivas y materiales del mundo, que promulgan las condiciones de posibilidad e imposibilidad del fenómeno medido. En este sentido, tales modelos es que se producen desde conocimientos y estructuras que reproducen las formas geométricas prexistentes de lo social ya que se fundan en una concepción compensatoria de la justicia y de los derechos. En particular, el trabajo que presentaré, se orientará a revisar cómo los procesos político sociales que hoy vive Chile, han levantado preguntas acerca de estos mecanismos y cuáles serían las posibles consecuencias del augurio de su necesario fin. Para esto revisaré cómo la demanda por la Dignidad -que se levanta desde Octubre del 2019-y cómo el reclamo de un Estado que garantice seguridad -a partir de la gestión de las consecuencias de la pandemia-dejan a la vista la inconsistencia e ineficacia de la focalización como principio constituyente y organizador de la acción pública. Si bien estas crisis han dejado de manifiesto la universalidad de nuestra vulnerabilidad han también reforzado la idea que no todos resultamos ser igualmente vulnerables. En este escenario de situaciones imprevistas e incontrolables, la rigidez y de tecnocratización de la acción pública (tanto a nivel de sus definiciones, instituciones e instrumentos de gestión) no permiten responder de la mejor manera en la coyuntura. Ha sido necesario flexibilizar, adaptar, y ajustar definiciones, problemas, instituciones, programas sociales, leyes, plazos, sistemas de asignación de recursos, etc. Es decir, todo intento precedente por tener grados de control sobre los procesos de la acción estatal, hoy parecen insuficientes, si no inútiles. En este sentido, reflexionaré acerca de cómo estamos frente un momento histórico que abre la puerta a la incorporación de losDESC en el debate y la acción pública y por tanto el desafío de su posible operacionalización tecnológica (indicadores, algoritmos, formas de asignación de servicios, transferencias y prestaciones).

Palavras-Chave: Derechos, Justicia, Focalización, Políticas Públicas, Tecnología.
Carolina Rojas Lasch Universidad Alberto Hurtado (Chile) 


\section{TECNOLOGÍAS, ESTADOY NUEVAS VULNERABILIDADES: UNA REFLEXIÓN DESDE UN ENFOQUE DE DERECHOS EN TIEMPOS DE PANDEMIA}

Paulina Morales-Aguilera
Ciertamente, en el debate acerca de la vinculación entre Bienestar, Estado y políticas sociales se hace necesario incorporar un enfoque de derechos humanos como lente para identificar algunos nudos críticos en relación con la generación de nuevos espacios de desigualdad y de vulneraciones para las y los ciudadanos. Esto se vuelve especialmente visible a raíz de los procesos de modernización delEstado y de implementación del gobierno digital, que han supuesto la emergencia de distintos dispositivos y plataformas orientados a la vinculación entre Estado y ciudadanía, en general, y a la entrega de servicios sectoriales, en particular. En este marco se juega también el reconocimiento de derechos de la ciudadanía.

En efecto, dicha senda modernizadora puede ser leída en su doble cariz, esto es, en tanto ampliación y mayor efectividad de la acción estatal, a la vez que como generadora de nuevas vulnerabilidades. A la luz de dichos procesos, no obstante, se generan importantes brechas en virtud de factores como: i) el acceso a dispositivos tecnológicos que permitan acceder a información o gestiones en línea, tales como computadores personales, teléfonosinteligentes o tabletas; ii) el grado de alfabetización digital de la población; iii) los dos puntos anteriores en intersección con elementos como la condición socioeconómica de los ciudadanos/as, la pertenencia a determinados grupos etarios o el género. Esta comunicación pretende abordar dichas realidades, centrando la mirada en lo relativo al acceso a la justicia, teniendo como trasfondo la situación de pandemia por
Covid-19 en que nos encontramos. Una de las aristas más preocupantes a este respecto dice relación con la tramitación de las causas por violencia de género, dada la complejidad de la problemática a la base y los riesgos y las limitaciones de su gestión remota. Un ejemplo elocuente para el análisis es la realización de audiencias en línea por videoconferencia, implementadas en virtud de la crisis socio-sanitaria. Esto, por cierto, en tensión con el aumento significativo de las denuncias por violencia de género producto del confinamiento masivo.

Sin un enfoque de derechos humanos la intervención estatal se caracteriza por la falta de transparencia, la ausencia de mecanismos de participación, responsabilidad y rendición de cuentas (1). En el caso de Chile, la estrategia de transformación digital del Estado 2018-2022 declara estar al servicio delas personas. Sus líneas de acción se dirigen a un Estado signado por: la identidad digital, la eliminación de las filas de espera presenciales, la eliminación del papel como soporte de la información y gestiones, el almacenamiento y uso de datos a la base, la protección ante las amenazas de la ciberseguridad, y la mirada puesta en el futuro (2). Pese a tratarse de lineamientos que se aproximan a algunas de las consideraciones desde un enfoque de derechos humanos, no hay referencia alguna a éstos en el el contenido de la aludida estrategia.

Palavras-Chave: Nuevas Tecnologías, Estado, Nuevas Vulneraciones, Derechos Humanos, Violencia de Género. 


\section{HACKEANDO EL GOBIERNO ELECTRÓNICO: ALTERNATIVAS CRÍTICAS AL GOBIERNO ABIERTO}

Gobiernos y diversas instituciones internacionales han promovido una creciente y cada vez más compleja utilización de tecnologías de información y comunicaciones (TIC) en procesos de gestión, difusión de información y conocimiento, y relación con la ciudadanía, lo que se ha asociado a las nociones de Gobierno electrónico y open government, constituyéndose en una dimensión fundamental de políticas públicas y sociales.

Sin embargo, podríamos hablar de las promesas no cumplidas de la democracia electrónica (Bobbio, 2001). Evaluaciones de procesos de implementación de TIC en contextos sociales y políticos diversos, dan cuenta de vacíos, faltas de adaptación, y finalmente producción de nuevas formas de desigualdad y exclusión en el acceso a servicios públicos electrónicos y los derechos asociados (Frei Toledo, 2007).

Es necesaria una evaluación de los discursos y las decisiones de política al seleccionar qué ámbitos del Estado son trasladados a lo electrónico, qué prácticas, servicios e interacciones se promueven, y cómo se definen los criterios técnicos. Planteamos como supuesto la contradicción entre una visión de sociedad democrática, participativa y transparente, pero "gestionada" tecnocráticamente desde un saber experto.

Esta lógica tiene que ver con el origen del diseño e implementación de las TIC en los espacios del capitalismo cognitivo (Zuboff, 2019), desde donde son traspasados al ámbito público. Eso que aceptamos irreflexivamente en el capitalismo del control y de la vigilancia, se transforma en un problema político de fondo al agregar el sujeto: control de la ciudadanía, vigilancia de la ciudadanía.

Se propone una reflexión crítica a partir de la metáfora de la Catedral y el Bazar (Raymond, 1999) y de la noción de Haking (Himanen, 2002; Levy, 2014). Raymond propone una distinción entre el software privativo donde, las decisiones técnicas se toman mirando hacia el cielo corporativo y de espaldas a las necesidades de los usuarios, que deben aceptar las decisiones "divinas" de los expertos; y el open source, en el que las decisiones técnicas son construidas comunitariamente, y adaptadas contextualmente, como ocurre en los espacios de intercambio de la feria o el bazar. El haking implica una búsqueda creativa y ética, una epistemología orientada a encontrar soluciones a problemas (no necesariamente técnicos), considerando siempre una relación crítica con el poder institucional.

Cuestionando la Catedral, y desde el Bazar se propone una interpretación alternativa para el diseño y la implementación de las TIC en el ámbito público. Una visión de sociedad múltiple y diversa que activamente busque hackear (buscar apasionadamente la solución) de la democracia, la participación y la transparencia.

Palavras-Chave: Gobierno Electrónico, Open Government, Ciudadanía, Vigilancia, Control.
Helder Binimelis Espinoza Universidad Católica de Temuco (Chile) 
Ref.: 299CEDHMI 2020

O CAPITAL NO BANCO DOS RÉUS: (RE)CONSTRUIR DIREITOS HUMANOS EMTEMPOS LÍQUIDOS

Isabella Faustino Alves

Universidade de Coimbra
A despeito do fim do colonialismo de domínio territorial por potência estrangeira e da apontada universalidade dos direitos humanos, constata-se a presença multifacetada de uma linha abissal, a distinguir, sobretudo, o norte do sul global -este marcado historicamente por dinâmicas de expropriação e violência -a resultar no fato de que aqueles que estão do outro da linha não sejam considerados ou tratados como humanos (SANTOS, 2009, p. 21-23; 2018, p. 28).

Considerando-se o aumento das desigualdades sociais mesmo no interior das sociedades tidas por mais desenvolvidas, e analisado o panorama global sob a perspectiva dos direitos humanos -ante a internacionalização iniciada no pós-segunda guerra mundial e aprofundada pela globalização -exsurge uma divisão evidente entre aqueles que desfrutam do estatuto de pessoa humana e aqueles que são privados mesmo dos bens essenciais a condições materiais condignas de existência.

A partir da teoria crítica dos direitos humanos e do enfoque das epistemologias do sul, propõe-se uma reflexão acerca da factibilidade dos direitos humanos na atualidade, e da consequente necessidade de uma jurisdição mundial de direitos humanos, com foco para condutas praticadas por atores que se articulam, de modo transfronteiriço, em nome da persecução dos interesses econômicos do grande capi- tal. Compreende-se que uma institucionalidade com esse mister promove o Direito "como modelo avançado de legítima organização social da liberdade" (LYRA FILHO, 1982, p. 121), com vistas a criar novas formas de garantir os resultados das lutas sociais" (FLORES, 2009, p. 59), o que se tem como indispensável à promoção de sociedades pacíficas, justas e inclusivas.

Desta feita, e tendo em vista a manifesta exploração das vulnerabilidades humanas geradas e agravadas por um mercado desregulamentado, o que se soma à reconfiguração da soberania dos Estados sob os influxos da globalização, a proposta em questão orienta-se por uma concepção contra-hegemônica e emancipatória, que tem como premissa uma dimensão relacional e sócio-histórica dos direitos humanos.

Palavras-Chave: Direitos Humanos, Factibilidade, Linha Abissal, Jurisdição Mundial, Paz. 


\section{A EMPRESA COMO INSTRUMENTO DE DESENVOLVIMENTO DOS DIREITOS HUMANOS}

O desenvolvimento de atividades econômicas de modo ordenado, a fim de distribuir ou produzir bens ao mercado (a empresa sob ótica objetiva), em análise precária, pode demonstrar razão de ser meramente patrimonial, cujo único resultado desejável é o enriquecimento do empresário. Deste modo, a empresa é interpretada meramente como o resultado do esforço organizativo de um sujeito, tomador de riscos e, portanto, legitimado a os perceber lucros. No entanto, existem outros objetivos e resultados desejáveis no desenvolvimento das empresas, não apenas o enriquecimento dos empresários. São estas as questões relativas à "função social da empresa". A dicotomia entre direito público e direito privado há muito gera discussões quanto aos limites da autonomia privada e da propriedade. Com o desenvolvimento de movimentos de constitucionalização do direito privado, percebeu-se a incidência de regras e princípios dos direitos fundamentais sobre os ramos do direito privado, o que resultou em uma nova visão sobre a empresa. O tratamento dado ao instituto, pelo ordenamento jurídico brasileiro, mesmo que através de interpretação sistêmica, é o de também garantir a sua função perante a coletividade, não se limitando a garantir apenas vantagens financeiras, mas também a distribuição de riqueza, bens, serviços e outros resultados positivos à sociedade, o que, inclusive, enseja em certa proteção da empresa, dada a sua importância meta individual. Relacionando o tema ao item 8 da Agenda 2030 da ONU (trabalho digno e crescimento econômico), podemos traçar os seguintes questionamentos: "o instituto jurídico da empresa pode servir aos direitos humanos como instrumento de promoção ao trabalho digno, desenvolvimento econômico e redução das desigualdades? Se sim, como o faz?". Partindo destes questionamentos, o artigo terá o condão de entender melhor a função social da empresa, as suas características e normas balizadoras, além de tratar do papel deste instituto na sociedade brasileira, e as suas benesses à coletividade e aos direitos humanos. O desenvolvimento do artigo se dará através de metodologia dialética, com pesquisa qualitativa e exploratória, trabalhando com bibliografia doutrinária, estatística e legislativa.

Palavras-Chave: Direitos Humanos, Empresa, Função Social, Desenvolvimento Econômico, Promoção Trabalho Digno.
Osvaldo Caetano Neto Universidade Presbiteriana Mackenzie 
Ref.: 254CEDHMI 2020

\section{O VIÉS COGNITIVO DO ALGORITMO NA INTELIGÊNCIA ARTIFICIAL}

Cláudio Teixeira Damilano

Pontifícia Universidade Católica

Do Rio Grande Do Sul
O propósito da pesquisa é compreender de que maneira ocorre a tomada de decisão pelo uso da inteligência artificial (IA). Por sua vez, o objetivo específico é descobrir se a inteligência artificial, por utilizar dados, realmente adota decisão racional livre de qualquer parcialidade. Para isso, o método de abordagem aplicado será o hipotético-dedutivo, em que se iniciará com hipóteses formuladas na condição de respostas provisórias aos problemas apresentados, submetendo-as a uma análise de falseamento, de modo a aceitá-las ou refutá-las. Cada hipótese corresponderá à maneira com que a inteligência artificial faz suas escolhas e adota as suas decisões. 0 método de procedimento será o comparativo e o método de interpretação será o sociológico. A pesquisa utilizará como base fontes bibliográficas e documentais. O resultado final alcançado é de que o viés nos sistemas de inteligência artificial pode acontecer em três fases: (i) na definição do problema -o que o modelo de aprendizado profundo irá alcançar; (ii) na coleta de dados os dados não são representativos da realidade ou refletem os preconceitos existentes; e (iii) na preparação dos dados -envolve a seleção de quais atributos você deseja que o algoritmo considere. A eliminação do viés no sistema de inteligência artificial é algo difícil de acontecer, assim como é difícil de acabar com a discriminação que existe na sociedade. Nos sistemas de inteligência artificial já existem diversos trabalhos sendo desenvolvidos para detectar e atenuar os vieses. O maior desafio em neutralizar o viés discriminatório está na inteligência artificial forte -aprendizado de máquina profundo -que é composta de várias camadas. Nesta hipótese, existem os chamados black box, em que não se sabe o percurso lógico-argumentativo para se chegar ao resultado final. Diferentemente ocorre na chamada inteligência artificial fraca em que se utiliza do procedimento de árvore de decisão (decision tree). Isto é, o caminho percorrido pela máquina é predefinido pelo criador e/ou programador do sistema. De qualquer forma, existe uma grande preocupação internacional em regular a inteligência artificial para que os usos de suas decisões sejam livres de quaisquer desvios lógicos e irracionais. A regulação deverá ser feita de forma adequada e ponderada para que os princípios éticos e os direitos relacionados à propriedade intelectual sejam observados, mas também para que a inovação não seja reprimida.

Palavras-Chave: Inteligência Artificial, Algoritmo,Viés Cognitivo, Regulação. 


\section{A SOCIEDADE CAPITALISTA, OS ODS E O IMPACTO EMPREENDEDOR NO BRASIL}

Na sociedade contemporânea, as novas práticas econômicas com perfis neoliberais, onde se aceita um Estado Mínimo, vem crescendo e aparece em plena discordância com os Objetivos do Desenvolvimento Sustentável. Percebemos o crescimento dos mercados, sociedades capitalistas e de consumo onde as grandes concentrações de renda se encontram na minoria dos poderosos que hoje ditam e/ou agem diretamente nas políticas públicas de seus governos. A pesquisa busca compreender as características de uma sociedade capitalista, descrevendo os impactos econômicos e sociais que interferem no dia a dia dos indivíduos. Devemos ter claro que todo movimento decorrente desta sociedade gera impactos no bem-estar social, onde há maior necessidade de ações que promovam a melhoria da qualidade de vida. Há, graças as características deste mercado capitalista, um maior crescimento das desigualdades sociais, das oportunidades de emprego, ação totalmente ligada a condições sociais, que levam a precoce saída dos bancos escolares em busca da sobrevivência, entre outros. Diante da informação da evasão escolar, precisamos ainda compreender a importância que a educação tem nesta mudança nas desigualdades sociais, onde conforme menciona Saviani (2009) em sua obra Educação e Democracia, aborda os caminhos da educação brasileira, defendendo a ideia de que a escola deve incitar os alunos a transformar a sua realidade, e ainda despertar neles o senso crítico, a conscientização, e mostrar que a realidade social é constituída nas relações de poder. As ferramentas utilizadas para a coleta de dados desta pesquisa foi a pesquisa bibliográfica e documental, com análise qualitativa e quantitativa da Global Entrepreneuship Monitor (GEM) e da Organização das Nações Unidas (ONU) sobre os Objetivos do Desenvolvimento Sustentável (ODS). A modificação do mercado tem gerado novas práticas de exploração do indivíduo com práticas precárias de trabalho, como podemos exemplificar a "Uberização" vindo de encontro a flexibilização das leis trabalhistas. A justificativa pela escolha destes documentos se dá por verificar o crescimento das práticas empreendedoras no Brasil e por entender que a ONU, através de suas práticas em busca da paz e desenvolvimento mundial podem interferir positivamente na melhoria da qualidade de vida dos povos. Observando os documentos analisados, os mesmos deveriam buscar melhoria e bem-estar social a população, porém não são aplicados em sua totalidade, fatores políticos e de classes dominantes fazem com que as políticas governamentais não sejam eficientes, pelo contrário, que favorecem apenas aqueles que estão no poder.

\section{Palavras-Chave: ODS, Impacto Empreendedor,} Bem Estar Social.
Georgia da Cunha Bem

Universidade Tuiuti do Paraná/Unespar - Campus Paranaguá 


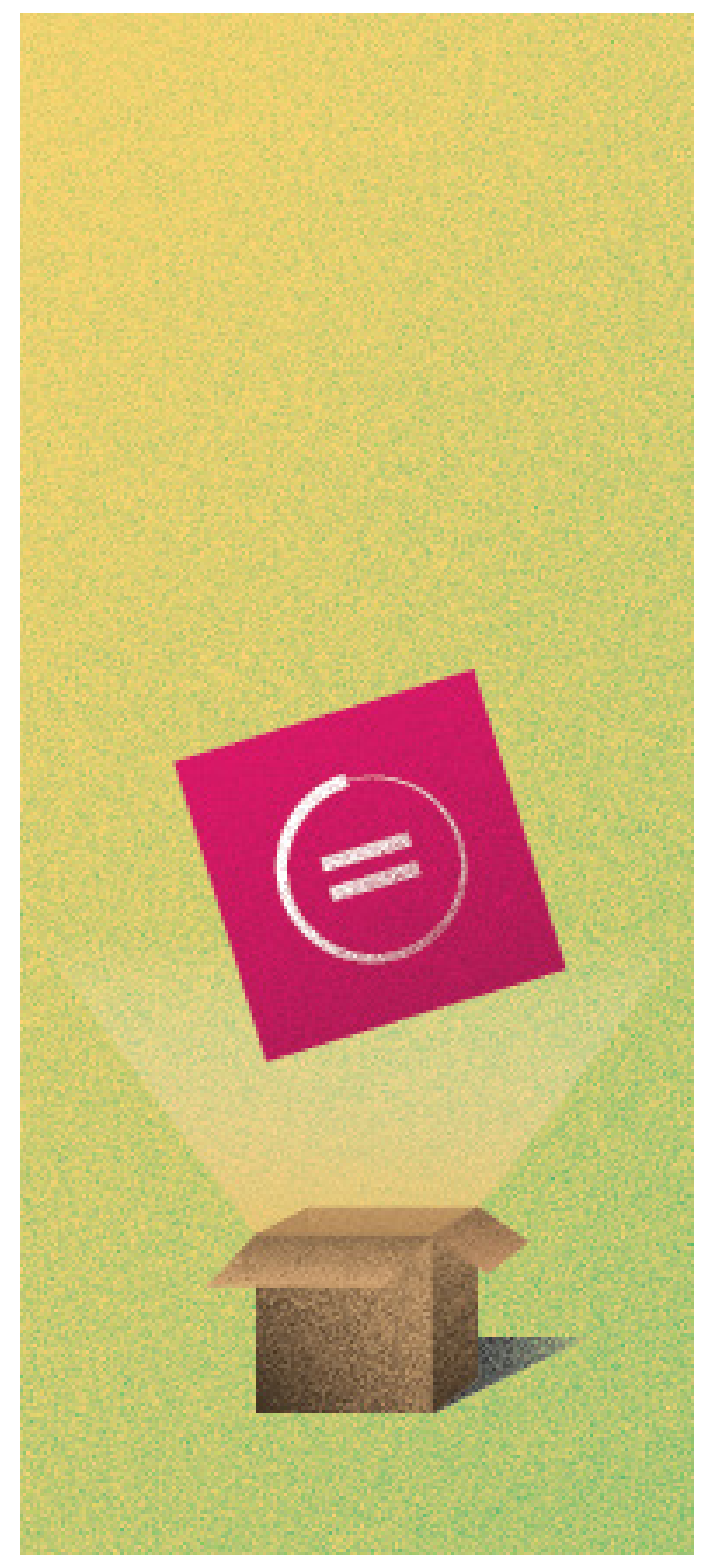

\section{ODS 10 \\ REDUZIR AS DESIGUALDADES}




\section{O NOVO LUGAR DO MINISTÉRIO PÚBLICO DE PERNAMBUCO E A INDUÇÃO DE POLÍTICAS PÚBLICAS PARA A PESSOA IDOSA}

O objetivo central deste trabalho é contribuir com o avanço da discussão sobre o lugar do Ministério Público na efetividade de diretos para a pessoa idosa via políticas públicas, entendendo que os projetos executados podem vir a se configurarem como respostas eficazes à garantia ao acesso e usufruto de direitos à população idosa. Considera-se este tema de grande importância, pois traz uma discussão sobre um "novo lugar" que o Ministério Público de Pernambuco -MPPE vem assumindo na condução de programas e projetos destinados à sociedade, cuja missão e razão de ser estão pautadas na Justiça Social e transformação da realidade social, por meio da aproximação com a sociedade e atuação preventiva na condição de protagonista das políticas públicas. Logo, discutir acerca de instrumentos de que dispõe o Ministério Público pernambucano para dar respostas sociais condizentes com a ampliação e garantia dos direitos e inclusão da pessoa idosa é de significativa importância no momento atual. É fato que há uma tendência demográfica de crescimento da população idosa e no Brasil, esse número vem aumentando progressivamente acompanhando a tendência mundial de aumento da expectativa de vida. No entanto, é importante destacar que a conquista do fenômeno da longevidade vem ocorrendo sem a contrapartida de políticas públicas, carregando condições desfavoráveis para que idosos, que estão em situação de maior vulnerabilidade, usufruam de uma velhice com dignidade. Trata-se de um estudo de abordagem qualitativa sob uma perspetiva crítica que considera a historicidade como categoria imprescindível de análise. Optou-se nesta pesquisa pela adoção da estratégia metodológica de revisão bibliográfica e de pesquisa à fontes secundárias disponíveis no site do MPPE e do Conselho Nacional do Ministério Público -CNMP. Para alcance dos resultados institucionais, o MPPE vem fortalecendo a atuação extrajudicial, através de uma maior sensibilização para as demandas coletivas e para a indução de políticas públicas por meio da implantação de programas e projetos que apresentam impacto coletivo em seus resultados e benefícios para a população. O estudo conclui que o Ministério Público de Pernambuco mesmo diante da complexidade, das resistências e limites institucionais para executar um trabaIho efetivo pela cidadania e pela justiça social, em meio a um contexto de profundos desafios no âmbito social e econômico enquanto obstáculos para o real acesso à justiça, vem apresentando mudanças ao longo dos anos no paradigma institucional e no seu foco de intervenção, incorporando valores e eixos de atuação mais abrangentes e se colocando como agente indutor de políticas públicas nas mais diversas áreas, incluindo a "pessoa idosa. Intervenções que fazem parte das incumbências do novo perfil do Ministério Público de Pernambuco, o qual ainda tem longo e complexo caminho a percorrer na direção da defesa e condução de políticas públicas alinhadas com a efetivação dos direitos e da justiça social.

Palavras-Chave: Estado, Ministério Público, Políticas Públicas, Pessoa Idosa, Justiça Social.
Amanda Maria Cunha Menezes

\& Ana Cristina Brito

Arcoverd

Universidade Federal De Pernambuco 
Maria Carolina Santos

Barreira

\& Daniela Castilhos

Universidade Portucalense

Infante D. Henrique
* O presente artigo é resultado da investigação realizada no âmbito do Módulo Jean Monnet The European Union as a global player for Democracy and Fundamental Rights pelo que é cofinanciado pela União Europeia. The European Commission support for the production of this publication does not constitute an endorsement of the contents which reflects the views only of the authors, and the Commission cannot be held responsible for any use which may be made of the information contained therein.
Ref.: I 25CEDHM42020

\section{A PROTEÇÃO INTERNACIONAL DOS DIREITOS SOCIAIS NA EUROPA: SURGIMENTO,AFIRMAÇÃO E PROTEÇÃO MULTINÍVEL*}

A globalização e o processo de integração europeu lançaram complexos desafios a proteção internacional dos Direitos Sociais. Este artigo pretende analisar a incorporação dos direitos sociais no contexto Europeu. Verificando-se que os direitos fundamentais são os direitos positivados numa ordem jurídica, conclui-se que para se chegar a esta positivação, percorreu-se um longo caminho, com o fito da construção progressiva desses direitos, tendo-se considerado o contexto histórico e cultural da sociedade. De maneira progressiva os direitos individuais começaram a ser aludidos pela ação das instituições comunitárias e, na falta de normas expressas de proteção dos direitos fundamentais, o Tribunal de Justiça da Comunidade Europeias seria capaz de construir a proteção desses direitos. O grande salto qualitativo para se atender o direito individual na sua vertente humana, verifica-se diante do Tratado de Maastricht, assinado pelo membro da comunidade europeia, em 1992. Consumou-se a integração assente nos pilares da Comunidade Europeia, Política Externa e de Segurança, Justiça e Assuntos Interno, e foram introduzidos elementos para uma efetiva união política e preparação de uma união econômica monetária. Relacionar a evolução da construção europeia com a implementação de direitos sociais enquanto direitos fundamentais, demonstrando a maneira progressiva em que esses direitos tiveram origem, ao tempo em que avançaram no orde- namento jurídico europeu. Demonstrar a origem dos direitos fundamentais, diferenciando-os, a priori, dos direitos humanos, tendo-se demonstrado a maneira progressiva em que esses direitos se originaram e avançaram no ordenamento jurídico europeu. Destacar a Carta de Direitos Fundamentais da União Europeia, a qual foi elaborada diante da necessidade de que se compilassem esses direitos, tendo em vista sua amplitude, bem como diante do acúmulo de jurisprudências. Verificar a Casta Social Europeia, considerando que esta enquadra-se como um documento legislativo internacional o qual prescreve os direitos sociais a um nível superior ao que, por vezes, preconizam alguns Estados-membros, questionando-se se, neste contexto, um acordo internacional se sobrepõe a ordem jurídica nacional. Analisar os principais documentos legislativos que consagram tais direitos, tendo em conta as diversidades culturais e específicas tradições legais de cada Estado membro. Concluímos que a conquista dos direitos fundamentais, dentre eles os sociais, está em constante evolução, para além do direito positivado nos tratados e demais legislações, as jurisprudências proferidas pelo Tribunal de Justiça da União Europeia, o qual é o máximo garantidor desses direitos fundamentais e sociais, podem ser geradores de novos direitos.

Palavras-Chave: Direitos Fundamentais,

Direitos Sociais, Evolução, Multinível. 


\section{A DISCRIMINAÇÃO É QUE AFLIGE. DIREITOS HUMANOS, PREVENÇÃO DA INFEÇÃO POR VIH E SEROFOBIA}

A discriminação das pessoas que vivem com VIH (PVV) e os Direitos Humanos foram a base das campanhas mundiais de luta contra a sida, para prevenir e eliminar todas as formas de discriminação. Além de ser uma violação dos Direitos Humanos, a discriminação representa um obstáculo à prevenção (pelo teste e pelo tratamento). O medo de uma doença marcada pelo estigma, leva as pessoas a não se identificarem com o risco ou a possibilidade de terem VIH e, por conseguinte, a não fazerem o teste de diagnóstico. Uma pessoa que não conhece o seu estatuto serológico tem maior tendência para ter comportamentos de risco pois não sabe que é um potencial veículo de transmissão do VIH, ao passo que uma pessoa que sabe ser portadora do vírus tem, regra geral, comportamentos preventivos, além do facto que, tendo acesso ao tratamento e uma carga viral indetetável há 6 ou mais meses, não há risco de transmissão do VIH.

Considerando que o estigma e a discriminação continuam a estar fortemente presentes na União Europeia, a Comissão Europeia considerou importante prosseguir com ações envolvendo os governos nacionais e as organizações não-governamentais que trabalham na defesa dos Direitos Humanos. Seguiram-se um bom número de recomendações e legislações. Ora, importa avaliar em que medida as disposições políticas vão além da mera discursividade e se traduzem, de facto, em instrumentos e formas de intervenção eficazes a nível da prevenção, da deteção precoce e dos apoios às populações mais vulneráveis, que se debatem frequentemente com constrangimentos severos, desde logo aqueles que remetem para o estigma e a discriminação.

Uma das primeiras decisões europeias no sentido de obstar à discriminação das PVV remonta a 1988, quando o Conselho Europeu e os representantes dos governos dos estados-membros acordaram em sublinhar a importância de uma abordagem comum e defenderam a prioridade à prevenção através da informação e da educação em matéria de saúde, e o combate a qualquer discriminação ou estigmatização das PVV, nomeadamente, mas não só, no que diz respeito ao emprego.

Considerando que o estigma e a discriminação continuam a estar fortemente presentes na União Europeia, a Comissão Europeia considerou importante prosseguir com as ações envolvendo os governos nacionais e as organizações não-governamentais que trabalham na defesa dos direitos humanos. Seguiram-se um bom número de recomendações e legislações. Mas a legislação, por mais meticulosa e ajustada que se afigure, por si só não basta. Mesmo depois de quadros políticos bem delineados e a priori adequados, importa avaliar em que medida as disposições políticas vão além da mera discursividade, são consequentes e traduzem-se, de facto, em instrumentos e formas de intervenção eficazes a nível da prevenção, da deteção precoce e dos apoios às populações mais vulneráveis, que se debatem frequentemente com constrangimentos severos, desde logo aqueles que remetem para o estigma e a discriminação (Sacramento el al 2016).

Palavras-Chave: Direitos Humanos, Serofobia, Estigma, Diagnóstico, SIDA.
Marta Maia

Instituto Universitário de Lisboa (ISCTE-IUL)

Centro em Rede de Investigação em Antropologia (CRIA) 


\section{AS RELAÇÕES DETRABALHO COM ÊNFASE AO MIGRANTE: E A POSSIBILIDADE DE VIOLAÇÃO DOS DIREITOS HUMANOS}

Najah Jamal Daakour

Barakat

Universidade Federal De Mato Grosso Do Sul

\& Eduardo Soares Da Silva Universidade Catolica Dom Bosco
O trabalho propõe analisar o fenômeno das migrações tendo como pano de fundo as relações de trabalhos na figura central do trabalhador migrante. As migrações têm uma nuance próxima em ser destacada a medida de uma busca de um indivíduo ou grupo em condições melhores de sobrevivência. Os fluxos migratórios são exclusivamente decorrentes de condições nas quais o indivíduo se torna migrante em face dificuldade de sobrevivência naquele seu local de origem. Nesta senda o migrante sai do seu contexto geográfico tendo a relação de vários fatores como perseguições políticas, culturais, raciais, religiosas, étnicas e outras. Ainda pode ser verificado conteúdos como sociais e econômicos, logo o conteúdo econômico tendo elementos como a globalização, atualmente é o fator preponderante sugestionado aos fluxos migratórios. Nesse viés, o fator econômico sugerindo a migração, os migrantes saem do seu país em busca de melhores condições de vida para sua família, sua sobrevivência, ou também o sonho de uma vida mais digna. A partir dessa premissa, as relações de trabalho e o migrante, configurado como trabalhador migrante, tem um apreço na verificação das possibilidades de violações dos Direitos Humanos sendo que o trabalhador migrante levanta a questão envolta no quesito de vulnerabilidade, muitas vezes a chegada num determinado país condiciona em face as relações de trabalho condições que fogem aos pressupostos referendados por organismos como a OIT e a ONU, que vinculam proteção aos seres humanos tendo como esteira os Direitos Humanos, e não poderia ser diferente no tratamento dispensados aos trabaIhadores migrantes nessa busca por melhores condições de trabalho e de vida. As violações dos Direitos Humanos nas relações de trabalho são apresentadas ao trabalhador migrante, que sofre condições degradantes de trabaIho, precariedade, jornadas exaustivas, analogia a escravidão, desconsideração da igualdade, cidadania e dignidade da pessoa humana. Na perceção do conteúdo de vulnerabilidade que recai sobre os migrantes e em especial ao sexo feminino, é crível que os mecanismos jurídicos tanto nacionais quanto internacionais contenham um apreço voltado na promoção de ambientes de trabalho com condições de segurança e de proteção e de assegurar medidas de combate a precariedade que rondam essas relações de trabalho. Assim, os Direitos Humanos na reservada proteção dos migrantes, concatenada ao pressuposto de sua humanidade e dignidade, contém elementos capazes a nortear todo quesito que resguarda direitos, assegurando garantias e promovendo combate a todo o tipo de violação. Todavia, mesmo tendo o olhar conferido por mecanismos de proteção ainda é imperioso um melhor aparato para postular os direitos e garantias a esses trabalhadores, minimizando a sua vulnerabilidade e postulando a possibilidade de que esse trabalhador tendo os Direitos Humanos e a dignidade da pessoa humana alcance seus objetivos numa nova pátria, temporária ou permanente.

Palavras-Chave: Migração, Trabalhador Migrante, Relação de Trabalho, Direitos Humanos, Violações. 


\section{PELA CONSECUÇÃO DOS OBJETIVOS PROSPECTADOS PELA AGENDA 2030 COM FOCO NA ÉTICA DO CUIDADO}

O presente estudo visa analisar de forma crítica as acentuadas desigualdades sociais que foram densificadas pela política neoliberal que tem prevalecido no século XXI, incorporada pelo mercado ocidentalizado internacional, que opera na lógica do capital, em busca da elevação do lucro em detrimento ao desenvolvimento humano e a estruturação de políticas públicas efetivas para a consecução do bem comum. Nesse sentido, verifica-se que a pandemia do Coronavirus Disease 2019 (COVID-19) trouxe a lume questões que por longa data permaneceram propositalmente invisibilizadas, para que o mercado pudesse expressar sua ferocidade com ares de legitimidade, ao incutir a lógica da política neoliberal como o modus operandi da sociedade contemporânea. Nesse sentido, a pesquisa com a utilização da metodologia bibliográfica com exame da doutrina e da literatura numa perspetiva multidisciplinar sobre a temática, justifica-se pela realidade circundante e pelas mudanças paradigmáticas provocadas pela pandemia do Coronavirus Disease 2019 na sociedade internacional, a desafiar medidas dos poderes constituídos para evitar a disseminação em massa do vírus e a contaminação de mais pessoas. Nesse cenário, a hipótese que se procurou verificar foi saber se isolamento social recomendado pela Organização Mundial de Saúde (OMS) e adotado pela maioria dos países, como forma de contenção da pandemia contribuiu para a maximização das desigualdades sociais, especialmente dos países que integram o terceiro mundo. Nesse cenário, verificou-se que, a quarentena, fruto do aconselhado isolamento social se mostrou árdua e desafiadora, notadamente para alguns grupos de pessoas tidas como vulneráveis, a saber: os deficientes, os imigrantes indocumentados, os idosos, as mulheres, os trabalhadores informais, os moradores de rua, os moradores de periferia entre outros. Nessa linha de intelecção, cabe esclarecer que, o presente estudo foi estruturado pelo referencial teórico emanado do sociólogo Boaventura de Souza Santos, que de forma magistral sinalizou para a trágica transparência do vírus que serviu inclusive para desvelar as condições desumanas suportadas pelas pessoas menos abastadas financeiramente ou tidas como vulneráveis e que estão tendo suas condições de existência desprestigiadas face ao desmantelamento das políticas públicas voltadas para saúde, educação, previdência, trabalho e segurança. A título de conclusão verificou-se que o neoliberalismo em termos de modelo social não pode prosperar, sob pena de acentuar ainda mais a pobreza, a miséria, as desigualdades sociais e outras mazelas evidenciadas no mundo contemporâneo. Assim, deve haver uma nova articulação política e humanitária, nesse sentido os objetivos prospetados pela agenda 2030 devem ser incorporados pelos países, para que haja respeito à humanidade que reside em cada pessoa, independente de sua raça, cor, sexo, orientação religiosa, filiação política, condição social, primando assim para a ética do cuidado.
Nivea Corcino Locatelli Braga

Doutoranda em Direito do Programa de Pós-graduação em Direito - PPGD-UNESA 
Ref.: 245CEDHM22020

\section{TEORIA CRÍTICA DOS DIREITOS HUMANOS E PENSAMENTO DECOLONIAL: UMA ANÁLISE DO PROCESSO SOCIOPOLÍTICO DE FORMAÇÃO DESIGUALDA AMÉRICA LATINA}

Luisa Vasconcelos Silva e Souza

Universidade Federal do Rio Grande do Norte (UFRN)
Com base no pensamento decolonial e na teoria crítica dos direitos humanos, o presente trabalho tem por objetivo principal estudar o contexto colonial, e posteriormente imperialista, da formação sociopolítica da América Latina, contrapondo-se ao discurso hegemônico dos direitos humanos, oriundo do Norte Global. Ao mesmo tempo em que almeja instigar os processos de compreensão do arcabouço histórico por trás do atual cenário vivenciado pela América Latina, de verdadeira imaturidade democrática, instabilidade política, fragilidade na proteção dos direitos humanos, desigualdade social e situações de extrema pobreza e miséria, busca estimular o questionamento das bases do pensamento moderno que sustentam essa estrutura injusta, opressora e desigual, conduzindo a uma urgente ressignificação dos direitos humanos, a partir de uma perspetiva crítica, transformadora e intercultural. A questão norteadora para este estudo surgiu da perceção de que à grande parte das populações latino-americanas, de origem não-branca, sobretudo às populações originárias e à população negra e quilombola, as condições materiais para a vivência plena da dignidade humana são negadas, e de que as necessidades desses sujeitos nunca foram verdadeiramente atendidas pelo discurso hegemônico dos direitos humanos, que privilegia a manutenção das relações de poder e do status quo dos Estados historicamente colonialistas ou imperialistas. O processo de formação política da América Latina é marcado pela ausência de diálogo, desde o período colonial, e mesmo após os processos de redemocratização perpassados por diversos Estados, principalmente, na década de 1980 . O silenciamento do povo e a ausência de participação popular na política são, portanto, as marcas da construção dos Estados latino-americanos, originalmente coloniais e fechados, o que explica a dificuldade na consolidação da democracia, que vive em constante ameaça, dando margem a incontáveis violações de direitos humanos. Assim, este estudo de abordagem qualitativa pretende, por meio de uma pesquisa bibliográfica, identificar os obstáculos que impedem a efetivação dos direitos humanos na América Latina, para que os compreendendo possamos transformá-los.

Palavras-Chave: Teoria Crítica dos Direitos

Humanos, Pensamento Decolonial, Colonialismo, Desigualdade Social, América Latina. 


\section{AS MÃES E SUA DOR: \\ DIREITOS HUMANOS E POLÍTICA COMO CONSTRUÇÃO DE IDENTIDADE NO ESPAÇO PÚBLICO NO CASO DOS MENINOS EMASCULADO}

Este estudo tem por objeto o crime que ficou conhecido como o "caso dos meninos emasculados", em que os danos causados pelos atos de omissão e negligência estatais levaram à morte de 28 (vinte e oito) crianças e adolescentes do sexo masculino, no decorrer de 10 (dez) anos, na região metropolitana da Grande Ilha, que compreende os Municípios de São José de Ribamar, São Luís e Paço do Lumiar, no Estado do Maranhão. O caso foi levado à Comissão Interamericana de Direitos Humanos e, entre as obrigações assumidas após a decisão da Comissão, havia aquelas referentes às famílias e outras relacionadas a políticas públicas, como a instalação da Delegacia Especializada de Paço do Lumiar, do Centro de Proteção à Criança e ao Adolescente na cidade de São Luís do Maranhão, local em que consta placa em memória dos meninos mortos e a instalação da Defensoria Pública Estadual na Comarca de Paço do Lumiar, as quais foram de fato cumpridas. Entretanto, havia outros compromissos para com a população da região, como a construção de escolas para crianças da região, políticas preventivas à violência contra crianças e adolescentes, os quais nunca foram cumpridos a contento, havendo, ainda hoje, pendências não sanadas. Quanto às famílias dos meninos, foi assumida a obrigação de solucionar o seu problema de moradia, pois todas eram moradoras de áreas de invasão, sem qualquer infraestrutura. Além do pagamento de uma pensão às mães, pais ou representantes legais das crianças e adoles- centes mortos ao longo de 15 (quinze) anos, com reajustes periódicos, o que se mostrou insuficiente para aliviar o inconformismo das mães. Embora o Poder Público tenha se comprometido a aliviar a situação econômica das mães que perderam seus filhos, a dor dessas mães não foi aliviada, tendo em vista que essas mulheres não se sentem cidadãs do Estado brasileiro, conforme seu próprio relato. Em suas falas, fica evidente o descaso sentido por elas, a invisibilidade, a falta de interesse na solução dos crimes e, principalmente, a certeza de que só passam por esses problemas em razão de sua cor e situação econômica, o que descredibiliza o Estado junto à população mais pobre. Assim, seus discursos são expressão de que o Estado é tido como violador de direitos humanos, em razão dos muitos atos de negligência e das omissões em relação ao caso que envolveu a morte de seus filhos. Finalmente, analisa-se a subjetividade dessas mães no processo de luto, vivido no espaço público, já que se mobilizaram politicamente em busca de justiça para seus filhos, o que as levou a uma indiscutível perda ou modificação de sua identidade enquanto pessoas, fazendo, dessa forma, que deixassem de ser vistas e como mulheres e passassem a ser permanentemente percebidas socialmente apenas como "as mães dos meninos emasculados". Viveram e vivem um processo de estigmatização que prolonga seu luto e sua insatisfação para com o Estado. A metodologia utilizada foi a análise documental das falas registadas dessas mães.
Ana Lourena Moniz Costa \& Gabriela Henrique Carvalho 
Ref.: 279BCEDHM32020

\section{VIOLÊNCIA OBSTÉTRICA: A (DES)HUMANIZAÇÃO DO PARTO NO BRASIL}

Alessandra Benedito \& Luciana Costa Silva
A violência obstétrica está diretamente relacionada à medicalização da assistência ao parto. Tudo o que se relacionava à gestação e ao parto, tradicionalmente, era um conhecimento próprio das mulheres, transmitido de geração em geração e muito associado à natureza, assim como o conhecimento do uso medicinal das plantas e das ervas. Com o desenvolvimento da ciência médica e com o fim de se exercer cada vez maior controle sobre as mulheres e seus corpos, esse conhecimento passou a ser desprezado, em detrimento do saber dito "científico" e a gestação e o parto passaram a ser protagonizados pelos médicos, assumindo a mulher um papel de objeto dois procedimentos, apesar desses fenômenos serem biológicos e ocorrerem em seus próprios corpos. A partir dessa medicalização, vários procedimentos clínicos que passaram a ser usados com frequência nas maternidades e hospitais brasileiros, assim como de muitos outros países do mundo. Entre esses procedimentos médicos, podemos citar os constantes "toques", para verificação da dilatação do colo do útero por ocasião do parto, o uso da ocitocina, para acelerar o trabalho de parto, a episiotomia e o "ponto do marido", havendo parto normal, e a manobra de Kristeller, só para citar alguns exemplos. A episiotomia foi responsável por inúmeras lacerações sérias no períneo de muitas brasileiras e o "ponto do marido" tem sido uma prática médica desnecessária, voltada ao futuro prazer do homem. Todos esses procedimentos têm sido compreendidos, nos últimos anos, a partir da edição de algumas normativas internacionais, como violência obstétrica, isso sem falar nas cesarianas desnecessárias, cujos números no Brasil são altíssimos, sobretudo na rede particular. Segundo dados da Organização Mundial de Saúde (OMS), desde 1985 a taxa considerada aceitável para procedimentos cirúrgicos no parto seria entre 10 a $15 \%$ dos nascidos, porém no Brasil, conforme pesquisa realizada pelo Instituto Fiocruz as cesáreas no setor público chegam a atingir um percentual de $46 \%$ e no setor privado este índice chega a $88 \%$ dos nascimentos. Esse tipo de intervenção cirúrgica pode acarretar sérios riscos à saúde da criança, além de expor a mulher a três vezes mais riscos de morte, segundo dados do Conselho Nacional de Saúde (CNS). Não são poucos os relatos de agressões verbais à mulher durante o parto, assim como de proibição de que ela se faça acompanhar de pessoa de confiança, de sua escolha, além do fato de que há uma espécie de compreensão sedimentada, sem qualquer fundamento científico, de que as mulheres negras teriam maior tolerância à dor, não precisando, portanto, de tanto anestésico quanto as mulheres brancas. Neste trabalho, a violência obstétrica será analisada sob uma ótica institucional e racial, já que as mulheres negras têm sido as principais atingidas pela violência obstétrica. A pesquisa será realizada por meio da revisão bibliográfica de livros, artigos documentos nacionais e internacionais sobre a matéria.

Palavras-Chave: Violência Obstétrica, Parto, Cesárea, Parto Humanizado, Mulheres Negras. 


\section{A REVITIMAÇÃO DAS MULHERES VÍTIMAS DE VIOLÊNCIA DOMÉSTICA PELO JUDICIÁRIO BRASILEIRO}

Apesar de o Brasil ser signatário da
Convenção Interamericana para Preve-
nir, Punir e Erradicar a Violência contra a Mulher e ter reconhecido a igualdade de gênero em sua Constituição de 1988, a questão da violência doméstica só ganhou ênfase no cenário nacional com o advento da Lei no 11.340, de 2006, fruto da condenação do Estado brasileiro pela Comissão Interamericana de Direitos Humanos no caso de violência sofrido pela farmacêutica Maria da Penha Fernandes. Com efeito, a Lei Maria da Penha representou um avanço ao transformar o panorama jurídico dos crimes de violência doméstica no Brasil e introduzir a perspetiva de gênero na condução dos casos violência doméstica. Contudo, ainda é possível constatar a manutenção de alguns entraves que acarretam a insatisfação das vítimas com a resposta estatal, seja do ponto de vista de ausência de efetividade dos instrumentos jurídicos, seja diante da perceção da permanência de práticas sexistas na aplicação da lei. Não é por outra razão que inúmeros estudos apontam o fenômeno da "revitimização" dessas mulheres pela atuação de instituições públicas, nota- damente o Poder Judiciário, demonstrando a falta de preparo da maioria dos profissionais para lidar com questões de gênero, bem como a legitimação de discursos machistas e em imposições contrárias aos princípios básicos da lei. Dessa forma, por meio de pesquisa bibliográfica e jurisprudencial, este trabalho busca identificar como se dá esse processo de "revitimização" a que as mulheres em situação de violência doméstica são submetidas, verificar a origem da inobservância dos princípios da Lei Maria da Penha por magistrados, membros do Ministério Público, delegados de polícia e outros profissionais da área, assim como analisar os instrumentos jurídicos que podem efetivar o acesso à justiça pelas vítimas de forma plena e satisfatória e representar um caminho para a diminuição dos casos de violência doméstica no Brasil.

Palavras-Chave: Violência Doméstica, Poder Judiciário, Revitimização, Machismo, Violência Por Poderes.
Camila Bertoleto Roque 
Ref.: 279DCEDHM32020

\section{VIOLÊNCIA INSTITUCIONAL NAS VARAS DE FAMÍLIA DE SÃO LUÍS DO MARANHÃO}

Natalie Maria de Oliveira de Almeida
O presente trabalho tem como objetivo abordar a utilização do princípio da boa-fé objetiva como fundamentação das decisões judiciais nas Varas de Família da comarca de São Luís/MA, no período de março a maio de 2019. Aborda-se o princípio da boa-fé objetiva no Código Civil, demonstrando que ele tem como principal objetivo ser um modelo de conduta entre as partes envolvidas em uma relação. Assim, pelo disposto no artigo 113, a boa-fé funciona como um critério hermenêutico com o objetivo de que o juiz, com finalidade de suprir lacunas das relações contratuais, deva observá-la objetivando preservar as justas expectativas das contratantes. Pelo artigo187 do Código Civil Brasileiro, a boa-fé não admite condutas contrárias ao dever de agir com lealdade e probidade, devendo buscar alcançar a função social do contrato e por fim, conforme o artigo 422, a terceira função, cujo objetivo é a criação de deveres anexos a serem observados em todas as fases do contrato. É a cláusula geral da boa-fé que se insere implicitamente nos contratos com a finalidade de obrigar os contratantes a observar os deveres específicos de comportamento, servindo como regra de correção (DUARTE, 2003). Ela se diferencia na boa-fé subjetiva porque esta faz uma análise da perceção individual do agente cuja conduta está sendo analisada com o objetivo de verificar se este acreditava que tal agir era correto, ainda que não seja o padrão de conduta do homem médio em determinada situação. Inicialmente, sua aplicação estava diretamente associada ao sentido negocial, no entanto sua expansão sobre outras espécies de relações jurídicas como critério de controle de legitimidade do exercício da autonomia privada em geral é inegável. Desse modo, o princípio da boa-fé objetiva passou a ser considerado nas relações existenciais e, no que interessa a este trabalho, a ser aplicado nas demandas de família, trazendo exemplos de sua utilização pelo Superior Tribunal de Justiça. Neste artigo, será feita uma análise de sua (in)aplicação nas decisões das Varas de Família de São Luís. A metodologia utilizada foi a de revisão bibliográfica, pois baseia-se em leis, doutrinas, jurisprudências e artigos encontrados em repositórios digitais de teses e dissertações, assim como entrevista não estruturada com juízes, secretários (a) s e analistas das varas pesquisadas; define-se também como qualitativa do tipo exploratória e avaliativa, visto que busca um tratamento interpretativo dos objetos de estudo. O civilista não pode continuar aplicando o princípio da boa-fé nas Varas de Família, se utilizando da mesma lógica empregada nas ações consumeristas ou nos contratos imobiliários, tendo em vista lidar com pessoas, em especial membros de grupos vulneráveis, como mulheres e crianças. Há de se considerar que a mulher pode estar sendo vítima de violência, ao celebrar o acordo, além de que é necessário se resguardar o melhor interesse da criança e do adolescente.

\footnotetext{
Palavras-Chave: Boa-Fé Objetiva, Direito De Família, Decisão Judicial, Varas De Família, Violência Institucional.
} 


\section{CONCEITOS JURÍDICOS INDETERMINADOS: A LUTA DOS DIREITOS HUMANOS CONTRA O ARBÍTRIO E A SELETIVIDADE PENAL}

O presente estudo busca refletir acerca da falta de harmonia entre garantia -e aplicação -dos direitos humanos e as políticas públicas de combate e prevenção à violência, e, desta forma, formular parâmetros que servirão de base para que se alcance o almejado equilíbrio, vez que, equivocadamente, são compreendidos como contraditórios. Nessa toada, a análise percorre os deslocamentos ocorridos entre a segunda metade do século XX com a popularização da teoria das janelas quebradas como meio de política criminal e a declaração de guerra às drogas pelo Estado brasileiro na primeira década do século XXI, até a intervenção federal no Estado do Rio de Janeiro, ocorrida no final da segunda década do século XXI, bem como os óbices enfrentados para a aplicação dos direitos humanos em cada momento histórico. O percurso da história do Brasil é marcado pelo solipsismo narcisista, evidenciado por Luiz Eduardo Soares, no prefácio do livro "A Síndrome da Rainha VermeIha", de Marcos Rolim, no qual o autor aponta a ineficácia, nunca assumida -mas sempre adotadas da mesma forma -, das soluções e explicações sobre crimes e violências, constituindo um Estado negligente às tragédias diárias e indiferente aos cidadãos, deixando-os desamparados. Nesse sentido, o Estado, não raras vezes, opta(ou) pelo caminho da relativização dos direitos humanos legitimados sob argumentos ad passiones e pelo combate ao inimigo criado através da teoria do etiquetamento (Labeling Approach). Este fenômeno é sintoma da pós-democracia, tida por Peter Crouch como o estado de coisas em que há um funcionamento aparente das instituições democráticas, quando, na realidade, estas estão a serviço da ideologia neoliberal, promovendo uma violência ainda mais perversa, porque quase imperceptível e, portanto, difícil de combater. Os efeitos recaem mais contundentemente sobre os indesejáveis, os inaptos para o consumo (portanto, inimigos do Estado), condição que Ihes foi imposta por razões de jaez histórico-ideológico. O caminho escoIhido para melhor compreensão do tema baseia-se na utilização de instrumentos de análise de dados e revisão bibliográfica pertinentes ao tema abordado.

A partir dos estudos realizados, sem a pretensão de esgotamento do complexo tema, os resultados parciais demonstram a necessidade de que os direitos humanos e a segurança pública sejam tratados de forma a se complementarem, com a devida prevalência dos direitos humanos, em caso de eventual tensão entre eles. Com efeito, é imperioso desmantelar a ideia de um "inimigo estatal" para que seja possível determinar a extensão que cada parâmetro terá a partir de critérios objetivos e determinados, ou seja, é indispensável a racionalização da persecução penal ainda fundada em uma legislação autoritária, que emprega expressões indeterminadas. No mesmo sentido, a formação policial formal é insuficiente para desconstituir a arraigada opressão vivenciada pelos oficiais tanto no âmbito civil quanto própria estrutura polícia.

Palavras-Chave: Direitos Humanos, Violência Policial, Direito Penal do Inimigo, Persecução Racional, Seletividade Penal.
Andressa Franch Carloni \& Rafael Ferreira de Albuquerque Costa Centro Universitário Ibmec-RJ 
Ref.: 202CEDHMI 2020

\section{MULHERES, DEMOCRACIA E CIDADANIA: O PLANEJAMENTO URBANO COMO FERRAMENTA DE REDUÇÃO DA DESIGUALDADE}

Raquel Gomes Valadares

Instituto de Arquitetura e Urbanismo da Universidade de São Paulo - IAU/USP
A proposta desta análise é identificar desajustes no planejamento urbano ou nas diretrizes de política urbana que promovem o tratamento desigual entre homens e mulheres no espaço público. Embora, no último século, tenha ocorrido experiências de conquistas e positivações de normas que possibilitam direitos e garantias para mulheres, ainda não há consolidação completa destes avanços. Os circuitos urbanos feitos por elas podem variam em virtude da condição social e sexual, do núcleo familiar e da etnia; configuram-se mapas simbólicos de possibilidade de circulação e acesso ao espaço urbano. As cidades com urbanização espraiada e concentração de empregos e serviços em área especifica da cidade culminam para uma divisão e hierarquização do espaço público. O planejamento urbano em si não cria espaços de violência, entretanto, escaIona e privilegia espaços em detrimento de outros, propiciando a construção de ambientes de maior vulnerabilidade, tornando-os inseguros. Isso implica em espaços públicos para poucos. No manifesto produzido pela ONU Habitat 2019, foram elencadas algumas ques- tões para a efetivação do direito das mulheres à cidade, dentre eles: combater a discriminação, garantir moradia adequada, possibilitar uma participação política plena e efetiva das mulheres e o acesso aos bens, serviços públicos e oportunidades oferecidas nas cidades. A cidade, sob a perspectiva feminina, precisa corresponder às necessidades de constituir espaços democráticos, em que a liberdade, igualdade e segurança são preservados para todos, nos quais, não haja intimidação, estigmatização ou violência sobre os corpos em virtude do lugar em que se encontram ou circulam. Utilizando o método explicativo-documental, em estudos que abordam a formação da política urbana, a compreensão de políticas de gênero e as orientações dos conselhos temáticos da ONU, busca-se pontuar sobre a necessidade do planejamento urbano sob perspectiva feminina, apresentando os fatos e marcos relevantes na política urbana e prováveis soluções para a formação e consolidação de espaços públicos democráticos.

Palavras-Chave: Igualdade, Gênero, Produção Social do Espaço, Cidades, Democracia. 
224 


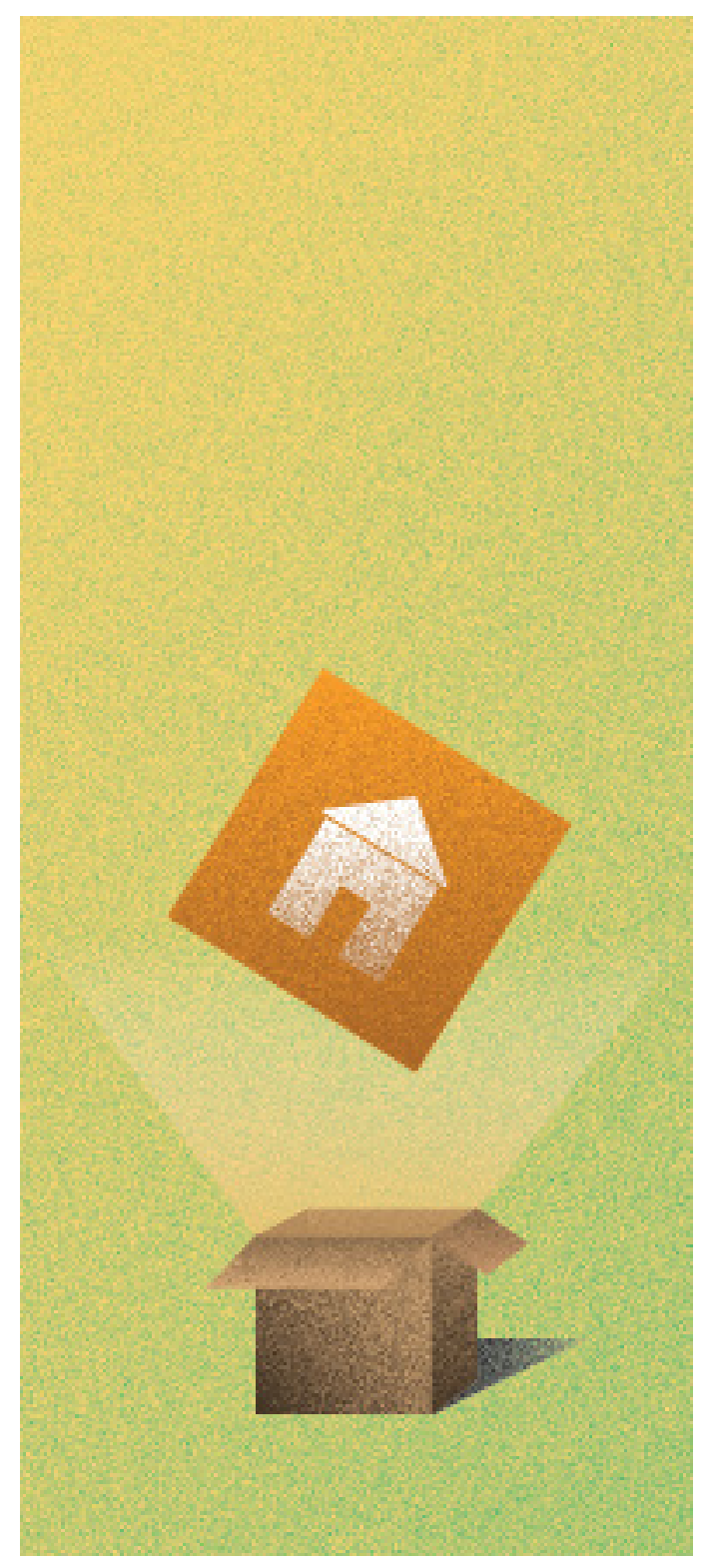

\section{ODS II CIDADES E COMUNIDADES SUSTENTÁVEIS}

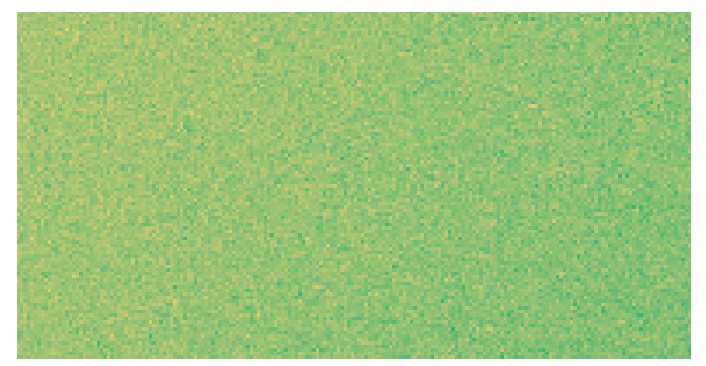




\section{TURISMO E DIREITO-DEVER DE PROTEÇÃO DO PATRIMÔNIO HISTÓRICO E NATURAL}

Traduzindo uma parcela essencial à identidade de um grupo social, o patrimônio histórico e natural prolonga-se ao longo do tempo e do espaço, de modo a constituir um dos pilares em que se sustenta a própria humanidade. A preservação dos elementos componentes do patrimônio histórico e natural revela-se substancial para a sua adequada fruição, já que apenas é possível desfrutar de algo que exista - e esteja em boas condições. Muito embora a atuação ativa do Estado seja de extrema importância à efetivação de medidas favoráveis à causa, a conservação do patrimônio não deve recair exclusivamente sobre as atividades estatais, uma vez que também depende da contribuição da coletividade, em uma verdadeira expressão de consciência social. O eixo histórico e natural, nessa perspetiva, atrai para si uma via dupla de efetivação, considerando que a partir do seu conteúdo extrai-se simultaneamente um sentido de fruição e um senso de defesa, de maneira a reportar-se à ideia de um direito-dever fundamental. Logo, aos membros da coletividade resta associado um direito e um dever relaciona- dos ao patrimônio histórico e natural, isto é, detêm, de um lado, o direito à usufruição do patrimônio, de modo a representar ingrediente determinante à composição de sua essência humana, e de outro, a incumbência de observar o seu dever para consigo mesmos e para com a sociedade quanto à conservação do patrimônio histórico e natural, manifestando a responsabilidade social e a solidariedade intergeracional. Tal cenário revela-se especialmente destacado quando envolve o turismo, já que o movimento de grupos humanos por lugares diversos de onde residem tem crescido substancialmente, afetando diretamente elementos do patrimônio que necessitam de práticas de conservação diferenciadas para sua manutenção pelo tempo.

Palavras-Chave: Patrimônio Histórico

e Natural, Direito ao Patrimônio Histórico

e Natural, Direito-Dever, Turismo, Solidariedade Intergeracional.
Suzana Mendonça Universidade de Lisboa 


\section{ÁREAS DE MAIOR E MENOR PODER AQUISITIVO EM LONDRINA/PR/BRASIL E O ESPRAIAMENTO ESPACIAL DO COVID-I 9}

Leia Aparecida Veiga

Universidade Federal da Integraçao Latino Americana/ Unila

Universidade Estadual de Londrina/UEL
No Brasil, assim como em diversas cidades da América Latina, se faz cada vez mais presente nas cidades médias e grandes, a segregação socioespacial materializada na habitação. A moradia em áreas com maior disponibilidade de equipamentos urbanos torna-se acessível somente para os sujeitos que podem pagar. Essa não é a realidade de grande parte dos trabalhadores, que na maioria das vezes não conseguem pagar por uma moradia em bairros próximos aos equipamentos urbanos essenciais no cotidiano urbano. Essa é a realidade na cidade de Londrina, localizada no norte do estado do Paraná, no Brasil. Londrina, criada em 1929, acabou por reproduzir a lógica desigual do processo de produção do espaço urbano capitalista. A desigualdade socioespacial em na cidade em tela já se fazia presente desde a fundação, com residências (casarões) na área central destinadas a residências de alto poder aquisitivo e outras de menor agregado construtivo para grupos com menor disponibilidade de recursos financeiros nas áreas periféricas ao centro. Nas décadas de 1960 e 1970, com a consequente expansão da malha urbana, a segregação dos grupos de menor poder aquisitivo foi sendo materializadas com ocupações irregulares em fundos de vale e construção de conjuntos habitacionais em porções distantes do centro da cidade. A partir dos anos 2000, destaca-se a ação de agentes produtores do espaço urbano que passaram a construir condomínios residenciais fechados horizontais e verticais de alto padrão em Londrina. Essa segregação do morar na cidade, em se tratando da população de baixo poder aquisitivo, pode ser entendida como uma das formas mais explicita de exclusão social de grande parte da classe trabalhadora, pelo fato da mesma revelar uma série de outros problemas como subnutrição, baixo índice de escolaridade, subemprego, trabalho mal remunerado e até mesmo o desemprego, dentre outros. É nesse ponto que podemos fazer correlações importantes entre a segregação socioespecial em Londrina e o atual momento de pandemia do Covid-19. Conforme dados da secretaria de saúde de Londrina (2020), os primeiros casos de contaminação pelo vírus foram verificados em áreas de alto poder aquisitivo, junto aos habitantes que residiam na porção denominada Gleba Palhano, cujo metro quadrado encontra-se entre os mais altos em termos de preço na cidade. Os primeiros casos foram identificados em pessoas que estavam viajando para países que já apresentavam o surto do Covid-19, passando em seguida a ter maior número de casos nessas áreas de maior pode aquisitivo no mês de março de 2020. A partir de abril casos de contaminação passaram a ser identificados em outras porções da cidade, mais distantes do centro e com população de menor poder aquisitivo. Diante dessa evolução do quadro de contaminação em Londrina, chama-se a atenção para a importância do atendimento de saúde para as famílias que moram em áreas de baixo poder aquisitivo.

\section{Palavras-Chave: Produção Do Espaço}

Urbano, Segregação Socioespacial, Moradias, Poder Aquisitivo, Dispersão Viral. 
Ref.: 207DCEDHM32020

\section{GEOPROCESSAMENTO E CARTOGRAFIA PARA A ANÁLISE DA GEOGRAFIA DOS RISCOS - MONITORAMENTO DA COVID-I 9 NA REGIÃO METROPOLITANA DE LONDRINA, PR}

O desenvolvimento desordenado das cidades, aliado aos fluxos econômicos intensos, criou um modelo de urbanização que dificulta a gestão eficiente do território, especialmente em tempos de pandemia. O processo de gestão do território objetiva a promoção da justiça social, o desenvolvimento econômico sustentável, o auxílio no ordenamento territorial, a promoção do gerenciamento de situações de risco, entre outros. Nesse sentido, pretende-se responder algumas demandas de gestão da crise que o Brasil e o mundo estão vivendo em função da pandemia da COVID-19, utilizando a cartografia e o geoprocessamento, por serem ferramentas que contribuem para a representação eficaz dos processos ocorridos no espaço geográfico, além da manipulação de informações e análises computacionalmente mais complexas do que o olho humano é capaz de perceber. Portanto, o presente artigo apresenta a pesquisa desenvolvida no Departamento de Geociências e no Programa de Pós-graduação em Geografia da Universidade Estadual de Londrina (UEL), que tem por objetivo auxiliar na busca por soluções de gestão e ferramentas que facilitem a otimização do trabalho desempenhado por pesquisadores, gestores públicos e demais agentes que atuam na pesquisa e combate a COVID-19 no Brasil, com olhar mais investigativo para o Estado do Paraná (PR) e para a Região Metropolitana de Londrina (RML). Para tanto, utiliza o conceito de território, o espaço geográfico como categoria de análise, e ferramentas de geoprocessamento e cartografia para o monitoramento da covid-19. Um site de divulgação dos mapeamentos gerados, denominado ATLAS COVID-19, encontra-se disponível em: http://www.uel.br/cce/geo/ portal/-Clicando no ícone ATLAS COVID19. As principais ações e pesquisas em andamento são: O Desenvolvimento do Sistema de Informações Geográficas e geoprocessamento no auxílio ao combate da COVID-19 no Brasil, Estado do Paraná (PR) e Região Metropolitana de Londrina (RML): modelo conceitual e análises geográficas; O Atlas dinâmico da COVID-19 no Brasil, Estado do Paraná (PR) e Região Metropolitana de Londrina (RML); O Mapeamento de fatores de risco relacionados aos óbitos por Síndrome Respiratória Aguda Grave (SRAG) por COVID-19: comorbilidades associadas e grupos de risco (Brasil, Paraná); As Vulnerabilidades socioeconômicas e populacionais e as relações com o avanço dos casos e óbitos relacionados à COVID-19 (Brasil, Paraná, RML, Londrina); As Populações tradicionais: vulnerabilidades e questões territoriais relacionadas à COVID-19 (Brasil, Paraná); O Mapeamento dinâmico das áreas de risco de acordo com a incidência de casos ativos de COVID19 (Paraná e Município de Londrina); e O Mapeamento do risco de morte por COVID-19: a relação entre a periculosidade e a vulnerabilidade nos municípios brasileiros. Espera-se, com tais ações e pesquisas, contribuir com os gestores públicos no fornecimento de informações relevantes e confiáveis ao monitoramento e combate da Covid-19 no Paraná e na RML Londrina.

Palavras-Chave: Covid-19, Geoprocessamento, Gestão Territorial, Desigualdades Socioespaciais, Mapeamento.
Adriana Castreghini de Freitas Pereira

Universidade Estadual de Londrina 


\section{ANÁLISE DO PRINCÍPIO DA PRECAUÇÃO PELA CORTE INTERAMERICANA DE DIREITOS HUMANOS NA PROTEÇÃO DO MEIO AMBIENTE COMO DIREITO HUMANO}

Henrique Lopes Dornelas

Doutorando do Programa de Pós-graduação em Direito PPGD-UNESA
O direito ambiental como conjunto de regras e princípios tem como objetivo a tutela do meio ambiente e sua preservação para as gerações presentes e futuras, com caráter intergeracional e transnacional, em razão do bem jurídico protegido. O direito ao meio ambiente sadio e equilibrado faz parte do catálogo dos direitos humanos de terceira dimensão, atrelado aos ideais de fraternidade e solidariedade. A Convenção Americana de Direitos Humanos não contém de forma direta a proteção ao meio ambiente, mas de forma indireta ou reflexa reconhece a proteção ao meio ambiente por meio da proteção do direito à vida e da integridade pessoal. A inserção da proteção ao meio ambiente se deu por meio do Protocolo Adicional a Convenção Americana de Direitos Humanos, o denominado "Protocolo de San Salvador". O objetivo específico foi analisar e verificar na doutrina do direito ambiental o conceito, características, base histórica, fundamento normativo e aplicação do princípio da precaução; analisar o entendimento do referido princípio pela Corte Interamericana de Direitos Humanos (CIDH) por meio da Opinião Consultiva OC-23/17 de 15 de novembro de 2017, solicitada pela República da Colômbia. Para a realização do trabalho foi realizada pesquisa teórica e documental (leis, tratados, convenções, regulamentos, entre outros). Constatou-se que o princípio da precaução de acordo com a abordagem da Corte Interamericana de Direitos Humanos na Opinião Consultiva OC-23/17 de 15 de novembro de 2017, se refere às medidas que devem ser adotados em casos onde não existe certeza científica sobre o impacto que possa ter uma atividade no meio ambiente; que o princípio da precaução foi incluído em diversos tratados internacionais sobre proteção do meio ambiente em diferentes âmbitos, com destaque para a Convenção Marco das Nações Unidas sobre a Mudança Climática que foi ratificado por todos os Estados membros da OEA, o Convênio de Estocolmo sobre Poluentes Orgânicos Persistentes ratificado por 32 Estados-Membros da OEA e o Convênio sobre a Diversidade Biológica ratificado por 34 Estados-Membros. Foi verificado que diversos Estados-membros da OEA, por meio de sua normatividade interna e da jurisprudência de seus tribunais, incorporaram o princípio de precaução, e, dessa forma foi expressamente incorporado em legislação de Estados como Antiga e Barbuda, Argentina, Canadá, Colômbia, Cuba, Equador, México, Peru, República Dominicana, Uruguai e Brasil. Igualmente, os tribunais superiores do Chile e Panamá reconheceram a aplicabilidade e obrigatoriedade do princípio de precaução. A Corte Interamericana de Direitos Humanos advertiu que diversos tratados internacionais contêm o princípio de precaução e que seu conteúdo sofre variação de acordo com o instrumento que o consagra, defendendo a sua aplicação para a proteção ambiental. A aplicação do princípio também se mostra de fundamental importância para o cumprimento da Agenda 2030 no que diz respeito ao desenvolvimento dos Direitos Humanos.

\section{Palavras-Chave: Corte Interamericana} de Direitos Humanos, Princípio da Precaução, Proteção Internacional, Direitos Humanos, Terceira Dimensão. 


\section{BIG PUSH PARA SUSTENTABILIDADE, COMPLIANCE E O SETOR ENERGÉTICO: ENERGIA E DESENVOLVIMENTO SUSTENTÁVEL NA AMÉRICA LATINA}

O presente trabalho tem por objetivo analisar o crescimento do desenvolvimento sustentável do setor energético na América Latina, a partir do crescimento sustentável na região, também chamado de "Big Push para Sustentabilidade" que é apoiado pela Comissão Econômica para a América Latina e o Caribe, órgão das Nações Unidas. Nesse sentir, uma série de políticas públicas devem ser adotadas de forma coordenada de modo a fomentar investimentos internacionais e nacionais e promovendo um desenvolvimento econômico sustentável. A abordagem de "big push" adotada pela CEPAL visa promover inovações no setor energético com o apoio e cooperação de fundações além do apoio dos poderes públicos. O "Big Push para Sustentabilidade" se relaciona com os OD'S. Os ODS's são a continuidade dos resultados positivos alcançados através dos ODM'S (Objetivos do Milênio). Foi a partir desse momento que o mundo conseguiu enxergar as possibilidades de transformação a partir da integração que pode ser entendida desde a sua aplicabilidade nos Estados quanto no setor privado, esse que tem papel significativo na otimização de um setor essencial para as metas pretendidas. No eixo do Desenvolvimento da Economia há muito a ser discutido para mudar o mindset dos investidores a respeito. A fim de contribuir com os estudos, pensamos que sob o viés econômico, a Governança e a Sustentabilidade têm um grande papel de destaque principalmente quando se pensa a longo prazo, que é o caso dos ODS. É um conjunto de processos que caminham juntos nessa nova trajetória para economias verdes, sendo este o cerne do presente trabalho. A transição para economias low carbon precisa de um apoio muito forte de discussões no âmbito privado porque como se sabe, 0 Setor Energético demanda investimentos vultuosos que o Estado por si só não suporta. Portanto, torna-se necessário incluir os investidores, e não só eles como veremos, mas a princípio, estes devem fazer parte dessa mudança estrutural de paradigma. A despeito do que foi falado, a economia atualmente se desenvolve voltado ao que se chama de capitalismo de stakeholders que prega a ideia de que a empresa tem um papel na sociedade e, por conseguinte, no meio ambiente. O principal objetivo desse novo pensamento é a integração, comportamento crucial que consegue envolver setor público, privado e a comunidade num objetivo comum que ultrapasse a compreensão de só gerar lucros, torna-se impreterível gerar valor, um dos maiores pilares da compliance ambiental no momento presente. Nesse sentido, são muitos os aspetos a serem abordados nessa nova relação, como compreender de plano a função da governança para gerir as figuras que integram esse processo, a importância de cada um e como a regulação tem sido exercida para auxiliar a cooperação destes.

Palavras-Chave: Compliance, Energia, America Latina, Big Push, Sustentabilidade.
Maria Luíza Diniz Almeida CEDIN

\& Larissa Emília Guilherme Ribeiro UNIESP 
Ref.: 286CEDHM22020

\section{HAVERÁ JUSTIFICAÇÃO PARA A DEPREDAÇÃO DE PATRIMÔNIO HISTÓRICO MORALMENTE QUESTIONÁVEL?}

Mickhael Erik Alexander

Bachmann

\& Elizeu de Oliveira Santos

Sobrinho

Centro Universitário

para o Desenvolvimento

do Alto Vale do Itajaí - UNIDAVI
A sociedade ocidental experimentou um movimento impactante de remoção de monumentos públicos que homenageavam figuras moralmente controversas. Talvez o episódio mais emblemático tenha sido a depredação da estátua de Edward Colston, que estava exposta em Bristol, na Inglaterra. Os manifestantes consideravam um ultraje que houvesse uma homenagem a um comerciante de escravos em espaço público. $O$ presente estudo busca avaliar, de um ponto de vista analítico, o que pode tornar a exposição pública do patrimônio histórico moralmente condenável, se existe justificativa apropriada para vandalizá-lo e se há algum outro tipo de conduta mais desejável do que o vandalismo. Os principais argumentos favoráveis e contrários serão expostos, visando estabelecer com clareza as razões para praticar ou deixar de praticar atos de remoção e/ou destruição dos bens públicos. Abordar-se-ão, com maior ênfase, os seguintes problemas: (i) a alegação de anacronismo; (ii) a dificuldade para delimitar o que pode ou não ser considerado moralmente reprovável (não visando relativizar todos os casos, mas apontando hard cases); (iii) o des- caso das instituições para com as comunidades que se sentem prejudicadas e; (iv) o respeito à manifestação pública da vontade de uma determinada parcela da sociedade. Se as razões e contrarrazões oferecidas forem apropriadas de um ponto de vista argumentativo, perceber-se-á que existem medidas mais apropriadas para o tratamento do patrimônio público. Ainda que se trate de um objeto de origem moralmente reprovável ou que represente algo que não é mais condizente com os padrões da razão ou de nosso tempo, a sua remoção para um museu, por parte do próprio poder público, parece ser mais condizente com o direito à história, por exemplo. A depredação só parece estar justificada nos casos em que o poder público foi acionado e se manteve inerte em relação ao caso ou patrocinou alguma violação de direito para proteger o patrimônio público.

Palavras-Chave: Patrimônio Público, Liberdade de Expressão, Direito à História, Dignidade, Filosofia da Moral. 


\section{DEVELOPING HUMAN RIGHTS SCALES FOR A NO HARMTOURISM}

Local and national governments share a responsibility to do no harm to its residents, the present work seeks to map the most relevant theoretical constructs that underpin human rights in tourism and management studies, especially from the perspectives of theoretical constructs such as the Tourist-resident conflict (Tsaur \& Teng, 2018), the Resident Empowerment through Tourism Scale (RETS) (Boley \& McGehee, 2014) and Community Scale and Resident Attitudes towards Tourism (Devine, Gabe \& Bell 2009), among others. The methodology of choice is a systematic review, which summarises research papers in tourism and human rights studies with the aim to guarantee accurate and reliable evidence-based results, with the support of the Content Analysis methodology. Based on a global citation database, this paper reveals that the relation between Tourism on Human Rights is an infrequent topic of research. In the last 5 years, only three academic papers touched upon issues such as (i) how employment in tourism raises fundamental concerns in the context of basic human rights (Baum \& Hai, 2019); (ii) what are the consequences of COVID-19-induced restrictions on people's capacity to travel at will, affecting the rights to participate in commercial hospitality and to be tourists(Baum \& Rai, 2020) and (iii) the extent to which tourism is a human right and a determining factor of longevity of older adults since it stimulates social interaction (Cruz, 2018). Yet, from a theoretical point, the categorisaation of human rights and tou- rism items can benefit from previous tourist-resident reserch. This paper therefore addresses a perceived gap in theorisation of constructs that underpin human rights in tourism and management studies. It proposes a human rights scales to compare tourism destinations and monitor the extent to which certain tourism activities are based on unequal, exploitative relationships and consequently, the poorer and more vulnerable groups in the country of destination suffer disproportionately from the negative impacts of tourism. The main hypothesis in this work is that Tourism is a tool for promoting economic and social development when in harmony with human rights principle, practice, and policy (Landman, 2004: 927). In this vein, tourism activities should be measured with attention to the UN's Sustainable Development Goals (SDGs) and its objectives The SDGs can provide guidance for tourism development and practice and enable the sector to play a better role in achieving the 2030 Agenda. Broad categories in the proposed scale are : (1) Inclusive and sustainable economic growth, (2) mutual understanding, peace, and security; (3) Resource efficiency, environmental protection, and climate change; and (4) Cultural values, diversity, and heritage, which are the main pillars in the 2030 Agenda. In the conclusions this paper discusses the advantages of measuring and comparing residents perceptions of themselves as being empowered from tourism.

Keywords: Human Rights, Tourism, Measurement Scales, Empowerment, Sustainable Development Goals (SDGs).
Fátima Lampreia Carvalho 


\section{POLÍTICAS PÚBLICAS TRIBUTÁRIO-AMBIENTAIS NO BRASIL E O ECODESENVOLVIMENTO: (CO)RELAÇÕES POSSÍVEIS}

Andreza da Cruz, UNESC e UNISUL

Kelly Gianezini, UNESC

Miguelangelo Gianezini UNESC

\& Silvio Parodi Oliveira

Camilo

UNESC
Em diversas regiões do mundo, a manutenção de atividades produtivas tem se deparado com a necessidade de investimentos e políticas que garantam harmonia entre o binômio desenvolvimento e sustentabilidade, em especial quando há atividades industriais relevantes para o desenvolvimento socioeconômico. Observando as premissas da agenda 2030 e os ODS, a exploração não consciente dos recursos naturais tem demandado ações e políticas voltadas à conservação ambiental e sua integração com os elos econômico e social. No Brasil, há estados que implementaram políticas públicas utilizando-se de critérios ecológicos na distribuição da arrecadação do ICMS, com base na necessidade ambiental, já que o meio ambiente ecologicamente equilibrado é um direito fundamental reconhecido pela Constituição Federal de 1988. Por conseguinte, a legislação permite que parte da arrecadação deste tributo seja alocada conforme disposição dos estados. Assim os mesmos podem se utilizar de instrumentos de políticas públicas tributário-ambientais, como o ICMS Ecológico (ICMS-E), adotando o critério ecológico na restituição das receitas devidas aos municípios. Observando estados que já implementaram o ICMS-E, esta pesquisa teve por objetivo compreender as políticas públicas tributário ambientais, suas perspetivas no âmbito brasileiro e as possibilidades de incorporação dos princípios do ecodesenvolvimento em suas propostas. Os procedimentos de investigação (com abordagem qualitativa) contaram com técnica de coleta de dados dividida em três etapas: estudo bibliográfico e teórico para aprofundar os conceitos chave do ecodesenvolvimento, das políticas públicas e do ICMS-E; e levantamento documental para auxiliar na caracterização da implantação do ICMS-E. Como resultado observou-se que a concretização de ideias do ecodesenvolvimento pode se dar de várias formas, sendo algumas mais ou menos fiéis aos seus preceitos. Portanto, ainda que parcialmente, a política do ICMS-E vai ao encontro do ecodesenvolvimento, no sentido de utilizar-se de um instrumento tributário ambiental para a preservação e/ou conservação do meio ambiente e consequentemente fomentar o desenvolvimento econômico e social das regiões que o implementarem.

Palavras-Chave: Agenda 2030, Meio Ambiente, Políticas Públicas, Desenvolvimento Socioeconômico, Direitos Humanos. 
234 


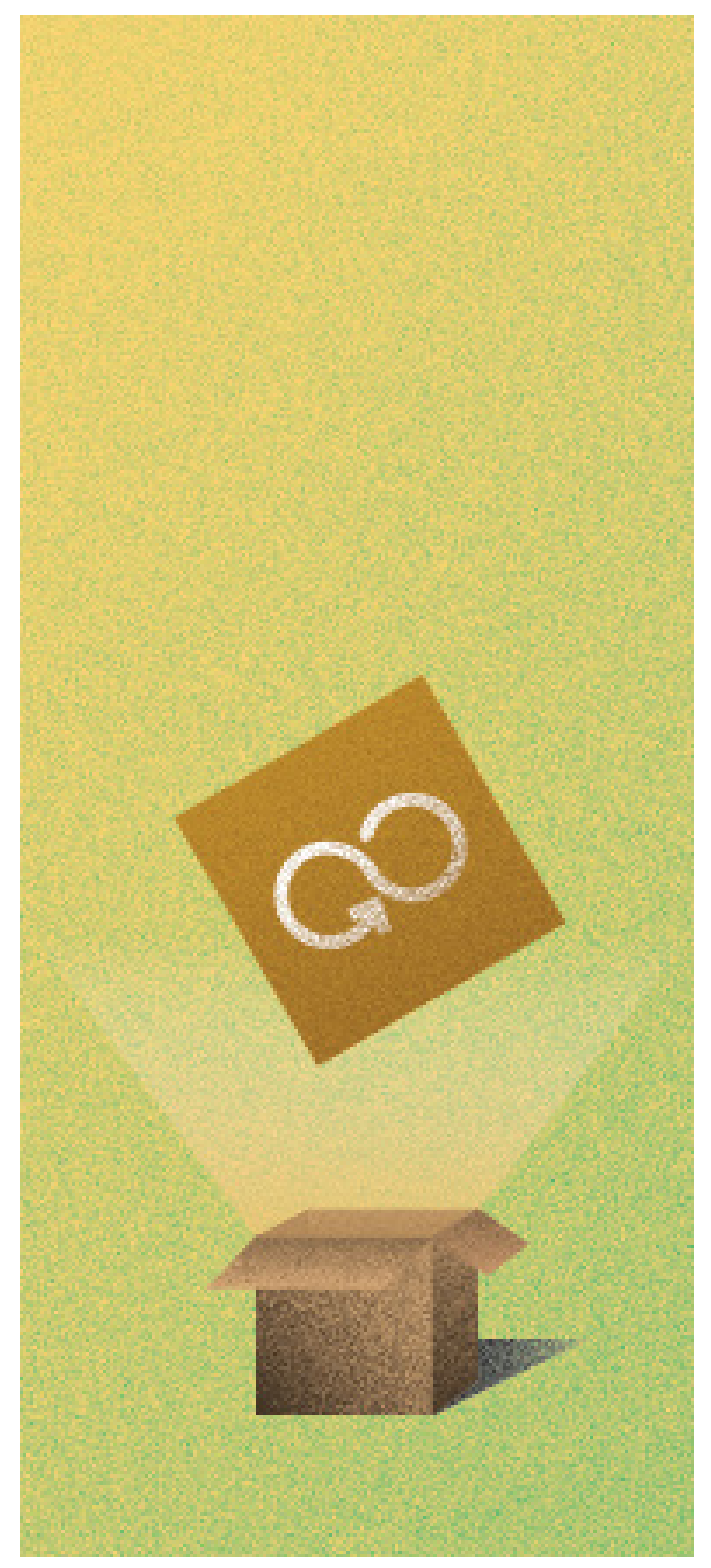

\section{ODS 12 PRODUÇÃO E CONSUMO SUSTENTÁVEIS}

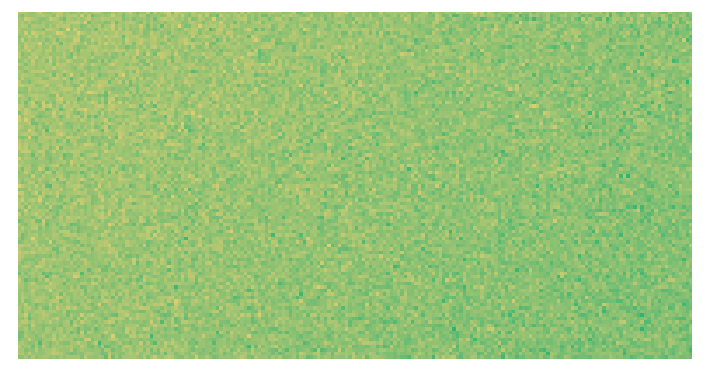




\section{UMA ANÁLISE BIBLIOMÉTRICA SOBRE ECONOMIA COMPARTILHADA:}

\section{I 7-2020}

O presente trabalho tem como objetivo identificar e analisar características bibliometricas de artigos científicos que versam sobre a economia compartilhada, utilizando a plataforma sucupira para encontrar os trabalhos mais relevantes e com nota $A 1$, com o intuito de identificar quais são as temáticas que mais interessam aos pesquisadores, e quais as direções futuras em relação esse tipo de economia, tem como objetivo identificar quais foram os maiores focos de pesquisas sobre economia compartilhada entre 2017 e 2020. Na primeira parte do trabalho foi realizada uma contextualização teórica sobre economia compartilhada. Em seguida foram expostos os conceitos de estado da arte, busca sistematizada e tratamento bibliométrico para seja justificada a escolha do método neste trabalho. Na segunda parte do trabalho foi apresentada toda a metodologia e sistematização utilizada para realizar o tratamento bibliométrico. Na terceira e última parte do trabalho foi exposto os dados encontrados, afim de que seja possível alcançar o objetivo do trabalho que é entender quais são as principais temáticas que foram discutidas entre
2017 e maio de 2020.Nesse sentido, Tulio de Bonis Martins percebe-se que os três conceitos abor- Faculdade Armando Alvares Penteado dados nesta referencial teórico estão ligados. Empreender é assumir riscos e iniciar algo novo; inovar é pensar em novas propostas e trazer vida e economia compartilhada. Esta é a tendência de mercado, isto é, uma inovação que possibilita o surgimento de inúmeros empreendimentos. O que a produção de informação científica e tecnológica sobre economia compartilhada pode nos dizer sobre os atuais tópicos de pesquisa e direções futuras em relação a essa economia? Com o intuito de entender os principais tópicos discutidos na atualidade referente a economia compartilhada. Para tanto, foi realizado um tratamento bibliométrico de artigos, Com 13 artigos selecionados que tem relação direta com o tema, buscou-se: (i) identificar os autores através dos indicadores, instituição de origem, pais de origem e proficiência; (ii) conceituar a econômica compartilhada; (iii) identificar e discutir as temáticas dos artigos, aplicações de economia compartilhada nos trabalhos selecionados.

Palavras-Chave: Economia Compartilhada, Consumo Colaborativo, Bibliometria, Tecnologia, Abordagens e Métodos. 
Ref.: 077CEDHM42020

\section{FEATURES FOR SUSTAINABLE ECONOMY BASED ONTHE RENEWABLE ENERGY. THE EUROPEAN POINT OF VIEW FOR 2030}

Ana Cristina Pego

Universidade Nova de Lisboa
The use of renewable energy in Europe and around the world has become an important political agenda. Renewable energies and their influence on the market are considered one of the biggest steps towards sustainable development, but also towards a balanced use of natural resources. The global agenda for 2030 has identified the affordable use of clean energy as one of its key objectives. The use of renewable energy is seen by business as the most important way to develop a new methodology for meeting environmental requirements. In fact, their consumption and production is the biggest step for 2030, and consumers, policy makers and producers are responsible for changing their attitudes towards the use of clean energy, for example in the recycling industry or in smart cities. Research has shown that Europe will be more willing to use renewable energy in 2030, and this will be more affordable than in 2020. It is expected that Agenda 2030 will bring more externalities of renewable energy into the European economy. This means that European countries are ready to change their energy market towards a sustainable and competitive purpose.

Keywords: Renewable Energy, Smart Cities, Ecosystems, Environment Policy. 


\section{ENTRE A NECESSIDADE E A SOCIABILIDADE: TRANSFORMAÇÕES NAS RELAÇÕES DE CONSUMO NA PANDEMIA COVIDI 9}

O decreto da pandemia por COVID19 e a adoção do isolamento social no Brasil teve como efeito imediato a restrição às saídas para as compras, consequentemente, diminuição das vendas nos mais variados tipos de comércio. Este estudo discute as relações de consumo assim caracterizadas, intermediadas pelos processos comunicacionais. É pelo consumo que nos fazemos sujeitos-agentes, abarcando isso o exercício da cidadania como prática social que permite que os indivíduos se sintam parte e construam vínculos como o momento e local em que vivem. O consumo é lugar de uma luta que não se restringe à posse dos objetos, pois passa ainda mais decisivamente "pelos usos que Ihes dão forma social e nos quais se inscrevem demandas e dispositivos de ação provenientes de diversas competências culturais" (Martin-Barbero, 1997: 290), e que confluiu com a cidadania, cujas possibilidades e formas de ser exercida foram modificadas pelas mudanças nas maneiras de consumir (Garcia Canclini, 1996). Incluímos aqui o consumo como uma forma de sociabilidade, na medida em que "não estamos preocupados apenas com nossa capacidade de exibir os produtos de nossa habilidade como consumidores competentes, mas também parecemos estar preocupados com o processo de consumo como algo que desejamos partilhar e que propicia um momento de sociabilidade numa vida, em outros aspetos, solitária" (Silverstone, 2005: 158). Uma sociabilidade decorrente do consumo dos produtos que, senso comum conceitual, se torna a pedra fundamental da sociedade da pós-mo- dernidade, centrada nos valores de uma cultura de consumo. Entretanto, estabelecido o cenário de isolamento social em resposta à pandemia do COVID19, o comércio é fechado, mas as necessidades de alimentação e vestuário, higiene, citando o mínimo, devem ser satisfeitas. Com a limitação de circulação por grandes espaços comerciais, a população retoma hábitos de compra no comércio local. Para conhecer os caminhos tomados nesse momento, realizamos um estudo exploratório entrevistando pequenos comerciantes (oito) sobre as formas de divulgação e comunicação utilizadas durante o isolamento, de forma a manter sua sobrevivência econômica. Do lado do consumidor, adotamos uma abordagem fechada (380), explorando as mudanças nas práticas de consumo, abrangendo o contato com os comerciantes, as escolhas, os meios de pagamento. A hipótese de trabalho que nos moveu neste estudo são as eventuais ruturas nas práticas de consumo, nas relações com os espaços de consumo - do físico ao virtual, e uma re-valorização do comércio local, o retorno, por assim dizer, a uma sociabilidade baseada na interação social, ainda que no isolamento, em que prevalece a preocupação com o outro, um certo racionalismo que pondera sobre as contingências das relações sociais (Gonçalves, 2009). Uma sociabilidade menos marcada pelo narcisismo, em que os indivíduos buscam seu eu não mais em seu "interior", mas no "consumo, na aparência e no desempenho social" (Slater, 2002: 90).

Palavras-Chave: Comunicação, Consumo, Sociabilidade, Isolamento.
Marcia Perencin Tondato

Programa de Pós-Graduação em Comunicação e Práticas de Consumo - ESPM

\& Dayse Maciel de Araújo Fundação Instituto de Administração (FIA) e MBA USP-Esalq (presencial e EaD) 


\section{ECONOMIA CIRCULAR COMO GARANTIA DE UMA GESTÃO SUSTENTÁVEL DOS RECURSOS GLOBAIS TERRESTRES}

Juliana Mattos dos Santos Joaquim

Universidade Federal do Estado do Rio de Janeiro - UNIRIO
Entendendo que há a emergente necessidade de defesa do sistema global terrestre, e aproveitando-se dos avanços tecnológicos possibilitados pela era antropocêntrica, nada mais útil e justo que a mentalidade da humanidade se modifique, e assim busque alternativas para as práticas reiteradas de exploração de recursos.

O sistema global terrestre -em crise -está sistemicamente interligado. A modernidade possibilitou a globalização dos avanços tecnológicos e interação entre as nações, mas em contrapartida permitiu a universalização dos riscos e das ameaças. Uma generalização dos riscos permitida pelo desenvolver das atividades humanas, ganhando raízes e se estendendo por todo o globo não considerando limites ou fronteiras.

A temática antes restrita a estudos científicos precisa ganhar extramuros e ser introduzida na doutrina jurídica de forma a permitir um pensar globalizado. Entender o mecanismo complexo e adaptativo do sistema terrestre permite compreender até que ponto a ação humana é prejudicial e pode ser revertida. E ainda, internalizar que sistemas desregulados refletem na qualidade de vida e no bem-estar da humanidade, a fome, a seca ou pandemias são os reflexos de uma interação humana desmedida.

É neste sentido que se propõe debater como políticas públicas podem reverter os riscos suportados diante de emissões de gases, perda de biodiversidade ou descarte excessivo em uma sociedade Consumo centrista, onde o consumir passou a fazer parte das necessidades básicas, assim como a obtenção de alimento, segurança e necessidades fisiológicas. A proposta é estudar ferramentas como a exemplo da Economia Circular, prevista na Política Nacional de Recursos Sólidos -Lei 12.305/10 que na tentativa de substituir a linear em prática desde os remotos tempos, busca reinserir no ciclo produtivo, itens que após toda a pressão exercida para sua fabricação, retornem ao meio ambiente ainda com um potencial de uso, se corretamente destinados e processados.

Usando como base a revisão bibliográfica e a pesquisa legislativa disponível será possível compreender como a substituição da economia linear pela circular pode trazer benefícios diretos para a humanidade, ao passo que possibilita que tanto a pressão por matéria prima quanto o descarte não sejam mais uma fonte de desregulação dos sistemas terrestres. Sob o viés da responsabilidade pós consumo, tenta-se fazer valer um desenvolvimento sustentável e garantidor da vida terrena e bem-estar na humanidade.

Palavras-Chave: Antropoceno, Recursos Sólidos, Consumocentrismo, Global, Política Pública. 


\section{AGENDA 2030 EN ESPAÑA: \\ UN ANÁLISIS DE LOS OBJETIVOS DE DESARROLLO SOSTENIBLE (ODS) DURANTE EL PERÍODO 20I5-2020}

Desde su firma en 2015 por los jefes de Estado y de Gobierno de los países miembros de Naciones Unidas, la Agenda 2030 para el Desarrollo Sostenible ha aumentado su importancia relativa y representación mediática. El avance de la sociedad hacia un crecimiento económico inclusivo, medioambientalmente sostenible y caracterizado por una mayor cohesión y justicia social, se ha ido articulando desde la difusión de los 17 Objetivos de Desarrollo Sostenible (ODS) que fija la Agenda 2030.

Los medios de comunicación son esenciales para la configuración de toda opinión pública. Su análisis permite objetivar un análisis de la estructura social a partir de la realidad refractada que se deriva del discurso articulado por los medios de comunicación.

Este estudio analiza la representación mediática de la Agenda 2030 en la prensa española durante el período 2015-2020. De este modo, se avanza en el estudio de los temas de interés para la opinión pública en términos de empresas, industrias relacionadas, principales autores y medios.

La búsqueda de las publicaciones relativas a la Agenda 2030 y los Objetivos de Desarrollo Sostenible (ODS) se rea-

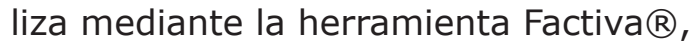
propiedad de Down Jones Company (C), que da acceso a más 260 medios y agencias de noticias españoles. La investigación se centra en48.290 contenidos aparecidos en prensa durante el
Iustro analizado, y lleva a cabo un análisis de la evolución temporal en atención al número de noticias publicadas cada año, los principales medios que incluyen en sus publicaciones referencias a la Agenda2030, las principales compañías vinculadas a los ODS, así como la evolución de su concentración mediática a lo largo del tiempo.

La búsqueda se centra en contenidos publicados en España desde la aprobación de la Agenda 2030, el 25 de septiembre de 2015, yse extiende hasta cinco años más tarde.

Los resultados de este estudio muestran una fuerte evolución de la representación mediática de la Agenda 2030 en la prensa española, y sugieren un papel importante de los ODS en proyección mediática de corporacionesprivadas e instituciones públicas, con especial incidencia sobre nuevos modelos de negocio orientados a impulsar la sostenibilidad ambiental y social, y el diseño de políticas públicas dirigidas a reducir la inequidad.

Palavras-Chave: Agenda 2030, Objetivos de Desarrollo Sostenible, ODS, España, Representación Mediática.
Fernando Castelló-Sirvent ESIC Business \& Marketing School 


\section{DESENVOLVIMENTO REGENERATIVO: A ECONOMIA CIRCULAR REDEFININDO A SUSTENTABILIDADE}

Jamile Gonçalves Calissi \& Renato Zanolla Montefusco

Professora de Educação Superior, Nível IV - Grau A, do quadro de pessoal da Universidade do Estado de Minas Gerais, Unidade Ituiutaba
Fronteiras emergentes marcam a ressignificação conceitual de sustentabilidade através do desenvolvimento e design regenerativos. Escola de pensamento vanguardista da Economia Circular, pois está além do mero design de sustentabilidade. O design sustentável, ou design ecológico, convergiu em dois caminhos: (i) sustentabilidade tecnológica baseada em técnica e engenharia, e; (ii) design "eco eficiente" baseando em processos construtivos de alta performance com impacto ambiental minorado ou neutro. O design ecológico buscou contingenciar e minimizar danos ao meio ambiente e saúde humana utilizando recursos com eficiência, minorando a degradação da biosfera, afrontada pelo impacto da tecnosfera. Entretanto, imergir na sustentabilidade, por si só, não é suficiente, quiçá plausível. Ao invés demitigar danos ao meio ambiente é imperioso interagir com a biosfera, pois, a sustentabilidade estabelece progressão a uma consciência funcional onde há simbiose entre sociedade, cadeia de produção e consumo, sistemas de comércio, construção, entre outros.No design regenerativo a percepção de sustentabilidade é apenas uma etapa a ser alcançada pela "sociedade" em prol da restauração/regeneração; com efeito, o desenvolvimento regenerativo redefine a percepção do design sustentável. Abordagens regenerativas traçam percepções mais aprofundadas não apenas para reverter danos aos sistemas naturais, equalizando-os a um mínimo de toxicidade, ao contrário, busca projetar sistemas humanos e naturais em "eco convergência e evolução". O abandono das práticas convencionais, ainda utilizadas, com origem na revolução industrial, o green, compreendido como esverdeamento, o design sustentável, o design restaurativo e, o design reconciliador são etapas necessárias, de maturação social, para ser alcançado o design regenerativo, com a gênese de culturas criativas capazes de interagir entre si. Posturas mais resistentes às mudanças propiciadas pela natural evolução da humanidade são descortinadas para entregar às próximas gerações um sistema mais rico e regenerado daquele herdado das gerações anteriores, essência principiológica da Constituição Federal brasileira de 1988, que prima pela solidariedade intergeracional. Diante do compromisso global para o Desenvolvimento Sustentável, é factível alicerçar condutas pautadas na contemporânea Escola da Economia Circular de regeneração, visto que há necessária convergência dos Estados-nações e partes interessadas em franca colaboração na implementação e execução dos 17 objetivos explicitados no documento final da agenda pós-2015. A tutela do capital natural e humano é fundamento garantidor ao direito de natureza, via sustentabilidade, sob a ótica regenerativa. Há relevância temática diante do esforço de integração transfonteiriça que até 2030 buscará: (i) reduzir geração de resíduos, e; (ii) garantir a conscientização para o desenvolvimento sustentável diante postura econômica circular mitigando o conceito "take-make-waste".

Palavras-Chave: Desenvolvimento

Regenerativo, Economia Circular, Direito

de Natureza, Sustentabilidade. 


\section{CARBON PRICING: A ECONOMIA CIRCULAR COMO GARANTIA DO DIREITO
FUNDAMENTAL À SUSTENTABILIDADE POR MEIO
DA PRECIFICAÇÃO DAS EMISSÕES DE CARBONO}

A Revolução Industrial descortinou um processo de degradação e devastação ambiental sem precedentes na história da civilização; manufatura substituída por maquinofatura, os processos evolutivos da tecnologia e, por fim a revolução técnico-científica contribuiu para a explosão demográfica; surgimento de grandes centros urbanos; formação de cadeias lineares de produção e consumo em larga escala e, por fim; demandas de consumo massivas. A ausência de pesquisa, desenvolvimento e investimento em infraestrutura conservadorista carrearam novas formas de poluição à ecosfera acarretando sensíveis mudanças climáticas. A mudança do clima é a maior e mais abrangente falha de mercado jamais vista; resíduos tóxicos, desastres ecológicos, aquecimento global, escassez de elementos naturais, compreendidos como capital natural, acarretaram o interesse pela temática ambiental e seus desdobramentos. Diante sinuosa alteração do clima e suas implicações para diversos setores da sociedade "o progresso a qualquer custo" tornou-se celeuma no cenário internacional. Novas posturas da comunidade internacional focadas na harmonização do desenvolvimento sócio-econômico convergiram em políticas transfronteiriças e escolas de pensamentos vanguardistas. Entrementes, a percepção de progresso científico-tecnológico acompanhado de alterações estruturais nas relações econômicas e no tecido social em prol da biosfera tornou-se uma meta para a sociedade global. Nesse sentido, a busca de novas tecnologias e instrumentos factíveis aos chamados "mecanismos de desenvolvi- mento limpo" balizou o pensamento da sociedade no séc. XXI. Ciente do caráter ecológico-climático transnacional a "Comunidade Global" fomentou conferências, dentre estas, (i) "O Homem e a Biosfera", da UNESCO (1971); (ii) a Conferência das Nações Unidas para o Meio Ambiente (1972); (iii) a Comissão Mundial sobre o Meio Ambiente e Desenvolvimento (1983) e, por fim; (iv) a Conferência das Nações Unidas para o Meio Ambiente e Desenvolvimento, onde foi oportunizado às Nações estabelecer critérios para se alcançar o almejado desenvolvimento sustentável. É nesse hiato temporal, onde a Comunidade Internacional convergia a "eco-identidade", que ocorria fomento sócio econômico circular. Há transversalidade na percepção de "circularidade" e sustentabilidade diante da necessidade global pelo fomento da Economia Circular (EC). É imperioso destacar que condutas em EC corroboram sobremaneira para assegurar produção e consumo sustentáveis adequando medidas urgentes para combater a mudança do clima e seus impactos, objetivos (12) e (13) da agenda 2030. Inclina-se nesse sentido a proposta da Lei Europeia do Clima que objetiva a neutralidade climática até 2050, estabelecido no Pacto Ecológico Europeu, com objetivo de diminuir emissões líquidas de gases com efeito estufa a zero através de redução das emissões totais; investimento em tecnologias verdes, e; proteção do ambiente natural para consolidação do consumo e produção responsável.

Palavras-Chave: Economia Circular, Escolas de Pensamento, Precificação de Carbono, Sustentabilidade, Agenda 2030.
Renato Zanolla Montefusco \& Jamile Gonçalves Calissi Universidade Estadual de Minas Gerais - UEMG 
Ref.: | 46CEDHM22020

\section{O DECRESCIMENTO COMO VIA PARA O DESENVOLVIMENTO SUSTENTÁVEL}

Arnelle Rolim Peixoto GEDAI-UFC/UNINASSAU

\& Arkaitz Pascual Martína Universidad de Salamanca
É inegável que, nos dias atuais, cada vez mais o sistema de produção e consumo cresce de forma exponencial com o advento das necessidades que a sociedade capitalista impõe. Essa forma de crescimento econômico acelerada ocasiona a degradação contínua do meio ambiente. Devido a essas consequências, é urgente a importância de serem criadas vias alternativas que sirvam para estabelecer parâmetros de consumo e produção que sejam compatíveis com a preservação do meio ambiente. Nesse sentido, o objetivo do artigo é analisar como o decrescimento vem a ser uma via para transformar as velhas práticas de consumo e produção enraizadas na sociedade capitalista, com a finalidade de alcançar as metas do Objetivo do Desenvolvimento Sustentável (ODS) da ONU no 12. Para isso, serão abordados os pilares do decrescimento como parâmetro para a discussão sobre a possibilidade de alcançar o desenvolvimento sustentável através das novas formas de consumo e produção que consigam suprir todas as necessidades do ser humano, para que os limites ambientais do planeta não sejam ultrapassados. A metodologia da pesquisa é bibliográfica, de método dedutivo e a abordagem qualitativa e exploratória, mediante análise teórica do decrescimento e desenvolvimento sustentável em conjunto com a análise das metas estabelecidas pelo Objetivo do Desenvolvimento Sustentável no 12. Conclui-se que as vias alternativas que antes não ocupavam atenção dentro da sociedade capitalista, pelo equívoco na crença de que representariam afronta ao desenvolvimento da sociedade, hoje vêm ocupando espaço principalmente dentro das agendas globais que possibilitam a pressão para a efetividade de práticas que resultem na prevenção e proteção de um meio ambiente sustentável. Com isso, poderá demonstrar que o discurso sobre a transformação de atitudes quanto ao consumo e a produção se encaixa em uma oportunidade de conseguir que todos, em uma visão de rede (pessoas e meio ambiente), estejam em harmonia e que possam perpetuar ações inovadoras no dia a dia.

Palavras-Chave: Desenvolvimento Sustentável, Decrescimento, Objetivo do Desenvolvimento Sustentável, Meio Ambiente. 


\section{A CARACTERIZAÇÃO DE PERFIL (PROFILING) DO CONSUMIDOR COMO MECANISMO PROPULSOR DO CONSUMO NÃO SUSTENTÁVEL}

A partir da $1^{a}$. Revolução Industrial, os processos de produção, moldados pela lógica capitalista, sofreram uma profunda transformação, dando origem a múltiplas e interconectadas crises sociais, sendo uma delas a crise ambiental advinda das técnicas industriais e da crescente cultura do desperdício e do consumismo. Com a $3^{a}$. Revolução Industrial e a posterior revolução baseada nas Tecnologia da Informação e Comunicação (TICs), os mecanismos capitalistas de estímulo ao consumo se renovaram e se fortaleceram com o suporte das novas tecnologias. Neste contexto, o consumidor se viu diante de novas possibilidades e acessos a produtos e serviços (online ou não). Porém as assimetrias, técnica e informacional, tornaram evidentes os problemas decorrentes do excesso de publicidades, muitas vezes carregadas de profiling (caracterização de perfil), desencadeando o consumo não sustentável. Tais técnicas têm como objetivo determinar o que é relevante dentro de um determinado contexto, por exemplo, quem pode estar interessado em um determinado produto. Estas técnicas auxiliam na representatividade estatística para assertivamente indicar produtos e/ou serviços aos consumidores. Busca-se generalizar a partir de uma amostra de indivíduos e dos seus respetivos interesses. Por exemplo, se um determinado grupo de pessoas está interessado em um determinado produto, outros grupos de pessoas ligados, conhecidos ou relacionados ao primeiro grupo também pode vir a se interessar por este mesmo produto. Portanto, tem-se uma ampliação de ofertas de publicidade ao consumidor. Importante observar que existe uma dualidade, ou seja, o consumidor tem o direito de ser informado pelos fornecedores, mas também tem o direito de se informar sobre produtos, serviços e práticas adotadas no mercado de consumo. E esta dualidade é afetada pela personalização voltada aos usuários da Internet, consumidores. O direito à informação está sob riscos quando as técnicas de profiling são aplicadas sobre dados (pessoais ou não) dos consumidores, uma vez que tais técnicas estabelecem novos conjuntos informacionais. Consumidores geram dados que geram informações sobre si mesmo e outros grupos de consumidores. $O$ artigo parte
Giovana Batisti Vieira \& Cinthia Obladen de Almendra Freitas Pontifícia Universidade Católica do Paraná (PUC/PR) 
Giovana Batisti Vieira \& Cinthia Obladen de Almendra Freitas Pontifícia Universidade Católica do Paraná (PUC/PR)
Ref.: I57CEDHM22020

A CARACTERIZAÇÃO DE PERFIL (PROFILING) DO CONSUMIDOR COMO MECANISMO PROPULSOR DO CONSUMO NÃO SUSTENTÁVEL

da hipótese de que o modelo de capitalismo do consumo estimula as emoções dos consumidores, por meio de técnicas de profiling, produzindo uma personalização excessiva e, portanto, incentivando ao consumo impulsivo, visando a maximização dos lucros. No entanto, na medida em que a população cresce e o consumo aumenta, o equilíbrio ecológico também está em risco. O artigo evidencia a função do direito à informação, como um meio de controle social, visando alcançar o desenvolvimento por meio de consumo sustentável, mitigando as assimetrias, técnica e informacional, e visando a regulação das técnicas baseadas em profiling do consumidor. $\mathrm{O}$ artigo é resultado de projeto de pesquisa e utilizou o método hipotético-dedutivo para relacionar as TICs com o consumo consciente.

Palavras-Chave: Economia Circular, Escolas de Pensamento, Precificação de Carbono, Sustentabilidade, Agenda 2030. 


\section{COMUNIDADES SUSTENTÁVEIS: COESÃO TERRITORIAL POR MEIO DOS PRINCÍPIOS DOS ODS I I E I 2 APLICADOS A ASSENTAMENTO PRECÁRIO NO BRASIL}

Como contraponto à Economia Linear, formato que visa à produção sem se preocupar com o limite de extração de matéria prima, surgem diversas propostas que abordam o Desenvolvimento Sustentável -DS -como solução para melhor relação das atividades humanas no Planeta. Os conceitos de DS são debatidos neste artigo com o intuito de criar uma base de pensamento que abranja ações humanas e impulsione um formato mais responsável de uso dos recursos naturais, em especial nas áreas mais urbanizadas. Os atuais conceitos de DS adotados pela Organização das Nações Unidas -ONU -e verificados nos Objetivos de Desenvolvimento Sustentável -ODS -tratam do processo evolutivo de pensamento sustentável que se iniciou na Conferência de Estocolmo em 1972, ampliou-se na Conferência realizada no Rio de Janeiro em 1992 e resultou em uma forma mais ampla de entendimento dos impactos causados pelas ações humanas e suas formas de mitigação. É certo que, em uma visão sistémica, os 17 ODS estão relacionados em processo acupuntural no qual são interdependentes para permanecerem fortalecidos e eficazes. Contudo, o presente artigo aborda em especial os Objetivos 11 e 12 que tratam dos conceitos de Cidades e Comunidades Sustentáveis e Consumo e Produção Sustentável. Com um mundo que se revela cada vez mais urbano, estabelecer soluções que possibilitem cidades sustentáveis é um grande desafio, principalmente em territórios mais adensados e em países com problemas urbanísticos mais evidentes. Aproximar os concentos dos ODS 11 e 12 ao orde- namento territorial de assentamentos precários por meio de ações de planeamento estratégico é um dos maiores desafios para gestores públicos. Verifica-se que a implementação da Economia Circular nos territórios urbanos pode ser grande impulsionador da sustentabilidade social, ambiental eeconômica, gerando ganhos em toda a cadeia de produção e consumo dos territórios. Como estudo de caso, apresenta-se uma comunidade brasileira localizada na cidade de Vitória, no Estado de Espírito Santo, que há alguns anos utiliza princípios da Economia Circular na busca do DS para este território. A comunidade denominada 'Território do Bem' engloba 9 bairros que formam a Poligonal 1, definida pela demanda de intervenções urbanísticas e sociais da Prefeitura de Vitória através do Projeto Integrado de Desenvolvimento Social, Urbano e de Preservação Ambiental em Áreas Ocupadas por População de Baixa Renda, denominado 'Projeto Terra'. A partir disso, apresenta-se a atuação da Organização Não Governamental -ONG -Ateliê de Ideias que vem desenvolvendo Projetos com soluções criativas ao mobilizar e potencializar vocações locais e possibilitar o desenvolvimento sustentável nesse Território. Nota-se que a atuação dessa Organização vem contribuindo para o desenvolvimento sustentável por meio do fortalecimento da economia local, da diminuição das discrepâncias sociais e das melhorias das condições ambientais, o que está a possibilitar melhor coesão territorial.

Palavras-Chave: ODS, Cidades Sustentáveis, Economia Circular, Assentamentos Precários, Ordenamento Territorial.
Rodrigo Moreira Universidade Nova De Lisboa 


\section{UM NOVO MODELO DE SOCIEDADE ATRAVÉS DA CIDADANIA GLOBAL, CONSUMO CONSCIENTE E ACESSO À JUSTIÇA}

Valeria Tavares De Santanna, Quarto Macaco Consumo Consciente

Bernardo Jose Ferreira Gicquel De Deus Instituto Dos Advogados Brasileiros \& Guilherme De Souza Santanna

UERJ - Universidade Do Estado Do Rio De Janeiro
Neste século, as mudanças não se confinam em territórios, áreas de conhecimento ou mesmo no mundo da vida. A tecnologia que costumava indicar a posição de determinada sociedade no contínuo civilizatório deve ser destacada e questionada, pois com o advento da maciça intervenção da tecnologia digital, sem qualquer avaliação de seu impacto socioeconômico que se estabelece sempre a partir de um discurso de modernidade e facilitação, mas se incorpora e movimenta exatamente de acordo com premissas seculares que criam assimetria exponencial entre as gentes, inverte-se a ordem oferta/ demanda: o mercado deixa de atender a demanda para, criá-la.

A Agenda 2030/ONU inspira a transversalidade entre os ODS como no Rizoma de Deleuze e Guattari, input ou output se conectam e tal mobilidade nos capacita a criação de novos sentidos e leva à reflexão sobre a fragmentação excessiva do conhecimento, conduz ao processo dialógico que orienta os cientistas, técnicos e pesquisadores das ciências denominadas exatas a ressignificarem seu ofício, através da apropriação de conceitos e métodos relacionados ao social e ao humano, como na economia comportamental que através da Psicologia identifica que o homem econômico age, sempre, em função de seu próprio bem-estar.

A sustentabilidade no século XXI é essencial e evidencia o protagonismo das pessoas. Kimberly Mann (ONU) destacou a importância do ODS 4 -educação inclusiva e equitativa e de qualidade e ao longo da vida para todos na Abertura do Seminário-Oficina Permanente Justiça, Bem-estar e Economia em novembro de 2019 realizado na sede do IAB Nacional (Pacto Global, desde 2019).

Os novos vetores da educação para formação da cidadania global são: estímulo à criatividade, ênfase em habilidades socio emocionais, saberes não fragmentados e protagonismo do aluno, ou seja, como preconizado por John Dewey: integração do aprendizado à vida como cidadão.

O ODS 16 - Paz, Justiça e Instituições Eficazes visa o respeito aos direitos humanos baseados no Estado de Direito e o efetivo acesso à justiça, a 
partir da transversalidade da Agenda 2030/ONU inspira a simplificação, através da desconstrução dos recortes e especializações, promovendo o encontro com a essência, com a filosofia.

A síndrome da fadiga democrática e o fundamentalismo eleitoral (DavidVan Reybrouck, Contra as Eleições), o distanciamento cada vez maior da política clássica determina a corrupção como uma constante no planeta, levando a democracia representativa a descuidar de suas precípuas funções como acesso à justiça para todos e educação para a cidadania (Norberto Bobbio, Futuro da Democracia). Nessa conjuntura qualquer desenho de compliance será insuficiente à construção do ODS 16 .

Em tempos líquidos, quase gasosos não há espaço para utopias. Justiça, Bem-estar e Economia, seminário permanente através da educação ao longo da vida visa a formação da cidadania global para a consciência da corresponsabilidade das pessoas no uso dos recursos no planeta, através da construção de uma matriz econômica de produção e consumo responsáveis/ conscientes associados à prosperidade compartilhada com vistas à paz, acesso à justiça (justice as fairness, John Rawls e Amartya Sen) e instituições eficazes (ação comunicativa, Habermas).

Palavras-Chave: Bem-Estar, Economia, Justiça, Seminário, Permanente.
Valeria Tavares De Santanna, Quarto Macaco Consumo Consciente Bernardo Jose Ferreira Gicquel De Deus Instituto Dos Advogados Brasileiros \& Guilherme De Souza Santanna

UERJ - Universidade Do Estado Do Rio De Janeiro 


\section{TECER FIOS E FAZER RENDAS. UM ESTUDO SOBRE AS RENDEIRAS DO NORTE DA IKHA DE SANTA CATARINA, FLORIANÓPOLIS, SANTA CATARINA, BRASIL}

\section{Arlete Assumpção}

Monteiro

Pontifícia Universidade Católica de São Paulo
Em 1817, D. João VI preocupado com as fronteiras brasileiras no sul do Brasil, determinou a fundação de uma colônia de pescadores no litoral sul brasileiro fundando a Colônia de Nova Ericeira. Na primeira leva vieram famílias inteiras e rapazes solteiros, além de uma botica e um pároco para fundação da colônia onde hoje se localiza o município de Porto Belo, em Santa Catarina. As mulheres que tecem fios e fazem rendas na ilha de Santa Catarina podem estar preservando um saber do outro lado do Atlântico, da região de Ericeira e Peniche de onde vieram os colonos portugueses para a fundação da colônia de Nova Ericeira no sul do Brasil, no período de 1818 a 1821 , devido a proximidade por mar do norte da ilha de Santa Catarina com as comunidades litorâneas da antiga colônia de Nova Ericeira. Com a Independência do Brasil em 1822 a Colônia de Nova Ericeira recebeu o nome de Porto Belo abrangendo um extenso território cujas comunidades foram se desenvolvendo e adquirindo autonomia no decorrer da segunda metade do século $X X$, como Camboriú, Bombinhas, itapema além de outras. Na atualidade, a região é procurada por veranistas da América do Sul, principalmente argentinos, uruguaios e chilenos e turistas europeus. As rendeiras da comunidade da praia do Sambaqui, distrito de Santo Antônio de Lisboa, se organizaram e tecem suas rendas no antigo casarão da Alfândega, onde de 5 as aos Domingos expõem e comer- cializam seus trabalhos e guardam seus apetrechos para a dança do Pau de Fitas, da Peneira e outras, que alegram as comunidades em datas comemorativas. Nas apresentações do Boi de Mamão algumas rendeiras cantam juntamente com os músicos, colaborando para o sucesso das apresentações do grupo. O saber de tecer fios com bilros e transformá-los em rendas está se perdendo, pois, as novas gerações não se interessam em aprender a fazer rendas. Estudam e buscam novas profissões como professoras, biólogas, administradoras, o fazer rendas de bilros é um saber exclusivamente feminino. As renderias da Praia do Sambaqui estão na faixa etária acimados 50 anos. Aprenderam a fazer rendas com suas mães e avós, diariamente, após o retorno das aulas e do fazer as atividades escolares. Era uma obrigação. Depoimentos apontaram que para muitas meninas era uma atividade que não as agradavam, faziam chorando o pedaço de renda que era determinado pela família, o que desagradava os meninos ao verem suas irmãs ou primas fazendo a tarefa das rendas como uma obrigação. Os bilros eram e continuam sendo feitos por homens que escolhem a madeira e os esculpem apropriados para o modelo específico da almofada onde a rendeira irá tecer os fios.

Palavras-Chave: Tradição Cultural,

Comunidades Litorâneas, Colonização Sul do Brasil, Mulheres Tendeuras, Herança Cultural. 


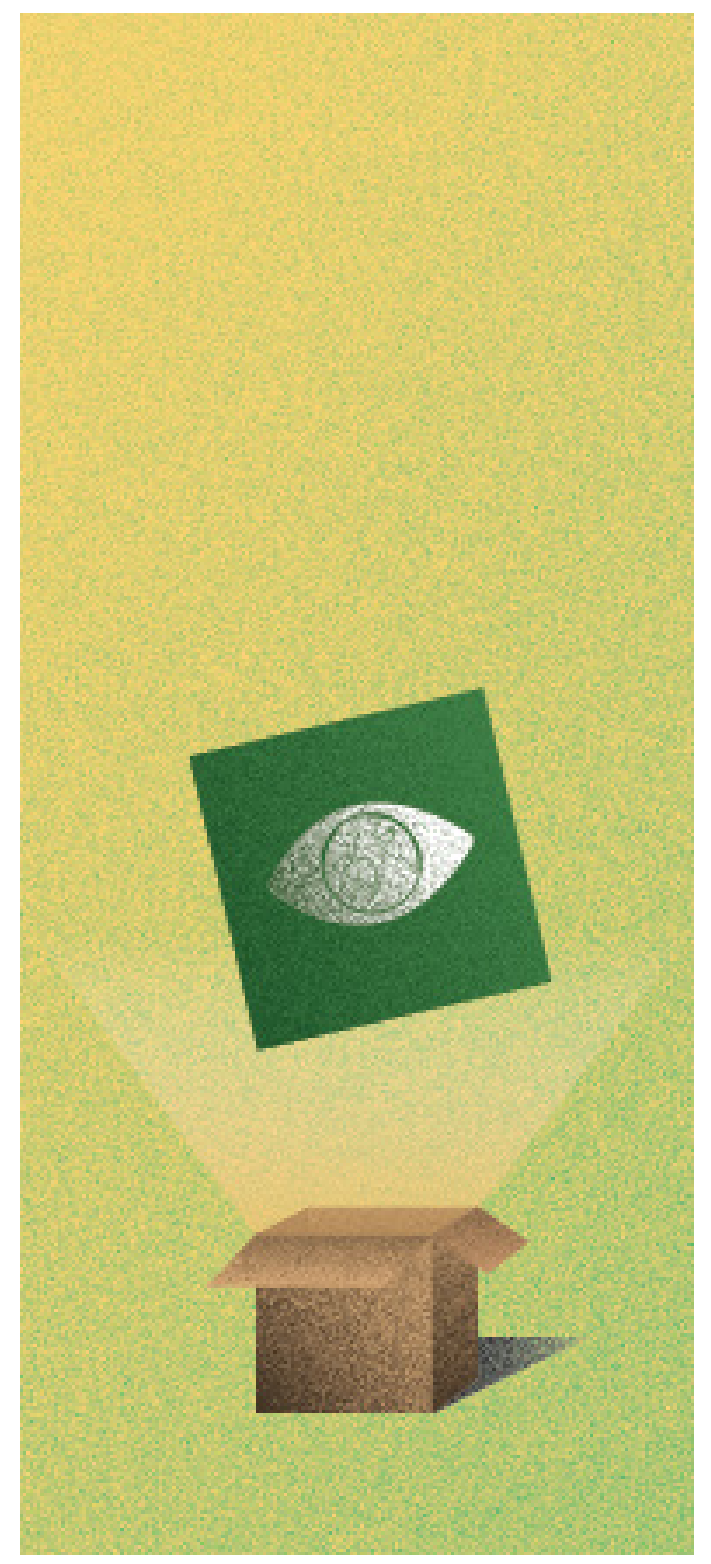

ATAS DA II CEDH:

AGENDA 2030 - UM NOVO CAPÍTULO

PARA A EVOLUÇÃO DOS DIREITOS HUMANOS

\section{ODS 13 \\ AÇÃO CLIMÁTICA}

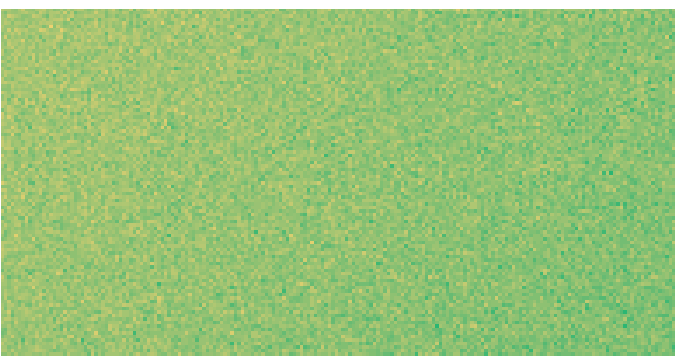




\section{TRANSIÇÃO ENERGÉTICA, MEIO AMBIENTE, DESENVOLVIMENTO HUMANO, SOCIAL E ECONÔMICO}

O Mundo está num momento de transição energética. A descarbonização e o empoderamento humano/social é um movimento irreversível, provocando numa das pontas uma eletrificação da economia com a substituição de combustíveis fósseis por fontes renováveis. Um novo modelo energético, limpo, seguro, eficiente e inteligente é essencial para o desenvolvimento social, humano e econômico em nível mundial. O setor energético mundial precisa, portanto, estar atento para observar as novas tecnologias, ser eficiente e ter menor custo, permitindo um maior nível de inovação e progresso tecnológico, com inclusão social e respeito ao meio ambiente.

Todavia, a transformação do sistema global de energia precisa acelerar para atender aos objetivos do Acordo de Paris e também ao ODS 7 - ONU Agenda 2030.

Em 2050, a eletricidade pode se tornar o principal fornecedor de energia (de $20 \%$ para quase $50 \%$ do consumo final). A energia renovável fornecerá a maior parte da demanda global (86\%). Estima-se que o sistema de energia precisaria de um investimento total de USD 110 trilhões até 2050 (cerca de $2 \%$ do PIB médio anual para o período).

Diante de tudo isso, novos mercados, produtos e serviços estão surgindo a cada dia, acompanhado de investimentos, ou seja, necessário um ambiente adequado, através de políticas publicas e regulamentação, com a participação das instituições e governos.

O debate das questões legais e éticas, que ora se propõe, parte dessas premissas, sendo atual e essencial.

Não é possível descarbonizar o planeta sem a participação de todos os atores envolvidos (ONU, Estados, empresas e consumidores).

Logo, para o atingimento do ODS 7 são necessárias propostas de legislação e cooperação mundial, com a participação de todos, sob pena da transição energética fracassar e não atingir os objetivos além de ser um simples movimento alternativo.

A transição precisa ser responsável, mas não pode ser modesta.

O trabalho a ser apresentado, ora resumido, se propõe, portanto, a apresentar alternativas legais para que a transição energética seja mundial, não apenas localizada, ou seja, eficaz e positiva ao meio ambiente, explorando energias renováveis e as tornando confiáveis e rentáveis, mas, tudo isso, sem prejuízo aos avanços sociais e econômicos envolvidos com as energias "antigas".

Palavras-Chave: Transição, Energética, Meio Ambiente, Desenvolvimento.
Bernardo Jose Ferreira Gicquel De Deus \& Carla Maria Alcofra Tocantins IAB - Instituto Dos Advogados Brasileiros 


\section{NÚCLEO DE GESTÃO AMBIENTAL DA DEFENSORIA PÚBLICA DO ESTADO DA BAHIA - NUGAMA}

Kaliany Gonzaga de Santana

Ribeiro

Defensoria Pública do Estado da Bahia
Política Nacional de Resíduos Sólidos foi instituída pela Lei $n^{\circ} 12.305 / 2010$ depois de duas décadas de tramitação legislativa, e, apesar de ter entrado em vigor há dez anos, o cumprimento dos seus objetivos, diretrizes e regras ainda é tímido e desafiador. Dentre os preceitos, a política exige que os órgãos da Administração Pública, a exemplo da Defensoria, disponham de plano de gerenciamento de resíduos, coleta seletiva e adequada destinação dos materiais descartados (resíduos ou rejeitos). Por isso, a DPE-BA instituiu a Política Institucional Socioambiental e criou o Núcleo de Gestão Ambiental (NUGAM) para executá-la. De outra senda, o eixo central de atuação do referido Núcleo visa a inclusão social das catadoras e catadores de materiais recicláveis, pois, ao passo que o cumprimento da PNRS garante a estes o acesso ao trabalho seguro e salubre, o seu descumprimento faz perpetuar o trabalho degradante e vexatório, que faz os catadores ocuparem a base vulnerável da cadeia econômica da reciclagem, não obstante serem estes responsáveis pelo retorno ao ciclo produtivo de quase 90\% dos resíduos reciclados no Brasil, de acordo com dados do IPEA-2013. Desse modo, a Política Socioambiental desponta como medida que opera não apenas como instrumento de sustentabilidade urbana e economia de recursos naturais, mas sobretudo como contributo ao exercício da cidadania e geração de renda aos catadores. Portanto, o NUGAM possui a missão de implementar o desenvolvimento sustentável à nível institucional e, concomitantemente, por meio do Programa Mãos que Reciclam desenvolve ações dirigidas a garantir a inclusão social dos catadores e o acesso ao trabalho digno, uma vez que essa atuação se dá sob condições precárias de trabalho, de forma individual e autônoma nas ruas e em lixões. O principal obstáculo ao exercício da profissão encontra-se na exigência legal de inclusão dos catadores em cooperativa/associação, por isso, a identificação territorial, cadastro socioeconômico e criação de associação de catadores compõem a etapa inicial de intervenção institucional. Apesar da catação ser uma atividade imemorial, as políticas públicas de assistência, via de regra, são tímidas ou pouco eficazes. Por isso, o programa dispõe de paradigmas de atuação multifacetárias -ações/ campanhas/parcerias - de fomento a emancipação dos catadores, por meio da implantação de coleta seletiva simplificada em grandes e pequenos geradores; educação ambiental; criação de ecopontos; distribuição de EPI's; obtenção de equipamentos e infraestrutura; incentivo à logística reversa de itens perigosos. Todas as atividades visam emancipar o catador para que seja reconhecido na comunidade, setor produtivo e poder público como agente ambiental que, de fato, exerce o serviço público de coleta, transporte, beneficiamento (ex.: triagem e prensagem) e destinação adequada de resíduos, em que pese não integrarem o sistema formal de gestão municipal de resíduos sólidos.

\section{Palavras-Chave: Catadores de Materiais} Recicláveis, Emancipação e Inclusão Social, Política Nacional de Resíduos Sólidos - PNRS, Responsabilidade Compartilhada pelo Ciclo de Vida do Produto, Coleta Seletiva Solidária. 


\section{A VIOLAÇÃO DO DIREITO À ÁGUA E DO SANEAMENTO BÁSICO ATRAVÉS DA IMPROBIDADE ADMINISTRATIVA}

O direito à água é considerado um direito fundamental, pois é a base para a garantia da dignidade da pessoa humana, já que a água é indispensável para a sobrevivência, e desta forma, está diretamente ligado a outros direitos fundamentais, como o direito à saúde e à própria vida, portanto, o direito à água deve ser garantido a todos. Porém, mesmo que muitos tratados e convenções internacionais afirmem a importância da água potável e do saneamento básico para manter uma vida digna, esse direito não é totalmente concretizado, pois de acordo com dados do "Progress on Sanitation and Water" de 2015, 633 milhões de pessoas no mundo não têm acesso a uma fonte de água potável e são 2,4 bilhões de pessoas vivendo sem saneamento adequado. Uma das principais causas deste problema é a improbidade administrativa, que pode ser configurada pelos atos que causam enriquecimento ilícito e englobam a corrupção, pelos atos que causam danos ao erário e por aqueles que atentam contra os princípios da Administração Pública. Com estes atos há o impedimento da realização de políticas públicas eficazes, deixando a população em situação precária no que tange o direito ao acesso à água potável e ao saneamento básico, prejudicando também outros direitos fundamentais, como o da saúde. Assim, o objetivo deste trabalho é deixar claro a importância do combate a improbidade administrativa para assegurar o acesso à água de qualidade e ao saneamento básico, mostrando a ligação existente entre esses institutos. $\mathrm{E}$ isto pode ser comprovado, através do método dedutivo, baseado em doutrinas do Direito Administrativo e Constitucional, e também, diante de uma análise entre os dados do Transparency International, sobre os países mais corruptos, e mediante os dados da OMS em parceria com a ONU sobre os países mais distantes ao acesso à agua de qualidade, e assim, pode-se perceber que os países com maiores índices de corrupção são os mesmos que não oferecem água e saneamento satisfatórios à sua população. Desta forma, conclui-se que o acesso precário à água e saneamento, não ocorrem somente pela falta de recursos hídricos, mas também, estão diretamente ligados a atos de improbidade administrativa, portanto para reverter essa situação, e até 2030 proporcionar um acesso eficaz e igualitário, é necessário o combate a improbidade, que pode ser realizado através de uma maior fiscalização do Legislativo, através do Tribunal de Contas, e atuação do Judiciário quando provocado perante as políticas públicas e a ineficiência administrativa, e também, pela elaboração de leis de combate a improbidade e a corrupção pelo Poder Legislativo, assim como, pode ocorrer pela conscientização da população acerca da postura de cada candidato das eleições, para que direcione seu voto aqueles que não tenham histórico de imoralidade em suas ações e que anseiem pela transparência. Além de que, de forma externa, pode se dar pela fiscalização de órgãos internacionais, e pela responsabilização dos Estados corruptos.

Palavras-Chave: Improbidade Administrativa, Corrupção, Políticas Públicas, Direitos Humanos, Direito à Água.
Ana Julia Ramos Padua \& Luiz Nunes Pegoraro Centro Universitário de Bauru mantido pela Instituição Toledo de Ensino (ITE) 


\section{OBSERVATÓRIO DE POLÍTICAS MARÍTIMAS: APORTE METODOLÓGICO DE ANÁLISE,AVALIAÇÃO E PROPOSITURA DE POLÍTICAS PÚBLICAS NO AMBIENTE MARÍTIMO}

André Panno Beirão \& Soraya Fonteneles de Menezes

Escola de Guerra Naval do Brasil
O presente trabalho tem o propósito de apresentar a metodologia inovadora adotada pelo Observatório de Políticas Marítimas do Brasil. O projeto, contemplado por Edital específico da CAPES/MD, teve início em 2018. Constituído inicialmente por pesquisadores de relevantes Universidades brasileiras (Universidade de Brasília, Universidade Federal do Ceará, Universidade Federal de Rio Grande e Escola de Guerra Naval -sendo a líder e sede do mesmo) hoje já agrega mais de uma centena de pesquisadores-doutores, da mais variada formação profissional (direito, relações internacionais, biologia marinha, oceanografia, geologia marinha, biologia, etc.). Em termos de Instituições, partindo de suas iniciais quatro fundadoras, hoje há agrega mais de um a dezena de Centros de Pesquisa e/ou Universidades, inclusive em Portugal. Ao longo desse amadurecimento, consolidou metodologia que esse trabalho apresenta, de suas três linhas de pesquisa: 1 -Acompanhamento e análise (inclusive utilizando método comparado internacional) de Políticas Públicas voltadas ao mar; 2 -Avaliação de Políticas Públicas (seja Avaliação Executiva, Ex-Ante ou Ex-Post); e 3 -Assessoria e Propositura de Políticas Públicas. Nessas três linhas de pesquisa, tem atuado estruturado sobre seis áreas temáticas (exploração de recursos vivos e não-vivos; regulamentações internacionais e questões estratégicas; sustentabili- dade e a questão ambiental marinha; novas ameaças à segurança marítima; questão econômica, social e tráfego marítimo/portuário; e, bioprospecção e novas tecnologias). Assim, o presente trabalho procura sistematizar a metodologia empregada como forma de agregação de visão intersistêmica que permita ações efetivas. Relevante aspecto é quanto à combinação de avaliações qualitativas com quantitativas fundamentadas em indicadores, nem sempre claramente identificados nas políticas públicas. A inovação da metodologia implementada é refletida pela visão matricial em que dados coletados e analisados na linha de pesquisa 1 , são insumos à avaliação (da linha de pesquisa 2 ), que, por sua vez, subsidiam as propostas da Linha de Pesquisa 3. Por fim, procura demonstrar que a propositura ou assessoria pode derivar de demandas do setor público (seja por nova política, quanto por aprimoramento de políticas vigentes), como também pode ter origem em necessidades oriundas do setor privado ou afetado por determinado fenômeno social, ambiental ou econômico. Ao final procura apresentar os desafios enfrentados e as dificuldades da reavaliação metodológica que realimente a proposta.

Palavras-Chave: Observatório, Políticas

Marítimas, Políticas Públicas, Arranjo

Metodológico, Institucionalidade. 


\section{AS TRANSFORMAÇÕES DO ÁRTICO EM DIÁLOGO COM A AGENDA 2030}

O Ártico é uma região em evidência na geopolítica, tendo em vista a possibilidade de uma rota perene de navegação pelo norte e da exploração de vasto depósito de hidrocarbonetos. Ao mesmo tempo, o alerta da comunidade científica acerca do papel crucial do Ártico na temperatura global, combinada com os efeitos das mudanças climáticas no frágil bioma marinho, coadunou em uma série de compromissos internacionais voltadas à mitigar tais mudanças e à proteção do meio ambiente. Nesse contexto, o objetivo do presente trabalho é analisar as transformações no Ártico por três perspetivas: o paradigma da geopolítica; o papel da região no que tange às mudanças climáticas; e os desafios da proteção ao meio ambiente marinho. Na perspetiva geopolítica, os oito "Estados Árticos" têm algum tipo de pleito territorial na região, como a extensão de suas plataformas continentais para o norte. Os interesses na região atraem outros players internacionais, como os treze Estados não-Árticos que foram aceitos como observadores no Conselho do Ártico: França, Alemanha, Itália, Japão, China, Polônia, Índia, Coreia, Singapura, Espanha, Suíça e Reino Unido. O entusiasmo com a região é justificável quando se observa que a "Rota do Norte" implica em uma transformação na indústria do transporte marítimo, reduzindo tempo e custo do transporte de carga. Na seara ambiental, observa-se que as mudanças climáticas na região impactam a dinâmica bioquímica dos oceanos: a elevação do nível dos mares, a acidificação, o comprometimento da vida oceânica, o derretimento do permafrost asso- ciado à liberação de metano e mercúrio. Diante dessa realidade multifacetada, o presente estudo, voltado a analisar as transformações no Ártico a partir de uma tríade perspetivas, empregou do método indutivo, cujo principal alicerce teórico foi o do Direito Internacional, cotejando os compromissos internacionais relevantes. Além disso, foram utilizados estudos acadêmicos, relatórios de Organizações Não Governamentais, bem como documentos e declarações oficiais dos Estados que manifestam interesses no Ártico. Os Objetivos de Desenvolvimento Sustentável, em especial os ODS13 E ODS14 foram utilizados como linha mestra para a consecução do trabalho, motivo pelo qual optou-se pelo quadro temporal com início 2015, quando foi estabelecida a Agenda 2030, e termino a metade do ano de 2020. Feitas essas considerações, o estudo desenvolvido nos permitiu conclusões nos três eixos propostos. Confirmou-se o aumento do interesse dos Estados pelo Ártico no binômio fonte abundante de recursos exploráveis e nova rota marítima. Constatou-se que os compromissos internacionais para o combate às mudanças climáticas, em especial sobre a emissão de dióxido de carbono, ainda não foi amplamente adotados pelos Estados, com repercussões negativas no Ártico. Por fim, muito além de acordos, observou-se a urgente necessidade de articulações voltadas à ações concretas para a preservação do meio ambiente marinho.

Palavras-Chave: Ártico, Mudanças Climáticas, Geopolítica do Ártico, Meio Ambiente Marinho.
Soraya Fonteneles de Menezes

Doutoranda em Estudos Marítimos na Escola de Guerra Naval

\& André Panno Beirão

Escola de Guerra Naval 


\section{DIREITOS HUMANOS E MEIO AMBIENTE ECOLOGICAMENTE EQUILIBRADO: ASPECTOS DA CONSTITUIÇÃO FEDERAL DE 1988}

Maria Damian Ribeiro

Pessoa,

Frank Pavan de Souza

\& Bianca Monteiro

de Castro

Institutos Superiores De Ensino

Do Censa (ISECENSA)
De acordo com a Constituição Federal do Brasil de 1988, todos têm direito ao meio ambiente ecologicamente equilibrado. Além disso, a Carta Magna estabelece que os recursos naturais constituem-se como bens de uso comum do povo e essencial a sadia qualidade de vida. Neste sentido, compreende-se que a Constituição Federal apresenta propostas para que os bens da natureza sejam utilizados de forma que a humanidade possa usufruir para as suas necessidades e ao mesmo tempo preservar para as futuras gerações. Neste sentido, esta pesquisa teve como objetivo, analisar os aspectos legais apresentados na Constituição Federal de 1988, que estejam relacionados com o atendimento das necessidades sociais humanitárias. Para a realização da pesquisa foi adotado o método dedutivo, pois buscou-se obter conclusões por meio de premissas verdadeiras. A pesquisa classifica-se como bibliográfica uma vez que utilizou-se embasamento teórico, jurídico e científico disponível em bases de dados digitais e físicas. Foi possível constatar, que apesar de haver um ordenamento jurídico, que apresenta uma estrutura que abarca as necessidades dos seres humanos, no que tange aos usos dos recursos naturais, há certa complexidade para aplicação das regras constitucionais, pelo fato do Brasil apresentar diversidade cultural em face de sua história e principalmente pela divisão geográfica e econômica discrepante em todo o País. Verificou-se que os serviços ambientais não estão distribuídos humanitariamente de forma igualitária. Em determinadas regiões não há acesso a água tratada e nem mesmo atendimento dos demais serviços de saneamento básico. Além isso, é possível perceber que nas regiões urbanizadas há parte da população que vive em áreas de risco, aglomerados e ocupações irregulares. Não obstante às ocupações, percebe-se, principalmente nas crianças, a constatação de doenças de veiculação hídrica, uma vez que convivem com esgoto ao céu aberto e resíduos sólidos amontoados, que podem promover a proliferação de vetores transmissores de doenças. Neste contexto, promover um ambiente equilibrado e ao mesmo tempo atender as demandas humanitárias não será uma tarefa efêmera. Ao final, conclui-se que há necessidade de se propor a integração das Políticas Publicas humanitárias e ambientais, para que a sociedade possa se aproximar do Pode Público na elaboração e aplicação das propostas para a gestão dos serviços ambientais, com vistas ao atendimento das necessidades humanas.

Palavras-Chave: Direitos Humanos, Meio Ambiente, Sociedade, Equilíbrio Ecológico. 


\title{
O ESTADO DE DIREITO ECOLÓGICO COMO CONDIÇÃO PARA O CUMPRIMENTO DOS OBJETIVOS DE DESENVOLVIMENTO SUSTENTÁVEIS FIXADOS PELA AGENDA 2030
}

\begin{abstract}
A Agenda 2030 traz um plano de ação para o desenvolvimento sustentável. Com fundamento na dignidade da pessoa humana, a Agenda exige uma parceria global. Entretanto, em que pese o respeito às diferentes realidades nacionais, deve-se questionar qual o modelo
\end{abstract} de Estado ideal à concretização do desenvolvimento sustentável. Tal discussão não é nova, mas resta atual ante a crise planetária e a falência do Estado na solução dessa. Desde 1972, quando da primeira conferência das Nações Unidas sobre o meio ambiente, pensa-se sobre um modelo de Estado sensível às questões ambientais. O "Nosso Futuro Comum" (1987) apontou para a necessidade de um desenvolvimento sustentável. Nesse sentido, Kloepfer (1989) propôs o Estado de Direito Ambiental. Entretanto, as questões socioambientais agravaram-se, exigindo respostas além do Direito Ambiental. Limites planetários são rompidos (ROCKSTRÖM, 2009; 2015) e as condições necessárias à vida, violadas (ARAGÃO, 2017). Urge-se por uma nova quebra de paradigma. Bugge (2013) sugere o Estado de Direito para a Natureza. A "World Commission on Environmental Law of International Union for Conservation of Nature" (2016) exige que o Estado se comprometa com a sustentabilidade forte, tutora dos direitos inerentes à Natureza. Para transposição da visão mecanicista, Capra e Mattei (2015) propõem uma Revolução Ecojurídica. A Agenda 2030 caminha no curso dessa revolução. Entretanto, esta só será alcançada e assegurada com a implementação do Estado de Direito Ecológico (POPE, 2017; DINNEBIER e LEITE, 2017), percursor da dimen-

são ecológica da dignidade da pessoa humana, condizente com o viés cultural dessa, afeto às transformações ocorridas (HÄRBELE, 2013). Assim, no contexto da Sociedade de Risco (BECK, 1986; LEITE e AYALA, 2004), a dignidade humana, fundamento da Agenda 2030, deve ser interpretada além das presentes e futuras gerações humanas, protegendo a Natureza em totalidade: elementos bióticos, abióticos e processos ecológicos (SARLET e FENSTERSEIFER, 2019). A inexistência do aparato institucional necessário ao pleno vigor do Estado Ecológico de Direito não impede que esse seja planejado, pelo contrário, protesta que o tema seja aprofundado. Esta pesquisa tem esse intento. Para tal, foram utilizadas fontes bibliográficas e documentais. Conforme apresentado, já se colhe exemplos de trabalhos doutrinários com o fito de propor modelos de Estado de Direito responsivos à crise. Simultaneamente, documentos como a Agenda 2030, a Opinião Consultiva no 23/2017 da Corte Interamericana de Direitos Humanos no âmbito da Opinião Consultiva 23/2017 e a decisão proferida na Ação Direita de Inconstitucionalidade $n^{\circ} 4.983 / C E$, julgada pelo Supremo Tribunal Federal, no Brasil, despertam para a insuficiência de uma perspectiva puramente antropocêntrica. Somente sob uma ótica ecocêntrica, própria do Estado de Direito Ecológico, podem ser forjadas as bases para cumprimento dos objetivos de desenvolvimento sustentáveis estabelecidos pela Agenda 2030.

Palavras-Chave: Estado de Direito Ecológico, Agenda 2030, Objetivos de Desenvolvimento Sustentável, Dimensão Ecológica da Dignidade da Pessoa Humana.
Camila Parente Almeida \& Carlos Teodoro José Hugueney Irigaray Universidade Federal De Mato Grosso 


\section{SUSTENTABILIDADE, OU UM PLANETA PARA TODOS - OS CAMINHOS DA AGENDA 2030}

João Guerra ICS-ULisboa
Sobretudo a partir de alguns alertas desafiantes para o status quo socioeconómico -e.g., "Silent Spring" (Carson, 1962), "Limits of Growth" (Meadows et al., 1972), "Small is Beautiful" (Schumacher, 1973).-o oximoro desenvolvimento sustentável ganhou aceitação e ubiquidade inegáveis (Redclift, 2005), tendo passado pelo Relatório Bruntdland (CMAD, 1987) e pela Agenda 21 (UNCED, 1992) e, mais recentemente, desembocado na Agenda 2030 (UN General Assembly, 2015). Este percurso - apesar dos discursos, por vezes, inflamados e, sobretudo, tendo em conta o estado do ambiente global atual (IPCC, 2018) -terá ficado muito aquém do inicialmente proposto (Guerra \& Schmidt, 2016). Decorrendo da ambiguidade e da adesão superficial e panfletária com que a sustentabilidade foi globalmente encarada (Redclift, 2005), os resultados mostram um agravamento das desigualdades e das condições de vida de largas faixas da humanidade que conflui com um incremento do processo de degradação ambiental. As alterações climáticas são uma das principais marcas deste processo, mas acompanham-nas inúmeras e apensas situações mais localizadas de desequilíbrio socioambiental e de catástrofes com origem antropogénica e/ou natural (Schmidt \& Guerra, 2018).Simultaneamente e, decorrendo em grande parte destas dinâmicas, o virar do Século XX para o Século XXI terá testemunhado a consolidação (nalguns casos apenas a emergência) de um novo quadro de pensamento. Uma cosmovisão alternativa que, globalmente, reflete uma maior preocupação para com as condições ecológicas, um reconhecimento mais efetivo dos seus limites e uma crescente constatação das consequências socioeconómicas da sua ultrapassagem (Schmidt \& Guerra, 2013; Xiao, Dunlap \& Hong, 2018). Estamos perante uma dinâmica de mudança que, até agora, e apesar de alguns avanços localizados e particulares, não se tem mostrado capazes de ultrapassar a lógica hegemónica de mercado -o imperativo "crescer ou perecer" (Flinders, 2012) -e a consequente agudização da escassez ecológica (Schnaiberg, 1980). Ficam, assim, postos em causa não só o futuro da humanidade, mas, muito particularmente, o presente e o futuro das comunidades vulneráveis (humanas e não humanas) e, por conseguinte, menos habilitadas a defender-se da adversidade crescente.

Neste contexto, propõe-se, aqui, uma análise fundamentalmente teórica destas dinâmicas de mudança atravessadas por vetores contraditórios, focando, nomeadamente, a conjuntura de implementação da Agenda 2030 e o seu slogan "não deixar ninguém para trás", bem como algumas propostas ou enfoques de reflexão, desenvolvidos a partir do viés das ciências sociais: "antropoceno" (Lidskog \& Waterton, 2016), "solastalgia" (Albrecht, 2014), "irresponsabilidade organizada" (Beck, 2009), "justiça ambiental" (Agyeman et al., 2016). O objetivo é sublinhar a importância da área de interceção entre ambiente e sociedade e seus fenómenos interconexos, como são os distúrbios ecossistémicos e as convulsões socioeconómicas.

Palavras-Chave: Sustentabilidade, Ambiente, Antropoceno, Justiça Ambiental, Solastalgia. 


\section{REGULAÇÃO E O NOVO MARCO LEGAL DO SANEAMENTO BÁSICO NO BRASIL: AVANÇOS E DIFICULDADES}

Segundo o Sistema Nacional de Informações sobre Saneamento (SNIS), quase metade da população do Brasil continua sem acesso a sistemas de esgotamento sanitário, o que significa o montante de quase 100 milhões de pessoas. São $47 \%$ dos brasileiros que utilizam medidas alternativas para lidar com os dejetos, como o uso de fossa ou o despejo de esgoto diretamente em rios. A falta de prestação de serviços públicos em relação ao mínimo existencial afeta diretamente o bem- estar da população, notadamente na saúde pública e da preservação do meio ambiente.

Como solução para o problema estrutural, foi publicado o novo marco legal do saneamento básico em julho de 2020, que pretende promover o federalismo cooperativo por uma complexa rede de regulação em âmbito local, estadual e federal com a atribuição da Agência Nacional de Águas (ANA) ao regular o setor pela elaboração de normas gerais e pela promoção de governança e metodologia de monitoramento de políticas públicas.

A análise legislativa proposta pelo presente artigo é fundamental para consolidar e expor a mudança de paradigma no desenvolvimento de políticas públicas em saneamento básico para prestação dos serviços essenciais por concessão, através de licitação, pela substituição dos precários contratos de programa vigentes. Dessa maneira, são debatidos dos avanços na universalização da prestação de serviços públicos essenciais, bem como as dificuldades tarifárias de implementação dessa agenda de políticas públicas.
Na presente pesquisa, as pesquisadoras pretendem realizar um recorte metodológico para discutir a falta de acesso a esgotamento como um fator importante da profunda desigualdade social estrutural no Brasil e os instrumentos jurídicos aptos a promover o investimento privado nesse setor. Portanto, o artigo é dividido em quatro partes: i) evidências empíricas da falta de saneamento básico como problema da saúde pública; ii) comentário legislativo do novo marco legal do saneamento básico; iii) federalismo de cooperação e a construção da rede regulatória tripartite; e iv) perspectiva crítica dos possíveis avanços e dificuldades das políticas públicas de saneamento básico. Assim, na conclusão, é possível relacionar a necessidade de adequada prestação de serviço público essencial de saneamento básico como fator de desenvolvimento sustentável no novo paradigma da regulação por concessão A metodologia utilizada para o trabalho foi a dedutiva, uma vez que o estudo foi constituído de análises de premissas gerais para adoção de uma conclusão específica sobre o novo sistema regulatório em políticas públicas de saneamento básico no Brasil. A pesquisa realizada foi de caráter documental e envolveu a análise do novo marco legal do saneamento básico, além de estudos doutrinários, jurisprudenciais e exame de artigos em periódicos.

\footnotetext{
Palavras-Chave: Regulação, Federalismo, Saneamento Básico.
}

Patrícia Regina Pinheiro Sampaio \& Juliana Patricio da Paixão FGV-RIO 
María del Carmen Ledo

García

CEPLAG - UMSS

Ref.: 37ICEDHM22020

\section{EL DERECHO HUMANO A LA DISPONIBILIDAD DE AGUA POTABLE DENTRO DE LAS VIVIENDAS EN COCHABAMBA, BOLIVIA}

Dentro del proceso de urbanización boliviano, resaltaCochabamba, por la acelerada expansión horizontal de su huella urbana, carente de planificación y con alarmantes niveles de inequidad y pobreza. La expansión urbana está creando serios problemas para el abastecimiento de agua, que coadyuva a entender su creciente demanda urbana insatisfecha, el avasallamiento de tierras ha provocado el cambio de uso del suelo, reduciendo la disponibilidad de agua para los cultivos agrícolas que eran un mecanismo de mitigación de la soberanía alimentaria. La Guerra de Agua en abril del 2000 mostró al mundo las consecuencias injustas de la privatización de los servicios básicos, sin embargo, después de 20 años, perduran las anomalías que no fueron superadas. La provisión pública del servicio del agua en Cochabamba, solo beneficia a los sectores de mayor poder económico que se localizan en no más del $50 \%$ de su territorio. En el otro $50 \%$ del territorio, la población recurre a ingeniosos mecanismos de abastecimiento alternativo, utilizando carros cisternas, pozos y pequeños sistemas de autogestión social, construidos a través de los movimientos sociales comunitarios. Se trata de familias que viven en precarias condiciones de vida, acompañados de altos niveles de pobreza, situación que revela la inequidad y exclusión social en la que se erige su desarrollo ya que sufren una multivariada gama de carencias.

Se persigue analizar las características de la oferta y demanda de servicios básicos en especial del agua procedente de la red pública y también las estrategias a las que recurren los sectores empobrecidos para cubrir sus necesidades básicas, como respuesta a una multivariada gama de insatisfacciones. Para la realización de esta investigación empírica se ha definido utilizar datos la Encuesta de Agua sobre consumo y opinión del servicio en los hogares de la zona donde opera SEMAPA en Cochabamba que fue levantada para la Asociación Nacional de Empresas de Servicio de Agua Potable y Alcantarillado (ANESAPA) el año 2016. Con el ánimo de demostrar la multidimensional cara de la pobreza, vulnerabilidad, deprivación y desigualdad social en Cochabamba, se ha aplicado una técnica multivariada, denominada modelo generalizado de correlación canónica (GCCA). Los resultados de la investigación visibilizan las inequidades en Cochabamba, se evidencia diferencias en las tasas de consumo sanitario entre los usuarios. A partir de los resultados de la investigación las autoridades locales y regionales deberían en coordinación con la población buscar medidas destinadas a garantizar el derecho humano al agua y asegurar estrategias que permitan que los sectores más pobres y vulnerables de la sociedad tener acceso al agua, que en el peor de los casos se traduce en muerte debido a las patologías que se derivan de la falta de acceso a agua de buena calidad entre los grupos más deprimidos.

Palavras-Chave: Derecho Humano, Urbanización, Agua, Inequidad, Pobreza. 


\section{A MUDANÇA CLIMÁTICA CONTEMPOR NEA: UMA QUESTÃO POLÍTICO-ECONÔMICA OU SOCIOAMBIENTAL?}

\begin{abstract}
A ação contra a mudança global do clima é um dos Objetivos de Desenvolvimento Sustentável - ODS, estabelecidos no âmbito da Organização das Nações Unidas - ONU para o período de 2015 a 2030. Tal ação se faz cada vez
\end{abstract} mais necessária e urgente, conforme destaca a maior parte da comunidade científica internacional. Isso porque o ser humano tem exacerbado sua influência sobre o sistema climático do planeta, principalmente nas últimas décadas. Essa influência antrópica sobre o clima da Terra é considerada a causa do processo de mudança climática atualmente em curso, ao contrário das demais mudanças climáticas pelas quais o planeta passou em escala geológica de tempo que ocorreram devido a fatores naturais, inclusive antes do surgimento da espécie humana. O gás do efeito estufa - GEE, naturalmente presentes na atmosfera terrestre, exercem um papel fundamental para o equilíbrio climático do nosso planeta, mantendo as temperaturas numa faixa ideal para a vida como conhecemos. No entanto, a concentração de gases do efeito estufa - GEE na atmosfera vem aumentando devido às atividades humanas, e, nunca foi tão alta desde o surgimento da nossa espécie e, com isso, as temperaturas registadas também aumentam. Dessa forma estão sendo alteradas as condições essenciais para a manutenção da vida humana assim como da grande biodiversidade que coexiste conosco na
Terra. Com o objetivo de conter esse processo contemporâneo de mudança climática, uma série de acordos internacionais tem sido assinados, o que, no entanto, não tem gerado a redução da concentração dos GEE necessária para reverter o processo de aquecimento global que vivemos. A questão climática tem sido cada vez mais debatida em diversas áreas do meio acadêmico, em diferentes esferas de governança política, por ambientalistas, pelo empresariado, na media, etc. Em meio a tantas vozes, muitas vezes dissonantes, surge a pergunta: seria a mudança climática uma questão de natureza essencialmente político-económica ou socioambiental? Partindo desse questionamento, o presente artigo tem como objetivo analisar os avanços e retrocessos da governança global do clima, especialmente a participação do Brasil nesse contexto. Para tal, está dividido nas seguintes partes: Introdução; O clima como tema da agenda política internacional; O papel do Brasil na mitigação da mudança climática; Os paradoxos do desenvolvimento sustentável e da economia verde; Considerações finais.

Palavras-Chave: Objetivos De Desenvolvimento Sustentável, Governança Global Do Clima, Mudança Climática, Gases De Efeito Estufa, Direitos Humanos.
Vanessa Cristina São Pedro Abreu da Costa

Universidade do Estado do Rio de Janeiro - UERJ 


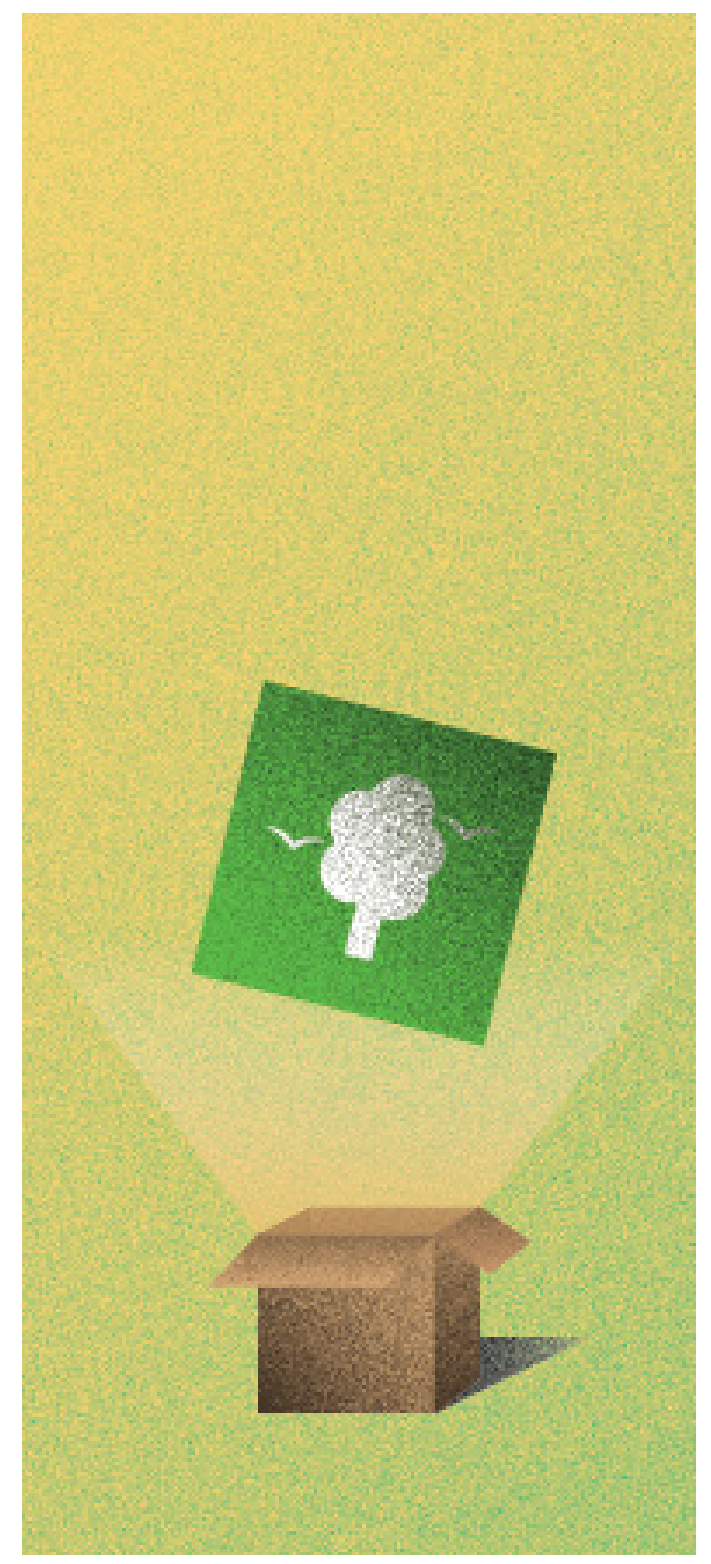

\section{ODS 15 \\ PROTEGER \\ A VIDA \\ TERRESTRE}

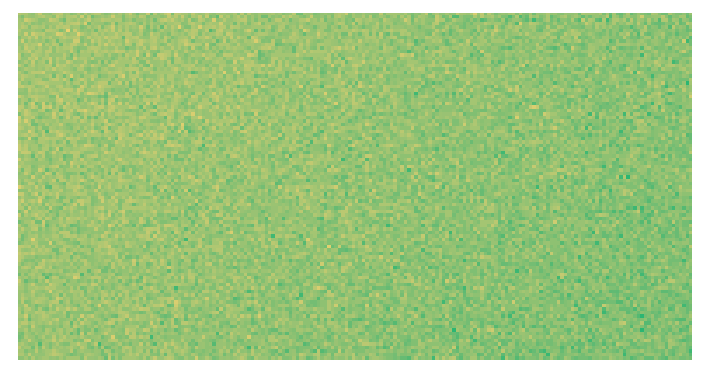




\section{BRUMADINHO E O DESASTRE AMBIENTAL, SOCIAL E COMUNITÁRIO: OS DIREITOS SECURITÁRIOS E A DIGNIDADE HUMANA}

A tragédia de Brumadinho, ocorrida em 25 de janeiro de 2019 no Brasil, produziu na região de Minas Gerais enorme dano ambiental e social com reflexos para o Sistema Nacional de Seguridade Social. Regram os princípios securitários da seletividade e da distributividade da proteção e da cobertura, a responsabilidade objetiva do Instituto de Seguro Social brasileiro -INSS, mediante a concessão de prestações de pensão por morte e aposentadoria destinados aos beneficiários (segurados e dependentes), vítimas diretas do desastre. Compreende-se, neste caso, o reconhecimento de novos riscos geradores de institutos protetivos que impactam sobremaneira, tanto o ideal de sustentabilidade ambiental e de desenvolvimento social, quanto impõe ao Sistema Social o dever de proteção aos vitimados, como os atingidos indiretamente pela gravíssima e enorme onda de lama movida pela catástrofe ambiental, de serem assistidos, inclusive pelo Benefício Programado e Continuado, independentemente de contribuição. Relevante tratar essa questão perquirindo os fundamentos inseridos nas doutrinas da solidariedade fiscal (Pierre Rossanvallon e Alain Soupiot); dos direitos públicos e subjetivos do cidadão e do assistido da Seguridade Social constitucional (Jorge Reis Novaes, Ilídio das Neves, Ingo Sarlet e Daniel Sarmento); da justiça, inclusão social, qualidade de vida e teoria das capacidades (Danny Dorling, Iris Marion Young e Martha Nussbaum, Amartya Sen); da sociedade de risco (Ulrich Beck); e dos riscos da relação jurídica de Seguridade e Seguro Social que, num ambiente de insegurança social(Robert Castel) e de banalização dos prejuízos individuais (Zygmunt Bauman, Christophe Dejours), geram incertezas e possibilidades de dessolidarização social. A medida da segurança social, como direito universal capaz de promover a dignidade e o bem-estar dos cidadãos, impõe a garantia a todos os indivíduos atingidos pelo acidente, um mínimo de condições existenciais e de vida digna. A Seguridade Social inserida no sistema constitucional, composta pelos ramos da saúde, assistência social e previdência social, é um direito social e fundamental, não podendo ser reduzido, apenas majorado. A previdência social constitui-se em um sistema de proteção aos segurados e seus dependentes, que mediante mecanismos de contribuição e filiação obrigatória, promove a concessão de benefícios previstos em lei. No entanto, sem olvidar, cabe aos não segurados, em face do maior acidente de trabalho do Brasil, o direito ao Beneficio Programado e Continuado, da Assistência Social, que malgrado a condição de não filiados da Previdência Social, são beneficiários do Sistema de direitos solidário, democrático e social brasileiro. No âmbito jurídico, a justiça social e o bem-estar social, são sem dúvida, os fins mais importantes do Estado Democrático de Direito, que na abordagem da proteção social e do princípio da dignidade da pessoa humana em prol dos vitimados do desastre em Brumadinho, deve ser célere.

Palavras-Chave: Direitos Subjetivos, Dignidade Humana, Proteção Social, Cobertura de Riscos, Justiça Securitária.
Eliane Romeiro Costa, Germano Campos Silva \& Mara Rúbia Mendes dos Santos Fernandes Pontifícia Universidade Católica de Goiás - PUC Goiás 
Ref.: I02CEDHMI 2020

\section{AS INDICAÇÕES GEOGRÁFICAS COMO FERRAMENTAS DE FORTALECIMENTO DA AGRICULTURA FAMILIAR E INCLUSÃO SOCIAL NO BRASIL}

Christiane Madalena Matheus de Alcantara da Costa

Universidade do Estado do Rio de Janeiro (UERJ)

e Instituto Nacional

da Propriedade Industrial (INPI)
O objetivo do trabalho é demonstrar que as Indicações Geográficas, podem ser utilizadas como ferramentas para valorizar produtos agroalimentares, 0 artesanato, bem como, pode ajudar no desenvolvimento da economia brasileira, em mundo globalizado e altamente competitivo. As indicações geográficas podem promover maior competitividade através de produtos reconhecidos por sua qualidade e diferenciação, uma cultura de inovação no agronegócios, e, principalmente, a inclusão social dos pequenos produtores rurais, tendo como consequência, o fortalecimento da agricultura familiar no Brasil, um setor cada vez mais fragilizado e ignorado pelas políticas públicas brasileiras, porém, representa, cerca de $80 \%$ das propriedades rurais no país, $75 \%$ da força de trabalho agrícola e é responsável por aproximadamente $10 \%$ do PIB nacional. Ou seja, extremante estratégico para o Brasil.

No continente europeu, as Indicações Geográficas, são amplamente disseminadas e consolidadas há mais de um século. Entretanto, apesar de sua grande importância econômica e social, o Brasil ainda pouco utiliza esse instrumento. As indicações geográficas no Brasil são um pouco mais conhecidas na região sul do país, devido a produção de vinhos na serra gaúcha. O tema além de muito recente no Brasil, necessita de maior apoio governamental, para que o mesmo seja devidamente disseminado e incentivado. O Brasil com sua agropecuária tão extensa e diversificada não pode mais enxergar as Indicações Geográficas como algo praticamente inexistente ou secundário em seus projetos ligados a competitividade e diminuição das desigualdades sociais e regionais. A redução das inúmeras desigualdades no Brasil, terá no médio/longo prazo, a diminuição da violência nos grandes centros urbanos do país. Pois, com a agricultura familiar fortalecida, a tendência é fazer com que os jovens sintam orgulho de permanecerem no campo produzindo e serem valorizados pelo trabalho desenvolvido.

Palavras-Chave: Desigualdade, Agricultura, Competitividade, Desenvolvimento Regional. 


\section{POLÍTICAS PÚBLICAS DE FORTALECIMENTO DA AGRICULTURA FAMILIAR NO CERRADO E COMBATE À FOME}

O objeto da pesquisa é analisar a agricultura familiar, no Cerrado brasileiro, a partir de Políticas Públicas específicas, como estratégia de combate à fome. O objetivo geral é investigar, criticamente, a presença do Estado, por meio de programas oficiais dirigidos ao fortalecimento da agricultura familiar e à promoção da sustentabilidade ambiental, econômica e social, com foco na segurança alimentar e o combate à fome. Abordagem metodológica dialético-reflexiva, revisão bibliográfica, perspetiva crítica da realidade sociopolítica. A agricultura mercantilista tem forte representação no Congresso Nacional, conhecida como bancada ruralista ou "partido da terra" (CASTILHO, 2012); são parlamentares, representantes do agronegócio, que interferem, disputando e se opondo à formulação e realização de políticas públicas destinadas à categoria da agricultura familiar. A agricultura familiar, presente na diversidade agrária brasileira, é muito distinta da categoria econômica que representa a agricultura de caráter capitalista. A agricultura familiar rompe com a imposição do modelo de desenvolvimento concentrador. $O$ pequeno agricultor, na sua atuação, se constitui e passa a existir enquanto sujeito de direitos. $\mathrm{Na}$ prática, gerou-se a necessidade de seu reconhecimento como sujeito de direito de políticas públicas específicas. O Programa Nacional de Fortalecimento da Agricultura Familiar (PRONAF) é fruto da luta pelo direito como efetividade porque significa um daqueles projetos "que começa de baixo para cima, pois, foi o movimento sindical de trabalhadores rurais que apresentou a proposta originária", se trata de "uma iniciativa que comprova o argumento da legitimidade da lei que deve se converter em direito, na prática, a partir da atuação política que o concebeu" (SIQUEIRA, 2016, p. 311). Posta em prática a política, teve o problema da falta de destinação de recursos para o seu financiamento, a recorrente não aplicação do "direito como efetividade" (SIQUEIRA, 2016). Somente a partir do governo Lula (2003-2010) houve investimentos orçamentários adequados a uma digna realização do PRONAF. Também, foi naquele período que se editou a Lei n. 11.326/2006, instrumento jurídico que estabeleceu as diretrizes para a formulação da Política Nacional da Agricultura Familiar e Empreendimentos Familiares Rurais. Defender o fortalecimento da agricultura familiar é defender geração de trabalho e renda, minimizar as desigualdades, concretizar uma ação governamental para a segurança alimentar, porque milhões de pessoas enfrentam a fome como mal crônico em suas vidas, como sintetiza ZIEGLER (2013, p. 37-39): "Os países em desenvolvimento em seu conjunto viram aumentar a quantidade de esfaimados (de 827 milhões, em 1990-1992, a 906 milhões, em 2010)". O tema é pertinente, pois, o problema insere no atual contexto brasileiro, de destruição do Estado Social pelo atual governo, pondo em risco a segurança alimentar de milhões, fazendo o Brasil, voltar ao desumano "mapa da fome".

\section{Palavras-Chave: Direito Agrário, Agricultura} Sustentável, Segurança Alimentar, Combate à Fome, Direitos Humanos.
Renata Martins Vasconcelos \& José do Carmo Alves Siqueira Universidade Federal de Goiás - UFG 


\section{A GRILAGEM QUE ESTRUTURA A ORGANIZAÇÃO FUNDIÁRIA DA AMAZÔNIA E SUA ÍNTIMA RELAÇÃO COM O DESMATAMENTO: UMA ANÁLISE DO DISCURSO PARLAMENTAR}

Vitória da Costa Caruso OAB/DF, FESMPDFT, UnB
A grilagem consubstancia-se na invasão de terras protegidas, realizando-se queimadas, extrativismo ilegal ou até confrontos com povos locais originários, com o intuito de caracterizar a propriedade como produtiva. Posteriormente, leva-se a terra ao registro que, em razão da desregulação entre os entes estatais, poderá ocorrer mais de uma vez, em entes federativos distintos, ou com uma extensão superior àquela que apresenta na realidade fática. $O$ Instituto de Pesquisa Ambiental da Amazônia (IPAM) caracteriza a prática criminosa da grilagem como histórica produtora de reflexos sociais e culturais, que transformaram a exploração ilegal do território amazônico em um negócio lucrativo em que muito se investe. O Greenpeace, em 2005, realizou um levantamento de corretoras virtuais que ofertavam terras na Amazônia com documentação de legalidade duvidosa em municípios cujos territórios eram de titularidade da União. Assim, a presente pesquisa inicialmente se propõe a realizar uma revisão bibliográfica das informações e estatísticas fundiárias disponíveis sobre a Amazônia Legal e delinear um panorama dos reflexos da grilagem na região. Nesse mesmo sentido, relaciona-se a grilagem com o crescente desmatamento da Floresta: dados do IPAM mostraram que, do desmatamento da Amazônia entre agosto de 2018 a julho de 2019, 35\% aconteceu em terras públicas de proteção florestal ou de povos originários protegidos, como indígenas ou quilombolas. Constata-se que o desmatamento é inerente à prática de grilagem que, perversamente, tenta se mascarar de mera ocupação irregular produtiva e se aproveitar de medidas de regularização historicamente apresentadas pelo governo federal e sancionadas pelo Legislativo, a exemplo das Leis 13.452 e 13.465 de 2017. A pesquisa se volta, então, à abordagem legislativa e à tendência parlamentar no trato da questão. Em 2020, discute-se um novo diploma mais permissivo quanto à regularização de terras ainda mais amplas. O PL 2633/2020 ganhou força no Congresso Nacional com o apoio da bancada ruralista, mas com enfática resistência dos ambientalistas que defendem que a aprovação importaria na legalização do crime da grilagem. Isso porque o PL propõe a regularização de propriedades na Amazônia Legal mais extensas que as tratadas pelas leis predecessoras -que já beneficiavam os pequenos produtores com o procedimento simplificado, nos termos da Lei 11.952/2009 vigente -e sua obtenção por mera declaração do possuidor, sem exigir qualquer tipo de vistoria. Em nota técnica, o Ministério Público Federal aponta inconsistências na proposta de texto legal que, além do evidente prejuízo a indígenas e quilombolas, representa também uma validação da destruição sistematizada, por verdadeiras empresas de ocupação ilegal, de áreas ambientalmente protegidas. A tendência que se observa com a normalização da prática grileira é o gradual desmonte da proteção ambiental, a vulnerabilidade dos povos locais e o encorajamento ao desmatamento ilegal na Amazônia.

Palavras-Chave: Grilagem, Amazônia,

Desmatamento, Congresso Nacional,

Direito Ambiental. 


\section{TERRITÓRIOS DE RESISTÊNCIAS NA LUTA POR UMA CIDADE INCLUSIVA EM LONDRINA - PARANÁ/BRASIL}

O processo de urbanização de Londrina tem como matriz um ordenamento territorial assentado na lógica capitalista que traz no seu cerne a desigualdade, o que gera um padrão segregacionista do espaço urbano. Esse padrão atinge diretamente a população que fica subjugada ao poder que emana da estrutura fundiária urbana concentrada, que se sedimenta com a força exercida pelo interesse do capital imobiliário, o qual interfere na política pública habitacional brasileira, seguido a linha de uma "urbanização segregacionista" (Rolnik, 2014). Os territórios de resistências são a expressão da luta para a superação da visão da habitação como mercadoria, marcada pelo valor de troca, que negligencia e subjuga a moradia como valor de uso. Essa conceção domina o Programa Minha Casa Minha Vida, a atual política pública de habitação no Brasil, a qual foi elaborada dentro de um projeto federal amplo para atacar a crise financeira internacional (2008), assim a política habitacional a nível federal se desvinculou da real necessidade da população local (município) e acabou por privilegiar o grande setor que envolve os capitais de incorporadores e da construção civil. Por conseguinte, o direito a habitação se atrela ao valor de mercado, o que forja a resistência, expressa nas favelas, que demonstra a possibilidade de rompimento/luta contra a homogeneização do espaço como mercadoria via a instauração de um espaço vivido, mesmo na luta desigual, sofrida, das famílias que fazem da moradia precária o seu espaço vivido, de sobrevivência, de luta, de resistência. No território municipal de Londrina essa resistência se expressa na existência de 68 favelas, com 3.890 famílias, sendo que 107 famílias se localizam no espaço rural, totalizando 3.997 (COHAB -Companhia de Habitação de Londrina, 2017). Em relação a demanda habitacional geral, eram 57.492 famílias na lista de espera, em 2018 (COHAB-LD), compreende-se por déficit habitacional as deficiências do estoque de moradias (quantidade disponível), além das moradias que não possuem condições de habitabilidade devido à precariedade das construções ou ausência de infraestrutura urbana. O objetivo que centraliza este artigo é apresentar o cenário da presença destes territórios de resistências no espaço de Londrina, mediante a análise da territorialização das favelas identificadas na investigação, com o escopo de demonstrar que a busca de sobrevivência destas famílias é a expressão da luta pelo direto a cidade. Os resultados da pesquisa indicam que esses territórios de resistência revelam a urgência de se elaborar políticas públicas de habitação que vise uma cidade inclusiva, segura, sustentável e a importância de se debater a política pública segregacionista que não consegue reduzir as desigualdades sociais. A metodologia pautou-se em uma base teórico-metodológico e no levantamento de dados de fontes secundárias e primárias (estudo de campo).

Palavras-Chave: Território, Resistência, Favelas, Inclusão, Cidade.
Ideni Terezinha Antonello Universidade Estadual de Londrina 


\section{DIREITO HUMANO À ÁGUA E SANEAMENTO NO BRASIL: O PAPEL DOS MUNICÍPIOS NA CONCRETIZAÇÃO DO ODS 6}

Cristina Veloso de Castro, UEMG - Universidade do Estado de Minas Gerais

Fausy Vieira Salomão UEMG - Universidade do Estado de Minas Gerais/UPM - Universidade Presbiteriana Mackenzie \& Solange Teles da Silva UPM - Universidade Presbiteriana Mackenzie
Os Objetivos do Desenvolvimento Sustentável (ODS) se inserem em uma logica de engajamento político de governos conduzindo a adoção de estratégias de planejamento e implementação de políticas públicas. Quando associados a instrumentos internacionais, como tratados sua interpretação passam a ter um caráter vinculativo. Esse e o caso do direito de todos ao acesso à água e saneamento, reconhecidos como um direito humano universal. Entretanto pode-se indagar como alcançar a concretização desses direitos. Assim, mesmo que os Estados nacionais tenham assumido obrigações internacionais, acaba sendo na esfera local que esses direitos são implementados. No caso brasileiro, o município tem um papel primordial na efetivação do direito de todos ao acesso à água e saneamento. O federalismo brasileiro divide o Estado em União, Estado-membro e município. A inovação e aprofundamento na descentralização adotados no Brasil a partir de 1988 é bastante salutar à medida que confere dignidade à cidade brasileira, impede ingerências indevidas no município por parte da União e do Estado-membro e dá ao cidadão mais uma opção de participação. A Constituição brasileira estabelece um modelo democrático participativo que tem como regra o regime representativo, todavia garante ao cidadão meios diretos de atuação e reivindicação. Especificamente quanto ao direito humano ao saneamento básico, a Constituição define ser esse de responsabilidade municipal mediante o estabelecimento de regras gerais por parte da União e regionais por parte do Estado-membro. Todavia, segundo números do Sistema Nacional de Informações sobre Saneamento (SNIS) e que se referem ao ano de $2018,47 \%$ dos brasileiros não têm acesso a sistemas de esgotamento sanitário, 16\% não têm acesso a água tratada e $46 \%$ do esgoto gerado não recebe tratamento. Em 15 de julho de 2020 o Brasil promulgou a Lei n. 14.026 que atualiza o marco legal do saneamento básico almejando a universalização do saneamento básico e acesso a água potável. A nova legislação, entre várias medidas, estabelece metas a universalização do saneamento básico e estimula a cooperação entre os entes federativos e reconhece a necessidade de realização de consultas e audiências públicas, de forma a garantir a transparência e a publicidade dos atos. A presente pesquisa almeja, então, a análise dos instrumentos de participação do cidadão na definição das políticas públicas de acesso à água e ao saneamento básico, bem como a contribuição delas na efetividade desse direito humano e cumprimento da Agenda 2030 para atingimento das metas propostas pelos 17 Objetivos do Desenvolvimento Sustentável (ODS).

Palavras-Chave: Direitos Humanos, Água, Saneamento, Sustentabilidade, Município. 


\section{A PROTEÇÃO DA BIODIVERSIDADE BRASILEIRA À LUZ DOS OBJETIVOS DO DESENVOLVIMENTO SUSTENTÁVEL (ODS)}

Os Objetivos do Desenvolvimento Sustentável (ODS) não tenham caráter obrigatório e se inscrevem em uma lógica de comprometimento político de governos. Todavia, eles propiciam a adoção de estratégias de planejamento e implementação de políticas e podem passar a ter um caráter vinculativo, uma vez que tenham sido inseridos em tratados internacionais, como é o caso da Convenção da Diversidade Biológica (CDB) e seus protocolos. Em realidade, os ODS oferecem uma oportunidade única para revigorar a agenda de pesquisa em prol da sustentabilidade (Leal Filho e al., 2018), que pode ser realizada a partir de três eixos: da compreensão da dinâmica do planeta, da integração da ciência de forma interdisciplinar para propiciar o desenvolvimento sustentável global e das transformações em direção a sustentabilidade a longo termo (Future Earth Strategic Research Agenda, 2014).

Considerando-se especificamente a proteção da biodiversidade -que se encontra diretamente no centro de diversas atividades econômicas -, trata-se de: a) compreender sua dinâmica - do local ao global -e as interações existentes entre as lógicas de proteção dos genes, espécies e ecossistemas a partir da relação entre a proteção dos direitos humanos e conservação da biodiversidade; b) analisar de forma interdisciplinar as perspetivas para sua proteção, sob o prisma da pluralidade dos espaços normativos e da fragmentação do direito ambiental internacional, indagando-se sobre a concretização de compromissos assumidos internacionalmente pelos Estados nacionais em dire- ção ao longo termo para a proteção da biodiversidade.

O objetivo do presente trabalho é realizar uma análise da proteção da biodiversidade no Brasil à luz dos ODS e os desafios para sua concretização. Essa análise, ao mesmo tempo histórica e prospetivas, a partir da promulgação da Constituição Federal de 1988, da ratificação da CDB, bem como de seus protocolos e, de textos do direito ambiental internacional, tem em sua centralidade a proteção da biodiversidade a parir de 3 (três) eixos estratégicos e complementares: (1) o das relações entre direitos humanos e biodiversidade; (2) o de conceitos emergentes tal qual o de solidariedade ecológica e; (3) o das normas jurídicas que asseguram a conservação e uso sustentável da biodiversidade, ecossistemas saudáveis e inclusão social e sua efetividade. Se por um lado, teoricamente há uma convergência entre direitos humanos e proteção da sócio e biodiversidade, bem como a compreensão da necessidade do estabelecimento de uma solidariedade ecológica, na prática observa-se que assegurar a efetividade da proteção da biodiversidade em face a governos autoritários tem sido uma verdadeira batalha que se dá igualmente no campo jurídico pautada pela resiliência e resistência. Assim, apenas com o fortalecimento da relação entre ciência, direito e sociedade haverá a possibilidade da construção de uma agenda para a implementação dos ODS em prol da conservação da biodiversidade.

Palavras-Chave: Biodiversidade, Conservação, Efetividade, Direitos Humanos.
Solange Teles da Silva UPM - Universidade Presbiteriana Mackenzie 


\section{DIPLOMACIAAMBIENTAL \\ - EFETIVIDADE DA RESPONSABILIDADE AMBIENTAL, GOVERNANÇA, GESTÃO DE SERVIÇOS ECOSSISTÊMICOS, PROTEÇÃO DA AMAZÔNIA}

Karla Karolina Harada

Souza

PUC-SP
Diante dos conflitos de interesses e pressões econômicas e políticas que compõem a problemática ambiental, aliados à pluralidade de discursos, com diferentes linguagens e visões de mundo, observamos imperar divergência onde deveria haver convergência para a solução de problemas comuns; daí a necessidade da diplomacia ambiental, que promova diálogo, através do aprendizado e trocas de conhecimentos (educação/ informação), possibilitando a harmonização/sintonia onde só ocorrem dissonâncias, gerando empatia, compreensão e abertura para cooperação e trabalho conjunto. Danos ambientais não conhecem fronteiras, delimitações geográficas não são reconhecidas pela Natureza, bem com os serviços ecossistêmicos não estão circunscritos dentro de uma única jurisdição. Assim, se um Estado não pode estar indiferente ao que ocorre com seus vizinhos, mas neles não pode intervir (princípio da soberania), é necessária a construção de diálogo de cooperação, pautado no princípio geral da solidariedade, para construir uma solidariedade ecológica, fundada no entendimento de que todos dividimos e dependemos do mesmo ecossistema. Amazônia, mesmo que não seja bem comum da humanidade, seus serviços ecossistêmicos o são, havendo interesse e necessidade comum da humanidade, sendo, portanto, importante a sua valoração. Devemos ampliar a disseminação das informações, promover educação ambiental e fiscalizar a transparência e publicidade de dados. Precisamos não apenas de compliance, mas também de auditoria. A diplomacia ambiental só conseguirá ser desenvolvida num cenário de reponsabilidade comum, reciprocidade, confiança e boa-fé, onde o princípio/dever da informação compõe due diligence. 0 presente estudo busca convergir estes conceitos de diplomacia ambiental (de conexão/articulação internacional) com as transformações em uma sociedade da informação digital, na era do antropoceno, buscando novos diálogos e formas de proteção e gestão dos serviços ambientais do planeta. Esta pesquisa busca ampliar o pensamento sobre diplomacia-gestão-tecnologia aplicadas à tutela ambiental, propondo uma estrutura de digital continuum: modelo conceitual ancorado em uma extremidade pelas informações e dados digitais e na outra pela pelos serviços digitais e comunicação e análise de dados. Discutiremos os benefícios e experiências acumuladas sobre tecnologias/sistemas de informação geográfica (TIGs/ SIGs), identificando os instrumentos de grande potencial para construção de uma diplomacia ambiental, possibilitando mapeamento e análise de dados ambientais em digital continuum framework, permitindo visualização/organização de dados, articulação de ações, identificação/avaliação de danos, para a gestão e valoração de serviços ecossistêmicos e respostas efetivas.

Palavras-Chave: Diplomacia Ambiental,

Governança Ambiental Nacional e Internacional, Efetividade Da Responsabilidade Ambiental, Serviços Ecossistêmicos, Proteção

Da Amazônia. 


\section{DIREITOS HUMANOS, DESLOCAMENTOS AMBIENTAIS E AUMENTO DO NÍVEL DO MAR: UMA REALIDADE EMERGENTE}

Por consequência das ações e decisões humanas sobre a natureza, o ambiente global tem demonstrado ao longo dos anos sucessivos sinais de exaustão, cujos efeitos e consequências projetam-se para diversas áreas. Um dos desdobramentos dessa crise ecológica instalada no Antropoceno é o deslocamento forçado de pessoas (ou mesmo comunidades inteiras), em magnitude cada vez mais elevada, devido a fatores relacionados ao ambiente. A subida do nível do mar é um dos vários motivos determinantes dessa migração forçada por razões ambientais e representa já um cenário factível de vir a ser sentido nas zonas costeiras em todo o globo. Esse contexto revela a necessidade premente de se introduzir na agenda política internacional mecanismos que assegurem tratamento adequado aos direitos humanos dos deslocados ambientais, que abranjam não apenas a adoção de medidas que antecipem situações ambientais alarmantes causadoras de migrações forçadas (em massa), mas também que prevejam ações tendentes a prevenir a ocorrência de deslocamentos humanos e, sobretudo, que forneçam condições dignas para acoIhimento e proteção jurídica adequada a essa categoria de pessoas. É pensar, portanto, em ferramentas de prevenção, de reação e, também, de reconstrução, sob a ótica da responsabilidade de proteger, e nos mecanismos à disposição dos Estados para fazer valer os com- promissos internacionais para com a tutela do ambiente e dos direitos da pessoa humana. Diante desse contexto, o estudo ora proposto intenta evidenciar a reflexão urgente e necessária relativa à proteção dos direitos humanos dos deslocados ambientais, por meio da abordagem dos instrumentos jurídicos existentes no âmbito internacional a partir de uma releitura possível do sistema jurídico internacional de proteção do ambiente e dos direitos humanos, de modo a fornecer soluções jurídicas possíveis para assegurar proteção efetiva àquelas pessoas sujeitas a deslocamentos por aumento do nível do mar. É preciso ter em mente que o deslocamento ambiental envolve um cenário complexo e dinâmico, pelo que não se afigura aceitável estar à mercê do desenvolvimento e da entrada em vigor de um sistema específico para conferir algum tipo de proteção jurídica a quem esteja na iminência ou já seja vítima das nefastas consequências a essa realidade atrelada. É por isso que um olhar mais humanizado para o problema e uma resinificação dos compromissos internacionais para com os direitos humanos e o ambiente é medida que se impõe. Uma conjuntura dessa ordem possibilitaria não apenas que a situação de vulnerabilidade a que estão expostas essa categoria de pessoas fosse de fato tutelada, mas privilegiaria, sobretudo, uma resposta efetiva e duradoura para a salvaguarda de seus direitos humanos e ambientais.

Palavras-Chave: Crise Ecológica, Direitos Humanos, Deslocados Ambientais, Proteção Jurídica.
Daniele Galvão De Sousa Santos

Universidade De Coimbra 
Ref.: 3 I 3CEDHM22020

\section{RACISMO AMBIENTAL E ACESSO À JUSTIÇA PELA VIA DOS DIREITOS: UMA REFLEXÃO SOBRE O DESASTRE AMBIENTAL EM BRUMADINHO E OS DESAFIOS PARA A CONCRETIZAÇÃO DA AGENDA 2030}

Adriana Goulart de Sena

Orsini,

Nancy Vidal Meneghini, Igor Sousa Gonçalves \& Juliana Castro Sander Morais

Universidade Federal de Minas Gerais
O desastre ambiental ocorrido em 25 de janeiro de 2019 em Brumadinho, na região metropolitana de Belo Horizonte, com o rompimento da Barragem $1 \mathrm{da}$ Mina Córrego do Feijão, da mineradora multinacional Vale S.A., demanda reflexão e agir face ao modelo econômico e as atividades extractivista-predatórias que as empresas mineradoras desenvolvem, além dos impactos socioambientais.

Dados revelados no relatório realizado pelo grupo Política, Economia, Mineração, Ambiente e Sociedade (PoEMAS), intitulado "Minas não há mais: avaliação dos aspetos econômicos e institucionais do desastre da Vale na bacia do rio Paraopeba" demonstra que os maiores afetados pela tragédia foram a população negra e de baixa renda.

A partir dos dados estatísticos fornecidos pelo referido relatório, acerca dos impactos econômicos e ambientais do desastre ambiental e sobre o perfil de raça e renda da população afetada, torna-se necessária a interpretação e problematização desses dados. Em outras palavras: é preciso questionar as razões pelas quais os maiores afetados pela tragédia ambiental foram a população negra e de baixa renda.

Para problematizar o tema aplicar-se-á a noção de Racismo Ambiental, explicada e desenvolvida por Razmig Keucheyan em sua obra "La nature est un champ de bataille". De acordo com o conceito nela desenvolvido, as grandes empresas (as mineradoras, in casu), considerando os riscos ambientais de seu empreendimento, optam por depositar a carga de impactos negativos (as barragens de rejeitos, no caso) em localidades onde residem e trabalham os grupos étnicos mais vulneráveis em multidimensões.

Essa opção por depositar a carga dos impactos negativos nas regiões ocupadas pelos grupos mais vulneráveis também está relacionada com outro conceito nuclear para a compreensão deste e outros fenômenos sociais: o acesso à justiça pela via dos direitos, o qual, em suma, engloba duas dimensões: "a ampliação da efetivação dos direitos e a ampliação da possibilidade de participação na conformação dos direitos" (AVRITZER; MARONA; GOMES, 2014). Os grupos socialmente mais vul- 
Ref.: 313CEDHM22020

RACISMO AMBIENTAL E ACESSO À JUSTIÇA PELA VIA DOS DIREITOS: UMA REFLEXÃO SOBRE O DESASTRE AMBIENTAL EM BRUMADINHO E OS DESAFIOS PARA A CONCRETIZAÇÃO DA AGENDA 2030 neráveis encontram maiores dificuldades para garantir o acesso à justiça pela via dos direitos, o que estimula ainda mais a prática do racismo ambiental. Os indivíduos que compõem os referidos grupos representam um contingente juridicamente invisível, a quem o acesso ao judiciário e o acesso à conformação de seus próprios direitos é sistematicamente negado, especialmente em razão de seu padrão de organização e de atuação. A situação de racismo ambiental e de falta de acesso à justiça pela via dos direitos, a qual a população negra e de baixa renda de Brumadinho se encontra caminha em direção oposta ao ODS10 da Agenda 2030: redução das desigualdades dentro dos países.

Palavras-Chave: Brumadinho, Racismo

Ambiental, Acesso à Justiça pela Via

dos Direitos, Agenda 2030, ODS 10.
Adriana Goulart de Sena

Orsini,

Nancy Vidal Meneghini, Igor Sousa Gonçalves \& Juliana Castro Sander Morais

Universidade Federal de Minas Gerais 
Ref.: 325CEDHMI 2020

\section{CIDADES INTELIGENTES: \\ A POLÍTICA DE RESÍDUOSSÓLIDOS E A NECESSIDADE DE IMPLEMENTAÇÃO DE POLÍTICAS PÚBLICAS SUSTENTÁVEIS - ESTUDO DE CASO P.}

Natália Mayumi Gonçalves Miyaza

\& Lucas Brito Silveira

Santos

Universidade Presbiteriana Mackenzie
O presente painel tem por objetivo apontar a responsabilidade do Estado com relação ao descarte de resíduos sólidos, sendo, portanto, observadas as regras ambientais e administrativas. Ilustrando a necessidade de desenvolvimento de programas específicos, estudamos o modelo de coleta e gerenciamento de lixo da cidade de Paulínia (SP), evidenciando o desenvolvimento de programas inteligentes, alinhado a necessidade urbana e a preservação ambiental, com a correta aplicação das diretrizes da política nacional de descarte de resíduos.

Objetiva-se demonstrar a importância e o impacto do desenvolvimento de políticas públicas que vão desde a coleta seletiva até o processo de descarte final em locais apropriados, dando maior ênfase ao sistema de coleta subterrânea desenvolvida em Paulínia (SP). Em observância das normas da CF/88 (incisos I e V do art. 30), e a PNRS (Lei 10.305/10) emerge a necessidade dos municípios de criar regras especificas para o descarte, ou incentivar a criação de cooperativas locais (CAIXETA, 2011). Paulínia se destaca pelo plano colaborativo que inclui a coleta porta a porta, convencional, e o sistema de coleta por container subterrâneo, sistema já utilizado em diversos países da Europa sendo, portanto, a primeira cidade da América Latina a desenvolver tal programa.

Trata-se de projeto de análise da legislação vigente, de pesquisa bibliográfica como livros, artigos, dissertações e teses que abordam a temática do lixo. Destacam entre estas as que focalizam a implantação de projetos como o da cidade de Paulínia, no interior do estado de São Paulo. Realiza-se, portanto, um estudo do desenvolvimento das políticas públicas de descarte de resíduos sólidos.

Este painel se organiza destacando dois aspectos de relevância. O primeiro se compromete com a análise dos conceitos jurídicos sobre lixo. O segundo aspecto se refere à questão da implantação de projetos do Poder Público. Tomamos como exemplo em especial o projeto da cidade de Paulínia, salientando a relevância da conscientização por parte dos cidadãos sobre a questão ecológica e, paralelamente, a 
CIDADES INTELIGENTES:A POLÍTICA DE RESÍDUOSSÓLIDOS E A NECESSIDADE DE IMPLEMENTAÇÃO DE POLÍTICAS PÚBLICAS SUSTENTÁVEIS - ESTUDO DE CASO P. necessidade de adequação da gestão pública. Graças ao desenvolvimento dessa pesquisa pode-se reconhece a positividade do programa; contudo também se evidencia que grande parte dos problemas na execução e desenvolvimento mais amplo são falhas da administração pública.

De forma igual, há necessidade de maior envolvimento da comunidade, o que pode ser feito tanto pela iniciativa pública quanto pela iniciativa privada. Há que reconhecer que a preservação ambiental infelizmente ainda se coloca como uma realidade romantizada, muitas vezes resumida ao simples plantio de árvores (ainda que, aliás, uma necessidade imperiosa num país como o nosso, de regiões predominantemente quente) ou a reutilização de garrafa pet para artesanato (ainda que se verifique a prática de coleta seletiva se bem que tímida no conjunto da comunidade; ela ocorre em condomínios fechados.

Palavras-Chave: Sustentabilidade, Cidades Inteligentes, Descarte Responsavel, Cidades Sustentáveis, Ecofriendly.
Natália Mayumi Gonçalves Miyaza

\& Lucas Brito Silveira

Santos

Universidade Presbiteriana Mackenzie 
Thaïs de Mendonça Jorge \& Francisco Verri

Universidade de Brasilia

Ref.: 352CEDHMI 2020

\section{VALORES NAS NOTÍCIAS, PATRIMONIALISMO E DIREITOS SOCIAIS}

Herbert Gansdefiniu os valores duradouros que os jornalistas carregam na prática profissional. Incorporados ao julgamento da importância dos acontecimentos (Gans, 2004), esses valores conduziriam a produção noticiosa, orientando sobre o que seria publicável. O jornalismo objetivo, condicionado a valores como imparcialidade, neutralidade e compromisso com a verdade, disciplinou a práxis profissional e se normatizou como modelo, junto a valores éticos compartilhados e convenções. Os valores constituiriam um mapa cultural, envolvendo certa concepção de mundo -a dos jornalistas (Cook, 2011; Wolf, 1994), o que se reflete na própria sociedade. Ao estudar a notícia em quatro veículos, na década de 1970, Gans identificou nas notícias dois tipos de valor: 1) valores tópicos e2) valores duradouros. Os primeiros seriam opiniões sobre atividades do momento, enquanto os duradouros se definiriam como aqueles que se mantêm durante longo tempo. Etnocentrismo, democracia altruísta, capitalismo responsável, pastorialismo bucólico, individualismo, moderação --são valores de longa duração que o autor apontou nas notícias, derivados da própria sociedade norte-americana. Os valores duradouros propostos por Gans podem ser compreendidos como valorações inerentes ao comportamento e à organização da sociedade em que o veículo e os profissionais estão inseridos. Esses valores, conforme Cook (2011, p. 207), revelam "não simplesmente o entendimento que os jornalistas têm de como o mundo funciona, mas também sugerem uma concepção de como o mundo deve funcionar". No Brasil, a dinâmica social afastou o ideal de democracia altruísta e de capitalismo responsável para se concentrar em características importadas da colonização portuguesa (Faoro, 1977). Interagindo com as especificidades de uma formação nacional marcada pelo individualismo, patrimonialismo e cordialidade (Faoro, 1977, Holanda, 2006), os valores duradouros brasileiros se sustentam sob uma agenda liberal de supervalorização do privado (Barros, 2002), remetendo ao processo de consolidação da esfera pública e da estruturação das instituições no Brasil. O presente paper sugere a ideia de domínio do privado como valor duradouro na sociedade brasileira, normatizado na produção noticiosa. A partir da análise de chamadas de primeira página dos jornais Folha de S. Paulo e O Globo, a proposta é compreender a submissão do público ao privado como valor de longa duração entre os acontecimentos noticiáveis. Os resultados da análise sugerem que o valor duradouro da predominância de um olhar privatista reafirma-se nos veículos de comunicação e ganha as capas em $75 \%$ das edições, estampando notícias relacionadas à política, governo e mercado financeiro. Vemos, então, que isso se liga às raízes do patrimonialismo no Brasil, componente da dominação tradicional apontada por Weber (1991). O tema se relaciona à forma pela qual se estruturou a sociedade brasileira em termos de direitos e como se desenvolve a luta de classes no país.

Palavras-Chave: Notícia, Valor, Público, Privado, Patrimonialismo. 


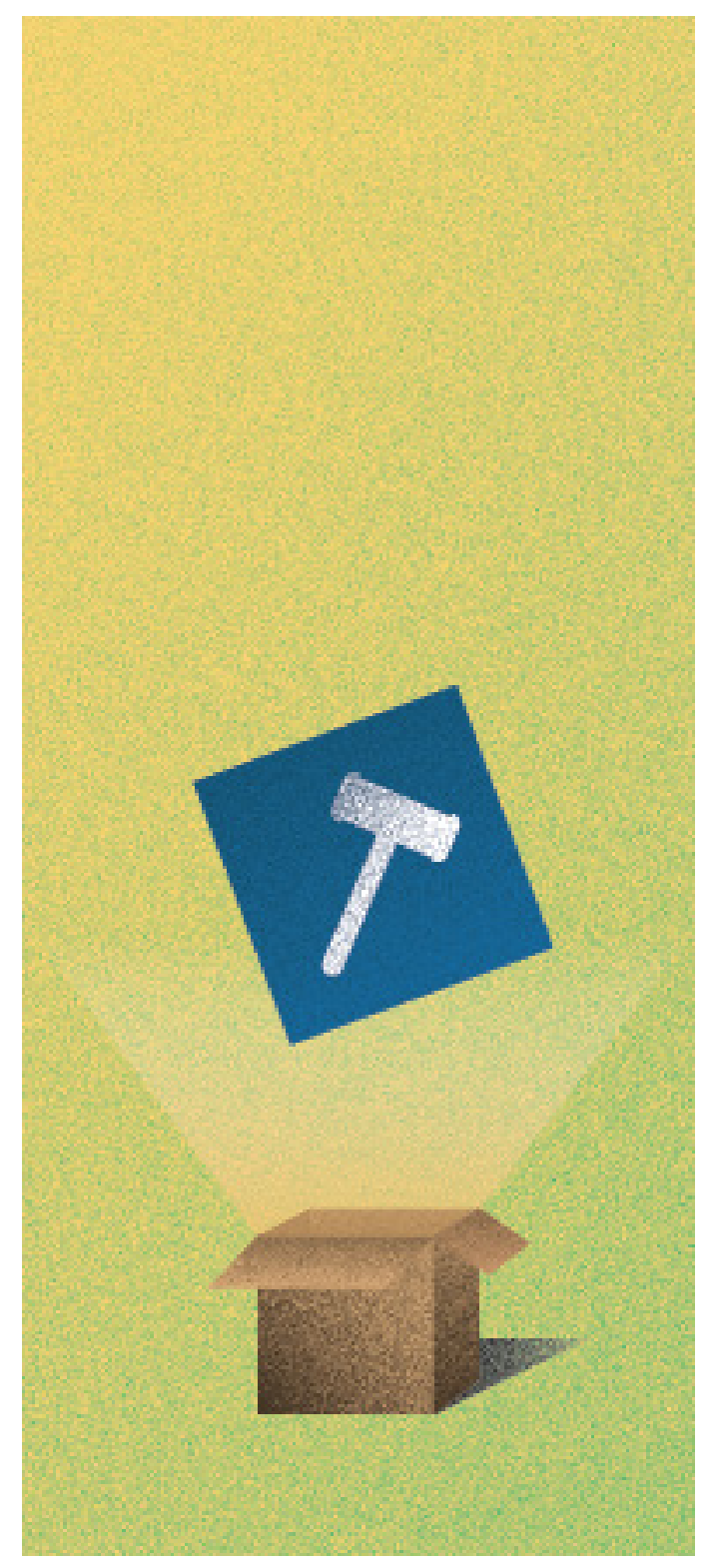

\section{ODS 16 PAZ, JUSTIÇA E INSTITUIÇC̃̃ES EFICAZES}




\section{JOSÉ SARAMAGO: OS DIREITOS E OS DEVERES HUMANOS}

A Declaração Universal dos Direitos Humanos, em seu artigo XXV, estabelece que "Todo ser humano tem direito a um padrão de vida capaz de assegurar-lhe, e a sua família, saúde e bem-estar, inclusive alimentação, vestuário, habitação, cuidados médicos e os serviços sociais indispensáveis [...]" (ONUBR, 2009, p.13). No entanto, a desigualdade social gerada pela globalização e o deslocamento do poder para quem detém o acesso à informação são desafios atuais e que são discutidos em várias obras de Saramago. Assim, Saramago encaminha seus leitores para a reflexão sobre o atuar do ser humano -direitos e deveres -num mundo globalizado. A pesquisa teve por objetivo buscar, em algumas das obras de José Saramago, citações que remetam à discussão dos direitos humanos na sociedade globalizada. 0 trabalho vale-se da pesquisa qualitativa em que são consideradas e analisadas publicações relativas ao tema globalização e direitos humanos. Saramago, através de seus romances, busca fazer com que seus leitores se questionem e questionem o mundo em que se vive. Assim, Saramago, sempre muito realista, afirma que "Há que ter em conta que a distância entre os que têm e os que não têm só tem paralelismo com a distância que existe entre os que sabem e os que não sabem, e os que não têm são os que não sabem: são condenados desde que nascem." (SARAMAGO, 2006, apud AGUILERA, 2010, p. 496497) e "Estamos rodeados de imagens que nos mostram que o mundo está mal, mas nós estaremos bem pior no dia em que nos tivermos acostumado tanto à violência que a consideremos natural -ou cultural, se assim preferirem." (SARAMAGO, 2011, p. 93). Neste sentido, ele alerta, no discurso pronunciado no Banquete Nobel em 10 de dezembro de 1998, que "As injustiças multiplicam-se no mundo, as desigualdades agravam-se, a ignorância cresce, a miséria alastra." (SARAMAGO, 1998, p. 22-23). E convoca os cidadãos para a ação: "Com a mesma veemência e a mesma força com que reivindicamos os nossos direitos, reivindiquemos também o dever dos nossos deveres. Talvez o mundo possa começar a tornar-se um pouco melhor." (SARAMAGO, 1998, p. 22-23). Portanto, não basta falar de direitos, mas discutir sobre os deveres de cada ser humano. A Fundação José Saramago tem dado continuidade a este discurso e em 16 de novembro de 2019 tornou publica, em seu website, a Carta Universal dos Deveres e Obrigações dos Seres Humanos. Este documento, desenvolvido por especialistas de diferentes áreas, com o apoio da Universidade Autônoma do México, foi, em 2018, apresentado a diferentes Comissões da ONU e entregue em mãos ao seu Secretário-Geral, António Guterres. A pesquisa conclui que, na visão de Saramago, a humanidade perdeu a razão e que, neste mundo globalizado, verifica-se o aumento simultâneo da riqueza e da pobreza. A humanidade se recusa a examinar os erros passados e produz novos erros.

Palavras-Chave: Direitos Humanos, Deveres e Obrigações dos Seres Humanos, José Saramago, Globalização, Humanidade.
Maria Irene da Fonseca e Sá Universidade Federal do Rio de Janeiro 
Milena de Bonis Faria

Universidade Autónoma de Lisboa

Ref.: 006CEDHMI 2020

\section{A PAZ E A SOLUÇÃO DE CONFLITOS POR UMA ÓTICA MULTIDISCIPLINAR, INTERDISCIPLINAR ETRANSVERSAL}

A mudança de perspetiva dos conflitos sob a ótica do judiciário tem respaldo na possibilidade de ser uma ferramenta de aplicabilidade infinita, necessitando assim, um ambiente que propicie o empoderamento das partes e da sociedade tornando-os pessoas autodeterminadas. O uso de novas tecnologias, novos achados científicos da neurociência por meio do neuro feedback são imprescindíveis no auxílio da justiça e direito, calcado em ir ao encontro dos anseios de uma sociedade globalizada, transfronteiriça, interconectada, gerando sentimento de justiça e paz na sociedade atual. $O$ aprimoramento da percepção dos fatos, dos atos, o respeito, quando trabalhados com atenção centrada nas partes, na família, na lei, na comunidade e sociedade como um todo propicia um mundo mais pacifico. A complexidade que envolve o fenômeno da neurociência tem como força motriz o sistema nervoso humano. Assim, desde sempre o ser humano tenta desvendar a complexidade e os mistérios que o cercam, atualmente subsidiada pelo avanço tecnológico galgou novos patamares acerca do comportamento humano, trazendo a possibilidade do neurofeedback, gerando a possibilidade de uma alteração mental voltada para um ambiente mais pacifico através de treinamento mental, gerando alteração (biofeedback) nas pessoas, reiterando os (achados) pós guerra e oportunizando um novo ambiente para as pessoas. Proporcionando, um upgrade do cidadão enquanto "ser humano", antes de qualquer outra questão, auxiliando no alcance máximo da dignidade humana, através uso e gozo não só de seus direitos, bem como na mesma proporção o cumprimento de seus deveres. Urge a necessidade de convergir diferentes ramos da ciência para a construção de um todo "mundo" mais pacífico. A adoção de critérios voltados para educação, orientação das partes e da sociedade no intuito de ampliar não só métodos de resolução de conflitos, como também torná-los mais eficaz, esse tem sido o alicerce do judiciário como meio de minimizar o aumento das demandas no judiciário. O desenvolvimento o presente resumo expandido, observou, quanto a sua abordagem o método dedutivo e método dialético e ainda utilizou método histórico e o comparativo, bem como estudo de casos, realizados através de pesquisa documental e bibliográfica.

Palavras-Chave: Conflitos, Direito, Conciliação, Neurociencia, Neurofeedback. 


\section{PARCERIAS ENTRE ÓRGÃOS PÚBLICOS E PRIVADOS NA EFETIVAÇÃO DE PROJETOS DE MEDIAÇÃO DE CONFLITOS}

Efetivação de parcerias entre setores públicos e privados revelam êxito na busca pelo alcance dos objetivos do milênio. Uma destas experiências é o funcionamento do Projeto Laços de Família -conhecer para amar, executado através da parceria entre a Defensoria Pública do Estado do Ceará e o Centro Universitário INTA-UNINTA desde setembro de 2014. Os principais objetivos do Projeto são: oferecer atividades de extensão, estágio e responsabilidade social para comunidade acadêmica do Centro Universitário INTA e para a população do município de Sobral; potencializar a atuação da Defensoria Pública na cidade de Sobral, notadamente na concretização dos direitos ligados à família; Intensificar ações de solução extrajudicial de conflitos, com vistas à promoção da paz social e prevenção de conflitos, notadamente de natureza familiar; potencializar o exercício e o cumprimento das funções institucionais da Defensoria Pública, com vistas à promoção de direitos humanos, à difusão da cidadania e à defesa dos direitos fundamentais de seu público alvo. O publico prioritário é população hipossuficiente que procura a Defenso- ria Pública com demandas envolvendo direito de família. Inicialmente o território prioritário era a população do Bairro D. Expedito e adjacências, nas proximidades da sede do UNINTA, onde estava instalado o projeto. Cinco após o início do funcionamento o projeto conquistou sede própria, com melhores condições de funcionamento, localizada no centro da cidade, com possibilidades de atender um número maior de sobralenses. A experiência revela o êxito da parceria na busca da efetivação dos objetivos de desenvolvimento do milênio propostos pela Organização das Nações Unidas Considera-se também prioridade as Escolas Públicas Pe. Osvaldo Chaves, Sinhá Saboia e Escola Profissionalizante, através da parceria com o projeto Amigos da Paz que promove ações de mediação na escola Tem como missão a promoção de ações de inclusão social e efetivação de cidadania por meio do exercício pleno dos direitos ligados à identidade e ao direito à família, através da oferta à comunidade de Sobral ações de mediação familiar com vistas a diminuir os reflexos jurídicos e sociais advindos de conflitos familiares.

Palavras-Chave: Parceria, Público, Privado, Mediação de Conflitos, Paz.
Emanuela Vasconcelos Leite Defensoria Pública do Estado do Ceará \& Cláudia dos Santos Costa Projeto Laços de Família/ UNINTA 
Ref.: 0I0CEDHM42020

\section{MEDIAÇÃO COMUNITÁRIA COMO ESTRATÉGIA DE PACIFICAÇÃO NO MUNICÍPIO DE FORQUILHA-CE}

Cláudia dos Santos Costa \& Sabrine Vasconcelos Guimarães

Prefeitura Municipal de Forquilha
O Município de Forquilha está localizado na zona norte do Estado do Ceará. Configura-se como um município de pequeno porte, com 21.786 habitantes. Como a maioria da população brasileira historicamente conflitos que poderiam ser resolvidas por outras estratégias são encaminhadas ao poder judiciário, gerando assim um acúmulo de demandas e um contexto de responsabilização a uma terceira pessoa, a um juiz, pela resolução de seus conflitos. Neste sentido a gestão municipal empreendeu uma parceria com o Ministério Público do Ceará na implantação de um núcleo de mediação comunitária. A razão da existência deste programa junto ao Ministério Público do Ceará é sua vocação que possui de ser protagonista da busca permanente de mecanismos extrajudiciais de solução de conflitos. A mediação é uma das técnicas de administração pacífica de conflitos que busca a pacificação social, propiciando o fortalecimento dos vínculos comunitários, bem como o desenvolvimento de uma cultura de paz. O Núcleo de Mediação Comunitária tem como objetivo contribuir para a redução da violência, pela solução pacífica dos conflitos; contribuir para a melhoria da qualidade de vida da comunidade; incentivar a prática do serviço voluntário na comunidade; instituir permanente hábito de estudos e pesquisas, visando à implantação de projetos que promovam a cultura da paz; orientar a comunidade sobre direitos e deveres dos cidadãos, dentre outros. O núcleo foi implantado em 2018 sendo seu principal desafio a formação de mediadores voluntários e a sensibilização da população da eficácia da mediação comunitária na solução dos conflitos. A experiência revela que a população tem compreendido da importância e da relevância da mediação comunitária na construção de processos de paz no município de Forquilha, todavia aponta a necessidade de maior divulgação entre os moradores, seja para adesão de mediadores voluntários, seja para busca dos serviços da mediação comunitária. De facto, o maior êxito desta experiência é a construção da parceria entre gestão municipal e Ministério Público Estadual na busca pela construção de caminhos de paz.

Palavras-Chave: Mediação Comunitária, Resolução de Conflitos, Redução da Violência, Paz, Parcerias. 
Ref.: 024CEDHM22020

\section{APAC'S: \\ A SOCIO-LEGAL ANALYSIS FOR THE CREATION OF PUBLIC POLICIES TOWARDS RESOCIALIZATION}

Law is a science that aims to contribute to the evolution and development of society, analyzing human behavior and social life.The Federal Constitution of 1988, the main Brazilian legal norm, known as the Citizen Constitution, provides for fundamental rights and guarantees, especially with regard to citizenship and the dignity of the human person. It happens that so much guarantor sometimes leads to a violation of other legal norms, creating chaos as is well known and notorious in the Brazilian penal system.

The penal system should re-socialize individuals who may commit crimes, to reinsert them in society and guarantee social peace.This, the development of a public policy, provided with resources, could prescribe forms of behavior and attitudes to be taken by the State and by the private initiative, encouraging the work of prisoners, with the aim of re-socializing them and generating wealth for the country.

Accordingly, the Association of Assistance to Convicts (APAC) Itis the ideal model for the true re-socialization of individuals who have committed a crime, given that the re-educated people work, study and become professional, thus avoiding idleness.

It is at this point that the work carried out by the prisoners deserves to be highlighted, since part of the defenders of the human rights chain argues that work should not be carried out while serving sentences.

The central point of the work is not really the lack of criminal establishments, but of criminal establishmentsthat really provide a change in the thinking of those who commit crimes.

The method applied today is flawed, and no longer deserves a speech about why it is flawed.

The discussion must be based on the alternatives so that the method can be changed and so that at each stage of serving the sentence, the re-educator can be transformed into a better individual.

This, the present is intended to address how the guarantee interferes in the enforcement of existing criminal laws and what new methods can be used to improve the Brazilian penal system.

Keywords: Law, Resocialization, Criminal Law.
Renata Caroline Pereira de Macedo

Pontifícia Universidade Católica de Minas Gerais 


\section{PROPOSTAS DE MODELOS DE SOLUÇÕES DE PROBLEMAS FUNDIÁRIOS A PARTIR DE DADOS DOS ÓRGÃOS PÚBLICOS DA CIDADE DE SÃO CARLOS - SP}

Raquel Lopes Queiroz

\section{Chacur}

Universidade Federal de São Carlos SP Brasil \& Universidade de Coimbra - Portugal
Esta tese aborda a problemática da litigiosidade das ações judiciais de conflitos fundiários urbanos e propõe modelos de soluções dos mesmos, nos órgãos públicos e delegados. Os objetivos foram identificar e analisar os conflitos undiários urbanos institucionalizados distribuídos nos órgãos públicos no Município de São Carlos SP, mapear a localização geográfica e sugerir modelos de Mediação. O método utilizado foi a abordagem quanti-qualitativo, com análise descritiva de dados, com observação e ação de pesquisa empírica, na linha transversal, no período de cinco anos dos processos da base de dados destes órgãos. Foi utilizado a plataforma Excel para tabular os dados em categorias previamente elaboradas, por assuntos de interesse da temática urbanística, compondo um conjunto de resultados do processo judicial, de cada órgão. Esse novo procedimento metodológico demonstrou uma sequência lógica das etapas de coleta de dados do rito procedimental, em cada órgão público, com suas especificidades apresentadas, discutidas e contempla o aprofundamento de assuntos, com a vantagem de chegar ao diagnóstico da efetividade dos processos e eficiência das gestões institucionais. Para o registro da localidade de ocorrência de cada conflito foi utilizado a plataforma de Sistema de Informações Geográficas, a qual representa a união de hardware e de software capazes de armazenar, analisar e processar dados georreferenciados, contendo os arquivos digitais no formato raster (imagens de satélite) ou vetorial (pontos, linhas ou polígonos), com o suporte de utilização do software Google Earth PRO, para a produção de mosaicos, com o desenho manual de recortes aleatórios da cartografia. Os resultados evidenciam a difusão da ilegalidade ambiental e urbanística da área de estudo mostrando a necessidade de mudanças de paradigmas teóricos da propriedade, uma nova teoria de conflito e modelos de resolução de conflitos ambientais e fundiários urbanos, para evitar o represamento litigioso nos órgãos públicos, extrapolando para a esfera administrativa de soluções de problemas fundiários. O implemento desta metodologia otimiza a comunicação interna e externa de informações de atos vinculativos do sistema informatizado entre os órgãos públicos judiciais e extrajudiciais. Confere múltiplas formas de legalização imobiliária e equações de preço de serviços de regularização fundiária. Apresenta novas formas e classificações de mediação, em seu caráter puro, misto ou híbrido, a depender da complexidade de solução do problema fundiário. Propõe escalas invertidas e cíclicas de participação popular nos eixos sistêmicos de processamento de solução. O novo diagrama estrutural e complexo possilita a governança interfederativa compartilhada desconcentrando os serviços públicos e descentralizando os protocolos e sua regulação. Essa nova visão de mecanismos alternativos reduz a litigiosidadade e favorece políticas públicas de regularização fundiária, com potencial de emprego nas cidades.

\section{Palavras-Chave: Propriedade, Conflitos}

Fundiários Urbanos, Regularização Fundiária,

Mediação, Governança. 


\section{SIMBOLISMO CONSTITUCIONAL E LEGITIMAÇÃO SOCIAL NAS DEMOCRACIAS RECENTES}

Desde o início do convívio do ser humano em sociedade, sempre haverá transgressões às regras de convivência impostas. Contudo, o simples ato generalizado de avançar um sinal vermeIho, recorrente na realidade brasileira, pode refletir uma situação constitucional complexa. Um descumprimento generalizado de determinada norma poderá apontar para uma realidade de legislação simbólica, ou seja, a previsão legal é discrepante da situação fática observada, hipertrofiando seu papel como símbolo e atrofiando sua função jurídico-instrumental; a força normativa da legislação perde gradativamente seu poder e o cumprimento da norma pode passar a ser, inclusive, considerado anormal por grande parte dos indivíduos. Essa situação se agrava sobremaneira quando a legislação a ser analisada se trata de norma constitucional que, ao não obter concretização na realidade social, pode se vir a se encaixar no conceito da constituição simbólica. No caso brasileiro, uma democracia recente e periférica no contexto de um mundo globalizado e de uma sociedade mundial, a constituição é, portanto, utilizada como um instrumento do jogo político para a manutenção das estruturas de poder e do status quo. Esse cenário ocorre inserido em uma sociedade hipercomplexa e assimétrica, incapaz de obter generalização congruente das expectativas normativas de comportamento e falta de representatividade dos mais diferentes interesses sociais. Dessa forma, ao ser utilizada como álibi, a constituição (de cunho nominal), tenta apresentar uma falsa preocupação dos detentores do poder -parcela sobre integrada - para com a efetivação de direitos daquela parcela marginalizada - parcela subintegrada -, quando, em realidade, busca o atendimento das finalidades econômicas dessa parcela sobreintegrada e de interesses de sociedades modernas, ou centrais. Com o esvaziamento da dimensão jurídico-instrumental da constituição, o desrespeito generalizado de seu conteúdo dá lugar a um recorrente questionamento quanto a falta de eficácia, levando à descrença na própria constituição, gerando anseio por uma reforma estrutural, que pode desencadear uma atuação mais incisiva das estruturas político-econômicas de poder e dar origem a uma constituição instrumental, típica de regimes autoritários. Democracias jovens, e fracas, como a brasileira, devem ser olhadas com especial atenção; a falta de um sentimento de "patriotismo constitucional", de uma identificação da sociedade para com sua constituição, gera alto grau de insegurança e possibilita o uso político-econômico da estrutura legiferante constitucional derivada e da interpretação da norma constitucional originária, o que pode hipertrofiar seu aspecto simbólico. De tal sorte, o objetivo desse trabalho se assenta na análise da atual conjuntura institucional e política do Brasil como um país periférico e de sua constituição como uma constituição simbólica, buscando respostas para a problemática existente ou, ao mínimo, um direcionamento para obtenção das mesmas.

Palavras-Chave: Simbolismo Constitucional, Legitimação Social, Democracias Recentes.
Luís Cláudio Martins de Araújo

\& Rodrigo Augusto Fatudo Magalhães

Instituto Brasileiro de Mercado de Capitais - IBMEC/RJ 


\author{
Ref.: 045CEDHM22020
}

\title{
COLISÃO DE DIREITOS FUNDAMENTAIS: ESTUDO DE CASOS DE DIVULGAÇÃO DE IMAGEM DE SUSPEITO DE CRIME
}

Deborah Bandeira de Deus e Mello

UNIFACOLFDUNL
O presente artigo propõe um estudo das colisões de direitos fundamentais e possíveis formas de solucionar juridicamente o eventual impasse, em especial nos casos de divulgação de imagem de suspeito de crime, pois há uma divulgação exagerada de imagem de pessoas sem autorização das mesmas, violando então seus direitos de imagem e acarretando muitas vezes em consequências desastrosas. Faremos uma análise doutrinária de diversos autores acerca do tema, a exemplo de Robert Alexy e Ronald Dworkin, assim como as soluções jurisprudenciais brasileiras no tocante a temática, observando como os tribunais superiores brasileiros vêm decidindo os casos. Como metodologia apresentaremos uma pesquisa qualitativa, desta forma será feita uma análise bibliográfica assim como uma análise de conteúdo no momento em que tratarmos dos estudos de casos jurisprudenciais. Durante o estudo do tema foi observado um caráter princípio lógico dos direitos fundamentais e uma não hierarquia entre tais eles, havendo uma impossibilidade de supremacia de um direito sobre o outro, sendo assim necessário um estudo específico em cada caso de colisão a fim de evitar uma possível censura. No tocante especificamente à divulgação da imagem de suspeito, foi analisado casos em que houve a divulgação de imagens sem a devida autorização das pessoas levando consequentemente a uma situação de total desrespeito, a exemplo do caso da Escola Base de 1994, em que os danos com a divulgação foram inúmeros, além de prejuízos profissionais e materiais, houve danos morais e perigo de vida. Por outro lado, houve casos estudados em que haveria sim a necessidade de divulgação da imagem de um suspeito, prevalecendo a liberdade de expressão em detrimento do direito de imagem, a exemplo dos casos em que o suspeito se encontra foragido. Desta forma, conclui-se pela necessidade de reiterar a não hierarquia entre os direitos fundamentais, assim como a imprescindível análise particular de cada caso levando em consideração todo os aspetos na ponderação entre os direitos.

Palavras-Chave: Direitos Fundamentais, Direito de Imagem, Liberdade de Expressão, Colisão. 


\section{A IMPORTÂNCIA DO LEGISLATIVO COMO INSTÂNCIA DE REPRESENTAÇÃO DEMOCRÁTICA}

No presente trabalho é analisado a importância do poder legislativo como instância de representação democrática. O trabalho aborda o papel do legislativo conforme a teoria da tripartição dos poderes elaborada na época do liberalismo político clássico por Montesquieu e seus desdobramentos, que chegam até $\mathrm{a}$ atualidade. $\mathrm{O}$ federalismo também é abordado, e também as formas clássicas de Estado. É feita a abordagem do papel do legislativo no federalismo uma vez que o Estado da qual partem as análises é o Estado brasileiro, que possui uma organização federalista, sendo dividido em estados-membros, que compõe a União federal. O papel do legislativo nessa organização é objeto de análise e reflexão. Ao fim do trabaIho, chega-se a uma conclusão a respeito do papel do legislativo, que possui importância dentro do sistema de divisão dos poderes. Com isso, entende-se que o legislativo é o poder que possui maior representação popular, uma vez que consegue congregar em seu seio diversas opiniões divergentes oriundas de sociedades plurais. O Poder Legislativo é de suma importância para o Estado, pois tem como funções precípuas criação de leis e a fiscalização, sendo aquela função imprescindível para que os Estados inovem e interpretem o Direito, cada qual dentro das suas competências.

Tal poder como forma de representação democrática decorre de lenta evolução ocorrida no seio da sociedade ocidental. Primeiramente, havia a democracia grega, onde não havia um conceito de representação propriamente dito, uma vez que o próprio povo, por meio da Eclésia tinha voz.

Essa evolução continuou em Roma antiga, onde o Senado era tido como representante da vontade popular. Ocorre que em realidade o Senado Romano era uma casa essencialmente aristocrática, e, apesar do lema "Senado e Povo Romano", os interesses que o senado representavam eram de pequena parcela da sociedade, não existindo realmente uma representação popular.

No entanto, a partir do iluminismo essa situação começa a mudar, mesmo que lentamente. O direito ao sufrágio fica cada vez mais amplo, e, finalmente, no início do século $X X$ se estende a minorias diversas, como as mulheres e aos negros (nos Estados Unidos com a campanha dos direitos civis).

O Brasil acompanhou essa evolução, e deu representação política a um número cada vez maior de pessoas. 0 presente trabalho trata do poder legislativo de forma geral, e tem por objetivo saber em qual medida ele representa a população. O Brasil será citado em algumas passagens apenas como um caso de referência, porém, servindo para qualquer democracia representativa moderna.

A Constituição brasileira de 1988 adotou, como forma de Estado, o sistema federativo, em que todos os entes possuem autonomia e capacidade de auto-organização, ou seja, a União, Estados-membros, Distrito Federal e Municípios não apresentam subordinação em relação aos outros.

Palavras-Chave: Legislativo, Representação, Democracia, Montesquieu.
Alexis Mendonça Cavichini Teixeira de Siqueira Universidade Portucalense - UPT 
Daniely Pinheiro Pimentel Clube Olímpico de Jacarepaguá \& Fábio Rodrigues Milioni Secretaria Municipal de Educação do Rio de Janeiro

Ref.: 059CEDHM42020

\section{DIREITOS HUMANOS CONSTITUÍDOS: AÇÕES E VALORES INCLUSIVOS NO DIÁLOGO COM O COTIDIANO DE ALUNOS DA REDE PÚBLICA DE ENSINO NO RIO DE JANEIRO/B}

Este artigo tem por objetivo esclarecer ações e reações observadas na relação desenvolvida por clube social esportivo, em cooperação com escola da rede pública municipal localizada no bairro de Jacarepaguá-Rio de Janeiro-Brasil. A parceria teve início em dezembro de 2016, motivada por processo de exclusão de uma aluna da escola da aula de natação do clube, por circunstância de exclusão econômica de sua responsável. A Organização Mundial da Saúde (OMS) sobre este tema, estima que no mundo $80 \%$ dos adolescentes não praticam exercícios físicos, e no Brasil o percentual é de $89 \%$. Neste contexto desenvolve-se pesquisa-ação através de projeto social esportivo para oferta de vagas na modalidade natação direcionadas para alunos da escola, sendo atendidos 70 alunos até dezembro de 2019. Todo diálogo, planejamento e programação das atividades entre as duas instituições foram mediadas pelo Index para inclusão: desenvolvendo a aprendizagem e a participação nas escolas, além do estudo da legislação relativa à atenção e cuidados da infância e adolescência: Constituição da República Federativa do
Brasil (1988) e Estatuto da Criança e Adolescente (ECA) (1990), para o diálogo entre culturas, políticas e práticas observados entre os elementos participativos. Dos alunos atendidos com suas demandas específicas foram realizados levantamento de dados, por observação assistemática e por entrevista não padronizada, que possibilitaram definir o perfil das barreiras de exclusão, que impedem crianças e adolescente de ter acesso à prática de atividade física. Em resultado a parceria foram observadas mudanças positivas no comportamento dos alunos e também dos responsáveis. Conclui que parcerias entre escola e comunidade possibilitam o desenvolvimento de capacidades que não são tangíveis no ambiente escolar, gerando entre outras construções sociais, postura participativa de todos, bem como permeabilidade para relações democráticas em função de ações que levam a valores inclusivos.

Palavras-Chave: Cooperação, OMS, Index para Inclusão, ECA, Valores Inclusivos. 


\section{O DIREITO HUMANO FUNDAMENTAL À PARTICIPAÇÃO POLÍTICA E A ATUAÇÃO DO MOVIMENTO INDÍGENA NA ESFERA PÚBLICA BRASILEIRA}

Considerando a participação política como uma das dimensões dos direitos humanos fundamentais, este trabalho insere-se no tema da relação do movimento indígena com a esfera pública brasileira na conformação de políticas públicas enquanto forma de realização da dignidade humana. Delimita-se o estudo à análise de dois instrumentos participativos à disposição dos povos indígenas brasileiros: a participação como membros na esfera pública institucionalizada pelo Estado, o Conselho Nacional de Política Indígena (CNPI), e a implementação dos protocolos de consulta prévia por comunidades afetadas por projetos e políticas públicas de infraestrutura. O objetivo é qualificar essas formas de participação a partir das categorias propostas por Juan E. Díaz Bordenave, que concebe a participação social em níveis e graus distintos, considerando os níveis da esfera pública apresentados por John Keane. Para tanto, desenvolveu-se um estudo descritivo com utilização de documentação indireta, artigos, revistas e livros sobre o tema. Os achados e análises indicam que apesar do alto nível de participação do movimento indígena no CNPI, considerando os temas tratados, ficou evidente a escassa capacidade de atuação e de modificação da realidade por meio daquela esfera pública. Por outro lado, as recentes implementações dos protocolos de consulta prévia previstos na Convenção no 19 da OIT indicam maior possibilidade de participação política efetiva dos povos indígenas, tendendo à maior capacidade de influência no processo decisório relacionado às ações estatais que os afetam, conforme qualidade da participação política atingida com esse instrumento e resultados, conforme decisões da administração pública e decisões judiciais no Brasil e decisões da Corte Interamericana de Direitos Humanos. Conclui-se, assim, que a participação política dos sujeitos do movimento indígena na esfera mesopública, em espaços institucionalizados pelo Estado, tende a ter menor efetividade na promoção da dignidade humana que a participação a partir da esfera micropública, articulada com as esferas mesopúblicas e macropúblicas, por meio dos protocolos de consulta prévia criados e debatidos dentro das comunidades interessadas. De todo modo, ficou evidente que a garantia dos direitos coletivos fundamentais dos povos indígenas pode ser efetivada por meio do acionamento de direito humano fundamental consagrado historicamente na Europa Ocidental e América do Norte ao indivíduo no âmbito civil e político: a participação política.

Palavras-Chave: Direitos Humanos

Fundamentais, Participação Política, Esfera Pública, Movimento Indígena, Políticas Públicas.
Luciano Alberto Ferreira

Doutorando em Direito

Socioambiental e Sustentabilidade pela Pontifícia Universidade Católica do Paraná (PUC-PR), Curitiba, Paraná, Brasil

\& Verçulina Firmino dos Santos

Mastering of Science in Legal Studies pela Ambra University, Orlando, Flórida, Estados Unidos da América 


\section{A INFILTRAÇÃO VIRTUAL DE AGENTES E O COMBATE À PEDOPORNOGRAFIA DIGITAL. ESTUDO DA LEI |3.44I, DE 8 DE MAIO DE 2017}

Gustavo Worcki Sato

Polícia Civil do Estado de São Paulo
O transtorno pedofílico é considerado pela Organização Mundial da Saúde como um transtorno mental e de comportamento (CID 10 -Classificação de Transtorno Mentais), no qual um indivíduo, via de regra do gênero masculino, padece de preferência sexual por crianças e adolescentes, estes especialmente ainda na fase pré-puberal. A externalização desse interesse pelo agente pedófilo dá ensejo à prática de fatos formalmente típicos e que produzem intensa repulsa no meio social. No Brasil, diversas são as condutas criminalizadas, das quais podem ser elencadas aquelas previstas no Título VI, Capítulo II, do Código Penal, destacando-se o crime de estupro de vulnerável (artigo 217-A) e a divulgação de cena de estupro de vulnerável, sexo explícito ou pornografia (artigo 218-C). Também a Lei 8.069/1990, previu uma série de tipos penais voltados ao combate da exposição de imagens, vídeos ou outra forma de registo que contenham cena de sexo explícito ou pornográfica envolvendo criança ou adolescente (artigo 241 ao 241-E). Não obstante as rigorosas penas dos delitos acima elencados, os transgressores prosseguem vitimando jovens de variadas idades, causando, por mais das vezes, traumas irreparáveis nos ofendidos e, pela via reflexa, a seus familiares. Sobre o tema, verifica-se que o agente pedófilo atua motivado por dois principais objetivos, quais sejam: (1) a satisfação da lascívia pessoal e (2) o abastecimento de redes vastas e obscuras de pedofilia digital, estas especialmente estabelecidas em redes não indexadas da internet e denominadas de "dark web". Dados da Associação Internacional "Meter" e do Observatório Mundial contra a Pedofilia, que monitoram a transmissão de dados pedopornográficos de forma on-line, apontam que, apenas no ano de 2019, foram transmitidas mais de 7 milhões de imagens ou vídeos envolvendo a exploração e violência sexual contra crianças e adolescentes, sendo, ainda, de conhecimento das entidades, a existência de mais de 300 salas de bate-papo voltadas à transmissão de conteúdo pedofílico e mais de 1000 grupos de videochat ao redor do mundo. Ante às reconhecidas dificuldades técnicas para a identificação e combate das organizações criminosas especializadas em pedopornografia, o legislador brasileiro, na esteira das obrigações assumidas pelo Brasil quando da assinatura da Convenção sobre os Direitos da Criança - promulgada pelo Decreto no 99.710, de 21 de novembro de 1990 -, editou a Lei 13.441 , de 8 de maio de 2017, que incluiu na Lei 8.069/1990 a moderna figura da infiltração virtual de agentes de polícia. Pretende, portanto, o presente trabalho, analisar a extensão do instituto do "undercover virtual agent" no Brasil, sua natureza jurídica de meio de obtenção de prova, características e requisitos, bem como a relevância de utilização dos modernos meios de investigação para o enfrentamento de delitos de pedofilia digital no Século XXI, além do desmantelamento de organizações criminosas especializadas em tais infrações penais.

\footnotetext{
Palavras-Chave: Pedopornografia, Infração Virtual De Agentes, Lei 13.44 //20 I7, Undercover Agente.
} 


\section{POLÍTICA JUDICIÁRIA NACIONAL PARA UMA JUSTIÇA \\ DOTRABALHO INCLUSIVA E ACESSÍVEL: PROGRAMAS E AÇÕES PERMANENTES VOLTADAS À PROMOÇÃO DA INCLUS}

Quase $24 \%$ da população brasileira é composta por pessoas que possuem algum tipo de deficiência e apenas 1\% estão no mercado de trabalho, apesar de uma legislação nacional e internacional ampla a respeito do tema da inclusão e acessibilidade. No Plano internacional, vigora a Convenção Internacional sobre os Direitos das Pessoas com Deficiência -ratificada pelo Brasil com equivalência de EC em 2008 -e a Agenda 2030 da ONU, onde ficou estabelecido, junto com outras Nações que a integram, objetivos para promoção de um crescimento econômico inclusivo e sustentável, a promoção de sociedades inclusivas, proporcionando o acesso à justiça para todos e construindo instituições eficazes, responsáveis e inclusivas em todos os níveis. No plano nacional, a concretização da dignidade da pessoa com deficiência é fundamentos do Estado Democrático de Direito (art. 10, III e IV, da CRFB) e não existe dignidade onde não há garantia de igualdade de oportunidades para as pessoas com deficiência. Temos também a Lei Brasileira de Inclusão (Lei 13.146/2015) que estabelece que a pessoa com deficiência tem direito ao trabalho de livre escolha e aceitação, em um ambiente acessível e inclusivo, em igualdade de oportunidades com as demais pessoas (art. 34), sendo finalidade primordial das políticas públicas de trabalho e emprego promover e garantir condições de acesso e de permanência da pessoa com deficiência no campo de trabalho (art. 35). Por outro lado, não obstante as normas internacionais e nacionais, as pessoas com deficiência continuam a enfrentar barreiras contra sua efetiva participação como membros iguais da sociedade, bem como a enfrentar violações de seus direitos humanos. Essas normas dizem o que devemos fazer, mas não dizem como devemos fazer. Essa é a resposta que podemos dar através de uma Política Judiciária Nacional de uma Justiça Inclusiva e Acessível. Não existe mundo sustentável se ele não for acessível, se ele não for inclusivo, e a Justiça do Trabalho possui autoridade moral capaz de influenciar e transformar a cultura da nossa sociedade, por meio da implementação de programas e ações. Autoridade moral é atitude. A legislação nos permite isso e a sociedade espera isso do Poder Judiciário. Esta pesquisa busca demonstrar a importância da implementação de política judiciária nacional inclusiva e acessível que promova práticas e ações essenciais a operar mudança cultural arraigada na sociedade. Por meio de método dedutivo-descritivo e com pesquisa legislativa, bibliográfica, documental e empírica, concluiu-se que a Política Judiciária Nacional com o objetivo de desenvolver, em caráter permanente, programas e ações voltadas à promoção da inclusão e acessibilidade da pessoa com deficiência no mundo do trabalho e promoção de uma Justiça inclusiva, atua efetivamente para o cumprimento dos objetivos estabelecidos por meio da Agenda 2030 da ONU.

Palavras-Chave: Acessibilidade, Inclusão, Política Judiciária Nacional, Justiça do Trabalho, Programas.
Déa Marisa Brandão Cubel Yule Tribunal Regional do Trabalho da $24^{a}$ Região 


\section{AS MANIFESTAÇÕES PELOS DIREITOS HUMANOS NAS REDES SOCIAIS GERAM ENGAJAMENTO NA LUTA PELA EFETIVIDADE DESSES DIREITOS? UMA ABORDAGEM NEUROC}

Cleber Mesquita dos Santos

Universidade Portucalense
Em 25 de maio de 2020, em plena pandemia da Covid-19, George Floyd, um homem negro de 46 anos, foi morto em Minneapolis, nos Estados Unidos, porque um policial branco pressionou o joelho no seu pescoço. Esse fato gerou uma série de protestos nas ruas das grandes cidades norte-americanas, alguns pacíficos e outros violentos. E gerou também protestos nas redes sociais, como Facebook, Twitter e Instagram.

A morte de Floyd gerou nas redes sociais o movimento denominado "Terça-feira do apagão", através do qual, mediante a utilização da hastag \#BlackoutTuesday, milhões de pessoas no mundo todo postaram imagens pretas nas suas contas no Facebook, no Twitter ou no Instagram. Simplesmente quadrados de cor preta. Só isso, com a hastag \#BlackoutTuesday, como forma de protesto virtual contra o racismo e a violência policial contra negros.

Porém, até que ponto esses protestos nas redes sociais geram engajamento pessoal na luta pela efetivação dos direitos humanos? Ou a adesão que houve foi meramente a um modismo? Afinal, quando alguns protestos nas ruas norte-americanas enveredaram por depredação de lojas e incêndios, também houve apoio nas redes sociais. Portanto, cabe questionar se as redes sociais contribuem para a difusão de uma cultura de paz ou são meras disseminadoras de modismos instantâneos e superficiais?
Serão a todas essas perguntas que buscaremos responder neste artigo.

Procuraremos responder mediante conhecimentos de neurociências, especificamente de neurobiologia, para verificarmos se o cérebro se satisfaz como uma simples postagem, ou se essa postagem desperta curiosidades sobre o assunto, se gera uma inquietação que induza a uma mudança de padrão de comportamento, e consequentemente a um engajamento na causa para a efetivação cotidiana dos direitos humanos e para a promoção de uma cultura de paz.

Portanto, o que vamos investigar, precipuamente, é se as redes sociais ajudam ou esvaziam a luta por essa supracitada efetividade dos direitos humanos. Ressalte-se que estamos falando de luta pela efetividade, pela concretização cotidiana.

Nosso referencial teórico serão artigos jornalísticos e científicos acerca dessa matéria.

Nosso método, portanto, será o de revisão de literatura.

A importância do presente estudo é despertar consciências para o que efetivamente gera engajamento para a concretização cotidiana dos direitos humanos, e se as redes sociais contribuem para isso, ou não. Se as redes sociais contribuem para a disseminação de uma cultura de paz. E caso ainda não contribuam, de que forma podem vir a contribuir, para que assim se comece um movimento no rumo correto.

Palavras-Chave: Direitos Humanos,

Redes Sociais, Efetividade, Neurociências. 


\section{O CRIME DE TRÁFICO DE PESSOAS: UM INCISIVO E TRANSVERSAL DESAFIO AOS DIREITOS HUMANOS}

O ainda atual fenómeno criminal de tráfico de seres humanos é matéria que lacera incisivamente a esfera nuclear dos direitos humanos, ameaçando -se quisermos uma fórmula genérica -sempre e impreterivelmente a dignidade da pessoa humana, valor absoluto e inalienável, consagrado entre nós, como se sabe, no artigo 1.0 da Constituição da República Portuguesa.

Acresce que o tráfico de seres humanos impele à violação de um conjunto de outros direitos humanos, como sejam, desde logo e em todas as suas dimensões, o direito à liberdade e depois, no caso do tráfico de seres humanos com finalidades de exploração sexual, o direito à liberdade e autodeterminação sexual, nas situações de tráfico de seres humanos para exploração laboral, o direito a trabalhar em condições justas e favoráveis, o direito à proteção social, entre outros.

Pela magnitude que este fenómeno assume nesta medida anulatória das mais básicas características da dimensão humana, não se julgue estranho o cuidado com que tem vindo a ser tratado por parte das mais variadas ins- tâncias nacionais e internacionais.

Entre nós, o tráfico de pessoas encontra-se criminalizado no artigo $160 .{ }^{\circ}$ do Código Penal e é, efetivamente, uma realidade presente no nosso país, como disso nos dão conta os vários Relatórios Anuais de Segurança Interna e os Relatórios do Observatório do Tráfico de Seres Humanos que nos propusemos analisar e que elevam este tipo de criminalidade a ameaça à segurança interna portuguesa.

Num patamar internacional, basta atentar à Agenda 2030 da Organização das Nações Unidas, constituída por 17 Objetivos de Desenvolvimento Sustentável (ODS), para percebermos que o tráfico de pessoas é um daqueles fenómenos criminais que transversa grande parte destes objetivos, colocando em causa o seu cumprimento. Pois, entre o mais, pretende-se para 2030 sociedades pacíficas, justas e inclusivas, livres do medo e da violência, sem espaço para abusos, exploração ou tráfico de qualquer género; tem-se como objetivo para 2030 combater o crime organizado, fortalecendo a capacidade das instituições nacionais e internacionais, inclu-
Ana Teresa Carneiro

Doutoranda na Universidade de Santiago de Compostela; Consultora em Jorge Carneiro \& Associados, Sociedade de Advogados, SP, RL; Assistente Convidada ISMAl; Colaboradora JusGov/EDUM e UICC/ISMAI

\section{\& Ana Guerreiro} Instituto Universitário da Maia Doutoranda em Criminologia na Faculdade de Direito da Universidade do Porto 
Ana Teresa Carneiro

Doutoranda na Universidade de Santiago de Compostela; Consultora em Jorge Carneiro \& Associados, Sociedade de Advogados, SP, RL; Assistente Convidada ISMAl; Colaboradora JusGov/EDUM e UICC/ISMAI

\section{\& Ana Guerreiro}

Instituto Universitário da Maia Doutoranda em Criminologia na Faculdade de Direito

da Universidade do Porto
Ref.: 088CEDHM22020

O CRIME DETRÁFICO DE PESSOAS:

UM INCISIVO ETRANSVERSAL DESAFIO AOS DIREITOS HUMANOS

sive através da prevenção e combate ao crime e da cooperação internacional; dentre as liberdades fundamentais protege-se o trabalho digno e seguro, o que passará pela eliminação de todas as formas de trabalho forçado, precário ou escravidão moderna. Desta mera enunciação resulta clara a relevância do tratamento do crime de tráfico de pessoas, desafio incisivo e transversal aos direitos humanos e, como tal, ao próprio cumprimento da Agenda 2030, razão pela qual é fundamental dar conta dos seus principais aspetos, nós górdio e, sobretudo, implicâncias com a matéria sobre que este trabalho gravita -a evolução e desenvolvimento dos direitos humanos $\mathrm{Na}$ verdade, o crime de tráfico de pessoas não está isento de incertezas e interrogações. Não tanto no seu regime legal, mas sobretudo em torno da realidade em que se manifesta e naquilo que contende com a investigação, pelo seu caráter.

Palavras-Chave: Crime de Tráfico de Pessoas, Direitos Humanos, Agenda 2030, Regime Legal, Panorama Nacional. 


\section{A GARANTIA COMPARTILHADA DOS DIREITOS HUMANOS NA AMÉRICA LATINA: A PARTICIPAÇÃO DA CORTE IDH NOS JULGADOS ADPF I 53 E CASO SIMÓN}

A presente pesquisa centra-se no analisar das interações transjudiciais entre cortes nacionais e internacionais no marco da proteção e garantia dos direitos humanos das vítimas dos regimes autoritários na América Latina. A fim de operacionalizar a análise do objeto de pesquisa, sua ocorrência é investigada nos julgamentos relativos à declaração da (in)constitucionalidade de leis de autoanistia em Brasil e Argentina, os casos ADPF 153 (2010) e Caso Simón (2005). Tais julgados foram selecionados porquanto preservam as circunstâncias fáticas e jurídicas ideais ao desenrolar do diálogo transjudicial, bem como por conta da importância das referidas decisões na efetivação do direito à justiça e persecução penal das graves violações aos diretos humanos perpetradas pelos regimes autoritários dos Estados. Assim, através de pesquisa documental e bibliográfica, propõe-se uma noção construtiva da interação entre cortes, demonstrando sua relevância à dialética entre Direito interno/Direito Internacional, e a viabilidade da referida prática comportar-se como alternativa extra-sistêmica de juridicidade, associada aos padrões pós-modernos e multiculturais de gestão e garantias dos direitos humanos. Neste sentido, a fim de colaborar com o aprimoramento técnico-conceitual deste assunto -mas sem pretender exaurir a pesquisa nesta ambiência -a interação transjudicial é pensado como alternativa extra-sistêmica de garantia judicial dos direitos humanos na América Latina, vez que se constitui como prática judicante asso- ciada à consolidação de uma dogmática jurídica pluralista e preocupada com a homogeneização na hermenêutica dos tribunais acerca da temática dos direitos humanos. O estudo sustenta-se na hipótese de que a proteção internacional dos direitos humanos na realidade do novo enquadramento jurídico pós-moderno, de extraterrialização dos espaços de decisão (FRASER, 2009), demanda atuação compartilhada dos agentes que compõem o constitucionalismo de níveis múltiplos (PERNICE, 2002). Contudo, da análise dos casos investigados, concluiu-se que, no Brasil, a interação transjudicial não é adequadamente deliberado pelo Supremo Tribunal Federal (STF), de modo que a Corte IDH teve atuação reduzida na colaboração da efetivação da justiça dos crimes da ditadura. Ao que tudo indica o sistema de justiça brasileiro, diferentemente do argentino, ainda necessita de prerrogativas formais, sendo incapaz de pautar sua atuação judicante conforme compromissos internacionais firmados, valores axiológicos comuns que sustentam a teoria dos direitos humanos ou a consonância teleológica que, em tese, amalgama os membros do Sistema Interamericano de Direitos Humanos. Por fim, a pesquisa justifica-se pela premente necessidade de se perscrutar novas formas de integração entre as estruturas judiciais dos Estados membros do SIDH e a Corte IDH, a fim de homogeneizar e racionalizar as abordagens exegéticas da proteção dos direitos humanos na América Latina.

Palavras-Chave: Interações Transjudiciais, Regimes Autoritários, América Latina, Brasil, Argentina.
Mateus Trinta Bruzaca

Universidade Federal do Maranhão 


\section{ACESSO À JUSTIÇA PELA VIA DA PROFISSIONALIZAÇÃO: CONTRATOS DE APRENDIZAGEM E OBJETIVOS DE DESENVOLVIMENTO SUSTENTÁVEL}

Igor Sousa Gonçalves

Filiação,

Universidade Federal de Minas Gerais

Nancy Vidal Meneghini,

Universidade Federal de Minas Gerais

Karem Carvalho Barcelos

Universidade Federal de Minas Gerais

\& Natália Campos de Souza

Pimenta

Pontifícia Universidade Católica

de Minas Gerais
O contrato de aprendizagem é o contrato de trabalho especial, ajustado por escrito e por prazo determinado, em que o empregador se compromete a assegurar formação técnico-profissional metódica ao adolescente maior de 14 (quatorze) anos e jovem menor de 24 (vinte e quatro) anos, que deve ser compatível com o desenvolvimento físico, moral e psicológico do aprendiz (art. 428 da Consolidação das Leis Trabalhistas).

A intenção desse artigo é trazer uma abordagem tanto sobre o sistema brasileiro de proteção legal à criança, ao jovem e ao adolescente, quanto sobre os Objetivos de Desenvolvimento Sustentável (ODS), e mostrar, em qual medida esses dois elementos estão conectados.

Nesse sentido, apresentar-se-á a relação de complementaridade entre os Objetivos trazidos na Agenda 2030, notadamente no que se refere à promoção do crescimento econômico sustentado, inclusivo e sustentável, emprego pleno e produtivo e trabalho decente para todos (ODS8), além do direito à educação técnica e profissional (ODS4.3) e o instituto legal da aprendizagem.

No contexto brasileiro é imprescindível analisar a questão do trabalho, considerando as peculiaridades sociais e históricas nacionais. A desigualdade social, concentração de renda e pobreza são elementos essenciais para a análise histórica da exploração do trabalho infantil como um dos pilares da manutenção das desigualdades sociais, ao fomentar o círculo vicioso: trabalho infantil, lapso educacional e manutenção da pobreza.

Diante disso, busca-se analisar se o instituto da aprendizagem profissional, nos moldes preceituados no art. $428 \mathrm{da}$ CLT, adequa-se aos preceitos subjacentes à Agenda 2030, sem perder de vista o objetivo de erradicação do trabalho infantil e de redução da quantidade de jovens sem emprego.

A fim de respaldar a presente indagação, este trabalho apresenta como metodologia a análise das normativas nacionais e internacionais que fundamentam a celebração dos contratos de aprendizagem profissional, bem como a revisão da literatura sobre o tema, adotando como marco teórico a perspetiva do acesso à justiça pela via dos direitos.

\section{Palavras-Chave: Aprendizagem Profissional,} Acesso à Justiça pela Via dos Direitos, Agenda 2030, Objetivos de Desenvolvimento Sustentável, Direitos Humanos. 


\section{COMUNICAÇÃO DEMOCRÁTICA E POLÍTICAS PÚBLICAS VOLTADAS PARA A SUPERAÇÃO DA DESIGUALDADE DE GÊNERO}

O direito à comunicação como direito fundamental é imprescindível para a sobrevivência da própria democracia. De outro lado, políticas voltadas para a superação das desigualdades de gênero são ínsitas um sistema político que se pretenda democrático. A comunicação democrática é aquela que consegue permitir a igualdade de gênero. A tese que se sustenta é de que a desigualdade de gênero não só se transpõe para a comunicação mediada pela internet, como pode até se agravar, considerando as próprias peculiaridades da comunicação virtual. Seriam imprescindíveis, portanto, políticas públicas voltadas é efetivação da igualdade de gênero na comunicação virtual. A avaliação das políticas públicas na área das comunicações que possam ter um papel relevante para a consecução desse direito à igualdade de gênero, bem como a eventual atividade propositiva de uma nova alternativa de política pública é uma necessidade premente. Como nos lembra Cass Sunstein (\#epublic Divide Democracy in the Age of Social Media, Princenton: Princenton University Press,2017.), se as preferências das pessoas são produto de injustiça ou de opções limitadas excessivamente, existe um problema do ponto de vista da liberdade. Não se pode tratar cidadãos como se fossem meros consumidores, transformando-se a comunicação virtual em mais um meio de precarização das relações sociais. A democracia supõe a esfera pública, se constituindo essa esfera como importante instrumento de luta política (Iris Marion Young). A esfera pública virtual, ao contrário do que certa idealização poderia aceitar, está longe de trazer uma simetria entre aqueles que nela estão. A visibilidade na esfera pública virtual é crucial, e ela supõe mais do que simplesmente a presença na esfera virtual. Os espaços virtuais são, portanto, menos igualitários que os espaços reais. Algumas outras características desses espaços virtuais, como a abertura e a velocidade, podem redundar em dificuldades adicionais em se preservar a comunicação democrática. De outro lado, o desafio de superação da desigualdade de gênero se coloca ainda como meta importante para o mundo democrático. Um olhar atento para a literatura sobre questões de gênero mostra como o processo de comunicação humana pode naturalizar e perpetuar desigualdades de gênero. É indispensável uma comunicação atenta para a vulnerabilidade de grupos de pessoas, especialmente quando diante de um processo de precarização das relações sociais e econômicas, apresentada, muitas vezes, como a única alternativa possível para a crise. Partindo desse referencial teórico, busca- se aferir a possibilidade de políticas públicas voltadas para a superação da desigualdade de gênero na efetivação do direito à comunicação, com ênfase na relevância que a comunicação virtual toma em nossos dias. Que tipo de políticas públicas poderiam ser pensadas? Políticas regulatórias, políticas de conscientização ou até nudges podem estar no espectro das possibilidades.

Palavras-Chave: Comunicação, Desigualdade, Gênero, Democracia, Políticas.
Maria Lucia de Paula

Oliveira

Professora Adjunta da Universidade Federal do Estado do Rio de Janeiro (UNIRIO) e Professora Agregada da PUC-RIO 


\section{MEMÓRIA, VERDADE E JUSTIÇA NO BRASIL APÓS A COMISSÃO DA VERDADE}

Bruna Ferrari Pereira

Universidade Federal de São Carlos
Este trabalho tem como objetivo analisar os projetos de lei votados na Câmara dos Deputados do Brasil com os temas memória, verdade e justiça entre os anos de 2010 e 2018, observando através de uma projeção longitudinal se houve ou não um aumento na quantidade de projetos votados após o ano de 2014. Para o recorte temporal considerou-se que a Comissão Nacional da Verdade lançou seu relatório final em dezembro de 2014, quando fez diversas recomendações para o avanço dos direitos humanos no país e para que violações de direitos humanos cometidas por agentes do Estado não voltassem a ocorrer. A metodologia utilizada para mensurar os projetos de lei tomará como base os dados disponibilizados pelo Siga Lei. Esta plataforma monitora, categoriza e armazena as tramitações que ocorrem nas principais casas legislativas do Brasil. Os dados são disponibilizados em tempo real e detalham o andamento das proposições, discursos e aprovações. Após este mapeamento traçaremos uma análise de como o Poder Legislativo no Brasil tem enfrentado as questões de memória, verdade e justiça no período recente, observando quais projetos avançaram, quais foram vetados e porquê. Outros indicadores que serão considerados na análise é a composição partidária da Câmara, o perfil dos representantes eleitos, a relação Executivo-Legislativo e a atuação de veto players neste processo. O artigo possui como embasamento teórico o conceito de justiça de transição, o qual se refere às medidas tomadas pelos Estados para lidar com as graves violações de direitos humanos cometidas em um passado recente. As primeiras medidas transicionais se iniciaram no período pós II Guerra, passando pelo período da Guerra Fria e chegando aos dias atuais. O conceito já se consolidou na literatura e é amplamente difundido (TEITEL,2003; BICKFORD,2004; KRITZ,2009).

Segundo a interpretação de Sikkink \& Walling (2007), nos últimos anos houve um aumento nos esforços dos Estados para apurar violações de direitos humanos nacional e internacionalmente. Este movimento gerou uma "revolução nas formas de accountability" destas violações, caracterizando o que os autores definiram como "Justice Cascade". Esta progressão foi notada pela expansão de Comissões da Verdade e julgamentos de direitos humanos nos países em transição, uma prática social que se difundiu mundialmente e não se trata mais de acontecimentos isolados ou marginais. Considerando a instituição da Comissão Nacional da Verdade como um momento chave no período analisado, também o esclarecimento deste conceito é importante. Estas Comissões são mecanismos oficiais de apuração das violações de direitos humanos para esclarecer crimes cometidos no passado. Ao final dos trabalhos, tornam públicas à sociedade as violações ocorridas, além de apresentar propostas e recomendações para evitar que estas voltem a ocorrer (POLITI,2009).

Palavras-Chave: Justiça de Transição, Comissão da Verdade, Direitos Humanos, Brasil, Ditadura Militar. 


\section{MEDIDAS DE SEGURIDADY RESTRICCIÓN DE LA MOVILIDAD TRANSFRONTERIZA ENTRE MÉXICOY ESTADOS UNIDOS EN EL MARCO DEL COVID I 9}

La frontera de México con Estados Unidos es considerada la más dinámica e interdependiente del mundo, principalmente por la intensa interacción bilateral transfronteriza comercial, laboral, flujo de personas, inversión, migración, turismo, medio ambiente, servicios de salud y cultura que se extiende a lo largo de 3,152 kilómetros, integrada por 6 entidades federativas y 38 municipios mexicanos asícomo por 4 estados y 23 condados estadounidenses, 15 pares de ciudades hermanas; se considera que la población en esta zona asciende a más de 15 millones de personas (EPA y SEMARNAT, 2016), sin embargo, se contempla que se duplique la cifra para el año 2025. Actualmente entre México y Estados Unidos existen 56 puertos de entrada, donde se realizan diariamente más de un millón de cruces legales de personas y 300 mil de vehículos, de los cuales 70 mil son de carga, representando la cuarta economía mundial por su importancia comercial transfronteriza, de acuerdo a estimaciones de la Secretaria de Relaciones Exteriores de México (S.R.E., 2017); por otro lado, el Instituto Mexicano del Transporte (IMT, 2020), considera que se ha reducido la movilidad de personas en vehículos particulares y peatonales en más del $30 \%$ de los cruces lo que representa varios millones de personas menos transitando por la frontera norte. Históricamente la relación México-Estados Unidos, ha generado importantes retos en temas de cooperación bilateral primordialmente después de los atentados terroristas del 2001 en los Estados Unidos, por lo que la seguridad transfron- teriza se ha vuelto un tema prioritario en la agenda diplomática que demanda soluciones funcionales, destacándose recientemente el Acuerdo de Restricción Fronteriza, implementado por el gobierno estadounidense a partir del 21 de marzo de 2020, con el anuncio del cierre parcial de sus fronteras con México y Canadá, mediante el control en todos sus puertos de entrada y cruces fronterizos a los viajes no esenciales con el objeto de proteger a su país, de las amenazas contra la salud y seguridad de sus ciudadanos ante la propagación del COVID19. En ese sentido, aunque el Departamento de Seguridad Nacional (DHS) de Estados Unidos señala que las restricciones actuales han cumplido su propósito, el cierre de la frontera continua, porque se ha prorrogado su apertura en tres ocasiones, hasta el 21 de julio, lo que ha provocado que la dinámica fronteriza habitual se altere, ocasionado grandes pérdidas en la economía local transfronteriza, principalmente a la estadounidense que depende en gran medida del turismo así como de compras de bienes y servicios de los residentes fronterizos mexicanos. El presente documento, pretende contextualizar mediante una descripción analítica el impacto social, cultural y económico que ha causado a la movilidad humana transfronteriza, las medidas de seguridad implementadas en la frontera México-Estados Unidos una de las más complejas del mundo.

Palavras-Chave: Frontera, Cruces Fronterizos, Seguridad, Restricción Fronteriza, Movilidad Transfronteriza.
Adriana Guillermina Ríos Vázquez

Universidad Autónoma del Estado de México, México

\& Luz Maria Consuelo Jaimes Legorreta Universidad Autónoma del Estado de México, México 


\section{A NOVA LEI DE MIGRAÇÃO NOS TRIBUNAIS E A PROTEÇÃO DOS MIGRANTES DIANTE DA PANDEMIA}

Luis Renato Vedovato

UNICAMP e PUC-CAMPINAS

\& Carolina Piccolotto Galib

PUC-CAMPINAS e PUC-SP
O ano de 2020 tem sido um ano difícil para a sociedade e para os governos. A pandemia do coronavírus alcançou um planeta que, há algum tempo, está tentando solucionar, sem sucesso aparente, grandes problemas no campo da desigualdade social, degradação ambiental e conflitos armados descentralizados. Todos esses fatores tornaram mais difícil que os países pudessem dar uma resposta efetiva de combate à disseminação do vírus com foco na proteção da saúde e na manutenção das rendas das pessoas. O Direito Internacional depara-se com a necessidade de lutar pela transparência em períodos de pandemia (Vedovato, 2020). Para grupos em situação de vulnerabilidade, como é o caso dos migrantes, o cenário pode ser entendido como mais delicado, pois a circulação pelo mundo fica restrita, o que impacta na tentativa de saírem de locais em que suas vidas correm risco (Portaria Interministerial n. 255, expedida pelo Governo Brasileiro, que restringe a entrada de migrantes no território nacional), o acesso a aparatos de saúde é precário, tendo em vista que há restrições a direitos sociais para migrantes em situação migratória indocumentada, e o socorro econômico pode não vir, posto exigir a apresentação de documentos que não são acessíveis a parcela dos migrantes (como é o caso do Cadastro de Pessoa Física -CPF -no Brasil, para se ter acesso ao auxílio emergencial). Os grupos em situação de vulnerabilidade podem ficar à margem do debate, especialmente quando, como no caso do Brasil, eles não possuem direito de participar das decisões políticas, tendo em vista que migrantes não votam no país. Encontrar meios de proteger a saúde da população, ao mesmo tempo em que se mantém em vigor a economia, atendendo aos anseios da população, é das maiores tarefas que muitas nações já enfrentaram na sua história. Inegavelmente, as pressões que nascem do lado daqueles que percebem a emergência sanitária são contrapostas por aquelas pressões provenientes de grupos que querem enfatizar o crescimento econômico a todo o custo. Diante dos desafios que os migrantes estão enfrentando no momento de pandemia no Brasil, é inegável a importância da Lei 13.445/17, a Nova Lei de Migração (NLM). Apesar dos vetos e do regulamento que comportam críticas, o alinhamento da lei a direitos humanos e o não tratamento dos migrantes como uma questão de segurança nacional trouxeram o aporte necessário para amparar minimamente esse grupo vulnerável nesse momento. O presente trabalho visa expor as decisões judiciais e os possíveis argumentos jurídicos para responder às questões de interesse dos migrantes no tocante ao acesso ao auxílio emergencial, direito de ingresso e atendimento de saúde, durante a pandemia, tendo em vista as soluções do direito posto brasileiro.

Palavras-Chave: Migração, Pandemia, Tribunais, Lei de Migração. 


\section{ENTRE POLÍTICA, ÉTICA E SUBJETIVIDADES: SOBRE O EXERCÍCIO E O OFÍCIO DE PROMOVER CIDADANIA}

A psicanálise não está fora da pólis e da política. Assim como a psicologia e o direito, a psicanálise não é um saber estritamente teórico e técnico. Tomando como base argumentativa, corroboram Freud (com sua produção), Safatle (2017) e Barbiere (2017). O primeiro quando afirma que "a psicanálise logo se consolidou como uma referência maior na análise de fenômenos de regressão social" e o segundo ao reforçar as conexões com gênero, etnia, raça e arte e que tal área "subverte a visão ingênua de um humano previsível, adaptável, perfeito e de verdades absolutas". Nesse sentido, não há como escapar do fato de que estamos inseridos em uma cultura e que esta repercute nas subjetividades. A psicanálise surge a partir do interesse de um jovem médico austríaco que deu atenção especial ao sofrimento do sujeito da Cultura na Civilização, ao se debruçar sobre o sofrimento de mulheres adoecidas no ambiente repressor de uma sociedade patriarcal. Desde Totem e Tabu, em 1913, Freud articula a psicanálise com saberes como antropologia, arqueologia, inaugurando a base fundamental. A partir da segunda década do século XX, em trabalhos como Psicologia das Massas e Análise do Eu (1921), O Futuro de uma Ilusão (1927), O Mal-Estar na Civilização (1930), Moisés e o Monoteísmo (1939),Freud estreita ainda mais as relações entre psicanálise, cultura e sociedade, demonstrando ser objeto basilar o psíquico em todas as suas manifestações dentro da clínica e nas interações entre os seres humanos, as identificações e modelos no ambiente em que vive, normas, valores, crenças, costumes (MEZAN, 2017). Analisar as aproximações, portanto, entre áreas jurídica e de subjetividades é objetivo dessa comunicação, ampliando para descrição dos Códigos de Ética profissionais de cada área, na conduta pautada em valores e princípios e que imprimem diretrizes claras para a formação desses profissionais e que balizam as suas ações, contribuindo para o fortalecimento e ampliação do significado social da sua conduta profissional. Como estrutura documental, neste trabalho, a ênfase recai sobre ambos códigos (Psicologia e Advocacia), ambos alicerçados no respeito aos Direitos Fundamentais e valores universais constantes na Declaração Universal dos Direitos Humanos, todos fontes construídas no século $X X$, perfazendo debates sobre contemporaneidade, direitos e saberes. Como resultados, para além da revisão de literatura e uso de instrumento que regulam ofícios, a abordagem ética e de promoção de direitos humanos desvenda-se como principal recurso formativo e de práticas interdisciplinares no campo jurídico e psicanalítico, almejando plena cidadania e atuação ética.

Palavras-Chave: Ética, Psicanálise, Psicologia, Direito, Cidadania.
Nadir Oliveira Galrão Leite de Almeida

Universidade Católica do Salvador (BA-BRASIL) 


\section{RESPONSABILIDADE INTERNACIONAL DO ESTADO POR OMISSÃO NA PROTEÇÃO DOS DIREITOS HUMANOS NA EXPLORAÇÃO DE BENS PÚBLICOS POR EMPRESAS PARTICULAR}

Fernanda Schuhli Bourges

\& Mariane Yuri Shiohara

Lubke

Pontifícia Universidade Católica do Paraná - PUC/PR
A barragem do Fundão, em Mariana, Minas Gerais, Brasil, construída e operada pela empresa Samarco Mineração S/A, controlada pela BHP Billiton Brasil Ltda. e pela Vale S/A rompeu-se em 05 de novembro de 2015, despejando no meio ambiente 40 milhões de metros cúbicos de lama contaminada com rejeitos de minério. O caso Samarco é uma das maiores catástrofes provocadas pelo homem no Brasil, com o gravame de se tratar da exploração de bens públicos não renováveis, expondo a fragilidade, omissão e ineficiência do aparato administrativo brasileiro na fiscalização de grandes empreendimentos, os quais, em tese, deveriam garantir padrões de consumo e de produção sustentáveis. Em vista desta espécie de problema, o Objetivo do Desenvolvimento Sustentável n. 11 tem como uma de suas metas, até 2030, alcançar a gestão sustentável e o uso eficiente dos recursos naturais, somado ao Marco de Sendai 20152030. Infelizmente, o rompimento da barragem do Fundão acabou por gerar diversos danos aos direitos humanos, seja de maneira direta, como a destruição ambiental e mortes causadas, ou de maneira indireta, a exemplo da redução do turismo local, em verdadeiro retrocesso à necessária proteção dos direitos humanos e à promoção do desenvolvimento sustentável. O objetivo do estudo é, a partir dos Princípios Ruggie, pelo método hipotético dedutivo, refletir criticamente acerca das omissões do Estado e das transnacionais na proteção, respeito e reparação das violações dos direitos humanos, no reconhecimento, tratamento e reparação dos danos às vítimas. Objetiva, ainda, demonstrar a grave violação de direitos humanos causada por uma suposta proposta de desenvolvimento sustentável e, em última análise, verificar que, se o sistema interno de responsabilização não for efetivo, o Estado brasileiro pode ser responsabilizado pelo Sistema Interamericano de Direitos Humanos. Eventual condenação do Estado brasileiro em sede internacional repercutirá sobremaneira à coletividade do país, que arcará com este ônus. Por isso, ressalta-se a importância da conscientização dos Estados, das empresas nacionais e transnacionais, e das pessoas, a fim de se solidarizem e somarem esforços no intuito de promover e respeitar os direitos humanos, preventivamente, em compatibilidade com o desenvolvimento sustentável. Passados quase 5 anos do desastre, as pessoas diretamente atingidas estão longe de serem indenizadas pois os danos, em sua maioria, são irreparáveis. Ademais, apesar da solução consensual adotada ser louvável, há dúvidas acerca da responsabilização e indenização efetiva das vítimas diretas do acidente, quiçá no tocante às indiretas. O caso propiciou, contudo, inovação ao viabilizar a possibilidade de responsabilizar uma das controladoras da Samarco, a BHP Billiton em foro britânico e indenizar as vítimas, o que, independentemente do resultado, é profícuo para a teoria da responsabilidade das empresas transnacionais pelo respeito aos direitos humanos e para a efetivação do ODS n. 11.

Palavras-Chave: Proteção Dos Direitos Humanos, Responsabilidade Internacional Do Estado, Fiscalização, Barragens, Objetivos Do Desenvolvimento Sustentável. 


\section{A EFICIÊNCIA DAS RAL'S REALIZADAS DE FORMA PRÉ-PROCESSUAL}

Com este estudo analisaremos os benefícios de resolver os conflitos através das Câmaras de Mediação de forma Pré-processual, ou seja, quando ainda não há litígios. A busca por resolver o conflito de forma pré processual ou sem litígios primeiramente demostra boa fé, pois o conflito é inerente a nossa vontade, mas decidir a forma como solucioná-lo é escolha pessoal. Ao se utilizar de alguma das formas de resolução de conflito, a saber: Mediação, Conciliação, Negociação ou Arbitragem, sem ir ao judiciário é demonstrar maturidade e entendimento que nem sempre as normas, jurisprudências, ou a própria lei confere ao magistrado o melhor julgamento para o caso concreto. Nas Câmaras Privadas, conveniadas ao Tribunal de Justiça, a exigência da qualidade e aprimoramento do profissional de mediação é grande e o Termo de Resolução de Conflito, documento lavrado a cada sessão é Titulo Executivo que poderá ser executado, caso o acordo não seja cumprido. Com isso, não há judicialização, bem como ocorre a solução do conflito de forma rápida, célere e eficaz, onde as próprias partes decidem e se comportem em cumprir o que foi acordado.

Palavras-Chave: Resolução, Conflito, Eficiência, Pré-Processual.

\author{
Alessandra Balestieri \\ \& Daniel Blume Pereira \\ de Almeida \\ AB Câmara de Mediação RJ
}


Arkaitz Pascual

Universidad de Salamanca

\& Arnelle Rolim Peixoto

GEDAI-UFC/UNINASSAU

Ref.: I 49CEDHM22020

\section{A IMPORTÂNCIA DE UMA POLÍTICA PÚBLICA DE SEGURANÇA COM ENFOQUE NOS DIREITOS HUMANOS NO BRASIL}

Diante do alto índice de violência que assola o Brasil desde há vários anos, é comum que se venha a estabelecer ou restabelecer políticas de segurança com a finalidade de conter esse número tão representativo. Entretanto, as políticas de segurança, na sua maioria, estão direcionadas para uma atuação cada vez mais repressiva, o que faz com que esse efeito ocasione consequências para a população mais vulnerável. Nesse sentido, é importante que venha a respaldar uma atenção maior em políticas públicas de segurança com o enfoque nos direitos humanos. O objetivo desse trabalho é analisar políticas públicas de segurança, baseadas no policiamento comunitário, voltadas à segurança cidadã, com respeito aos sujeitos de direitos e contrapondo ao policiamento repressivo. Para isso serão abordados tanto a questão de segurança pública, polícia comunitária e segurança cidadã, esse último com base no Informe da Comissão Interamericana de Direitos Humanos, na importância de que esse enfoque dentro da política pública de segurança seja um caminho a ser repensado para alcançar algumas metas estabelecidas no Objetivo do Desen- volvimento Sustentável (ODS) da ONU no 16 da Agenda 2030. A metodologia da pesquisa é bibliográfica, de método dedutivo e a abordagem exploratória, mediante análise teórica do tema e dos dados de informes. Conclui-se que a aplicação de uma política pública de segurança com o enfoque nos direitos humanos dentro do contexto brasileiro é de inegável importância para que sejam respeitados os direitos de grupos vulneráveis que vivem em zonas conflituosas e, ao mesmo tempo, seja uma via para que se possa reduzir a violência e as altas taxas de mortalidade, como forma de alcançar as metas do Objetivo do Desenvolvimento Sustentável no 16. Com isso, observa-se a importância do papel de trabalhar o conceito de segurança cidadã, interligando diversos autores, para concretizar os direitos, tanto no plano normativo como no operativo.

Palavras-Chave: Direitos Humanos, Política De Segurança, Segurança Cidadã, Brasil, Objetivo Do Desenvolvimento Sustentável. 


\section{UM DIA O ACESSO À JUSTIÇA SERÁ PARA TODOS}

O 16. O Objectivo de Desenvolvimento Sustentável da Agenda 2030 da Organização das Nações Unidas, designado por "Paz, Justiça e Instituições Eficazes" constitui uma das vertentes da referida Agenda 2030 que tem por missão a criação de um modelo universal, de índole social, económica e ambiental, estimulador do bem-estar geral.

Entre outros propósitos, o $16 .^{\circ}$ objectivo visa "promover o Estado de Direito, ao nível nacional e internacional, e garantir a igualdade de acesso à justiça para todos". É justamente na discussão da igualdade de acesso à justiça por parte de todos e para todos que centramos o nosso escrito, com recurso a fontes doutrinárias e legislativas sobre o tema. Cruzámos caminhos práticos e tentámos jeitos explicativos da importância e extensão do acesso à justiça. A vertente consequencialista assume preponderância neste espaço. O preâmbulo da Constituição da República Portuguesa, de 1976, afirma, entre outros desígnios, a garantia os direitos fundamentais dos cidadãos, o estabelecimento dos princípios basilares da democracia, o asseguramento do primado do Estado de Direito "tendo em vista a construção de um país mais livre, mais justo e mais fraterno". É incontroverso que dignidade humana, liberdade e justiça são peças substanciais de uma qualquer sociedade organizada e civilizada. O acesso igualitário de todos os cidadãos à justiça é apenas uma formulação do todo fundante do valor da Justiça. São muitos os instrumentos que consagram a garantia do acesso à justiça, entre os quais destacamos o direito à acção e a um tribunal imparcial na Carta dos Direitos Fundamentais da União Europeia, perspectiva que é acentuada nos demais documentos nacionais e internacionais. O diálogo prático entre as mais diversas coordenadas do pilar da Justiça é intenso, difícil e, por vezes, assimétrico, sendo necessário encontrar um equilíbrio conciliador e dinâmico entre elas, bem como o seu sentido intencional.

Palavras-Chave: Agenda 2030, Acesso

à Justiça, Acesso Igualitário, Apoio Judiciário,

Direitos Fundamentais.
Ana Paula Guimarães \& Fernanda Rebelo Universidade Portucalense 
Ref.: I 66CEDHM22020

\section{CRISE E ORÇAMENTO PÚBLICO: A NECESSIDADE DE SE ACOMPANHAR A DISTRIBUIÇÃO DE RECURSOS PARA EFETIVAÇÃO DOS DIREITOS FUNDAMENTAIS NO BRASIL}

André Luiz de Matos

Gonçalves

\& Júlio Edstron S. Santos

Uninassau/Palmas
O primeiro semestre do ano de 2020 foi singular para toda a humanidade devido ao enfrentamento da maior pandemia deste século causada pela COVID 19, uma doença letal que em poucas semanas foi disseminada em todos os países do mundo, desafiando os sistemas de saúde para que fossem salvas vidas humanas. No Brasil, há a manifestação de três crises simultâneas, política, econômica e sanitária, por causa da COVID 19 e, devido a esta tríplice dificuldade, a população convive com a insegurança e o medo. A palavra crise está presente no cotidiano das pessoas. Além do que, ao se somar estes fatores, verifica-se que a ação estatal não consegue avançar rapidamente na agenda de efetivação dos direitos sociais, como a saúde e o trabalho. A crise brasileira atual foi sintetizada em três dimensões distintas, mas que são complementares; a primeira, o desafio político que, pelo menos desde o ano de 2005, está em constante atrito entre correntes ideológicas diferentes que têm tido dificuldade de dialogar e buscar soluções possíveis, tal qual é o procedimento democrático. As dificuldades do atual momento também foram sintetizadas por Luiz Felipe Pondé com a afirmação de que: "uma agenda para o contemporâneo é um ato de coragem!" (2019, p.20). Isto porque Estado está sobrecarregado. O Mercado parcialmente esvaziado devido à necessidade de isolamento social, os índices de produção e contratação da indústria e do comércio brasileiros estão em queda. Somente o agronegócio se mantém lucrativo no Brasil no ano de 2020. É possível reconhecer que o rol de dificuldades enfrentadas, neste momento, gerará problemas para toda a nação, dado que, sem se concretizar as relações de consumo, haverá uma diminuição de arrecadação de tributos e, em situação tautológica, ao se minimizar as relações empresariais, tornam-se indisponíveis novos recursos financeiros para investimentos sociais estatais que, por sua vez, também podem diminuir as relações de consumeristas por diminuição da renda familiar. Neste ambiente de crise, volta à tona a cantilena de que a efetivação dos direitos fundamentais e humanos precisam de investimentos financeiros estatais. Somando-se a esta situação ouve-se a adverte de que "os direitos não nascem em árvores", como 
Ref.: I66CEDHM22020

CRISE E ORÇAMENTO PÚBLICO:

A NECESSIDADE DE SE ACOMPANHAR A DISTRIBUIÇÃO DE RECURSOS PARA EFETIVAÇÃO

DOS DIREITOS FUNDAMENTAIS NO BRASIL

lecionou Flávio Galdino (2005, p; 15), e um Estado sem dinheiro não consegue proteger os direitos fundamentais, segundo o ensinamento de Holmes e Sunstein (2015). Logo a dimensão econômica não pode ser dissociada da aplicação do Direito, mas, também, as construções dos direitos essenciais não podem ser subordinadas às leis de mercado. Como uma das consequências há um ambiente de insegurança que abalou o consumo brasileiro, a geração de capitais, aumento do número de desempregados, diminuição de renda dos trabalhadores informais, acarretando a frustração de receitas públicas, que são necessárias para a efetivação de políticas públicas e da concretização dos direitos fundamentais e humanos.

Palavras-Chave: Orçamento Público, Direitos

Humanos, Direitos Fundamentais, Legística,

Responsabilidade Fiscal.
André Luiz de Matos

Gonçalves

\& Júlio Edstron S. Santos Uninassau/Palmas 


\section{A PROPOSTA DE UNIVERSALISMO DAS NAÇÕES UNIDAS E A EFETIVAÇÃO DE DIREITOS HUMANOS NO CENÁRIO MUNDIALTRANSNACIONAL}

Regiane Nistler,

Universidade Estácio de Sá (UNESA), campus do Rio de Janeiro (R)J

Jéssica Cindy Kempfer Universidade Luterana do Brasil (ULBRA), campus de Carazinho (RS)

\& Caroline Bresolin Maia

\section{Cadore}

Centro Universitário Leonardo da Vinci (UNIASSELVI), campus de Florianópolis (SC)
O estudo em apreço tem como objeto estudar o universalismo proposto pelas Nações Unidas de forma crítica e a demonstração de seu aparente fracasso no que tange a efetivação de direitos humanos no cenário transnacional decorrente da globalização.

Por isso, ostenta a seguinte problemática: o trôpego universalismo do sistema internacional de proteção dos direitos humanos tem sucesso na efetivação de direitos humanos a nível global em razão das mudanças decorrentes do transnacionalismo?

Para tanto, a pesquisa foi separada em três unidades intituladas da seguinte forma: (1) direitos humanos e a proposta universalista das Nações Unidas; (2) globalização e transnacionalismo: análise das mudanças pelo globo; e (3) a efetivação dos direitos humanos a nível global. O método utilizado foi o indutivo e a técnica de pesquisa foi a bibliográfica.

Nas seções descritas foi possível verificar que os direitos humanos são difíceis de serem conceituados, principalmente porque representam um tema que muda de acordo com os acontecimentos históricos. Contudo, percebe-se que é um direito humano que está em análise quando há sensação de pavor e inconformismo com a sua não efetivação.

Ainda, a breve pesquisa permitiu estudar os direitos humanos no sistema internacional, notadamente com a criação da Organização das Nações Unidas
(ONU) e os documentos internacionais de proteção, que significam, no período pós-guerra um crescimento relevante para a sociedade mundial.

Todavia, o que se apresentou muito relevante no texto em tela é que há imprescindibilidade de afastamento das formalidades exageradas quanto aos direitos humanos, pois a importância não está na formalização do direito, sem desmerecer a relevância desse expediente, mas na sua efetivação.

Dessa forma, é inevitável a conclusão pela indispensabilidade de substituição do pseudo critério universalista dos direitos humanos proposto pelo sistema internacional, considerando que ele existe tão somente num plano teórico e não se apresenta eficaz para efetivar direitos humanos, pelo contrário, pode significar fundamento para a falta de igualdade entre os países membros e não-membros, por exemplo.

Ou seja, o sistema internacional dos direitos humanos e sua proposta universalista representam nítida separação entre as bases dos direitos humanos, fundamentadas principalmente pelo humanismo na sua conceção com as características do renascimento, que posiciona o ser humano no núcleo do mundo e não entrega ao mesmo valor e dignidade em razão do espaço territorial no qual ele é encontrado, assim como pela nacionalidade que lhe assiste, mas exclusivamente por ser humano e pelo isso que representa.

Palavras-Chave: Direitos Humanos,

Universalismo, Transnacionalismo, Globalização, Nações Unidas. 


\section{O IMPACTO DAS FAKE NEWS NA DEMOCRACIA: ANÁLISE DE ESTUDOS REALIZADOS NO BRASIL}

O uso de notícias falsas com objetivo de manipular a opinião pública não é um fenômeno recente, principalmente nos processos eleitorais. Porém com o advento das redes sociais e do uso de dados massivos, a capacidade de produção e disseminação de informações falsas foi ampliada. As pesquisas que relacionam fake news e propaganda ideológica ainda estão em seu início no Brasil. Os resultados apresentados na literatura sugerem a vulnerabilidade do diálogo na construção da democracia deliberativa. Guimmler (2001) destaca a importância da discussão aberta, da participação cidadã e da existência de uma esfera pública. Segundo Habermas (1997), a troca argumentativa constitutiva do processo democrático deve ocorrer em variados espaços da sociedade, com autonomia da influência do poder administrativo e do mercado, formando assim uma esfera pública que implicará na formação da opinião e vontades coletivas. A pesquisa apresenta uma revisão sistemática da literatura sobre fake news em uma das principais bases de pesquisa brasileira, o Portal de Periódicos CAPES. No mecanismo de busca do Portal de Periódico da CAPES (BRASIL, 2019) foram utilizados os termos "fake news" "and" "propaganda ideológica", aplicados ao campo "busca por assunto", com os filtros "qualquer" e "contém", retornando nove resultados, cujos resumos foram lidos e os trabalhos selecionados, em função da sinergia de títulos correlatos ao tema de pesquisa. Os trabalhos selecionados foram: o de Pérez (2019), sobre desinformação; de Rodríguez-Fernández (2019), acerca do impacto das fake news na comunicação social; o artigo de Magallón-rosa (2018), sobre o efeito das fake news na campanha estadunidense de Donald Trump; o trabalho de González, Cabrero e García (2017) acerca dos fundamentos dapós-verdade. Os autores defendem o desenvolvimento pelos poderes públicos de medidas efetivas para evitar os efeitos deletérios para a democracia, oriundos de fenômenos emergentes, próprios das redes sociais, tais como fake news, shitstorms e candystorm, os quais permitem que o debate democrático seja sufocado, ou direcionado, por meio da aplicação de técnicas de manipulação de dados em larga escala, favorecendo o abuso de poder econômico em campanhas eleitorais por meio de impulsionamento pago de informações falsas. O enfrentamento das cascatas de desinformação é fundamental para garantir o processo democrático deliberativo, contribuindo para "tomada de decisão responsiva, inclusiva, participativa e representativa em todos os níveis" como preconiza a "Agenda 2030" da Organização das Nações Unidas (ONU).

Palavras-Chave: Fake News, Democracia Deliberativa, Esfera Pública, Rede Sociais, Opinião Pública.
Carlos Henrique Vale de Paiva

Universidade Candido Mendes \& Natália Andrade Rocha Universidade do Estado do Rio de Janeiro 
Musa M.Yusupov

Chechen State University

Ref.: I85CEDHM42020

\section{VALUE-BASED INTERPRETATION OF HUMAN RIGHTS INTHE POST-CONFLICT REGION}

In recent decades, interstate conflicts have decreased, but many intra-state regional, inter-ethnic, national-political conflicts, active and frozen in the Balkans, the Caucasus, the Middle East and the countries of Africa, Asia. They pose a serious challenge to general stability, recurring conflicts in European countries between representatives of different ethnic communities, migrants from different continents and parts of the world. Radical changes can occur in domestic politics and ideology in a number of countries as a result of a wave of racial protests and continuing cultural traumas as a legacy of the distant past. This article discusses the value and understanding of human rights in the general context and on the example of regional conflict in Chechnya.

The aim of the study is to identify the level and dynamics of human rights violations in conflict and post-conflict situations.

Subject of the study: ideas about the protection of human rights in various social groups.

Object of the study: the state of respect for human rights in different periods of conflict.

Method. The study used conflictological and sociocultural approaches, used quantitative analysis methods, provided data from sociological surveys in 2003, 2009, 2017.

Result. The value of human and civil rights in society depends on understanding traditional and modern culture, national legislation and international humanitarian law, socio-cultural and historical experience, type of state structure, political regime in the country.
The escalation of regional social tension into a political and pre-conflict situation is accompanied by a violation of ethical and legal norms and a disruption of the rule of law. During the armed conflict, the parties do not comply with international conventions on human rights, destroy life-support facilities, and violations of the human rights to life, movement, housing and others become total. The issue of establishing security zones and developing effective control mechanisms remains a weak link in the international impact on the conflict. The problem of terrorism and the struggle for the rights andfreedoms of citizens or the independence of the region need to be distinguished. The consequences of the conflict largely depend on the way in which it is resolved. Forceful methods of destroying one side of the conflict lead to the use of violence against civilians by the victorious side. Force, violence become an element of administrative management, civil institutions are blocked. In a post-conflict situation, there is a different understanding of human rights by human rights defenders and authorities. However, the restoration of socio-economic, educational and cultural infrastructure lays the foundations for strengthening civil and democratic freedoms in the future.

Conclusion. The modern world at the global and regional level is characterized by new challenges and threats in the field of human rights and sustainable development of society.

Keywords: Values, Rights, Conflict, Violence, Peace. 


\section{AS REGRAS GERAIS DE PROTEÇÃO INTERNACIONAL DOS REFUGIADOS}

Com a especial situação de vulnerabilidade em que se encontram os refugiados, justifica-se respostas específicas que ultrapassaram o quadro da protecção nacional. A solidariedade internacional implica que a protecção dos refugiados esteja ligada à protecção internacional dos Direitos Humanos. Para além da referência ao proclamado na Declaração Universal dos Direitos do Homem, foi necessária uma resposta conjunta dos Estados, através das organizações internacionais e regionais, para fazer face à deslocação de milhares de pessoas resultante de conflitos internos e internacionais, apelando a Comunidade internacional a intervir para assegurar a proteção dos refugiados.

A Convenção relativa ao Estatuto dos Refugiados, de 28 de Julho de 1951 e o Protocolo Adicional de Nova Iorque, de 31 de Janeiro de 1967 contêm uma definição geral e estabelecem certos critérios que determinam o estatuto de refugiado, proporcionando aos Estados contratantes uma base uniforme para o tratamento dos mesmos. Cabe a cada Estado parte, em cujo território o requerente se encontra, avaliar a situação pessoal do refugiado e o pedido de reconhecimento do estatuto de refugiado. Tanto a Convenção como o Protocolo requerem a cooperação dos Estados contratantes e do ACNUR para assegurar a proteção dos refugiados, delimitando as circunstâncias em que essa proteção pode ser assegurada.

Para além do regime universal, foram, entretanto, celebradas outras convenções sob os auspícios da União Europeia, que acabam por alargar ainda mais o conceito de refugiado e o conceito de perseguição. As características próprias da União Europeia enquanto União de Direito implicam que o indivíduo seja destinatário directo da sua produção normativa, pelo que no seu âmbito de aplicação, deve ser reconhecido ao indivíduo não nacional, carente de protecção internacional.

A cada Estado compete, pois, fixar as suas regras próprias de procedimento destinado à atribuição do estatuto de refugiado, tendo em conta os instrumentos internacionais e regionais sobre esta matéria. Todos os instrumentos jurídicos em vigor terão alguma eficácia se ao nível dos Estados forem aprovadas regras específicas que complementem estas regras gerais e que possam orientar os requerentes sobre os procedimentos a adotar em termos de concessão ou recusa de asilo, de atribuição e renovação de autorização de residência e de declaração de perda do direito de asilo. Face ao elevadíssimo fluxo de refugiados, não basta criar um procedimento interno rápido e flexível se os Estados não admitem mais pedidos de asilo e criam entraves à admissibilidade de refugiados nos seus países. Razão pela qual, tal protecção internacional universal está dependente da boa vontade dos Estados em admitir refugiados nos seus territórios e proporcionar condições de modo a facilitar a sua integração à semelhança dos estrangeiros residentes.

Palavras-Chave: Refugiados, Proteção, Direitos, Estatuto, Reconhecimento.
José Campos Amorim Instituto Superior de Contabilidade e Administração do Porto 


\section{MÃES IMIGRANTES E FILHOS BRASILEIROS: OS DESAFIOS DA CIDADANIA}

Dessana Paiva De Oliveira

Assessora Jurídica No Serviço Jesuíta a Migrantes e Refugiados - Manaus
O direito de nascer perpassa pelo direito à emissão da certidão de nascimento que é o primeiro documento conferido aquele que nasce com vida no Brasil e imprescindível para assegurar o acesso à direitos sociais básicos e fundamentais, principalmente aos cuidados de saúde e acesso à educação. As crianças têm direito à própria identidade constituído em um documento oficial de quem são, que inclui nome, sobrenome, filiação e nacionalidade. Neste sentido, a certidão de nascimento permite ainda o acesso a outros documentos como o Cadastro de Pessoas Físicas, bem como a inclusão em programas sociais, sendo um importante instrumento de inclusão social. As organizações da sociedade civil atuantes com a questão migratória são importantes aliados para a efetivação do direito ao registo de nascimento, considerando que são os locais de referência aos imigrantes que necessitam informar dificuldades e violações de direitos. Os recentes fluxos migratórios na Amazônia, especialmente na cidade de Manaus, mostraram a ausência de preparo de agentes públicos para tratar de questões peculiares referentes aos imigrantes, principalmente mulhe- res grávidas, condicionando o registo do nascimento de seus filhos brasileiros à apresentação de documentos que essas mães imigrantes não possuem ou mesmo exigências indevidas, colocando mãe e criança em situação de vulnerabilidade social. O presente artigo baseia-se no relato de experiência como Advogada atuante na questão migratória, é de natureza qualitativa e tem como proposta realizar uma análise do processo de emissão de certidão de nascimento de crianças brasileiras filhas de mães imigrantes na cidade de Manaus. Tomando como aporte teórico a questão das tecnologias de controle, buscando analisar como esse processo pode ser discriminatório e excludente. Para alcançar o objetivo deste estudo utilizou-se o aporte teórico referentes às tecnologias de controle, mostrando como exigências indevidas os relegam mães e filhos à exclusão de seus direitos. Assim, tornou-se evidente que as imposições desnecessárias, burocracias descabidas e despreparo de agentes públicos agravam a situação de vulnerabilidade e culminam com violação de direitos de mulheres migrantes e seus filhos brasileiros.

Palavras-Chave: Direitos Humanos, Direitos Sociais, Migração, Amazônia, Direitos das Crianças. 


\section{JUSTIÇA PÓS-TRANSICIONAL \\ - O PAPEL DAS INSTITUIÇÕES NO DIREITO À MEMÓRIA, À VERDADE E À JUSTIÇA NO BRASIL}

Este trabalho tem por objetivo analisar as incumbências das instituições brasileiras no contexto de justiça pós-transicional -posterior às ações estabelecidas como Justiça de Transição Tardia, de meados dos anos 2000 até 2014. A pesquisa, qualitativa, é bibliográfica, considerando os relatórios finais da Comissão Nacional da Verdade em comparação com os projetos desenvolvidos pela Secretaria Especial dos Direitos Humanos da Presidência da República entre os anos de 2012 e 2020.

O conceito de Justiça de Transição corresponde ao alinhamento das Instituições ao Estado de Direito estabelecido após um período de rupturas constitucionais, que garantirá a proteção deste Estado, proporcionando à sociedade civil os instrumentos orientados à reparação -da memória, da verdade e da justiça. No Brasil, democracia jovem que num passado recente viveu uma ditadura militar entre 1964 e 1985, intentou-se estabelecer um processo de Justiça de Transição Tardia por meio da criação da Comissão Nacional da Verdade, em 2012.

A instalação de processos de reparação, entretanto, pode torná-los instáveis ou superficiais -ou ainda, falhar na tentativa de estabelecer vínculos com a sociedade e atuar efetivamente na reparação pretendida. No caso brasileiro, a Justiça de Transição Tardia se estabelece décadas após o restabelecimento democrático: vinte e sete anos após o último governo militar, vinte e cinco anos após a promulgação da Constituição de 1988, que fundamenta o Estado Democrático de Direito. Além dessa distância temporal, a chamada Lei da Anistia, $n^{\circ} 6.683$, sancionada pelo presidente militar João Batista Figueiredo em 28 de agosto de 1979, exime o Estado, suas instituições e agentes de responsabilização -assim como aqueles que se posicionaram contra o regime e foram presos ou exilados -em quaisquer crimes cometidos durante a ditadura, inclusive os de lesa-humanidade.

Em respeito à lei da Anistia, a Lei $n^{\circ}$ 6.683 sancionada pelo presidente militar João Batista Figueiredo em 28 de agosto de 1979 e que exime o Estado e suas instituições e agentes de responsabilização, a Justiça de Transição Tardia brasileira ganhou contornos únicos, sem punir crimes cometidos, atuando pela reconciliação nacional. O processo de inicia antes da instalação da Comissão Nacional da Verdade, que reunia investigações baseadas em relatos orais e documentos, e buscava clarificar quais foram as ações das Instituições e seus agentes durante a ditadura, permitindo às vítimas reconstruir e ressignificar suas trajetórias à luz do reconhecimento e do aprendizado sobre a verdade dos fatos. Finalizada em 2014, a CNV terminou popularmente associada aos governos de esquerda que a instalam, e não ao Estado Brasileiro -mesmo sendo Política de Estado. Com o impeachment de Dilma Roussef em 2016, as ações das instituições nos governos de esquerda são questionadas e deslegitimadas como projetos enviesados, situação reforçada pelo ascendente revisionismo histórico e conservadorismo de extrema direita.

Palavras-Chave: Justiça de Transição, Justiça

Pós-Transicional, Comissão Nacional da Verdade, Regimes Autoritários, Revisionismo Histórico.
Aline Michele Nascimento 
Ref.: 228CEDHM22020

\section{VINGANÇA PRIVADA E EXPRESSÕES NA AMÉRICA LATINA: UMA ANÁLISE HISTÓRICA, POLÍTICA E FENOMENOLÓGICA SUL-AMERICANA}

James Gabriel Mendes

Garcez,

Talles Evangelista Silva

Araujo,

Augusto Daniel Pessoa

Gabina de Oliveira,

Gabriella Barbosa Pereira

Zayringue Ribeiro

\& Thiago Allison Cardoso

de Jesus

Universidade CEUMA
Entende-se o fenômeno vingança privada "como em uma forma específica de reação social, onde a vítima busca a satisfação das suas pretensões com os seus próprios meios, como uma possibilidade de autotutela ou autodefesa"(FILHO; PRADO, 2018) decorrente do fato da racionalização do poder de punir nas mãos do Estado não ser, no pensamento popular, condição suficiente de punição. Nesse sentido, o presente trabalho se justifica como um contributo à literatura especializada acerca desses fenômenos violentos e sua repercussão na América Latina e, de modo particular, considerando seus fundamentos históricos, políticos, ideológicos e incidência no subcontinente América do Sul. Em subcontinente tão vasto e à luz da literatura sul-americana, como é tratado o fenômeno da autotutela pelos pensadores e teóricos das ciências sociais, no tocante ao multiculturalismo das distintas regiões e quais os fundamentos históricos, políticos e ideológicos? O presente trabalho objetiva analisar, no contexto Sul-americano, o movimento teórico-conceitual sobre o fenômeno complexo da vingança privada bem como seus fundamentos históricos, políticos e ideológicos, a partir da sistematização da literatura sul-americana, verificando suas incidências e no sentido de sistematizar, a partir do uso da literatura especializada, o trato dado ao fenômeno pelo sub continente, bem como as diferenças nas estatísticas, quanto à vingança privada, ocorridas nos diversos contextos do nicho de pesquisa. Com base na literatura sul-americana e em pesquisas estatísticas atualizadas, a pesquisa possui caráter exploratório e abordagem qualitativa e quantitativa, com utilização de aplicação das técnicas de pesquisa documental acrescidas das técnicas de análise do discurso (FOUCAULT,2013) e de conteúdo (BARDIN, 2009) e bibliográfica com o fito de, a partir da literatura especializada pátria e internacional, investigar o fenômeno para fins de pesquisa e publicação dos resultados. Assim, depreende-se que: a) Há uma aceitação, em certa medida, da vingança privada pela população. b) De acordo com o Relatório de Desenvolvimento Humano (2019) a média do IDH latino-americano ajustado à desigualdade é de $0.589 \%$, o que aponta que a desigualdade social é fator que, no mínimo, influencia na aceitação popular.

Palavras-Chave: Vingança, Sul-Americana, Histórico, Ideológico, Análise. 


\section{AS PRÁTICAS RESTAURATIVAS COMO MEIOS EFETIVOS PARA A TRANSFORMAÇÃO DE CONFLITOS FAMILIARES}

A forma como o conflito é encarado é que o define como destrutivo ou construtivo, o conflito traz a possibilidade de autopercepção, interconexão, respeito aos direitos humanos e transformação de relações, famílias, comunidades ou nações. É certo que a sistemática perpetrada atualmente pelo Poder Judiciário está nitidamente enfrentando uma crise de efetividade, uma vez que a reincidência de ações e execuções, envolvendo as mesmas partes e objetos já discutidos, abarrota os gabinetes dos magistrados, que passam a julgar, de maneira generalista, casos com peculiaridades únicas que deveriam ser detidamente analisados. O Estado deve atuar positivamente para permitir o acesso à justiça que assegure o respeito aos direitos fundamentais. Nessa toada, o Conselho Nacional de Justiça incluiu a utilização de práticas restaurativas como política pública nacional (Resolução no 225/2016), com atuação fulcral no direito criminal, para o qual a Justiça Restaurativa foi inicialmente concebida. Essa pesquisa objetiva ultrapassar a utilização dessa abordagem e colocar a Justiça Restaurativa como novo paradigma de justiça, mormente no direito de família, sem excluir a atuação do Poder Judiciário, mas o fazendo pela percepção dos direitos humanos nas relações familiares, pautada na comunicação não-violenta, na identificação das necessidades dos prejudicados e na transformação de pessoas e conflitos. Foi feita uma pesquisa qualitativa e teórico-descritiva das práticas restaurativas nos conflitos familiares e da bibliografia nesta temática, apresentando a viabilidade dos processos circulares serem utilizados para transformação destes conflitos, já judicializados ou não, por meio de uma análise dialética e tendo como base o trabalho desenvolvido no Núcleo de Autocomposição em Matéria de Família do Ministério Público do Rio Grande do Norte, no qual encontros liderados por facilitadores oferecem um ambiente seguro para as partes falarem sobre suas vulnerabilidades, expressarem seus sentimentos e trabalharem para chegar a uma decisão mutuamente aceitável. Conclui-se que a redução da reincidência é um subproduto da prática da Justiça Restaurativa, reflexo do seu potencial de pacificação social. Aplicação do modelo restaurativo em conflitos familiares humaniza o processo e depende da voluntariedade dos interessados, passa pela percepção das necessidades dos envolvidos e das causas que levaram ao conflito instaurado, não com o escopo de retornar ao estado pré-conflitual, mas para rememorar o melhor de cada um e como aquelas pessoas já foram interconectadas positivamente. Mostrou-se premente a transformação das pessoas em protagonistas dos seus próprios conflitos, para que participem ativamente da busca pela transformação de vínculos. Ora, não basta existir uma sentença que põe fim à lide, de maior valia é a sensação de se empoderar da situação e participar da decisão que efetivamente satisfaça a realidade vivenciada (e não gere repercussões futuras negativas).

Palavras-Chave: Conflito, Família, Justiça Restaurativa, Empoderamento, Comunicação Não-violenta.
Lorena Nogueira Rêgo \& Ana Evelyne Cavalcante Costa Cerqueira Universidade Federal do Rio Grande do Norte - UFRN 
Ref.: 232CEDHM22020

\section{VINGANÇA PRIVADA NO ESTADO DO MARANHÃO: SUA PERPETUAÇÃO ATRAVÉS DO ESTADO EMTEMPOS DE DES ENCANTAMENTO DO PÓS-88}

Gabriella Barbosa Pereira

Zayringue Ribeiro,

Augusto Daniel Pessoa

Gabina,

Thiago Allisson Cardoso

de Jesus,

James Gabriel Mendes

Garcez

\& Talles Evangelista Silva

Araujo

Universidade CEUMA e UEMA
É sabido que a sociedade brasileira possui uma raiz histórica que a torna uma sociedade punitivista. Esta, se manifesta nos dias hodiernos através da legitimação pelo corpo social da vingança privada, dos altos índices de encarceramento e pela popularização do discurso do ódio, como o do "bandido bom é bandido morto". Analisando essa faceta punitivista conjuntamente com a Constituição Federal de 1988, torna-se evidente que os direitos fundamentais não são garantidos de forma igualitária a todos os cidadãos brasileiros, principalmente aos que se encontram em conflito com a lei. Assim, dentre as falhas na execução do Estado Democrático de Direito percebe-se o fenômeno da vingança privada, que se trata da reação de um ser ou corpo social perante um crime ou tentativa de crime cometido contra alguém, normalmente esse alguém é um familiar, amigo ou conhecido. Essa reação se dá através da execução de um novo crime -uma punição ilícita -desta vez contra o transgressor, gerando assim, um falso senso de justiça (falsos juízes que condenam a preço de morte). Nesse diapasão, essa "justiça privada" além de ilícita, é desprovida de proporcionalidade jurídica, tendo em vista que ela não observa e rasga a legislação penal brasileira, legitimando a barbárie, a intolerância, a violência e a brutalidade para a solução dos anseios populares. Elegeu-se como problema de pesquisa: De que forma o Estado garante a perpetuação do fenômeno da vingança privada? O presente trabalho busca analisar a) o fenômeno da vingança privada e b) o cunho político-criminal desse fenômeno, através de estudos de casos e com lócus no Estado do Maranhão, tomando por base o cenário de desencanto pós1988. Como metodologia utilizou-se da pesquisa exploratória, com abordagem qualitativa e quantitativa, referenciais teóricos especializados, técnicas de pesquisa bibliográfica, documental e análise do conteúdo de dados colhidos. Assim, como hipóteses/resultados alcançados, depreende-se que o fenômeno da vingança privada cresce: a) numa constante com o aumento da descredibilidade do Sistema de Justiça Criminal brasileiro e b) com o não combate à cultura do punitivismo, que ainda assola a sociedade brasileira.

Palavras-Chave: Vingança Privada, Punitivismo, Sociedade, Maranhão, Estado. 


\section{CIBERCRIME, INTERNET E DIREITOS HUMANOS NO BRASIL: UMA PERSPECTIVA DE OLHAR PELA SOMBRA E NÃO SOBRE A SOMBRA}

A rede mundial da Internet proporcionou uma aproximação intercultural nunca antes vista, estreitando e diminuindo o espaço simbólico entre pessoas, povos e sociedades, afetando o tempo entre o dado e a absorção do seu conhecimento. Novos processos culturais -ou tecnoculturais -surgiram, permitindo discutir inúmeros aspetos de sua interação reflexiva com o direito, porquanto a cada surgimento de uma nova tecnologia, gerando uma nova cultura tecnológica, os efeitos sobre e com relação ao direito podem ocorrer no menor ou maior espaço de tempo, dependendo de como os valores são percecionados e formados, gerando a reivindicação de uma formação de uma cultura jurídica correspondente.

Um dos temas que têm preocupado a sociedade é a cibercriminalidade, resultante da exploração da rede mundial com o fito de cometimento de delitos, sejam eles praticados com a utilização da Internet sejam eles executados tendo em vista "a rede das redes". Ela pode ser o objetivo principal do criminoso ou, também, seus dados e informações, relativos ou não à honra, à privacidade, à intimidade ou à liberdade das pessoas. Naturalmente, tendo em vista os direitos fundamentais já assegurados por algum ato normativo, seja internacional ou nacional, surgem o ou os conflitos entre os direitos já assegurados, especialmente o de segurança e/frente aos de liberdade e igualdade. Outros pontos geram discussão, como os de extimidade $x$ intimidade, livre manifestação $x$ ofensa, mas os mais emblemáticos são os relativos à liberdade de opinião/manifestação $x$ restrição de acesso (à Internet).
Assim, pretende-se discutir as relações entre o cibercrime e os direitos humanos no Brasil, partindo de uma perspetiva crítica, ou seja, como é possível garantir os direitos humanos no Brasil e, ao mesmo tempo, promover a segurança cibernética no ambiente virtual nacional e, reflexivamente, internacional com a utilização do direito?

Dividir-se-á o trabalho em dois tópicos principais, sendo o primeiro deles genérico, quando se avaliará a reconstrução dos direitos humanos a partir de uma perceção crítica de um novo contexto real: o ciberespaço. Parte-se, neste primeiro momento, de uma matriz teórica crítica de direitos humanos, especialmente tendo em vista os marcos teóricos de Herrera Flores (2009) e Wolkmer (2017). Procurar-se-á comparar as teorias tradicional e crítica dos direitos humanos e, a partir da perspetiva de deveres, contextualizar a necessidade de uma abordagem a partir do entorno, pela sombra e não para a sombra gerada pelos sistemas hegemônicos. Já o segundo tópico visa a delinear e a avaliar os direitos e deveres na e, com base na internet no Brasil, tendo o Marco Civil da Internet e a Lei Geral de Proteção de Dados, a pretensão em fundamentalizar o direito de proteção de dados pessoais na Constituição Federal brasileira. A metodologia é de uma revisão bibliográfica e, também, de pesquisa empírica da linha do tempo sobre o direito legislado no Brasil, sendo o método é dedutivo.

Palavras-Chave: Ciberespaço, Cibercrime, Dados Pessoais, Direitos Humanos, Teoria Crítica.
Emerson Wendt Universidade La Salle - Canoas/RS 
Ref.: 239CEDHM22020

\section{INTELIGÊNCIA ARTIFICIAL: \\ A PERSONALIDADE ELETRÔNICA DE SISTEMAS AUTÔNOMOS À LUZ DO DIREITO PORTUGUÊS E BRASILEIRO}

Milena De Carvalho Neves Mendoza

Universidade Autônoma De Lisboa UAL
O avanço tecnológico tem dominado toda a sociedade, transformando a rotina das pessoas de forma nunca antes cogitado. A consequência desse crescimento acelerado tem proporcionado muitas mudanças, desde as mais benéficas às mais desafiadoras. Nesse contexto de acelerado desenvolvimento, pode-se considerar que a tecnologia evoluiu e atingiu sua forma mais aprimorada com a inteligência artificial. Podemos compreender que a inteligência artificial é uma habilidade de criar sistemas dotados de funcionalidades inteligente que antes só poderiam ser realizadas pelo homem, sendo capazes de observar o ambiente, aprender com ele e aumentar as chances de sucesso. Atualmente, a inteligência artificial alcançou um patamar complexo e de bastante avançado capaz de gerar, inclusive, sistemas dotados de autonomia com poder de escolha e decisão sem qualquer influência humana, por meio da evolução do aprendizado de máquina (machine learning e deep learning) e coleta maciça de dados (big data). Os sistemas autônomos dotados de inteligência artificial, a partir dos dados disponibilizados, aprendem com os novos comportamentos e tomam decisões baseadas nesse aprendizado de máquina, gerando uma nuvem de imprevisibilidade que o homem desconhece. É nesse contexto que o problema do presente estudo sobrevoa, se os sistemas autônomos, máquinas com capacidade de escolha, tem personalidade eletrônica e podem ser responsabilizados por seus atos. Para fundamentar o presente trabalho, primeiramente iremos estudar as noções de inteligência artificial. Em seguida, será analisada a personalidade eletrônica dos sistemas autônomos dotados de inteligência artificial. E, por fim, estudaremos a responsabilidade civil de sistemas autônomos com personalidade eletrônica em caso de dano, levando em consideração os aspetos do Regulamento 2015/2103 do Parlamento Europeu. Atualmente, se discute muito sobre a responsabilidade civil dos agentes inteligentes (sistemas autônomos), devendo responder pelo dano causado o ser humano, seja ele fabricante (produtor), operador, proprietário ou utilizador. Mas há pouca discussão sobre a possibilidade de adoção de personalidade eletrônica a esses sistemas autônomos para tratar da responsabilidade civil em caso de dano. Tal questão ainda se mostra muito controversa para muitos pesquisadores por ser incompatível com os Direitos Humanos. Diante do exposto, observa-se que a presente pesquisa mostra ter grande relevância, pois, além de ser um tema recente e ainda pouco discutido, é carente de legislação específica e envolve temática de interesse cada vez maior e evolução constante. A metodologia adotada no presente estudo foi a bibliográfica, a partir de análise de legislações, regulamentos, doutrinas, artigos científicos e teses, sob método de abordagem dedutivo e de procedimento comparativo.

\footnotetext{
Palavras-Chave: Tecnologia, Inteligência Artificial, Sistemas Autônomos, Personalidade Eletrônica, Responsabilidade Civil.
} 


\section{A DIRETIVA (UE) 20I6/343 DO PARLAMENTO EUROPEU E DO CONSELHO DE 9 DE MARÇO DE 2016 - CONFRONTO COMA LEGISLAÇÃO NACIONAL}

A DIRETIVA (UE) 2016/343 DO PARLAMENTO EUROPEU E DO CONSELHO, de 9 de março de 2016, relativa ao reforço de certos aspetos da presunção de inocência e do direito de comparecer em julgamento em processo penal (referida adiante como Diretiva), devia ter sido transposta por até abril de 2018. Portugal é um dos poucos países da União Europeia que ainda não concretizou nenhuma medida de transposição. Sendo certo que o conteúdo da Diretiva terá de ser integrado na legislação nacional e que, por via da cláusula de não regressão, a transposição da Diretiva não poderá redundar num enfraquecimento dos direitos dos Arguidos já tutelados a nível interno, europeu ou internacional, torna-se pertinente apreciar os impactos reais que a transposição da Diretiva expectavelmente terá na esfera jurídico-subjetiva do Arguido em sede de alargamento previsível dos seus direitos de defesa. Este é um tema que se integra no eixo temático Paz, Justiça e Instituições Eficazes, no pressuposto que a aplicação da justiça penal, num Estado e numa União que se assumem como defensores dos direitos fundamentais e da dignidade humana de todos, pressupõe a atribuição de uma defesa sólida ao Arguido face à perseguição penal estadual, independentemente da sua culpabilidade, aliás apenas estabelecida a posteriori. Uma justiça robusta e credível é aquela que pune quem deve punir, sem que para tal implique uma lesão não justificada de direitos fundamentais os envolvidos, maxime o Arguido. Metodologicamente, vai-se proceder à com- paração do regime jurídico processual penal português, nos pontos abordados pela Diretiva, com o que esta impõe, de modo a constatar-se onde a lei interna já cumpre à partida e suficientemente a Diretiva, onde vai além das cautelas da mesma e onde fica aquém. Nesta última hipótese, serão apontadas desconformidades entre a lei interna e o preconizado pela Diretiva e adiantadas hipóteses plausíveis de alteração da lei interna em função do cumprimento da Diretiva. Acessoriamente, vai-se proceder à consulta de medidas de transposição já adotadas noutros países, no pressuposto que podem auxiliar a uma transposição mais bem-sucedida a nível interno. Será ainda trazida à colação jurisprudência interna e europeia que se afigure pertinente. Este é um estudo elaborado antes da efetiva transposição, no que corre o risco sério de ser a qualquer momento confirmado ou contrariado pela realidade legislativa. Aceitamos de bom grado o desafio, apresentando um estudo que, caso seja contestado pela realidade legislativa futura, não deixa de representar, deste já, uma crítica conceptual a uma transposição que possa vir a ser menos feliz e/ou uma configuração alternativa do modo como a transposição poderia ter sido concretizada. Caso seja confirmado pelo conteúdo da transposição, funcionará este estudo como uma legitimação da mesma. Em ambos os casos, daremos a assunção deste desafio como plenamente justificado.

Palavras-Chave: Direitos Do Arguido, Presunção de Inocência, Direito a Estar Presente e Julgamento, Garantias

Fundamentais, Transposição.

\section{Sandra Tavares}

Escola do Porto da Faculdade de Direito da Universidade Católica Portuguesa 
Ref.: 25ICEDHM42020

\section{O PRINCÍPIO ANTICORRUPCCÃO COMO INSTRUMENTALIZAÇÃO DO OBJETIVO N. 16 DA AGENDA 2030 DA ONU}

Aline Betiatto

Universidade de Coimbra
O escopo da pesquisa é analisar a influência negativa que a corrupção causa sobre as democracias e os direitos humanos e propor uma solução jurídico-hermenêutica-normativa por meio do Princípio Anticorrupção. Para tanto, usa-se como lastro o artigo XXVIII da Declaração Universal dos Direitos Humanos, o qual prevê a garantia de uma ordem social e internacional justa, cujas condições sejam favoráveis ao desenvolvimento e efetividade dos direitos e liberdades enunciados na própria Declaração. Tal premissa traz à lume a necessidade de instrumentalizar o objetivo número 16 da Agenda 2030 para o Desenvolvimento Sustentável das Nações Unidas, o qual apregoa, genericamente, a construção da paz, justiça e instituições eficazes, e mais especificamente, a redução da corrupção e do suborno. Nota-se, sobremaneira, nos países cujas democracias são de baixa intensidade, altos níveis de corrupção pública e privada que enfraquecem o Estado de Direito e interferem negativamente na promoção dos direitos humanos: o conluio entre governos e empresas despenca os níveis orçamentários para promoção de serviços de saúde e educação, prejudicando a possibilidade de os cidadãos atingirem padrões de vida adequados e dignos, conforme o disposto no também artigo XXV da DUDH. A corrupção impede ao Estado de aplicar o máximo de recursos para a realização do bem comum, direitos sociais e econômicos, frustrando o desenvolvimento e gerando uma pobreza generalizada -quando não sua manutenção por prolongados períodos -reforçando as desigualdades sociais. Inter alia, a mera existência de práticas corruptas deturpa a premissa do artigo XXVIII, uma vez que a corrupção torna a ordem social injusta e imprópria para a realização dos demais direitos previstos na DUDH e por isso deve ser combatida. Para tanto, vislumbra-se a aplicação das práticas de good governance, aliadas ao Princípio Anticorrupção, de forma que conduzam ao desenvolvimento sustentável tendo como foco a pessoa humana e o respeito aos direitos humanos e liberdades fundamentais, primando pela democracia assente no Estado de Direito. Ex positis, delineia-se o Princípio Anticorrupção como um princípio constitucional que atue no mesmo nível dos Princípios Estruturantes Democráticos e que funcione como protetor do próprio Estado de Direito e dos direitos humanos dele adjacentes frente às violações causadas pela corrupção. Sugere-se que a interpretação constitucional seja orientada para o combate à corrupção, a fim de se axiomatizar tal Princípio como componente do sistema jurídico-constitucional na luta contra a corrupção: propõe-se o reconhecimento deste como legítimo princípio estruturante do Estado de Direito, detentor de funções hermenêuticas e jurídicas, devendo ser empregado na elaboração de leis, em decisões judiciais e no controle de constitucionalidade preventivo ou repressivo e ainda como norteador dos todos os atos dentro de um Estado, ou seja, a real instrumentalização do objetivo número 16 da Agenda 2030.

Palavras-Chave: Anticorrupção, Direitos Humanos, Instrumentalização, Democracia. 


\section{MEDIAÇÃO DIGITAL: \\ A TECNOLOGIA A FAVOR DO ACESSO À JUSTIÇA À LUZ DO DIREITO PORTUGUÊS E BRASILEIRO}

Atualmente é possível observar que os Poderes Judiciários de Portugal e do Brasil enfrentam uma crise em decorrência da sobrecarga de processos judiciais. A cultura da judicialização generalizada contribuiu para essa realidade, uma vez que as pessoas passaram a adotar o judiciário como único meio de solução de conflitos. E em consequência a isso, outros problemas surgiram como a demora da prestação jurisdicional, elevado custo processual, déficit de servidores e impedimento ao acesso à justiça. Com a intenção de melhorar essa situação, foram criados meios alternativos de resolução de conflito para oferecer às pessoas outras formas de solução positiva, que não sejam apenas as vias judiciais. Considerando que hoje vivemos na sociedade da informação, umas dessas alternativas é a mediação digital, objeto do presente estudo, que se utiliza de meios eletrônicos para proporcionar aos interessados maior simplicidade e celeridade nos procedimentos, menor custo e eliminação de barreiras territoriais. Nesse contexto, o problema principal que a presente pesquisa buscará responder é se a mediação digital é capaz de proporcionar às pessoas maior acesso à justiça em decorrência da sua natureza essencialmente tecnológica, no âmbito do direito Português e Brasileiro. Para responder a esse questionamento, primeiramente o estudo pretende investigar os aspetos gerais do acesso à justiça. Num segundo momento, vai fazer uma análise comparativa entre mediação tradicional e mediação digital sob a ótica do acesso à justiça. E, por fim, vai analisar especificamente a mediação digital. Tanto a mediação tradicional como a mediação digital são alternativas de solução de conflito e visam oferecer às pessoas maior acesso à justiça. No entanto, ao aderir a mediação digital, deve-se considerar suas vantagens e desvantagens. A principal desvantagem diz respeito a exigência de meio eletrônico e internet para sua realização, provocando exclusão digital dos hipossuficientes que carecem de condições para atender a essa exigência. No que tange às vantagens da mediação digital, considera-se que esse mecanismo proporciona simplicidade, mais celeridade, menor custo e aproximação territorial. Dessa forma, acredita-se que na mediação digital, as vantagens superam as desvantagens. No entanto, para que a mediação digital realmente seja conveniente, faz-se necessário que se elimine ou até mesmo amenize as desvantagens, viabilizando sua estrutura e fomentando políticas públicas de inclusão digital, para que a mediação digital seja um propagador do direito fundamental de acesso integral à justiça e dos direitos humanos. Diante do exposto, observa-se que a presente pesquisa mostra ter grande relevância, pois, além de ser um tema recente, pode ser um instrumento de grande valia se utilizado de forma adequada. A metodologia adotada no estudo foi a bibliográfica, a partir de análise de legislações, doutrinas, artigos científicos e teses, sob método de abordagem dedutivo.

Palavras-Chave: Acesso à Justiça, Meios Alternativos, Resolução De Conflito, Tecnologia, Mediação Digital.
Milena De Carvalho Neves Mendoza

Universidade Autônoma De Lisboa UAL 


\section{A MEDIAÇÃO COMO INSTRUMENTO DE PROMOÇÃO DO DIREITO DE ACESSO À JUSTIÇA E CONSTRUÇÃO DE SOCIEDADES PACÍFICAS E INCLUSIVAS}

\author{
Cátia Marques Cebola \\ IJP-IPLeiria, ESTG \\ - Politécnico de Leiria \\ \& Susana Sardinha Monteiro \\ IJP-IPLeiria, ESECS \\ - Politécnico de Leiria
}

O direito de acesso aos Tribunais constitui um direito fundamental que encontra consagração expressa em Constituições e leis fundamentais dos modernos Estados democráticos, bem como nos principais textos internacionais de proteção dos Direitos Humanos. De entre estes, destacamos, a nível universal, o artigo 8.0 da Declaração Universal dos Direitos do Homem (DUDH) adotada a 10 de dezembro de 1948 pela Assembleia Geral das Nações Unidas e a nível regional, o artigo $6 .^{\circ}$ da Convenção Europeia dos Direitos do Homem $(\mathrm{CEDH})$, adotada pelo Conselho da Europa, em 1950 e mais recentemente, o artigo 47. ${ }^{\circ}$ da Carta dos Direitos Fundamentais da União Europeia (CDFUE).

Sem embargo, o modelo tradicional de Administração da Justiça, assente num quase monopólio da atuação dos Tribunais, não se coaduna com o atual conceito de Estado de Direito democrático nem com um novo modelo de cidadania. Uma cidadania ativa, participativa e responsável que reclama uma maior intervenção no espaço público $e$, consequentemente, no acesso à Justiça. Nesta senda, os meios extrajudiciais de resolução de conflitos têm vindo a afirmar-se como concretizadores da justiça de cada caso, não contrariando o art. 6. ${ }^{\circ}$ da $\mathrm{CEDH}$, mas antes densificando os comandos operativos desta norma atendendo à conceção atual de justiça, que pretende incluir os cidadãos na sua realização. Estes objetivos e moderna conceptualização encontram-se, de resto, refletidos na Agenda 2030 da ONU para o Desenvolvimento Sustentável, em concreto no seu desafio (ODS) 16 que almeja a construção de sociedades pacíficas e inclusivas, devendo proporcionar-se o acesso à justiça a todos e a construção de instituições eficazes e responsáveis em todos os níveis.

Neste trabalho propomo-nos estudar de que forma a mediação, enquanto meio extrajudicial de resolução de conflitos, pode concretizar estes objetivos. Com efeito, enquanto procedimento que visa a promoção do diálogo entre todos os stakeholders numa determinada situação conflitual tendo em vista a construção de uma solução que conjugue os interesses dos mesmos, a mediação afirma-se como um procedimento inclusivo e promotor da paz social.

Demonstrar como as técnicas e ferramentas ao dispor de um mediador possibilitam a inclusão de todos os interessados na resolução de conflitos, ao mesmo que responsabiliza as partes pelas soluções acordadas é o objetivo primordial deste trabalho. Assim, serão analisadas as fases do processo e as técnicas subjacentes à mediação, bem como o âmbito de aplicação social e jurídico deste meio por forma a traçar as virtualidades na concretização da Agenda 2030 da ONU.

Palavras-Chave: Direitos Humanos, Acesso à Justiça, Mediação, Cidadania, Estado de Direito. 


\section{A IMPORTÂNCIA DA SENTENÇA PENAL CONDENATÓRIA PARA A REPARAÇÃO DO DANO PROVENIENTE DA PRÁTICA DA INFRAÇÃO PENAL À LUZ DO ART. $5^{\circ}$ DA CF/88}

O presente artigo tem por objetivo analisar a nova perspetiva de indenização dos danos à vítima, através da fixação de valor mínimo já na sentença penal condenatória, do dano proveniente da prática da infração penal, à luz do artigo 50, XLV, da Constituição Federal da República. Para tanto, foram realizadas pesquisa doutrinária e jurisprudencial, em livros, artigos jurídicos e jurisprudência, além da análise da legislação nacional. A abordagem do tema se justifica porque é tendência internacional a revalorização da vítima no processo penal e determinada pelos Direitos Humanos, sendo imperioso que não se pairem dúvidas sobre a forma de reparação de danos para a vítima, quando fixada na sentença penal condenatória Este artigo tem como objeto esclarecer e especificar os critérios para a fixação de valor mínimo na sentença penal condenatória, a título de reparação de danos proveniente do ilícito penal. De início, pesquisaram-se na legislação penal brasileira os principais critérios para a quantificação do dano material, do dano moral e do dano in re ipsa na esfera penal e as possibilidades para a sua liquidação, e o recurso cabível para impugnar a decisão que teve por base o art. 387, inciso IV, do Código de Processo Penal. Pesquisou-se acerca do momento da aplicabilidade da lei, da possibilidade da fixação pelo juiz de ofício de valor mínimo a título indemnizatório, sobre os legitimados para o requerimento do pedido de indenização e os parâmetros para a sua fixação. A Lei n. 11.719/08 trouxe inovações sobre a reparação do dano ex-delito para a legislação brasileira, pois passou a permitir que o juiz ao proferir a sentença condenatória, fixe um valor mínimo a título de reparação dos danos causados pela infração, considerando os prejuízos sofridos pelo ofendido. O legislador quis com isso dar maior celeridade ao recebimento de indenização pela vítima, ao permitir que os juízes criminais, após o trâmite do processo penal, determinem a sentença condenatória o mínimo indemnizatório. Assim, fundiu em um mesmo processo pretensões processuais diversas e buscou com isso, chamar a vítima ou seus descendentes para o processo penal. A Reparação do dano ex delito tem por fim evitar sentenças conflituantes, pois diminui o caminho a ser percorrido pelo ofendido, já que há unidade de fato e do agente, podendo o juiz criminal desde já avaliar tais provas, e fixar valor mínimo indemnizatório. No final, conclui-se que a Lei n. 11.719/08 permite que o juiz ao proferir a sentença condenatória, fixe um valor mínimo a título de reparação dos danos causados pela prática da infração penal, considerando os prejuízos sofridos pelo ofendido, como consequência natural e automática da própria sentença, com o fim de tornar mais célere para o ofendido a reparação dos prejuízos experimentados pelo ato ilícito.

Palavras-Chave: Reparação De Danos, Sentença Penal Condenatória, Infração Penal, Critérios, Constituição Federal.
Luciana do Amaral Rabelo \& Rejane Alves de Arruda Universidade Federal de Mato Grosso do Sul 


\section{A REMIÇÃO DA PENA PELA LEITURA NO ESTADO DE MATO GROSSO DO SUL: ANÁLISE A LUZ DOS DIREITOS HUMANOS}

Luciana do Amaral Rabelo, Andréa Flores \& Fernanda Proença Azambuja Universidade Federal de Mato Grosso do Sul
O presente artigo tem como objetivo analisar a Remição pela Leitura no âmbito dos estabelecimentos penais do Estado de Mato Grosso do Sul, como standard de proteção aos Direitos Humanos. Faz a análise dos documentos internacionais que falam sobre 0 cumprimento de pena, a luz do princípio da dignidade humana e das Regras de Mandela. $O$ estudo dos presos deve ser incentivado como forma de ressocialização para que o preso respeite a lei após a prisão e tenha condições de fazê-lo. Assim, medidas curativas devem ser adotadas no sistema penitenciário, para se garantir a ressocialização dos condenados. E o estudo na prisão é essencial para reduzir as diferenças existentes entre a vida na prisão e a vida livre, servindo para trazer senso de responsabilidade aos condenados, possibilitando a saúde física e mental, e garantindo-Ihes a dignidade humana. Assim, o presente artigo tem por objetivo analisar a remição pela leitura no Mato Grosso do Sul, a luz dos documentos internacionais, de acordo com as alterações normativas que permitem a remição da pena mediante o estudo, e a possibilidade de tal instituto ser estendido à prática desportiva. $O$ artigo analisa a Lei $n^{\circ} 12.433$ de 29/06/2011 que disciplina a remição de pena pelo estudo e o Projeto de Leitura nos estabelecimentos penais do Brasil, regulamentado pela Recomendação n. 44 do Conselho Nacional de Justiça. Nos estabelecimentos penais de
Campo Grande, o Projeto de Leitura é feito em parceria com a Universidade Federal de Mato Grosso do Sul, com a participação de alunos de graduação em Direito, sendo que tais alunos ficam responsáveis pela correção das resenhas de livros feitos pelos reeducandos de vários estabelecimentos penais. Os reeducandos elaboram a resenha, na presença dos integrantes do projeto, após terem um período de trinta dias para realizarem a leitura. O projeto de leitura contribuiu para a educação em direitos humanos e auxilia na ressocialização e na dignidade, pois possibilidade a descoberta de conhecimento, do mundo, de si mesmos, e de novos direitos. Na Comarca de Corumbá-MS foi também instituído um projeto pioneiro de aulas de xadrez, sendo que a remição é disciplinada por uma portaria do juiz da execução penal. Verificou-se a importância da implementação de políticas públicas voltadas à assistência educacional das pessoas privadas de sua liberdade, concluindo-se que a remição pela leitura, possui amparo legal no artigo 126, caput, da Lei de Execução Penal que trata sobre a remição por estudo, e na Resolução N. 44 do CNJ, e em jurisprudência de nossos tribunais. A pesquisa parte do método hipotético-dedutivo, com a auxílio dos tipos de pesquisa bibliográfico e documental.

Palavras-Chave: Remição Da Pena, Educação, Leitura, Execução Penal, Dignidade Da Pessoa Humana. 


\section{O ATIVISMO JUDICIAL NA SAÚDE EMTEMPOS DE PANDEMIA}

As demandas judiciais envolvendo a saúde fazem parte da realidade do Judiciário e do Sistema Único de Saúde (SUS). O desenho institucional brasileiro atribui a gestão dos serviços de saúde a todos os entes da Federação: União, Estados, Distrito Federal e Municípios. As ações da saúde são realizadas de maneira solidária e participativa por estes entes, englobando diversos setores, como: distribuição de medicamentos, campanhas nacionais de vacinação, vigilância sanitária e intervenções cirúrgicas complexas, como transplantes. A Constituição Federal confere a toda a população do país acesso a saúde, integral, universal e gratuito. Essa gama de possibilidades de serviços de saúde, quando não atendidos, são direcionados ao Judiciário. O protagonismo para a solução de conflitos ficou a cargo deste poder da República, designado a falar por último. Num cenário de crise sanitária, as decisões judiciais nas ações versando sobre direito a saúde esbarram na impossibilidade de se tornarem efetivas, pois o colapso do sistema provocado, dentre outras razões, por um aumento não previsto de demanda faz com que todos os atendimentos sejam urgentes e prioritários. O objetivo deste estudo é refletir sobre as interferências das decisões judiciais no contexto atual de crise sanitária no sistema de saúde. A metodologia consistiu na análise de sentenças proferidas no âmbito do Tribunal de Justiça do Estado do Rio de Janeiro (TJRJ) no período compreendido entre os meses de março a julho de 2020, período que coincide com o início da pandemia no país e com o declínio de casos no Estado do Rio de Janeiro. As decisões analisadas são provenientes das diversas comarcas do estado, coletadas no site do TJRJ utilizando os seguintes descritores: internação, transferência, urgência, atendimento, saúde. Os documentos analisados são públicos e representam uma amostra aleatória disponibilizada pelo Tribunal. Nas decisões foram identificadas as seguintes variáveis: risco de morte, urgência do pedido, tempo de concessão do pedido, enfermidade e prazo para cumprimento judicial. A discussão confronta a prioridade de atendimento estabelecida pelas decisões judiciais e situações fáticas de urgências apresentadas na pandemia. Observa-se que as ordens advindas do Poder Judiciário geram um critério de preferência de atendimento para aqueles que judicializam sua demanda em detrimento daqueles que chegam, de maneira convencional, pelo Sistema de Saúde. Além dessas evidências demonstrarem traços de desigualdade e privilégios de acesso à saúde, um efeito perverso provocado pelas ordens judiciais é o de estabelecer critérios de urgências dissociados das decisões necessárias que devem ser tomadas pelos responsáveis em executar as ações de saúde em tempos de pandemia. Por outro lado, as decisões judiciais, individualmente consideradas, representam o único caminho para garantir a sobrevivência em casos em que a urgência pela vida não suporta aguardar a providência administrativa.

Palavras-Chave: Ativismo, Judicialização,

Pandemia, lgualdade, Saúde.
Fabiana Gomes Rodrigues, Faculdade Miguel Ângelo da Silva Santos (FeMASS)

Gilza Santos Simão Ferreira Faculdade Miguel Ângelo da Silva Santos (FeMASS)

\& Juliano Soares Rangel Faculdade CNEC Rio das Ostras 
Kelda Sofia Da Costa

Santos Caires Rocha

Universidade Estadual Do Maranhão

Ref.: 288CEDHM22020

\section{A PROTEÇÃO AO DIREITO DE LIBERDADE DE CRENÇA E O IMPACTO DO DIREITO INTERNACIONAL QUANTO A PROPOSITURA DE POLÍTICAS PÚBLICAS DE ENFRENTAMENTO}

A violência não é decorrente de palavras ou atos coativos ou constrangedores inicialmente, dando-se de maneira sutil e travestida de outras intenções, sendo que é tão eficazmente realizada que os dominados acreditam que os conceitos que são reproduzidos por eles são os seus próprios e não os oriundos de uma classe dominadora (BOURDIEU, 1989). Para que a violência simbólica seja perpetuada é necessário que tanto os dominados quanto os dominantes perpetuem identidades sociais, ou papéis sociais, que sejam adequados ao comportamento exigido, tais como a ideia de que mulher é um sexo frágil ou homens não choram, tolhendo as possibilidades de escolha da forma como cada pessoa deseja viver. Mecanismos de poder simbólico atrelados a violência simbólica criam um campo fértil para o desenvolvimento da intolerância entre as pessoas que não conseguem reproduzir os papéis impostos a elas no meio social. O Código Penal brasileiro dedica um capítulo inteiro voltado a defesa coletiva do sentimento religioso, todavia, conforme julgados selecionados para exemplificação, a questão do direito de exercício religioso sem o medo de sofrer extorsões, abusos e outras violências ainda se encontra muito longe da realidade, pois onde mais impacta a vida de alguém, nesse aspeto espiritual, é onde existe a menor tutela jurídica. Zaffaroni e Pierangeli (2015) diferenciam a existência de condutas que estão previstas no direito penal positivo, ofendem bens jurídicos protegidos, são crimes, mas que socialmente são suportáveis. Andrade (2012) cita que não é bem a questão de serem mais aceitos uns cri- mes do que outros, mas do que a sociedade consegue suportar sem maiores sacrifícios e permite que não sejam tão rigidamente cobrados, todavia, o que determina o nível do sacrifício é oque o poder instrumentaliza a partir das ideologias que Ihe são úteis. Nota-se que a tutela penal obedece a proteção nos termos de grandes aglomerações, - que caracteriza poucas vertentes religiosas brasileiras comprometendo o direito previsto no artigo II da DUDH. A metodologia adotada incluiu o método dialético que foi aplicado ao propor que todas as nuances da realidade, sejam elas sociais ou naturais, estão interligadas de forma a ser necessária a análise de determinada situação mediante a ótica das circunstâncias determinantes e explicativas do fato (MARCONI; LAKATOS, 2003). Utilizou-se a pesquisa exploratória com o propósito de realizar levantamentos bibliográficos adequados ao desenvolvimento de uma demonstração panorâmica do posicionamento doutrinário de autores jurídicos e de outras áreas e observação de exemplos nacionais mediante análise de casos e a sua repercussão consoante o direito internacional em face de proteção da liberdade de religião. Propõe-se como perspetiva de estudo a avaliação do direito internacional e o seu impacto na legislação e jurisprudência brasileira em prol da proteção da dignidade da pessoa humana. As pesquisas bibliográficas e estatísticas complementam o estudo.

\footnotetext{
Palavras-Chave: Liberdade Religiosa, Direito Internacional, Violência Simbólica, Criminologia Cultural, Antropologia Simbólica.
} 


\section{EL IMPACTO DE LA ROBOTIZACIÓN DEL RAZONAMIENTO ÉTICO-JURÍDICO SOBRE LOS DERECHOS HUMANOS}

Organizaciones como el World Economic Forum o la Fundación Friedrich Ebert Stiftung prevén que el ámbito de la administración pública va a experimentar grandes transformaciones en este siglo debido al impacto de la robotización en la burocracia. Uno de los grandes desafíos para el futuro de la humanidad, al menos desde el punto de vista organizativo y técnico, es el diseño del modelo de burocracia del futuro.

Entre los especialistas de las Ciencias Humanas, Sociales y Jurídicas que investigan en universidades y centros de investigación de Europa y América existe cierto consenso en torno al impacto de la Inteligencia Artificial en el futuro de la burocracia y, en general, en las Administraciones públicas. Existe consenso en torno a la idea de que las Administraciones públicas utilizarán en el futuro algoritmos y normas para efectuar las tareas de vigilancia democrática más elementales (e.g. asegurar la neutralidad, promover la igualdad, garantizar la equidad).

Estas tareas de vigilancia, en ocasiones injustamente subestimadas debido a su carácter estandarizado y repetitivo, forman parte del conjunto de tareas que pueden llevar a cabo los operadores jurídicos. De una manera muy general, puede decirse que los operadores jurídicos actúan cuando es necesario revisar las redes normativas.

En este artículo se plantean los temas anteriormente mencionados con el propósito ulterior de analizar el robot Watson producido por IBM. El robot Watson es un ejemplo de sistema de tecnología cognitiva, y está diseñado originariamente para ejercer una labor de control eficaz sobre el razonamiento jurídico. Nos referiremos a esta tecnología cognitiva con el objetivo específico de presentarla en los términos de un caso paradigmático de ética y filosofía política aplicada.

Partimos de la hipótesis de que existe la posibilidad de problematizar la finalidad y las funciones de dicha tecnología utilizando para ello una perspectiva dilemática, propia de las ciencias humanas y jurídicas, y con ayuda de la cual se establece un diagnóstico y pronóstico acerca del robot Watson. Para llevar a cabo este tipo de reflexión, muy necesaria para entender cuál es el futuro del razonamiento ético-jurídico y cómo puede afectar su robotización en organizaciones humanas, se llevará a cabo un análisis acotado de literatura científica procedente del área de la Filosofía moral y política contemporánea.

Palavras-Chave: Inteligencia Artificial,

Derechos Humanos, Robotización, Razonamiento Ético-Jurídico, Operadores Jurídicos.
María G. Navarro

\& Jonathan Piedra Universidad de Salamanca 
Ref.: 386CEDHMI 2020

\section{THE PARADOX OF MODERNIZATION: THE ALLEGED TERRITORIAL HEGEMONY OF THE BRAZILIAN STATE AGAINST CAPITAL'S STRUCTURAL CRISIS}

Antonio Carlos da Silva

Universidade Católica de Salvador
Aiming at a theoretical and critical analysis of the Brazilian's development our approach aims to contribute to an analysis of current power relations and the prominent role that Latin America, represented by Brazil, can play in setting another new world order. Redeemthe historical dimension of socioeconomic life, reduced by immediate interests that consolidates power relations, is to assert that any contribution to the critique of International Political Economy not expend effort to emphasize the paradox of modernityis just a baseless justification for restoration of bubbles financial characteristics of a system that was built on the pillars of inequality and monetary rationality. After power relations underlie the idea that underdevelopment is the reverse of the development and the two poles are the same historical field. Therefore, only with an International Political Economy, which prioritizes the principle of interdependence, can engender the actual development. Brazil to consolidate its power will be, leave the state of historical aporia, must confront the current model of production based on capital, to free themselves from the shackles of a modernization process intrinsically linked to increased production of inequality. One way to establish a Latin American contribution to overcome obstacles in the development and rescue the load of our historical time. Perhaps a review of the proposed processing of "lefts" in allusion theses Mészáros and Alain Badiou, as the horizon needed to overcome this stage of the crisis triggered by the transformation of the capital, a means to an end in himself. One of the effects of the global economic crisis is to allow the entry of some countries to the so called "rich club" (under the guidance of capitalization interests of transnational corporations) without due equal privileges. This reveals an asymmetry between economic and political institutions such sediments with globalizing profile structure.

Keywords: Brazil, International Relations, Crisis, Economy, Critical Theory. 


\section{A NATUREZA DO DECRETO CONDENATÓRIO PENAL DE PRIMEIRO GRAUNO BRASIL: JUÍZO DE PRELIBAÇÃO OU SENTENÇA INEFICAZ?}

O presente artigo visa analisar se a sentença penal condenatória no Brasil guarda ainda algum grau de eficácia, diante da decisão do Supremo Tribunal Federal nas Ações Diretas de Constitucionalidade n043, 44 e 54, que analisou a constitucionalidade do artigo 283 do Código de Processo Penal Brasileiro, entendendo só ser possível a execução da pena de prisão após o trânsito em julgado. Para tanto, são estudados, inicialmente, aspectos gerais sobre a natureza da sentença penal condenatória, buscando explorar a sua conceituação e carga decisória. Na segunda parte do trabalho far-se-á uma análise da decisão do STF nas ADC's mencionadas, em confronto com postulados jurídicos que regem o tema, notadamente quanto ao esvaziamento da efetividade do processo penal, diante do panorama criminal no Brasil. A partir daí é exposta a incompatibilidade da decisão do STF com o caráter de sentença do decreto penal condenatório, estabelecendo-se que sua manutenção faz nascera necessidade de se revisar o conceito e a nomenclatura da decisão que põe fim ao processo penal de conhecimento. Adotou-se na pesquisa a metodologia referencial bibliográfica, utilizando-se de livros, artigos e obras que versam a respeito do tema ora estudado e da legislação brasileira.

Palavras-Chave: Condenação, Sentença,

Processo Justo, Penal, Prisão.
Isabelle Rocha Valença

Figueiredo

\& Rogério Rodrigo Ferreira Mota

Promotor(a) de Justiça (MP/TO) 


\section{JUSTIÇA RESTAURATIVA PENAL NO BRASIL: É O ACORDO DE NÃO PERSECUÇÃO PENAL UM CAMINHO?}

Isabelle Rocha Valença

Figueiredo

\& Maria Carolina Silveira

Beraldo

Promotora(s) de Justiça (MP/TO)

\begin{abstract}
O presente artigo visa analisar se 0 acordo de não persecução penal, na forma como previsto no artigo 28-A do Código de Processo Penal Brasileiro, é medida eficiente para a implementação da justiça restaurativa penal no Brasil, de acordo com os seus primados, comunidade, autor do delito e vítima. Para tanto, são estudados, inicialmente, aspectos gerais sobre a justiça restaurativa penal, buscando explorar a sua conceituação mais atual. Na segunda parte do trabalho far-se-á uma análise do Acordo de Não Persecução Penal, na forma como constante no Código de Processo Penal no Brasil, notadamente quanto aos sujeitos envolvidos na consecução do referido acordo, bem como os requisitos para a sua formalização. A partir daí é traçada a eventual ligação do instituto com a justiça restaurativa penal e a construção de uma análise da eficiência do instituto na formulação de justiça, neste modelo. Adotou-se na pesquisa a metodologia referencial bibliográfica, utilizando-se de livros, artigos e obras que versam a respeito do tema ora estudado e da legislação brasileira.
\end{abstract}

Palavras-Chave: Justiça Restaurativa, Penal, Acordo de Não Persecução, Vítima, Dignidade Humana. 


\section{AVANÇOS E DESAFIOS DOS DIREITOS HUMANOS \\ NO BRASIL DO SÉCULO XXI: \\ O CASO DA CONSULTA PRÉVIA JUNTO AOS POVOS INDÍGENAS}

\begin{abstract}
A partir do final da primeira metade e do limiar da segunda metade do século $\mathrm{XX}$, os povos indígenas começam a experienciar em escala global, de modo geral, e latino americano, em particular, um processo organizativo sociopolítico de (re)etnização, crescente e enfrentamento da colonialidade do poder hegemônico representado pela ocidentalidade moderna. Nesse contexto, o dispositivo legal da consulta prévia emerge historicamente como um instrumento de reparação ao secular processo etnocidario e de marginalização a que foram submetidos os povos indígenas latino-americanos. Conquanto a vigência de tal dispositivo na Convenção 169 da OIT, os povos e suas coletividades continuam sendo alvo de violência, repressão e desrespeito sistemáticos em seus direitos políticos e constitucionais de grupos sociologicamente minoritários diferenciados, seja por obra dos próprios Estados Nacionais como por uma gama de empresas extrativistas, minerárias e pelos megaprojetos (neo) desenvolvimentistas e por várias corporações transnacionais.
\end{abstract}

Em se tratando do caso brasileiro no campo dos direitos humanos, em que pese os compromissos firmados pelo Estado nação a partir da promulgação da constituição cidadã de 1988, os povos, coletividades e pessoas indígenas permanecem enfrentando desafios de diferentes naturezas para consolidação dos direitos fundamentais à vida e aos territórios tradicionais. $\mathrm{Na}$ conjuntura nacional presentista de desdemocratização e neoliberalização da realidade social, agravada pelas crises sócio sanitária e econômica, a efetivação dos direitos humanos indígenas permanece, no limite, constrita em função da não implantação integral dos processos de reconhecimento e da autonomia indígena, bem como esse exercício fundamental, no domínio de um estado democrático de direito, persiste insuficiente e disfuncional em relação à história de implementação do mecanismo internacionalmente consagrado, a partir da materialização da Convenção 169 da OIT, de consulta livre, informada e culturalmente correspondente.

Palavras-Chave: Direitos Humanos, Povos

Indígenas, Direitos Humanos Indígenas,

Convenção 169 da OlT, Consulta Prévia.
Walmir Pereira UNISINOS/COGIPIT 
Claudia Maria Barbosa Pontifícia Universidade Católica do Paraná

Ref.: 397CEDHMI 2020

\section{A FRAGILIDADE DA ACCOUNTABIITY SOCIAL JUDICIAL EXPRESSA NOS INDICADORES EUROPEAN NETWORKS OF COUNCILS FOR THE JUDICIARY (ENCJ)}

O protagonismo político do Judiciário traz consigo a necessidade de reequilibrar independência e a accountability judiciais, por meio da qualificação da política judiciária, concebida como a política pública para o sistema de justiça, cujo objetivo é garantir uma prestação jurisdicional capaz de assegurar a efetividade do direito humano e fundamental do acesso à justiça. A combinação dos Indicadores da European Networks of Councils for the Judiciary (ENCJ) e a taxonomia da Escada de Participação cidadã proposta de Sherry Arnstein parece proporcionar uma análise mais aguçada sobre a accountability social judicial. Para testar esta hipótese, procede-se à análise da política judiciária operada no Brasil principalmente pelo Conselho Nacional de Justiça, e testou-se 34 mecanismos de accountability judicial brasileiros, de acordo com os indicadores do ENCJ, e se os aplicou à escada de Arnstein que, em 7 degraus diferencia níveis diferentes de participação cidadã que favorecem o cidadão passivo, o responsivo e o ativo. Os resultados obtidos revelaram que os indicadores da ENC] são atendidos sem que a accountability judicial seja ampliada, porque o nível de participação e controle sociais por eles contemplados favorecem sobretudo cidadãos passivos, esvaziando-se a accountability social, que se consubstancia em mecanismos ativos de participação e controle sociais sobre a política judiciária. Conclui-se que o judiciário brasileiro, reconhecido por seu altíssimo grau de independência, sem a correspondente responsabilidade, atenderia aos critérios de accountability propostos pelo ENCJ. Este resultado sugere que os parâmetros de accountability sociais propostos para avaliar qualificar o grau de accountability dos judiciários europeus seja frágil e insatisfatório para tal fim.

Palavras-Chave: Judiciario, Accountability Social, Indicadores, European Networks of Councils for the Justice, Conselho Nacional de Justiça. 


\section{NÃO-VIOLÊNCIA E RESTAURAÇÃO: UMA QUESTÃO DE DIREITOS}

De acordo com o Mapa da Violência -série de estudos e pesquisas realizadas periodicamente com foco na problemática da juventude e violência realizados pela Faculdade Latino-Americana de Ciências Sociais (Flacso) -o Brasil encontra-se na faixa dos países com alto índice de desigualdade social, apresentando indicadores alarmantes de violência e violação de direitos humanos, cujas causas estão relacionadas a fatores socioeconômicos, ao enfraquecimento das instituições e a negligência ou ineficiência do Estado. Além disso, formas estruturais de opressão de pessoas estigmatizadas social e historicamente agravam essa conjuntura, consolidando uma cultura naturalizada de discriminação e intolerância. Por outro lado, no plano jurídico e acadêmico, desde a promulgação da Constituição da República de 1988, que consagrou o Estado Democrático de Direito e reconheceu, entre seus fundamentos, a dignidade da pessoa humana e os direitos inerentes ao exercício da cidadania, o debate sobre os direitos humanos e a formação para a cidadania conquistou espaço e relevância no Brasil. Contudo, apesar do compromisso internacional com uma agenda de políticas para reverter o cenário de violências e violações de direitos firmado por meio da ratificação de tratados internacionais de direitos humanos, a atual realidade brasileira não sinaliza avanços, pelo contrário, prenuncia retrocessos. Diante disso, as pesquisas de caráter científico nas áreas das ciências sociais aplicadas são fundamentais para provocar mudanças e transformações socialmente relevantes. É dentro desse escopo que os pesquisadores proponentes visam apresentar na II Conferência Euroamericana para o Desenvolvimento dos Direitos Humanos, as informações levantadas e dados empíricos sobre a) o papel da universidade pública no cenário global para o exercício da cidadania de jovens e adultos; b) a relevância de temas como Comunicação Não-Violenta e Justiça Restaurativa como propostas contra-hegemónicas de superação das desigualdades sofridas por crianças e adolescentes e c) uma agenda de propostas, ideias e ações de alcance à década de 2030 para a promoção da cultura de paz e não-violência como políticas sistemáticas e não apenas ações esparsas, voluntariosas e de caráter assistencialista. Autores como Nancy Frase, Raul Calvo Soler, Leonardo Avriter, Boaventura de Sousa Santos, Marshall Rosenberg, Kay Pranis, e Howard Zehr são algumas das referências teóricas para a proposta que se segue para debate e compartilhamento, tendo em vista o período de crise global vivenciado na contemporaneidade. Decerto, a Universidade Pública apresenta-se como um espaço estratégico de promoção da agenda de educação de qualidade no século XXI e, como nunca antes, precisa ser inserida nas agendas de discussão internacional.

Palavras-Chave: Cultura de Paz, Comunicação Não-Violenta, Justiça Restaurativa, Universidade Pública, Educação.
Lucas Jeronimo Ribeiro da Silva

\& Elaine Cristina da Silva Doutorando - Universidade Federal de Minas Gerais 
Eduardo Pereira Monteiro Faculdade de Direito da Universidade de Coimbra

\section{Ref.: 248CEDHM22020 \\ O USO DA FORÇA NO DIREITO INTERNACIONAL: AS MISSÕES HUMANITÁRIAS}

O respetivo trabalho versa sobre o uso da força no direito internacional, e mais especificamente sobre as missões humanitárias em que o indivíduo, e os seus direitos fundamentais, encontram-se em um papel central de proteção.

Será feito um apanhado histórico do recurso à força pelos Estados e os seus respetivos conceitos e fundamentações, desde Tomás de Aquino, dentro do conceito de guerra justa, até o advento da Declaração Universal dos Direitos Humanos e as consequentes mudanças de paradigmas de cada período até o pós -11 de Setembro.

Com o aprimoramento de atuação da ONU houve um reforço em sua capacidade de resposta, passando a ser mais rápida e efetiva para os principais problemas da comunidade internacional. 0 desenvolvimento de sua normatização, à luz da Declaração dos Direitos Humanos, acompanhado com a crescente cooperação estratégica com a comunidade internacional parece consolidar um caminho efetivo e juridicamente assegurado em que o indivíduo terá sempre um lugar essencial.

Somado a isso, com o advento da doutrina da responsabilidade de proteger, parece que se encontrou uma projeção maior para as finalidades da ONU no tocante aos direitos fundamentais através de um possível reforço mais direto por parte dos Estados. Desde que de forma descentralizada e paralela, obedecendo a critérios estreitos, nunca com o objetivo de substituir à ONU, mas aprimorando a sua própria atuação, parece ser eventual atuação por parte de um Estado um grande avanço nos objetivos fundamentais de proteção e promoção dos direitos humanos.

Apesar de todas as dificuldades enfrentadas pela ONU e pela comunidade internacional no intuito de fazer valer a Declaração Universal dos Direitos Humanos, não podemos deixar de notar os caminhos que estão se consolidando positivamente para esse fim. Ainda temos uma longa caminhada, mas parece que do ponto de vista jurídico já demos um grande salto, necessitando, principalmente, do reforço de estratégias políticas e diplomáticas preventivas, para que tal caminho possa continuar se compondo de forma progressiva e eficaz.

Esse trabalho não tem como objetivo esgotar a temática das missões humanitárias dentro do domínio do recurso a força no direito internacional, antes, procura trazer uma análise sistematizada e reflexiva dentro dos principais pontos jurídicos de discussão que envolvem as respetivas questões.

Assim, procura-se compreender a importância que a regulação jurídica e a sua eficácia têm quando analisamos uma intervenção em um determinado território. Consolidar e aprimorar juridicamente os mecanismos de intervenção internacional com a garantia dos direitos fundamentais consagrados e normatizados parece ser um desafio complexo, mas substantivamente promissor para a humanidade.

Palavras-Chave: Missões Humanitárias,

Direitos Humanos, Regulação Jurídica, Nações

Unidas, Responsabilidade de Proteger. 


\section{ACESSIBILIDADE DEMOCRÁTICA \\ E O AMICUS CURIAE NO PROCESSO CIVIL BRASILEIRO: ESPERANÇA OU DESALENTO}

A legitimidade das decisões judiciais,
por muito tempo, residiu, em síntese,
em dois fatores: a previsão de compe-
tência constitucional do órgão julgador
e o desenvolvimento do procedimento
em contraditório substancial e mate- p
rial. Todavia, diante de novas técnicas processuais de tutela de direitos e interesses coletivos, bem como do estabelecimento de um sistema vertical de precedentes, pelo Novo Código de Processo Civil (Lei n.o 13.105, de 16 de março de 2015), a legitimidade das decisões judiciais, em seu aspeto democrático, precisa ser reforçado e a intervenção do amicus curiae, na qualidade de terceiro, pode constituir-se em importante instrumento de legitimação democrática das decisões judiciais. Neste contexto, o presente trabalho busca, através da elaboração de pesquisa documental e bibliográfica, analisar as principais regulamentações desta nova modalidade de intervenção de terceiros, constante do Novo Código de Processo Civil brasileiro, bem como o tratamento jurisprudencial desse terceiro no âmbito do Supremo Tribunal Federal. A justificativa que inspirou a pesquisa relaciona-se com o fato de que o Poder Judiciário tem assumido, desde o fenômeno da constitucionalização do direito, um destaque importante no debate político nacional, proferindo decisões com alto impacto social e financeiro e precisa encontrar elementos que o legitime democratica- mente. A partir dos resultados obtidos, foi possível constatar a possibilidade de que a função de amicus curiae seja desempenhada por pessoas naturais ou jurídicas e mesmo por entes despersonalizados, em processos judiciais objetivos ou subjetivos, apreciados por órgãos singulares ou colegiados, em uma evidente opção por uma sociedade aberta de intérpretes do ordenamento jurídico. Todavia, a legislação não tornou obrigatório o ingresso de amicus curiae em processos judiciais com grande repercussão social, nem definiu objetivamente quais são os poderes e as faculdades que podem ser desempenhadas no processo, submetendo o instituto a uma instabilidade procedimental indesejável. Por fim, demonstrou-se que os acórdãos oriundos do Supremo Tribunal Federal não elaboram a apresentação individual dos argumentos articulados pelos amicus curiae, o que pode comprometer o seu compromisso com a legitimação democrática, especialmente em sua perspetiva deliberativa, considerada a impossibilidade de verificar de que forma a pretensão argumentativa foi sopesada.

Palavras-Chave: Processo, Democracia, Legitimidade, Amicus Curiae, Supremo Tribunal Federal.
Rafael Da Silva Menezes

Universidade Federal Do Amazonas 


\section{ANÁLISE DA COECV NA IMPLEMENTAÇÃO DA MEDIAÇÃO NOS CONFLITOS COLETIVOS FUNDIÁRIOS NO MARANHÃO}

Dyhelle Christina Campos Mendes

\& Kelda Sofia Da Costa

Santos Caires Rocha

Universidade Estadual Do Maranhão
Os dissensos como notório, são intrínsecos à natureza humana. Assim, a busca por dirimi-los preservando direitos e princípios fundamentais, torna-se preponderante, diante do escopo na preservação de Estado Democrático de Direito. Com isso, no Brasil, pretendendo-se respeitar normas nacionais bem como dispositivos internacionais, 0 constituinte deixou a encargo de gestores a implementação de direitos sociais, isto é, de políticas públicas nesse viés, chegando-se à moradia, prevista no artigo $6^{\circ}$ da Carta Magna. Nessa linha, estima-se que 60 milhões de pessoas passem pela retirada de suas casas, inclusa a questão dos despejos, acrescentando-se que cerca de 1,6 bilhão de indivíduos vive em moradias indignas (LUDERMIR; COELHO, 2018), cuja violência e vulnerabilidade, giram em torno dessas famílias atingidas pela luta relacionada à terra. Segundo a Comissão Pastoral da Terra, conforme dados disponibilizados em 2018, há registro da totalidade de 1.124 ocorrências relacionadas a conflitos por terras, no Brasil, sendo que, no caso do Maranhão, a respeito do assunto, são 1.6154 famílias envolvidas, incluindo categorias de quilombolas, posseiros, indígenas, assentados, sem terra, por exemplo (CONFLITOS..., 2014) Assim, tendo em vista as arbitrariedades ocasionadas nas ações de reintegração de posse, surge de forma pioneira no Maranhão, a Comissão Estadual de
Prevenção à Violência no Campo e na Cidade (COECV) criada após a morte de jovem perante cumprimento de decisão judicial em prol de despejo, como forma de mediar os conflitos coletivos fundiários, seja urbano ou rural, a fim de preservar a dignidade da pessoa humana, princípio norteador do Estado Democrático de Direito no Brasil, bem como um dos fundamentos da República (artigo 1, III, da CRFB/88). Com isso, a mediação consiste em forma de acesso à justiça pautada na busca pelo diálogo, primando por espaço mais apropriado na discussão em torno desses conflitos coletivos relacionados à terra. Viana e Chai (2017, p. 45) sobre a temática dispõem que esses dissensos submetidos ao Poder Judiciário, poderão não ser dirimidos da melhor forma, pois, "transcendem o jurídico, envolvendo o social, o humano, o urbano, o rural e o territorial". Partindo-se disso, pretende-se analisar acerca da COECV como política pública em prol de assegurar a dignidade dos envolvidos nesses conflitos coletivos fundiários, através da mediação, verificando-se como essa forma de resolução de conflitos poderá ser mais satisfatória à temática, incluindo a busca pela observância na efetividade da medida, na paridade entre as partes e na redução da violência. Para isso, ir-se-á utilizar o método indutivo, acrescentando-se da técnica da pesquisa bibliográfica e documental.

Palavras-Chave: Comissão Estadual

De Prevenção À Violência No Campo

E Na Cidade (Coecv), Mediação, Dignidade

Da Pessoa Humana, Conflitos Coletivos

Fundiários. 


\section{JUSTIÇA PREDITIVA: VANTAGENS E PERIGOS DO USO DA INTELIGÊNCIA ARTIFICIAL EM SISTEMAS JUDICIÁRIOS}

A contemporânea sociedade da informação tem acarretado verdadeira revolução tecnológica em todas as áreas do conhecimento. Na seara jurídica, ferramentas de inteligência artificial vêm sendo desenvolvidas com o intuito de tornar os sistemas judiciais mais previsíveis, confiáveis, céleres e eficazes. Esses objetivos certamente são nobres. Porém, os riscos de manipulação da própria Justiça e da utilização equivocada de dados coletados também são grandes e reais, o que sugere a adoção de algumas precauções. Não é sem razão que o sistema francês, por exemplo, resiste à adoção da chamada "justiça preditiva" -entendida como uma subcategoria da justiça algorítmica que designa qualquer sistema automático de tomada de decisões legais que identifique prováveis resultados decisórios (o que é possível a partir da tecnologia de 'aprendizagem de máquina'). Recentemente, inclusive, houve a criminalização da utilização de dados de identificação dos magistrados e servidores do Judiciário para fins de avaliação, análise, comparação, previsão de futuras decisões e publicitação de estatísticas (Art. 33 da Loi $n^{\circ} 2019$ 222 , de 23/03/2019, sobre a reforma da justiça). Outros países, porém, não veem problemas em adotar sistemas preditivos que podem variar desde os mais simples (que apenas fornecem dados comparativos e probabilidades de êxito em demandas judiciais), até os mais complexos (que envolvem toda as fases do processo, inclusive a decisória, adotando-se o 'juiz robô' em substituição ao juiz humano, como é o caso da Estônia -para pequenas causas, assim consideradas as de até sete mil euros). Preocupa o fato de que algumas dessas ferramentas tecnológicas podem conter potenciais falhas de conceção, como talvez seja o caso do sistema COMPAS, utilizada em alguns estados norte-americanos para cálculo de probabilidade de reincidência em matéria penal (acusado de conter algoritmo que discrimina a população negra). Por certo, qualquer decisão judicial envolve uma parcela de incerteza, e os programas de predição podem ser importantes aliados na garantia da segurança e estabilidade jurídica. Contudo, não podem (e não devem) ser adotados de forma açodada, sendo recomendável, no mínimo, a observância dos princípios ditados na Carta Ética Europeia para o Uso da Inteligência Artificial nos Sistemas Judiciais. No Brasil, o debate ainda é incipiente, não obstante ferramentas desta natureza já venham sendo utilizadas por bancas de advogados e se inicia também em algumas unidades judiciárias (Sistemas Radar, Ellis, Sinapse, Jerimum, Clara, Victor, Poti e Sócrates, por exemplo). Objetiva-se, assim, mediante pesquisa comparativa, analisar as principais ferramentas de inteligência artificial utilizadas pelos sistemas jurídicos norte-americano, europeu e asiático, a fim de verificar qual é o grau de eficácia e segurança que oferecem, permitindo-se eventual incorporação ao sistema brasileiro, com as cautelas e adaptações necessárias.

Palavras-Chave: Justiça Preditiva, Inteligência Artificial, Acesso à Justiça, Princípios Éticos.
Karine Silva Demoliner \& Eugênio Facchini Neto Universidade Federal Do Amazonas Pontifícia Universidade Católica do Rio Grande do Sul (PUCRS) 
Ref.: 270CEDHMI 2020

\section{MEDIAÇÃO COMO PROCEDIMENTO POSSÍVEL NO CAMINHO DA CONSTRUÇÃO DE PAZ}

Diego El-Jaick Rapozo

Faleck \& Associados
No caminho da construção de paz nas mais diversas comunidades e sociedades do mundo existirão sempre inúmeros desafios. Desafios sociais, culturais, de comunicação dentre outros tantos possíveis que podem dificultar ou mesmo distanciar essas sociedades de políticas que sejam capazes de orientá-las e movê-las a um caminho de paz social.Em inúmeros contextos sociais as barreiras poderão ser vencidas com o uso das mais diversas técnicas de comunicação, negociação e mediação. $\mathrm{O}$ uso de mediadores neutros e experientes capazes de se aprofundar em um processo onde se busca uma justiça possível torna o procedimento confiável à vista dos envolvidos.

A condução de processo de pacificação poderá passar, sem nenhuma dúvida, por processos de comunicação e mapeamento das relações e situações as quais determinadas sociedades e/ou comunidades possam estar inseridas. Analisar o contexto social e os atores envolvidos no fomento da paz social será de grande importância ao longo de todo o processo e a utilização de mediadores e/ou facilitadores neutros, poderão ampliar as chances de êxito em menor tempo. Tratam-se aqui e situações em que o acordo é a melhor estratégia, mas que por alguma razão possa estar difícil de alcançar. Na dinâmica da construção de paz, pode-se dar voz a pessoas e/ou comunidades tidas como "excluídas sociais" ou mesmo, numa perspectiva mais filosófica, tidas como "invisíveis". Colocar luz nas diferenças ao invés de eliminá-las e buscar, através do diálogo e da cooperação alcançar resultados de resultados de benefícios múltiplos fazem da mediação uma ferramenta apta a facilitar o implemento da cultura de paz.

Ao longo do processo de monitoramento das políticas de paz deverá ser feito monitoramento contínuo dos resultados com mapeamento de stakeholders que devam fazer parte da construção de projetos que visem à pacificação social, sejam eles autoridades públicas ou privadas. Uma negociação com enfoque empático trazendo para a prática estratégias de busca por uma justiça possível poderá trazer resultados fáticos positivos fazendo com que os envolvidos se sintam co-contrutores de um projeto amplo que visa alcançar o interesse de todos, qual seja, a paz social. Os métodos adequados de solução de disputas têm em sua essência o objetivo desejado pela ONU na construção da paz social. São estes, por experiência em diversos países, métodos capazes de transformar e reconstruir relações e construir soluções com as partes presentes nesses processos sendo capazes de, com o apoio de um facilitador, sair de posições estanques geradoras de impasses para a iluminação de reais interesses na busca efetiva de resultados benéficos. São assim, os métodos adequados de solução de disputas, dos quais a mediação está inserida, mais uma ferramenta procedimental possível na busca e concretização da tão sonhada paz social.

Palavras-Chave: Mediação, Paz, Processo, Disputas, Sociedades. 


\section{INSUFICIÊNCIA DOS MECANISMOS DA JUSTIÇA \\ DETRANSIÇÃO BRASILEIRA: O CASO CELSO DA ROCHA MIRANDA}

O presente trabalho tem como objeto relatar as violações de direitos humanos e fundamentais atinentes ao Caso Celso da Rocha Miranda, que se estendeu aos seus ex-colaboradores e às suas empresas no regime ditatorial militar brasileiro, comprovadamente, por motivação política, conforme Relatório Final da Comissão Nacional da Verdade do Brasil, demonstrando os meios de reparação aos casos desta natureza mesmo sob o entrave prescricional, como hipótese, sem, contudo, ter a pretensão de esgotar o tema. Os meios de reparação da justiça de transição brasileira, não permitem, em termos pecuniários, uma fiel compatibilidade numerária dos danos causados, limitando-se, na maioria das questões judiciais, a determinar indenizações em valores de mesmo patamar dos processos administrativos em curso perante a Comissão de Anistia brasileira. Já no que tange à prescrição, é fato que a imprescritibilidade tão bem defendida em cortes internacionais no que tange a direitos fundamentais violados em regimes de exceção, e que devem ser indubitavelmente aplicados aos casos brasileiros, uma vez que o Brasil é signatário de tratados internacionais que visam a proteção destes direitos, com caráter constitucional, é um entrave que não poderia ser utilizado como limitador de deferimento dos casos similares apreciados pelas cortes brasileiras, uma vez que somente a partir lei brasileira de acesso à informação
(Lei no 12.527/2011), foi possível que os vitimados tomassem real conhecimento das perseguições políticas as quais foram submetidos.

Portanto, foram identificadas as normas jurídicas violadoras à época, realizadas análises e estudos das leis, artigos, obras literárias e audiovisuais, autos de processos judiciais, relatórios de comissões da verdade, depoimentos, documentos, arquivos apenas acessíveis a partir da quebra de sigilo permitida pela lei brasileira no $12.527 / 2011$, através da pesquisa descritiva, investigativa, explicativa e bibliográfica. Foram pesquisados, inclusive, documentos oriundos do advento do "Obama's papers", constatando-se, enfim, a insuficiência dos meios de reparação ofertados pela Justiça de Transição brasileira e a consequente fragilidade do Estado Democrático de Direito, justificando-se a necessidade de rediscussão e reabertura dos casos de violações julgados conforme a conveniência do cenário político da época. Desta forma, concluímos que o acesso completo à justiça é totalmente obstaculizado para efeito de uma reparação plena, perpetuando injustiças, havendo extrema necessidade de redefinições de políticas sociais e estruturais de satisfação judicial e administrativa, para efeito do cumprimento de metas de reorganização global da sociedade moderna.

Palavras-Chave: Justiça De Transição, Caso

Celso Da Rocha Miranda, Comissão

Da Verdade, Direitos Humanos, Direitos

Fundamentais.
Valéria Reis Gravino

Academia de Letras do Brasil, Panair do Brasil, OAB/RJ 
Ref.: 296CEDHM22020

\section{DIREITO DOS EXCLUÍDOS: ANÁLISE DO DIREITO DE ACESSO À JUSTIÇA PROPORCIONADO AOS CIDADÃOS DO INTERIOR DO ESTADO DO AMAZONAS}

Igo Zany Nunes Corrêa,

Universidade Federal do Amazonas

Laura Fernanda

Nascimento,

Universidade Federal do Amazonas

Dorinethe dos Santos

Bentes

Universidade Federal de Minas Gerais

\& Rafael Vinheiro Monteiro

Barbosa

Universidade Federal do Amazonas
Este trabalho tem como finalidade demonstrar a ineficiência estatal na efetividade do direito de acesso à Justiça nos interiores do Estado do Amazonas, analisando a atuação da Justiça, através dos instrumentos e números da Justiça Estadual, Federal e do Trabalho, bem como as adaptações estruturais tomadas para o acesso à ordem jurídica justa, até os obstáculos enfrentados na região. O Estado do Amazonas é o maior estado em área territorial do Brasil, possuindo a maior faixa de preservação da floresta que the dá o nome e abrigando 4.144.597 habitantes em estimativa dentre eles uma diversidade de povos e comunidades tradicionais como: ribeirinhos, indígenas, quilombolas, pescadores artesanais, piaçabeiros, dentre outros que formam o complexo amazônico. Todavia, as barreiras geográficas e socio ambientais que se instauraram na região acabam por gerar assimetria de densidade demográfica entre capital e interiores e neles residindo abismos de desigualdades no acesso a direitos fundamentais, tanto individuais, quanto sociais como: liberdade, saúde, educação, transporte, trabalho etc. O meio instrumental capaz de reparar lesões e ameaças a lesões a tais direitos, que em muitos casos são precarizados pela própria invisibilização tolerada pelo Estado, é o direito de acesso à Justiça, previsto no art. 50, XXXV, da Constituição Federal e seus instrumentos positivados. A importância do direito de acesso à Justiça é abalizada nas suas aceções estrutural e valorativa, como binômio indissociável para busca da igualdade material e para atingimento da finalidade constitucional de redução de desigualdades sociais. Entretanto para essas localidades distantes dos centros urbanos, discutem-se os impactos da ausência estatal tolerada sobre o direito de acesso à Justiça, sobretudo, considerando a exclusão digital, inexistência de unidades permanentes do Poder Judiciário e a ausência de acesso a advocacia regular. Para subsidiar a análise do presente trabalho, firma-se, a partir do conceito da sociologia das ausências (SANTOS, 2002) a necessidade de superação sistemática da invisibilização dessa população e do modo de vida dela para o centro de discussão das transformações democráticas da Justiça, principalmente, quando se vislumbra que as estruturas atuais não servem da mesma forma aos locais mais distantes dos centros urbanos, bem como carece de legitimidade social quando inseridas no contexto socioambiental e nas peculiaridades regionais. Para tanto, a metodologia deste estudo se deu, por meio da pesquisa quantitativa e qualitativa, baseada em dados bibliográficos e estatísticos condensados pelos Tribunais, utilizando-se do método dialético. Como resultados da pesquisa até então, tem-se que o direito de acesso à justiça é proporcionado de forma deficitária pelo Estado nos interiores amazônicos, considerando os obstáculos socioambientais e geográficos somados à ausência generalizada do Estado em tais localidades, violando a efetividade de direitos humanos.

Palavras-Chave: Acesso à Justiça no Amazonas, Barreiras Socioambientais, Desigualdade Social, Violações Direitos Humanos, Sociologia das Ausências. 
Ref.: 323CEDHM22020

\section{POLICIAMENTO PREDITIVO \\ - ESTUDO DO CASO PREDPOL E POSSÍVEL APLICAÇÃO}

O avanço da tecnologia permitiu inovações que alteraram e alteram completamente as relações sociais. Entre elas, o policiamento preditivo foi uma inovação que visa prever quando e onde um crime irá ocorrer, exercido por empresas como a PredPol nos Estados Unidos. Porém, questiona-se se esse tipo de sistema é de fato eficaz e, além disso, se o seu uso resultaria em um policiamento discriminatório em razão dos dados tendenciosos usados nos cálculos algorítmicos. Desta forma, o presente trabalho pretende analisar bibliografias e artigos científicos sobre o tema para discutir a possibilidade de aplicação do policiamento preditivo algorítmico no Brasil, com base em pesquisas e estudos internacionais já realizados. Logo, conceitua-se o policiamento preditivo, expõe-se problemas e possíveis soluções e, por fim, opina-se quanto a sua implementação.

Policiamento preditivo pode ser definido pela aplicação de técnicas analíticas de identificação para direcionar a intervenção policial na prevenção de crimes, utilizando previsões estatísticas. A ideia é que seja possível prever quando e onde atividades criminosas ocorrerão, por meio de algoritmos e da inteligência artificial, como é o caso do programa PredPol. Todavia, a aplicação deste método é questionável, haja vista a possibilidade de enviesamento dos dados fornecidos, situação que resultaria, por exemplo, em ações policiais excessivas num determinado bairro ou região.

Nesse sentido, foi feita uma análise de bibliográfica a respeito do policiamento preditivo. Mais especificamente, analisou-se o mencionado programa a partir do artigo publicado pela Royal Statistical Society que demonstrou a falta de ineficácia do método preditivo em razão do uso de dados enviesados pelos sistemas de predição. Logo, a aplicabilidade do método preditivo de policiamento deve ser estudada com meticulosidade pois o impacto social discriminatório causado pelo seu mal uso, é notório, conforme expos o presente trabalho.

Policiamento Preditivo: O direito penal estuda formas de amparar as relações sociais por meio de normas que estipulam condutas consideradas ilícitas
Lucas Brito Silveira Santos \& Natália M. G. Miyazaki Universidade Presbiteriana Mackenzie 
Lucas Brito Silveira Santos \& Natália M. G. Miyazaki

Universidade Presbiteriana Mackenzie
Ref.: 323CEDHM22020

POLICIAMENTO PREDITIVO

- ESTUDO DO CASO PREDPOL E POSSÍVEL APLICAÇÃO para o ordenamento jurídico adota. De fato, se fosse possível prever o futuro, muitas das teorias e doutrinas criadas seriam descartáveis, porque bastaria impedir aprática reprovável antes mesmo que ela ocorresse. Todavia, as inovações tecnológicas abriram espaço para a criação de mecanismos como o algoritmo, definido por um conjunto de métodos utilizados na realização de cálculos, resolução de problemas e na tomadade decisões, por exemplo.

Sua definição, pode ser explicada por uma analogia da receita culinária. 0 algoritmo seria a receita, como de uma sopa de legumes, enquanto o passo a passo seria sua programação (separar os legumes, esquentar a água, temperar etc.). Isto, deflagra que algoritmos de aprendizado automático são projetados para armazenarem, calcularem e reproduzirem padrões somente a partir dos dados fornecidos, independentemente dos resultados.

Palavras-Chave: Tecnologia Inovação, Dados

Enviesados, Segurança Publica, Análise

Tendenciosa, Infraestrutura. 


\section{RESPONSABILIDADE CIVIL POR ABANDONO AFETIVO}

Este estudo objetiva a análise da possibilidade de responsabilização do genitor por abandono afetivo, partindo da premissa de que o afeto dos genitores é fundamental à formação psicológica, moral e emocional dos filhos, enquanto seres em desenvolvimento, e de que a falta de convivência familiar e afeto coloca a prole em situação de desamparo afetivo. O objetivo geral é analisar a possibilidade de responsabilização do genitor por abandono afetivo. Conclui que apesar da paradigmática decisão proferida no âmbito do Superior Tribunal de Justiça, de relatoria da Ministra Nancy Andrighi, os Tribunais Estaduais ainda relutam em reconhecer o dano moral proveniente do abandono afetivo, apesar de serem evidentes as consequências para o filho, e flagrante a violação dos princípios constitucionais. Como resultados, pode-se mostrar que os pais não são obrigados a amar os filhos, porém, é um direito inalienável da criança, o cuidado que é responsabilidade dos pais inscrita na Constituição Federal. Assim, nos casos em que estejam comprovados os prejuízos psicológicos e, quiçá, materiais sofridos pelo filho em decorrência do abandono afetivo, a justiça deve estabelecer o quantum indenizatório para ressarcir o mal causado por este progenitor.

Muito se tem discutido, nos últimos anos, a possível responsabilização civil do(s) genitor(es) por abandono afetivo, temática que gera muitas controversas no âmbito doutrinário e jurisprudencial, e que se encontra longe de sedimentação, principalmente porque inexiste diploma legal a regulamentar especificamente o abandono afetivo no ordenamento jurídico brasileiro.

Nesse contexto, enquanto parte dos estudiosos do tema preconizam que a falta de afeto vai de encontro ao dever jurídico de cuidado, imposto aos pais em relação aos filhos, e que decorre do disposto no art. 227, da Constituição da República de 1988, e que gera, por conseguinte, a responsabilização daquele que não cumpre o preceito constitucional.

Factualmente, a Constituição da República de 1988 assegura à criança e ao adolescente, com prioridade, uma gama de direitos fundamentais, além de colocá-los à salvo de toda forma de negligência, discriminação, exploração,
Natália Mayumi Gonçalves Miyaza

\& Lucas Brito Silveira

Santos

Universidade Presbiteriana Mackenzie 
Natália Mayumi Gonçalves Miyaza

\& Lucas Brito Silveira

Santos

Universidade Presbiteriana Mackenzie
Ref.: 324CEDHMI 2020

RESPONSABILIDADE CIVIL POR ABANDONO AFETIVO

violência, crueldade e opressão.

Pois, o progresso da doutrina da proteção integral, que converteu a criança e $o$ adolescente em sujeitos de direitos, destinatários de tratamento especial, a conceituação de poder familiar obteve também um novo significado, deixou de ter sentido de dominação, como outrora prevaleceu, para se tornar sinônimo de proteção. Outra questão a ser enfatizada é que, na atualidade, o princípio da proteção integral da criança e do adolescente, consagrada expressamente na Constituição da República de 1988 , e que norteia também o Estatuto da Criança e do Adolescente, está umbilicalmente unido ao princípio da dignidade da pessoa humana, consagrado no direito pátrio como fundamento da República Federativa do Brasil, e ainda possui relação com os princípios da paternidade responsável.

Palavras-Chave: Justiça Social, Abandono Afetivo, Paz Social, Criança E Adolescente, Direito De Família. 


\section{THE BRAZILIAN CRIMINAL JUSTICE SYSTEM AND ITS DIMENSIONS WITH PUBLIC HARM REDUCTION POLICIES: EFFORTS OF THE “JUSTIÇA PRESENTE” PROGRAM}

This article intends to expose the institutional design of the "Justiça Presente" Program, a public policy developed by the United Nations Development Program (UNDP), in partnership with the National Justice Council (CNJ) and the United Nations Office on Drugs and Crime (UNODC) to combat prison overcrowding. The choice of the agenda occurs in a global scenario in which Brazil ranks as the 3rd largest prison population in the world, with short-and medium-term growth forecasts. In domestic jurisdiction, the prison system was lifted to the Unconstitutional State of Things by the Federal Supreme Court (STF) in the September 2015 ADPF 347 MC / DF judgment as it operates $70 \%$ above its capacity. The data point to a flow in the criminal justice system of undermining constitutional criminal rights and procedural guarantees. One of the alternatives found by the Brazilian State was the investment in public policies implementing Human Rights, such as the recently agreed "Justiça Presente" (2018), an unprecedented partnership between the National Council of Justice (CNJ), the United Nations Development Programme (UNDP) and the United Nations Office on Drugs and Crime (UNODC). The "Justice Present" Programme is the first international technical cooperation project signed between the UNDP and the Judiciary to be implemented in Brazil. It is a public policy promoted through an internatio- nal technical cooperation agreement for the strengthening of the monitoring and supervision of the prison and socio-educational system. In this context, this article will conduct a empiric research based on documentary analysis of the JP project with the purpose of investigating if the initiative of the National Council of Justice with the United Nations Program for Economic Development, called"Justiça Presente", as a public policy for harm reduction, represents an efficient tool in the construction of an alternative paradigm for criminal justice in the short and medium term, especially in combating the excess of provisional prisons. The partial conclusions lead this research to an affirmative perspective. The results found so far indicate that the State's actions, even if they are carried out through organs of the judiciary in cooperation with international organizations such as the UNDP/UN, have the capacity to articulate among the main actors and managers of the criminal justice system. This is an initiative that does not end in itself but invests in the demarcation of the political and civilizing value that the Brazilian State intends to giveto the target subjects of the criminal justice system.

Keywords: Public Harm Reduction Policy, De-Incarceration, Prison Overcrowding, Alternative Criminal Policy, Criminal Minimalism.
Helena Rocha Matos, Taiguara Libano Soares e Souza,

Roberta Duboc Pedrinha \& Bruno Joviniano de Santana Silva Universidade Federal Fluminense 


\section{A NECESSÁRIA VIRTUALIZAÇÃO DAS AUDIÊNCIAS JUDICIAIS PARA A GARANTIA DO ACESSO À JUSTIÇA E DO DEVIDO PROCESSO LEGAL EMTEMPOS DE CRISE}

Hannah Pereira Alff

Mestranda em Direito pela PUCRS Bolsista Integral CAPES/PROEX

\& Sérgio Augusto da Costa

Gil

Doutorando e Mestre em Direito e Especialista em Direito Processual Civil pela PUCRS. Bolsista Integral CAPES/PROEX
Por mais que a humanidade saiba que depende de adaptações cotidianas para a manutenção de sua existência, a imprevisibilidade de uma pandemia potente como a da COVID-19 abalou o mundo em 2020 e colocou todos frente a uma série de rápidas adaptações e inovações necessárias no período de crise. Para o Direito, portanto, não poderia ser diferente.

O distanciamento social, enquanto recomendação da Organização Mundial de Saúde na busca de evitar o aumento no número de contágios, fez com que diversas atividades essenciais ligadas ao exercício da jurisdição se tornassem home office em curto período. Desta forma, o que se conhece como direito à conexão ganhou intensidade. No período de isolamento, o acesso às informações globais e a comunicação com outras pessoas torna-se possível pelo uso das Tecnologias de Informação e Comunicação (TICs), de modo que, assim como diversas atividades, o acesso à justiça passou a depender de amplo acesso também a estas TICs.

É preciso observar que, apesar de as mudanças ocorrerem tão rapidamente, não se pode desvalorizar a essencialidade da justiça e o fato de que, em momento de crise, é ainda mais necessário que indivíduos com direitos ameaçados ou lesados tenham acesso a meios adequados para sua asseguração. Portanto, é necessário o questionamento do quanto é possível adequar um procedimento de modo tão rápido para atender às necessidades sociais latentes, mediante utilização das TICs sem que o devido processo legal seja relativizado a ponto de tornar-se ficção judiciária.

A virtualização do procedimento jurisdicional possibilita que as audiências judiciais de toda natureza sejam realizadas também de forma virtual, para além da tramitação eletrônica dos autos judiciais. Com a necessidade do isolamento social, a possibilidade precisou tornar-se realidade, de forma que as audiências judiciais virtuais passaram a ser a regra para que os processos jurisdicionais em andamento não continuassem suspensos. A justiça, ainda que tardia, precisa andar e entregar o bem da vida se for de direito sem pôr em risco os agentes processuais. 
Ref.: 340 CEDHM22020

A NECESSÁRIA VIRTUALIZAÇÃO DAS AUDIÊNCIAS JUDICIAIS PARA A GARANTIA DO ACESSO À JUSTIÇA E DO DEVIDO PROCESSO LEGAL EMTEMPOS DE CRISE

As audiências judiciais no Código de Processo Civil estão previstas para ocorrerem de forma física, dado que a infraestrutura do juízo ou do fórum asseguram que as disposições sejam cumpridas, como o depoimento de uma das partes não poder ser visto pela outra que ainda não depôs (art. 385, § $2^{\circ}$ ). Neste sentido, a audiência judicial realizada integralmente por videoconferência precisa assegurar o cumprimento deste dispositivo, em atenção ao devido processo legal, por exemplo.

Destarte, pretende-se analisar de forma indutiva como a virtualização integral das audiências judiciais precisa que, primeiramente, todos os agentes processuais tenham o direito à conexão garantido para, em seguida, discutir a melhor forma de esta virtualização acontecer em atenção ao devido processo legal, garantindo que o direito de participação nos atos processuais seja exercido de forma equivalente às audiências físicas. Para tanto, utilizar-se-á de levantamento bibliográfico e documental sobre como tem sido operado pelo Poder Judiciário e quais ferramentas ou técnicas podem ser uti- lizadas para garantir o devido processo legal e o acesso à justiça na virtualização das audiências judiciais.

Palavras-Chave: Virtualização das Audiências Judiciais, Acesso à Justiça, Devido Processo Legal, Pandemia, Crise.
Hannah Pereira Alff

Mestranda em Direito pela PUCRS. Bolsista Integral CAPES/PROEX \& Sérgio Augusto da Costa Gil

Doutorando e Mestre em Direito e Especialista em Direito Processual Civil pela PUCRS. Bolsista Integral CAPES/PROEX 


\section{“LAWFARE” E O USO DO DIREITO COMO INSTRUMENTO DE GUERRA: \\ UMA ANÁLISE SEGUNDO CLAUSEWITZ}

Guilherme Berriel

Universidade Nova de Lisboa - NOVA School of Law
Em 2012, um navio russo chamado MV Alaed estava levando um carregamento de helicópteros militares para o regime de Bashar Al-Assad na Síria. O Reino Unido queria parar o carregamento, mas não podia fazê-lo por meio do uso da força, sob pena de desencadear a Terceira Guerra Mundial ao cometer um ato de guerra contra a Rússia. Então, os ingleses convenceram a seguradora do navio, a London's Standard Club, a retirar o seguro do transporte e este não teve outra escoIha a não ser retornar ao país de origem levando sua carga. O Talibã e a Al-Qaeda ao temer os bombardeios de precisão, passou a posicionar suas instalações próximas a hospitais e escolas, ao mesmo tempo, tentando demonizar os ataques aéreos por meio da media afegã, caracterizando-os como injustos, desumanos e iníquos. Como resultado, as tropas da NATO modificaram as regras de engajamento, afirmando que não mais iriam atacar posições se soubessem que poderia haver sequer uma baixa civil, o que reduziu a eficácia da sua ação em benefício dos adversários.

Para designar tais condutas, o conceito de "lawfare" foi cunhado no ano de 2001 pelo General Charles Dunlap Jr., e aprofundado em obras posteriores, expressando "o uso da lei como arma de guerra" ou "a estratégia de usar -ou abusar -da lei como substituta para um meio militar tradicional a fim de alcançar um objetivo bélico" (tradu- ção nossa). Significa, portanto, a utilização do Direito como instrumento para a obtenção de uma vantagem militar.

Contudo, a incipiente literatura sobre o tema e a ausência de métodos e critérios para sistematizar tal uso de mecanismos jurídicos, permite o emprego do "lawfare" de forma propositadamente vaga e flexível, a fim de facilitar a legitimação de hostilidades perante as instituições nacionais, internacionais e à opinião pública. O objetivo deste trabalho é analisar a prática do lawfare segundo a teoria da guerra de Clausewitz, para possibilitar a compreensão do fenômeno do ponto de vista estratégico por meio de uma pesquisa exploratória, segundo o método hipotético-dedutivo que utilizará como procedimento a investigação bibliográfica. Como resultado, a prática do "lawfare" é um fenômeno estratégico que se mostra compatível com a teoria clausewitziana, nomeadamente pela relação estreita entre Política, Direito e Guerra, pela limitação da guerra pelo propósito político e militar e pela influência no fenômeno na trindade suprema concebida pelo autor. Dessa forma, a referida análise contribui para maior embasamento teórico do tema e futuros desenvolvimentos, especialmente no que concerne aos estudos relativos à paz, justiça e instituições eficazes para garantia da segurança internacional e redução da capacidade destrutiva dos conflitos armados.

Palavras-Chave: Lawfare, Direito, Estratégia, Guerra, Clausewitz. 


\section{THE COLLECTIVE HABEAS CORPUS AS A MITIGATING INSTRUMENT FOR WOMEN MASS INCARCERATION PROBLEMATICS IN BRAZIL}

This paper aims to discuss the relationship between gender and incarceration, especially bearing in mind the social-normative system in Brazil that does not provide the bases for a bias equalization. Particularly, the Brazilian Criminal Code is a quite outdated patchwork, focus on, mostly, in the deprivation of liberty. Thus, in this scenario, Brazil raised up in the world incarceration rate, becoming the third largest prison population in the world. Taking into consideration the criminal offenses, drug dealing takes on a prominent position among the crimes that incarcerates the most, even without violence or serious threat. Within this perspective, a distortion must be observed, the quantitative growth of female prisoners is greater than the equivalent when compared to males. This fact must be pointed out, especially because, currently, the woman in prison is, mostly, black, young and poor, that faces the rules of a silent and unwritten social contract imposed on by her gender role. At this point, the critical theory shows the need of a breakdown of a classic cause and effect analysis of female incarcerations, from the starting point of the structures of power and domination, including gender, that reflects a historical social process, due to the lack of equality, access to education, living situation, ethnicity, and, mainly, treatment in relation to the authorities. The 2019 Atlas of violence reaffirms this hypothesis, stating that, in relation to the inequality of racial lethality, "in the period of a decade (2007 to 2017), the rate of black people increased $33.1 \%$, while that of non-black people presented a small growth of 3.3\%. Analyzing only the variation in the last year, while the death rate of non-black people showed relative stability, with a reduction of $0.3 \%$, from black people increased by $7.2 \% "$. Furthermore, this number, in regard of imprisoned women, is not just an outcome of this historical process, but primarily, the lack of social support in Brazil, that creates a misrepresented system, in which her life is determinate before her arrest.

Moreover, must be highlighted that, most of women prisoners fulfill all the requirements for home prison, but do not receive this benefit, showing the rough face of a selective criminal jus-
Carolina Pasin, Luís Claúdio Martins de Araújo \& Rodrigo Augusto Fatudo Magalhães

Instituto Brasileiro de Mercado de Capitais - IBMEC/RJ 
Carolina Pasin,

Luís Claúdio Martins de Araújo

\& Rodrigo Augusto Fatudo Magalhães

Instituto Brasileiro de Mercado de Capitais - IBMEC/RJ
Ref.: 359CEDHM22020

THE COLLECTIVE HABEAS CORPUS AS A MITIGATING INSTRUMENT FOR WOMEN MASS INCARCERATION PROBLEMATICS IN BRAZIL

tice, based on the social iniquity, that toughly distress women, as merely responsible for raising her children and maintaining the pregnancy. In this sense, it is necessary to give a step further, balancing these distortions historically created and currently applied, using some mechanisms, such as constitutional writs and procedural guarantees. Particularly, in Habeas Corpus no 143.641, the Supreme Court of Brazil delivery a decision ordering that "all women subjected to precautionary detention in the national penitentiary system, who are pregnant, postpartum or mothers with children up to 12 years of age under their responsibility, and of the children themselves" should be released.

Keywords: Collective Habeas Corpus, Women Mass Incarceration, Gender Inequality, Isonomy Principle. 


\section{A ERA DIGITAL E O DESAMPARO DO CONTRIBUINTE ANTE A AUSÊNCIA DE LEGISLAÇÃO ACERCA DAS NOVAS TECNOLOGIAS: UM ESTUDO COMPARADO DO ORDENAMENTO PORTUGUÊS E BRASILEIRO}

Os direitos humanos surgem na medida em que surge o poder de tributar, tendo em vista que a partir do momento que o cidadão paga para a manutenção do Estado é que passa a existir o seu direito de liberdade e propriedade, desse modo o direito tributário se torna um garantidor dos direitos humanos. Nos dias atuais vive-se uma era digital, em que os serviços e produtos vem mudando constantemente ante as novas tecnologias. As locadoras de dvd já não existem mais e até mesmo os aparelhos que os reproduziam já são escassos. Estes, deram espaço as plataformas de streaming que dominaram o mercado de filmes e series em pouco tempo. Ressalta-se também o crescimento do número de negócios virtuais, a loja física cada vez mais vem sendo substituídas por lojas virtuais inseridas dentro das redes sociais, e a maioria delas sem a devida regulamentação o que dificulta na hora da tributação. Justamente diante desses novos modelos de serviços, bem como outros inúmeros que a era digital implementou que fica o questionamento se seria correto adequar os tributos já existentes ou o certo seria a criação de novos tributos voltados especificamente a essa nova realidade. Não só os novos negócios são alvo de questionamento como também a extensão de imunidades já previstas as novas tecnologias, como ocorreu no caso dos novos tipos de livros, os e-books, por exemplo. O objetivo do presente estudo científico é, portanto, a análise das novas tecnologias que ainda não possuem um amparo legal acerca de qual a tributação pertinente, no ordenamento jurídico brasileiro e português. A justificativa se encontra justamente no desamparo em que se encontra o contribuinte atualmente, que corre riscos de sofrer até mesmo uma bi-tributação, ante a ausência de uma legislação clara acerca dessas novas tecnologias.

O Estado é capaz de ferir o contribuinte na seara da tributação, reduzindo-Ihe a dignidade, a individualidade e a privacidade. Ante a ausência de uma legislação especifica quanto a tributação das novas tecnologias, o governo pode acabar contrariando a Constituição Federal, por exemplo, nos princípios do devido processo legal, da igualdade, da razoabilidade e da moralidade, sendo ambos instrumentos dos Direitos Humanos.

O desenvolvimento do presente trabalho será conduzido pela metodologia dedutiva e pelo método comparativo, sendo entendidos, respetivamente, como um processo de uma construção lógica que parte de uma informação geral e redunda em uma conclusão específica, e a análise desses dados com a finalidade de apresentar as semelhanças e diferenças entre eles, bem como a sua conexão . Para atendimento dos objetivos do trabalho, será utilizada a pesquisa bibliográfico-documental de textos, doutrinas e jurisprudência, nacionais e internacionais sobre o conteúdo desenvolvido. O presente estudo científico tem como objetivo final obter uma resposta clara acerca de quais tributos devem ser atribuídos as novas tecnologias, como os serviços de streaming e os downloads.

Palavras-Chave: Era Digital, Tributário, Novas Tecnologias, Streaming.
Renata Lorena Rebouças \& Josemita Rebouças 


\section{PROMOÇÃO E DEFESA DOS DIREITOS DAS CRIANÇAS EM RISCO/PERIGO EM CONTEXTO DE PANDEMIA POR COVID-19, EM PORTUGAL}

Jenny Gil Sousa

Escola Superior de Educação e Ciências

Sociais - Politécnico de Leiria
O presente trabalho pretende levar a cabo uma reflexão em torno da temática da promoção e da defesa dos direitos das crianças portuguesas no contexto atual, amplamente marcado pela pandemia por Covid-19 e pelo confinamento social. Diretamente relacionado com o primeiro Objetivo do Desenvolvimento Sustentável -erradicar a pobreza em todas as suas formas, em todos os seus lugares -será realizada uma análise ao modo como está a ser cumprido, nos dias de hoje e no contexto específico já apontado, 0 artigo 27 da Convenção dos Direitos das Crianças (Nível de Vida), sobretudo no que se refere à forma como o governo e as instituições estão a assegurar o bem-estar das camadas mais vulneráveis, neste quadro contemporâneo atípico. O ano de 2020 trouxe muito mais que um vírus nunca visto; trouxe uma nova realidade e uma nova forma de viver, que tocou todo o planeta e todas as camadas sociais, mas que teve uma repercussão mais nociva nas populações mais vulneráveis, designadamente nas crianças em risco e em perigo.

Ao longo das semanas de confinamento social, muitas foram as crianças que se viram permanentemente expostas aos seus agressores, vivendo quotidianamente em vulnerabilidade social. Que papel tiveram os sistemas de proteção social? Que medidas foram tomadas para apoiar as crianças em situação de maior vulnerabilidade? O governo e as instituições portuguesas estiveram despertos para esta situação e desencadearam mecanismos responsáveis e eficazes? Estas são as questões que norteiam a reflexão que se pretende apresentar.
Assim, no primeiro ponto, realizar-se-á uma breve abordagem teórica ao conceito de criança bem como, de criança em risco e em perigo, enquadrando-o desde a perspetiva de proteção e promoção dos seus direitos. Lançaremos, de seguida, um olhar retrospetivo à realidade jurídica e legislativa, a nível internacional e nacional, em matéria de proteção e promoção dos direitos das crianças e jovens.

Posto isto, e no segundo ponto, serão destacados alguns movimentos e organizações que desenvolvem a sua ação no âmbito da promoção e defesa dos Direitos das Crianças e realiza-se uma análise à forma como esses direitos, mais concretamente, o bem-estar e nível de vida, estão a ser cumpridos nos dias de hoje, em Portugal. Tomando como eixo central o artigo 27 da Convenção dos Direitos das Crianças, analisamos a situação atual da infância na sociedade portuguesa e o modo como o contexto pandémico teve impacto na efetivação dos seus direitos. Este estudo terá por base a análise de conteúdo de notícias publicadas em meios de comunicação de referência em Portugal e de entrevistas semiestruturadas a técnicos que trabalham em Comissões de Proteção de Crianças e Jovens, a professores e a profissionais de saúde, designadamente médicos de família e médicos pediatras de um hospital central distrital.

Por fim, no terceiro ponto, tecem-se conclusões à luz do apresentado e discutido nos momentos anteriores.

Palavras-Chave: Direitos da Criança, Criança em Risco/Perigo, Contexto Pandémico, Respostas e Medidas Sociais. 


\section{A MUDANÇA DA VISÃO SOCIAL SOBRE A INFÂNCIA E A REDUÇÃO DA MAIORIDADE PENAL NO BRASIL}

No presente trabalho, buscamos analisar a criança como autor de delitos e como a mudança de visão social sobre a infância altera a perceção do tratamento diferenciado à aplicação de penalidades a estes menores. No Brasil, a maioridade penal aos 18 anos foi instituída em 1927, e prevalece até os dias de hoje. Abaixo de 18 anos, não se comete crime, mas sim, ato infracional. O Estatuto da Criança e do Adolescente traz as regras sobre a Apuração de Ato Infracional Atribuído a Adolescente, sendo uma das polêmicas a atribuição máxima de pena de internação por 3 anos, mesmo em caso de crimes hediondos. A ideia sobre a infância como detentora de necessária proteção, bem como, de uma crença maior na recuperação do indivíduo pela possível personalidade ainda em formação, fundamenta o tratamento punitivo diferenciado e o discurso da ressocialização. A punição criminal é fundamentada na tríade formadora do crime: fato típico, antijurídico e culpável. O ato infracional guarda a tipicidade e a anti juridicidade, deixando de fora apenas o elemento da culpabilidade. A culpabilidade reside na perceção da ilicitude da conduta. $O$ Código Penal traz que "A pena pode ser reduzida de um a dois terços, se o agente, em virtude de perturbação de saúde mental ou por desenvolvimento mental incompleto ou retardado não era inteiramente capaz de entender o caráter ilícito do fato ou de determinar-se de acordo com esse entendimento". A ideia de que existe uma perceção parcial da ilicitude da conduta, capaz de reduzir a pena aplicada, já é prevista no Código Penal. Portanto, o argumento de que os menores de 18 anos (e maiores de 12), não teriam plena capacidade de compreender e, portanto, necessitam de normas específicas mais brandas já é previsto em nossa legislação penal geral. Porém, não foi considerada suficiente. O ECA, ao prever a pena máxima de 3 anos de internação, desconsidera, em nosso entender, que existe uma gama muito variável na perceção sobre a ilicitude de sua conduta entre um adolescente de 14 ou de 17 anos. A depender do contexto social em que estão inseridos, mesmo dentro de uma mesma faixa etária, haverá discrepâncias entre o desenvolvimento mental de um e outro. A norma geral de culpabilidade que leva em conta particularidades quanto ao desenvolvimento mental do agente e, portanto, sobre o real grau de perceção de ilicitude da conduta, nos parece ser mais adequada. A infância e a compreensão da fragilidade emocional e intelectual do indivíduo menor foram uma construção sociológica e histórica. Mas a sociedade muda. Instituir um marco etário como fundamento único para a penalização com prisão de um indivíduo, pode parecer uma ideia condizente com sua condição de especial fragilidade. Mas não o é, em nosso entender. A análise concreta, mais complexa sobre a conduta exercida, e sobre o agente que a cometeu, parece-nos ser uma melhor resposta do especialmente do ponto de vista de resposta social da pena.

Palavras-Chave: Infância, Ato Infracional, Culpabilidade, Menoridade, Penalidade.
Paulynne Rocha Valença

Figueiredo

Universidade Federal de Pernambuco

\& Isabelle Rocha Valença

Figueiredo

Ministério Público do Tocantins 


\section{A RETÓRICA GOVERNAMENTAL E A PROTEÇÃO DA PESSOA HUMANA NO ESTADO FEDERAL BRASILEIRO: CORONAVÍRUS - COVID-19 - E OSD3}

Jesus Tupã Silveira Gomes, Sergio Urquhart de Cademartori \& Lucas Uelinton Graciolli Universidade La Salle
A realização das metas inscritas nos Objetivos de Desenvolvimento Sustentável para a área da saúde (ODS-3) exige um esforço constante dos Estados no sentido da promoção e desenvolvimento das ações de prevenção e de combate às doenças. A pandemia causada pelo Coronavírus -Covid-19, por sua vez, representa uma oportunidade para a implementação de tais objetivos, diante do seu potencial para unir governos e sociedade civil para a superação da crise, e, ao mesmo tempo, um risco, quando o dissenso existente venha a impedir uma atuação conjunta e coordenada. No Brasil, a proteção da pessoa humana constitui um dos fundamentos do Estado, e deve ser realizada simultaneamente em todas as suas dimensões (individual, econômica, sanitária), mostrando-se indispensável a discussão a respeito do distanciamento físico, das ações de saúde realizadas pelo governo, da restrição às atividades econômicas e eventuais compensações fiscais aos setores produtivos, e do estabelecimento de garantias de emprego aos trabalhadores e de renda mínima aos indivíduos em situação de vulnerabilidade. No entanto, a retórica adotada pelo Governo Federal, centrada na implementação de um modelo econômico neoliberal e no discurso de ódio contra todos aqueles que divergem de suas ideias, apresenta potencial de colocar em risco os esforços realizados pelas autoridades regionais e locais no combate à pandemia. O presente estudo tem como objetivo principal aferir em que medida a retórica do alto comando do Estado brasi- leiro impõe obstáculos à atuação dos governos regionais e locais. O trabalho encontra-se dividido em três capítulos: inicialmente, mapeamos os diversos elementos que compõem a proteção à pessoa humana e o deveres de atuação constitucionalmente impostos ao Estado em cada nível de governo; em seguida, apontamos os canais de diálogo existentes entre os governos locais, regionais e federal para a proteção da pessoa humana e, por derradeiro, examinamos em que medida a retórica do Governo Federal implica prejuízos aos esforços dos agentes políticos regionais e locais no combate à pandemia causada pelo Coronavírus - Covid-19 e implica efeitos nefastos ao cumprimento das metas inscritas no OSD3. O trabaIho foi elaborado por meio da pesquisa documental, com revisão da bibliografia a respeito do tema, bem como de atos normativos expedidos pela União Federal, pelo Estado do Rio Grande do Sul e pelo Município de Porto Alegre. As conclusões preliminares indicam que a retórica adotada pelo alto comando do Governo Federal brasileiro vem implicando efeitos nefastos no combate à pandemia - com o potencial de reduzir a eficácia das medidas adotadas em âmbito regional e local -, com risco de prejudicar o cumprimento das metas propostas pela Organização das Nações Unidas nos OSD3.

\footnotetext{
Palavras-Chave: Estado Brasileiro, Pandemia (Coronavírus-Covid-19), Objetivos de Desenvolvimento Sustentável 3 - OSD3, Proteção à Pessoa Humana; Retórica Governamental.
} 
Ref.: 379CEDHM22020

\section{OS INDÍGENAS E O PLURALISMO JURÍDICO: UMA POSSÍVEL RESPOSTA EFETIVA AOS DIREITOS HUMANOS DOS POVOSTRADICIONAIS LATINO-AMERICANOS}

O processo de colonização deixou marcas profundas, tão profundas que seguimos reproduzindo os passos do colonizador, uma vez que, nossos olhares, nossos quereres nossos gostos, nossas vontades, nosso "eu" continua colonizado. Nosso conceito de cultura é um conceito colonizado, nosso olhar para os povos tradicionais é um olhar colonizado, que desmerece suas tradições, sua cultura, sua ancestralidade, sua dignidade. Nesse sentido, o trabaIho faz uma ligeira incursão, mais provocativa, que conclusiva, acerca dos limites e possibilidade de o pluralismo jurídico enquanto uma resposta à questão da efetivação dos Direitos Humanos dos povos tradicionais.

De forma genérica a coexistência de diferentes ordens jurídicas simultaneamente vigentes em um mesmo território e para diversos Estados é o que se denomina pluralismo jurídico. $O$ que se busca tutelar com o pluralismo jurídico em nosso caso é a cultura dos povos tradicionais e com isso, sua própria existência.

Percebe-se que a atual situação e forma de atuação do governo brasileiro para com os povos indígenas brasileiros é insustentável, deficiente e extremamente colonial, o que acaba por sufocar, destruir e invisibilizar culturas milenares. Os próprios dados trazidos pela Fundação Nacional do Índio (FUNAI) nos apresentam números alarmantes. E, talvez, os números sejam ainda mais alarmantes do que apresentados tamanha a inépcia do poder estatal de gerir pesquisas, e fomentar políticas públicas nessa área.

As transformações políticas e sociais na sociedade latino-americana apontam na direção da necessidade de um maior reconhecimento dos nossos povos ancestrais, algo que já é enfrentado por outros países latino-americanos e esquecido pelo Brasil. Iniciarmos uma movimentação ao encontro de um pluralismo jurídico, seria uma forma de respeitarmos os Direitos Humanos desses povos, e ao mesmo tempo, evitarmos a perda de conhecimentos milenares.

Palavras-Chave: Pluralismo Jurídico, Direitos

Humanos, América Latina, Indígenas,

Povos Tradicionais.

\section{Jacson Gross}

\& Daniela Mesquita

Leutchuk de Cademartori UNILASALLE 


\section{SEQUESTRO INTERNACIONAL DE CRIANÇAS E A CONVENÇÃO DE HAIA: PROTEÇÃO AOS DIREITOS HUMANOS}

João Luiz Lessa Neto

Universidade de São Paulo

\& Paulynne Rocha Valença

Figueiredo

Universidade Federal de Pernambuco
As relações familiares, numa sociedade globalizada, se tornam cada vez mais internacionalizadas, o que gera a necessidade de criação de mecanismos de cooperação e de defesa dos direitos humanos, particularmente na preservação dos direitos dos infantes. O sequestro internacional de menores é situação normalmente relacionada à separação de casais de nacionalidades diferentes. É o caso em que um dos genitores do menor o retira do país em que tem residência habitual e leva-o a outro, confiando que a demora no procedimento de localização e restituição da criança irão torná-la inviável. É também a ideia de que a Justiça do país para o qual houve o deslocamento da criança, geralmente o país de nacionalidade do genitor sequestrador, será mais amena com relação ao seu pleito da guarda. Esta situação atenta gravemente contra os direitos fundamentais não só do genitor ou guardião ludibriado, mas principalmente os direitos da própria criança. As situações ligadas à custódia de crianças que envolvem mais de um ordenamento jurídico trazem a complexidade de questões quanto a lei aplicável, a jurisdição, o reconhecimento e execução de decisões estrangeiras.

A Convenção sobre os Aspetos Civis do Sequestro Internacional de Crianças de Haia, de 1980, centrada na instituição de mecanismos de cooperação jurídica internacional, procurou atingir uma fórmula equilibrada entre a regra geral de devolução do menor, e as exceções a serem admitidas e é uma das mais importantes elaboradas nesse sentido.
A restituição da criança ao seu domicílio busca preservar seu bem-estar, visto que com a subtração essa não é impedida apenas da convivência com o outro genitor, mas também coma família estendida e com o ambiente no qual estava habituada e familiarizada culturalmente, sendo transferida a um local estranho, com o qual a criança não possui laços culturais evidentes.

Pela Convenção, tanto a Autoridade Central do país onde se encontra a criança, quanto o genitor que teve seu filho subtraído, têm legitimidade para propor a ação de busca e apreensão com fins de repatriação. Trata-se de legitimidade concorrente do genitor e, igualmente, da autoridade central do país onde se encontra a criança. Podendo até mesmo, haver um litisconsórcio entre eles. Em regra, a demanda judicial tende a ser proposta pela Autoridade Central, porém não há empecilho para que o genitor da criança também intente a demanda judicial, pois há co-legitimidade entre eles para propor a ação de busca e apreensão. Trata-se de legitimidade concorrente já que não é apenas o pai ou a mãe, privado do convívio com o filho, mas também a Autoridade Central que podem requerer a busca e apreensão do menor que fora subtraído de seu domicílio regular. Revela-se então aspetos que denotam a atuação internacional dos sujeitos envolvidos, mas, também, o dever de cooperação no âmbito do Direito Internacional Público entre os Estados, na salvaguarda dos Direitos Humanos.

Palavras-Chave: Sequestro Internacional de Crianças, Convenção de Haia, Direitos Humanos, Direitos da Criança, Legitimidade. 


\section{THE RIGHTTO LEGAL AID INTHE CONTEXT \\ OF INTERNATIONAL JUDICIAL COOPERATION: TOWARDS THE IMPROVEMENT OF EQUAL ACCESS TO JUSTICE FOR ALL?}

Being involved in criminal justice procedures may entail tremendous challenges. In this context, safeguarding procedural rights is not always easy, especially in what concerns legal aid and every other legal right to which it is intrinsically linked. In fact, despite its recognition by the European Charter of Fundamental Rights of the European Union (EU), legal aid is still far from its ideal implementation. Directive (EU) 2016/1919 aims at closing existing gaps in this regard. Yet, and despite the efforts from the regional organisation and overall international community in this regard, several elements contribute to hindering this right's full implementation. An imbrication of multi-level issues and difficulties, ranging from police officers as first-line practitioners, to the international divergences in the judicial systems create severe and Iong-lasting impacts. The erosion of the overarching principles meant to guide our justice systems is further deepened by the concrete and practical negative consequences faced by the individual in these circumstances. In the context of the EU, the first noteworthy factors are blockades associated with differences in EU Member States's (MS) judicial systems, which directly undermine the cited Directive. While legal provisions concerning the right to legal aid are defined in all EU MSs' national legislation, the Directive's implementation is not always guaranteed. Notably because of the manifest shortcomings on the practitioner's side related to informing the individual of their rights (e.g., cost exemption). This situation proves to be especially problematic by harming the quality of the legal aid service provider's work and consequently calling into question the fairness of criminal justice proceedings. In the midst of such a complex field of work, the role of legal aid service providers takes on a renewed importance. Regardless, literature highlights the lack of quality of their work and inadequacy of their skills. As a result of these factors, suspects or accused people are often prevented or discouraged from exercising their rights, leading to the under-representation of vulnerable groups. In turn, SDG 16 is also undercut, as the present situation actively prevents equal access to justice for all. The introduction of international judicial cooperation instruments (e.g., European Arrest Warrant) creates other issues for the fulfilment of the Right to Legal Aid, by demanding a closer interaction between very different judicial systems, first-line practitioners (e.g., police officers) and legal aid service providers, therefore exacerbating pre-existing flaws. In this context, our proposal seeks to explore the present and prevailing obstacles to the respect of this right, while keeping in mind the continuous efforts for furthering international judicial cooperation and multi-agency information sharing led by the EU, striving to build a fair and inclusive society which guarantees access to justice to all.

Keywords: Legal Aid, European Union, Procedural Rights, Judicial Cooperation, Access to Justice.
Joana Apóstolo, Pedro Liberado \& Pedro das Neves Innovative Prison Systems 


\section{RECONHECIMENTO DE SENTENÇA ESTRANGEIRA: UM DEVER DO ESTADO PORTUGUÊS ANTE A INFRINGÊNCIA DA SUA ORDEM PÚBLICA?}

Adriana Sawaris Henriques Universidade De Coimbra
As novas necessidades da vida somadas às facilidades do livre trânsito de pessoas e bens entre os Estados da União Europeia e o mundo sem fronteiras, fez com que as pessoas singulares ou coletivas passassem, com maior frequência, a estabelecer relações especialmente de natureza jurídica, de forma transfronteiriça. Tal situação exigiu do poder judiciário uma nova postura ante a permissão de que um decisum estrangeiro adentre às fronteiras nacionais e gere efeitos, passando a participar do contexto jurídico da ordem interna. Para garantir e assegurar a continuidade das situações jurídicas internacionais e dar estabilidade a estas relações, importante valer-se de normas de conflito que orientem o método de escolha mais expressivo ao direito material aplicado às situações plurilocalizadas. O que tem sido objeto de tratados internacionais bilaterais e multilaterais em vigência atualmente, especialmente em países membros da União Europeia, reforçados pelo princípio do reconhecimento mútuo e extrajudiciais em matéria cível. A questão levantada inicialmente é: quais os fundamentos deste reconhecimento, execução ou da recusa da sentença estrangeira, tendo em conta a reserva que os Tribunais devem ter em relação ao mérito da decisão estrangeira. O que verificamos se tratar de um ponto obscuro no direito processual civil internacional, tornando-se necessária a reflexão a respeito do assunto que se faz neste trabalho. Na busca de mais questionamentos que possam orientar o caminho na solução da questão posta é que motiva a presente pesquisa. Não desconsiderando o dilema instaurado entre a necessária proteção do Estado da ordem jurídica interna e de mesma importância a participação deste Estado nos ideais do direito processual civil internacional apresentados pela União Europeia. Neste contexto a recusa ao reconhecimento de uma sentença estrangeira, e o consequente impedimento de que essa surta os efeitos desejados pelo Tribunal de origem, deve se tratar de medida excepcional. Mormente quando falamos deste impedimento motivado pela infringência da ordem pública. Trata-se de um posicionamento atual dos Tribunais portugueses de repelir os abusos que podem ocorrer nas decisões discricionárias, e pela utilização do fundamento proteção da ordem pública, os julgadores desconsideram o princípio fundamental da proibição de revisão de mérito da decisão estrangeira. Especialmente pelo fato de que o julgador dificilmente conseguirá se afastar da análise dos fundamentos da decisão ao julgar se o decisum fere ou não o princípio da ordem pública, e por esta motivação negar os efeitos pretendidos ao julgado externo. O posicionamento atual dos Tribunais portugueses de que os limites estreitos da legalidade neste caso, atingindo o mérito ou não da questão, devem expressar o sentimento maior de proteção do Estado naqueles valores que entende como fundamentais e que não podem ser retirados da ordem jurídica nacional, sob de perturbar a paz jurídica do povo de cada nação.

Palavras-Chave: Sentença, Estrangeira, Ordem, Pública, Mérito. 


\section{ECONOMIA SOLIDÁRIA E DELIBERAÇÃO PARTICIPATIVA. UM IMPORTANTE RESGATE DA SOBERANIA POPULAR E ACCONTABILITY PARA A RESPONSABILIZAÇÃO SOCIAL}

A crise no equilíbrio e tripartição de poderes que sustentou o Estado moderno pode ser analisada em diferentes perspetivas. O artigo explora a tensão existente entre democracia, entendida como soberania popular, e poder legislativo, um poder assentado no princípio majoritário, mas enfraquecido por uma crise de legitimidade e pela baixa densidade da representação democrática. No artigo apresenta-se as bases teóricas da soberania e da representação populares e identificam-se algumas das razões para a sua perda de legitimação, ressaltando-se a ausência de mecanismos capazes de substituir com êxito a representação, conceito que se tornou chave para a organização política moderna. A hipótese é de que os minipúblicos e a economia solidária podem constituir-se em espaços e formas de organização capazes de oxigenar a representação democrática e amplificar a legitimação do exercício da soberania popular. $\mathrm{O}$ artigo divide-se em quatro subtópicos: O primeiro relaciona a democracia e constitucionalismo e demonstra que há uma crise dos poderes em relação ao processo democrático de construção legislativa, cuja solução seria o resgate da democracia pela soberania popular. O segundo subtópico objetiva a análise do ressurgimento da participação deliberativa e a formação dos minigrupos com o fito de legitimar a soberania popular como guardiã da democrática. No terceiro, a proposta é explicar como a economia solidária, através da deliberação participativa, se firmou como minipúblico e conseguiu estruturar-se em todos os órgãos federais, estaduais e municipais fiscalizando-os pela accountability, na formação do processo legislativo e cobrando a responsabilização social, para o desenvolvimento de empreendimentos solidários. E finalmente, o quarto subtítulo demonstra como exercer a prestação de contas, -accountability no poder legislativo, executivo e nos próprios minigrupos para realizar de forma eficaz a responsabilidade social. Minipúblicos e economia solidária, cada um à sua forma, por princípio, privilegiam a deliberação participativa e a responsabilidade como elementos centrais nos processos de tomadas de decisão. O resgate destes elementos pode amplificar a legitimidade da representação democrática e tornar-se um importante meio de superação da crise da legitimidade dos Legislativo nos dias atuais, fortalecendo dois pressupostos essenciais da soberania popular: participação e responsabilidade. A metodologia utilizada foi a dedutiva, com procedimento de pesquisa de levantamento bibliográfico.

Palavras-Chave: Democracia, Legislativo, Soberania Popular, Minipúblicos, Economia Solidária.
Yuri Fedrigo Dutra

\& Claudia Maria Barbosa Pontifícia Universidade Católica do Paraná 


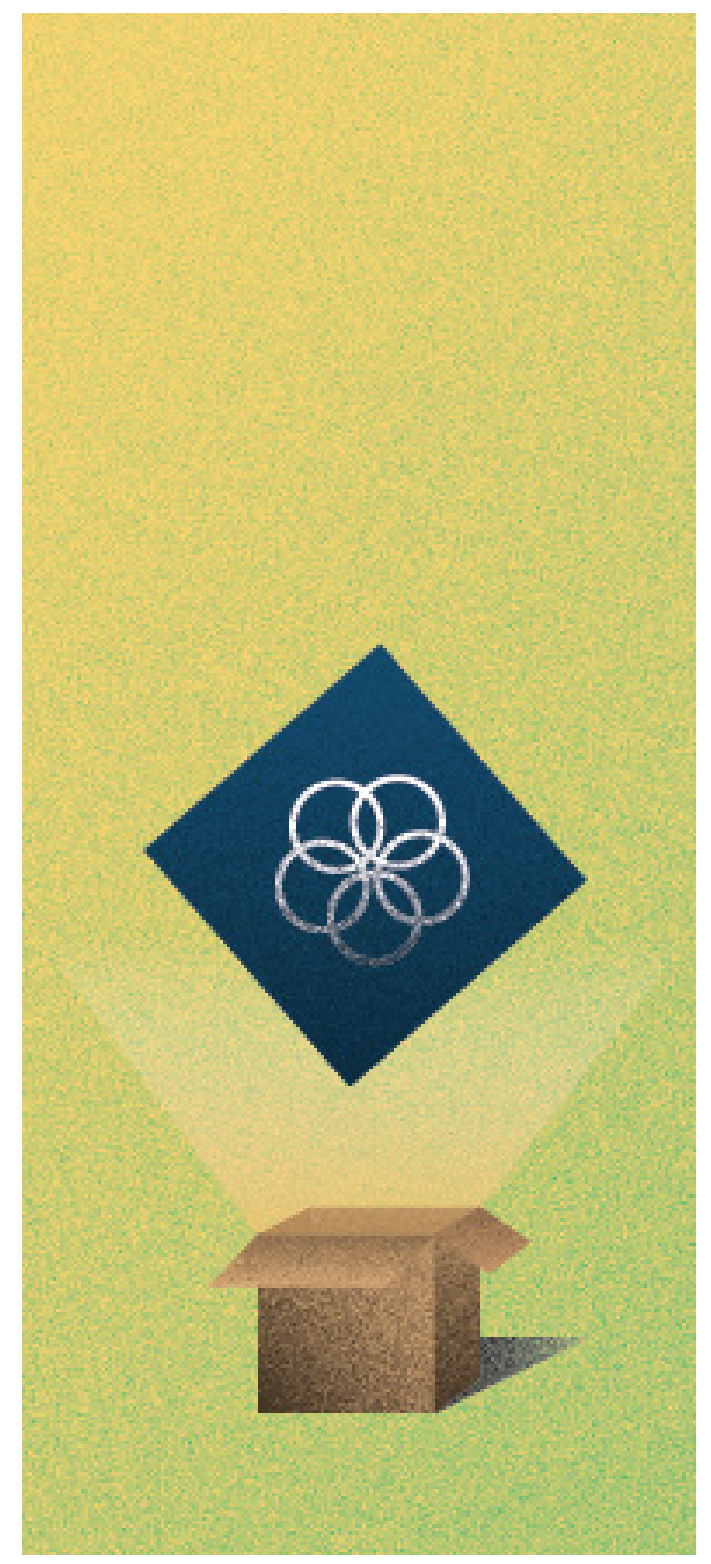

ATAS DA II CEDH:

AGENDA 2030 - UM NOVO CAPÍTULO

PARA A EVOLUÇÃO DOS DIREITOS HUMANOS

\section{ODS 17 \\ PARCERIAS \\ PARAA \\ IMPLEMENTAÇÃO \\ DOS OBJECTIVOS}

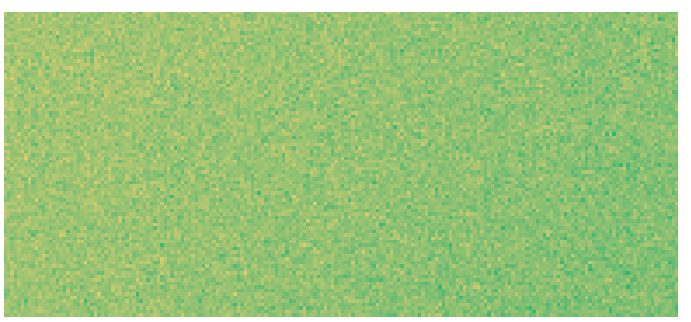




\section{O PAPEL DAS ENTIDADES FISCALIZADORAS \\ NA EFETIVAÇÃO DAS SALVAGUARDAS SOCIOAMBIENTAIS: A AGENDA 2030 EM PERSPECTIVA}

Os Objetivos do Desenvolvimento do Milênio (ODM), firmados no ano 2000 e com prazo para alcance das metas até 2015, foram insuficientes à superação da crise socioambiental planetária. Em continuidade, a Organização das Nações Unidas instituiu a Agenda 2030 (2015), com enfoque no desenvolvimento sustentável, o que pressupõe o equilíbrio dos interesses econômico, social e ambiental. Ciente disso, o Banco Mundial, primordialmente, instituiu as salvaguardas socioambientais, visando uma padronização de programas de proteção e de garantias mínimas de ordem ambiental e social a serem seguidas pelos beneficiários de políticas de financiamento da instituição. Ainda assim, medidas devem ser adotadas para que os Objetivos do Desenvolvimento Sustentável -ODS sejam incorporados também a essas políticas e não falhem como os ODM, bem como para que as salvaguardas socioambientais sejam efetivamente observadas. Nesse intento, indispensável uma atuação mais enérgica das entidades fiscalizadoras. A Agenda 2030 fomenta a construção de instituições eficazes, responsáveis e inclusivas. Sob essa égide, foi elaborada a Declaração de Moscou (2019), por meio da qual as entidades fiscalizadoras comprometeram-se a utilizar de seus conhecimentos transversais para colaborar com a consecução dos Objetivos do Desenvolvimento Sustentável. Tais diretrizes, entretanto, precisam tomar forma e este trabalho visa apresentar uma das atuações possíveis -e exigíveis -dos órgãos de controle. Ao mesmo tempo em que é óbvia a urgência de que transformações sejam feitas na economia, há uma ficção de que o "status quo" é imutável (CAPRA e MATTEI, 2015). As salvaguardas socioambientais auxiliam a rompê-lo. No Brasil, os Tribunais de Contas auxiliam para que essas sejam respeitadas também nas relações envolvendo entes públicos. Realizada pesquisa documental, já se colhem casos em que órgãos de controle agiram sob esse paradigma. Para citar alguns, o Tribunal de Contas do Sergipe, Acórdão no 1403/2012, em sede de Auditoria Operacional, obrigou que banco público implantasse política socioambiental, e o Tribunal de Contas da União, após o recebimento de representação, determinou, via Acórdão no 211/2018 -Plenário, a abstenção de liberação de recursos por instituição financeira até que o estado beneficiado cumprisse a legislação ambiental. Também no contexto brasileiro, a II Carta da Amazônia (2019), fruto de Simpósio Internacional sobre Gestão Ambiental e Controle das Contas Públicas, alertou para a obrigatoriedade de que os entes públicos ajam de maneira "integrada, preventiva, precatória e eficaz" para que os ODS sejam cumpridos. É tempo de mudanças, para as duas décadas que virão, instituições devem reinventar-se para adequarem-se e fazerem cumprir a Agenda 2030. As entidades fiscalizadoras, representantes do controle, são peça-chave para esse desiderato.

\section{Palavras-Chave: Agenda 2030, Objetivos} do Desenvolvimento Sustentável, Entidades Fiscalizadoras, Tribunal de Contas,

Desenvolvimento Sustentável.
Camila Parente Almeida, Barbara Natali Botelho Rodrigues Dos Santos \& Carlos Teodoro José Hugueney Irigaray Universidade Federal De Mato Grosso 


\section{PROFESIONALES PSICOSOCIALES EN JUSTICIA: REVISIÓN DE LA EXPERIENCIA CHILENAY PERSPECTIVAS}

Fabiola Miranda-Pérez

Universidad Alberto Hurtado
A mediados de los años 2000 se terminan de implementar las reformas a la justicia familiar y penal en Chile. Habiendo pasado quince años de aquello, aún no se ha profundizado en investigar los cambios que han implicado dichas reformas en las rutinas de trabajo de los equipos de profesionales delas instituciones de justicia. Frente a esto, se plantea un análisis de las condiciones de inserción de los profesionales no jurídicos en espacios de justicia, en especial, de aquellos del ámbito psicosocial (trabajadores sociales y psicólogos) desde las reformas. Lo anterior, nos permitirá establecer en primer lugar un diagnóstico de qué manera dicha inserción afecta y tensiona la administración de justicia en su interior, para luego abrir perspectivas de cómo esto impacta en la ciudadanía más vulnerable - si lo entendemos en términos de acceso a la justicia. Se pretende así mostrar los primeros resultados de un proyecto de investigación en curso sobre nuevos repertorios de la acción pública en este ámbito. Así, se observará a) las condiciones de inserción de los profesionales psicosociales y sus saberes en estos espacios; b) las estra- tegias de trabajo conjunto entre actores jurídicos y psicosociales. La hipótesis principal que se plantea aquí, es que los procesos de reforma procesal penal y familiar han modificado las dinámicas internas de las instituciones de justicia. En efecto, la incorporación de profesionales provenientes del ámbito psicosocial ha sido un factor determinante en la creación de nuevas prácticas en las instituciones de justicia que pretenden un enfoque más integral dando paso a la validación de nuevos saberes que han contribuido a generar cambios en la aplicación del derecho y que han implicado repensar el enfoque de derechos de los y las usuarias de la justicia. Planteamiento que será revisado de manera crítica a lo largo del artículo.

Palavras-Chave: Justicia, Reformas, Profesionales Psicosociales, Acción Pública, Acceso a La Justicia. 


\section{MEASURING THE IMPLEMENTATION OF PLANET GOVERNANCE}

Many are the inherent characteristics of sustainable development at a global level: Ecologic integrity, Economic security, Responsibility and social welfare. The world has undergone many changes in recent decades, changes derived mainly from globalization, which leads to business management being taken to another level. According to Dragomir and Constantinescu (2018) the focus is on harmonizing economic, social and environmental problems in ordert o ensure prosperity for future generations. In other words, the problem of the company moves to a global sphere.

Given the relevance of the subject, and to point out that already Guimarães (1997) when presenting the different dimensions and operational criteria of sustainability, presents "planetary sustainability" as one of the dimensions. It also considers the dimensions: ecological, environmental, demographic, cultural, social, political and institutional sustainability. It considers that the objective of planetary sustainability has as its main objective "to revert the global processes of ecological and environmental degradation". Our objective goes a little further, because we do not want to associate the concept of "Planet Governance" only with the ecological-environmental aspect.

In this work, and after presenting the concept of Planet Governance and demonstrating its relationship with the concept of Corporate Governance, we present the concept of Planet Governance which will be understood as a concept that will evaluate, in a first phase, the performance of the governments of each country in terms of the Government of the planet... in the future, we intend to define the strategies capable of achieving sustainable development at a planetary level.

This measurement will be made through a composite indicator, which is why we present the advantages of considering such an indicator and also the steps inherent to its construction. This indicator, formed by us, will have the designation of "Planet Governance Index".

From this construct a Planet Governance Index can be conceived, whose model for its determination will be developed in the future by the authors, in order to be able to assign governments a classification in this regard by verifying the impact of the adoption of Planet Governance's best practices in macroeconomic indicators.

Thus, we present the composition of the indicator with its three dimensions, justifying its importance and its associated benefit in measuring the implementation of Planet Governance. This indicator will allow us to measure the "position" of the country in the adoption of the best practices of Planet Governance. This measure will allow the authorities to define strategies at the macroeconomic level, should any adjustment be necessary.

Keywords: Index Planet Governance, Planet

Governance, Composite Indicators,

Sustainability.
Sandra Ribeiro

\& Ana Quaresma OBSERVARE - Observatório de Relações Exteriores da Universidade Autónoma de Lisboa 


\section{AS PARCERIAS MULTISSETORIAIS COMO INSTRUMENTOS DE EFETIVAÇÃO DE POLÍTICAS E PRESTAÇÃO DE SERVIÇOS PARA O DESENVOLVIMENTO SUSTENTÁVEL}

Renata Hellwig Ferreira

Universidade Federal do Rio Grande - FURG
A presente pesquisa objetiva analisar as parcerias entre os setores econômicos -Estado, sociedade e mercado - a fim de efetivar políticas e prestar serviços públicos em redes de cooperação. Isso porque, as sociedades democráticas demandam a socialização do poder, o que ocorre com a descentralização e a participação social na gestão pública. Cumpre ressaltar que a atuação com múltiplos atores não objetiva reduzir o papel do Estado, e sim, fomentar sua capacidade de cooperação, denotando a importância estatal e de suas instituições na coordenação social em geral e nos arranjos multissetoriais em particular. Os países em desenvolvimento, nos quais há forte contexto de exclusão social, desigualdades e pobreza, demandam uma instituição estatal fortalecida que seja núcleo de articulação de parcerias entre os setores econômicos. Este modelo privilegia a mobilização social apta a gerar conexões solidárias, bem como altera o modelo de gestão das políticas e de serviços públicos. No Brasil, o marco regulatório das organizações da sociedade civil (Lei no 13.019/2014) definiu o procedimento das parcerias dessas entidades com o Estado que podem ocorrer nos Direitos Humanos, Educação, Cultura, Ciência e Tecnologia, Desenvolvimento agrário, Assistência Social Moradia, Saúde dentre outras áreas. A referida norma dispõe sobre a possibilidade de realização de chamamento público para selecionar as entidades para firmar termos de parceria ou de fomento com o Estado, mediante a transferência de recursos públicos, observando os princípios da impessoalidade e da publicidade. Entretanto, a gestão em redes de cooperação permite a ordenação dos interesses governamentais e sociais em face de metas coletivas, e ainda, a mobilização de recursos para a sua efetivação. Dessa forma, a escassez de recursos e a necessidade de desenvolvimento sustentável demandam processos de governança baseados na busca pela solução de problemas, efetivação de políticas e prestação de serviços, sendo um dos papeis mais relevantes do Estado a articulação para a obtenção de recursos privados para o financiamento das parcerias, o que ora se propõe. Com isso, as parcerias multissetoriais visam a otimizar recursos, notadamente com a participação do mercado na rede cooperativa, uma vez que se deve evitar que nas parcerias haja dependência do Estado, permite a participação social nas políticas e serviços públicos e demanda ao Estado a articulação necessária ao desenvolvimento sustentável.

Palavras-Chave: Parcerias Multissetoriais, Políticas, Serviços Públicos, Redes de Cooperação, Otimização de Recursos. 


\section{A COOPERAÇÃO INTERNACIONAL E A AGENDA 2030 PARA O COMBATE À MACROCRIMINALIDADE E À CORRUPÇÃO}

A macrocriminalidade e o crime de corrupção são fenômenos que impedem o desenvolvimento econômico e social de um país. Os resultados lesivos impactam a sustentabilidade da sociedade, com injustiças, desigualdades e seletividades.

Compreende-se que nominadas espécies delitivas são complexas, detentoras de sofisticada estrutura organizativa, com capacidade de penetração e de expansão, por vezes transnacional, imbricada nas instituições de poder. Sob o Objetivo 16 da ODS da Agenda 2030 da Organização das Nações Unidas, segundo o qual visa "promover sociedades pacíficas e inclusivas para o desenvolvimento sustentável, proporcionar o acesso à justiça para todos e construir instituições eficazes, responsáveis e inclusivas em todos os níveis", estão as metas 16.4, 16.5 e 16.a, e nesse sentido, ínsitos os esforços ao enfrentamento à macrocriminalidade $\mathrm{e}$ à corrupção.

A Convenção das Nações Unidas contra o Crime Organizado adotada em 2000, também conhecida como Convenção de Palermo, e a Convenção das
Nações Unidas contra a Corrupção de 2003, conhecida como Convenção de Mérida, dispõem sobre as cooperações internacionais de medidas administrativas ou judiciais em matéria penal.

Na ambiência da cooperação internacional em matéria penal, pode-se elencar a promoção de responsável intercâmbio de informações e atividades, de assistência judicial recíproca, de mecanismo para obtenção de provas, de recuperação e de repatriamento de ativos. Nessa dimensão, pretende-se desenvolver o estudo da cooperação internacional como instrumento eficaz no combate à criminalidade globalizada, em consonância aos objetivos da Agenda 2030 da ONU.

Por meio da metodologia mista, será conduzida a pesquisa, cujo escopo é concluir que a cooperação internacional em matéria penal, plasmada em tratados internacionais, está correlacionada às metas do Objetivo 16, e pode contribuir para efetividade dos Objetivos do Desenvolvimento Sustentável da Agenda 2030.

Palavras-Chave: Agenda 2030, Objetivos

do Desenvolvimento Sustentável,

Macrocriminalidade, Corrupção, Cooperação

Internacional.
Suzana Massako Hirama Loreto de Oliveira

Universidade Portucalense Infante D. Henrique

\& José Luiz Loreto de Oliveira

Ministério Público do Estado do Paraná 


\section{COMISSÃO ORGANIZADORA}

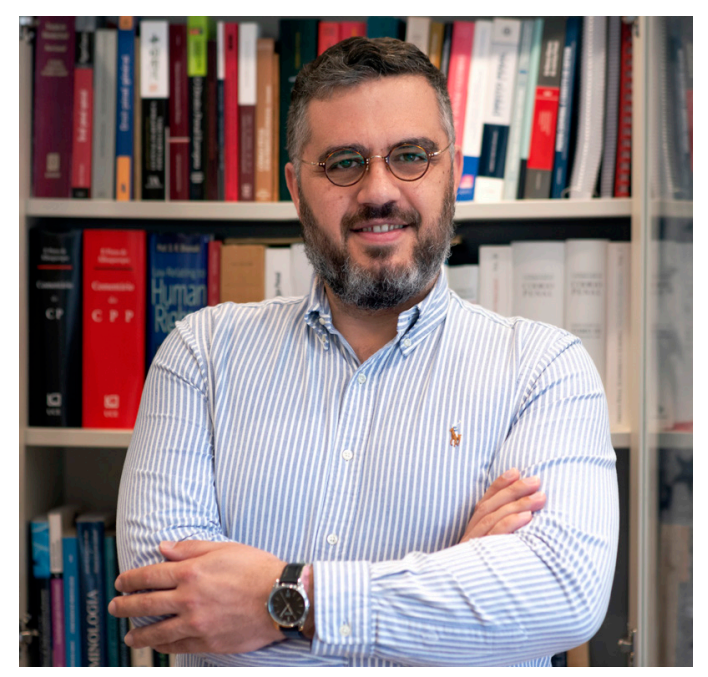

\section{Marco Ribeiro Henriques}

Assistente Convidado no Instituto Superior Miguel Torga em Coimbra e investigador na área dos direitos humanos, é mestre em direito e pós-graduado em direitos humanos, direito penal económico e europeu. É bolseiro de doutoramento FCT em Direito na NOVA School of Law.

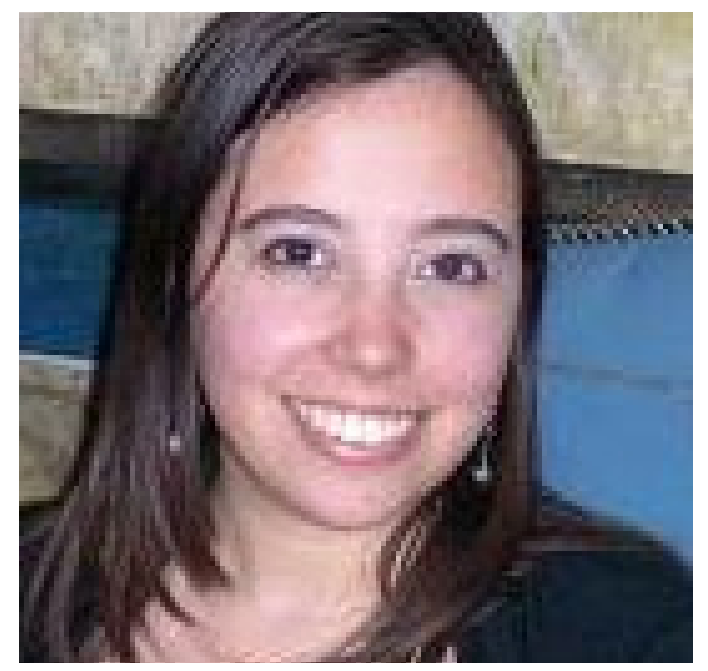

\section{Daniela Serra Castilhos}

Professora Auxiliar da Universidade Portucalense. É doutora em Direitos Humanos pela Universidade de Salamanca.

Coordenadora do Módulo Jean Monnet The European Union as a global player for Democracy and Fundamental Rights. 


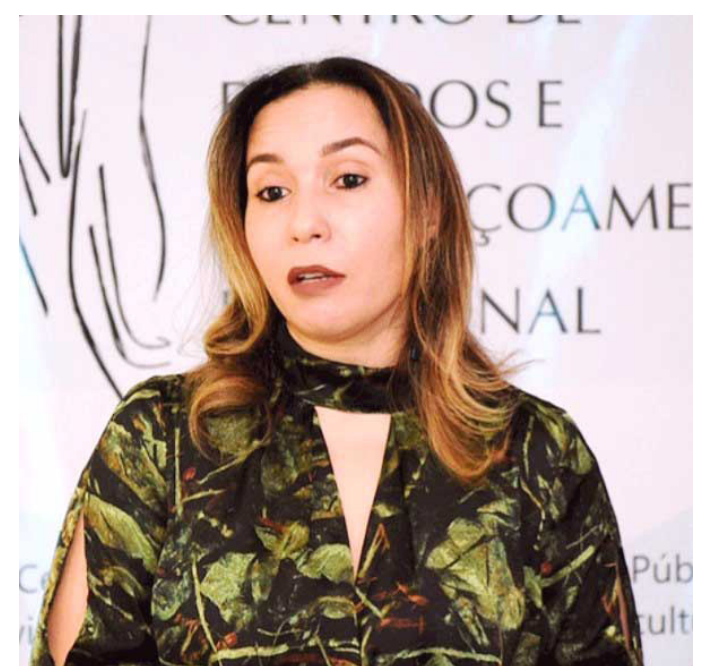

\section{Isabelle Figueiredo}

Promotora de Justiça do Tocantins (MP/TO).

Pós-graduada em Estado de Direito e Combate à Corrupção (ESMAT), com extensão em Combate ao Crime Organizado. Especialista em Direito Público e em Direito e Processo Penal. Bacharela em Direito pela (UNICAP - 2006).

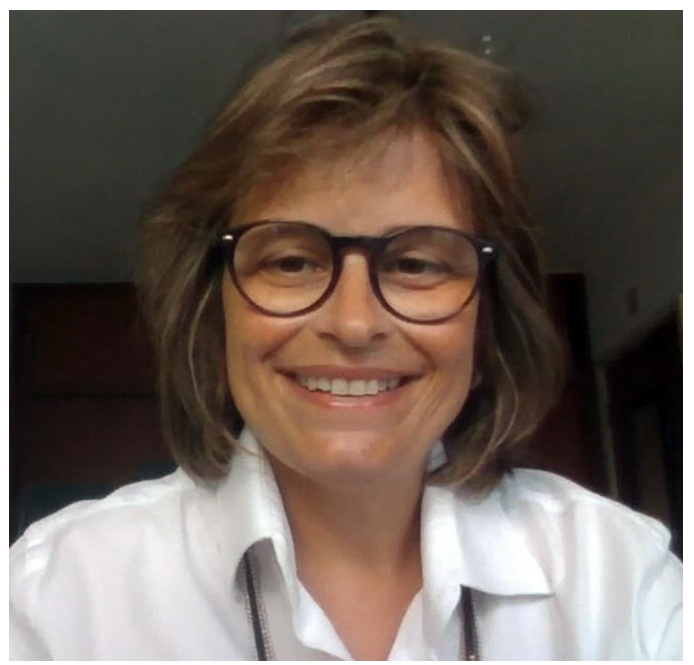

\section{Anabela Paula Brízido}

Mestre em direito em ciências jurídicas internacionais. É bolseira de doutoramento FCT em direito na Nova School of Law, Investigadora no Centro de Investigação e Desenvolvimento sobre Direito e Sociedade (CEDIS) e membro da Ordem dos Advogados em Portugal. 


A Agenda 2030 desafia a economia global a reinventar-se, para atingir as metas propostas pelos 17 Objetivos para o Desenvolvimento Sustentável (ODS), metas ilustrativas de um novo paradigma para a sustentabilidade global. Desde o plano das alterações climáticas, à redefinição das políticas sociais e criminais, à exclusão social ou à reinvenção da base estrutural das relações laborais, as sociedades modernas procuram reinventar, todos os dias, o modelo económico presente, burilando sociedades mais justas e inclusivas.

A Agenda 2030 sucede à Declaração do Milénio e fundamenta-se em diversos princípios plasmados em instrumentos internacionais como a Declaração Universal dos Direitos Humanos, a Declaração do Milénio, a Declaração do Rio sobre Meio Ambiente e Desenvolvimento, entre outros. Diferentemente dos Objetivos do Milénio, a Agenda 2030 e os ODS vêm reforçar o papel do setor privado na estratégia global, direcionando-o como um dos atores essenciais na resolução dos maiores desafios globais.

A cooperação regional - Europa-América -, enquanto ferramenta de desenvolvimento das economias e mote para o progresso da qualidade de vida dos povos, pode constituir-se, simultaneamente, um duro processo de densificação da identidade do Estado de Direito através das políticas públicas.

Preocupações que são transversais às sociedades e às várias áreas do saber. Um paradigma que nos convoca a todos/as para a necessária reflexão académica multidisciplinar e intersectorial sobre o desenvolvimento dos Direitos Humanos no século XXI.
Agenda 2030 challenges the global economy to reinvent itself to meet the targets proposed by the 17 Sustainable Development Goals (SDGs), which illustrate a new paradigm for global sustainability. From climate change to redefining social and criminal policies to social exclusion or reinventing labor relations' structural basis, modern societies seek to reinvent the present economic model every day, building more just and inclusive communities.

Agenda 2030 is the successor to the Millennium Declaration. It is based on several principles set out in international instruments such as the Universal Declaration of Human Rights, the Millennium Declaration, and the Rio Declaration on Environment and Development. Unlike the Millennium Development Goals, Agenda 2030 and the SDGs reinforce the private sector's role in the global strategy, directing it as one of the key actors in addressing significant global challenges.

Regional cooperation - Europe-America - as a tool for the development of economies and as a motto for progress in the quality of life of peoples, can at the same time constitute a challenging process of densification of the identity of the rule of law through public policies.

These concerns are transversal to societies and the various areas of knowledge. A paradigm that calls us all to the necessary multidisciplinary and intersectoral academic reflection on human rights development in the 21 st century. 